

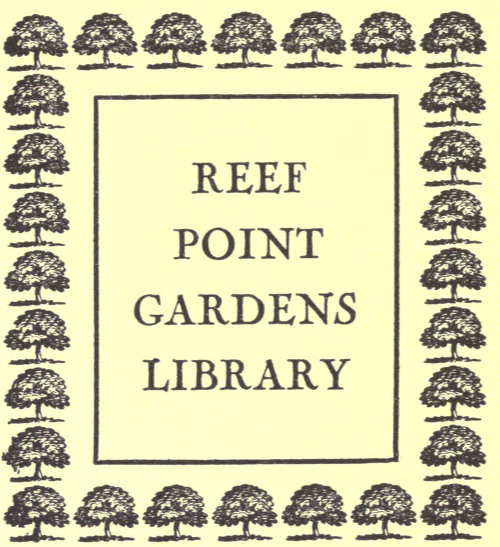

The Gift of Beatrix Farrand to the General Library University of California, Berkeley 




SCIENCE AND FRUIT GROWING 




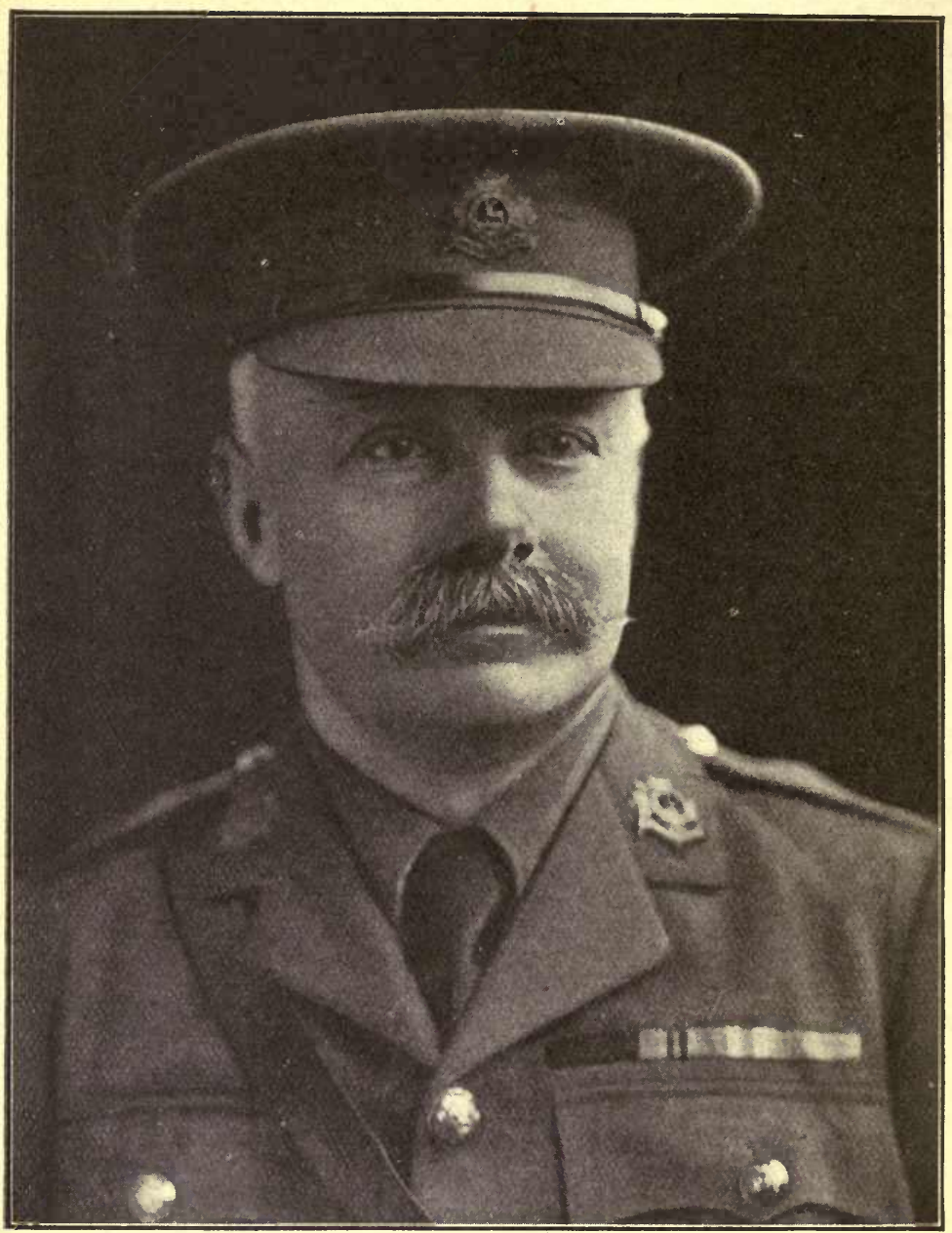

From a Photograph by Elliott \& Fry, 1918.]

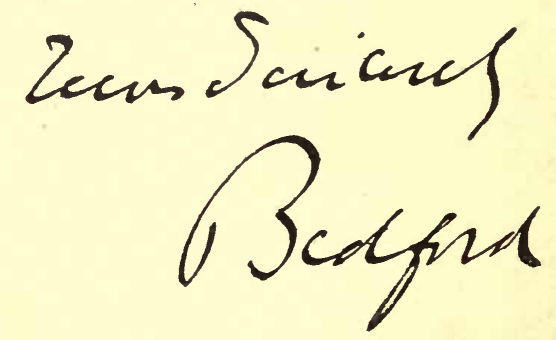




\section{SCIENCE AND \\ FRUIT GROWING}

Being an Account of the Results obtained at the Woburn Experimental Fruit Farm since its foundation in 1894.

BY THE

DUKE OF BEDFORD, K.G., F.R.S.

AND

SPENCER PICKERING, M.A., F.R.S.

MACMILLAN AND CO., LIMITED ST. MARTIN'S STREET, LONDON 
Copyright

Ad ब.7

LANDSCAPE ARGMITECTURE

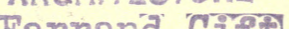




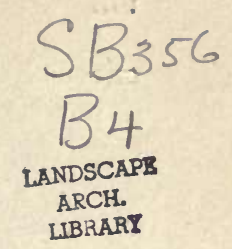

\section{PREFACE}

IT is several years since the suggestion was first made that the time had come for publishing a connected account of the results obtained at the Woburn Experimental Fruit Farm, but the advent of the war rendered it advisable to defer any such undertaking to some more suitable time : the same cause, however, operated at a later date in the opposite direction, for the economic conditions engendered by the war soon rendered it impossible to continue the Farm on its original basis, and, as stewards of the undertaking, we now find ourselves called upon to render an account of our stewardship.

Fortunately, however, it is not altogether a case of Te morituri salutamus! for thanks to the broad-minded views now held by the Board of Agriculture and the Development Commissioners, and thanks, also, to the kindly exertions of the Committee of the Lawes Agricultural Trust, the Farm will be continued for the present on nearly the same lines and under the same management as heretofore, though the funds necessary for the purpose will be derived from Government.

The origin of the Farm, which was established in June I894, may be suitably described by a quotation from Nature of September I9, I895:-

"The object of this institution, which, under the above somewhat unpretentious title, has been established by the joint action of the Duke of Bedford and Mr. Spencer Pickering, F.R.S. in order to supply what has hitherto been a great national want, is to provide an experimental station where all matters connected with horticulture, and especially with the culture of hardy fruits, may be investigated both from the scientific and practical point of view.

"The origin of such an enterprise is always a matter of some interest, and it becomes all the more so in after years, when, too often, the details of its conception and evolution are irretrievably lost. In the present instance we may trace the origin to an accident in a chemical laboratory. It was owing to such an accident some years ago that Mr. Pickering, whose work in 
physical chemistry is well known, was driven to seek health in a partial existence in the country. Not having the means, however, to procure this in the orthodox manner without abandoning his scientific work, he resorted to the somewhat unusual means of getting air and exercise by becoming an agricultural labourer at Rothamsted. From an agricultural labourer to a small farmer and landowner the steps were not so tedious as is generally the case, and for some few years past Mr. Pickering has turned his attention, after the manner of many landowners, to horticulture and practical fructiculture. To any one of a scientific turn of mind the unsatisfactory basis on which the culture of fruit depends cannot fail to be apparent. Its present condition is little better than that of agriculture some fifty years ago. It rests mainly on the hard-earned and often one-sided experience of practical men, gardeners, for the most part, or nurserymen.

"But the pressure of business will rarely allow a nurseryman to indulge in anything approaching to systematic research, and even when he does obtain any important results, they are liable to be looked on askance, as being possibly tinctured by mercenary considerations. Moreover, even amongst the highest practical authorities there is hardly a single point in the cultivation of fruit on which unanimity of opinion prevails; indeed, on some of even the most elementary processes there seem to be as many opinions as there are so-called authorities.

"The desirability of having some station where such matters might be patiently investigated, and from which results might issue free from any taint of commercial expediency, was evident to Mr. Pickering, and not having himself the capital or land necessary for such an undertaking, he applied for assistance to a former college friend, the Duke of Bedford. The Dukes of Bedford have during generations past identified themselves with the progress of agriculture and horticulture, ${ }^{1}$ the present holder of the title showing no tendency to be eclipsed by his predecessors in these matters. As was probable, such a scheme met with the hearty approval of the Duke, and the result was the establishment of the present institution, conducted jointly by himself and Mr. Pickering.

1 It may be of some interest to note that the great-granduncle and great-grandfather of the present Duke of Bedford and of Mr. Pickering, respectively, namely, Francis, Fifth Duke, and Coke of Norfolk, afterwards Lord Leicester, were intimately associated, one century ago, in their endeavours to benefit English Agriculture. 
"The Fruit Farm is on the Duke's land near Ridgmont Station, and almost adjoins the land which is given up to the use of the Royal Agricultural Society as an experimental agricultural station. About twenty acres have been devoted to the purpose, and of this some fifteen have already been planted."

In the quarter of a century which has elapsed since the foundation of the Farm, events have forced such a profound change in the popular view as to the relation between science and practice - the practice of the arts both of war and of peacethat it is no longer necessary to apologise for any attempt to apply the teachings and the methods of science to any branch of industry; but it may be pointed out that the methods of science may justly claim to be those which are really practical in the strictest sense, since they consist of ascertaining by direct trial the true behaviour of the subjects in question under given circumstances, instead of accepting the generally held beliefs and the rule-of-thumb methods of former generations. As might naturally have been expected, the work at Woburn exposed the fallacy of some of these popular theories, and, as might equally have been expected at the time, such exposure met with violent opposition, supported sometimes even by personal abuse. The more enlightened spirit pervading the country at the present day must make such a reception appear to belong to very distant times.

Some of our visitors to the Farm who hailed from Kent have asked why it was that this experiment station was not located in that fruit-growing county; others from Herefordshire have wanted to know why the claims of that land of the apple were not duly considered by establishing the Farm in their county. These are questions which should be put to, and answered by, the large landowners in Kent and Hereford: it should hardly be necessary to point out that a landowner in Bedfordshire who takes so great an interest in fruit-growing as to devote his land and money to the establishment of an experiment station, would scarcely establish such a station on some one else's land, remote from his own ken and supervision.

Much has been said, some of it with justice, and some without, as to the unsuitability of the site chosen for the Woburn Farm. On a private estate, however large, many circumstances other than the suitability of the land have to be taken into consideration when establishing an institution of this sort; but it may be mentioned that this site was selected as eminently suitable for fruit-growing by one of the highest practical authorities on 
the subject then living; an instance, perhaps, that practice without science is not always a sure guide.

The Farm occupies some twenty acres of land near the village of Ridgmont, the formation consisting of the Oxford clay, of which a tongue projects into the greensand formation prominent in the neighbourhood. The ground is of a somewhat peculiar nature, there being in the lower portion of the farm a preponderance of fine particles (clay) in the upper layers, whereas in most soils it is the lower layers which are richest in the finer particles : analyses of the soil will be found below (p. 8I). The surface soil is shallow, and difficult to work, becoming sticky in winter, and baking very hard in summer; added to which, it is a soil which is very favourable to the growth of weeds. These objections, which, of course, would be fatal for commercial fruitgrowing, do not constitute any serious drawback to the ground as an experiment station; indeed, for such a station, exceptionally favourable conditions are as disadvantageous as exceptionally unfavourable ones.

Fruit trees generally, and apples in particular, flourish well at the Woburn Farm, though their life there is probably not a very extended one, and the main drawback to its position as an experiment station is that it is low-lying, and subject to spring frosts: this, of course, interferes with the regular cropping of the trees, and causes an irregularity in those records which depend on the fruit.

From the first it was realised that the station would probably never be equipped as such a station ought to be so as to fulfil the highest ideals of investigation. For that purpose, half a dozen branches of science would have to be represented, each with its laboratory and staff, the whole forming an establishment which could scarcely be maintained except by the State or some large corporate body. Hence the goal which we set ourselves was the investigation of those cultural problems in which much work could be done without the assistance of special scientific investigation, and it is only in the direction of chemistry that we have at all over-passed these self-imposed limits.

In looking back on the work of past years, it is inevitable that Wolsey-like reflections must arise, as to how much more might have been done had circumstances been otherwise than they were, and how much more ought to have been done under the existing circumstances. But whatever has been done or left undone, it may be pleaded that the work is the work of one man only, not very well equipped for his task, handicapped 


\section{PREFACE}

by residence at a distance, and, in recent years, by ill health. Let our critics take note, and be lenient: they have been severe enough at times in former years.

It remains for us to express our thanks to two of the staff at the Rothamsted Experiment Station for the kindly assistance which they have given us in preparing this volume: to Miss Adam for verifying the references contained in it, and to Dr. Winifred Brenchley for writing a short account of the nature and functions of plants; to Mr. J. Scott Taylor our thanks are likewise due for his kindness in reading and correcting the proof sheets.

B.

S. P. 



\section{CONTENTS}

\section{CHAPTER I}

PLANTS, FUNGI AND INSECTS .

Herbs, shrubs and trees; roots, stems, leaves and flowers; propagation by seed and by grafting; physiological functions of a plant; respiration, water-absorption, transpiration, elaboration and translocation of food. Fungi :-reproduction; parasites and saprophytes; moulds and mildews; means of combating attacks. Insects :- stages of life; metamorphosis ; caterpillars; methods of treatment.

\section{CHAPTER II}

THE MEASUREMENT OF RESULTS • • • • •

Difficulties peculiar to horticultural experiments; number of trees required in each plot; number of varieties to be examined; pruning and thinning difficulties; length of time required; the crops; measurements of growth and vigour; general agreement of different methods of measurement; expression of the results; proportionate percentages; taking means.

\section{CHAPTER III}

TRENCHING .

Bastard trenching; the soils examined; smallness of the effect in altering the character of the soil, and the growth of plants in it; adverse effect of trenching on gooseberries and currants.

\section{CHAPTER IV}

\section{PI.ANTING}

Results of rough planting; effect on fruiting; items constituting rough planting; injury to roots; the Stringfellow method; unimportance of trimming; removal of fibrous roots; roots huddled together; deep planting of stocks; difference in the behaviour of paradise and other stocks; effect of ramming; loose planting; effect of ramming on the soil; preliminary retardation of growth by ramming; no results in light soil. 


\section{CHAPTER V}

PLANTING (continued) • • • • •

Root-injury of nursery stock; evils of excessive root-injury; root-pruning; effect on the crop. Lifting nursery stock. Best age for transplanting. Best time for planting. Exposure of trees before planting. Depth of planting. Working stocks above and below ground. Planting trees and cuttings in sand. Distribution of new rootlet formed by trees. Arrangement of trees in a plantation; orientation of the rows.

\section{CHAPTER VI}

PRUNING

Under- and over-pruning; effect of pruning on growth; self pruning; effect of pruning on fruit production; necessity for some pruning.

\section{CHAPTER VII}

PRUNING (continued)

The pruning of older and ailing trees; lopping; lopping at different times of the year; cutting back trees when transplanted; deferred cutting back. Pruning at different times; summer pruning; pinching, breaking and twisting the shoots. The manner of pruning. Root-pruning; reciprocal effect of root- and branch-pruning.

\section{CHAPTER VIII}

\section{SOIL-ANALYSES}

Mechanical and chemical analyses of the soils at Ridgmont and Millbrook.

\section{CHAPTER IX}

\section{MANURES}

Supply of available food in a soil; difference between trees and farm crops; general results at Ridgmont. Results with apples; with mixed plantations; with farm crops. Experiments in poor soil; effect of omitting certain manurial elements. Results with gooseberries; with currants and raspberries; with strawberries.

\section{CHAPTER X}

\section{MANURES (continued)}

Discussion of the general results; artificials and dung; food requirements of farm crops and trees; analyses of fruits and fruit trees; peculiarities of gooseberries, etc., as contrasted with fruit trees; practical conclusions. Green manuring. Loss of weight of manure in transit. 


\section{CHAPTER XI}

Twenty years' records; comparison of results at two stations at different altitudes; bearing of the results on the activity of radiation in different situations.

\section{CHAPTER XII}

SPRING FROSTS

Wind-frosts and radiation-frosts; shelter hedges; formation of dew; radiators and absorbers; air drainage; injury by cold; prevention by smoke clouds, or by heating the trees or the air; effect of the proximity of water, and of irrigation; heating the air by small flames; possible application in practice.

\section{CHAPTER XIII}

THE FRUITING OF TREES IN CONSECUTIVE SEASONS .

General beliefs; preventing young trees from bearing; methods of observation; extraneous conditions the chief factor in determining the relative bearing of individual trees; difference in results obtained in two localities; alternation of good and poor seasons in a plantation; not traceable to alternation in meteorological factors.

\section{CHAPTER XIV}

THE FLOWERING OF APPLE TREES .

Date of blossoming in different years, and on different stocks; dates of blossoming and of ripening; relative behaviour of different varieties in different seasons; duration of the blossoming period.

\section{CHAPTER XV}

INSECTICIDES, FUNGICIDES, ETC. . • .

\section{Plant-sprays}

Synopsis of the solids, liquids and gases used for plant treatment.

\section{CHAPTER XVI}

INSECTICIDES, FUNGICIDES, ETC. (continued) . . .

\section{Paraffin and Paraffin Emulsions}

Paraffin oils, etc., used for spraying; emulsification by soap; variation in recipes; solar distillate; variation in activity with the volatility of the oil; influence of weather conditions on the results; dipping young trees in oil; spraying trees with undiluted oil or strong emulsions; effect of paraffin on the soil. The nature of emulsions; action of soap in causing emulsification. De-emulsification; solid emulsifiers; quasi-emulsions; recipes for emulsions for summer and winter use; detergent action of soap; paranaph. Nature of the action of paraffin on vegetable matter; reducing character of the action. 


\section{CHAPTER XVII}

INSECTICIDES AND FUNGICIDES (continued)

\section{Alkaline Washes}

The terms, soda and potash; no reason for using a mixture of the two; changes undergone by soda after spraying; effect of rain falling after the spraying; insecticidal value of alkalis increased by addition of paraffin; not so their detergent value; the strength of alkali required; relative efficiency of lime and soda; attempts to improve the adhesiveness of alkaline washes. Lead arsenate; differences in its character when prepared from different reagents; its use with other spray substances; calcium arsenate.

\section{CHAPTER XVIII}

INSECTICIDES AND FUNGICIDES (continued) . . .

\section{Copper Fungicides}

Origin of Bordeaux mixture; the basic sulphates of copper; necessity of the presence of soluble copper for fungicidal action; action of air on Bordeaux mixture; soluble fungicides; liberation of soluble copper from the basic sulphates; bulkiness of the different basic sulphates; Bordeaux paste; relative efficiency of Bordeaux mixture and paste; their relative adhesiveness, and that of Burgundy mixture; methods of preparing and testing Bordeaux mixture; changes undergone by it on keeping; bulkiness of it dependent on the manner of mixing; Bordeaux mixture and treacle; alkaline and solid copper fungicides. Burgundy mixture; proper proportions of the ingredients; scorching produced by the mixture; change undergone by it on keeping.

\section{CHAPTER XIX}

\section{INSECTICIDES AND FUNGICIDES (continued)}

\section{The Fungicidal and Scorching action of Copper}

American work on fungicidal action; its dependence on the amount of copper in solution, and not on the nature of the compound; the question of excretions from the fungus; entry of copper into the leaf of the plant; the effect of copper on plant growth; the effect of copper spraying on soil-fertility. Copper injury; unavoidable in many cases; American work on the subject; connection between fungicidal and scorching action; experiments on scorching action; " natural" scorching; preservative effect of copper; variation of scorching and fungicidal action with the strength of the substances; action of lime; effect of the presence of neutral salts; action of electro-negative copper; the wetting of the leaves by the fungicide; action of saponin. 


\section{Mussel Scale}

Description of the insect; its enemies; damage done by it; character of investigation of insecticides; effect of alkalis, alone and with paraffin, soap, alcohol, etc.; effect of paraffin; of different soaps; winter washing on different dates; effect of other insecticides; lime and lime-sulphur washes; fumigation; check experiments by counting the hatchings; glueing of the scales to the bark by alkalis; summer treatment; effect of rain after spraying; nature of the action of the insecticides.

\section{INSECTS (continued)}

\section{CHAPTER XXI}

\section{Currant Gall Mite}

Life-history; treatment with paraffin, carbolic acid, etc.; possible infestation of the ground; cutting down infested bushes; fumigation; treatment with hot water; susceptibility of different varieties.

\section{INSECTS (continued)}

\section{CHAPTER XXII}

(I) Woolly aphis; spraying with paraffin; fumigation of young trees; dipping in hot paraffin or hot water. (2) Apple sucker; damage done by it; winter treatment with various insecticides; spring treatment; lime-salt washes; nicotine. (3) Aphis; treatment with weak emulsions and with nicotine. (4) Caterpillars; treatment with various poisons; efficacy of lead arsenate and paraffin emulsions; importance of winter washing.

\section{CHAPTER XXIII}

FUNGI

\section{Silver Leaf Disease}

Nature of the disease; plants attacked by it; recent spread of it; attacks dependent on inoculation; inoculation in stem, roots, or branches; inoculation at different times; recovery from attacks; susceptibility of different kinds of trees; of different varieties of plums; of strong and weak trees; possible immunisation from attack; treatment with iron sulphate; preventive measures; disease communicated solely by spores.

\section{CHAPTER XXIV}

\section{Potato Disease}

Treatment with copper fungicides; average benefit ensuing; measurement of results; fallacy of drawing conclusions from the state of the haulms; possible deleterious effect of spraying; effect of spraying influenced by the manurial treatment; general view of the problems involved; steeping the seed potatoes; cutting down diseased haulms. 


\section{CHAPTER XXV}

\section{HEATED AND TREATED SOILS}

Effect on bacterial growth; effect on soluble matter present; changes after treatment; germination of seeds in heated soils; results not due to bacterial changes; action of antiseptics; plant-growth in heated soils; trees grown in heated soils; the bacterial and chemical explanations of the results.

\section{CHAPTER XXVI}

THE EFFECT OF GRASS ON TREES . . . •

General characteristics of the action; independent of the age of the trees; action on different kinds of fruit trees; on forest trees; of different kinds of grasses; in different soils; effect on the roots; on the colouring matter; limited action of grass; possible recovery from the effect; grassing to different extents; gradual grassing.

\section{CHAPTER XXVII}

POSSIBLE CAUSES OF THE GRASS EFFECT • • •

Aëration of the soil; carbon-dioxide contents of the soil; soil-temperature; bacterial conditions; alkalinity; physical condition; the water-supply; evaporation from soil with and without a surface crop; water contents of grassed and tilled soil ; pot experiments on the subject; the food-supply; feeding off the grass; enrichment of the soil by grass.

\section{CHAPTER XXVIII}

THE TOXIC ACTION OF ONE CROP ON ANÓTHER

Pot experiments; universality of the action; variation of the effect; action of plants on others of the same and of different sorts; recovery from the effect; surface crop not deleterious if the toxin from it is retained; the importance of drainage explained by the removal of toxin; effect of trees on grass and other crops. The general question of toxin-formation; relative action of weeds and grass on trees; richness of soil from grassed land; destruction of the toxin by aëration; grassing trees to different extents; possible beneficial action in some cases; variability of the grass effect under different conditions; gradual grassing; effect of depth of soil; the manner of toxin-formation; the rapidity of the decomposition of the toxin. 


\section{CHAPTER XXIX}

THE BEHAVIOUR OF PLANTS IN MASSES

Action on a plant by the toxin formed by itself; pot experiments on plants with and without root interference; growth in a limited supply of soil; branch interference; different numbers of plants grown in the same amount of soil; evidence of toxic action when the plants are dissimilar in age; importance of uniform germination in a seed-bed; inadvisability of filling up gaps in a plantation; difference in magnitude of the toxic action with mustard and wheat; behaviour of the outside rows in a plantation; impossibility of explaining this by the extra food-supply.

\section{CHAPTER XXX .}

\section{FLOCCULATION}

Characteristics; Brownian motion arrested and size of particles increased on flocculation; explanations offered; reason of the formation of flocs; action of alkalis; the liming of fields; adsorption compounds; effect of rainfall on the distribution of clay-particles in the soil; action of frost on clay.

\section{CHAPTER XXXI}

ODDS AND ENDS

Comparative bearing of apples on crab and paradise stocks. Influence of the stock on the growth of trees; relative merits of budding and grafting; influence of the scion on the stock; the question as to what characteristics of the scion are reproduced in subsequent growth from it; the possible deterioration of varieties by continued re-working on to fresh root-stocks. Relative behaviour of different varieties of strawberries under different conditions; futility of variety testing. Continuous cropping with strawberries. Behaviour of late and early strawberry runners. Germination of apple seeds from large and small fruits, and from cells containing different numbers of seeds. Potatoes; early and late planting ; planting differentsized sets; change of seed. A disease of plum trees. 



\section{LIST OF ILLUSTRATIONS AND DIAGRAMS}

FIG.

The Duke of Bedford.

PAGE

1. Plant-roots

2. The stem and lenticels

3. The leaf . . . . . . . . . . 7

4. Flowers and fruit . . . . . . . . 9

5. Paradise stocks before and after being planted at ordinary level

6. Similar stocks planted 24 inches deep .

7. Roots of rammed and unrammed trees : roots huddled together

Plate I-View of the farm and office from the entrance . . 44

8. Diagram of arrangement of trees . . . . . . 55

9. Unpruned and over-pruned trees . . . . . . 58

10. Hard-pruned and unpruned trees . . . . . . 60

11. Growth of similar shoots shortened to different extents . 62

12. Diagram of crops from trees pruned to different extents . . 65

13. Effect of not cutting back on planting . . . . 72

14. " " " $"$ • • • • . 74

Sketch plan of the ground . $\quad$. $\quad$ - $\quad$. 82

15. Diagram showing the effect of dung on different plants . . 102

I6. Rate of growth during the season, and rainfall . . . III

Plate II-View of the brook in the farm . . . . II5

17. Diagram illustrating the differences between temperatures at the highest and lowest parts of the ground . . . I2I

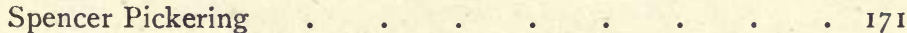

I8. Diagram of rate of settlement of Bordeaux mixtures, etc. $\quad$ I80

19. Diagram of settlement of Bordeaux mixtures prepared in different ways - . . . . . . . 181

20. Tree attacked by mussel scale . . . . . . 197

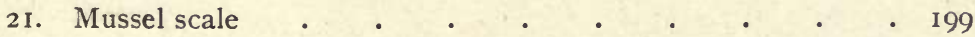

22. Currant gall mite _ . . . . . . . 213

Plate III-Bramley Standard plot, 1905. Forking and pruning 230

23. Stereum purpureum on plum . . . . . . 233

24. Diagram of organic matter in soil after heating . . 250 


\section{xxii LIST OF ILLUSTRATIONS AND DIAGRAMS}

25. Diagram of relative amounts of organic matter, and of the incubation periods of seeds, in heated soils . . . $25 \mathrm{I}$

26. Plants growing in soils heated to different temperatures . 255

27. $", \quad, \quad, \quad, \quad, \quad, \quad 256$

28. Diagram of growth of grasses and non-grasses in soils heated to different temperatures . . . . . . 258

29. Bramley standard apple trees in grass and in tilled soil . $\quad 260$

30. Bramley bush apple trees in grass and in tilled soil . . 26I

31. Cox's Orange apple trees grassed after four years . . . 263

32. Standard trees grassed after twenty-three years . . . 264

33. Pears in grass and in tilled soil . • • • . . 266

34. Plums in grass and in tilled soil . . . . . . 267

35. Cherries in grass and in tilled soil . . . . . 269

36. Trees growing with their roots buried i 3 feet deep . . 277

37. Diagram showing the distribution of fine particles in grassed and tilled soil . . . . . . . . $28 \mathrm{I}$

38. Diagram showing the variation in the water contents of grassed and tilled soil . $. \quad . \quad . \quad . \quad 283$

Plate IV-Snow scene, April 25, 1908 . . . . 290

39. Pots used in pot experiments . . . . . . 292

40. Plants grown in pots with and without a surface crop . . 294

4I. Mustard in pots with and without a surface crop . . . 295

42. Effect of a surface crop grown in perforated and unperforated trays • . . . . . . . . . 299

43. Effect of weeds on a tree, and its recovery on their removal . 305

44. Roots of trees of the crab and pear stock in the Ridgmont soil 309

45. Plants grown at different distances apart . . . . 3 316

46. Diagram of distribution of soil particles compared with rainfall 327

47. Paradise and crab roots, and trees grown on these stocks . 331 


\title{
SCIENCE AND FRUIT GROWING
}

\author{
Chapter I \\ PLANTS, FUNGI AND INSECTS
}

THIS chapter contains such elementary information as to the structure and functioning of plants, fungi and insects as may be of assistance in interpreting the results of the Woburn experiments. To most of our readers this information will be superfluous; but to others a brief statement on the subject may be a convenience.

\section{Plants}

The popular conception of a plant is that of an organism which grows in the soil, and which possesses structures known as roots, stems, leaves and flowers. This conception is really much too circumscribed, as many plants of lower degree exist, such as algæ and fungi,-which bear no resemblance to ordinary plants, and do not necessarily inhabit the soil. But the popular conception of a plant may be taken as that most suited for our present purpose.

Such plants may be classified into three sections-

(I) Herbs. - Low-growing plants, which usually are short-lived, often only annual in duration ; e. g. buttercups, grasses, speedwell.

(2) Shrubs. - Woody plants, which branch out from just above the surface of the ground, and are usually perennial in duration : e. g. privet, laurel.

(3) Trees.-Woody plants which throw up a stout unbranched bole, or trunk, for some distance above the ground, and then branch out in various ways. These are mostly long-lived, some surviving for hundreds of years.

All three types are similar in general structure, but the stems and roots of trees and shrubs naturally become much stronger and more developed than those of herbs. 
Roor.-Roots are specially adapted for anchoring the plant in the ground, and preventing it from being blown over by strong winds, or washed out of the soil by heavy rains; in addition to this, they form the channels through which all the water and the raw food-material, necessary for the various functions of the plant, are absorbed.

The structure of the root differs from that of the stem in some particulars. If a transverse section be made (Fig. I) of a fairly young root it is seen to consist of-

(I) An outer layer of rather thin-walled cells, called the piliferous layer, from which root-hairs are formed.

(2) A broad band of cells forming the cortex, bounded on the inner side by the endodermis with thickened walls. The cortex of the root does not contain any green colouring matter.

(3) A stele, or central cylinder, of which the outer layer is called the pericycle. Within this, groups of xylem, or wood, (water-conducting tissue,) and of phloem, or bast, (conveying elaborated food throughout the plant,) are arranged alternately, the xylem being nearer the centre than the phloem. Within these, again, there is a certain amount of pith, made up of thinwalled cells.

As the root gets older, a cambium, or reproductive layer, forms between the groups of xylem and phloem, and by the division of its cells gives rise to more wood and bast, the volume of the wood being greater than that of the bast. In course of time the pith often becomes crushed and unrecognisable. While the root is thus growing in thickness, the friction of the earth rubs off the root-hairs and the piliferous.layer, and gradually abrades the cortex. The particles thus rubbed off from the root materially increase the supply of organic matter in the soil. A very old root consists of little but the strong vascular cylinder and shreds of cortex, and becomes a mere conduction channel.

The continuance of the function of absorption is provided for in a very remarkable way. Towards the end of a root is the growing point, consisting of tissues which are constantly dividing, and adding to the length of the root. This root-tip, or growing point, is covered with a thick layer of cells, called the root-cap, which protects the tender tip from injury as it forces its way through the soil. Just behind the root-tip, constant supplies of new root-hairs are formed to replace those higher up, which have finished their work and have been rubbed off.

A healthy growing root puts out large numbers of lateral rootlets, originating from the central cylinder, and making their 


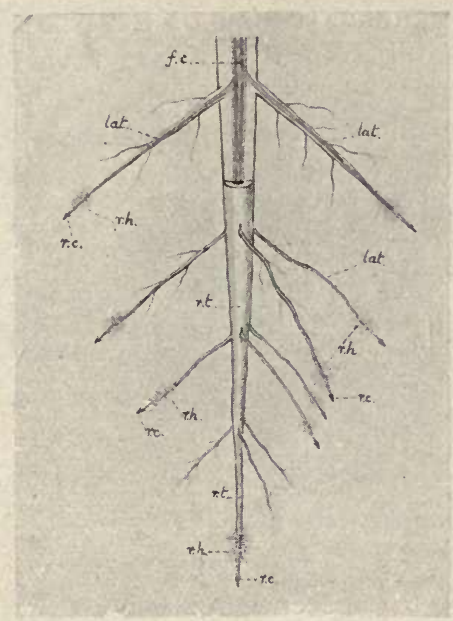

Main Root and Laterals.

$r t$, primary root; lat, lateral roots; $r h$, root-hairs ; $r c$, root-cap; $f c$, inner tissues.

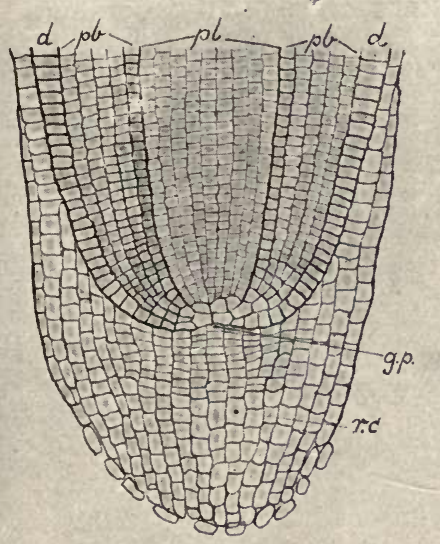

Apex of Root.

$r c$, root-cap; $g p$, growing-point; $p l$, leroma (developing into vascular ystem); $p b$, periblem (developing ito cortex); $d$, dermatogen (develop$1 \mathrm{~g}$ into piliferous layer).

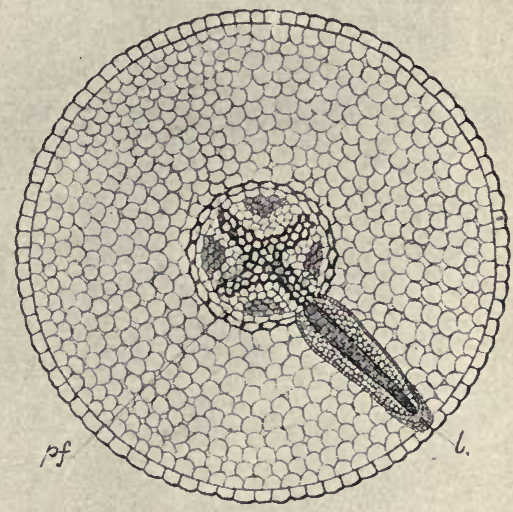

Section through Root with Lateral. $p f$, pericycle; $l$, lateral root.

FIG. I.-THE ROOT. ${ }^{1}$

Reproduced, by permission, from Laurie's Elementary Botany, and Flowering Plants. 
way through the cortex into the soil. The structure and development of these is similar to that of the main root, and, as time goes on, the plant becomes furnished with a widely ramifying system of roots, provided with multitudes of very fine rootlets, each of which is constantly forming new root-hairs, which more than counterbalance the loss of those from the older parts of the roots. When the tip of a root is broken off, that root cannot grow any more in length, as it has lost its growing point, and in such a case, fresh laterals are produced from the root, or even from the lower parts of the stem. These stem-roots are said to be adventitious, and an excellent example is seen whenever a cutting is "struck," whereby a new plant is formed from the portion of a stem inserted in the soil.

STEM.- The main function of the stem of a plant is to act as a support for the branches, and as a channel for the translocation of foodstuffs between the roots and the leaves. Its structure is specially adapted to this end, for the size and strength of the stem are adjusted to the burden of leaves that it has to bear, and, therefore, as will be seen later, to the amount of work it is called upon to carry out in connection with the process of nutrition.

A transverse section of a young stem of a dicotyledonous plant (Fig. 2) such as an apple shows-

(I) An outer layer of regularly shaped cells - the epidermisof which the outer wall is usually thickened or corky, forming the cuticle. Scattered over the epidermis are numberless pores, or stomata, which communicate with the interior of the stem, and play an important part in the functions of breathing and feeding.

(2) A broad band of thin-walled cells forming the cortex, bounded on the inner side by the endodermis with thickened side walls. The outer layers of cortical cells contain granules of green colouring matter, called chlorophyll.

(3) A stele, or central cylinder, the outer layer of which is the pericycle. Within the pericycle is a ring of vascular bundles, each consisting of a group of xylem and phloem, connected by a layer of actively dividing cells called the cambium. The phloem is on the outside, and the spaces between the bundles are occupied by thin-walled ground tissue, which also fills up the middle of the cylinder, and is called the pith.

As the stem gets older various important structural changes occur. The cambium ultimately extends across the ground tissue between the bundles, and, as it continues to divide, throwing 


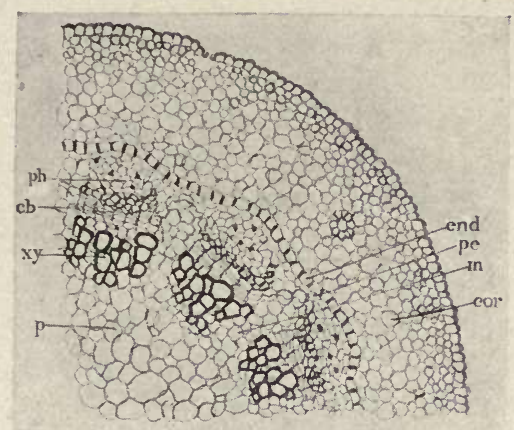

Portion of Transverse Section of Young Stem. ${ }^{1}$

cor, cortex; end, endodermis; pe, pericycle; $p h$, phloem; $c b$, cambium; $x y$, xylem; $p$, pith; $m$, medullary ray.
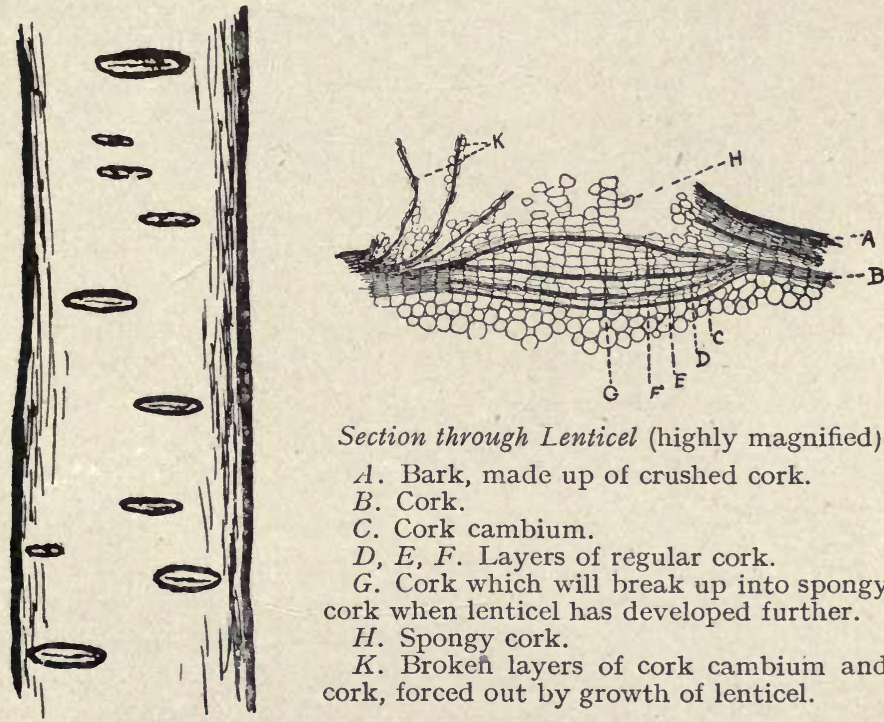

Section through Lenticel (highly magnified).

A. Bark, made up of crushed cork.

$B$. Cork.

C. Cork cambium.

$D, E, F$. Layers of regular cork.

$G$. Cork which will break up into spongy cork when lenticel has developed further.

$H$. Spongy cork.

$K$. Broken layers of cork cambium and cork, forced out by growth of lenticel.

Diagram of Plum Branch showing Lenticels (natural size).

FIG. 2.-THE STEM.

1 Reproduced, by permission, from Johnson's Text Book of Botany. 
off new phloem on the outer side, and new xylem on the inner, the vascular tissue becomes concentric, instead of being in groups. The older wood is towards the centre, and, in trees which live for many years, this gradually ceases functioning, forming what is known as heart wood: the younger wood nearer the cambium carries on the necessary activities, and forms the sap wood. The epidermis cannot stretch sufficiently to keep up. with the growth in thickness of the stem, so a fresh protective coat is formed, known as bark: a cork cambium is developed from cells towards the outer limit of the cortex, and the cells actively divide, forming a layer of cork, with rectangular cells arranged very regularly. As growth proceeds, and the pressure from within becomes greater, this cork is ruptured, and a new cork cambium is formed further in. The layer of cork, with the broken and dried-up tissues outside, forms the bark. Breathing spaces are provided by means of lenticels in the bark (see Fig. 2)-small openings in the regularly arranged cork, filled with spongy cork, made up of round cells, loosely packed, and permitting the passage of air. In the winter, when the physiological functions of the plant are largely in abeyance, these lenticels are blocked up by a layer of regular cork, which is broken down again as soon as active growth is resumed in the spring.

When an old stem is cut across, the wood is seen to be arranged in concentric rings, due to a difference in the growth of the new wood in spring and autumn. In the first flush of the year, when the plant is growing very actively, there is need for an abundant supply of water from the roots, and the wool vessels formed at that time have large cavities to meet this need: as time goes on, and the rate of growth slows off, less water is needed, and the autumn wood has, consequently, only small cavities. The alternation of large and small wood vessels results in the concentric rings which are called annual rings, and these enable the approximate age of a tree to be estimated.

LEAF.-The leaf may be regarded as the main laboratory of the plant, as it is so intimately associated with the physiological processes of nutrition, of breảthing, and of the excretion of water. The essential part of a leaf is its broad flat blade, which is bounded on its upper and lower surfaces by an epidermis (Fig. 3). Between these are a few layers of cells, of which the upper rows are often arranged more or less regularly, forming the palisade tissue, while the lower cells are arranged very irregularly, with large intercellular spaces, forming the spongy mesophyll. Vascular bundles_branch off from those in the stem, and, passing up 
the leaf-stalk from the main veins, then ramify between the palisade and spongy mesophyll, thus providing a continuous connection by way of the stem and branches of the tree between the finest roots and every part of the leaves. The leafcells, except those of the epidermis, are abundantly supplied with chlorophyll, which plays a most important part in nutrition. The epidermal cells of young leaves have thin walls, which are permeable to gases and water vapour, but, as the leaf gets older, the outer walls of the cells become cuticularised and impermeable.

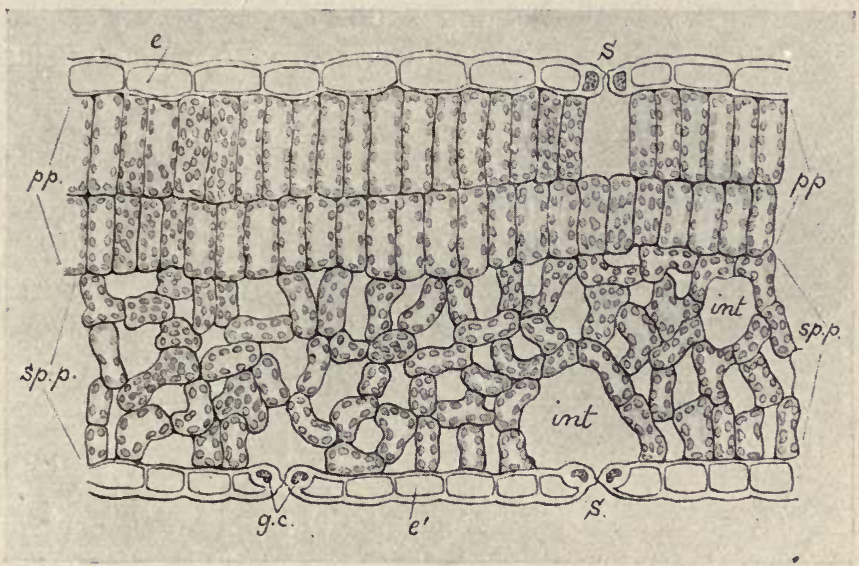

Transverse Section of Blade.

$e$, upper epidermis; $s$, stomata; int, intercellular spaces; $p p$, palisade parenchyma with chlorophyll; $s p . p$, spongy parenchyma; $e^{\prime}$, lower epidermis; g.c., guard cells.

\section{FIG. 3.-THE LEAF. 1}

At this stage communication with the outer air is provided for by means of stomata, which are so very numerous that a single leaf may possess millions. As a general rule the majority of the stomata, sometimes all of them, are on the underside of the leaf, but the distribution of them between the two surfaces varies in different plants.

During the winter most trees enter upon a resting period, and, to reduce the physiological functions as far as possible, generally shed their leaves. Preparatory to this, all useful substances are passed back from the leaves to the branches, and frequently waste products, which are not required by the plant, are left in

1 From Laurie's Flowering Plants. 
the leaves: then a cork cambium forms across the base of the leaf-stalk at the junction with the branch, and a few layers of cork, called the separation layer, isolate the leaf. The dead leaves may hang on for some time, but high winds, or the first touch of frost, will bring them off, leaving the scar already healed over by the layer of cork.

FLOWER.-The usual method of plant-reproduction is by seeds, and flowers are necessary that these may be produced. A complete flower (Fig. 4) consists of calyx, corolla, stamens and pistil, but only the last two are really necessary in order that seeds may be formed. The calyx and corolla are essentially protective in their nature, and guard the delicate reproductive organs inside. The corolla, also, is frequently brightly coloured, in order to attract insects for effecting fertilisation, without which no seed can develop.

The undeveloped seeds or ovules are contained in the ovary at the base of the pistil. Above the ovary is the style, bearing at its summit the stigma, which has some part of its surface specially adapted to catch the pollen grains, which appear as a yellow dust on the stamens, and are carried to the stigma by insects, wind, or in some other manner. When a pollen grain reaches a receptive stigma, the former puts out a tube which penetrates the style below, enters the ovary, and makes its way to the ovule. The contents of the pollen grain pass down the tube, and fuse with part of the ovule (the egg cell), thus effecting fertilisation. Changes then occur, the ovary and ovule develop more or less rapidly, and, finally, the fruit and seeds become fully formed. Sometimes other parts of the flower help to form the fruit, as in the apple, where the receptacle, or top of the flowering stalk, develops to form the fleshy part of the fruit.

From this it will be evident that the seed which is formed, being the product of the fusion of the male and female elements, will, as in the case of animals, produce an individual resembling, but by no means identical with, the parents : resemblance to the female, indeed, is often very remote, inasmuch as flowers of cultivated fruit trees are often self-sterile, that is, they can only be fertilised by pollen from a different variety. Where large plantations of any one variety of apple, pear or plum are grown, it is generally necessary that every third or fourth tree be of some different variety, in order to ensure fertilisation.

Cultivated varieties of fruit trees cannot, therefore, be propagated by sowing the seeds produced, and they have to be multiplied by grafting, or budding, operations wherein a shoot, or 


\section{PLANTS, FUNGI AND INSECTS}

scion, or else only a single bud, of the variety it is desired to reproduce is induced to effect a union with a more strongly rooted

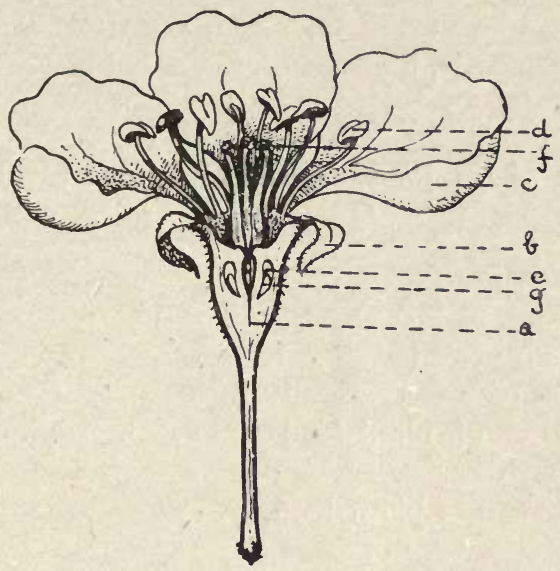

A. Flower.

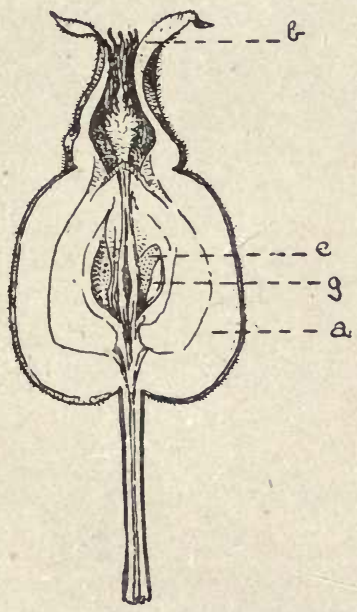

B. Half-developed Fruit.

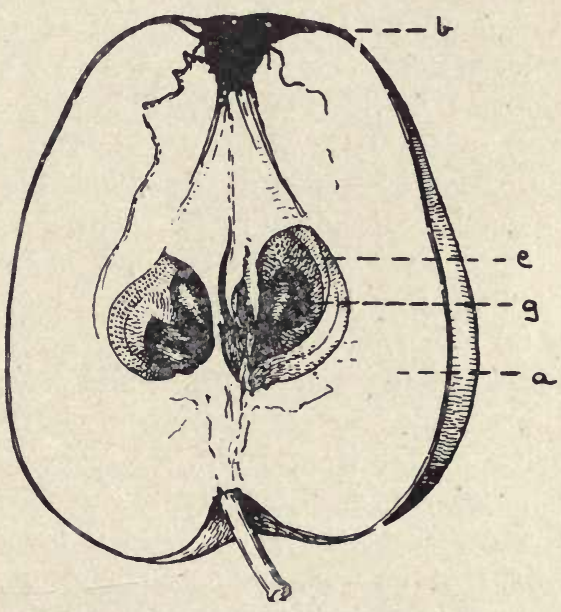

C. Fully developed Fruit.

$a$, floral receptacle; $b$, sepals ; $c$, petals ; $d$, stamens ; $e$, carpels ; $f$, stigmas; $g$, ovule; $g^{\prime}$, seed.

FIG. 4.-VERTICAL SECTION THROUGH APPLE BLOSSOM AND FRUIT.

variety, or stock. The stock and scion are cut in various ways, and the cut surfaces are closely applied to one another, so that the cambiums or living tissues of the two are brought into contact. 
Air is carefully excluded from the junction to prevent it from drying up, and ere long a perfect union between the parts takes place. The fruit that is produced on branches formed above the junction will be that of the scion, but if suckers or branches appear below the graft, the fruit on them will be that of the stock, which is generally worthless.

\section{Outline of the Physiological Functions of a Plant}

The main functions of a plant may be grouped under five headings-

(I) Respiration, or breathing.

(2) Absorption of water.

(3) Excretion of water, usually by transpiration.

(4) Elaboration of plant-food under the influence of light (photosynthesis).

(5) Translocation of plant-food.

(I) Respiration, or breathing.-This is a physiological process which takes place in every part of a plant-root, stem, leaves and flowers. It is independent of light and of the presence of chlorophyll. Oxygen is taken in from the air by way of the stomata, lenticels or permeable cell-walls, when, much as in the case of animals, waste products are oxidised, resulting in the formation of carbon dioxide, which is expelled through the same channels. Respiration is carried on at all times and in all seasons, and does not cease, either at night or in the winter, though at such times its activity is diminished.

(2) Absorption of water.-Water, with various food-salts (minerals and nitrates) in dilute solution, enters the plant from the soil by way of the root-hairs. It is passed on through the delicate root tissues until it reaches the wood of the vascular bundles, and then travels upwards through the plant by way of the vessels of the wood, until it reaches the leaves. The water acts, therefore, mainly as a carrier of such substances as may be present in the soil; at the same time, however, the roots have a certain power, by means of osmotic action, of absorbing some of these substances to a greater extent than others.

(3) Excretion of water, or transpiration.-The bulk of water needed to convey the requisite amount of food for an actively growing plant is very great, and the excess is got rid of by transpiration, whereby water vapour is passed out from the cells into the intercellular spaces, and thence into the outer air by way of the stomata. In very young or delicate parts of the plant, in 
which the epidermal cells are not cuticularised, water passes off from the whole leaf-surface, but this ceases when a cuticle is formed, and the rate at which transpiration occurs is then controlled by the stomata, which have the power of opening and closing as circumstances demand.

(4) Elaboration of plant-food (Photosynthesis).- The mineral salts absorbed in solution by the root-hairs are of no use in feeding the plant until they have undergone various chemical changes, and have been built up into more complex substances. This is effected in the green parts of the plant, and can go on only in the presence of light. Carbon dioxide is taken in from the air, and, through the agency of chlorophyll, the carbon is combined with water into carbohydrates. The oxygen from the carbon dioxide is liberated, and passed back into the air through the stomata. Further chemical changes take place in which the nitrates are built up into more complex nitrogenous substances. The whole process is very complicated, but; ultimately, sugars, starch and nitrogenous foods are formed, and are passed on to the other parts of the plant. This photosynthesis is carried out chiefly by the leaves, and light is essential for the process, so that whenever a plant is much shaded, its development is arrested; on this account the leaves of a tree are arranged so as to form a kind of mosaic, whereby the fullest use is made of the light available.

During the daytime respiration and assimilation go on side by side, so that the plant is absorbing oxygen and giving out carbon dioxide at the same time as it is absorbing carbon dioxide and giving out oxygen, but usually the output of oxygen is greater than that of carbon dioxide. At night, in the absence of light, assimilation ceases, and the plant only absorbs oxygen and exhales carbon dioxide.

(5) Translocation of plant-food.-It has already been seen that the raw food material dissolved in water is carried up to the leaves through the cavities of the wood vessels. The prepared food is transferred from the leaves through the phloem or bast, and is utilised in building up the tissues. Starch is insoluble, so that, before it can be moved from the leaves, it is converted into sugar, and then, if an excess be formed, it may either be stored up in some part of the plant as sugar, e.g. beetroot, or else re-converted into starch, and stored up in that form, as in the potato. 


\section{FUNGI ${ }^{1}$}

A fungus is a plant of the lower order (Cryptogams), which differ from the higher plants by possessing no flowers, and by producing none of the green colouring matter (chlorophyll) which characterises the leaves of ordinary plants. It forms seeds, however, known as spores, and also roots, in the form of exceedingly fine filaments (hyphæ), known as the mycelium, or, more commonly, as spawn. It is this mycelium by which the damage is done to trees attacked by a fungus; the hyphæ make their way through the wood, etc., breaking down the cells of which it is composed, and thus destroying the plant. This renders it practically impossible to apply any remedy once a tree has been invaded by a fungus, unless we can remove the whole of the part attacked; and our efforts, therefore, must be directed to preventing the fungus from seeding, and propagating elsewhere.

The seeds, or spores, which are microscopic in size, are produced in several ways. The mycelium itself in some cases becomes converted into a chain of spores, but the more usual process is for it to send out a number of branches, each bearing at its end a spore, or a receptacle containing many spores (conidia spores). The summer spores of a fungus are formed in this way, and the masses of spore-bearing filaments or branches produce the appearance of a downy covering over the object attacked, familiar to us in the form of mildew or mould. The branches and spore receptacles constitute, in the larger fungi, the portion of the plant which is commonly called the fungus itself, such as the puff-ball, mushroom and toadstool.

The mycelium of a fungus also produces other spores, known as perithecia, which are often formed inside the host plant, and these are enclosed in a tough, leathery receptacle, which renders the destruction of them very difficult. These are the winter, or resting spores, and they are capable of resisting the most intense cold without being injured, and may remain unchanged for years, starting into activity only when they find themselves placed under favourable circumstances. This, as a rule, is in the spring.

A fungus, however, besides reproducing itself by means of spores, does so, also, more directly by means of its mycelium, parts of this becoming changed, and hardened into what is called sclerotia, in which condition it passes the winter, and develops in the following year, spreading itself through the soil, and attacking fresh plants.

1 This description of fungi, and that of insects, is borrowed from Fruit Trees and their Enemies, by Pickering and Theobald. 
Fungi which attack living plants-parasites-are, naturally, of more importance to the fruit grower than those which feed on dead tissue-saprophytes; but the two classes sometimes merge into each other, and a fungus which is usually a saprophyte may, under altered conditions, become a parasite, and attack living plants. In some cases, also, a parasitic fungus reaches the seeding stage only when on the dead wood of the plant which it has killed.

Moulds and mildews are commonly differentiated from other fungi by being confined more to the surface of the host plant, their mycelium penetrating only a short distance into the substance of the leaves, shoots, etc.

For the destruction of fungus spores, the fungicide must be applied either in summer or in winter, according as it is the summer spores or winter spores which have to be attacked. One essential to the successful dealing with the summer spores is to do the spraying on the very first appearance of the disease : in most cases, however, such spraying results only in a checking of the attack, for the mycelium is not destroyed by it, and a renewed formation of spores occurs later on, necessitating a repetition of the spraying operation.

Besides spraying the trees in winter for the destruction of the winter spores, it is very important that all dead leaves, shrivelled fruit, and prunings should be collected and burnt, for it is on them that the spores are generally found. All wounds should be attended to and tarred, for in many cases it is through some wound that the fungus spores gain an entry into the tree; unfortunately they may enter through wounds too minute to be noticed, such as those made by the woolly aphis, and the destruction of pests of that description is, therefore, one of the best ways of keeping the trees free from the attacks of fungi.

\section{INSECTS}

A knowledge of the life-history of an insect is essential whenever it is a question of destroying it, for there is often only one period in its life when it is vulnerable. Generally speaking, there are four distinct stages in the lives of all insects: (I) the egg, (2) the larva, maggot, grub or caterpillar, (3) the chrysalis, nymph or pupa, and (4) the perfect insect or imago. The true pupal stage is absent in the case of mites and spiders, whilst in that of some insects, such as aphides and leaf-hoppers, there is no pupal stage similar to that existing in the case of a moth, where the pupa is quiescent, and does not feed. 
Those insects which have a quiescent pupal stage, for the conversion of the caterpillar, maggot or grub into the adult form, are said to undergo a "complete metamorphosis": beetles, sawflies and flies undergo such a change, as well as moths. Aphides, scale-insects, leaf-hoppers and bugs undergo what is called an "incomplete metamorphosis," wherein the changes between the larva and adult are gradual, the insect in the pupal stage resembling that in the larval stage, except that "wingbuds" appear, these giving place at the next moult to fully developed wings, and the insect then becoming perfect. During the pupal stage in this case, the insect is active, and feeds throughout it, and these insects, therefore, are injurious all their lives. In the other cases, where the pupa is quiescent, damage is done during the larval and adult stages (beetles), or during the larval stage only (moths and sawflies).

True caterpillars have a pair of jointed legs on each of the first three segments of their bodies; the fourth and fifth segments have no legs, and on the next four segments, as well as on the last, or anal, segment, there are pairs of soft pro-legs, or sucker feet. In the case of "looper-caterpillars," this arrangement is modified, there being only one pair of pro-legs in addition to the anal pair, and these are on the ninth segment. False caterpillars, as the larvæ of sawflies are called, have always more than four pairs of pro-legs.

With moths and butterflies, the insect can rarely be attacked when in the perfect state; it must be dealt with, either in the winter, by destroying the eggs and chrysalids, or in summer, by destroying the larvæ. In the former case, a strong insecticide can be used, for the trees are then devoid of foliage, and the substances selected should have, if possible, the twofold property of not only destroying the eggs, etc., but of removing moss, lichen and dead bark from the trees, thus reducing the number of lurking-places available for harbouring insects and their eggs: indeed, this is often the chief way in which winter washes are beneficial; for insect eggs are generally so resistant, or so well protected, that they cannot be destroyed by such washes without injuring the trees. For cleansing properties in a winter wash, we rely mainly on caustic substances, such as caustic soda or caustic lime, but the destructive action may often be enhanced by the addition of some other substances, notably paraffin oil.

For summer treatment, a much weaker insecticide must be used, or the foliage of the tree will be injured. With mothsthe damage being done by the insect when in the caterpillar or 
larval stage - the method of attack is generally based on poisoning its food, rather than on destroying its body by corrosive substances; with aphides (green-fly or black-fly), poisons are often ineffective, for the insect simply punctures the leaves and extracts the juices: in that case an insecticide must be used which acts externally on the body of the insect, either by corroding it, or by stopping, or otherwise interfering with, the breathing of the insect through the apertures in its body provided for that purpose. Nicotine appears to act by producing paralysis.

It will readily be seen from this how essential it is to have a knowledge of the life-history of the insect. But more than this is required; we ought to know the exact action which the various insecticides have on it at various times in its life-history, and in many, it may be said in most cases, our knowledge on this point is very deficient, and can only be increased gradually by very extended and laborious investigations. Every individual case has its own complications; thus, the larval stage of an insect is generally divided into various sub-stages, the grub moulting (often five times) and changing its nature, and in some of these stages it may be more sensitive to poisons, or less protected by external hairs, than in others. It does not necessarily follow that the earlier stages of the insect are those in which it is most sensitive, but it would appear that, as a rule, poisons are most effective in the earlier stages, and corrosive substances most effective in the later stages. 


\section{Chapter II}

\section{THE MEASUREMENT OF RESULTS (Reports, I, 57;}

II, II3; V, 7; VII, 7 ; XIII, 82) ${ }^{1}$

ONE of the first problems which presented itself at Woburn was, how to measure the results of the experiments. It might appear at first sight, that, with fruit trees, the matter is a simple one, and that all that is necessary is to record the crops produced. But a little consideration will show that this would be a very inadequate means of measurement. Even if the crop records could be dealt with in a simple manner, it is clear that any conclusions based on such records for one season, or even for one period of the life of a tree, might be very misleading, and that it is only the total yield throughout the whole life of the tree which would give a satisfactory measure of the behaviour of that tree. To obtain such records would require a length of time for the experiments hardly compatible with the duration of human life.

There are other features, however, besides the length of life of the plant, which cause special difficulties in horticultural experiments, as contrasted with those existing in agricultural experiments, these are : the relatively small number of plants which it is possible to include in each experiment; the necessity for some branch-treatment, such as pruning, thinning of fruits, etc., which introduces 'unknown factors into the results; and the large number of varieties which exist of each kind of fruit tree, many of these varieties showing marked differences in habit and behaviour.

With trees such as apples and pears, it is only in exceptional cases that the individuals constituting an experiment should be planted within $20 \mathrm{ft}$. of each other: lesser distances may be adopted with certain varieties of feeble growth, or where the experiment is likely to be completed within a few years; but even greater distances must be allowed in the case of free-growing standard trees. A distance of $20 \mathrm{ft}$. between the trees admits of only a hundred trees to the acre, and if each plot were to contain

1 These references, and similar ones in the text, are to the Reports of the Woburn Experimental Fruit Farm, a list of which will be found at the end of this volume. 
several thousand plants, as in the case of agricultural plots, the area required would be preposterously large. Nor is it probable that, in this country, additional accuracy would be obtained at all commensurate with any great increase in the size of the plots ; for the land in England is so lacking in uniformity, that it is difficult to secure any one field where fruit trees do equally well in all parts of it. More satisfactory results seem to be obtainable by planting small plots in situations where the conditions appear to be strictly uniform, and duplicating the experiments by repetitions in other situations where a similar uniformity exists.

The first question which arises is, the minimum number of trees or bushes which each plot should contain. Judging by the results obtained at Woburn, this number may be placed at 6 to I2 for fruit trees, 20 to 50 for fruit bushes, and Ioo to 200 for strawberries. But such an estimate requires many qualifications. It applies only to the case where one variety of the plant is under investigation, and to a case where all the trees or bushes have been very carefully selected, so as to be as uniform as possible in the first instance. This may be effected by making a rough preliminary selection, then weighing each plant, and arranging the plants in groups, such that the average weight of each group is the same, and that the difference in the weight of the individuals is but small. Trees thus selected behave in a surprisingly uniform manner during the first few years of their life, $i . e$. so long as they are occupied in growing, rather than in bearing: as they get older, the peculiarities of the individuals assert themselves, and the behaviour becomes less regular; hence this estimate of the number of trees required must depend on the nature of the experiment: if the results are to be measured by the crops borne when the trees have matured, the minimum number given above for trees should be increased two- or three-fold. With bush fruits and smaller plants, the results would nearly always be measured by the crops.

The nature of the investigation must also in other ways modify the estimate of the number of plants required. For an isolated experiment, where a plot under some special treatment is compared with a plot under normal treatment, six trees to each plot would not be enough; but generally there will be many plots bearing on the same question, and in that case, a minimum number of trees may be used for each. Thus, in manurial experiments, there would probably be a dozen different plots, each receiving different doses of manure, and the regularity of the results in these would usually serve as a check on too readily accepting abnormal behaviour in any one plot. 
Where more than one variety of any kind of fruit is under investigation, the experiments have to be multiplied in a corresponding ratio. In the case of apples, pears and plums, three or four well-selected varieties with distinct and different habits would seem to lead to safe conclusions as to the behaviour of these kinds of fruit trees under most conditions of culture; but on certain questions, such as those of pruning, a larger number of varieties would be required. With bush fruits, from three to six varieties may be used for experiments on general questions; and, with strawberries, about a dozen. Care should be taken that none of the varieties selected are such as are known to be unsuitable to the locality.

The necessity for pruning does not raise any serious difficulties in the case of bush fruits, for it is easy to adhere to some general rule in the treatment of such plants; but with the larger fruit trees, the behaviour of a tree may be rendered abnormal if any general scheme of pruning is adhered to too rigorously, for, apart from the fact that different varieties require totally different branch-treatment, individuals of the same variety will vary considerably in the number of shoots formed, and the position of these shoots on the tree; and, when the shoots are ill-arranged or cross each other, the trees will suffer, unless matters are remedied. Still, such pruning as was left to the discretion of the pruner at Woburn was always reduced to a minimum, and any rule adopted as to the extent to which the main and side growths were to be shortened, was adhered to in all but excessive cases. In the same way, the thinning of the fruit on a tree was not left to the discretion of the operator; but consisted of reducing the number of fruits in a truss to two.

Logically, as has been said, a complete experiment should embrace the whole period from the grafting of the tree to its ultimate death; but this is neither practicable, nor would the results be of much benefit to fruit growers, for the economy of a fruit plantation, like that of a gold mine, consists in producing the highest returns in the shortest time-there being, however, a limit below which precocity and rapid exhaustion of the tree ceases to be profitable, owing to the expense of replanting the ground. So far as experiments are concerned, the life of a tree may be divided into two periods : the first, during which active growth is progressing, and new branches are being formed; the second, that of fruit-bearing, when growth is restricted to a gradual enlargement of the trunk and main branches, and to the formation of only small subsidiary shoots. A third period follows, 
when vigour is decreasing; this is generally characterised by the spasmodic production of heavy crops of inferior fruit.

In any measurement of results based on the crops produced, it must be remembered that the point of view of the fruit grower is not identical with that of the tree. A small badly-developed fruit contains a relatively large amount of solid matter compared with a well-developed fruit, and represents nearly the same drain on the resources of the tree (see p. I06); but it would rarely happen that the results should be measured from this point of view. In general work, size of fruit must be given as much consideration as quantity, though another factor which is of great importance-quality - has usually to be left unconsidered. It becomes a question, therefore, how fruit crops may best be dealt with, so as to take into proper consideration weight of crop and the average size of the fruits. In practice, the value of a sample of fruit varies very rapidly with the size of fruits. One sample with fruits half the size of another sample will generally fetch much less than half the money-probably only about a quarter as much-and such a proportion, i.e. a value varying as the square of the size, or rather weight, of the fruits, has been taken at Woburn as a convenient basis. The total "value" of the crop of a tree, or of a plot of trees, is, therefore, found by multiplying the square of the average size of the fruits by the number of fruits, or, what comes to the same thing, multiplying the average size of the fruits by the total weight of the crop. ${ }^{1}$ Of course, the numbers expressing such "values" have no monetary significance, but simply give the relative values in different cases, and may, for convenience, be reduced so that the value in the check plots are expressed by Ioo. The values in the case of apples of different varieties cannot be compared together. In most cases the results have been examined independently from the three points of view of the weight of crop, size of fruits, and value of crops.

As to what variations may be expected in the cropping of similar trees under the same conditions, or what is the probable experimental error in cropping experiments, no useful estimate can be made, except in cases where the trees are bearing freely; with young trees, which have come only partially into bearing, with trees which are naturally shy bearers, and with all varieties in a bad season, many trees will be barren, and the variation in cropping will be numerically enormous. To obtain a reasonable ${ }_{1}$ Value $=(\text { size })^{2} \times$ number $:$ but size $=\frac{\text { weight }}{\text { number }}$, or number $=\frac{\text { weight }}{\text { size }}$ : hence, value $=(\text { size })^{2} \times \frac{\text { weight }}{\text { size }}=$ size $\times$ weight. 
estimate under ordinarily favourable conditions, the crops from a hundred trees in a plantation of Bramley's Seedling in I909 may be taken; these trees were on the paradise stock, and were eighteen years old at the time. They bore from $2 \frac{1}{2}$ to 6 bushels per tree. Taking the weight of crop, and comparing together only such trees as were under similar treatment, it was found that the average difference between the crops of any individual tree and the mean of the trees in the whole plot was 24 per cent.; this would give the " probable " error (using the term in its mathematical sense) of the mean results deduced from a plot of six trees as being $\pm 7 \cdot I$ per cent., or $\pm I 7 \cdot 5$ per cent. for that of the results of a single tree.

Such a variation, it must be remembered, applies only to trees in contiguous positions, and a considerably greater variation would generally occur in similar experimental plots, if these were situated in distant parts even of the same field: but it must also be remembered that no conclusions would be likely to be based on the crops of a single season only.

As to the measurement of a tree when no crops are available for estimating the results, or when growth or vigour have alone to be studied, a considerable number of methods have been adopted. The most certain one was to ascertain the increase in weight of the whole tree ; but that could only be done when the experiment was not to be continued for more than a few years: in other cases, yearly measurements of some portion of the tree were made. These consisted of measurements of-the general size of tree, taking the mean of its height, spread of branches, and girth of stem at some selected distance above the ground: the weight of the prunings (when the trees were all pruned in the same way); the length of new shoots formed, and, sometimes, the stoutness of these shoots, as given by their weight per unit of length; the weight of the total leaf-crop of the trees; the weight or size of the leaves, as determined by weighing or measuring certain selected leaves, such as the sixth leaves from the ends of about ten shoots; or, lastly, the nitrogen assimilated in the leaves. These various measurements were, of course, not always equally applicable or convenient, nor could they always be expected to give values even in the same direction : e.g. a certain form of treatment might lead to the production of long, feeble shoots, the total length of which would not be in proportion to the real vigour of the tree: still less could they be expected all to give values of the same magnitude; for instance, the percentage increase or reduction in the size of the leaf would, as a rule, be much less than 
that of the length of new wood formed; for, if the leaf-size were reduced by Ioo per cent. it would mean that there were no leaves, i.e. that the trees were dead, whereas the growth may well be reduced to nil while the trees are still very far from being dead. But it has been well established by the observations themselves that all these measurements yield results of the same character in ordinary cases, and that any one of them may generally be taken as a criterion of the condition of the tree. One example of the numerous instances available may be quoted here : this refers to eight sets of experiments with apple trees grown in pots (only two or three trees in each experiment) under various conditions (XIII, 82). The results are entered below in the order of the vigour of the trees as measured by the length of new wood formed, whilst the values in the other columns are those given by taking measurements of seven other features. All of these eight sets of measurements lead to practically the same order of merit, there being only two out of the eight experiments in which any anomalous results were obtained (enclosed in brackets), and, as a matter of fact, in one, if not in both of these, there was a good reason why the results should be anomalous.

\begin{tabular}{|c|c|c|c|c|c|c|c|c|}
\hline \multirow[b]{2}{*}{ Expt. } & \multirow{2}{*}{$\begin{array}{l}\text { Length } \\
\text { of } \\
\text { shoots. }\end{array}$} & \multirow[b]{2}{*}{$\begin{array}{l}\text { Leaf- } \\
\text { size. }\end{array}$} & \multirow{2}{*}{$\begin{array}{l}\text { Weight } \\
\text { of leaf- } \\
\text { crop. }\end{array}$} & \multirow{2}{*}{$\begin{array}{c}\text { Increase in } \\
\text { weight of } \\
\text { trees. }\end{array}$} & \multicolumn{2}{|c|}{$\begin{array}{l}\text { Dry matter in } \\
\text { leaves. }\end{array}$} & \multicolumn{2}{|c|}{$\begin{array}{l}\text { Nitrogen in } \\
\text { leaves. }\end{array}$} \\
\hline & & & & & $\begin{array}{l}\text { Per } \\
\text { cent. }\end{array}$ & $\begin{array}{l}\text { Total in } \\
\text { crop. }\end{array}$ & $\begin{array}{l}\text { Per } \\
\text { cent. }\end{array}$ & $\begin{array}{l}\text { Total in } \\
\text { crop. }\end{array}$ \\
\hline I & I 63 & I 53 & I 47 & I 59 & $93 \cdot 2$ & I 52 & 117 & I 78 \\
\hline 2 & I39 & I 44 & I 40 & I 39 & $92 \cdot 7$ & I 44 & 105 & I $5 I$ \\
\hline 3 & 128 & 120 & I 37 & $(146)$ & $(79 \cdot 6)$ & $(120)$ & (I4I) & $(\mathrm{I} 7 \mathrm{O})$ \\
\hline 4 & 100 & IOO & IOO & Ioo & $90 \cdot 5$ & IOO & Ioo & 100 \\
\hline 5 & 77 & 97 & 72 & $5^{8}$ & - & - & 79 & 57 \\
\hline 6 & 71 & $7^{6}$ & 66 & 24 & - & - & 69 & 45 \\
\hline 7 & 69 & 69 & 66 & 24 & 一 & - & 66 & 44 \\
\hline 8 & 60 & $(76)$ & 63 & $(28)$ & - & - & $(84)$ & (53) \\
\hline
\end{tabular}

The features of growth which were generally found to afford the simplest means of ascertaining the well-being of a tree, were the length of new wood formed, or the leaf-size, selecting the sixth leaves from the shoot ends. The former exhibits far greater differences (often several hundreds per cent.) than the latter with trees under different treatment, and it is free from the obvious source of experimental error which is inherent in any method dependent on the selection of particular leaves ; but it cannot well be applied to trees of any considerable size. Taking the results with 200 apple and pear trees of six years of age, the measurements of those which had been similarly treated indicated a probable error of \pm 20.5 per cent. in any one tree due to its individual peculiarities, or an error of \pm 8.3 per cent. in the values from a plot of six trees. 
With the leaf-size, the probable error, as determined from measurements of these same trees in the same season, was $\pm \mathrm{I} 6 \cdot 7$ per cent. for one tree, or $\pm 6 \cdot 3$ per cent. for the mean of six trees, and independent observations showed that, of this latter error, $2 \cdot 2$ units were due to errors consequent on having to select certain leaves, for that was the probable error between repetitions of the measurements of the same plots.

It will be noticed that the errors of the measurements of leafsize, length of shoots, and crops (in a good cropping season), do not differ much in magnitude-6.3, $8 \cdot 3$, and $7 \cdot$ I per plot-and as the length of shoots shows much greater variation under differences of treatment than the leaf-size, a measurement of the former is generally preferable to that of the latter.

It does not seem possible to combine the evidence derived from the growth measurements of a tree with that based on its cropping into one general expression, and these features must be treated separately; indeed, they are to a considerable extent opposed to each other, for heavy bearing acts as a check on woodformation, and vice versa.

In all experiments with plants, one individual is liable to behave anomalously owing to accidental circumstances, such as insect attacks, etc., and if the number of plants in a plot is small, as in experiments with trees, such exceptional trees must be eliminated in dealing with the results. It is objectionable, of course, to have to exercise any selection in dealing with experimental results, but it cannot always be avoided, though it is rarely needed. Care, however, must always be exercised in examining the results of the check plots before accepting them; if the behaviour of the trees in these, where presumably the treatment is of a normal character, is not such as general experience would lead one to expect-if the trees, for instance, are sickly and show little growth-it is probable that some adverse conditions have prevailed, and it would not be safe to accept these trees as standards of comparison for the others. It has been a matter of observation at Woburn that the normal plots often appear to be more subject to accidental variations, and to show greater differences between themselves, than plots where some special treatment has been adopted. This is not altogether surprising; most forms of special treatment tend to make the plants behave specially well or specially badly, and in such cases, chance conditions would have less effect than in the normal plots, where there was no special stimulus in one direction or the other. This source of error can be guarded against only by multiplying the number of these normal plots, 
and, where such plots are distributed throughout a series of experimental plots, it is sometimes found advisable, instead of taking the average of the results from them, to draw a smoothed curve through these results, and to compare those of the experimental plots with readings taken at corresponding points of this curve.

The proper expression of results in horticultural experiments presents several special difficulties. It is well, of course, to represent the values in the check plots as Ioo, and then the differences exhibited in the other plots will be percentage differences; but ordinary percentages may be quite misleading. Owing to the smallness of the number of trees in each plot, or to differences in behaviour with different varieties, etc., the results of similar experiments often show considerable variation, and may even be in opposite directions, and to take a mean of positive and negative percentage differences is open to error : thus, if we have double the normal growth in one case, and half the normal growth in another, it is clear that, on the average, the trees show no divergence from the normal; but, expressed as percentages, there is an increase of roo per cent. on the normal ( + I0o) in the first case, and a decrease of 50 per cent. $(-50)$ in the second, the mean of the two being +25 . To obviate this source of error, which is serious only when large percentage differences have to be dealt with, what may conveniently be termed " proportionate percentages ". have sometimes been used; these are obtained by always dividing the smaller quantity into the larger, and then putting the sign + or - to the result, according as the experimental plot has given larger or smaller values than the check plot; thus, in the above instance we get-

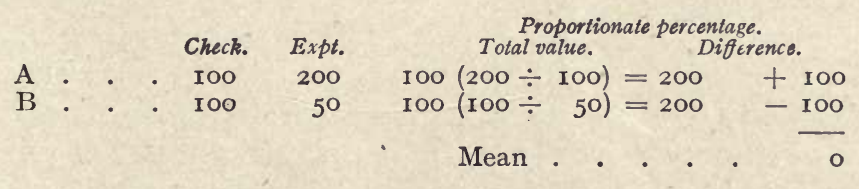

The only objection to this method of dealing with results is that negative values greater than Ioo per cent. are sometimes obtained, which have the appearance of being impossible.

Though the above is an exaggerated instance of discrepancy, it is in the nature of horticultural experiments that the results in some cases may be in the opposite direction to those in the majority. It must be remembered, however, that such discrepancies do not invalidate the conclusion drawn from the means of the results, any more than the measurement of the distance of 
a star is invalidated by some of the determinations of parallaxes giving negative values. Misconception on this point is often shown by horticulturists, who imagine that the general results of a large number of experiments can be upset by producing results of an opposite character in some one experiment with, perhaps, half a dozen trees.

Another difficulty of a serious nature is repeatedly met with in dealing with horticultural experiments. The individual experiments from which a mean has to be deduced are often varied in character-and, indeed, must be varied, if the conclusions are to be generally applicable-the number of the trees comprised in the plots may be different, the varieties may be different, and their general vigour may have differed. If it is only a case of differences in numbers, that may easily be dealt with by weighing each result according to the number of trees under examination; but other differences cannot be dealt with so easily. To take an instance: some special method of planting may have been adopted in the case of three different varieties of apple trees, two of them, I. and III., are vigorous growers, but have not shown much increase in growth under the special treatment, whilst the variety No. II. has shown very poor actual growth, but a relatively large increase under the special treatment. The actual growth measured in the check and experimental plots is given under $\mathrm{A}$ and $\mathrm{B}$ below.

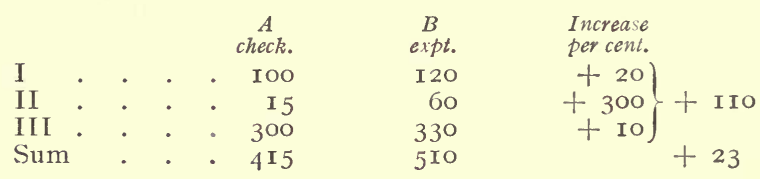

On working out the results with each variety separately, and taking the mean ( + IIO), it is evident that the results with the feeble variety (II) influence the value much more than they ought to do, considering the smallness of the actual amount of growth measured; whereas, if the sum of the measurements of the check and experimental plots be taken, and treated as if the three varieties were all one, we get a mean $(+23)$ which almost entirely swamps the large increase under treatment shown by the second variety.

The only safe rule for dealing with cases of this sort is to take the mean in both these ways: if these prove to be very different, the results must be considered as highly uncertain; if they are not so, the mean of them may be accepted with some confidence. 


\section{Chapter III}

TRENCHING (Reports, V, 56; IX, 65; XIV, 33)

In the natural course of events, the preparation of the ground for planting must precede the planting itself, and a description of any investigation of the former may, therefore, claim priority over matters dealing with the trees themselves.

The subject of trenching has occupied attention at the Fruit Farm since its foundation, though, perhaps, it is one which is of more importance to the market gardener than the fruit grower; for in fruit growing, at any rate when on a large scale, the trenching of the ground is not usually attempted. It is, however, occasionally done, and still more often a substitute for trenching is adopted, in the form of subsoiling by plough cultivation, often at considerable expense.

In considering the results obtained, it must be borne in mind that bastard trenching-in which the layers of soil are broken up, but replaced in their natural order-is alone dealt with, and that no manure or other matter was buried in the trench. Whenever anything is thus buried, whether it be manure, turf from the surface, or the top spit of the soil itself, it is clear that the whole character of the soil must be affected, and to an extent which must vary so greatly with its original character, and with the nature of what is buried in the trench, that no investigation of any particular cases would form a guide as to the results likely to be obtained elsewhere, or under other circumstances. Such a subject, in fact, is hardly amenable to investigation, and bastard trenching of arable land, without the addition of dung, was alone examined, the two upper spits being dug, moved, and then replaced in their natural order, the third spit having been broken up, but not moved.

There is one special case where such trenching must, presumably, do good; namely, where a hard pan has formed under the surface soil, preventing the roots of plants from extending downwards, and thus restricting their supply of nourishment. No such case, however, was included in the Woburn work, the 
instances selected being such as are of more general occurrence. One of these was a light, sandy soil, where little or no effect might have been expected from trenching (without manuring), but the other three were eminently cases where trenching would génerally be advocated, and where, as a matter of fact, it has been adopted wherever high-class fruit culture has been embarked upon. Two of these were at the Fruit Farm, one on the heavy clay soil at the lower part of the farm, and the other on the upper ground, where the proportion of sand in the soil justifies its being termed a loam, though it is, in winter, as heavy and sticky as most clay soils (see p. 8I). Both stations, in fact, are on the Oxford clay formation, and the shallowness of the surface soil, and the compactness of the subsoil, are very unfavourable for the penetration of roots (see p. 309). It is certainly a soil which would be likely to benefit by trenching, as the subsoil evidently requires aëration. The other instance was a heavy loam, overlying clay with chalk under it, in Broadbalk field at Harpenden. The differences between these soils are brought out by the following analyses of them.

MECHANICAL ANALYSIS OF THE SOILS ${ }^{\mathbf{1}}$

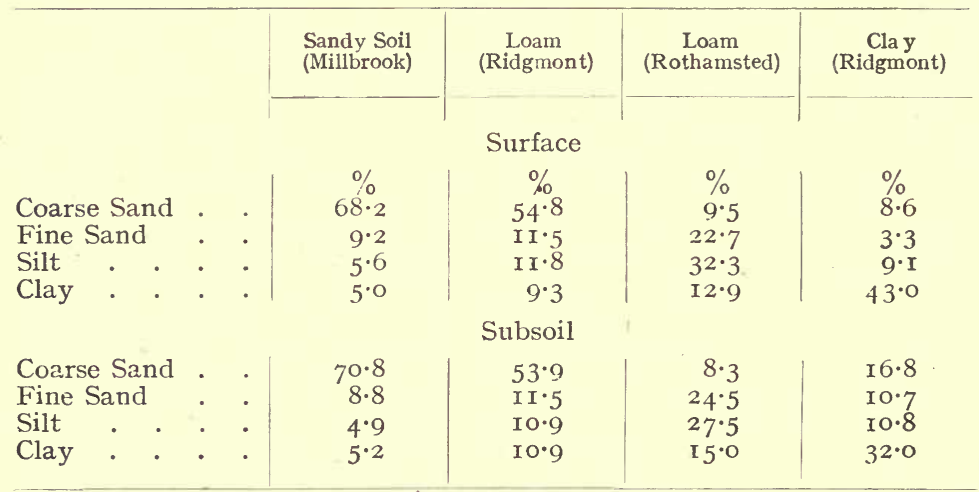

The investigation, in which Dr. E. J. Russell participated, was of a twofold nature, consisting, on the one hand, of ascertaining the behaviour of trees and bushes planted in trenched and untrenched sections of the ground, and, on the other hand, determining the effect of the trenching on the water contents and nitrates in the soil, the latter affording evidence of such changes as had occurred in the bacterial conditions from the physical alterations produced by the trenching.

1 For more detailed results, see p. 83 . 
The observations on the behaviour of the trees extended in some cases over a considerable number of years, though in others they applied only to the first few seasons after planting; but, of course, the results during these first seasons are of the greatest importance, as it is during them that the effect of the previous trenching would be most prominent. In one instance it was possible to investigate the effect of trenching the same piece of ground at dates fifteen years apart, and it was found that, whereas on the first occasion the trenching had produced no good result, it had done so to an appreciable extent on the second (Ridgmont loam, first and second series). It would appear from this that the effect may vary with the nature of the seasons immediately following the operation; and this is, certainly, a very probable proposition. It also appears, especially from the results at Harpenden, that, even in the same season, different plants may be affected to very different extents, and even in opposite directions, by the trenching.

The bulk of the experiments extended over the four seasons from March Igog to the end of IgI2, a period which included the unusually hot, dry summer of IgII, the cold, wet summers of I909 and I9I2, and the season I9I0, which was of intermediate character.

Samples of soil were periodically taken for determinations of moisture and nitrate, and observations were made on the growth of fruit trees in the plots. The following is a summary of the results, the sign + being used where the result was in favour of trenching, and - where it was against trenching.

Speaking generally, the values for tree-growth and for the soil factors are fairly closely connected. In the sandy soil (first series), where the water supply is apt to be a limiting factor, we find a drier subsoil and a reduced tree-growth to result from trenching (though the results of the second series make it more than doubtful whether the trenching was really the cause of the extra dryness of the soil) : in the loams, trenching has had, in most cases, only a small effect on the water contents, and none on the nitrates; and the effect on plant-growth has, on the average, been nil: on the clay, where the nitrogen supply assumes considerable importance, there is a small gain in nitrate on the trenched plot, and a small gain in growth also. Thus, trenching is seen to have had no greater effect on the development of the trees than it has had on the moisture and nitrate content of the soil; indeed, if a general mean is taken of all the plant data above, it is found to be exactly nil. Evidently it is 
SUMMARY OF RESUI,TS SHOWING THE EFFECTS OF TRENCHING

\begin{tabular}{|c|c|c|c|c|c|}
\hline & \multicolumn{2}{|c|}{ Effect on Soil } & \multicolumn{3}{|c|}{ Effect on plant-growth } \\
\hline & $\begin{array}{c}\text { Effect on } \\
\text { percentage of } \\
\text { water present. }\end{array}$ & $\begin{array}{l}\text { Effect on } \\
\text { nitrate: } \\
\text { parts } \\
\text { per million. }\end{array}$ & \begin{tabular}{|c|} 
Effect on \\
leaf-size; \\
proportionate \\
percentage.
\end{tabular} & $\begin{array}{l}\text { Effect on } \\
\text { growth; } \\
\text { proportionate } \\
\text { percentage. }\end{array}$ & $\begin{array}{l}\text { Effect on } \\
\text { crops; pro- } \\
\text { portionate } \\
\text { percentage. }\end{array}$ \\
\hline $\begin{array}{c}\text { Sandy Soil } \\
\text { Ist Series . } \\
\text { 2nd Séries } \\
\text { ", }\end{array}$ & $\begin{array}{l}\text { Surface + } 0 \cdot 4 \\
\text { Subsoil - } 0 \cdot 9 \\
\text { Surface - } 0 \cdot 3 \\
\text { Subsoil + } 0 \cdot 2\end{array}$ & $\begin{array}{l}+\mathrm{I} \\
\mathrm{Nil} \\
+\mathrm{I} \\
+\mathrm{I}\end{array}$ & $\begin{array}{r}+4 \\
-\end{array}$ & $\begin{array}{l}-\mathrm{I} 6 \\
-\end{array}$ & $\begin{array}{l}-2 \mathrm{I} \\
-\end{array}$ \\
\hline $\begin{array}{l}\quad \text { Loam } \\
\text { Ridgmont } \\
\text { Ist Series . } \\
\text { 2nd S"eries } \\
\text { Rothamsted }\end{array}$ & $\begin{array}{l}\text { Surface Nil } \\
\text { Subsoil + O.4 } \\
\text { Surface + } 0 \cdot 6 \\
\text { Subsoil + O.I } \\
\text { Surface + } 0 \cdot 6 \\
\text { Subsoil + I.2 }\end{array}$ & $\begin{array}{l}\mathrm{Nil} \\
\mathrm{Nil} \\
-\mathrm{I} \\
+\mathrm{I} \\
-\mathrm{I} \\
\mathrm{Nil}\end{array}$ & $\begin{array}{l}+10 \\
- \\
- \\
-\end{array}$ & $\begin{array}{c}+3 \\
+39^{1} \\
\left.+83^{2}\right\}-30^{4}\end{array}$ & - \\
\hline Clay $^{5}$ & $\begin{array}{l}\text { Surface }-\mathbf{I} \cdot \mathbf{O} \\
\text { Subsoil }+\mathbf{I} \cdot 8\end{array}$ & $\begin{array}{l}+3 \\
+3\end{array}$ & +5 & $+I^{\prime} 5$ & - \\
\hline
\end{tabular}

not an operation on which a fruit grower should spend his money.

Special attention should be directed to the very adverse effect which trenching had on bush fruits at Rothamsted, the effect being persistent throughout the four years embraced by the observations, and applying equally to black currants and gooseberries. This is only one out of several instances in which bush fruits show a marked, and, at present, unexplained difference in

1 The value in this case, as it appeared in the original report, was +72 , showing a large, and altogether exceptional, balance in favour of trenching: special attention was directed to it (XIV, App., pp. 494. 496). Observations in subsequent years proved, however, that it was erroneous. There were in this case two plots of untrenched ground; these had not up to that time yielded very concordant results, but there was not sufficient evidence to justify one of them being discarded : the records of subsequent years, however, clearly showed that one of them was being affected by the neighbourhood of a shelter hedge, and when the results in the other, and unaffected, plot were alone considered, the value became reduced from +72 to +39 . The value, when the records for four subsequent years were included, was +9 .

2 Large fruits only. $\quad 3$ Small fruits only.

4 Large and small fruits together.

5 Retrenched ground compared with ground trenched I 2 years previously. 
their behaviour as compared with apples, etc. (see pp. 35, 54, I07). Unfortunately, no bush fruits were included in the plantations in the other soils. Except in the case of the Ridgmont series in loam, where bush apple trees alone were grown, these other plantations contained standard and bush trees of apples, pears and plums. 


\section{Chapter IV}

\section{PLANTING (Reports, II, I77; V, 56; IX, I; XV, 20)}

GREAT stress has always been laid by horticulturists on the methods employed in the planting of fruit trees after their removal from the nursery. The numerous experiments on the subject made at the Woburn Farm during fourteen years derive a special interest from the mode of their origin, and their value is enhanced by their not having been obtained in order to establish any preconceived opinions on the subject. They originated in certain plots of ground having been set aside to test the evil results of careless planting, in the expectation that a demonstration would thereby be furnished in confirmation of the current teaching of horticulturists, in which, be it mentioned, those conducting the experiments had implicit belief at the time. The results obtained from these plots, however, belied this teaching, and were consequently set aside as having probably been invalidated by some unknown accidental cause. Two other series of experiments were then made in the hope of securing more acceptable results, and when these also gave similar evidence, even of a still more decisive character, they, too, were rejected, and yet other series instituted. It was only when these last confirmed the evidence previously obtained that the observations were accepted as correct, and a search for an explanation was made. Perhaps the experiments were multiplied beyond the limits necessary for proof, but this was rendered advisable from the rabid character of the criticisms levelled against the conclusions of the previous ten years' work on the subject, which could best be answered by accumulating a weight of evidence sufficient to place the results beyond question. Though the facts observed may contradict " orthodox " teaching, a rational explanation can be offered of them in accordance with present botanical knowledge of the structure, physiology and mode of growth of plants.

Coming to details: the original roughly planted trees consisted of eighteen dwarf apples, representing three different varieties, planted in I894-5, in ground which had not been 
trenched. The roots of the trees were not trimmed, they were huddled into small holes, and then rammed into the ground. The branches of the trees, however, were duly cut back, and they were in every respect other than the method of their planting, treated in orthodox fashion.

Though these trees, when compared with their carefully planted fellows in the neighbouring plot, showed some deficiency in leaf-vigour, especially during the first year after planting, they showed an excess of vigour, both as regards the number of shoots and the length of new wood formed, the excess of this latter amounting to $3 I$ per cent. in the second year. In the four sets of repetitions of these experiments which were made at the farm in subsequent years-under the superintendence of different managers, it should be noticed-the roughly planted trees in all cases showed some deficiency in leaf-vigour during the first season after planting, though this always disappeared later on, and was generally succeeded by an increased vigour during the next two seasons; but when the trees were lifted at the end of three years, and the increase in their weight since planting determined, it was found that in all cases there was a considerable balance in favour of those which had been roughly planted, ranging from I7 per cent. up to as much as $4 \mathrm{I} 7$ per cent. The trees examined in these series included dwarf and standard apples, and dwarf pears and plums, whilst the character of the soil in which they were planted varied considerably in the different cases.

As a result of these experiments it was concluded that the increase in vigour consequent on adopting rough methods of planting must be accepted as a reality, and a search was instituted to ascertain which particular feature of this rough treatment was responsible for such a result. At the same time steps were taken to place the main facts on a more extended basis, by enlisting the kind offices of fruit growers in various parts of the country to make trials of rough planting, allowing measurements of the growth of these trees and of the corresponding carefully planted ones to be taken after one and two years. Including the experiments made at the Fruit Farm, these trials took place in different localities from Cornwall in the west, to Cambridgeshire in the east, and Cheshire in the north, and, besides apples, pears and plums, they included cherries, apricots, peaches, nectarines, damsons, gooseberries, raspberries and currants. Reckoning each kind or variety of tree examined as one set, there were 146 sets, comprising nearly 
I500 trees; but, for reasons detailed in the Reports, it is fairer to group these sets together in some cases, and, when this is done, it is found that out of 70 such grouped sets, 4I (or 59 per cent.) showed increased growth to follow the rough planting in the first season, and that out of 54 sets in which measurements were made after the first season, 39, or 72 per cent. of the whole, showed a similar advantage in the second year. Thus the superiority increases as time progresses, and this is shown also by the actual magnitude of the increased growth, for it amounted, on the average, to 38 per cent. in the first year, and to 54 per cent. in the second year.

Increased growth, however, was not, as will be seen, an invariable consequence of rough planting; in about 20 per cent. of the cases available the results were negative, there being a difference of less than Io per cent. between the roughly and carefully planted trees; whilst in a certain number of cases the balance was in favour of careful planting: these cases represented I4 per cent. of the total number when the first year's measurements alone were considered, and II per cent. in the case of the second year's measurements; but, as this means that there were between four and seven times as many cases where rough planting was more beneficial than careful planting, the balance is considerably in favour of the former. It is probable that the absence of definite results in the case of some of these trials was due to the difficulty in persuading the planters to be sufficiently rough in their handling of the trees, owing to their fear of injuring them; indeed, in one case no persuasion would induce a Scotch gardener to try such outlandish methods, though he was actually in the employment of the owner of the Fruit Farm.

That the excess of growth shown by the roughly planted trees was attributable to that growth being of a more whippy character, was sufficiently disproved by the fact that in some of the series the results were based on the actual increase in weight of the trees, whilst in several other series the stoutness of the new growth was directly measured, and was found to be substantially greater-to the extent of 15 per cent.-with the roughly, than with the carefully planted trees: out of 35 pairs of trees there were only four cases where the reverse obtained (IX, 2I).

How far the excess of growth produced by rough planting is maintained in after years was, perhaps, not investigated so fully as it might have been, for in most cases the experiments or the measurements were discontinued after two years; but in two instances, where observations were continued throughout seven 
years on two plantations containing Ioo trees, no reduction occurred in the superiority (amounting to 50 per cent. in growth) of the rammed trees. Nor did this excess of growth seem to be accompanied by any loss of cropping power, even during the early years after planting, for, in the plantations in question, the crop produced by the rammed trees was in excess of those from the unrammed ones to the extent of 22 per cent. in one case, and over Ioo per cent. in the other; whilst in a third series, wherein records of the fruiting were kept for ten years, there was an excess of 13 per cent. With gooseberries, currants and raspberries equally good results were obtained as to fruiting; the crops from the rammed bushes of the first two species showing in the second season an excess of Ioo per cent. over those of their unrammed fellows (IX, 25).

In these trials by independent growers the special item in rough planting to which attention was drawn was the ramming of the ground after the roots had been covered with the soil, but the roots were not purposely illtreated by being broken or unduly huddled together, since other experiments, which were in progress at the farm, had already indicated that it was this ramming which was responsible for the benefit, and that rootinjury, unless carried to an excessive extent, was an unimportant factor in the case.

In these other experiments the three main items of rough planting were examined separately :-

(I) Ramming the trees forcibly into the soil, a heavy rammer being used for the purpose, and the process continued till the soil was puddled, and shook like a jelly.

(2) Leaving the roots untrimmed, or injuring them abnormally by hacking them with a spade.

(3) Huddling the roots together into a small hole, with the majority of them pointing downwards.

The first two sets of experiments on these points $(\mathrm{V}, 68)$ did not yield satisfactory results; they agreed in showing that a considerable benefit resulted from ramming, but as to the other points there was too great a divergence to lead to any safe conclusions, the probable indications keing that neither root-injury nor the huddling together of the roots had any appreciable effect. A more extensive series of experiments was, therefore, initiated (IX, 38). In the first place the behaviour of two small plantations was examined, one of which had been planted carefully, the other carelessly, but without either purposely injuring the tree-root, and also without ramming. The 
results of six years' observations gave an average balance of 5 per cent. in favour of the carelessly planted trees, which, in view of the variations in different seasons, was a negligible quantity. In other sets of experiments deliberate injury to the roots was practised, removing certain fractions of all the roots, these fractions amounting to from one-tenth to seven-tenths of the whole length of the roots. A general view of five series of such experiments, made with dwarf trees of apples, pears and plums, shows that a curtailment of the roots by removing from twoto four-tenths of their length generally results in no injury to the tree-indeed, from some points of view, in a slight benefit; but that when this limit is exceeded, the growth is adversely affected.

The existence of some limit beyond which the tree must suffer from root-injury seems, indeed, self evident, merely. from general considerations; and as these experiments showed that that limit was reached long before the tree was reduced to the form of a bare pole, such as the condition recommended in the Stringfellow method of planting, ${ }^{1}$ an examination of the latter method was not undertaken.

Injury to the roots by breaking them off roughly, as, for instance, with a spade, instead of trimming them carefully with a knife, appeared to have but little effect on the subsequent behaviour of a tree. With 42 somewhat old apple trees which were planted after treatment in these two ways, and lifted again

1 The New Horticulture, by H. M. Stringfellow, Galveston, Tex., I 896. The method of planting consists of reducing the stem to the condition of a bare pole, leaving only 2 or 3 inches of the main roots, and planting firmly in a small hole in the ground. The ground over the roots is handweeded at first, and laid down to grass after 4 or 5 years. The present writers have not been able to find a copy of Stringfellow's book in any public or private library in this country, nor to obtain a copy of it from America; they have, therefore, been dependent on the account of the method given by Richter (Pomologie Nouvelle, Paris, I912), who himself adopts it, with the modification of leaving 2 or 3 inches of the main branches of the tree, instead of removing them entirely. It appears that both Stringfellow's and Richter's methods are based merely on the "ideas" of the originators, and not on definite experiments.

Experiments on root-pruning on the "Stringfellow" method were at one time tested in many districts in the United States. The results on the whole were not satisfactory. Unfavourable results were obtained in Alabama (Agric. Expt. Bull. 98, 1898), Delaware (Agric. Expt. Sta. Bull. 45, I 899), Nebraska (Agric. Expt.Sta. Bull. 56, I 898), New Jersey (Agric. Expt. Sta. Ann. Rpt. I901), Oregon (Agric. Expt. Sta. Ann. Rpt. I901), Rhode Island (Agric. Expt. Sta. Ann. Rpt. I90I), Texas (Agric. Expt. Sta. Bull. 58, 1900). Favourable results with some kinds of trees were obtained in Georgia (Agric. Expt. Sta. Bull. 40, I898), Indiana (Agric. Expt. Sta. Ann. Rpt. I896), and Montana (Agric. Expt. Sta. Bull. 24, I 899).

The severe restriction of the root-system on replanting a tree, and not getting out a large hole for setting it, was advocated early in the eighteenth century by J. Laurence (see A. E. Bunyard, Jour. Roy. Hort. Soc. XL, 420). 
before the following spring, it was found that the production of new rootlets had been decidedly greater in the case of the trees with the mangled roots (IX, 52); whilst, on the other hand, in some later experiments $(X V, 25)$, where the question was investigated more systematically by planting some 60 apples, pears and plums, on which the same number of roots of equal size ( $\frac{1}{4}$ to $\frac{1}{2}$ an inch in diameter) had been selected, and had been broken in one case and carefully cut in the other, it was found that the new rootlets formed from the old roots which had been broken showed a deficiency of about I5 per cent. as compared with those formed in the case where the roots had been cut. But in another similar experiment with 50 apples trees of five different varieties, the results showed practically no difference between trees with trimmed or mauled roots. With currants and gooseberries, however, the results were very definite, for the new root-formation from the broken roots was two-and-a-half times that from the cut roots, a superiority which was very surprising and difficult of explanation (cf. p. 54).

Thus, with one series giving results in favour of trimming, two giving results against it, and a fourth giving no results at all, the only possible conclusion is that trimming is altogether unimportant, and that the omission of it may sometimes have one effect, sometimes another.

The effect of the removal of the fibrous roots was investigated in a separate experiment (IX, 46), plum trees being planted after the removal of all rootlets up to I mm., $2 \mathrm{~mm}$., and $4 \mathrm{~mm}$. in diameter in different cases. After two years' growth, the trees when lifted showed by the increase in their weight that the removal of the smallest fibres ( I $\mathrm{mm}$.) had been beneficial to the extent of I7 per cent.; that the removal of the fibres up to $2 \mathrm{~mm}$. had produced no effect; whilst the removal of fibres up to $4 \mathrm{~mm}$. had produced a bad effect, amounting to a loss of 9 per cent. in growth - thus affording another instance of detriment to the tree not following injury till the latter exceeds a certain limit. But the effect of the removal of the fibrous roots must vary, as might naturally be expected, with the readiness with which the tree will send out new rootlets, and hence with its character and age : accordingly, in the case of some beech trees of about ten years of age, it was found that the removal of fibres, even up to only I mm. in diameter, had a markedly deleterious effect.

At the same time some pear trees were planted with their roots all tied together in a ball (Fig. 7, D, p. 4I), in order to 
measure the effect of neglecting to spread the roots out in the usual way; but this excessive treatment in the opposite direction had no effect whatever on the growth of the trees as measured by their increase in weight after two years, though the length of new wood formed by them during the first season was deficient.

Thus, in every instance, those forms of root-injury which are involved in the rough planting of trees, are either without effect, or have even a slightly beneficial effect, and would not result in detriment to the tree unless carried to a much greater extent than they are in such planting. That limited injury to a plant should be inoperative, or ultimately beneficial, can scarcely be a matter of surprise, seeing that nearly all cultural operations consist of such injury, from the rough root-pruning of trees in the nursery, to all the varied processes of pruning and disbudding practised on trees in after life.

Whilst root-injury to the tree in rough planting results in no damage, it fails, however, to account for the great benefit generally attendant on such planting, and leaves this benefit to be accounted for solely by the ramming of the soil. How can this be explained?

Light was first thrown on the question by a series of experiments in which improper planting of a different character was investigated; namely, planting at an abnormally deep level. But, before dealing with these results, it is necessary to point out that the deep planting of fruit trees has never been advocated, or even investigated at the Fruit Farm; the experiments in question were made on fruit stocks only, and solely with the object of examining the correctness of certain observations which had been made by a well-known grower-observations which these experiments proved to be correct, though not attributable to the cause assigned by him.

Fig. 5 shows a set of paradise stocks before planting; they were planted at 6 inches below the surface of the ground, which is represented by the horizontal line on the photograph. Another photograph of the same stocks was taken when they were lifted two years later, and is reproduced in the lower part of the figure. Fig. 6 shows a similar set of stocks which were planted 24 inches below the surface: the difference between them and less deeply planted sets is remarkable. In the shallow-planted stocks the original roots have developed, but only to a moderate extent, whereas in the deep-planted ones they have not developed aț all, and in some cases have evidently dwindled, and were dying ; 


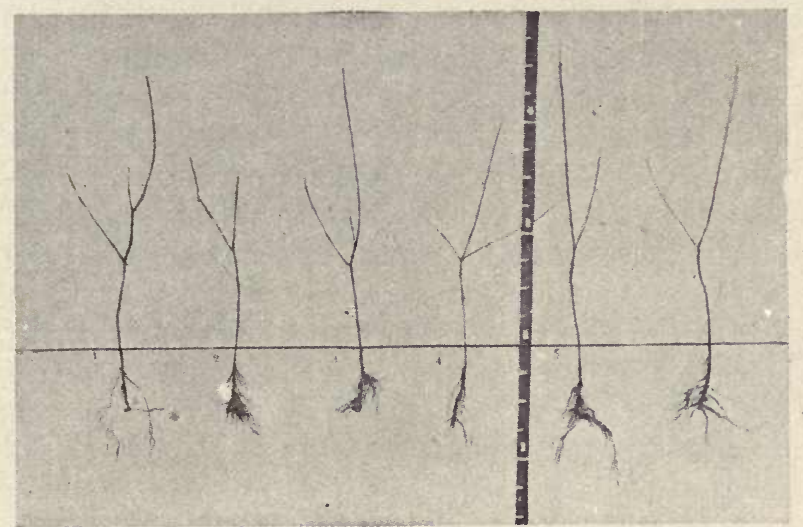

A. Before Planting.

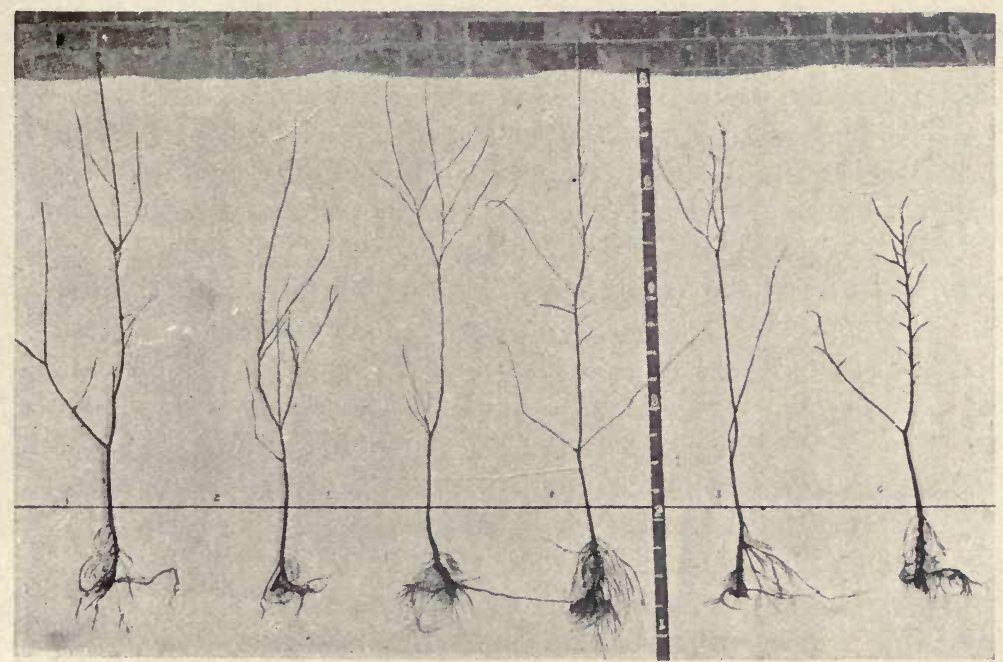

B. After Two Years' Growth.

FIG. 5.-PARADISE STOCKS PLANTED SIX INCHES BELOW THE SURFACE. 
but in their place there has developed a new root-system from the buried portion of the stem, and these new roots, having been unchecked in their growth since first coming into existence, have developed exceedingly, so much so that their weight proved to be over three times that of the roots of the stocks planted at a depth of six inches; and the branch growth, consequent on this large root-formation, showed almost as great an increase. A series of experiments with stocks planted I2 inches below the surface gave results intermediate between those at 6 and 24 inches. These results were obtained at Harpenden, where the soil is favourable to the growth of young trees, but similar, though less conspicuous results were obtained at Ridgmont. On the other hand, a series made in the light sandy soil at Millbrook gave ambiguous results, for though the deeply planted stocks were superior to the others as regards the weight of roots and branches formed, the total weights of the trees on lifting showed a deficiency. It is evident that the optimum depth below the surface for the development of roots is mainly conditioned by aëration, and in a sandy soil, where aëration extends to a great depth, differences between deep and shallow planting would be less conspicuous. This was shown by some earlier experiments on the subject $(\mathrm{V}, 69)$, in which some of the deeply planted stocks were planted in ground with the layers of soil inverted, that is, with the upper nutrient layers placed round the deeply buried roots, and the clay subsoil round the stems: but the original roots, in spite of their rich environment, did not develop, whilst the stems, in spite of their unfavourable surroundings, sent out strong new roots, though not so strong as in the case where the good soil was kept at the surface.

The paradise stock, which was used in these experiments, develops new roots very easily, but that is not so with the crab stock, and similar experiments made with this led only to a great decrease in growth when the depth of planting was increased, the increments in the tree weights after two years being in the proportion of I00:6I:33, when the depths were 6 , I2 and 24 inches, respectively. Even in the case of paradise stocks it is evident from an inspection of Fig. 6 that the extent of the new root-development varies very much with the individual plant. Subsequent experiments with quince stocks showed that they behaved in the same way as crab stocks, and not like paradise stocks, as had been expected.

One feature of these results requires special mention, namely, that, in all cases where the buried paradise stocks eventually 


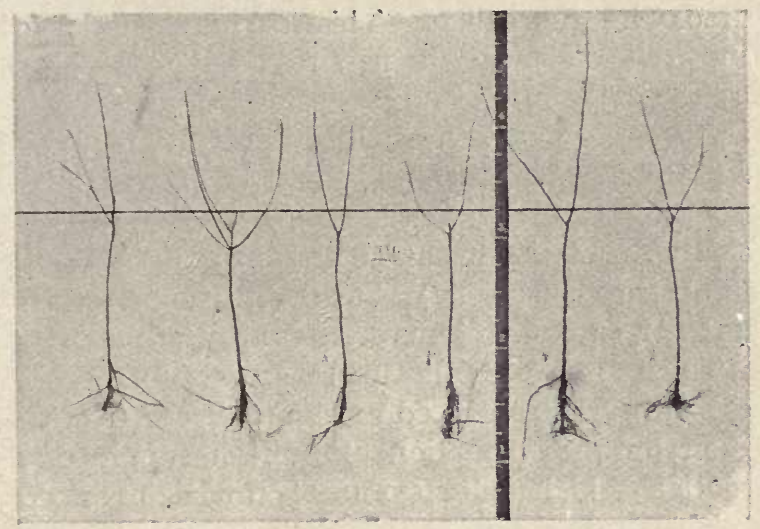

A. Before Planting.

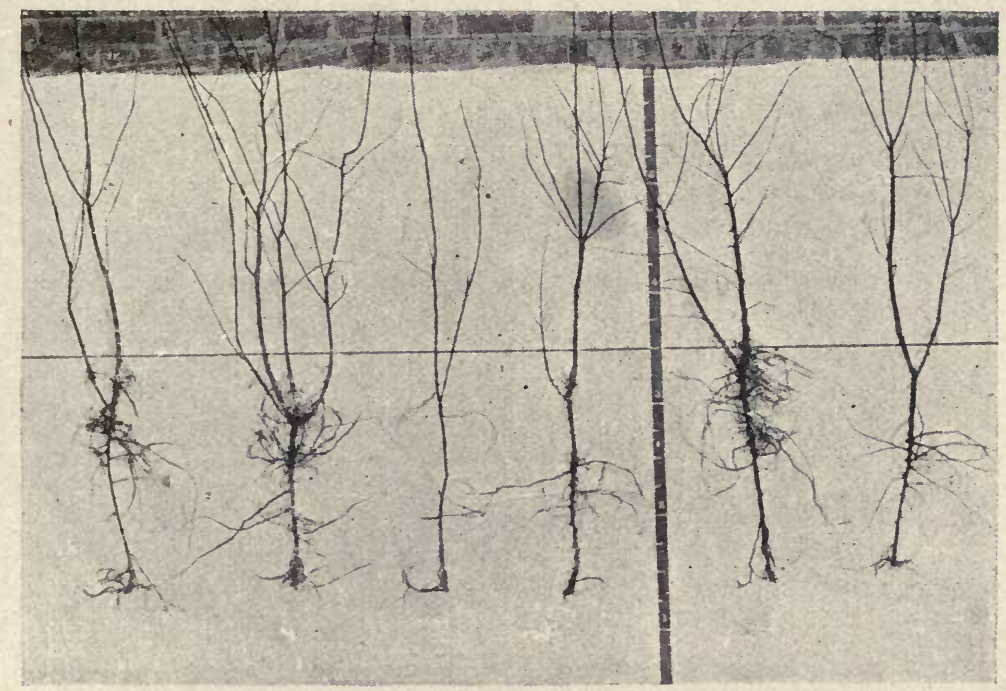

B. After Two Years' Growth.

FIG. 6.-PARADISE STOCKS PLANTED TWENTY-FOUR INCHES BELOW THE SURFACE. 
outstripped the others, they always, during the first season, showed a deficiency of growth-extending up to 20 per cent.as compared with the others. This is but natural; for some interval must elapse before the new root-system which they are developing can come into effective operation.

Now, as to the application of these observations to the effect of ramming trees on planting. The seat of growth in the rootsystem of a tree is situated at the tips, just behind the root-cap, and no extension of the root-system can occur if the root-tips have been destroyed (see p. 2); but in lifting and transplanting a tree, however carefully it may be done, the majority of the root-tips, which are very delicate, become broken off, or dried up by exposure : the continued existence of the tree, therefore, is dependent on the formation of a fresh supply of actively growing rootlets, which under favourable conditions are developed laterally, either from special cells in the existing roots, or, in some circumstances, from the base of the stem itself, and the transplanted tree is thus saved from death. The conditions essential to the formation of these new rootlets are moisture and intimate contact with the soil: the latter is secured more effectively by ramming than is possible in any other way, and hence the beneficial effect of this ramming.

The formation of new rootlets from a transplanted tree may easily be verified by lifting it a month or two after it has been planted, when the new roots, which at that stage are almost white, may easily be seen emerging from the older roots and even from the stem, whilst many of the original lateral roots, even those of considerable size, will be found to be practically lifeless, and if they have been marked by tying silk round them, and the tree has been left for a twelvemonth in the ground, they will be found to have died off entirely.

That ramming increases the root-formation may be seen from Fig. 7, A and B, which represent typical examples of an unrammed and a rammed tree lifted one year after the planting, whilst the vigour of growth exhibited by these new roots may be judged from another photograph, C, of a similarly treated tree, where all the new roots have been painted white in order to render them distinguishable from the old ones. As will be seen, a large number of these new roots originate from the stem itself, the exceptional vigour displayed by them being attributable to the greater store of material available there to start them into growth. Something more will be said later on (p. 53) of the distribution of the new roots on different parts of the tree; it 


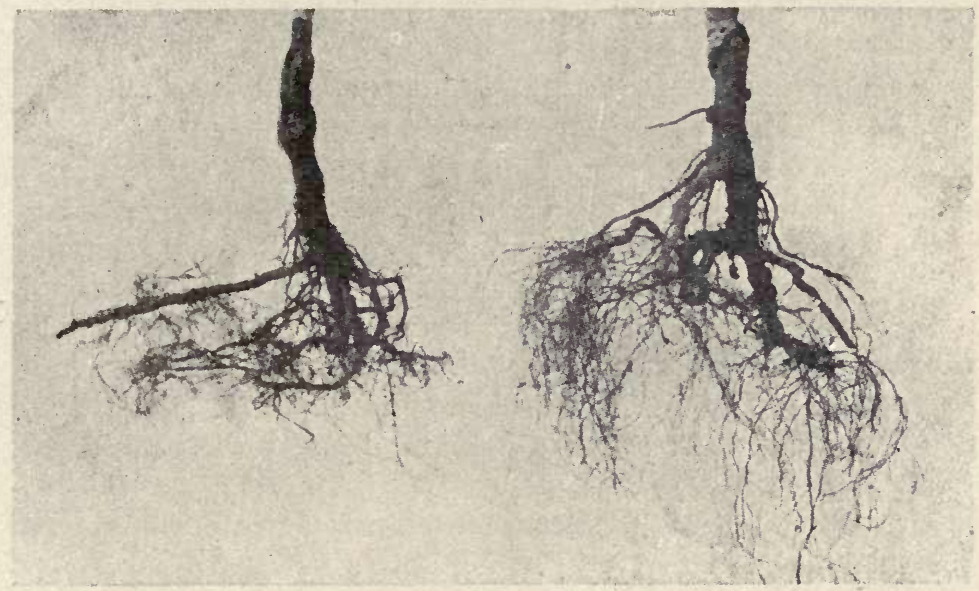

A. Not Rammed.

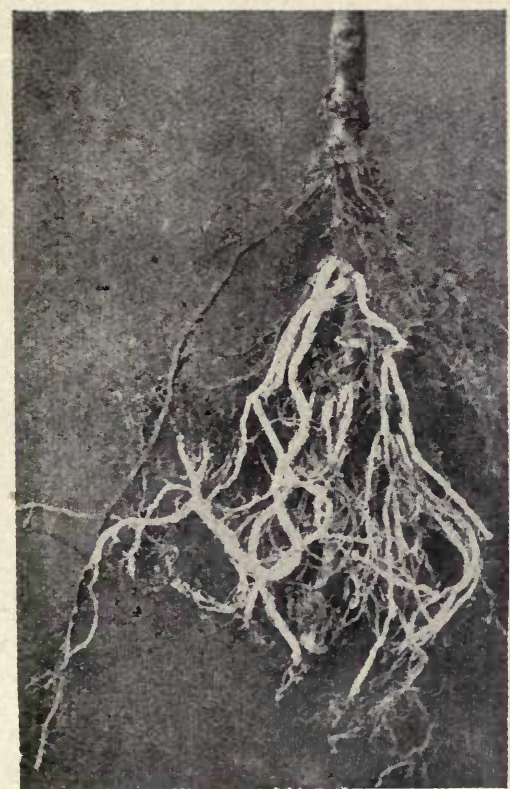

C. Tree lifted one year after planting. (New roots painted white.)
B. Rammed.

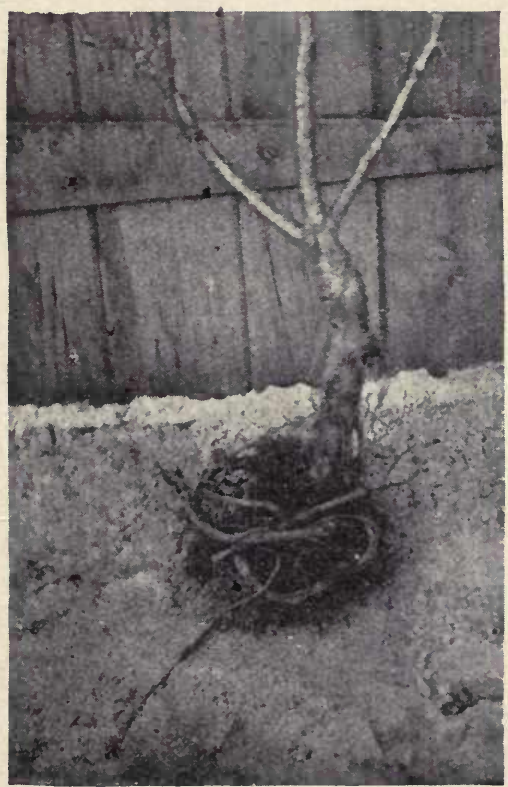

D. Tree with roots tied up in a ball before planting (see p. 35).

FIG. 7.-ROOT DEVELOPMENT. 
is sufficient to mention here that those originating from the stem were found to be on the average 20 per cent. stouter than those arising from the old roots.

As ramming the tree into the soil is beneficial, it follows that any erring in the opposite direction will be prejudicial, and this is the chief reason why, when planting in the ordinary way, it is essential for the soil to be in a fairly dry, friable condition, for, when it is wet and sticky, it cannot be shaken in between the roots, and contact between it and these is imperfect. The extent to wh ch the condition of the soil at planting affects the wellbeing of a tree when ordinary methods are adopted, was measured in the case of 70 trees of various sorts, half of which were planted with the soil in a favourable condition, and half of them in soil which had been rendered sticky and unsuitable by artificial watering. On lifting the trees three years later it was found that those planted in the soil in good condition had increased 50 per cent. more in weight than the others.

On the other hand, when ramming is adopted, the condition of the soil need not be considered; indeed, it is preferable that it should be in a wet condition, rather than dry, and hundreds of trees have been planted at the Fruit Farm, without a single case of failure, when the soil was in a condition such that planting in the ordinary way would have been madness. This, naturally, is a consideration of much practical importance to planters.

That firm planting is advocated by all horticulturists is wellknown, but, as will have been gathered from what has already been said, ramming is something more than mere firm planting, and may be more aptly described, in the language of one of the critics of the method, as planting a tree in gatepost fashion. In heavy ground the consolidation of the soil by this process is considerable, and even after two years it is possible to recognise the rammed ground by stamping on it; yet the resistance which it would offer to the penetration of the roots is not very materially increased; this was measured by firing bullets into the rammed and unrammed soil, the relative depth of penetration in the case of the Ridgmont soil being found to be in the proportion of Ioo to I26. That any such consolidation is good for the soil cannot be maintained, and if the whole ground were treated in the same way the result would, no doubt, be disastrous; but it is only the earth immediately surrounding the roots which is thus consolidated, and the roots soon penetrate this hard ball, and find themselves in surroundings more congenial for continued growth. In the initial stages of new root-formation, where these 
roots are dependent more on the nutrient stored in the plant than on that obtained from outside, the root-environment is of subsidiary importance; and if it is such as to increase the number of roots formed-as ramming does by keeping the roots wetthen the drain on the tree will be increased, and the effect of this drain on the branch-growth should be apparent. This is actually what is noticed in the case of rammed trees: with II plots of trees (IX, 28), where the excess of growth of the rammed trees over the unrammed ones amounted to 94 per cent. at the end of the first season, the excess, when measured in the previous July, amounted to only 55 per cent., and on June I to only 7 per cent., at which date, indeed, but for the exceptional values in the case of one plot, it would actually have shown a deficit. When the leaf formation was taken as the criterion of vigour, such a deficit was always observed during the first season $(V, 66)$. Thus the beneficial effect of ramming does not show itself at once, and, in fact, does not show itself fully till the second season after planting, as the results quoted above (p. 32) have already established.

Those who give but a partial adhesion to ramming, whilst admitting its efficiency in fairly light soils, consider it as inapplicable to heavy ones. This is certainly a mistake; for if ramming is beneficial, the benefit must be greater, according as the effect on the soil is greater. In a light sandy soil where all effects of ramming would disappear before the trees started into growth, the result of the ramming must be nil, as it was found to be at Millbrook, where the soil is of such a character. On the other hand, the good results obtained elsewhere embraced numerous instances where the soil was of a very heavy character, as, indeed, it is at the Fruit Farm itself, the formation there being that of the Oxford clay. Only in one case which has occurred in subsequent years has the effect of ramming. been found to fail, and that was on the London clay; the result there was that sulphuretted hydrogen developed in the rammed soil, and killed the trees. Fortunately the London clay is not a formation which would be selected by a planter for fruit-growing. 


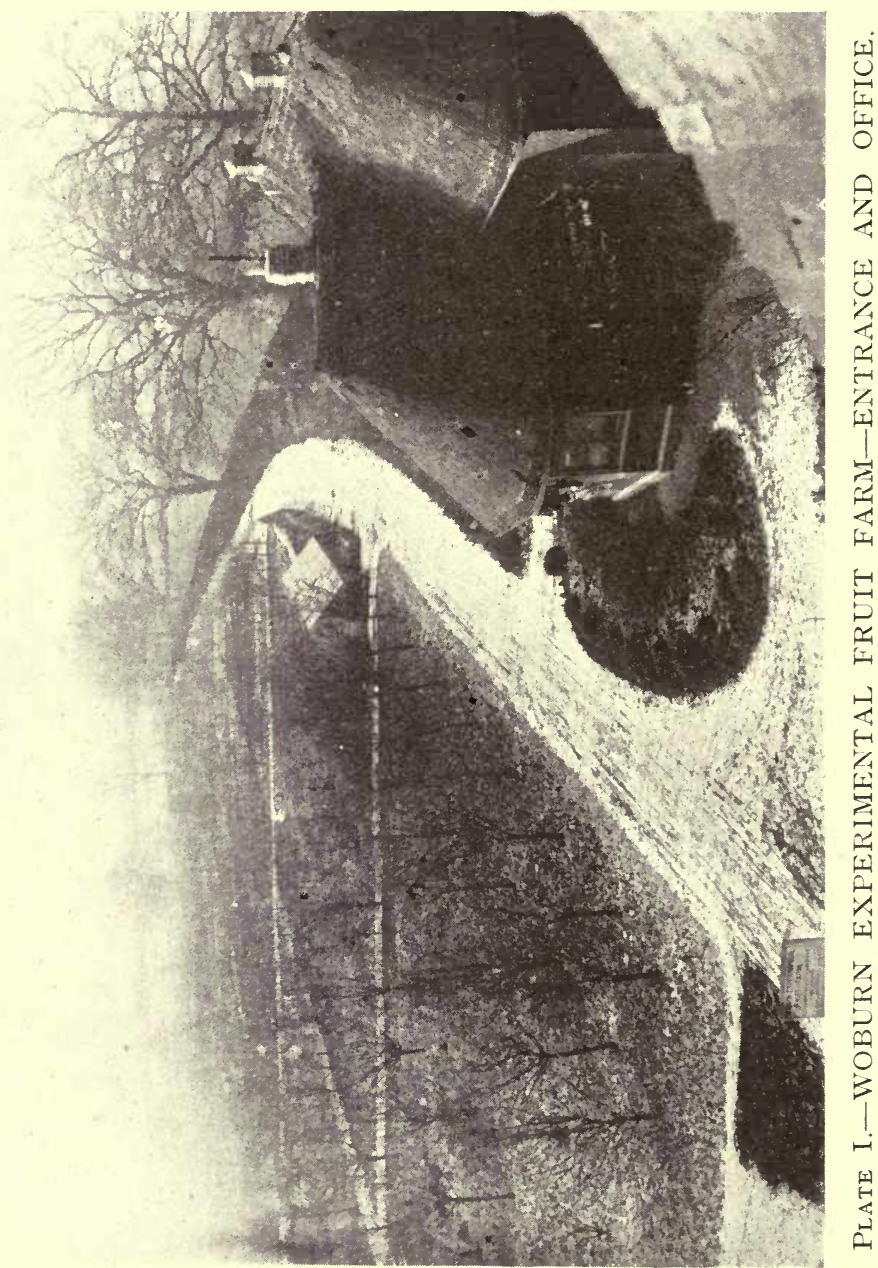




\section{Chapter V \\ PLANTING (continued)}

\section{NURSERY STOCK}

IN the treatment of young trees in the nursery, a rough and severe form of root-pruning is practised, with the object of restricting the extension of the roots, and of developing a compact root-system consisting mainly of small fibrous rootlets; and experienced planters set much store on a tree being well provided with such rootlets, in order that it may thrive after transplantation. Yet, as has been seen, tíese rootlets are mostly killed in the transplanting, and are of no importance for the future welfare of the trees. This does not imply, however, that the nurserymen and planters are wrong in their practice : the practice may be correct, but the reasons given for its adoption are erroneous. The rough removal of a tree from the nursery involves serious damage to the roots, whilst the exposure incident on transportation to a distance greatly increases the injury suffered, and, had the roots not been restricted and compacted during the years of early growth, the damage thus caused would have been much greater. At the same time, though the existing rootlets themselves may be of no value in continuing the life of the tree, the fact that a tree has produced an ample supply of such rootlets in the nursery, is an earnest that it will do so again after transplantation. Hence, the planter is quite right in preferring a tree which is well provided in this respect.

\section{ROOT-PRUNING}

Injury to roots, when it exceeds certain limits, has, naturally, a disastrous effect on the welfare of the tree. This is well illustrated by the Woburn experiments on root-pruning. These were undertaken, not with the object of determining how and under what circumstances such an operation might be advisable, but as affording some measure of the check on growth caused by it. The trees examined were apples of the varieties Bramley, 
Cox and Potts grown on the paradise stock, and even the first named, though a strong grower, does not exhibit such rampant growth as is sometimes found with pears and plums, where a severe check may be economically desirable. In one series the trees were root-pruned every year, in another every other year, and in a third every fourth year; actual lifting from the ground being adopted, till they became too large for this to be done without excessive injury. The check caused to the growth of the trees was apparent from every point of view $(V, 38)$, and its extent may be gathered from the weights of the trees when they were ultimately removed. Thus with the Cox, which were removed after fifteen years, the weights of those trees which had been root-pruned every fourth year were only 43 per cent. of those which had not been root-pruned; where the operation had been performed every other year, the weights were 7 per cent. of the non-treated trees, and with the yearly operation, 3 per cent.; indeed, in the last case, the trees had scarcely increased in weight since they had been planted, and had been dead for several years before they were removed.

The effect of root-pruning on the crops may be conveniently mentioned here, though it belongs of rights to another chapter. That increased cropping follows any restriction of growth, is well known, and was duly apparent in these experiments; but it was very noticeable that this increase did not occur till the second season following the root-pruning, the tree having suffered too much for recovery in any form to occur during the first season. In the case of Cox and Potts the response in the form of an increased crop was maintained till the root-pruning had been performed twice, and in that of Bramley some slight response was observable after the third performance of it; but subsequently the trees became too much enfeebled for any response to be made, and the crops dwindled till they became quite insignificant. Under less severe treatment, and with trees of more rampant growth, the results might, perhaps, be economically advantageous, and the response more prompt. Certainly, however, root-pruning is an operation which should be practised with extreme moderation, and only in those cases where excessive branch-growth calls for stringent measures.

\section{Lifting Nursery Stock}

It seems highly probable that the younger a tree is, the more readily will it send out fresh rootlets, and recover from any injury inflicted on it, though it would be difficult to establish 
this by direct experiment, as there is no standpoint from which we can determine the proportionality of injury done to trees of different sizes; yet, even with young nursery stock, the check to their growth caused by lifting or root-pruning them is very appreciable. A number of stocks of paradise, crab, quince and pear were planted, and, after the lapse of a year, budded. In each case a certain proportion of the trees were left in the ground where they stood, whilst others were lifted and replanted in successive seasons, either once, twice or thrice. Observations on their growth were continued for seven years after the first lifting, with the result that during this period the average growth of the trees was reduced by the lifting from roo down to 46 where there had been three such liftings, or to lesser extents with less frequent liftings.

$\begin{array}{ccccc} & \text { Not } & \text { Lifted } & \text { Lifted } & \text { I ifted } \\ \text { tifted. } & \text { once. } & \text { twice. } & \text { thrice. } \\ \text { Growth } & \text {. I00 } & 83 & 65 & 46\end{array}$

Some recovery of vigour after the lifting was evidenced in all cases as the years passed, but it was only in the case of those trees which had been lifted but once that this recovery brought the annual growth up to the level of that of the trees which had not been lifted at all, and this it did four years after the lifting. A similar recovery might eventually occur with the other trees, but in all cases there would be a loss of growth during the years following the lifting, and there was no evidence, even with the once-lifted trees, that this would be made up by extra growth in subsequent years. It is, therefore, clearly to the advantage of the tree to lift it as seldom as possible, and, if other economic considerations are favourable, a plantation will be best made by planting the stocks where the trees are to stand, and working them in situ.

\section{AgE For TRANSPLANTING}

As working the stccks in situ is not always possible, the question arises at what age can trees be removed from the nursery to the plantation with the minimum amount of injury. This was examined by planting at the same time trees of different ages, received from a distant nursery, and recording the crops borne by them during the succeeding ten years $(V, 44)$. They included bush apples and pears of different varieties, and standard apples and plums. With the bush apples, those trees which were two years old from the graft gave decidedly better results than either 
younger or older trees: with the bush pears, the two- and threeyear-old trees gave equally good results, but both better than those from younger or older trees: with the standards, only two ages at planting were examined, and the results were in favour of the younger trees-two years in preference to four years.

Relative Crops during Ten Years from Trees Planted at Different Ages

\begin{tabular}{|c|c|c|c|c|c|c|c|}
\hline Age at Planting & . & . & . & I & 2 & 3 & 4 years. \\
\hline Bush Apples & . & . & . & 44 & IOO & 72 & 59 \\
\hline Bush Pears . & . & . & . & 62 & IOO & IOI & 56 \\
\hline Standard Apples & . & . & . & - & IOO & 一 & 79 \\
\hline Standard Plums & . & . & . & - & Ioo & 一 & $8 \mathrm{I}$ \\
\hline
\end{tabular}

\section{Time of Planting}

Then came the question as to the best time for planting. The general belief is that the earlier trees are-planted after the fall of the leaf, the better, because trees thus planted will throw out a certain number of new rootlets before the winter, and thus be more prepared to make an early start into growth when the spring comes. That rootlets are thrown out in this way, may be easily established by lifting the tree again before the winter is over: out of forty-two trees, representing apples, pears, and stocks of apples, pears and plums, which were planted in November, twenty-nine were found to have formed a more or less considerable output of rootlets before the middle of January (IX, 53). Where trees have to be obtained from a distant nursery, however, the date at which planting can be performed is rarely early enough for this factor to operate to any appreciable extent. Observations made with such trees when planted in the winter and the spring revealed no differences exceeding 3 per cent. in their subsequent behaviour; but with trees raised in the farm nursery, and available, therefore, for transplantation at any moment, the case was otherwise (II, I92). These trees were apples on the crab and paradise stocks, and all of them three years old. Batches of them were planted on the dates indicated below, and the increase in their weights determined four years later $(\mathrm{V}, 82)$.

\begin{tabular}{cccccc} 
& \multicolumn{7}{c}{ Planted on } \\
Increase per cent. & Oct. 30 & Dec. 3 & Mar. I3 & Mar. 30 & Ap. I6 \\
I07 & $6 \mathrm{I}$ & 67 & $(37)$ & 56
\end{tabular}


Thus, the advantage of the early planting, when it can be done sufficiently early, is evident: but, if it cannot be done thus early, the date of planting appears to be immaterial. (The low values obtained as above for the trees planted on March 30 are probably accidental, since better values were obtained with those planted at a still later date.)

Yet, even where trees for planting cannot ke obtained at a very early date, there are reasons why early planting should be advocated in preference to late planting, these being the condition of the soil, and the prevalence of drying winds. Where ordinary methods of planting (without ramming) are adopted, a fairly dry condition of the soil is essential for success, and such a condition obtains more often in the early part of the winter than later on. In February the soil is at its worst in this respect, and it is owing to this fact that February has acquired its appellation of Fill-dyke, and not to the exceptional extent of the rainfall in that month, which is generally less than that in several other months in the year. The bad results obtained on planting trees in soil when in a wet, sticky condition has already been mentioned (p. 42).

\section{Exposure Before Planting}

The damage which may accrue to trees on exposure to drying winds during the interval between their removal from the nursery and their being planted, may, also, be very great. Even exposure of a very moderate character was found to do material damage, for in the case of maiden apple trees which had been left for four days under cover in a shed before being planted, a deficiency of from 66 to 33 per cent. in their subsequent growth occurred, the comparison being made with similar trees which had been replanted immediately after lifting (IX, 50; XV, 65). Analogous results were obtained with older trees which were lifted and replanted, either with or without three days' exposure to the air: exposure was found in that case to have caused a deficit of 53 per cent. in the subsequent year's growth, and though the deficit disappeared in after years, the loss experienced at first was never made good (I, I05; V, 4I).

\section{Depth of Planting}

The depth at which a young tree has been growing in the nursery, as indicated by the collar mark on the stem, is the only safe guide as to the depth at which it should be replanted. It does not follow, however, that that is the depth where it will 
flourish best in its new surroundings, but from what has been seen as to the behaviour of tree-stocks when planted at a considerable depth (p. 38), it is clear that the tree will have little difficulty in adjusting itself to these surroundings, either by the extension of some of the older roots, or by the development of new roots at that level where root-action is most vigorous. Whether the tree ever alters its depth in the soil by movement as a whole, may be doubted; numerous cases where roots are found to be partially above ground are probably explicable by the denudation of the soil from above them; a sinking of the tree is more likely to occur: this is the explanation given of the fact that the Cowthorpe Oak, which in I700 measured 78 feet in circumference at ground level, now measures only 54 feet 3 inches. Measurements made in 1904 of the apple-trees planted at Ridgmont ten years previously indicated a general sinking of $\mathrm{I}$ to 2 inches : but definite evidence on such a point could not be obtained in the absence of observations made by means of bench marks on the trees. Certain it is, however, that a tree will adjust itself within moderate limits, either by direct or indirect processes, to the most suitable level for growth in the soil, and the behaviour of trees planted either 4 inches too high, or 4 inches too low, as judged by the nursery collar mark, has been found to be practically identical $(\mathrm{V}, 76)$. In another case, there were records extending over eight years of 84 trees, where half of them had been planted at the ordinary level, and half of them at the surface level with their roots mounded over with earth. The object of the experiment was the investigation of the effect of high planting on the behaviour of the tree towards canker, but its effect on the general growth of the tree was also recorded, and, on the whole, was decidedly the reverse of beneficial, for in only one season out of the eight was there any balance in the favour of the trees on mounds, a deficiency amounting to an average of 22 per cent. being observed in the other seven years. No connection was traceable between the behaviour of the trees and the rainfall in successive years $(\mathrm{XV}, 42)$, and it is not justifiable, therefore, to recommend such high planting-so far as the general welfare of the trees is concerned-even in localities where the rainfall is heavy.

The great advantage gained in the case of paradise stocks by planting them at an abnormal depth below the surface has been described (p. 38), and means were sought whereby these results might be put to practical use in the raising of trees on this stock. To bury the stocks two feet below the surface 
would involve too much labour in practice, but equally goud results might, it was thought, follow, if the same length of stem were buried in the ground in a slanting direction, so that none of it should be below the usual depth. This, however, did not prove to be the case. A comparison throughout eight years of stocks worked after they had been planted (a) at a depth of 6 inches, (b) at a depth of 24 inches, and (c) at a depth of 6 inches, but with 24 inches of stem buried, showed a very great advantage in favour of deep planting, but not so great a one in favour of shallow planting with the stem buried slantingly, though during the first three years these latter trees had been somewhat ahead of those with the stems buried vertically.

$\begin{array}{cccc} & \text { 6" deep. } & 24 \text { " deep. } & 6^{\prime \prime} \text { deep, } 24^{\prime \prime} \text { of } \\ \text { stem buried. }\end{array}$

In the first set of trees, it should be mentioned, the stocks were budded at a height of 24 inches above the roots, so as to be strictly comparable with the other sets.

Similar experiments with pears on quince stocks gave very different results, for, as had been ascertained in previous experiments (p. 38), the burying of the roots of this stock at a great depth leads to very bad results, consequently the trees with the 2 feet of stem buried at a depth of only 6 inches did much better than those with the 2 feet buried vertically, but they showed no advantage over those with only 6 inches of stem in the ground. The values were-

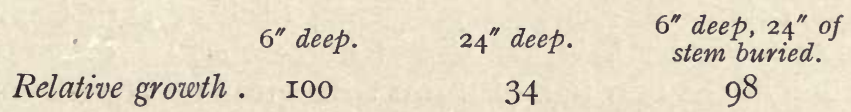

Working Stocks Above or Below Ground Level

In connection with this experiment the question of the relative advantage of working stocks above or below the ground level was investigated. The results were confined to pears on the quince and pear stocks, for in the case of apples, which had been similarly treated, there were too many failures to admit of any conclusions being drawn. The effect of the different methods of working the stocks was measured by. lifting and weighing the trees after ten years. There were six trees of each of six different varieties in each plot, making $2 I 6$ trees altogether, and the results were- 
Relative weight of trees.

\begin{tabular}{|c|c|c|c|}
\hline - & $\begin{array}{c}\text { On } \\
\text { Quince. }\end{array}$ & $\begin{array}{c}\text { On } \\
\text { Pear. }\end{array}$ & Mean. \\
\hline Worked above, and kept ${ }^{1}$ above & . IOO & IOO & IOO \\
\hline ,, ,, , but put ${ }^{1}$ below & 97 & I06 & IO2 \\
\hline ,, below, and kept ${ }^{1}$ below & IOO & 93 & 97 \\
\hline
\end{tabular}

From which it must be concluded that these different methods of procedure are without any appreciable effect on the results obtained.

\section{Planting Trees in Sand, etc.}

The advantage generally following the ramming of a tree on planting, due to the intimate contact thus obtained between the roots and the soil, led to attempts to ascertain whether similar, or better, results could not be obtained by other means. The effect of plastering the roots before planting with a mixture of clay, cowdung and plaster of Paris was tried, but proved to be detrimental. The effect of imbedding the roots in fine sand was then examined.

It had been ascertained that when trees are grown in pots containing sand and artificial nutrients, instead of earth, a remarkably exuberant root-production occurs during the first season, the weight of new roots amounting to twelve times that of those from earth-grown trees (IX, 32), though this superiority is not maintained in subsequent years, and, even from the first, there is no corresponding superiority in branch-formation; indeed, the latter is always below that of the earth-grown trees, to the extent of about 30 per cent. Such a fact, it should be noticed, must have an important bearing on the general question of the nutrition of plants : the great root-development unaccompanied by any corresponding branch-growth, implies that the tree requires some form of nourishment, or some substance necessary for the assimilation of the nourishment present, which soil contains, but which sand with artificial fertilisers does not, and the abnormal root-development of the sand-grown trees may be regarded as an effort on the part of the tree to obtain that which it is in need of, this effort probably being aided by the high water-content which must be maintained in the sand to prevent it from drying up. It appeared possible that advantage might be taken of this excessive rootdevelopment by planting trees in holes in the ground filled with

1 After transplantation. 
sand, so that the abundant roots formed might, when they reached the surrounding soil, find such substances as they required to continue their growth. But the results proved otherwise; experiments with 36 different kinds of trees showed little or no advantage as regards those planted in the sand pits (IX, 33). Still more unsatisfactory results were obtained when cuttings of various sorts were put into holes dibbed in the ground and filled with sand, the number which struck being less than half of those which struck when imbedded in earth.

These results led to an investigation as to what happens as regards the water present when masses of sand and soil are in contact with each other, and it was found that under such circumstances the earth takes nearly the whole of the water, leaving the sand too dry (unless a state of saturation of the earth is approached) for the proper support of vegetable growth. Hence the difference in the behaviour of trees in sand, when that sand is in contact with earth instead of being isolated and kept moist, as it is in a pot.

\section{Distribution of New Roots}

This section may be concluded with a more detailed reference to an inquiry into the formation of roots by transplanted trees which was omitted from its proper place, in order not to interfere with the general account of the conditions governing the planting of trees.

The distribution of new rootlets forming on trees was examined by planting I50 young apples, pears and plums, lifting a certain number of them at monthly intervals between April and November, and counting the rootlets which had formed (a) within a quarter of an inch of the root-ends, $(b)$ on the main body of the old roots, and $(c)$ on the stems. Out of every Ioo rootlets (I6,000 were counted) I5, $7 \mathrm{I}$ and $\mathrm{I} 4$ originated from these three loci, respectively $(\mathrm{XV}, 2 \mathrm{I})$, and such proportions remained fairly constant throughout the eight months. In another series, carried out three years later, where apples on the paradise stock alone were examined, the distribution was $4 \mathrm{I}, 24$ and 35 per cent., respectively. The high value in this case for the rootlets forming from near the ends of the old roots was partially accounted for by a length of half an inch, instead of a quarter of an inch, from the ends having been selected for the count; but that did not explain the whole of the difference in the two series, and left much to be attributed to differences in the season and in the individuality of the 
plants examined. Both series, however, agreed in showing that the extreme ends of the old roots are not the chief seat from which new rootlets arise, as is generally stated to be the case; and, even if we embrace under the term "extreme end" a stretch of a quarter or half an inch from that end, these rootends still do not occupy a position of paramount importance as seats of origin for new rootlets, especially when it is borne in mind that the new roots originating from them are more feeble than those originating from elsewhere (p. 42).

With gooseberries and currants, however, the results appear to be different-one of the several instances in which these bushes seem to differ materially from fruit trees (see pp. 29, 35, 107)for the proportions were-

Half inch from ends.

57
On rest of roots.

38
On stems.

5

both kinds of bushes giving nearly identical values.

Some further experiments were made to see whether the omission of careful trimming of the old roots was detrimental to the formation of new rootlets; the trimmed and untrimmed roots (purposely broken off in a rough manner) being equal in number and diameter on each tree. Out of three series of experiments, one showed no difference, either as regards the total weight or stoutness of the new roots, and the other two showed differences in opposite directions, so that the general conclusion must be that the trimming of roots is a work of supererogation. Here again, however, remarkable results were obtained with gooseberries and currants, for they both showed a great advantage from every point of view in favour of broken, as against trimmed roots, the superiority applying to the rootlets forming from all parts of the original root-system and the stems, and amounting to an advantage of from 50 to 550 per cent. This remarkable behaviour remains unexplained (cf. p. 35).

\section{Arrangement of Trees in a Plantation}

The simplest method of arranging any given number of trees in a plantation, or, more strictly speaking, of arranging them so that each tree has the same space allotted to it-for, when the area of the plantation is limited, the actual number of trees which can be fitted in must depend to a certain extent on the distances selected, and on the contour of the ground-is on what may be termed the square system (Fig. 8, A), with all the trees equidistant from their neighbours in two directions at 
right angles to each other. This distance may be called I. By shifting every alternate row so that the trees in it come opposite the vacancies in the neighbouring rows, the average distances between the trees will be increased: in the rows-shown vertically on the paper-the distances will still be I, but between the trees in neighbouring rows they will be $I \cdot I 2$. Such an arrangement is known as the quincunx, or opposite vacancy arrangement (Fig. 8, B). Each tree, it will be seen, is in the centre of a hexagon formed by the six neighbouring trees around it : but the hexagon is not a regular one, and to make it so, the various distances must be increased somewhat in one direction, and reduced in the other: when this is done, maintaining the same average space per tree, the distance between every tree

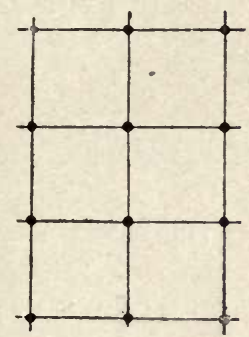

A. Square.

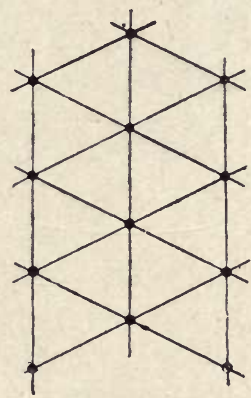

B. Quincunx

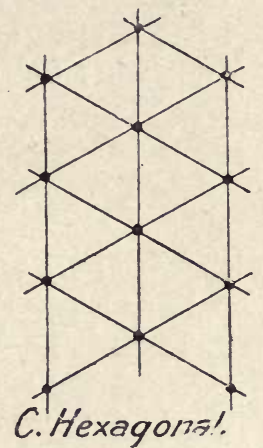

FIG. 8-DIFFERENT ARRANGEMENTS OF THE SAME NUMBER OF TREES IN A GIVEN SPACE.

and all its nearest neighbours will be found to be $\mathrm{r} \cdot 088$. This is termed the hexagonal or equilateral triangular arrangement (Fig. 8, C), for any three neighbouring trees in it form a triangle of this description. It constitutes the ideal uniform arrangement of similar objects, and is familiar to every one as being the arrangement existing in the honeycomb, where it results from the fact that it permits of the greatest number of bees to work economically in a given space.

Though the hexagonal arrangement is preferable to the square arrangement in giving the trees the same amount of room in all directions for their development, it will be seen that it is not so convenient for cultivation, for the alleys between the trees are narrower in the proportion of 0.942 to $\mathrm{I}$. The laying out of a plantation on the hexagonal system, also, is not so simple as when the square system is adopted. The question 
arises, therefore, whether the advantage given to the trees on the hexagonal system is sufficient to counterbalance these disadvantages.

To settle this, plantations of 36 plum trees of three different varieties were made on the two systems, and each plantation was further extended so that none of the 36 trees in it should be outside trees. At the same time a third plantation was made on a rectangular system wherein the distances between the trees were twice as great in one direction as in the other. Close planting was adopted, in order that results might be obtained early, the actual distances between the trees being:- square arrangement, 6 feet; rectangular, 4.24 and 8.48 feet; hexagonal, 6.53 feet. The fruit crops afforded no certain evidence, owing to the damage done by spring frosts, so the weights of the trees, when these were lifted eleven years later, had to be taken as expressing the results: they were-

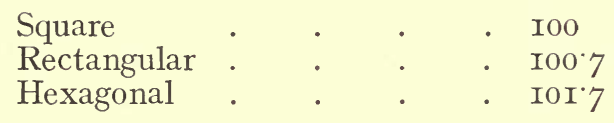

showing only an inappreciable difference in favour of the hexagonal arrangement, certainly not sufficient to counterbalance any disadvantages from the point of view of ease of cultivation.

When the square, or any rectangular system of arrangement is adopted, the question arises whether it is better to have the rows running due N. and S., E. and W., or running to intermediate points of the compass. This was examined by planting sets of trees, with each tree surrounded by four canvass screens representing neighbouring trees, these screens being located towards the different points of the compass, and being enlarged each year, and moved further away, as the trees grew. At the end of seven years the trees were lifted, when their relative weights showed that no appreciable difference had keen made by the different positions of the screens; and it thus appears immaterial in what direction the rows of trees in a plantation are set.

$$
\begin{aligned}
& \text { Square system (N. S., E. W.) ioo } \\
& \text {, ", (N.E., S.W., etc.) . • } 102
\end{aligned}
$$


PRUNING (Reports, I, IOI; II, I37; V, 2I; VII, 5; XV, 48)

PRUNING has, perhaps, given rise to as much literature, mostly of the didactic kind, as any branch of the horticultural art. As an art, it does not lend itself very freely to scientific investigation, and where scientific investigation can be brought to bear on it, the teachings of the artist have not always been confirmed. Amongst the many dreadful accusations brought against the Woburn farm, one is that the work there has led to the recommendation that pruning should be abandoned. The upper figure in the accompanying plate (Fig. 9) shows one of the trees in a plot at the farm where pruning was purposely omitted, and no one with such an example before him would be likely to recommend the omission of it, at any rate, in all cases. This tree, if it were a standard, would be a not unfair specimen of those which may be found in farm orchards all over the country. That shown below it illustrates a hardly less familiar type, prevalent in private gardens, where the gardener holds the view that the more a tree is pruned the more it will flourish, with the result that all the growth made by it in its endeavour to extend its branches consists of a number of small shoots, which are cut off regularly every year to feed the bonfire.

That pruning encourages growth, is, except under certain special conditions, one of the fallacies prevalent in horticulture, a fallacy which can be readily exposed by considering the case where the pruning is so excessive and oft repeated, that no growth is allowed to occur at all; and investigation shows that it is fallacious, even when not pressed to such extremes.

The general questions raised as regards the effect of ordinary pruning on a healthy tree may be stated as follows-

(I) Does pruning favour growth to such an extent that a pruned tree becomes actually larger than an unpruned one?

(2) If not, does it yet favour growth so far that the pruned tree forms more new wood than the unpruned one, due allowance being made for the wood removed in the pruning? 


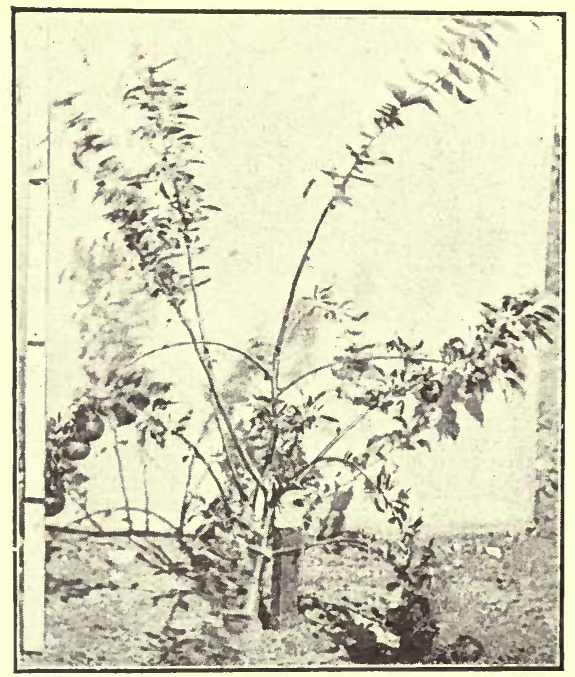

Unpruned Tree.

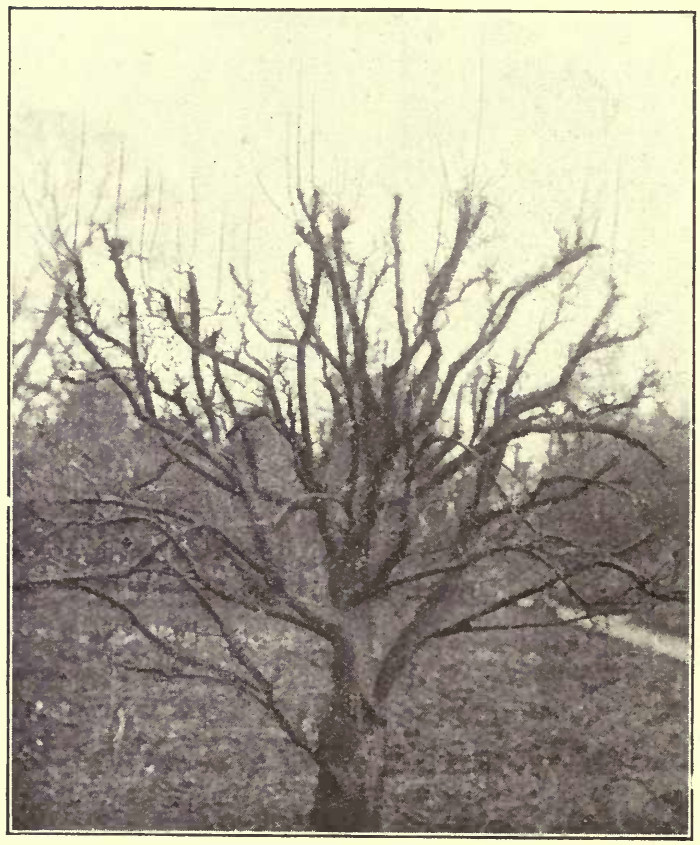

Over-pruned Tree.

Fig. 9.-EXTREMES IN PIRUNING. 
(3) Even if it does not favour the formation of fresh shoots, does it favour wood-formation in the stem and older branches, the tree thus becoming heavier than an unpruned one?

(4) Does pruning increase the number of new shoots formed?

To each of these questions the answer which would generally be given would be in the affirmative : yet to each of them actual experiment answers, either with a direct negative, or with a much qualified affirmative.

Of the plots of dwarf apple trees originally planted at Woburn, eleven were devoted to experiments on branch-pruning. Each of the plots contained eighteen trees, six of three different varieties, Bramley's Seedling, Cox's Orange Pippin and Potts' Seedling ; whilst some of the experiments were repeated with Stirling Castle, and, in later years, with Gascoyne's Scarlet Seedling. In some of these plots the trees were left unpruned, or the amount of pruning practised was very slight; in others the pruning was moderate, consisting in the removal of about one-third of the length of new wood formed during the season; whilst in others, again, the pruning was hard, about two-thirds of the annual growth being removed.

As to the general results, a good idea may be formed from the photographs of representative trees taken from the hard-pruned and unpruned plots, as shown in Fig. ro. No doubt can exist that the absence of pruning has resulted in an increase in the general size of the tree as compared with that of its hard-pruned neighbour: the moderately pruned trees (of which, unfortunately, no photographs were taken at the same time) were intermediate in size between the two shown here. The variety selected for illustration is Bramley, twelve years after the trees had been planted; but any of the other varieties might have been taken, and would have told the same tale.

Coming to actual measurement: The size of the trees as given by their height, the spread of the branches and the girth of stem (see p. 20), is given below, the values being the means for all the varieties examined, and being those obtained in I904, ten years after they had been planted (V, II4; VII, I3). Together with these are given values based on the weights of the trees when some of them were removed in the following winter.

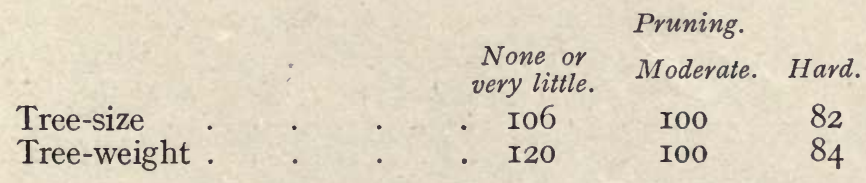




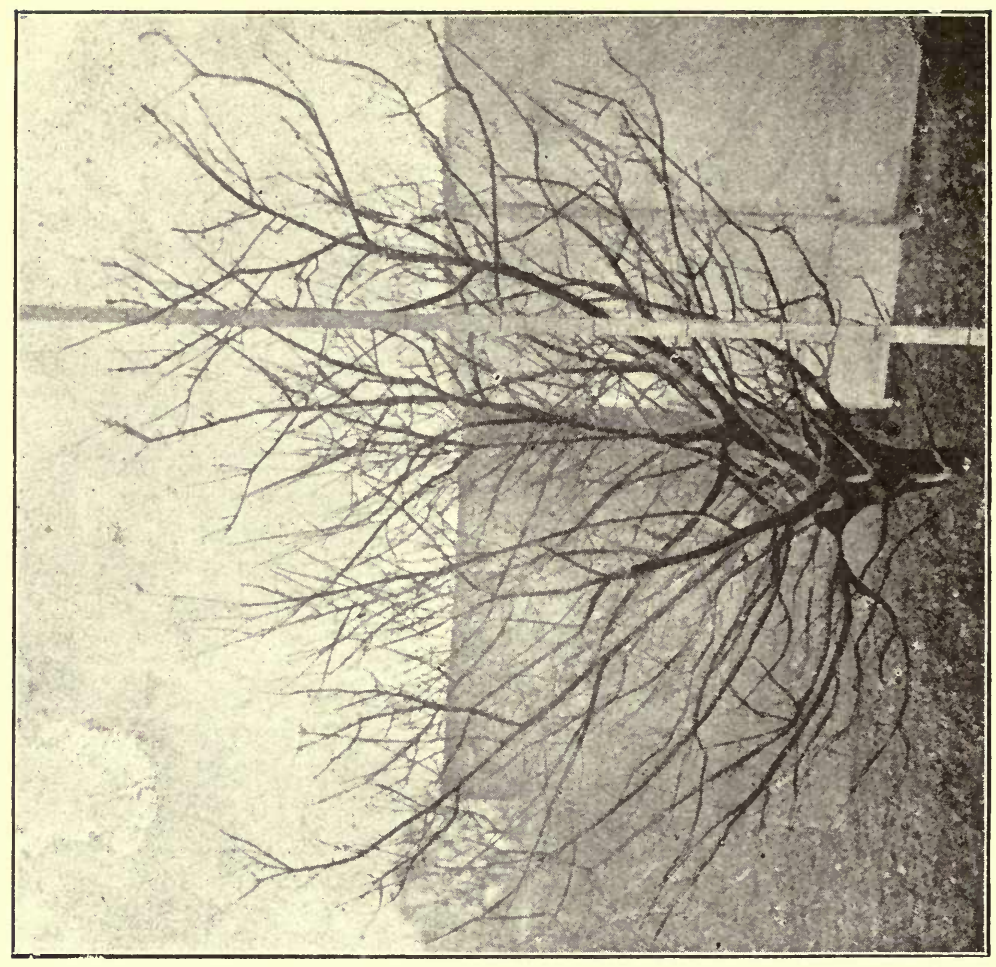



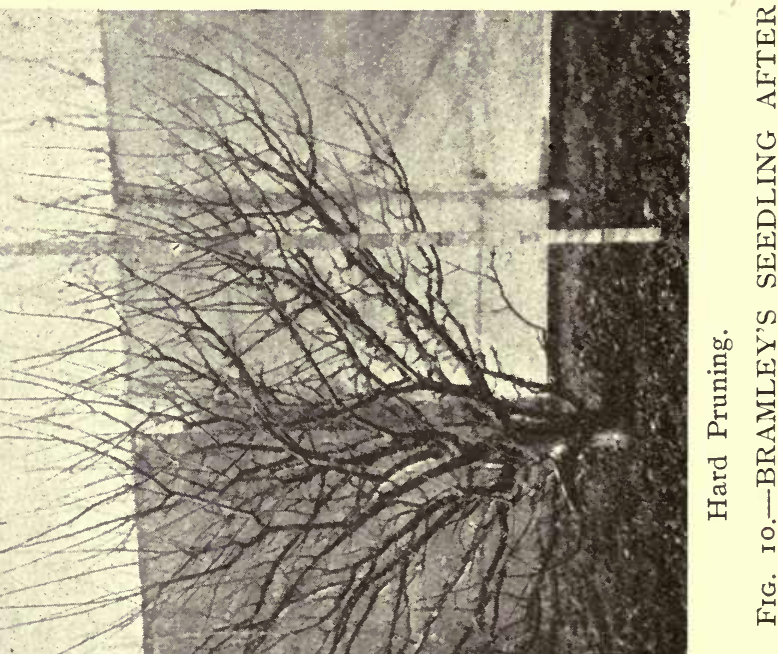


We have here a definite answer to the first of the questions set above; for the less a tree is pruned the larger it becomes. But it also becomes heavier, and it even gains more in weight than it does in size; moreover, this increase in weight must be due to an increase in weight of the stem and main branches, for it cannot be accounted for merely by the weight of wood removed during pruning : the prunings would, on an average, have amounted to $27 \mathrm{lb}$. per tree during the ten years in the case of the moderately pruned trees, whereas these trees at the end of this time showed a deficit of $49 \mathrm{lb}$. (VII, I5) as compared with the unpruned ones. This answers the second and third of the above questions.

So far as appearances go, it would seem, judging from the illustrations in Fig. Io, that hard pruning may have increased the number of shoots formed by the tree-the fourth question. But the case here is a more complicated one, and we may first consider some more exact information on the point afforded by another series of experiments.

In these, one particular tree was taken, and a number of similar shoots of the preceding year's growth selected; these were all of the same length, and of the same diameter at the base : they were then shortened to different extents in different cases, as illustrated in the top photograph in Fig. II-to 6 inches, to I 2 inches, to 24 inches and to 36 inches (which last meant merely the removal of the terminal bud) - and at the end of the following season the results were examined. The examination was also extended to the older wood 6 inches below the original shoot; this older wood being then three years of age, and the original shoot two years. Three varieties of apples were examined in this way, some on the crab stock, and others on the paradise, 96 branches in all being treated. Two sets after the year's growth are illustrated in Fig. II : the base of the original shoot being placed at the line marked 0 .

Taking the young shoot only, without including the 6 inches of older wood below it, the following were the average-results obtained at the end of the season-

$\begin{array}{lcccc} & 6^{\prime \prime} & \text { Cut back, leaving } & \\ & \text { I2" } & 24^{\prime \prime} & 36^{\prime \prime} \\ \text { Weight of shoot and side shoots } & \text { I0O } & \text { I79 } & 3 \text { IO } & 562 \\ \text { Thickening of the shoot }{ }^{1} & \text { IOO } & \text { II4 } & \text { II7 } & \text { I29 }\end{array}$

\section{New Shoots Formed}

Number

Length

Weight

$\begin{array}{llll}\text { IOO } & \text { II6 } & \text { I98 } & 292 \\ \text { I00 } & \text { II3 } & \text { I45 } & \text { I83 } \\ \text { I00 } & \text { I08 } & \text { I23 } & \text { I42 }\end{array}$

1 From the weights of the basal 6 inches of the young shoot. 


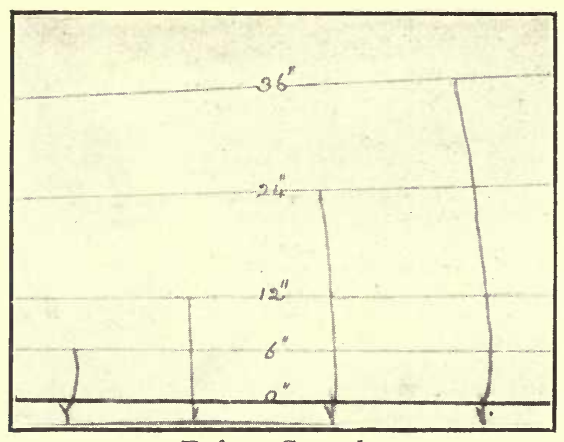

Before Growth.

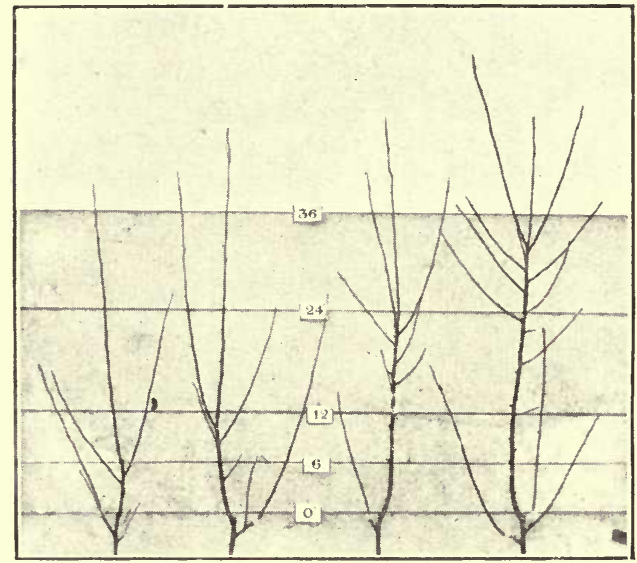

Early Peach on Crab-after Growth.

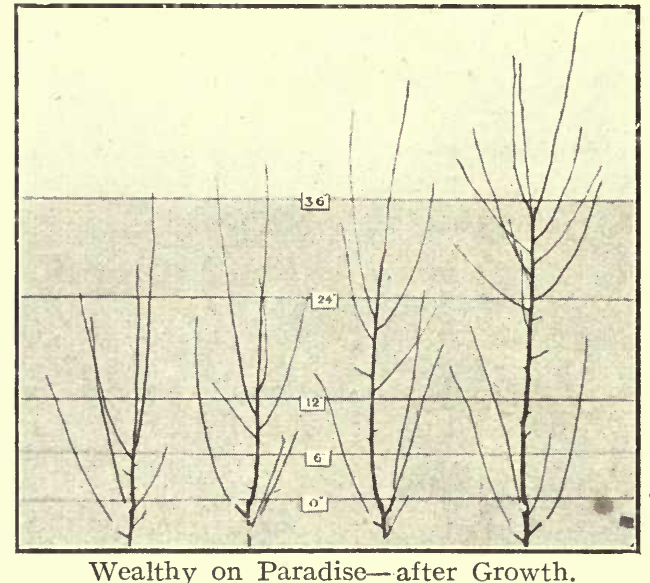

FIG. II.-GROWTH OF SHOOTS CUT BACK TO DIFFERENT EXTENTS. 
These values show that, from every point of view, growth has been favoured by a reduction of the pruning: when this is reduced to a minimum, the increase in weight of the shoot as a whole has been $5 \frac{1}{2}$ times greater than with the maximum amount of pruning, and the advantage has been gained, not only by an increased thickening of old wood left, but by an increase in the number, length and weight of new shoots formed.

The formation of so much extra new wood from the original two-year shoot, results, however, in a reduction in the amount of new wood formed from the still older portions of the tree. Taking the six inches of the three-year-old branches below the line 0 , the values were-

\section{New Shoots Formed on Older Wood}

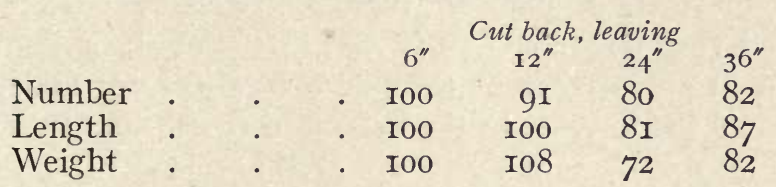

thus illustrating an effect which is well known, namely, that hard cutting back tends to force into growth buds on the lowèr portions of the branches.

The response given by different varieties of apple trees to variations in the extent of the pruning appears to vary considerably: thus, taking the relative weights of the branches which were cut back to the greatest and least extent in the case of the three varieties selected, the values were-

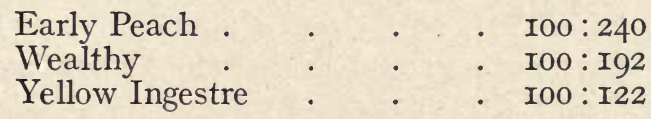

but the effect did not appear to be influenced much by the root stock, at any rate in the two cases where data for such a comparison were available, the relative effect of the lighter pruning being 2 per cent. more favourable on the paradise stock in the case of Early Peach, and 4 per cent. less favourable in the case of Wealthy.

An increase of several hundreds per cent. in the weight of a very lightly pruned branch over a hard-pruned one, may appear inconsistent at first sight with the difference of only 36 per cent. between the weights of the hard-pruned and unpruned trees as given on p. 59; but there is a difference between a case in which a single shoot has been left unpruned for one season, and one in which a tree has never been pruned at all. The single 
unpruned shoot has multiplied in the one year, giving rise to from three to ten new shoots, and if multiplication continued at the same rate in subsequent years, the tree would become a thicket of growth; but, as a matter of fact, in the absence of pruning, a tree prunes itself, and new shoots arise and develop only where there is space for their development. Hence, by a continued omission of pruning we cannot reproduce the results obtained by the omission of one pruning only; and hence, also, with older trees, the harder pruned individuals may form the greater number of new shoots, though in earlier years the reverse was the case. This answers the fourth question on p. 59.

Closer examination of the branches cut back to different extents gave evidence on a point more important even than that of wood-formation, namely, that of fruit-production; for it appeared that the reduction in the extent of the pruning had resulted in an increase in the number of blossom buds, quite as great as the increase in the weights of the shoots; in fact, the two sets of results were almost identical in magnitude-

\begin{tabular}{lcccc} 
& \multicolumn{4}{c}{ Cut back, leaving } \\
& $6^{\prime \prime}$ & I2" & $\mathbf{2 4}^{\prime \prime}$ & $36^{\prime \prime}$ \\
Weight of shoots and side shoots & Ioo & I79 & 3 I0 & 562 \\
Fruit buds & Ioo & I93 & 400 & 547
\end{tabular}

This result held good in individual cases as much as in the averages; for, when the values for each of the 32 cases available were examined separately, there were only four instances where reduced pruning was not accompanied by an increased formation of blossom buds (VII, 25). It was found, too, that a similar favourable effect, but much smaller in extent (about 20 per cent.), was produced on the older wood of three years' standing, though as regards wood-formation the effect, as has been seen, was the opposite (p. 63).

The unfavourable influence of pruning on fruit-production foreshadowed by these results was fully established by an analysis of the fruiting records of the plots pruned to different extents. These records are depicted in Fig. I2, being divided into two five-year periods and one ten-year period, the latter, however, depending mainly on the records from Bramley's Seedling. Comparing the moderately pruned trees with the others, the omission of pruning has doubled the crops, and hard pruning has almost halied them.

Another series of experiments, wherein a number of dwarf apples of the varieties Cox's Orange Pippin, Mr. Gladstone and 
Worcester Pearmain, planted in I905, were subjected from I908 to I9I4 to different branch treatment, gave further evidence of a similar character, the results being measured by counting the number of blossom trusses, so as to avoid the disturbing factor of the destruction of the fruit by spring frosts. The results, omitting two exceptional values of opposite characters, were-

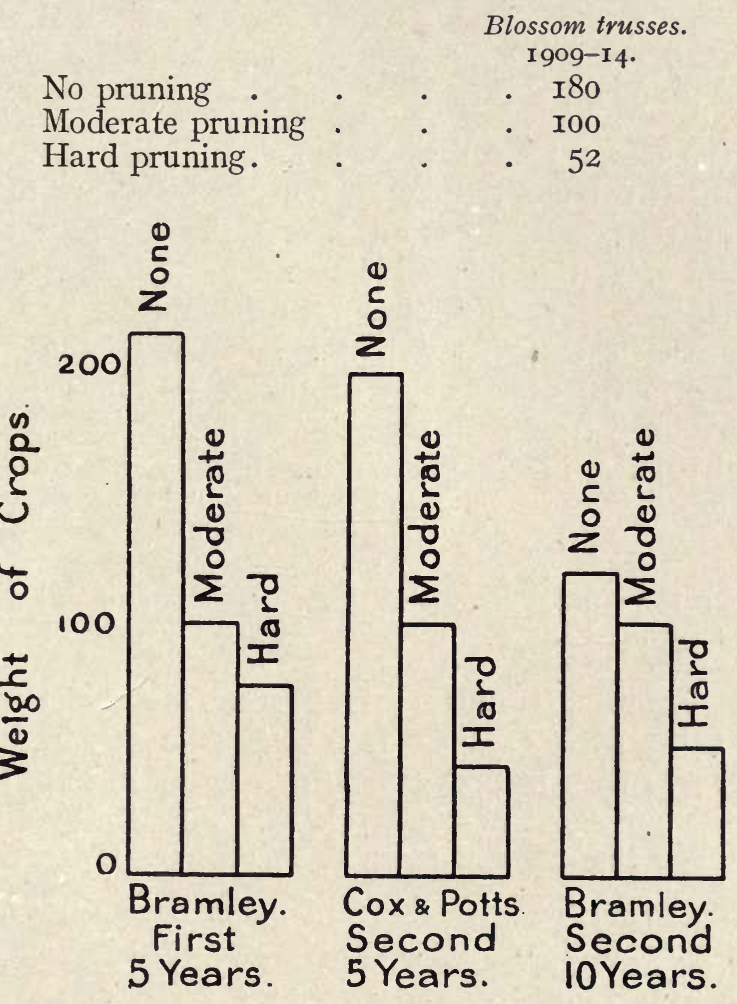

FiG. I2.-WEIGHT OF CROPS FROM TREES PRUNED TO DIFFERENT EXTENTS.

these values being very nearly in the same proportion as in the previous experiments.

A much more extensive series of records was presented by the fruit crops from eight trees of each of II7 different varieties of apples, half of them grown on the paradise stock, and half on the crab. The trees had all received the same branch treatment till I905, when this treatment was modified so that half of the trees on either stock were pruned more severely than the others, 
though the harder pruning in this case consisted (except during the first season) of only moderate pruning, and the lighter pruning of very slight branch treatment.

The average results for the twelve years which have since elapsed gave-

\section{Relative Weights of Fruits}

Crab stock. Paradise stock. Both stocks.

$\begin{array}{lllll}\text { Moderate pruning } & \cdot & \text {. IOO } & \text { I0o } & \text { I0O } \\ \text { Light pruning } & \cdot & \text {. I82 } & \text { I40 } & \text { I6I }\end{array}$

showing, again, a large balance in favour of the lighter pruning, though that balance, it may be remarked, appears to be somewhat on the decline, for, on taking the means for the last six years only, the values are found to be I3I, II4 and I23.

What was a matter of surprise, however, was that this superiority in cropping was not secured at the cost of a reduction in the average size of the fruits; indeed, the more lightly pruned trees actually showed, during the twelve years, a small balance in their favour in this respect, thus-

\section{Relative Size of Fruits}

Crab stock. Paradise stock. Both stocks.

$\begin{array}{lllll}\text { Moderate pruning } & \cdot & \text { IOO } & \text { IOO } & \text { IOO } \\ \text { Light pruning } & \cdot & \cdot \text { IIO }^{1} & \text { IOI }^{1} & \text { IO }^{1}\end{array}$

This, of course, is only an average result, and different varieties would naturally be expected to behave differently in this respect, according to their manner of fruiting. On setting out the results so as to show what percentage of the varieties bore the larger fruits under the different methods of pruning, it was found that

46 per cent. bore largest fruits under moderate pruning,

54 per cent. bore largest fruits under light pruning,

the relative values on the two root-stocks being practically identical. A similar examination of the size of the fruits borne by Bramley, Cox and Potts in the experiments previously described (p. 59) showed a small balance in the opposite direction, namely-

Average size of fruits during ro years.

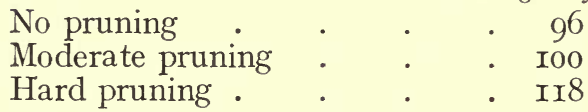

1 Omitting the results in 1907 , which appeared exceptional, these values become IOI, IO2 and IO2. 
But, even if the differences were always in this direction, and were always of this magnitude, they would by no means compensate for the much greater differences in the weight of the crops, for the values of the crops-as given by the weight of fruit multiplied by the size of the fruits (p. I9)-still show a large balance in favour of reduced pruning ( $\mathrm{V}$, II 7$)$.

\section{Value of crops}

during 10 years.

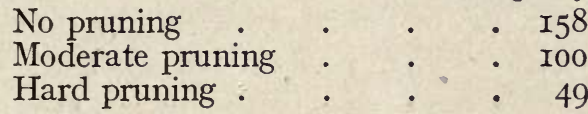

Other data may be adduced, all showing the benefit on fruitproduction by a reduction in the extent of the pruning. Thus, a mixed plantation of one-quarter of an acre was divided into three similar sections, each of which was pruned to a different extent, and the relative values of the crops from these during the nine years that the experiment lasted were-

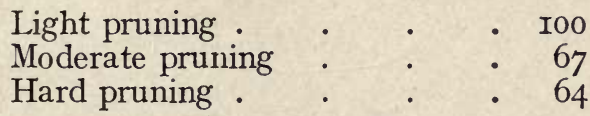

A very striking illustration of a similar effect is afforded by the fruit trees constituting the shelter hedges at the farm: these are pruned very hard, and consequently bear little or no fruit; but here and there branches have been left unpruned, so as to extend and form arches, and such branches, in contrast with the rest of the hedges, are usually loaded with fruit.

From every point of view, therefore, it would appear that pruning is disadvantageous to a fruit tree, and that the more it can be reduced, the better. ${ }^{1}$ But this does not by any means imply that it ought to be dispensed with. A fruit tree is an instance of a plant which has been developed by selection and cultivation till it has become abnormal in certain respects, and consequently requires abnormal or unnatural treatment. It has been developed so as to bear a much heavier crop than it would naturally do, and to bear it at an earlier age; such crops are in many cases greater than the branches can carry without distortion or injury, and hence, if pruning is dispensed with, the tree may be ruined, as is seen in the illustration in Fig. 9, p. $5^{8}$, which represents a tree of a very precocious variety and somewhat weak growth-Stirling Castle. Where a stronger and less

1 Similar results were obtained by K. Koopman, Elementalehren aus dem Gebiete des Baumschnitts, Landw. Jahrbuch., xv. 1896, pp. 97-618. 
precocious variety is in question, as in the case of Bramley, shown in Fig. Io, p. 60, the absence of pruning produces far less deleterious effects, and, though the shape of the tree and the disposition of the branches might clearly have been improved by some pruning, the result is by no means so bad as might have been anticipated. Similar results were obtained with Potts' Seedling, whilst Cox's Orange Pippin afforded an instance intermediate between this and Stirling Castle.

The simple conclusion, therefore, is that pruning should be reduced so far as is consistent with the formation of a well-shaped tree, capable of carrying such a crop as it is likely to produce. The pruning will, of course, retard the development of the tree, but the extension of the branches is arrested more than the filling out of the branches, and hence a more compact and sturdier tree will be produced. 


\section{Chapter VII}

\section{PRUNING (continued)}

\section{The Pruning of Older or Ailing Trees}

IT is, thus, during early years, when the foundations of its future life are being laid, that pruning is of most importance, and no objection, therefore, can be raised to the above conclusions on the ground that they are based on experiments with comparatively young trees, mostly under fifteen years of age. Pruning in the strict sense of the word-the cutting back of some of the new wood formed in the season-is but little required with trees in full bearing, because little new wood is made by them, and, owing to their size, much pruning of that sort is often impracticable.

That the effect of pruning on a young tree, where growth is active, must differ from that on an older tree, where growth is feeble and its energies are directed mainly to fruit-bearing, is fairiy evident; accordingly, it is found that the effect of heavy. pruning in such a case tends in the opposite direction to what it does in the case of younger trees; it checks fruiting and increases growth. That was shown by measuring the length of new wood formed during the season by trees of fifteen years of age when under different treatment, the results proving that the unpruned trees were then forming comparatively little wood-being chiefly occupied in bearing - whereas the hard-pruned trees were forming. as much as those which were pruned moderately, just the reverse of their behaviour in earlier years (VII, 42).

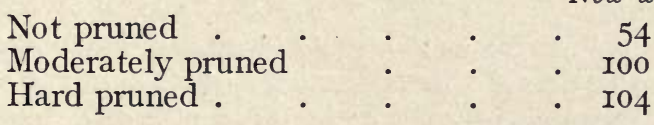

Such a reversal will tend to the eventual equalisation of the results of different degrees of pruning, the trees which have been retarded in their growth by this pruning eventually catching up their less pruned fellows, who have come to maturity earlicr. 
This was shown by the measurements made at successive dates of the size of trees planted in I904-5; these were-

\begin{tabular}{|c|c|c|c|c|}
\hline $\mathrm{I} 004$ & 。 & No pruning. & $\begin{array}{c}\text { Moderate pruning. } \\
\text { I00 }\end{array}$ & $\begin{array}{l}\text { Hard pruning. } \\
82\end{array}$ \\
\hline I908 & •. & . 105 & IOO & 83 \\
\hline IgII & & 100.5 & IOO & 86.5 \\
\hline IgI4 & & IOI 5 & IOO & $88 \cdot 5$ \\
\hline
\end{tabular}

Whether the equalisation in size will eventually become complete, or not, still remains to be seen; but, it must be remembered that, even if it does, this will not imply that the results have been equally advantageous, for there will have been a heavy deficit in crops from the harder pruned trees during all these years.

The antagonism between hard pruning and fruit-bearing was well illustrated by applying such treatment to some fifteenyear-old apple trees which had up to that time been only lightly pruned; the operation resulted in reducing the crops to less than one-tenth of that borne by similar trees on which the light pruning had been continued (VII, 27).

The effect of cutting off a shoot or branch is to force into growth those buds or dormant buds, on the thicker portions of the branches below it (see p. 63), and in this way we may often obtain good, vigorous growth from a tree which has become enfeebled, and which is incapable of producing such growth from the thinner wood at a distance from the stem. Thus a hide-bound tree may often become rejuvenated. But the amount of pruning necessary to effect this is usually much greater than what can properly be termed pruning; and wood of much more than one year's standing is generally removed : it may be more suitably called lopping.

Experiments on such lopping were made, both at Ridgmont and at Harpenden, on plums and damsons which had become stunted by being transplanted in previous years; and at the same time the effect of varying the date of the lopping was investigated. It often happens that with a tree which has been stunted, there is a temptation to give it another chance, and leave it one year longer to see whether it will not recover of its own accord; and, if it is found not to be showing much promise of doing so when spring comes, the question arises whether it is better to cut it back at once, or to wait to do so till the following winter. The results obtained at Ridgmont-those at Harpenden being in every way similar-may be summarised as follows, the values 
entered being the relative lengths of new wood formed in Igo6 only-

\section{Date of Cutting Back}

\begin{tabular}{|c|c|c|c|}
\hline $\begin{array}{l}\text { Iay } 27, \\
\text { I } 905 . \\
\text { I } 25\end{array}$ & $\begin{array}{c}\text { July I 4, } \\
\text { I905. } \\
75\end{array}$ & $\begin{array}{c}\text { Nov. 2, } \\
\text { I905. } \\
\text { I00 }\end{array}$ & $\begin{array}{c}\text { Mar I6, } \\
\text { I906. } \\
\text { I00 }\end{array}$ \\
\hline
\end{tabular}

The benefit of cutting back, when that operation is performed in the dormant season, is undoubted, for the resulting growth has been half as much again as where the trees were not cut back (100:67), and it has made no difference whether the lopping was done in November or in the middle of March. When it was deferred to May of the same year (Igo6) no advantage seems to have accrued (65), and when deferred to July the results appear to have been disastrous (I9); but this may be apparent only, for the wood formed in the season was necessarily underestimated, since much of it had been removed in the lopping operation itself. To ascertain what is the real effect of lopping on these dates we must take the trees which had been lopped on the corresponding dates in the previous year, and see what growth they made in I906; in that case it is found that the lopping, even as late as May 27, was decidedly advantageous, resulting in twice as much growth in I906 as where there was no lopping (I25:67), and that even when done in July there was some slight advantage -75 against 67 . There are various circumstances, however, which render it impossible to base a comparison between trees lopped in two successive years on the growth made by them during the second of these years, and it is evident from such other cases where comparison is possible, that delaying the lopping till the tree is in active growth is very deleterious; thus, when the trees lopped in May and July I905 are compared, the growth in $I 906$ is in the proportion of 125 to 75 , showing that the summer lopping has produced bad results, still very appreciable in the following season, and, as will be seen from results quoted below (p. 75), appreciable for many seasons afterwards. It is probable, therefore, that the lopping in May I905 also would show to some disadvantage had there been data for comparing it with a lopping done earlier in the same year. The general conclusion is that, though such lopping is effectual in restoring the tree to active growth, it should be done during the dormant season, and if not done before May, had better be postponed till the following winter. 


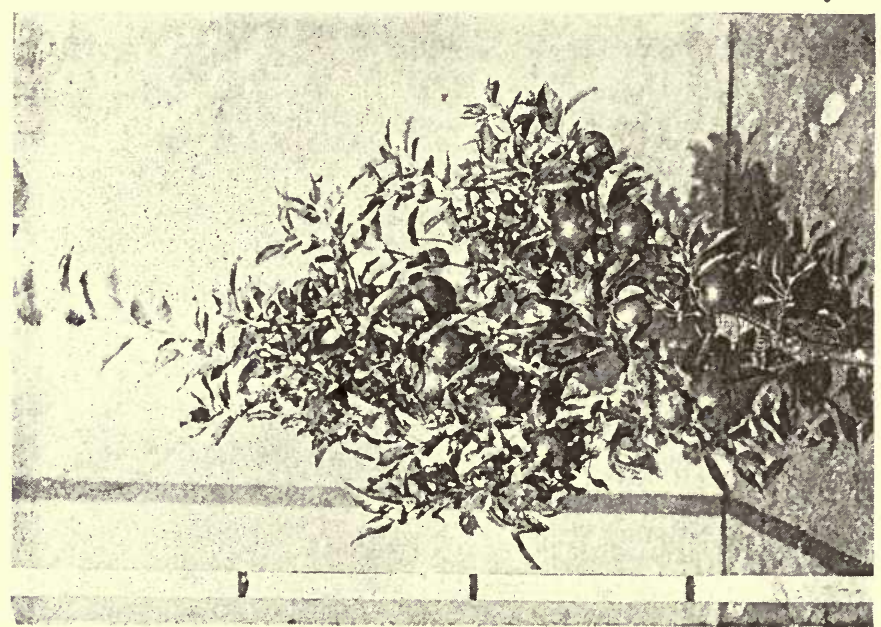

0
$\infty$
$\curvearrowleft$

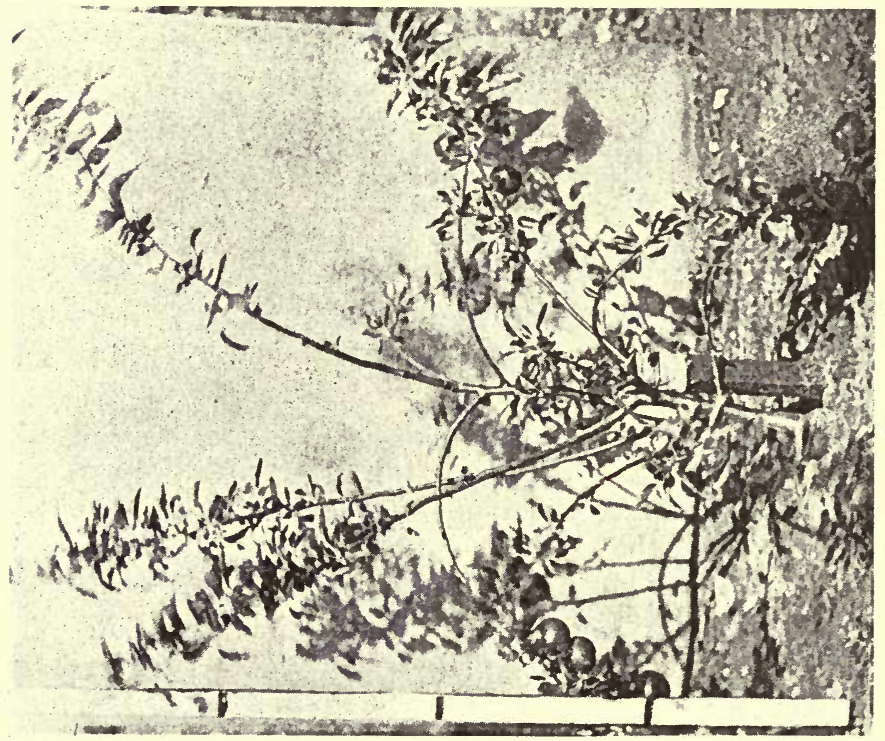




\section{Cutting Back Transplanted Trees}

That trees after they have been transplanted should be severely pruned, or cut back, removing one-half to two-thirds of the previous year's growth, is almost universally accepted by horticulturists; but much diversity of opinion exists as to when the operation should be performed; some holding that it should be done at once, others advocating deferring it till the trees are starting into growth, and others, again, deferring it till the following winter.

The reason for such cutting back depends on the necessity of preserving a proper balance between the roots and branches, a necessity which cannot be too persistently borne in mind; for the tree obtains some of its materials for growth by means of its leaves, and some by means of its roots; if these two sets of organs are not working in harmony, the tree cannot be properly fed. When a tree has been transplanted, its roots will have inevitably suffered much damage, as has been already explained (p. 40), and to preserve the balance between roots and branches, a considerable restriction of the latter is necessary.

The effect of not cutting a tree back after it has been planted is illustrated in Figs. I 3 and 14 by photographs taken twelve months after the planting. The trees made practically no growth during the season, and measurements showed that, on the average, the leaf-size was deficient to the extent of 24 per cent. and the total leaf area to an extent of I5 per cent., in spite of there being three times the length of leaf-bearing branches on the trees as on those which had been cut back (I, I02); whatever the subsequent behaviour of the tree may be, this diminution in leafsurface during one season must imply diminished energy, and affords a strong argument against deferring the cutting back till the end of the first year. When eventually the cutting back was performed, it was followed by a burst of energy in the following year, the leaf-size showing an excess of 20 per cent.; but this was not maintained, and in succeeding years it again fell below the level of that of trees which had been cut back at once (V, I04). There was not much, however, in the ultimate behaviour of the trees, when measured either as to their size or as to the size of their leaves, to differentiate between the respective advantages of immediate or deferred cutting back, and it was chiefly as regards fruiting that early cutting back showed to advantage; for, during the first five years after planting, the trees which had 


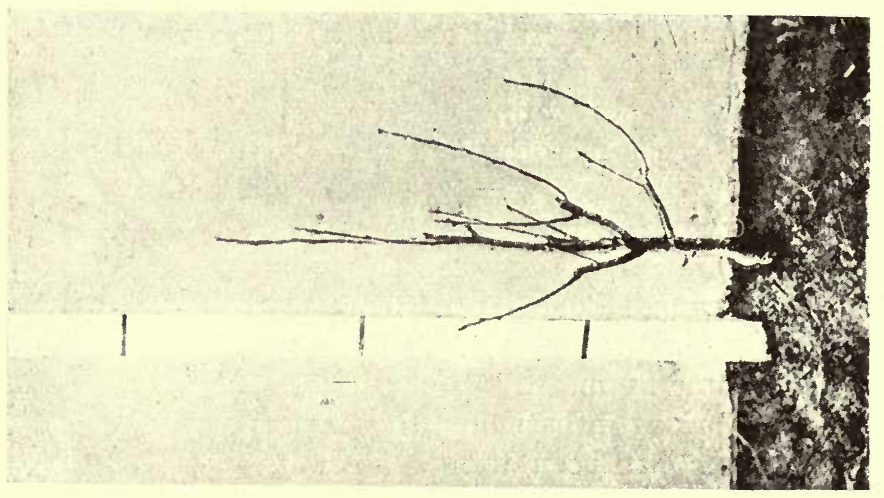

至

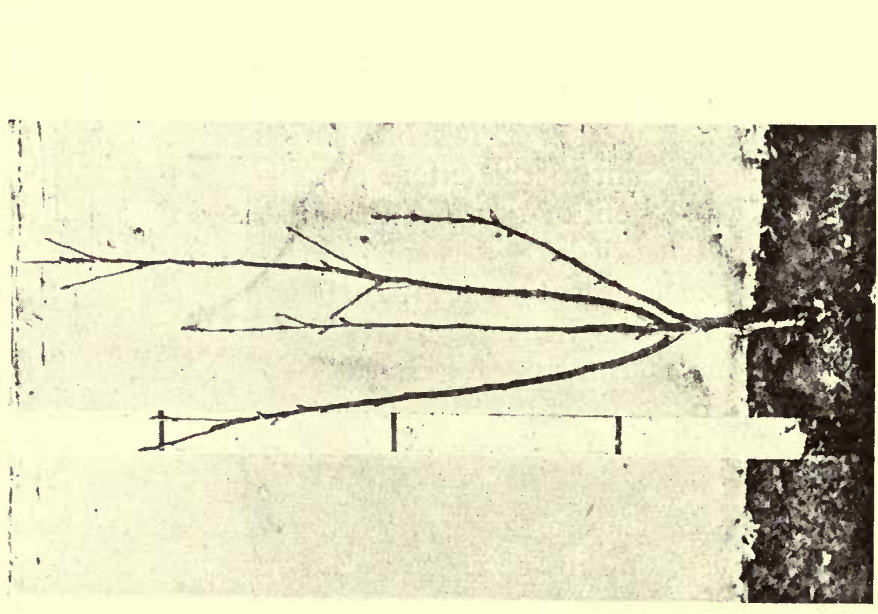


been thus treated bore five times as much fruit as those where the cutting back had been delayed (V. 22).

A more extensive series of experiments on apples, pears and plums (I26 trees in all) was carried out, in which the effect of performing the cutting back on different dates was examined, the examination being extended throughout nine seasons. The average results during these years were-

\begin{tabular}{|c|c|c|c|c|c|}
\hline & & & Cut back & on & \\
\hline d formation & $\begin{array}{l}\text { Dec. } 7 \text {, } \\
1905 .\end{array}$ & $\begin{array}{c}\text { Feb. } 27 \\
\text { 1906. }\end{array}$ & $\begin{array}{c}\text { April 2I, } \\
\text { I906. }\end{array}$ & $\begin{array}{c}\text { July I } 3, \\
\text { 1906. } \\
761\end{array}$ & $\begin{array}{l}\text { Dec. } 7 . \\
\text { r9o6. }\end{array}$ \\
\hline Leaf-size & - IOO & IOO & IO2 & 94 & 99 \\
\hline Blossoming & IOO & IO2 & Io6 & $8 \mathrm{I}$ & 79 \\
\hline
\end{tabular}

Delaying the cutting back for a whole year has clearly been somewhat disadvantageous (cf. first and last columns), but it may be delayed until growth starts in the spring without any detriment; indeed, a slight benefit is indicated by the values for April 2I, though, owing to the variations in the different seasons being large, the differences shown are within the limits of experimental error. Delaying the operation till July, however, has undoubtedly been very detrimental-just as it was with the lopping of older trees (p. 7I) -and it is remarkable that the bad effect of it should persist throughout so many years : there were some signs of it becoming obliterated towards the end of the nine years, but, as the following details show, these signs were by no means certain-

\section{Relative Behaviour of Trees when Cutting Back had been Deferred till July}

$\begin{array}{lccccccccc} & \text { I907. } & \text { I908. } & \text { I909. } & \text { I9ro. } & \text { I9II. } & \text { I9I2. } & \text { I9I3. } & \text { I9I4. } \\ \text { Wood formed } & 82 & 76 & - & 82 & 80 & 60 & - & - \\ \text { Leaf size } & 90 & 87 & 96 & 96 & 99 & 98 & - & - \\ \text { Blossoming } & - & - & 62 & 70 & 97 & 79 & 81 & 99\end{array}$

The question of deferring the cutting back till twelve months after the planting received still further attention in a series of experiments with bush apples and pears, in which it was sought to ascertain the effect, both on the roots and the branches of the trees, when the latter were not cut back after the trees were transplanted. By lifting the trees twelve months after the planting, it was found that, in the case of apples, the omission of cutting back had affected the branch-growth much more than

1 Omitting the first year's record, when the value was 36 . 
the root-growth. As compared with the cut-back trees represented by I0o, the weights of new wood formed were-

$\begin{array}{ccc}\text { Branches. } & \text { Roots. } & \text { Total new growth. } \\ 40 & 90 & 65\end{array}$

whilst with the pears a similar result, but to a much exaggerated extent, had occurred, the root-formation having actually exceeded that of the cut-back trees, and having been sufficient to more than counterbalance the diminished branch-formation, so that the total of the new wood formed, branches and roots together, was greater with the not-cut-back than with the cut-back trees. The values were-

$\begin{array}{ccc}\text { Branches. } & \text { Roots. } & \text { Total. } \\ 65 & \mathrm{I} 54 & \mathrm{I} 37\end{array}$

As such results might have been due to some accidental circumstances, a further examination appeared necessary, and a fresh series of experiments on a more elaborate plan was arranged, some of the cut-back and not-cut back trees being left in the ground for various intervals up to five years before being lifted for examination. Unfortunately the variations in the results obtained were too great to lead to any safe conclusions $(\mathrm{XV}, 62)$, and the matter must, therefore, rest for the present on the results of the former experiments, which are nearly unanimously opposed to delaying the cutting back of a young tree till the year after it has been planted, the only partial exception found being that of the pear trees mentioned above.

\section{Pruning at Different Times. Summer Pruning ${ }^{1}$}

Just as in the case of cutting back a tree after it has been transplanted, or of lopping an ailing tree, so as regards the ordinary pruning of a healthy tree, the operation may be done at any time during the dormant season without affecting the result. This was shown in the case of a mixed plantation of one-quarter of an acre in extent, which was divided into three strictly similar sections, the trees in these being pruned in early autumn, mid-winter and spring, respectively: the original cutting back had also been done during these same times of the year. The values of the crops from the three sections

1 Discussions on summer pruning may be found in Jour. Roy. Hort. Soc.. I908, xxxiii., pp. 487-499, and in Garden Chron., I907, xli., pp. 400-3, 406-7. 
during the following eight years were practically identical, being in the proportions of-

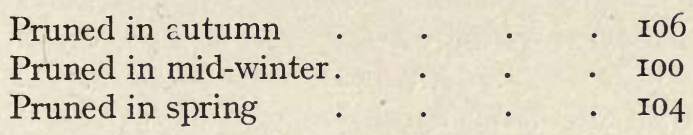

In no case did any damage ensue from the pruning in mid-winter, however severe the weather was $(\mathrm{V}, 38)$.

That the effect of pruning in the summer must be detrimental to the growth of trees, is sufficiently evident from the results obtained in the case of cutting back or lopping in summer, but the annual performance of such an operation interferes with the means at disposal for measuring growth or leaf-size, so that the general size of the tree, or the fruit-crops, are the only means left for measuring the results. Of the original plots of dwarf apple trees several were devoted to summer pruning in various forms, but the results obtained from them as regards growth were of a negative character, the average size of the trees during the next twenty years being within 2 per cent. (below) the winterpruned ones; but the weight of fruit from them was decidedly deficient, being only 70 per cent. of that obtained from similar autumn-pruned trees.

The subject was then examined by applying summer pruning - using pruning in its strict sense, and not applying it merely to pinching or stopping the growth-to a number of apple trees of the varieties Cox's Orange Pippin, Mr. Gladstone and Worcester Pearmain, performing the operation on different dates, and observing the results on the fruiting, as measured by the number of blossom trusses formed in the following year. The observations during six years gave the following values-

$\begin{array}{ccccc}\text { Pruned, Dec. I. } & \text { July 15. } & \text { Aug. I. } & \text { Aug. I5. } & \text { Sept. I. } \\ \text { I00 } & \text { II3 } & \text { II9 } & \text { I24 } & \text { I4I }\end{array}$

showing uniformly an excess of fruiting as compared with the winter-pruned trees - the reverse of what was shown in the previous experiments - and a steady increase in this effect according as the date of the summer pruning was postponed. The increase, however, it may be remarked, is much less than that produced by omitting all pruning, the value obtained in such a case being 180 , as quoted on p. 65 ; and, as regards summer pruning, as well as winter pruning, it is found that a reduction in the extent of that pruning favours fruit-production, for 
moderate and hard pruning practised on August ${ }_{5} 5$ were found to result in blossom production in the ratio of $100: 52(\mathrm{XV}, 68)$.

Actual pruning in summer is, however, not a very practical operation, and even summer treatment of a less drastic character can only be attempted in small fruit gardens. The form of pruning then adopted generally consists of such methods as will check the growth of the shoots, without actually removing any part of them : the terminal buds may be pinched off, the shoots may be broken and left hanging, or they may be twisted so as to loosen the bark from the wood. Experiments are in progress on these three methods of treatment, applying them on different dates from July 20 to August 3I, but they have not been continued long enough to allow of any definite pronouncement as to the results, beyond that such summer treatment has so far increased the blossoming by about 13 per cent., and has reduced the growth by 16 per cent., and that, in both cases, the effect is greater the earlier the operation is performed between July 20 and August 3I (the reverse of what was found in the case of summer pruning in its strict sense): but the increase in the blossoming has not, so far, been followed by any increase in the fruiting, the results for three years showing, fairly uniformly, a deficiency of twenty per cent. as regards the fruiting of the summer-treated trees. So far, therefore, the results obtained on summer pruning have been very contradictory. ${ }^{1}$

\section{The Manner of Pruning}

Much store is often set on the nature of the cut which should be made in pruning a shoot, it being held that the cut should slope upwards and outwards, and be made at the level of a bud which points away from the centre of the tree. Much attention cannot be given to such niceties when pruning extensive plantations, or in dealing with large trees where long pruners have to be used, and, fortunately, except in one particular, these niceties do not appear to be of much importance. A series of experiments with young apple trees, extending over seven years, gave some information on the subject. No appreciable difference in the vigour of growth of the trees was made, either by using secateurs instead of a knife, or by pruning to an inside instead of an outside bud. In the latter case some effect was

1 So also do they appear to have been in the United States. Good results were obtained by Drinkard at the West Virginia Agric. Expt. Station, Tech. Bull. 5, I9I5, and also by Dickens at the Kansas State Agric. Coll., Bull. r36. Unfavourable results were obtained by Batchelor and Goodspeed at the Utah Agric. Coll. ExI t. Station, Bull. I40. 
produced on the character of the trees, making them more compact than when they were pruned to outside buds, but the effect was less than might have been anticipated, and was not always apparent. In some cases an increase in compactness would be a disadvantage (e.g. King of the Pippins, which was one of the varieties examined), whereas in others, where the tree is naturally of a spreading habit (Lane's Prince Albert, for instance), it would be an advantage. It was only in the case where the twig was cut one inch above a bud, that a definite effect on the vigour of the tree was apparently produced, the values indicating that this vigour had been reduced by about one-third; a similar result had been obtained in a previous series of experiments extending over three years. The explanation of such a reduction is probably as follows : when the twig is cut, a callus forms, sealing up the ruptured cells; wherever the cut is made, this callus forms just above the bud next below the cut: if the cut be made much above the bud, the formation of the callus will probably be a much slower operation than where it is made at the bud itself, and, consequently, before it forms, there will have been a much greater loss of water from the neighbouring cells; the adjacent bud may thereby have been enfeebled, and the ultimate growth from it affected.

\section{ROOT-PRUNING}

An investigation on root-pruning should, perhaps, be confined to cases where such root-pruning appears to be called for by some excessive vigour of growth: but to produce a sufficient number of such instances suitable for definite experiments would, if practicable at all, have required the lapse of many years. A measurement of the extent to which root-pruning checks the growth was, therefore, made on trees which showed no such excessive growth. The results have already been described in a former chapter (p. 45), and it will only be necessary to recall that root-pruning every fourth year reduced the size of the trees to 43 per cent. of that of trees not so pruned, without any compensating advantage of increased crops, except after the first and second performance of the operation; whilst root-pruning every year, or every second year, either actually, or nearly, killed the trees.

Root-pruning is not an operation which is applicable to commercial fruit growing, and it is only in small gardens that it is practised : that it should ever be necessary to injure a tree to such a serious extent in order to make it function properly, 
implies that the treatment to which the tree has been subjected must have been very improper in some other way: excessive branch-pruning is, obviously, where the error lies. Such excessive branch-pruning upsets the balance between branches and roots, the tree no longer functions as a healthy fruit-producing plant, and the balance can only be restored by inflicting a corresponding injury on the roots, or otherwise injuring the vitality of the tree by ringing its bark, etc., as is sometimes practised. But to injure a tree in one respect, and then to correct that injury by injuring it in another, is not a rational method of procedure : if there was less branch-pruning, and, perhaps, less over feeding, of fruit trees, we should hear very little of root-pruning.

Just as injury to the roots affects branch-growth, so injury to the branches affects root-growth: the hard-pruned trees, as the values quoted on p. 59 showed, were only two-thirds as heavy as the unpruned ones, but it was found that, on the average, the proportion between the weights of the roots and branches was almost independent of the extent of the pruning, the values being-

\section{Percentage of Roots to the Whole Tree}

$\begin{array}{ccc}\text { No pruning. } & \text { Light pruning. } & \text { Hard pruning. } \\ \text { I9 } & 2 \mathrm{I} & 23\end{array}$

so that pruning the branches must have affected the root-development nearly as much as it affected the branch-development itself $(\mathrm{XVI}, 56)$.

Of course, in the case of trees trained against a wall, excessive branch pruning is necessary, or the trees would not long remain as wall trees, and then root-pruning may be inevitable; but that is only an instance of a special case calling for special treatment. ${ }^{1}$

${ }^{1}$ References to the results obtained in America on root-pruning-most of which were unfavourable-will be found on p. 34, footnote. 


\section{ChAPTER VIII}

\section{SOIL ANALYSES (Reports, I, 4; IV, I)}

Some account of the character of the soil at the Woburn Experimental Fruit Farm, so far as it can be elucidated by analysis, must be given by way of an introduction to a description of the results of the manurial experiments conducted there.

The soil consists mainly of a sandy loam, resting on a bed of Oxford clay, the good surface soil being about seven inches deep. There is, however, a very considerable difference between the soil in the upper portion of the ground, A, B, C, in the plan, on the following page, and the lower portion, D, E, which latter contains so little sand, and such a large proportion of clay, that it can only be described as a clay soil. The dotted lines, $a, b, c, d$, indicate the line of separation between these two classes of soil.

The subsoil consists of a bed of clay of considerable depth. Borings were sunk in two places to forty-five feet below the surface, without reaching the bottom of it. At depths below about ten feet the clay is blue, and in parts very hard. It does not appear to contain any stones, and the surface soil also contains very few-about 2 per cent. of the weight of dried soil.

Throughout the greater part of the field there is a gentle slope towards a brook, which runs along the south-west side of it. The highest point of the ground is marked $\mathrm{H}$ on the plan, the heights at other points, measured in feet below $\mathrm{H}$, being given by values enclosed in circles. The highest point is about $15^{\circ} 4$ feet above the road by the brook, the distance from this road being 750 feet, and the average slope, therefore, I in 49.

The brook runs between banks, three to four feet high; it is never dry, and in flood time it occasionally overflows its banks, swamping the lower portion of the ground: and it is probably due to such flooding in past years that the differences between the upper and lower portions of the ground are to be attributed.

A summary of the analyses of the soil in these two portions of the farm is given in the accompanying tables, together with 


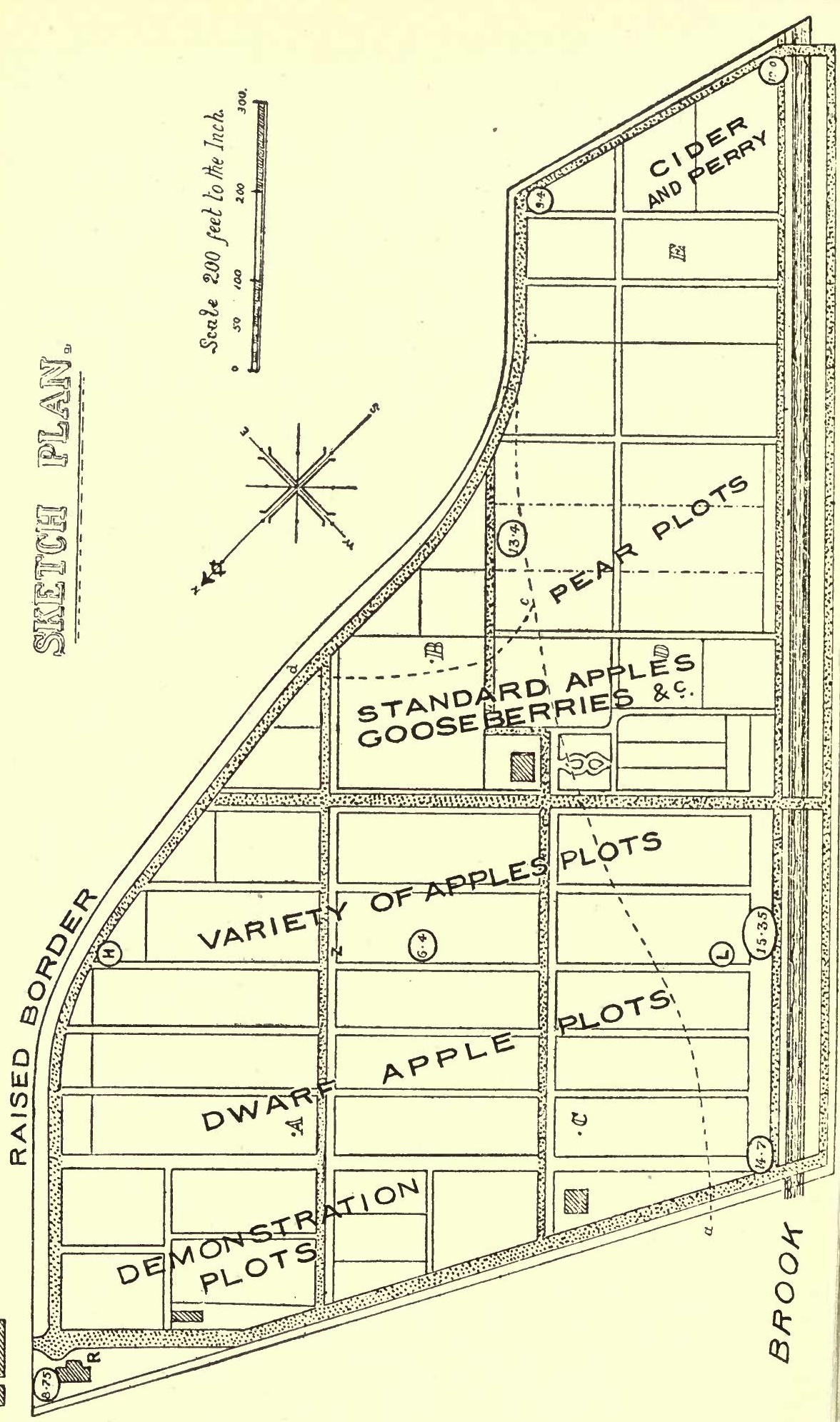


analyses of the coarse, sandy soil at Millbrook, where certain manurial experiments were conducted (p. 93).

\section{MECHANICAL ANALYSIS OF SOIL AT RIDGMONT AND MILLBROOK, IN AIR-DRIED CONDITION}

Size of Particles.

\begin{tabular}{|c|c|c|}
\hline \multicolumn{2}{|c|}{ Ridgmont. } & \multirow{2}{*}{ Millbrook. } \\
\hline Station A. & Station E. & \\
\hline \multicolumn{3}{|c|}{ First Depth of 9 ins. } \\
\hline $2 \cdot I$ & $0 \cdot 3$ & $4 \cdot 3$ \\
\hline $48 \cdot 3$ & $6 \cdot 7$ & $7 \cdot 04$ \\
\hline $7 \cdot 7$ & $2 \cdot 2$ & $7 \cdot 2$ \\
\hline $7 \cdot 3$ & $2 \cdot 3$ & $I \cdot 7$ \\
\hline $9 \cdot 5$ & $12 \cdot 7$ & $4 \cdot I$ \\
\hline $3 \cdot 3$ & $8 \cdot 7$ & $2 \cdot 7$ \\
\hline $15 \cdot 3$ & $5 \mathrm{I} \cdot 5$ & $6 \cdot 0$ \\
\hline $3 \cdot 5$ & II $\cdot 2$ & $2 \cdot 6$ \\
\hline $3 \cdot 0$ & $4 \cdot 4$ & $I \cdot O$ \\
\hline $100 \cdot 0$ & $100 \cdot 0$ & $100 \cdot 0$ \\
\hline
\end{tabular}

Fine gravel

Coarse sand

Sand

Meal

Silt . :

Dust

Clay

Water, soluble matter, 002

Loss .

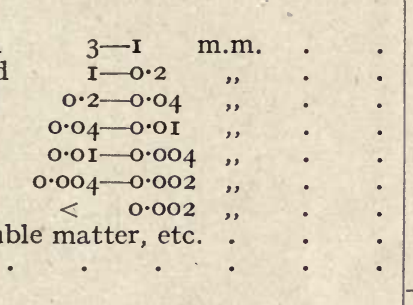

- .


CHEMICAL ANALYSIS OF SOIL AT RIDGMONT AND MILLBROOK, BY TREATMENT WITH HYDROCHLORIC ACID, AFTER DRYING AT $100^{\circ} \mathrm{C}$.

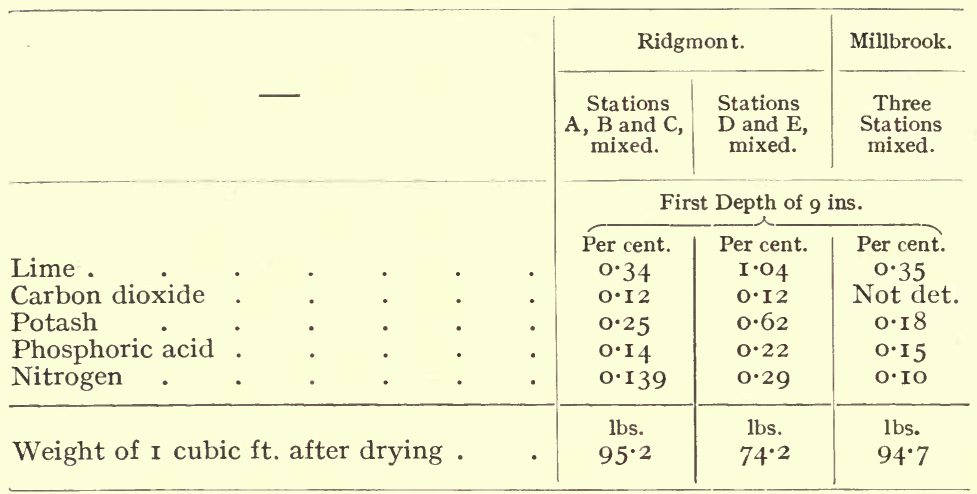

\begin{tabular}{|c|c|c|c|c|c|c|c|c|}
\hline \multirow[b]{2}{*}{$\begin{array}{l}\text { Lime } \\
\text { Carbon dioxide } \\
\text { Potash acid } \\
\text { Phosphoric acid } \\
\text { Nitrogen }\end{array}$} & \multirow[b]{2}{*}{$\dot{.}$} & \multirow[b]{2}{*}{$\dot{\dot{r}} \dot{.}$} & \multirow[b]{2}{*}{$\dot{.}$} & \multirow[b]{2}{*}{ 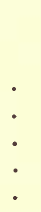 } & \multirow[b]{2}{*}{$\dot{.}$} & \multicolumn{3}{|c|}{ Second Depth of 9 ins. } \\
\hline & & & & & & $\begin{array}{l}\text { Per cent. } \\
0.58 \\
0.20 \\
0.34 \\
0.13 \\
0.086\end{array}$ & $\begin{array}{l}\text { Per cent. } \\
0.97 \\
0.06 \\
0.52 \\
0.18 \\
0.170\end{array}$ & $\begin{array}{c}\text { Per cent. } \\
\text { o.o9 } \\
\text { Not det. } \\
\text { o. I } 4 \\
\text { O.I } 4 \\
\text { O.044 }\end{array}$ \\
\hline Weight of I cubi & ic $\mathrm{ft}$. & - & - & - & - & $\begin{array}{l}\text { lbs. } \\
\text { I08.2 }\end{array}$ & $\begin{array}{l}\text { lbs. } \\
70 \cdot 6\end{array}$ & $\begin{array}{l}\text { lbs. } \\
93 \cdot 4\end{array}$ \\
\hline
\end{tabular}

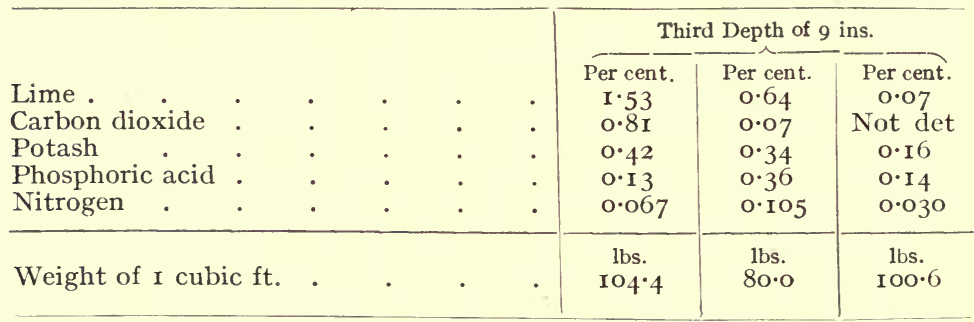

From the mechanical analyses it will be seen that the soil at the Upper Station at Ridgmont, A, contains a large proportion of coarse sand, nearly 50 per cent., but not corresponding proportions of the next two grades, sand and meal; and this fact, coupled with high proportion of clay present, indicates that it is essentially a clay soil, into which there has been an irruption of a coarse, sandy soil. This is emphasised by the character of lower depths of the soil, for when the third 9 inches 
is reached, the clay attains a proportion of 45 per cent., and comparatively little coarse sand is left.

At the lower station, E, the soil is a heavy clay throughout, the actual proportion of clay in it varying from $4 \mathrm{I}$ to 53 per cent., and it presents the unusual feature of there being a larger proportion of fine particles in the top 9 inches than in the second 9 inches, this probably being the result of flooding, as indicated above. That the soil in the two portions of the ground is fundamentally of the same character, modified only in the surface layers, is shown by the close similarity of composition of the third 9 inches.

The Millbrook soil, it will be seen, is of a very sandy nature, the coarse sand in it amounting to over 70 per cent., and the proportion of finer particles being very small.

The chemical analyses of the soils, as given in the second table, do not indicate any marked sterility as regards the Millbrook soil; the phosphoric acid and nitrogen in it comparing well with that in the Ridgmont soil, and the potash alone being somewhat deficient. In the lower depths a deficiency of nitrogen in the Millbrook soil becomes more marked, but the poverty of this soil is not apparent till the results of the determination of the available food-materials in it are considered; these are given, approximately, at any rate, by the citric acid method of analysis, and are contrasted below with the total amounts of food materials, as given by the hydrochloric acid method in the previous table.

TOTAL AND AVAILABLE PLANT-FOODS

First Nine INCHES

\begin{tabular}{|c|c|c|c|c|c|}
\hline \multirow{2}{*}{\multicolumn{2}{|c|}{ Constituent. }} & \multicolumn{2}{|c|}{ Ridgmont, A, B and C. } & \multicolumn{2}{|c|}{ Millbrook. } \\
\hline & & $\begin{array}{l}\text { Total by } \\
\text { Hydrochloric } \\
\text { Acid. }\end{array}$ & $\begin{array}{l}\text { Available } \\
\text { by } \\
\text { Citric Acid. }\end{array}$ & $\begin{array}{l}\text { Total by } \\
\text { Hydrochloric } \\
\text { Acid. }\end{array}$ & $\begin{array}{l}\text { Available } \\
\text { by } \\
\text { Citric Acid. }\end{array}$ \\
\hline Potash & . & $\begin{array}{c}\text { Per cent. } \\
0.25\end{array}$ & $\begin{array}{l}\text { Per cent. } \\
0.025\end{array}$ & $\begin{array}{l}\text { Per cent. } \\
\text { O.I } 8\end{array}$ & $\begin{array}{c}\text { Per cent. } \\
0.006\end{array}$ \\
\hline Phosphoric acid & . & 0.14 & $0 \cdot 01_{4}$ & $0 \cdot 15$ & 0.024 \\
\hline
\end{tabular}

Such poverty as the Millbrook soil exhibits is evidently due to a lack of potash, and not to a lack of phosphoric acid, for the amount of this latter which is present in an available form, is considerably greater than in the Ridgmont soil : the available potash, however, is only one-fourth of that in the Ridgmont 
soil, and constitutes a very small proportion of the total potash present. The soil is probably very near the limits of potash starvation, which, according to Dr. Dyer, is less than $0^{\circ}$ or per cent. for cereals. The very dry character of the soil would help in rendering it unsuitable for farm crops.

In cases where a general artificial manure has been applied in the manurial experiments, the mixture used was the following :-

\begin{tabular}{|c|c|c|c|c|c|c|c|}
\hline & - & & & & & $\begin{array}{l}\text { Lbs. } \\
\text { per Acre. }\end{array}$ & $\begin{array}{l}\text { Grams per } \\
\text { sq. m. }\end{array}$ \\
\hline Potassium sulphate & . & - & . & . & • & 94 & $9 \cdot 7$ \\
\hline Superphosphate & . & . & . & . & . & 152 & $15 \cdot 8$ \\
\hline Magnesium sulphate & - & - & • & - & . & 32 & $3 \cdot 3$ \\
\hline Sodium nitrate & . & . & . & . & . & 97 & $10 \cdot 0$ \\
\hline
\end{tabular}

Such a mixture is, probably, equivalent to a dressing of 12 tons of dung to the acre, and in these quantities it was used in the normal plots, i.e. those plots which were taken as the standards of comparison for other differently treated plots. Except in certain special cases, the nitrate was applied in February, and the other minerals in winter.

The top nine inches of soil at the upper stations, A, B and C, at Ridgmont were found, after drying, to weigh 318 kilos per square metre, equivalent to $636 \mathrm{lbs}$. per square yard, or $3,080,000 \mathrm{lbs}$. per acre; the second and third nine inches weighed six per cent. more. At the lower stations, D and E, the weights for the top nine inches were 248 kilos per square metre, $500 \mathrm{lbs}$ per square yard, or $2,420,000$ lbs. per acre; the lower layers weighing I'7 per cent. more. 


\section{CHAPTER IX}

\section{MANURES}

THE food-constituents in soil may, from one point of view, be roughly divided into two classes, according to the condition in which they are present, namely, those which are soluble in water or in very weak acid, and which are, therefore, immediately available for absorption by the roots of plants; and those which are insoluble, becoming available for food only gradually, after being converted into soluble compounds by the slow processes of chemical change occurring under the action of water, air, carbon dioxide, etc. We have no means of ascertaining with certainty the amount of readily available food-supplies in a soil, though approximate values may be obtained in some cases by determining the quantities which are dissolved by a weak solution of citric acid. Only a portion of this available food is ever removed by any crop : the roots do not penetrate every space where the food exists, and even if they did, their power of absorbing it would be arrested or counterbalanced by other forces long before they had entirely depleted the soil of the soluble salts in it. Indeed, an excess of available food over and above the actual requirements of the plant is essential to the well-being of that plant; and plants differ materially as to the magnitude of the excess which is necessary for their welfare: two different plants may remove about the same amount of food-material from the soil, but the one will not flourish unless there is present a larger amount of such material than that which would produce an excellent crop of the other. It is not merely a question of the amount of food present, but of the power of the plant to reach it and assimilate it.

The simpler question of the amount of readily available food in the soil is complicated by the gradual change of the materials from the insoluble into the soluble form, and the rate of this change, besides depending on physical circumstances, must depend to a considerable extent on the rate at which the soluble constituents are removed, and, hence, on the nature of the crops grown in the soil. Judging by the results with wheat in 
Broadbalk field at Rothamsted, a condition of equilibrium between the soluble salts removed and those becoming soluble is not attained till after about fifty years of continuous cropping.

Another element of uncertainty lies in the different depths to which plant-roots extend. This must affect the question in more ways than one. A plant which draws any considerable portion of its nourishment from the subsoil must be comparatively insensible to the richness of the surface soil, and will respond less readily to any dressing applied to this latter; whilst, at the same time, the tapping of the resources of the soil at lower depths cannot fail to influence the progress of the changes occurring in the constituents of the soil. Not only do different kinds of trees and plants extend their roots to different depths below the surface, but trees of the same kind will differ materially in this respect in different soils, the chief factor conditioning the level at which the roots flourish appearing to be more dependent on the aëration of the soil than on the food supply in it. A striking instance of this has already been adduced from the planting of paradise stocks with their roots 2 feet below the surface (p. 39).

Contrasting fruit trees with ordinary farm or vegetable crops, there is a marked difference in the mass of soil from which their nourishment is drawn. With farm crops there is considerable diversity as to the depth of rooting, but it is probable that in most cases the bulk of nourishment is drawn by them from the top nine inches of soil. With fruit trees, in most instances, the case is very different: the bulk of the roots are not in the surface soil at all, and many of them will extend to several feet below the surface. This difference, however, does not apply with so much force to plant-growth in the soil of the Fruit Farm at Ridgmont, for there we are dealing with a shallow surface soil overlying the Oxford Clay, and in it all fruit trees assume a remarkably shallowrooting habit (p. 309). But the extent to which roots penetrate into the subsoil is not the only way in which they may, by their habit of growth, affect the manurial requirements of the soil; for roots which are concentrated within a small area must soon exhaust the soil immediately surrounding them, and, as the motion of water in the soil is often a slow process, time must elapse before supplies from a greater distance can reach the plant. In such a case the plant would require a greater concentration of foodmaterial in the soil than in other cases where the roots were more openly distributed through the ground, even though the actual amount of food required was the same in both cases. Naturally, too, the rapidity of root-action, as determined by the physical 
peculiarities of the roots themselves, would affect the case in the same way as the distribution of the roots in the ground, and the extent of any action of this sort would depend on the relation of the factors concerned to the requirements of the plant.

With all these elements of uncertainty it is impossible to dogmatise as to the effect of manures on fruit trees, and no conclusions based on what has been established respecting farm crops can with safety be applied to the case of trees. This is evident from the mere fact that forest trees may continually be found flourishing on land which is too poor for ordinary agricultural crops. Even if a crop of apples, including the wood formed by the trees, removes as much material from the soil as does a crop of wheat, this material would generally be drawn from a much wider area, and there should be nothing to justify surprise if it were found that the food-supply were not materially affected by the removal of ten or twenty annual crops, or that manure applied to the surface had had no appreciable effect during that period. That the process of drawing on the supplies without replenishing them can be continued indefinitely is, of course, out of the question; but the total store of food-material in any ordinary soil is so enormous, and we are yet so ignorant of the rate at which it may be brought into the available condition under various circumstances, that it is impossible to set any limit to the lapse of time occurring before a tree would begin to suffer from exhaustion. There are thousands of orchards in England where apples have been grown for centuries with little or no manuring, and in which young trees will still flourish when planted under proper conditions as to light and the removal of grass.

The question of manuring is one on which the grower is not likely to be influenced by considerations of the possible exhaustion of the soil in future generations; the practical problem for his consideration is whether manuring will repay him, either now or within a reasonable period.

The results obtained at Ridgmont during twenty-two years lead to the conclusion that the apple trees which have been dressed every year throughout that period with various dressings of artificial or natural manure have shown no appreciable advantage over similar trees which received no dressing whatever. Whilst this, however, has been the case with dwarf and standard apple trees, and also with mixed plantations of apples, pears and plums, the reverse has proved to be the case with bush fruits, such as currants, gooseberries and raspberries: those which were left unmanured have been practically exterminated, whilst those 
which were manured, flourished. But the manure which was essential in these cases was a bulky organic manure, such as dung, since artificial manures produced but little more effect than no manure at all.

Results with Apples at Ridgmont (Reports, I, IIo; II, I93;

$$
\text { IV, } 53 ; \mathrm{V}, 53 ; \mathrm{XVI}, 6)
$$

Coming to particulars, the main group of trees to which the experiments related consisted of twenty-one plots of eighteen trees, six of Bramley's Seedling, six of Cox's Orange Pippin, and six of Potts' Seedling in each, all on the paradise stock; there were also some similar plots of Bramley, Cox and Lane's Prince Albert, grown as standards on the crab stock in another part of the farm, as well as some dwarf trees of Gascoyne's Scarlet Seedling, which had been planted in Igro in the place of the trees of Cox, which had by that time been removed, as also had been the Potts, and some of the Bramleys.

Of the twenty-two years over which the results had extended when a summary was made of them, the first (I895) was a blank year, for the manures were not applied till twelve months after the trees had been planted, and the last year (IgI6) was also a blank, owing to the absence of fruit.

The results from various plots have been grouped into three classes, according as the annual dressing of manure received was normal, less than normal, or more than normal. The normal amount was either I2 tons per acre of stable manure, or its equivalent of a mixed artificial manure (see p. 86). There were eleven of these normally treated plots, interspersed with five or six plots receiving less than the normal amount of manure-in some cases none at all, and in others a dressing which was incomplete owing to the omission of one of the constituents - and with five or six plots receiving more than the normal amount, the excess going up to ten times the normal quantity in case of artificial, and to 30 tons of dung in the case of the dunged plots. As a result of the changes in the number of trees in the plots, the various groups under different manurial treatment contained from 246 to I 20 trees during the earlier years, and from 93 to 47 in later years, the records for these later years applying chiefly to Bramley, and depending mainly on the crops borne.

The various features examined were seven in number, of which, however, one of them-the value of the fruit-is not an independent feature, being deduced from the weight of the crops 
and the average size of the fruits (p. Ig).

A summary of the measurements gave the following results-

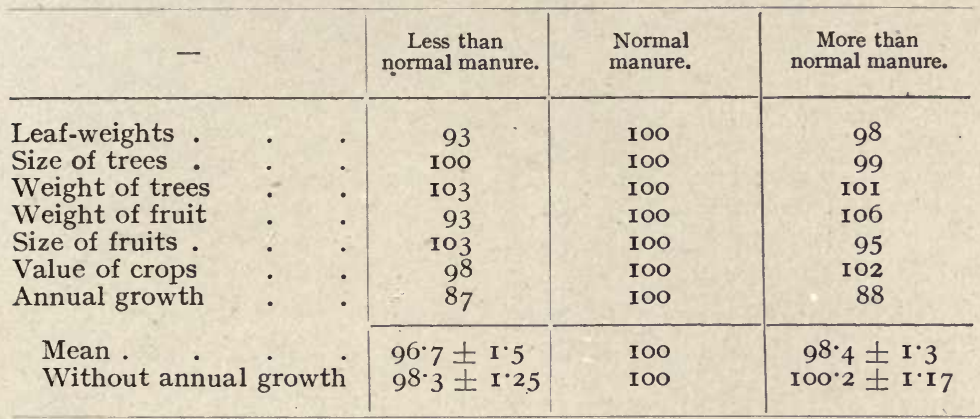

There are here three features which show an advantage in favour of the highly manured plots, and three which show the opposite : there are only two-the weights and values of the crops-which show any regularity in the variations of the results of the three groups with the amounts of manure received by them. If the annual growth-measurements are omitted (which apply to the young trees of Gascoyne only), the mean values (last line) show a slight decrease with a reduction below normal of the manure applied, but no appreciable increase (only 0.2 per cent.) with an increase of that manure above the normal. The variation observed, however, must be regarded as insignificant, for on determining the probable errors of the results in the usual way, those of the two groups under extreme manurial treatments amount together to \pm 2.4 , whereas the differences between the means for these groups is only $I^{\circ} 9$; that is, the means are identical within the limits of experimental error. The conclusion to be drawn must be that differences in the amount of manure have produced no measurable differences at all.

A similar conclusion was drawn from results obtained in two mixed plantations of one-quarter of an acre, each containing bush and standard apple trees, with a few pears and plums; these had, since I905-6 - eleven years after they had been plantedbeen subdivided into sections receiving different manurial treatment. The average gross values of the crops for the following ten years showed in one case (A) ${ }^{1}$ a considerable balance against manuring either with dung or artificials, whereas in the other, though there is a balance in favour of the more heavily dunged

1 The values given in the Sixteenth Report, p. 23, are erroneous, owing to a miscalculation. 
section, it is not significant, for it was found that, if the returns for one exceptional year (I9I5) were omitted, this favourable balance would be converted into an adverse one of 16 per cent.

Plot A. Nomanure $t s$.

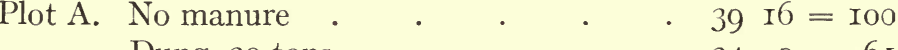
Dung, 30 tons . . . . $249=6 \mathrm{I}$

Artificials equal to 30 tons dung $\quad .32 \mathrm{I} 4=8.2$

Plot B. Artificials and Io tons dung . . $4 \mathrm{I} \quad \delta=\mathrm{I} 00$ Artificials and 30 tons dung . . $45 \quad 0=103$

With such a general absence of all effects from manure, ${ }^{1}$ it was useless to examine the details of those experiments wherein the nature of the manure was varied by leaving out one or other of its constituents. Only in one case were results obtained which appeared, though doubtfully so, to lead to some positive conclusion: that was in the case where nitrate of soda was applied in the summer, instead of in the spring, the weight of the crops and the size of the fruits being thereby notably increased. But there were reasons for questioning these results (XVI, 2I). In the same way, extra coloration of the fruit was observed in the case of a plot dressed with iron sulphate at the rate of 2.8 grams per square metre, but only in one season out of the twenty-two. No such extra coloration was noticed in a corresponding plot dressed with manganese sulphate.

\section{Farm Crops at Ridgmont (XVI, 25)}

That the almost entire absence of effect of manures on fruit trees at Ridgmont was due to any exceptional richness of the soil there, was prima facie improbable, for, according to the analysis of it (p. 84), it would be classed as a soil of not more than average fertility.

To place the matter beyond doubt, however, certain farm crops were grown in the very plots formerly occupied by trees, after some of these had been removed. As a result of five years' trials with onions and potatoes, the following values were obtained-

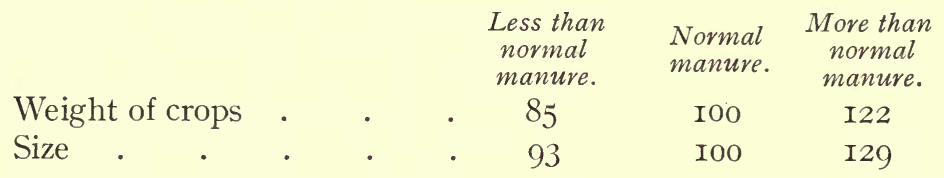

1 Similar results have been obtained in America. U. P. Hedrick, New York State Agric. Expt. Sta., Bull., 339, I9I I. C. D. Woods, Maine Agric. Expt. Sta., Bull., 236, I915, pp. 52-3. 
showing that manures exercised their ordinary beneficial effect on such crops, though that effect was, doubtless, reduced by the fact that the ground was not a suitable one for potatoes, and that the particular manures applied were, for the most part, not specially suited to the crops grown.

It was found, also, that, on the average, the magnitude of the effect increased with the heaviness of the dressing : thus-

\section{Dose of dung or its equivalent} of artificials.

$\begin{array}{ccccc} & & \text { Nil. } & \text { I2 tons. } & 30 \text { tons. } \\ \text { Crops } \quad . \quad & \text { I00 } & \text { II5 } & \text { I24 }\end{array}$

It was ascertained that nursery stock, grown in the Ridgmont soil, behaved like farm crops and not like the more mature apple trees. Some thousands of crab and paradise stocks were planted in the plots previously occupied by the apple trees constituting the manurial experiments, and the growth of the young trees during the two years after they had been worked gave the following values, which, as will be seen, are very similar to those obtained with farm crops-

$\begin{array}{ccccc} & \begin{array}{c}\text { Less than } \\ \text { normal } \\ \text { manure. }\end{array} & \begin{array}{c}\text { Normal } \\ \text { manure. }\end{array} & \begin{array}{c}\text { More than } \\ \text { normal } \\ \text { manure. }\end{array} \\ \text { Growth } & \text {. } \quad . \quad & 85 & \text { Ioo } & \text { II4 }\end{array}$

A liberal supply of manure to ground used for raising nursery stock is the usual, and, evidently, well justified practice amongst nurserymen.

\section{Experiments in Poor Soll (Reports, IV, 84; XVI, 29)}

The next step, by way of testing the validity of the Ridgmont results, was to examine the behaviour of apple trees towards manure in a poor soil. The soil at Millbrook, which was chosen for the purpose, is of a light, sandy, and decidedly poor character, having, owing to its poorness, been abandoned for agricultural purposes many years ago; it is not, of course, land which a commercial fruit-grower would be likely. to select. An analysis of the soil there will be found on p. 83. The plantation made consisted of 15 plots, each containing 20 trees on paradise stock, Io of Cox's Orange Pippin, and ro of Potts' Seedling, which were all two years old when planted in I899-I900. Three of the plots, distributed throughout the others, received the normal amount of artificial manure. The area round the trees which was dressed, 
was increased year by year, so that in 1908 the whole area occupied by the trees (Ioo square feet for each) was manured.

The general results obtained during the next six years, and, as regards the fruit statistics, during the next eleven years, were-

\begin{tabular}{|c|c|c|c|}
\hline & $\begin{array}{l}\text { Less than } \\
\text { normal } \\
\text { manure. }\end{array}$ & $\begin{array}{l}\text { Normal } \\
\text { manure. }\end{array}$ & $\begin{array}{l}\text { More than } \\
\text { normal } \\
\text { manure. }\end{array}$ \\
\hline $\begin{array}{l}\text { Leaf-size, Growth, Weight of fruit, } \\
\text { Size of fruits, Value of crops }\end{array}$ & 80 & IOO & I67 \\
\hline
\end{tabular}

showing that in this poor soil, in contradistinction to the results obtained at Ridgmont, manures have their anticipated effect, and have an effect even greater than that which they have on farm crops in the Ridgmont soil. The effect, too, increased on the whole when the dressing was increased, and it was much greater-to the average extent of 63 per cent.-with dung than with artificials, as would be but natural in a light, sandy soil.

\begin{tabular}{|c|c|c|c|c|c|c|c|}
\hline \multirow{3}{*}{ Growth of crops } & \multirow{2}{*}{$\begin{array}{l}\text { No } \\
\text { manure. } \\
\text { S IOO }\end{array}$} & \multicolumn{3}{|c|}{$\begin{array}{l}\text { Dose of artificials. } \\
\text { Single. }{ }^{1} \text { Double. Treble. }\end{array}$} & \multicolumn{3}{|c|}{$\begin{array}{l}\text { Dose of Dung. } \\
\text { Single. }{ }^{1} \text { Double. Treble }\end{array}$} \\
\hline & & I40 & I36 & I65 & I66 & 224 & 240 \\
\hline & & & I 47 & & & $2 \mathrm{IO}$ & \\
\hline
\end{tabular}

These results were further emphasised by others obtained from mixed plantations of apples, pears, plums, cherries and bush fruits, in the same soil, the average values during five years being-

\section{Leaf-size, Growth, Weight of fruit $\quad 78$ Ioo I4I}

It was clear, therefore, that, as such results were obtained at Millbrook, the absence of results at Ridgmont could not be attributed to any fault in the experiments themselves.

Some of the plots at Millbrook, as in the case of those at Ridgmont, were designed to show the effect of the omission of one or other of the constituents of the artificials applied, and in this case, where manures operated, it was possible to draw conclusions from the results. These were-

No Potash Phosphate Nitrogen Complete manure. omitted. omitted. omitted. manure.

Growth, Weight of crops, Size of fruits

$\begin{array}{ll}72 & 67\end{array}$

II7

I03

I0O

1 A single dose was twelve tons of dung to the acre, or its equivalent of artificials. 
Thus, when potash is omitted, the result is as bad as when no manure at all is applied : the omission of nitrate has no effect, the results obtained in that case being as good as when the complete manure is applied: and the omission of phosphates is actually beneficial, to the extent of about I7 per cent.

These results are entirely in accordance with what might be anticipated from the character of the soil as indicated by analysis (p. 85). This showed that there was a considerable deficiency of readily available potash-namely, 0.006 per cent., against $0^{\circ} 025$ per cent. at Ridgmont-but that as regards phosphates, the Millbrook soil was rich, and actually richer than the Ridgmont soil, containing $0^{\circ} 024$ per cent. of phosphoric acid, against o'oI4 per cent. at. Ridgmont. Since it is, therefore, available potash which this soil requires, manures will do no good unless they contain that element, and, when it is omitted, the results are, as has been seen, just as bad as when no manure at all is given. But phosphates are already present in sufficient quantity in the soil, and the addition of a further amount of them in the manure is not required; indeed, we find that if we supply the potash without the phosphates (" phosphates omitted") we get even better results than if we apply both together (" complete manure"), for, in the absence of the phosphates, the relative proportion of potash in the total food available for the plant will be greater.

That nitrate should have had little or no effect on the results at Millbrook is not surprising, in view of the fact that the soil there is one of the coarsest of sands, from which nitrate of soda would very readily be washed out; added to which, it already contained a fair supply of nitrogen, namely, o.I per cent. in the top nine inches, as compared with 0.136 per cent. at Ridgmont.

\section{Results With Gooseberries (Reports, IV, 35; XVI, 29)}

There were two main series of experiments with gooseberries, the plots consisting of about 200 representatives of all the principal varieties. In one series, A, the records extended from I897 to I9II, inclusive, in the other from IgI2 onwards. The main feature of the results in both cases was the extraordinarily great effect of dung; this, however, did not, in the case of the first series, begin to be very apparent on the crops till after the fourth season, the effect till then being mainly one on the growth. To obtain a fair estimate of the results from the fruit crops, it is well, therefore, to omit the records for these first years, and 
also those for the last four years, for these give abnormally high values for the dunged, as compared with the undunged, plants, owing to the plots having been maintained for some years after the majority of the bushes had become exhausted, and many of those in the undunged plots had died; but even when these last few years are omitted, the values are sufficiently striking, showing an increase of 544 per cent. with a dressing of 30 tons to the acre, and of 346 per cent. with one of $\mathrm{I} 2$ tons. These values are fully borne out by the second series, $\mathrm{B}$, where the results with the crops were further substantiated by the weights of the bushes themselves, one row of them having been lifted and weighed at the end of five years.

Artificials.

\begin{tabular}{|c|c|c|c|c|}
\hline A. I900-7 & $\begin{array}{c}\text { manure. } \\
\text { IoO }\end{array}$ & $\begin{array}{l}\text { dung. } \\
70\end{array}$ & $\begin{array}{l}\text { dung. } \\
\text { II } 3\end{array}$ & $\begin{array}{l}\text { tons. } \\
446\end{array}$ \\
\hline B. IgI3-I7 . & Ioo & 87 & I40 & 3 I 5 \\
\hline B. Weight of bushes & IOO & 92 & I 24 & 210 \\
\hline
\end{tabular}

Whilst dung has had such a great effect on the results, artificials have had comparatively little; indeed, with the smaller dressing of the latter, the effect seems to have been actually deleterious.

There were two other series of experiments with gooseberries: in one of these the effect of omitting one or other of the constituents of the artificial manure was examined. The amount applied was the equivalent of 30 tons of dung. The general effect on the crop was decidedly greater than in the two series mentioned above, the values being raised by it to about 200 , as compared with the unmanured plot as Ioo; but the omission of either nitrate or potash had no effect on the results, and the omission of phosphates actually improved them, as in the case of the apple plots at Millbrook. Five years' averages gave-

Complete artificials . $\quad . \quad$. $\quad$. $\quad$. $\quad$. 203

Artificials without nitrate . . . . . . 219

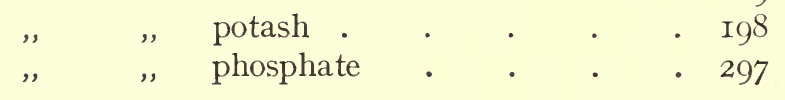

In the other series of experiments, also extending over five years, an attempt was made to ascertain whether the addition 
of a bulky, comparatively inert, material, such as chaff, to a dressing of artificials (equivalent to 30 tons of dung to the acre), would result in the artificials having the same effect as dung, which it might do, if the advantage of dung lay merely in its lightening the soil. But the chaff had no effect in increasing the crops, either in the absence or presence of artificials. Thus-

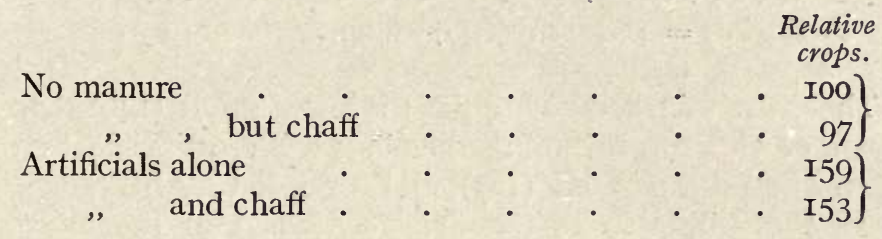

\section{Results with CuRrants and RASPBERRIES}

(Reports, II, 98; IV, 45; XVI, 38)

Owing to the incidence of disease and other troubles, the original experiments with these were not continued long enough. (only three to five years) to show whether their behaviour was similar to that of gooseberries; but it probably was, for such results as were obtained bear a close resemblance to those yielded by the first series of experiments with gooseberries during the first five years over which that series extended.

Artificials.

Dung.

\begin{tabular}{|c|c|c|c|c|}
\hline \multirow{2}{*}{$\begin{array}{c}\text { No } \\
\text { manure. }\end{array}$} & \multicolumn{2}{|c|}{ lezals. } & \multicolumn{2}{|c|}{ Dung. } \\
\hline & $\begin{array}{l}=\text { I } 2 \text { tons } \\
\text { dung. }\end{array}$ & $\begin{array}{c}=30 \text { tons } \\
\text { dung. }\end{array}$ & $\begin{array}{c}12 \\
\text { tons. }\end{array}$ & $\begin{array}{c}30 \\
\text { tons. }\end{array}$ \\
\hline & I08 & I37 & I49 & 125 \\
\hline IOO & II4 & I 28 & I6I & $2 \mathrm{I} 4$ \\
\hline IOO & I26 & I02 & I30 & I95 \\
\hline IOO & 9I & I07 & I32 & I3I \\
\hline
\end{tabular}

The general results show that some increase is caused by artificials, but a considerably greater increase by dung.

Other experiments with these plants are in progress.

The question has also been investigated as to whether the addition of artificials to dung is capable of enhancing the effect of the latter in the Ridgmont soil, as it seems to have done elsewhere, according to the results of Dyer and Shrivell. ${ }^{2}$ Two series of experiments with red currants, extending over seven

1 Mean of results from the crops and the weight of the bushes.

2 B. Dyer and F. W. E. Shrivell, "The Manuring of Market Gardening Crops." London, I9r3. Also Jour. Roy. Hort. Soc., 1903, xxvii, pp. 995x059. 
and three years, respectively, gave the following average values-

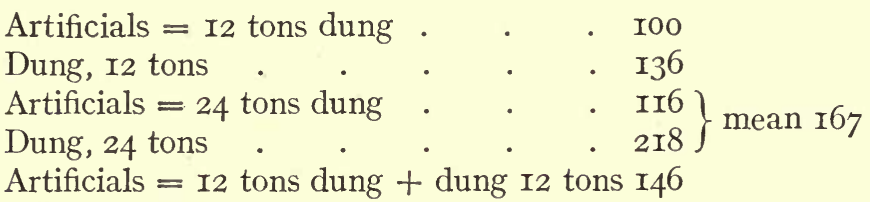

Thus, the mixed dressing gave a lower result (I46) than the mean of the corresponding dressings with artificials or dung when applied separately (I67), and a result very little in excess of that attributable to the dung contained in the mixturenamely, I36.

Results with Strawberries (Reports, I, I47; II, 83; IV, Io; XVI, 48)

The results of various manurial experiments with strawberries were somewhat surprising in the fact that they did not show such a marked superiority of the dressed plants over the undressed ones, nor of those receiving dung over those receiving artificial manures, as might have been anticipated, either from the results with gooseberries in the same soil, or from the views generally (though perhaps not universally) held as to the proper manurial treatment of strawberries.

The general results (IV, I4, I7) were, that the application of manures had increased the yield of fruit by only about I2 per cent., whilst a comparison of the plots receiving artificial manure with those receiving dung, showed a superiority in favour of the latter to the extent of at the most 8 per cent., or, indeed, of only 2 per cent., if the whole life of the plants-which had been somewhat unduly extended-was considered. Another peculiarity in the results, though one which is easily intelligible, was that an increase in the dressings produced comparatively little increase in the crops : raising the dressing from one of 12 tons of dung per acre, or its equivalent in artificials, to one of 30 tons, produced an increase of only about ro per cent. in the yield. One redeeming feature, however, in favour of the use of dung was that it evidently improved the size and quality of the berries, and also increased the longevity of the plants.

Three other series of experiments were carried out, similar to those with red currants, to ascertain whether a mixed dressing 
of dung and artificials presented any advantages. The results were purely negative, as the following mean values show-

\begin{tabular}{|c|c|c|}
\hline Artificials $=12$ tons dung & & IOO \\
\hline Dung, I2 tons . & $\because$ & II6 \\
\hline Artificials $=24$ tons dung & . & I20 I mea \\
\hline Dung, 24 tons . & . & Io8 $j$ \\
\hline Artificials $=I 2$ tons dung & I2 tons dung & II2 \\
\hline
\end{tabular}

As mentioned above, the application of dung increases the longevity of the plant: this was evidenced by the mortality in the variously manured plots at the end of seven years: that in the unmanured plots and in those dressed with artificials was the same, and amounted to 27 per cent., whereas that in the plots dressed with dung was only 2 I per cent.

A careful analysis of the results was also made to see whether the dressing had any effect on the date of ripening of the crop, or on the length of the cropping period. But the results were negative $(I V, 23)$. The percentages of the total crops gathered during the first third of the pickings were found to be practically identical throughout the five years over which the observations extended-

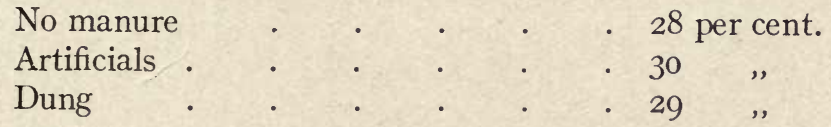

and the dates of the first pickings, as expressed in days from the earliest date on which any picking had been recorded, were also practically identical -

No manure

Artificials

Dung

$$
\begin{aligned}
& .0 .7 \text { days } \\
& .0 .69, \\
& .0 .63 \text {, }
\end{aligned}
$$

As to the average period in days over which the pickings lasted, there was some slight superiority of the dressed over the undressed plots, but no difference between those dressed with dung and those dressed with artificials.

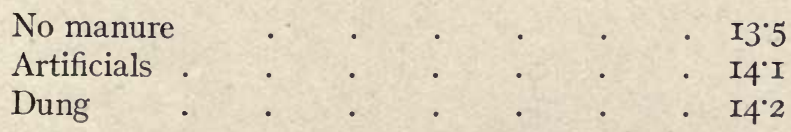

Two series of experiments were conducted on the application of liquid dressings to strawberries during the swelling of the 
fruit, the dressing consisting either of water only, or water containing ammonium sulphate, sodium nitrate, potassium nitrate, or a mixture of ammonium and iron sulphates. The results in different seasons showed considerable variations, as might naturally be expected owing to differences in climatic conditions, but they certainly did not indicate that any beneficial results had followed from the application of the minerals, either as regards the total crops or the date of ripening; such advantages, or disadvantages, as may have accrued from the treatment being attributable to the watering only; indeed, the minerals in one respect appeared to have been decidedly detrimental, for in both series those plots which had received nitrate suffered a mortality from two to six times greater than any of the other plots, and in both these series sodium nitrate had proved more deleterious than potassium nitrate.

The general results, or rather, absence of results with strawberries at Ridgmont may seem surprising, but they are not altogether at variance with those which are sometimes obtained in practice, for the strawberry seems to be a plant which is greatly affected by the character of the soil and by its environment, and, under conditions which are not favourable to it, which is the case at Ridgmont, it may give but little response to such manurial treatment as would under other circumstances have a considerable effect. 


\section{CHAPTER X}

\section{MANURES (continued)}

\section{General Results (Report XVI, 59)}

THE two salient features of the manurial experiments at Ridgmont are, the almost entire absence of effect of all manures on apple trees, and the extraordinarily great effect of dung on bush fruits, especially gooseberries.

As regards artificial manures, the differences in behaviour of the various plants are not very striking, and may be sufficiently illustrated by the following rough summary-

\begin{tabular}{|c|c|c|c|c|}
\hline - & & Nil. & Single Dose. & $\begin{array}{l}\text { Double or } \\
\text { Treble Dose. }\end{array}$ \\
\hline $\begin{array}{l}\text { Apples } \\
\text { Strawberries } \\
\text { Gooseberries } \\
\text { Raspberries } \\
\text { Currants } \\
\text { Potatoes, etc. } \\
\text { Apples (Millbrook) }\end{array}$ & $\dot{:}$ & $\begin{array}{l}100 \\
100 \\
100 \\
100 \\
100 \\
100 \\
100\end{array}$ & $\begin{array}{r}102 \\
92 \\
79 \\
126 \\
\text { III } \\
107 \\
140\end{array}$ & $\begin{array}{l}\text { IO2 } \\
\text { I } 13 \\
\text { I } 27 \\
\text { IO2 } \\
\text { I } 33 \\
\text { I39 } \\
\text { I } 51\end{array}$ \\
\hline
\end{tabular}

Gooseberries certainly do not show any exceptional sensitiveness to these manures, and neither they, nor any of the other plants examined, are affected by artificials to the same extent as are even apples in the Millbrook soil.

The results in respect to dung are, however, of much more interest. They are depicted in the accompanying figure (Fig. I5). The effect in the case of apples is represented by a nearly horizontal line, there being no appreciable rise in the values as the dose is increased; with strawberries the increase is very small, but with potatoes and onions it becomes more significant, rising to 40 per cent. A very much greater rise, however-up to an increase of roo per cent., or more-is experienced with raspberries and currants, and it is of interest to note how similar the results with them are to those with apples in the Millbrook soil (Apples (M.)). When we come to gooseberries, however, the increase is 


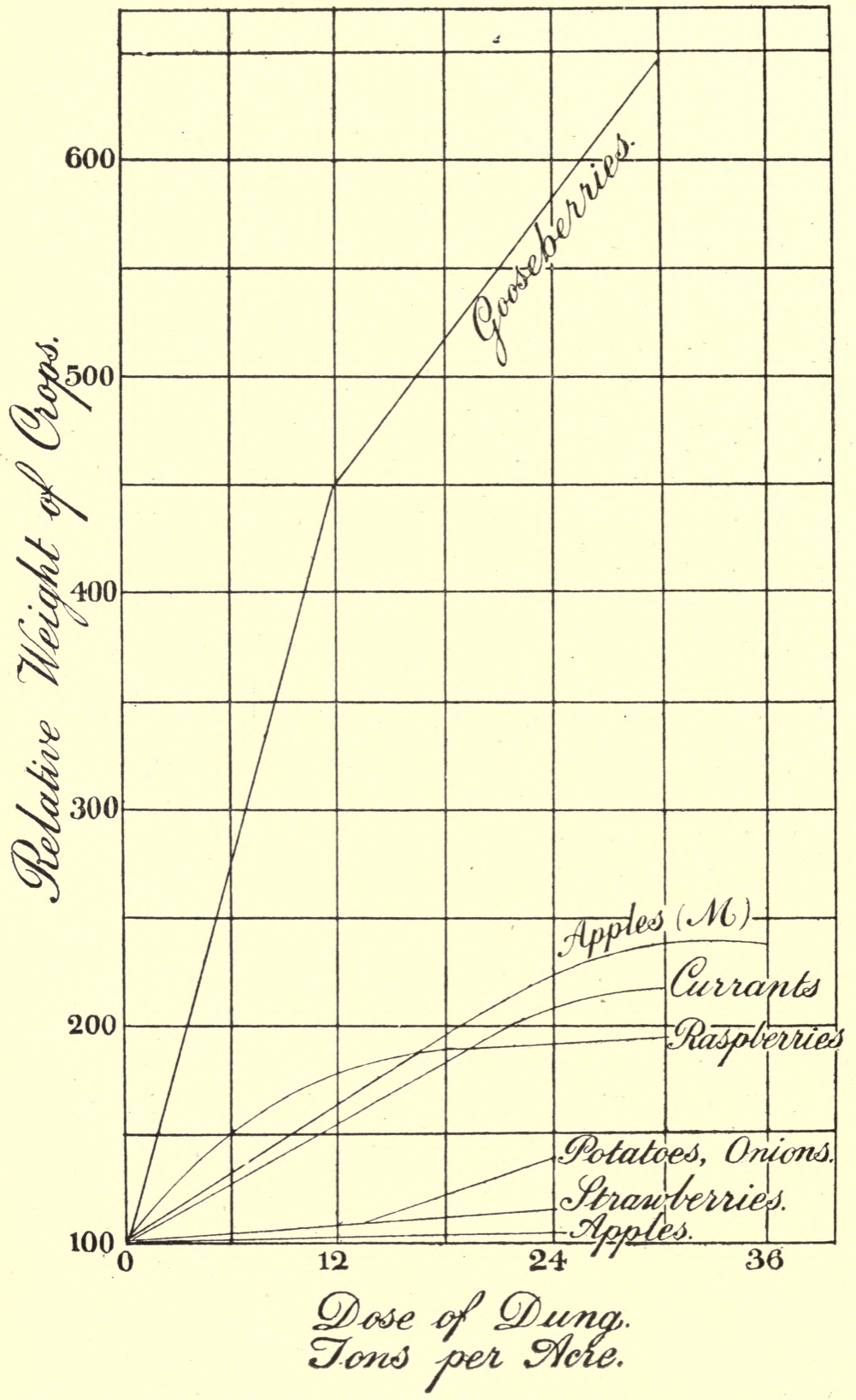

FIG. 15 
of a very different order of magnitude, and they are evidently altogether exceptional in their behaviour, though we must remember the possibility (see p. 97) of other bush fruits showing a similar effect if the experiments on them were sufficiently prolonged.

Dealing, first, with the absence of effect of manures on apple trees, a comparison of the Ridgmont soil with that at Harpenden (XVI, 62), which latter may be taken as representing a soil of average fertility, shows to the disadvantage of the former, and renders it impossible to explain the Ridgmont results on the ground that the soil there is exceptionally rich. The next question which arises, therefore, is whether the material removed annually from the soil by growing apple trees in it is less than the material which becomes available for growth through the gradual decomposition of the insoluble mineral matter in the soil and subsoil. The Rothamsted experiments ${ }^{1}$ show that, as regards wheat, a crop which requires only $4^{*} 3$ kilos, or less, of potash a year, might conceivably be grown for an indefinite time without the addition of manure, potash to this amount becoming available from that in the subsoil ; and Ebermayers' 2 results show that, in the case of forest trees, even when these are regularly cropped, the removal of potash is considerably less than this ( $r \cdot 6$ to $2 \cdot 8$ kilos), so that land under forest must tend to increase in richness, as, indeed, would be inferred from the fertility exhibited by virgin soil, and by land from. which plantations of forest trees have been cleared.

But many points of uncertainty arise in applying data from forest plantations or from the growing of wheat, to the case of apple trees: it appears fairly clear, however, that the latter remove considerably more material from the soil than forest. trees do, and that it must generally amount to more than the 4.3 kilos of potash required as a minimum by wheat without the soil becoming depleted.

To enable some estimate to be formed, determinations of the potash in the branches, roots and fruit of apple trees, and also of gooseberry bushes, were made: further, to apply these results, it was necessary to ascertain what proportions the roots bore to the branches. For Bramley's Seedling on paradise stock, the roots were found to represent $\mathrm{r} 6$ per cent. of the weight of the

1 Dyer, Bernard : "Results of Investigations of the Rothamsted Soils," U. S. Dept. of Agric., Bull., 106, 1902.

2 "Waldstreu," p. I I6, and "Physiologische Chem. der Pflanzen," pp. 709, 782 : see also Warington, Chemistry of the Farm, 18th ed., pp. 74, 81, and The Woburn Report, XVI, p. 69. 
whole tree, though in most other cases the roots are accountable for a larger proportion of the total, the averages from the number of instances indicated below being-

Apples (46I instances). Roots $=22^{\circ} 9$ per cent. of total.

Damsons (6 instances). " " " $=25^{\circ} 2$,

Pears (I5 instances). " " $=23.5$

Plums (44 instances). ", " ,

The trees examined varied much in age and size-weighing from 4 to I48 kilos per tree-but no connection was observable between such variations and the existence of higher or lower values for the proportional weight of the roots.

The results of the chemical analyses were-

\begin{tabular}{|c|c|c|c|c|c|}
\hline & $\begin{array}{l}\text { Branches } \\
\text { and stem. }\end{array}$ & $\begin{array}{l}\text { Roots. } \\
\text { Apples. }\end{array}$ & $\begin{array}{c}\text { Whole } \\
\text { tree. }\end{array}$ & $\begin{array}{l}\text { Green } \\
\text { fruit. }\end{array}$ & $\begin{array}{l}\text { Ripe } \\
\text { fruit. }\end{array}$ \\
\hline Water. & . $45^{\circ} \mathrm{O}$ & $49^{\circ} 7$ & $45^{\cdot 8}$ & - & $86 \cdot 4$ \\
\hline Ash . & I'I 26 & I.5I 5 & I’I88 & - & 0.282 \\
\hline Potash. & o. I92 & 0.184 & $0 \cdot \mathrm{IgI}$ & - & 0.123 \\
\hline
\end{tabular}

Gooseberries.

\begin{tabular}{|c|c|c|c|c|c|}
\hline Water. & - & - & $53^{\circ} \mathrm{O}$ & $89 \cdot 8$ & $84^{\circ} 3$ \\
\hline Ash . & 一 & - & $2 \cdot I 33$ & 0.384 & 0.3 \\
\hline Potash. & - & - & 0.218 & 0.198 & 0.148 \\
\hline
\end{tabular}

These values, combined with a knowledge of weights of the trees, the prunings and the fruit crop, led to the conclusion that the average annual production per acre during twenty-two years had been, in the case of Bramley-

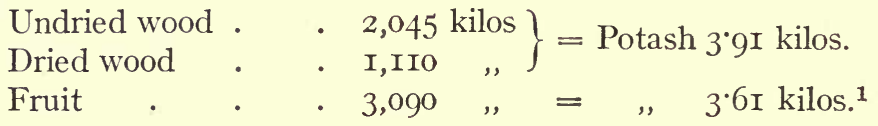

The total potash removed thus amounts to 7.52 kilos per annum, a quantity considerably in excess of the 4.3 kilos, which the Rothamsted experiments on wheat would lead us to suppose the soil could supply without the addition of manure. There is, however, in the case of trees, a factor which increases the capability of the soil to support growth-namely, the formation of leaves: this, it is true, constitutes an extra drain on the

1 Cf. Van Slyke, Taylor and Andrews, "Plant-food constituents used by bearing fruit trees," New York State Agric. Expt. Sta., Bull., 265, 1905; also P. Collier, " Analysis of Fruit Trees," New York State Ann. Rep., I892, I 73-209. 
soil, but of a temporary character only; and, since much of the material accumulated in the leaves is derived from the lower depths, it will enrich the surface soil, providing an easily available supply of mineral food (as well as of organic matter) for further growth.

There is, where the ground is tilled, another circumstance which operates in the same way; this is the growth of weeds. In a soil like that at Ridgmont, where six or seven hoeings of the ground during the season are necessary to keep it clean, the amount of food-material which is thereby brought to the surface will be considerable, and such ground may be considered as being continually under green manurial treatment, with the beneficial results attendant thereon.

As to the practical conclusions which are to be drawn from these results : since it is certain that the absence of any effect of manures on fruit trees at Ridgmont is not due to any exceptional fertility of the soil, it is evident that similar results must be expected elsewhere under like conditions, and that, in such cases, all money spent in manuring the land would be thrown away, just as it has been at Ridgmont. But before interpreting this as a general conclusion that manuring is unnecessary, we must carefully consider what the conditions at Ridgmont really were. In the first place, the soil is heavy and fairly fertile, and not deficient in any one of the elements essential to plant-growth ; where the soil is poor, either in one or all food constituents, and especially where it is light, and where such nourishment as it contains is easily washed down beyond the reach of the roots, manuring is essential, as was clearly shown by the results at Millbrook. In the second place, the crops at Ridgmont were light, owing to circumstances independent of the soil; thus the records refer to the first 22 years of the life of the plantation, not to 22 years of its existence after it had attained full maturity, whilst the natural cropping of the trees was much reduced by the destructive action of spring frosts. Under other circumstances, the average cropping might have been three or four times as great as it was, and probably in such a case the soil could not have borne the drain on its resources without the addition of manure. Observations made at Harpenden, however, seem to point to the contrary, and it must be remembered that the drain caused by increased cropping is always discounted to a certain extent by diminished growth, and that there is, consequently, not so much difference as might at first 
sight be imagined between the requirements of a plantation in full bearing, and of a young plantation in vigorous growth.

Passing on to the question of the radical difference in behaviour of apples and bush fruits, especially gooseberries, it is clear that this cannot be accounted for by the deeper-rooting habit of the former, for in the Ridgmont soil such deep-rooting does not occur (see p. 309); the question arises, therefore, whether the requirements of bush fruits are much greater than those of apple trees. They appear not to be so. Estimates based on the analyses quoted above, and on certain probable values for the crops produced ${ }^{1}$ during 22 years, lead to the following values for the annual production per acre in the case of gooseberries-

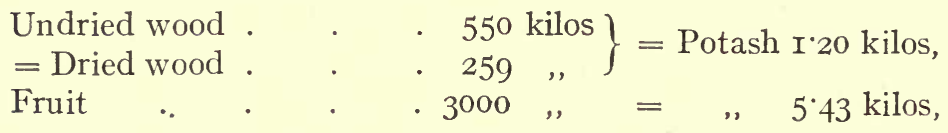

or a total of 6.63 kilos, against 7.52 kilos in the case of apples, so that the cultivation of gooseberries creates a somewhat smaller drain on the mineral resources of the soil than the cultivation of apples. The comparative inefficiency of artificials as a manure for gooseberries harmonises with this conclusion, and it cannot be merely the nitrogen in dung which accounts for the great effect of natural manure, for the artificials applied contained ample nitrogen.

That dung does materially improve the physical character of the soil, rendering it more friable and more retentive of moisture, is, of course, well known, but there is no reason, so far as we know, why such an alteration should be essential to gooseberries, and altogether ineffectual in the case of apples,

1 Taking two-thirds of the fruit as being gathered when green. It is interesting to note that the difference between the composition of green and ripe fruit is mainly a question of the amount of water present, the actual weight of potash shows very little increase during the ripening, and that of the ash not very much. Thus-

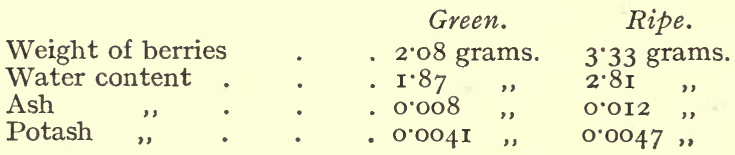

The water increases during ripening by 50 per cent., while the potash increases by only I 7 per cent. A similar observation has been made by Clark in respect to apples (Missouri Dep. of Horticulture, Bull. Io, I890). 
strawberries, etc., and there is one consideration which seems to negative such a suggestion; for the two series of experiments with gooseberries are remarkably concordant in the general tenor of their results (see p. 96), although the soil in which they were made was very different in character; that in which the first series was made was, for the most part, sandy, and that used for the second series was clayey, containing, moreover, more than double the proportion of food-constituents than the former did. The composition of the two soils may be contrasted thus-

First series.

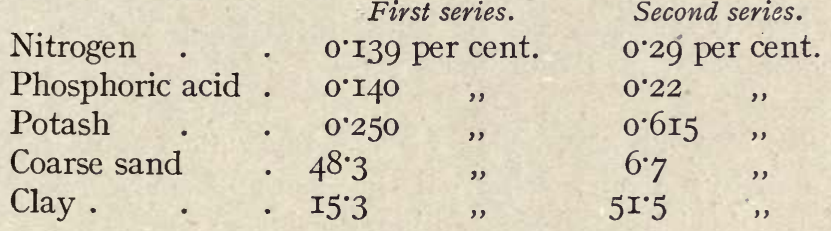

and it is extremely improbable that in two such very different soils the physical alteration produced by dung would have had such a closely similar effect on the behaviour of the bushes.

The extraordinary action of dung in this case suggested at first that it might be due to the presence in it of what have been termed auximones, that is, substances which are not in themselves nutrients, but which, by their presence, even in minute quantities, render the plants capable of absorbing such nutrients as are present. The results, however, hardly favour this explanation, for the yield of fruit is more or less proportional to the dressing applied. Yet it is a point which calls for further investigation. The more probable explanation at present is that dung contains its nutrients-particularly the nitrogenous nutrients -in a form which is specially suited to the requirements of gooseberries, though comparatively inefficient in the case of apples, etc. Such a conclusion indicates how much we have still to learn as to the physiological differences between plants.

It is highly suggestive that this is not the only instance in which gooseberries, and probably other bushes, 'show a radical difference in behaviour from apples, etc.; such differences have also been noticed in the results of trenching the soil (p. 29) and of root-injury on planting (pp. 35,54$)$.

One of the most important teachings of the Woburn manurial results, especially as regards apples, is to emphasise the view 
that the modern farmer, if he is to be successful, must, to a certain extent, be an experimentalist, though, perhaps, not quite in the sense in which he generally understands that term. An experimental station may determine for him facts of fundamental importance, and may indicate the direction in which special observations for each locality should be made; but, as the observations at such a station must necessarily be confined to the particular soil on which the station is situated, there must be many details, dependent on the peculiarities of other soils, which cannot there be ascertained. These should be determined by each farmer for himself.

An experiment, to the ordinary farmer, often consists in trying some advertised manure, probably during one season only, and probably, also, on the whole of a field, which may often be ill-adapted to the purpose : from the result of such a so-called experiment (which may be exceptional owing to some exceptional character of the season) he will either adopt that manure as infallible, or reject it, and abuse experiments generally. But such haphazard trials cannot be ranked as experiments at all. For a grower to obtain information of real value, he has only to select some uniform field, or portion of a field, and treat one part of it with one dressing, and the rest with some other dressing, repeating the treatment for several seasons, and, perhaps, after a time, reverse the treatment in the case of the two portions: the results would tell him which dressing paid him best. It might cost a few shillings extra in labour, and an hour or so in calculation, but would probably be worth many pounds a year to him in his future crops. On a subsequent occasion it would be easy for him to try a further experiment, such as a combination of natural and artificial dressings, and ascertain whether any advantages accrued, sufficient to compensate him for the additional expenditure.

Such simple experiments, or trials, are not beyond the means or capacity of any fruit-grower of average ability: the marvel is that they are so rarely made, and that men whose existence depends on the correctness of their practice, should not adopt the most practical of all methods of obtaining the knowledge which they require-that of ascertaining for themselves by direct trial what treatment of their crops is the best. Special training, no doubt, is necessary for the execution of elaborate experiments, and special knowledge is necessary to teach how far the results can be generalised so as to be applicable to other land and circumstances: but the case is quite different 
when a grower has only to ascertain what treatment succeeds best on his own land. Perhaps the oft-repeated, and more often mistaken cry of the antagonism between theory and practice, is the reason why growers are so prejudiced against experiments, mistaking experiment for theory, and the blind observance of traditions for practice. The spirit of investigation, when properly directed, can never fail to advantage the investigator, and, if this spirit could but be developed amongst fruit-growers, we should soon have a mass of observations which, when properly digested, would be of incalculable benefit to the whole industry.

\section{GREEN-MANURING}

The green-manuring of orchards is not a procedure which is much in vogue in this country, for the difficulties in adopting it are greater, and the advantages attending it are less, than they are in other climates. The principle underlying it consists in growing a surface crop, which causes a drain on the soil only during the later part of the season when the trees are not in active growth, and of ploughing in the crop in the early spring, to enrich the soil with the food-material accumulated by it. A nitrogen-fixing, leguminous crop is, naturally, the most suitable one to grow. A further advantage attending green-manuring is that it affords a covering to the ground during the winter, and diminishes the washing out of the soil by heavy rains. In this country, where manure of other sorts is easily procurable, and where excessive wet in the winter is not usual, green-manuring presents less advantages, and the fact that many of our plantations are not adapted for being ploughed, and that our uncertain climate often renders the success of a late-sown crop impossible, presents decided disadvantages.

At the Woburn Fruit Farm, where all manuring of the trees has proved to be without benefit, and where all surface crops have proved to be so prejudicial, it was not to be anticipated that any benefit would accrue from green-manuring: and such has been the case.

Three plantations of dwarf and standard apples and pears were planted in $1907-8$ : in one of these the ground was kept tilled, in the other there was grown a permanent crop of lucerne, whilst in the third, lucerne was sown every summer, and the crop ploughed in in the spring. These different treatments were not initiated till I9II, and their full effect was not apparent till I9I3: since that date the behaviour of the plots has been very 
uniform, and the average results, as shown by the relative vigour of the trees, has been-

Ground tilled. IOO
Green-manuring.

84

\section{Permanent crop.}

45

Thus, the green-manuring has, as compared with the tilled ground, done nothing but harm, though this harm amounts to only one-third or one-quarter as much as that done by the permanent surface crop. ${ }^{1}$

The reduction in the deleterious effect of the surface crop in this case depends, as indicated above, on the growth of the surface crop not being coincident with the period of greatest activity of the trees, and to obtain more definite information on this point, the rate of growth of trees throughout the season was determined in two instances-I9o6 and I9I8-by making weekly measurements of the length of new wood formed by apple trees. In the first series of experiments, 48 young trees were taken, representing three different varieties, half of them having been established in the ground for one year, and half having been planted in the previous winter. They all exhibited substantially the same rate of growth, which is portrayed by the upper curve in Fig. I6. Growth had ceased by about the Ist of August, and 90 per cent. of the total growth had occurred by the second week in July (XIII, 58). Below the growth-curve is given the rainfall for the seven days preceding each measurement, and apparently, in this case, there is no direct connection between the two: the rainfall was small and fairly uniform throughout, except for the week preceding July 2, and the heavy fall then evoked no response in the growth of the trees.

In the second series, I9I8, measurements were made on trees of Gascoyne's Scarlet Seedling, eleven years of age, and the values are also depicted in Fig. I6, with the weekly rainfall below. Here the results are very different, but are easily explicable by differences in the character of the two seasons. In I9I8, a spell of dry weather throughout the greater part of June had brought active growth prematurely to a standstill by June I7, and then, when a heavy fall took place after the first week in July, the growing energy of the trees not having been exhausted, active growth was resumed. There seems also to have been some response during this season to the increased rainfall of May 20-27.

1 Green-manuring (" cover crops") is a practice often successfully employed in America, but it has been found inferior to clean cultivation in Illinois. T. J. Burrill and J. C. Blair, Illinois Agric. Expt. Sta. Bull., 52, I 898 . 
Taking the results of the two years together, it is evident that -growth-activity, and, consequently, sensitiveness to the evil effects of a surface crop, may practically cease at an early period in the season-from mid-June to mid-July - and that, whilst the

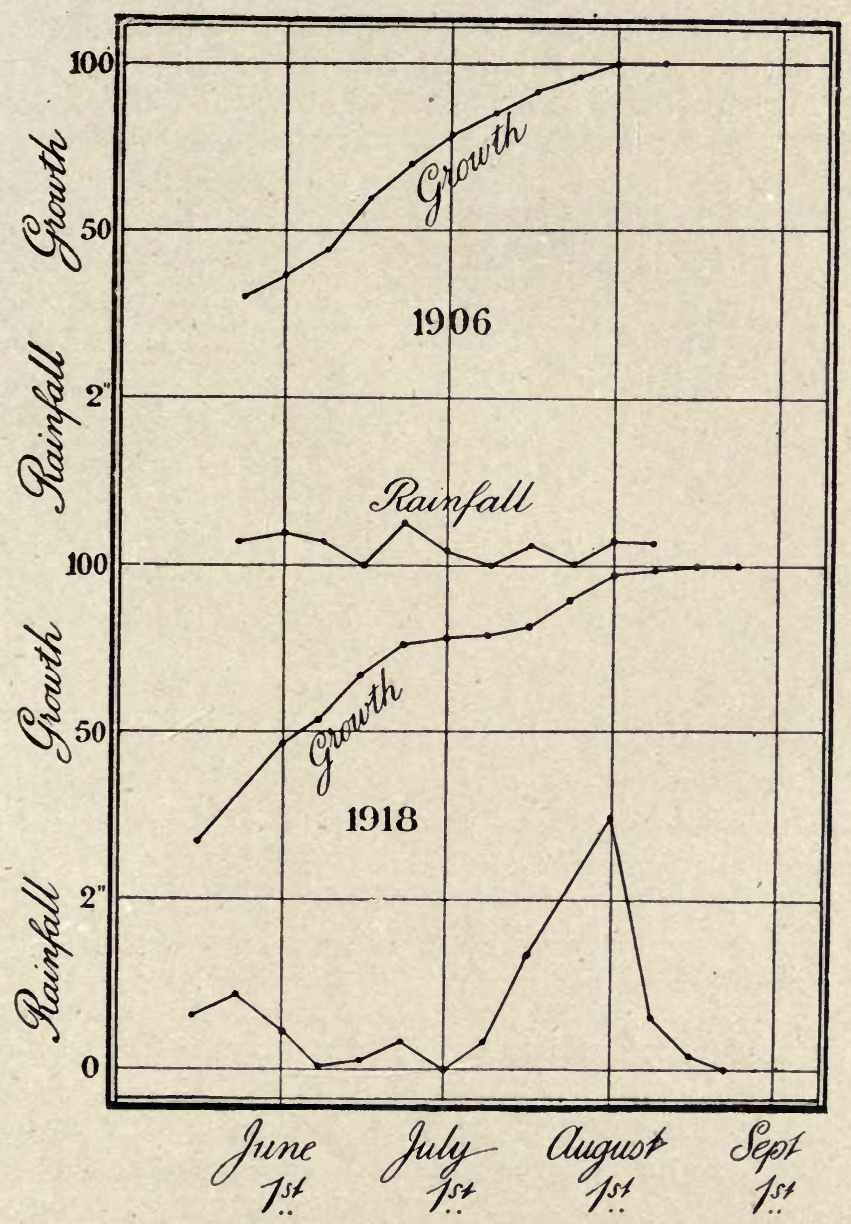

FIG. 16.

periodic rainfall undoubtedly may influence considerably the rate of growth, conditions will often occur, as in 1906, when such influence is inappreciable, the growth in that case having probably been more dependent on the condition of moisture of the soil, than on the fluctuations of the rain falling at the time. 


\section{Loss of Weight of Manure in Transit (Report XIV, 73)}

An investigation dealing with manure, but of a very different character from the foregoing, was undertaken at Woburn, namely, the determination of the loss in weight which is likely to occur through evaporation in the case of stable manure sent by rail from towns into the country. The question is one of great practical importance to the market gardener, for the amount of such manure which he has to buy is very large, and the differences in the weight which he receives, and which he has to pay for, often represent 25 per cent. of the total. He is practically powerless to contest any assertion by the company or the contractor, that this discrepancy is due to the natural loss of water in transit. In the case of certain records of manure received at a station 60 miles from London, the average deficit during three years was 22 per cent., and the deficit with individual trucks reached as high a value as 46 per cent. Such a loss, however, was clearly not a legitimate one, for when the same manure was sent from the same starting-point to the same destination, but by a different railway company, the average loss, during three years, was only $4 \frac{1}{4}$ per cent.: during one year when the manure was sent simultaneously by both companies, the loss in one case was $31 \frac{1}{2}$ per cent., and in the other $4 \frac{3}{4}$ per cent.

Where the large loss had occurred, this loss had been determined by weighings made by the same carrying company at the despatch and receiving stations, and, being thus excluded from attributing it to any errors of weighing, they had to have recourse to the plea of loss of water in transit, in spite of the fact, which was duly established, that the manure in question when received would not retain more than Io per cent. of additional water.

The consignee is at great disadvantage in contesting the railway company's weighings. The contractor does not weigh the manure himself, and bases his charge on the company's weighings; the company, however, do not weigh it for him as his agent, but for themselves, in order to determine their freight charge, therefore, as regards any dispute between the consigner and consignee, the company is in the position of an independent third party, and their weighings would override those of the consignee, even when he is in a position to weigh the manure himself. If there is a cart weighbridge at the receiving station, the consignee can get the company themselves to weigh it for him, but that is of little avail, as he is at once met by the theory of loss of water in transit. 
To minimise the chances of obtaining deficient weight, the consumer should, wherever possible, obtain his manure from a station where a truck weighbridge is in use : it will then be weighed after being loaded into the truck, and a falsification of weight can only occur through the improbable contingency of fraud on the part of the railway employees. Another precaution is to have the manure sent " carriage forward," not " carriage paid." Should any dispute arise, the Board of Trade have no power to intervene in any contract between the sender and receiver of the manure : they can only do so where a public carrying company is concerned, i.e. their power is confined to inquiring as to the correctness of the freight charges, and if the receiver is not directly responsible for these, he has no locus standi in the matter.

To investigate the question, two trucks of manure, which was said to be fresh, but which had evidently already been heated, were carefully weighed in London, despatched on a journey of 60 miles, and then returned to London for re-weighing. They were finally sent a second time to their destination, and the contents weighed out into carts. In one truck the manure had been piled up, in the other it had not been piled, in order that evidence as to mechanical loss, as well as loss by evaporation, might be obtained. The total loss during the journey of I 20 miles was $2 \frac{1}{2}$ per cent. from the piled truck, and $I \frac{1}{2}$ per cent. from the non-piled one, showing a loss of I per cent. from mechanical causes where the trucks are piled, and $I_{2}^{\frac{1}{2}}$ per cent. from evaporation. The journey occupied nearly four days, and the daily loss by evaporation was, therefore, 0.4 per cent. This took place in January, when an east wind was blowing, and the weather was dry.

At the same time further evidence was obtained by keeping manure in carts in an open shed during the months of November till February. In one case the manure was, to start with, quite fresh from the stables, and daily observations of the weight, the temperature and humidity of the air, and the mean temperature of the manure were taken. The daily loss of weight amounted to $2^{\prime} 73$ per cent. during the first seven days while heating was occurring, it then fell to 0.53 per cent. and remained at this value for the next three or four weeks. This compares well with the daily loss of 0.4 per cent. observed in the experiments with trucks, the evaporation from the latter being necessarily smaller, owing to the smaller proportion borne by the exposed surface to the total weight. 
As a general result, the following values were obtained for the loss occurring under various conditions.

\section{Loss in Weight on a Two Days' Journey}

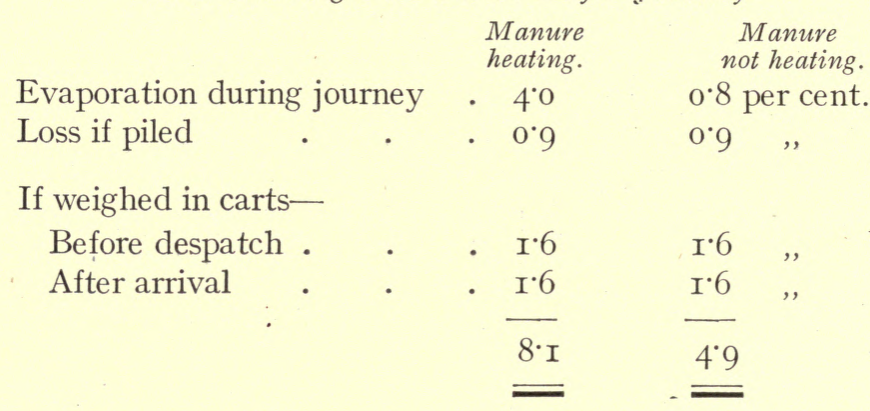

The loss, therefore, may vary, according to the character of the manure and the manner of handling, from 0.8 to about Io times that amount. Roughly speaking, the loss should generally be well under half a ton per truck. The legitimate loss, however, is often increased by the manner of weighing the trucks, for these are not uncoupled for the purpose, and the weighings are often taken while the train is in motion, so that what is recorded as the weight, is really the kick of the beam, and there is a drag downwards from the coupling irons at both ends of the trucks. 


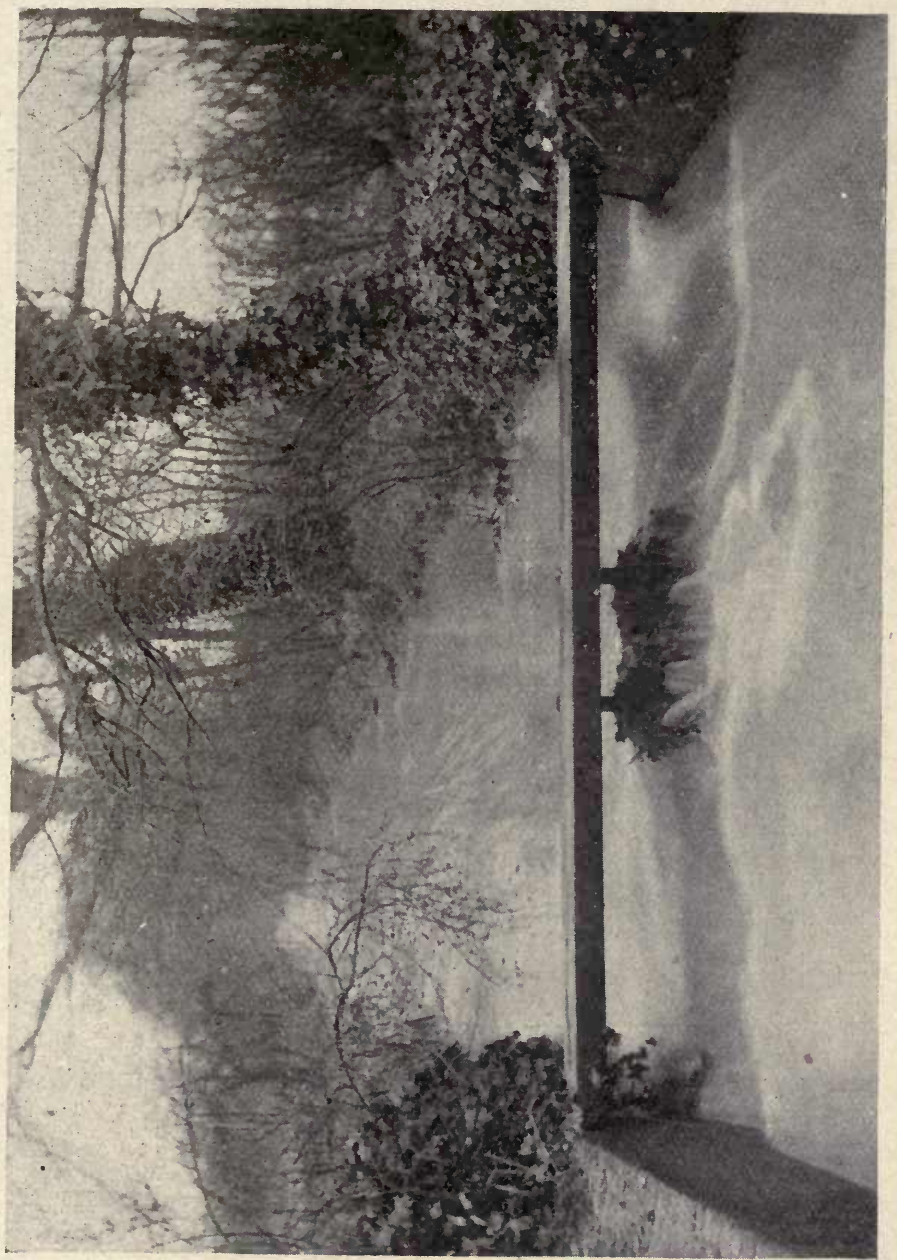

О

근

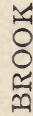

告

占

点

告 


\section{Chapter XI}

\section{METEOROLOGICAL OBSERVATIONS (Reports, I, I75 ; II, 238$)^{1}$}

With a view to throwing some light on the conditions causing a more serious incidence of radiation-frosts in the lower than in the higher portions of the ground, meteorological observations at the Woburn Farm were duplicated, one station being situated at the highest point in the ground, marked $\mathrm{H}$ on the plan, given on p. 82 , and the other at the lowest, L. This latter is 15.35 feet lower than $\mathrm{H}$, and is 65 feet distant from the brook, in which the average water level is about 4 feet below the level of the field. The height of various other parts of the ground, in feet below $\mathrm{H}$, are given by the numbers enclosed in circles. A solar radiation thermometer is situated at $Z$, and the rain gauge at $\mathrm{R}$; the other lettering on the plan, A, B, etc., refer to the points where the soil was sampled for analysis.

The meteorological observations for twenty years have been dealt with. These have been worked up by Mr. C. A. Bracey, of the Meteorological Office, and it will be sufficient here to give a summary only of the results. In their bearing on horticultural problems it was considered advisable not to follow the ordinary division of the year into four equal portions, but to take the four months, May to August, as representing the season of activity, or summer (Su.), and the four months, November to February, the dormant season, or winter (W.), leaving the other two pairs of months to represent spring and autumn (Sp., Au.). The average values, for successive years, divided on this principle, as well as the values for the whole twelve months from May to April (I2 m.), are given in Table I, those obtained at the upper station only being quoted: an entry against any given year, such as 1896 , refers to observations from May r895 to April 1896.

1 When these Reports were published there were records available for only one year and four years, respectively; but the conclusions to which they led were, in nearly every detail, the same as those to which the observations of twenty years now lead. 


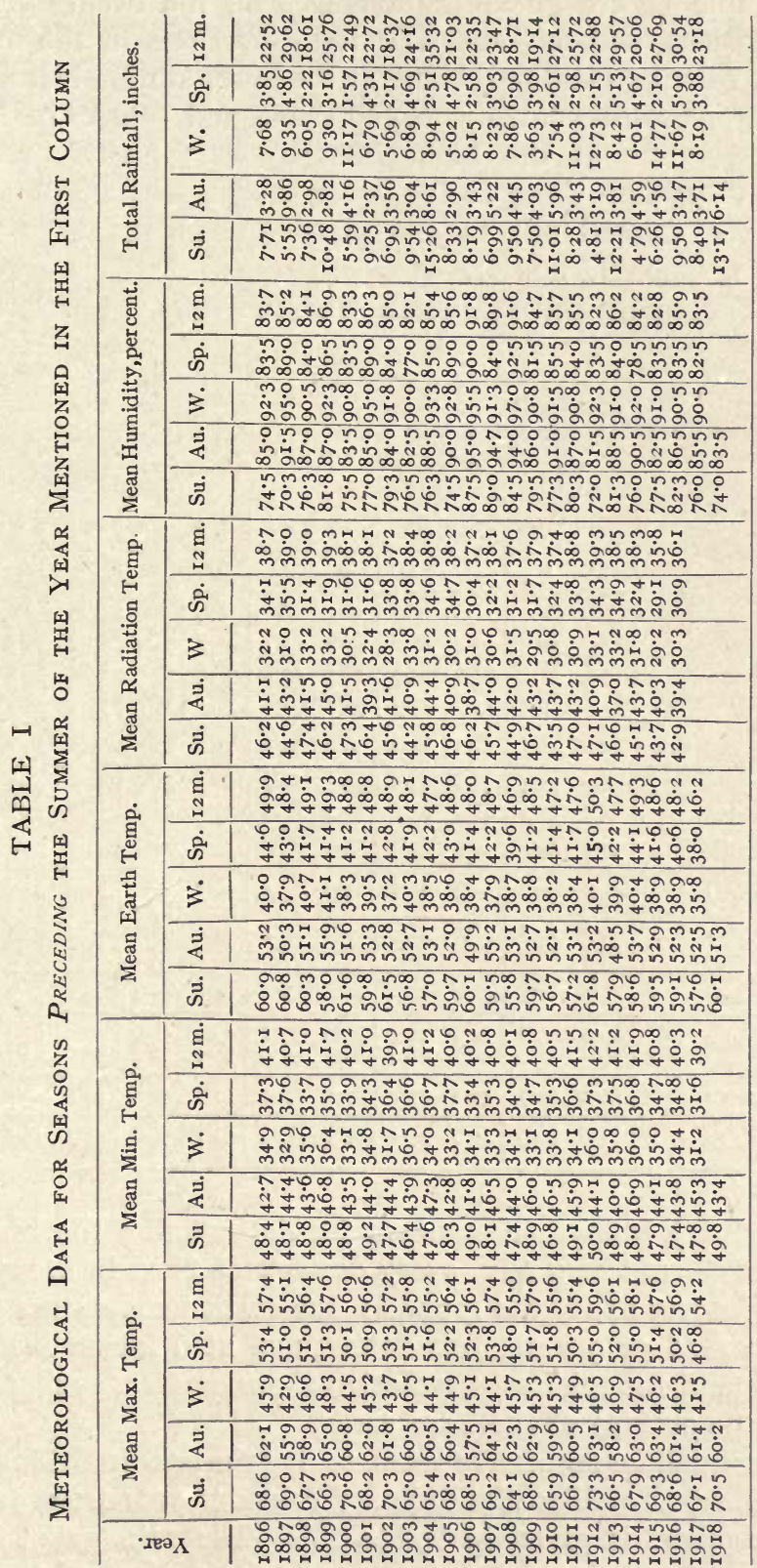


In Table II are given the averages for the twenty years at both stations, and in Table III, the differences in the average values at the two stations, those at the lower station being taken as the standard of comparison, and the + and - signs indicating that the values at the higher station were higher or lower, respectively, than those at the lower station. These differences have been worked out to one place further than the values entered in Tables I and II.

The maximum and minimum thermometers, as well as the

TABLE II

Meteorological Results for the Twenty Years (November, i895, to OCTOBER, I9I5)

\begin{tabular}{|c|c|c|c|c|c|c|c|c|c|c|c|c|}
\hline \multirow{2}{*}{\multicolumn{2}{|c|}{ Month. }} & \multicolumn{2}{|c|}{ Mean Max. } & \multirow{2}{*}{\multicolumn{2}{|c|}{$\begin{array}{cc}\text { Mean } & \text { Min. } \\
\text { U } & \text { L }\end{array}$}} & \multicolumn{2}{|c|}{ Rel. Hum. } & \multicolumn{2}{|c|}{ Radiation. } & \multicolumn{2}{|c|}{ Mean E.T. } & \multirow{2}{*}{ Rainfall } \\
\hline & & $\mathrm{U}$ & $\mathrm{L}$ & & & $\mathrm{U}$ & $\mathbf{L}$ & $\mathrm{U}$ & $\mathrm{L}$ & $\mathrm{U}$ & $\mathrm{L}$ & \\
\hline $\begin{array}{l}\text { November } \\
\text { December } \\
\text { January. } \\
\text { February }\end{array}$ & $:$ & $\begin{array}{l}{ }^{\circ} \mathrm{F} . \\
48 \cdot 8 \\
44^{\cdot} \cdot 8 \\
43^{\circ} \cdot 3 \\
45^{\circ} \mathrm{I}\end{array}$ & $\begin{array}{l}{ }^{\circ} \mathrm{F} . \\
48 \cdot 9 \\
44^{\circ} \cdot 8 \\
43^{\circ} \cdot 2 \\
45^{\circ} \mathrm{I}\end{array}$ & $\begin{array}{l}{ }^{\circ} \mathrm{F} . \\
36 \cdot 7 \\
34^{\circ} \cdot 7 \\
33^{\circ} \mathrm{I} \\
33^{\circ 2}\end{array}$ & $\begin{array}{l}{ }^{\circ} \mathrm{F} . \\
36 \cdot 3 \\
34^{\circ} \cdot 4 \\
32^{\circ} \cdot 9 \\
32^{\circ} \cdot 9 \\
\end{array}$ & $\begin{array}{c}\% \\
91 \cdot 9 \\
92 \cdot 9 \\
92 \cdot 6 \\
91 \cdot 4\end{array}$ & $\begin{array}{c}\% \\
92 \cdot \mathrm{I} \\
93^{*} \cdot 0 \\
92 \cdot 7 \\
9 \mathrm{I} \cdot 2 \\
\end{array}$ & $\begin{array}{l}{ }^{\circ} \mathrm{F} . \\
33 \cdot 7 \\
3 I^{\circ} \cdot 4 \\
30^{\circ} \cdot 2 \\
30 \cdot 1\end{array}$ & $\begin{array}{l}{ }^{\circ} \mathrm{F} . \\
32^{\circ} \cdot 4 \\
30^{\circ} \cdot 5 \\
29^{\circ} \mathrm{I} \\
28^{\circ} 9\end{array}$ & $\begin{array}{l}{ }^{\circ} \mathrm{F} . \\
42 \cdot 3 \\
39 \cdot \mathrm{I} \\
37 \cdot 3 \\
37 \cdot 4\end{array}$ & $\begin{array}{l}{ }^{\circ} \mathrm{F} . \\
43 \cdot 3 \\
40 \cdot 3 \\
38 \cdot 2 \\
38 \cdot 2\end{array}$ & $\begin{array}{l}\text { Ins. } \\
2 \cdot 06 \\
2 \cdot 75 \\
\mathrm{I} \cdot 83 \\
\mathrm{I} \cdot 62\end{array}$ \\
\hline November- & February & $45 \cdot 5$ & $45^{\circ} 5$ & $34^{\circ} 4$ & $34^{\circ} \cdot 1$ & $92 \cdot 2$ & $92 \cdot 3$ & $3 \mathrm{I} \cdot 4$ & $30 \cdot 2$ & $39^{\circ} 0$ & $40^{\circ} 0$ & $2 \cdot 07$ \\
\hline $\begin{array}{l}\text { March } \\
\text { April }\end{array}$ & : & $\begin{array}{l}48 \cdot 7 \\
55^{\circ} 0\end{array}$ & $\begin{array}{l}48 \cdot 9 \\
55^{\circ} \cdot 4\end{array}$ & $\begin{array}{l}34 \cdot 5 \\
36 \cdot 9\end{array}$ & $\begin{array}{l}34 \cdot 2 \\
36 \cdot 6\end{array}$ & $\begin{array}{l}88 \cdot 4 \\
8 \mathrm{I} \cdot 4\end{array}$ & $\begin{array}{l}88 \cdot I \\
8 \mathrm{I} \cdot 8\end{array}$ & $\begin{array}{l}3 x \cdot 5 \\
34^{\cdot} \cdot 1 \\
\end{array}$ & $\begin{array}{l}30 \cdot 2 \\
32 \cdot 6 \\
\end{array}$ & $\begin{array}{r}39^{\cdot} \cdot 6 \\
44^{\cdot 6} \\
\end{array}$ & $\begin{array}{l}40 \cdot 3 \\
44 \cdot 9 \\
\end{array}$ & $\begin{array}{l}2.00 \\
1.51\end{array}$ \\
\hline March-Apr & il & $5 \Gamma \cdot 9$ & $52 \cdot 2$ & $35 \cdot 7$ & $35 \cdot 4$ & $84 \cdot 9$ & $85^{\circ} 0$ & $32 \cdot 8$ & $3 I^{\circ} 4$ & $42 \cdot x$ & $42 \cdot 6$ & $\mathrm{I} \cdot 76$ \\
\hline $\begin{array}{l}\text { May } \\
\text { June : } \\
\text { July } \\
\text { August }\end{array}$ & $:$ & $\begin{array}{l}61 \cdot 8 \\
67 \cdot 9 \\
7 I \cdot 7 \\
70 \cdot 3\end{array}$ & $\begin{array}{l}62 \cdot 2 \\
68 \cdot 2 \\
72 \cdot 3 \\
70 \cdot 9\end{array}$ & $\begin{array}{l}42 \cdot 3 \\
48 \cdot 1 \\
5 \mathrm{I} \cdot 6 \\
50 \cdot 9\end{array}$ & $\begin{array}{l}41 \cdot 6 \\
47 \cdot 5 \\
50 \cdot 8 \\
50 \cdot 2 \\
\end{array}$ & $\begin{array}{l}78 \cdot 9 \\
78 \cdot 9 \\
76 \cdot 8 \\
80 \cdot 6\end{array}$ & $\begin{array}{l}78 \cdot 5 \\
78 \cdot 5 \\
76 \cdot 4 \\
79 \cdot 3 \\
\end{array}$ & $\begin{array}{l}39^{\circ} \cdot 7 \\
45^{\circ} 9 \\
49^{\circ} 2 \\
4^{\circ} \cdot 3\end{array}$ & $\begin{array}{l}38 \cdot 1 \\
44^{\circ} \cdot 4 \\
47 \cdot 8 \\
46 \cdot 9\end{array}$ & $\begin{array}{l}52 \cdot 5 \\
59^{\circ} \cdot 5 \\
63^{\circ} \cdot 2 \\
6 \mathbf{I}^{\cdot} \cdot 1\end{array}$ & $\begin{array}{l}51 \cdot 7 \\
58 \cdot 3 \\
62 \cdot 0 \\
6 \circ \cdot 8\end{array}$ & $\begin{array}{l}\mathrm{x} \cdot 89 \\
2 \cdot 17 \\
1 \cdot 94 \\
2 \cdot 37\end{array}$ \\
\hline May-Augus & st. & $67 \cdot 9$ & $68 \cdot 4$ & $48 \cdot 2$ & $47 \cdot 5$ & $78 \cdot 8$ & $78 \cdot 2$ & $45 \cdot 8$ & $44 \cdot 3$ & $59^{\cdot I}$ & $58 \cdot 2$ & 2.09 \\
\hline $\begin{array}{l}\text { September } \\
\text { October }\end{array}$ & : & $\begin{array}{l}65 \cdot 3 \\
56 \cdot 8 \\
\end{array}$ & $\begin{array}{l}65 \cdot 8 \\
57 \cdot 3 \\
\end{array}$ & $\begin{array}{l}46 \cdot 9 \\
42 \cdot 1 \\
\end{array}$ & $\begin{array}{l}45 \cdot 9 \\
41 \cdot 5\end{array}$ & $\begin{array}{l}84^{\cdot} \cdot 4 \\
9^{1 \cdot 2} \\
\end{array}$ & $\begin{array}{l}83 \cdot 7 \\
90 \cdot 4 \\
\end{array}$ & $\begin{array}{l}43^{\circ} 9 \\
39^{\circ} 5 \\
\end{array}$ & $\begin{array}{l}42 \cdot 6 \\
38 \cdot 3 \\
\end{array}$ & $\begin{array}{l}55^{\circ} \cdot 9 \\
49^{\circ} \mathrm{I} \\
\end{array}$ & $\begin{array}{l}55^{\circ} .9 \\
49^{\circ} 8\end{array}$ & $\begin{array}{l}I \cdot 7 \mathrm{I} \\
2 \cdot 6 \mathrm{I}\end{array}$ \\
\hline September- & October & $6 \mathrm{I} \cdot \mathrm{I}$ & $6 \mathrm{r} \cdot 5$ & $44 \cdot 5$ & $43^{\circ} 7$ & $87 \cdot 8$ & $87 \cdot I$ & $4 x \cdot 7$ & $40 \cdot 5$ & $52 \cdot 5$ & $52 \cdot 9$ & $2 \cdot 16$ \\
\hline Year & . & $56 \cdot 6$ & $56 \cdot 9$ & $40 \cdot 9$ & $40^{\circ} 4$ & $85^{\circ} 8$ & 85.5 & $38 \cdot 1$ & $36 \cdot 8$ & $48^{\circ} 5$ & $4^{8 \cdot 6}$ & $24 \cdot 46$ \\
\hline
\end{tabular}

wet and dry bulb thermometers for determining the humidity of the air-read at 9 a.m. every day-were fixed in Stevenson's screens, 4 feet above the ground: the earth temperature (E.T.), likewise read at 9 a.m., was determined at 6 inches below the surface, and the minimum radiation thermometers were 4 inches above the surface of the bare earth.

The rainfall for successive years, taking the year from November to October, as well as the ordinary calendar year from January to December, is given in Table IV. The rain gauge was a five-inch gauge placed 8 inches above the surface of the soil.

The differences in the readings at the two stations on any 
TABLE III

VALUES AT THE UPPER Station COMPARED WITH THOSE at THE LOWER Station

\begin{tabular}{|c|c|c|c|c|c|}
\hline Month. & Mean Max. & Mean Min. & Rel. Hum. & Radiation. & Mean E. T. \\
\hline $\begin{array}{l}\text { November } \\
\text { December : } \\
\text { January } \\
\text { February }\end{array}$ & $\begin{array}{l}-0.06 \\
+0.01 \\
+0.08 \\
-0.03\end{array}$ & $\begin{array}{l}+0.40 \\
+0.32 \\
+0.25 \\
+0.28\end{array}$ & $\begin{array}{l}-0.2 \\
-0.1 \\
-0.1 \\
+0.2 \\
\end{array}$ & $\begin{array}{l}+0.29 \\
+0.90 \\
+1.06 \\
+1.23 \\
\end{array}$ & $\begin{array}{r}-\mathrm{I} \cdot 03 \\
-\mathrm{I} \cdot 18 \\
-0.85 \\
-0.82\end{array}$ \\
\hline Nov.-Feb.. & 0.00 & +0.31 & $-0 \cdot I$ & +0.87 & -0.97 \\
\hline $\begin{array}{l}\text { March } \\
\text { April . }\end{array}$ & $\begin{array}{r}-0.18 \\
-0.44 \\
\end{array}$ & $\begin{array}{r}+0.32 \\
+0.42 \\
\end{array}$ & $\begin{array}{l}+0.3 \\
-0.4 \\
\end{array}$ & $\begin{array}{r}+I \cdot 24 \\
+I .53 \\
\end{array}$ & $\begin{array}{r}-0.66 \\
-0.19 \\
\end{array}$ \\
\hline Mar.-April & -0.31 & +0.37 & 0 & $+1 \cdot 39$ & -0.44 \\
\hline $\begin{array}{l}\text { May } \\
\text { June } \\
\text { July } \\
\text { August }\end{array}$ & $\begin{array}{r}-0.44 \\
-0.36 \\
-0.57 \\
-0.62 \\
\end{array}$ & $\begin{array}{l}+0.60 \\
+0.60 \\
+0.76 \\
+0.76 \\
\end{array}$ & $\begin{array}{r}+0.4 \\
+0.4 \\
+0.4 \\
+\mathrm{I} 3 \\
\end{array}$ & $\begin{array}{r}+r .67 \\
+r .54 \\
+I .35 \\
+I .36 \\
\end{array}$ & $\begin{array}{r}+0.78 \\
+1.18 \\
+1.22 \\
+0.27 \\
\end{array}$ \\
\hline May-Aug. . & -0.50 & +0.68 & +0.6 & $+\mathrm{I} \cdot 48$ & +0.86 \\
\hline $\begin{array}{l}\text { September } \\
\text { October }\end{array}$ & $\begin{array}{r}-0.46 \\
-0.47 \\
\end{array}$ & $\begin{array}{r}+0.93 \\
+0.62 \\
\end{array}$ & $\begin{array}{r}+0.7 \\
+0.8 \\
\end{array}$ & $\begin{array}{r}+I \cdot 28 \\
+I \cdot 24 \\
\end{array}$ & $\begin{array}{r}-0.10 \\
-0.71 \\
\end{array}$ \\
\hline Sept.-Oct. & -0.47 & $+0^{\circ} 78$ & +0.8 & $+I \cdot 26$ & $-0.4 \mathrm{I}$ \\
\hline Year & -0.28 & +0.52 & +0.3 & $+I \cdot 22$ & -0.14 \\
\hline
\end{tabular}

TABLE IV

YEARLY RAINFALL

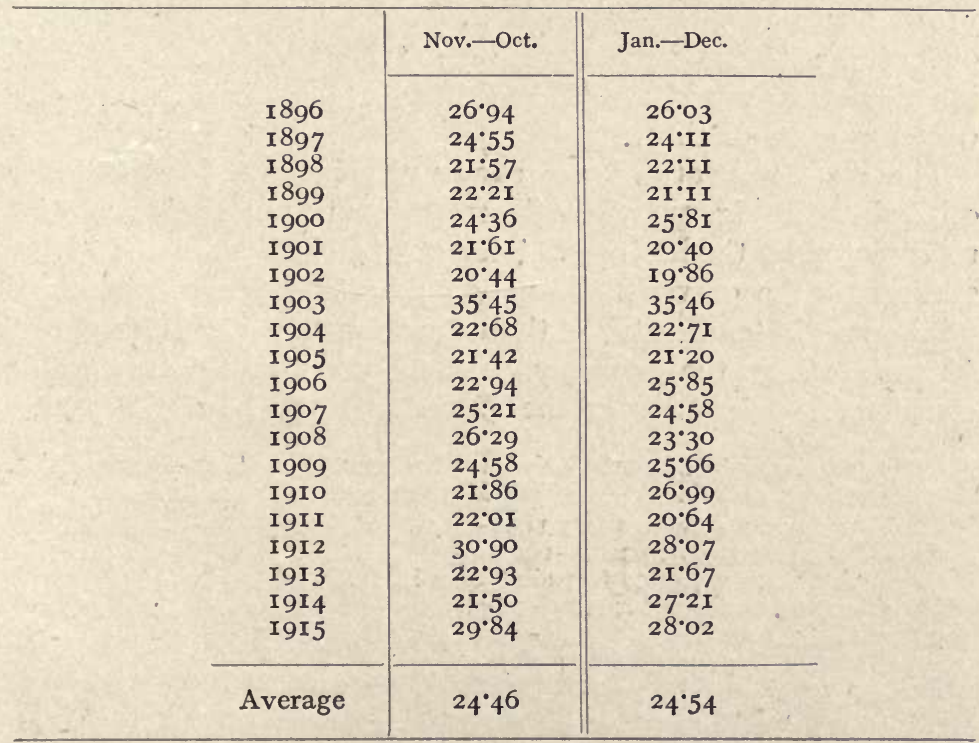


particular occasion may be considerable: with the maximum and minimum air temperatures, and with the minimum radiation temperatures, differences of $5^{\circ} \mathrm{F}$. were sometimes noticed, and with the earth temperatures the extreme differences were rather greater; but when the averages for the twenty years are considered, the differences are by no means large. The average maximum air temperatures at the two stations are identical for the winter months, and the difference between them reaches its highest value in the summer, the temperature at the upper station being then the lower to the extent of $0.5^{\circ}$ : the difference is nearly as great in the autumn $\left(0.47^{\circ}\right)$, but less in the spring $\left(0.3 \mathrm{I}^{\circ}\right)$. Whilst the upper station is the cooler as regards the miaximum temperatures, it is the warmer as regards the minimum temperatures, the differences in these being greatest in summer and autumn $\left(0.68^{\circ}\right.$ and $\left.0.78^{\circ}\right)$, and least in the winter and spring $\left(0.31^{\circ}\right.$ and $\left.0.37^{\circ}\right)$. In no single month are the differences in the opposite direction. Thus, the variation of air temperature is less at the upper than at the lower station to the average extent of-

$\begin{array}{cccc}\text { Winter. } & \text { Spring. } & \text { Summer. } & \text { Autumn. } \\ 0^{\circ} 3 \mathrm{I}^{\circ} & 0.68^{\circ} & \mathrm{I} \cdot \mathrm{I}^{\circ} & \mathrm{I} \cdot 25^{\circ}\end{array}$

Whilst the average values for the air temperatures at the two stations show such close agreement, it is only very rarely that the readings at the two are identical. The results for fourteen years, up to Igog, were examined from this point of view, and out of the I0,220 sets of readings taken during that period, identity was found on only fifteen occasions, representing $0 \cdot$ I5 per cent. of the total. ${ }^{1}$

The air temperatures are shown graphically, together with other data, in Fig. I7, where the readings at the lower station are represented by the horizontal lines at $\mathrm{o}$, and those at the higher station by the curved figures. As regards the maximum and minimum air temperatures, the values are fairly complementary of each other, the monthly readings in both cases showing considerable regularity in the variation throughout the year.

1 Observations at different levels have been made at other observatories, and the results may be found at the Meteorological Office, London.

Camden Town : 4 and $20 \mathrm{ft}$.; I867-I 872.

Oxford : 5 and ro5 ft.; I862-I908.

Greenwich : 4, 22 and $50 \mathrm{ft}$; ; six weeks in $\mathrm{I} 868$.

Kew : 22,69 and $129 \mathrm{ft}$; $1873-1875$.

Greenwich : 4 and $20 \mathrm{ft}$. ; $1886-1909$.

Peel House : 6, 52 and $86 \mathrm{ft}$; $1872-1874$.

Berlin : 1909. 
Passing to the radiation temperature, it will be seen that there is a considerable difference between the values at the two stations: the thermometer at the upper station shows a higher reading than that at the lower during every month in

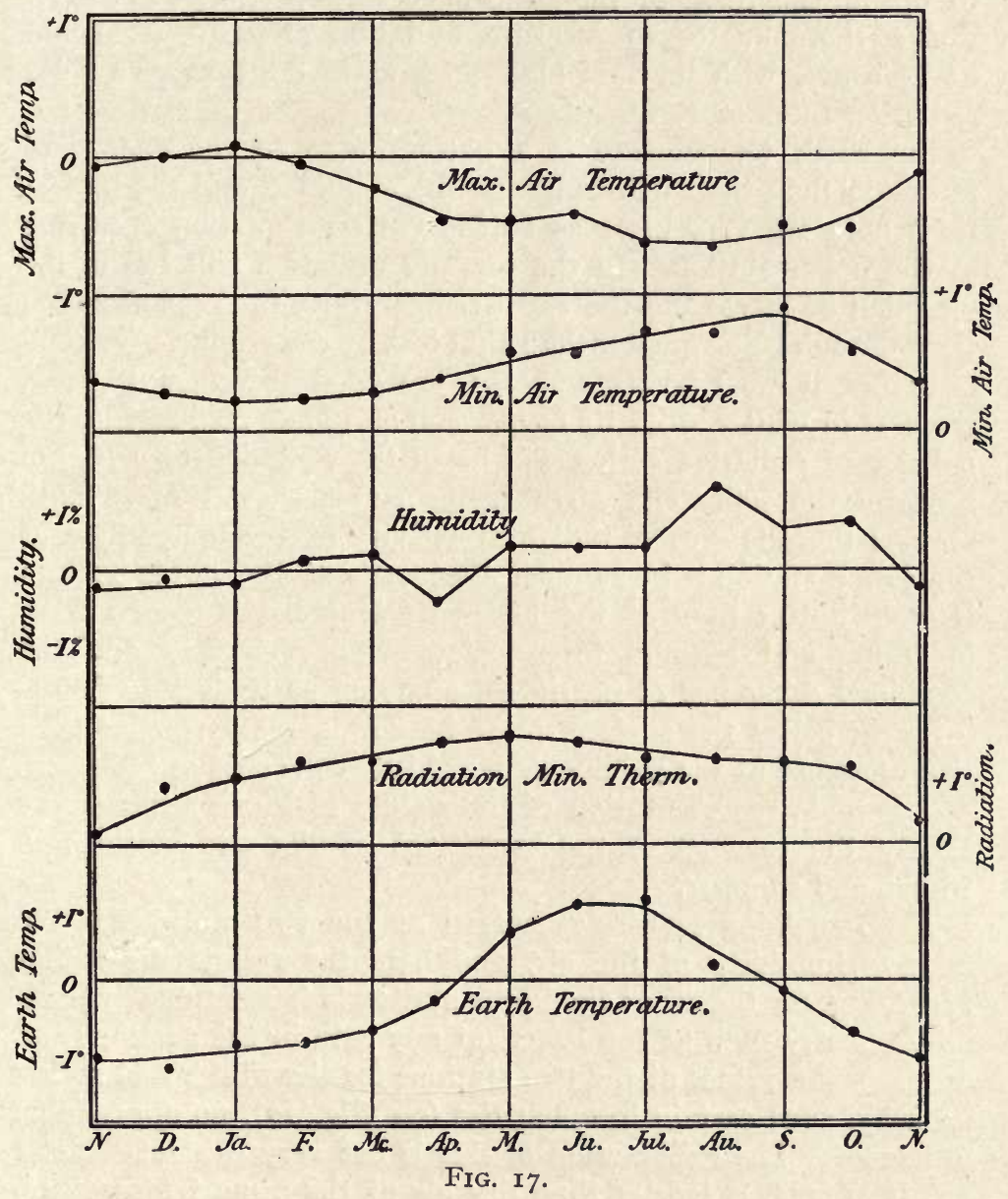

the year (Tab. III, Fig. I7) : the difference amounting to nearly $I .5^{\circ}$ in spring, summer and autumn, that in winter alone being less than $I^{\circ}$. The average difference for the whole year is $I \cdot 22^{\circ}$. At first sight this might appear to offer a contradiction of the statement made below (p. I27) that radiation is more active on higher ground where the air is clearer, than on lower ground; but there is, in fact, no contradiction, for a so-called radiation 
thermometer does not really measure the amount of radiation occurring, but is affected chiefly by the temperature of the air surrounding the instrument, and this temperature will be higher on the high ground, though radiation is most active there, owing to the flowing away of the air as it becomes cooled (see p. I27). For a thermometer to measure radiation properly, it should be in vacuo, with its bulb blackened, as in the case of a solar radiation thermometer.

The earth temperature is a better guide to the energy of radiation than the earth radiation thermometer, and the indications here are very clear as to the greater radiation occurring at the upper station. In the summer radiation will tell in the direction of increasing the earth temperature, the heat absorbed from the sun being greater than that lost by the ground-for good radiators, it must be remembered, are good absorbers (p. I26) ; whereas in winter, with its feebler sun and long, cold nights, the balance of radiative action will be in the direction of a loss of heat by the soil. The earth temperatures show that in both seasons there is greater radiation activity at the upper than at the lower station: in summer the earth at the upper station is $0.86^{\circ}$ hotter than at the lower, in winter it is $0^{\circ} 97^{\circ}$ colder, in spring and autumn intermediate values obtain; and the combined difference of nearly $2^{\circ}$, applying as it does to points 6 inches below the surface, must be considerably smaller than the difference at the surface itself, which is the seat of radiation. The graphic representation of the values in Fig. I7 show very clearly the reversal of the conditions at the two stations in winter and summer.

The remaining feature measured at the two stations is the relative humidity of the air, and here the results are rather surprising, for the air at the upper station is found to be appreciably moister than at the lower, at any rate in the summer and autumn, the values at the two stations for the winter and spring showing, with certain irregularities (see Fig. I7), no appreciable difference. The explanation of this is not very evident. Moist air, it is true, is lighter than dry air at the same temperature, it consequently rises and expands, becoming cooled in so doing, and its relative humidity is thereby increased, even to the point of water separating from it in the form of mist-one of the modes of origin of clouds; but it is difficult to imagine that any such action can occur to an extent sufficient to produce measurable results when a rise of only $I_{5}$ feet is in question. It is more likely that the differences observed are, in a sense, 
accidental, due to the fact that the observations apply only to one particular time of the day, the sun having by 9 a.m. gained sufficient power to cause a greater evaporation from the surface of the soil at the higher than at the lower station, though not having had time to have produced any effective drying of the soil and of the air above it. Observations taken at other times of the day might settle this point. Explanations based on the relative position of the two stations in relation to the direction - of the prevalent wind (S.W.) appear to be unsatisfactory.

The values for the rainfall entered in Table II, show that the average monthly falls during three of the four divisions of the year are very nearly equal, 2.07 to 2.16 inches, that in the spring months alone showing any marked difference ( 176 inches); though when the year is divided into the ordinary four equal quarters, the falls exhibit a fairly regular increase throughout the year : Ist quarter, $I \cdot 82$, 2nd quarter, $I \cdot 86,3$ rd quarter, $2^{\circ}$ or, and 4 th quarter, 2.47 inches. The average rainfall for the twenty years during individual months gives the following order for these months when arranged from the driest to the wettest, and the arrangement is, in several respects, not that which general opinion would anticipate: April, February, September, January, May, July, March, November, June, August, October, December.

The annual rainfall for the twenty years, as set out in Table IV, shows that the driest year of the series was I902, and the wettest I903. During the latter year the rainfall was nearly 50 per cent. in excess of the average, and much of this fell in the summer, the result of which was a water-logging of the soil, followed by rootasphyxia of the trees. Much damage was done to the trees at the farm, as well as in other parts of the country, in this way, though the full extent of the injury was not manifest at once, the trees gradually dying off during many succeeding years, and it is questionable whether the evil results have yet been exhausted. 


\section{Chapter XII}

\section{SPRING FROSTS}

OF the numerous considerations which should influence a fruit-grower in the choice of a situation, one of the most important is the liability of the position to spring frosts. The Woburn Farm offered special facilities for investigating the incidence of such frosts, but, unfortunately, the work initiated on the subject was cut short, owing to the exposure entailed in taking observations having proved nearly fatal to the manager, and other circumstances have interfered with the resumption of the work until quite recently.

Injury to fruit blossoms occurs whenever the temperature is lowered to such a point that the contents of the cells freeze and the cell-walls are ruptured: this temperature is, according to Church and Fergusson, ${ }^{1} 27^{\circ} \mathrm{F}$. when the trees are in bud, $29^{\circ}$ when they are in blossom, and $30^{\circ}$ when the fruit is setting. A lowering of temperature may occur under two essentially different types of meteorological conditions: either during windfrosts, or radiation-frosts. In the former, the temperature of the whole air is sufficiently low to cause freezing, and the cooling effect is augmented by cold winds, generally from the north or east; in the latter, the cooling occurs at and near the ground level only, and is due to heat being radiated into space at night by objects on the earth when the air is clear and still.

Very little can be done to mitigate the damage caused by wind-frosts, except by sheltering the trees from the winds, either by establishing the plantation in a situation where protection from the east or north is afforded by natural objects, or by interspersing shelter hedges throughout the ground, to act as wind-breaks. Heating the air by fires made to the windward of the plantation is, however, sometimes resorted to in the United States, though the results are poor whenever the velocity of the wind exceeds certain very moderate limits. At the Woburn Farm some thirty shelter hedges were planted, all consisting of fruit trees of different descriptions, and all of them

1 Agric. Expt. Station of Nevada, Bulletin 79, 1912. 
treated as regards pruning just as ordinary hedges would be. Such hard pruning, however, renders the trees composing them useless as fruit producers: often there is practically no fruit throughout the run of the hedge, though profuse fruiting occurs on any branches which may have been left unpruned with the object of overarching a path, etc.; thus affording a striking illustration of the antagonism between hard pruning and fruiting (p. 67). Lists of these hedges, arranged according to their merits from various points of view, are given below.

\begin{tabular}{ll}
$\begin{array}{c}\text { Quickest growing and } \\
\text { best wind-breaks. }\end{array}$ & \multicolumn{1}{c}{$\begin{array}{c}\text { Strongest as fences } \\
\text { against live stock. }\end{array}$} \\
Dartmouth Crab & Cherry Plum \\
Cherry Plum & Crittenden Damson \\
Rivers' Early Prolific & Prune Damson \\
American Crab & Dartmouth Crab \\
Siberian Crab & Shepperd's Bullace \\
Shepperd's Bullace & American Crab \\
Crittenden Damson & Siberian Crab \\
Prune Damson & Rivers' Early Prolific \\
Medlar & Medlar \\
Nuts & Quince \\
Quince & Nuts
\end{tabular}

Heaviest croppers.

Dartmouth Crab Rivers' Early Prolific Shepperd's Bullace

Siberian Crab

American Crab

Nuts

Crittenden Damson

Prune Damson

Medlar

Cherry Plum

Quince

\section{Most valuable}

cropper.

Rivers' Early Prolific

Shepperd's Bullace

Nuts

Crittenden Damson

Prune Damson

Dartmouth Crab

Siberian Crab

American Crab

Medlar

Cherry Plum

Quince

The damage done by wind-frosts, however, is not confined to that taking place when the blossoms are actually killed, for indirect damage occurs through the cold interfering with the visits of those insects on which pollination depends.

As to radiation-frosts, a few words on the general principles governing them may be necessary, for these principles are not very widely known, as may be gathered from the frequency with which are heard such expressions as "dew falling," " mist rising," etc.

Heat may be received, or lost, by a body in two distinct ways : by conduction, as when heat passes gradually from the hot end of a metal bar to the cooler end, there being a regular gradation of temperature from one end to the other; or by radiation, as when we warm ourselves by standing in front of a fire, the heating in that case being due to the rays of heat which are given out by the burning coal being absorbed by our bodies, though they pass through the air without raising its temperature appreciably. Such exchange of heat is always occurring between bodies, whatever their temperatures may be, and whether a body becomes cooler or hotter, depends on whether it loses more heat than it receives, or vice versa.

During the day the earth receives more heat from the sun than it loses, and, consequently, becomes hotter; but during the night it loses more heat than it gains, for the temperature of space is excessively low, and practically no heat is radiated 
from this space to the earth to counterbalance the heat which the earth is radiating into space. Any cloud in the sky, though its temperature may be low, is warm in comparison with outer space, and it consequently sends back some heat to the earth, the fall of temperature of the latter being thus checked: this will occur even if the cloud is not directly overhead. It is only on clear, bright nights that the earth loses much heat by radiation, and that heavy dews or night frosts occur.

Different substances differ greatly in their powers of radiating heat and of absorbing heat radiated to them; but the power of radiation and absorption go strictly together: the better a substance is as a radiator, the better is it also as an absorber. Dry air is a bad radiator and absorber, yet, owing to the great bulk of the atmosphere, the actual amount of heat which it absorbs is very large, and hence the atmosphere prevents both an excessive heating of the surface of the earth during the day, and an excessive cooling during the night, such as occurs on the moon, rendering the existence of life there impossible.

Water, even when it is in the form of invisible moisture in the air, is a good radiator and absorber, and hence there is less cooling of the earth's surface when the air is moist than when it is dry, even if there are no actual clouds (condensed moisture) in the sky. ${ }^{1}$

For the production of dew or hoar frost there must, also, be no wind, for with wind there is a continual circulation of air over the ground, preventing the latter from getting cooled down by radiation. The air, being a bad radiator, loses but little heat directly by radiation at night, but it does, however, get colder when radiation is active: it is cooled by contact with the ground, which is radiating away its heat and becoming colder, and, when the air gets sufficiently cold, it is no longer able to retain the moisture present in it, and this latter separates out in minute droplets, producing a mist; these droplets attach themselves to any solid with which they come in contact, forming dew, or, if the temperature is below the freezing point, hoar frost. Thus, dew neither falls, nor does it rise out of the ground, but originates in the air itself. In the same way the mist, which produces the dew, does not rise, though the layer of air

1 For a summary of the evidence on this point, see Wells, " On Dew," Appendix, by R. Strachan; edition by L. P. Casella, I866, p. I23. Carbon dioxide is also a better absorber than air, and attempts have been made, though without success, to protect orchards from frost by flooding them with streams of that gas (West and Edlefsen, Utah Expt. Station, Bulletin I6I, I9I 7). 
containing it gradually gets deeper and deeper as the lower layers cool those immediately above them.

Cold air is denser than warm air, and the layer of air which has been cooled by contact with the cooling earth will remain stagnant on the surface, if the ground is quite level; but if the ground slopes, the heavy, cold air will gradually flow away, just as water does, though much more sluggishly, and will accumulate in any valley or hollow, forming a pond or lake of cold air. ${ }^{1}$ If this air be laden with mist, the mist will, of course, also accumulate in the hollow, and will give the impression that it has been formed there, though in reality it has been formed on the higher ground, and has only slid down into the hollow. The higher ground, in fact, is the seat of manufacture of the cold air, for there the air is clearer, and radiation is more active ; in the hollow radiation is less active, and, as soon as the mist accumulates there, will cease altogether, for the mist covers the ground with a cloud, and prevents radiation, just as a cloud in the sky would do.

From these facts it is clear that one of the chief considerations in selecting a site for a fruit plantation is to avoid the presence of any hollows where cold air can accumulate: good air-drainage is of just as much importance as good waterdrainage.

There is no reason for supposing that the mist which accompanies the cold air in a hollow is itself the direct cause of damage to the fruit blossoms, by increasing the fall of temperature, and, inasmuch as it hinders radiation, it must tend to retard the cooling of the trees by radiation. Erroneous conclusions must not be drawn as to the relative effect of damp and dry air on trees, from relative effect of them on the human body. Cold, damp air, of the same temperature as dry air, feels much colder to us, simply because we are warm-blooded animals, and because moisture, being a good conductor of heat, causes a rapid loss of heat from our bodies; this would be so to only a very small extent, if at all, with trees; they would be practically unaffected by the dryness or moistness of air at any given temperature, just as would a thermometer. Yet the view commonly held ${ }^{2}$ that dampness in the atmosphere increases injury by frost, is, apparently, not without foundation, for West and Edlefsen (loc. cit.) found that the spraying of trees, even with warm water, before a frost, whilst

1 See L. D. Batchelor and F. L. West, "Variation in Minimum Temperatures due to the Topography of a Mountain Valley in its Relation to Fruit Growing," Utah Agric. Coll., Bulletin I4I, I9I5.

${ }_{2}$ G. F. Hooper, Board of Agric. Journ., 1907, XIV, 25. 
it resulted in but a slight lowering of their temperatures, caused a considerable increase in the extent of the damage done, this being probably due to the cells under the moister condition becoming more full of water, and hence suffering more when the water in them froze (cf. p. I3I).

Another view which is commonly held is, that much of the damage done by spring frosts occurs during the thawing of the frozen blossoms, a rapid thaw being the most harmful. That this should be the case is not improbable, and harmonises with what is known as to the necessity for very gradual heating in the case of frozen meat, frost bites, etc.; it also harmonises with the practice of watering with very cold water plants $(e . g$. chrysanthemums) which have been slightly touched by frost. In the United States smoky fires, or smudges, are sometimes started at dawn, to prevent the rapid heating of the frozen buds by the sun. ${ }^{1}$ On the other hand, evidence has recently been adduced by W. G. Reed ${ }^{2}$ which throws doubt on the conclusion that rapid thawing causes damage.

The three chief principles on which attempts have been made to mitigate the damage done by spring frosts have been based on (I) the formation of artificial clouds-the smoke clouds, or smudges, just mentioned-which would impede radiation from the ground, and hence cut off the supply of cold air; (2) raising the temperature of the trees by means of radiant heat or by hot gases, given out by fires in their vicinity; and (3) raising the temperature of the air by artificial heating.

Direct experiments on the subject are difficult to make. There are rarely two or three occasions in a season-often not one during several seasons-when any experiment dealing with the incidence of frost on the trees themselves could be made, and on no two occasions are the conditions strictly similar, so that comparisons are impossible, and the fallacious "post hoc, ergo propter hoc" argument has often to be resorted to. ${ }^{3}$ It is, at present, more profitable to examine the principles on which such methods of prevention must be based; and, in the first place, we have to admit some uncertainty as to how the damage to the trees occurs : is it solely by the low temperature of the air around them, or do they become cooled below the

1 P. J. O'Gara, Farmers' Bulletin 40I, I9I 5.

2 Pan-American Scientific Conference, Washington, I9I 7.

3 For trials carried out in Gloucestershire and Kent, see F. G. Hooper, loc. cit, and S. T. Parkinson, Journ. S. E. Agric. Coll., I908, 235-28I. Of the numerous contributions on this subject in American Journals, a comprehensive list up to I9I 7 is given by West and Edlefsen (loc. cit., p. I 26). See also U. S. Dep. of Agric., Weather Bureau, Publication 542. 
temperature of the air by themselves radiating away their heat? That radiation occurs from the trees cannot be questioned, but it is very doubtful whether such radiation would lower their temperature. to any appreciable extent; the blossoms are for the most part.situated many feet above the ground, and any air cooled by contact with them would at once sink down, and be displaced by warmer air, thus preventing any continuous fall of temperature, such as occurs with vegetation on the surface of the ground; it seems very improbable that the temperature of any small, thin objects, such as the pistils or petals of a blossom, could ever fall much below that of the air surrounding them, for even with much larger objects, such as the bulbs of a thermometer, it would appear that differences of about $2^{\circ}$ are the greatest which can be obtained in this way. ${ }^{1}$ The fact that damage by frost is more severe in the lower portions of the ground, where radiation is least active, is a strong argument against the view of that damage having been caused by radiation from the trees themselves.

It is very doubtful, therefore, whether smudges will, from the mere fact of their being smoke clouds, have any effect in reducing damage, unless they can be extended sufficiently, not only to cover with a pall the trees themselves in the lower portions of the ground, but also to cover the higher ground in the neighbourhood, where the cold air is being manufactured. To do this effectively in a country such as England, with its broken, undulating surface, would be a very difficult matter.

It is more by the heat generated, than by the smoke produced, that such smudge fires are likely to do good, and this seems to be fully recognised in America, where the operation is described as " orchard heating." A significant observation, bearing out this point of view; has been made, namely, that the benefit produced increases with the area treated, 400 fires in ten acres being more effective than $4^{0}$ fires in one acre: if it were a question of a smoke cloud, this would not be so, but if it were a question of heating, it would be, for the larger the area heated, the further removed will the bulk of it be from the surrounding unheated area. Indeed, the number of fires used is such that a considerable amount of heat must be generated : 40 per acre is a minimum-about one fire to every four trees-and 50 to Ioo are frequently lighted; in some cases even, where the fires consist of burning oil in three-gallon containers, there may be as many as one to three of these fires to every tree, the fires 
being placed actually under the trees, so that the hot gases from them pass between the branches. ${ }^{1}$ In such a case direct heating of the trees by contact with the products of combustion occurs, and this must also occur to a limited extent in other cases where the fires are placed near, instead of actually under the trees, though under those circumstances, the bulk of the hot gases will rise beyond the trees without having come into contact with them, and such heating as has occurred will have been caused mainly by the heat radiated from the fires.

Heating by radiation, however, is a very inefficient and uneconomical method of heating: according to West and Edlefsen (loc. cit., p. I26) the column of hot air from these heaters rises to a height of 50 to 75 feet, that is, far above the tops of the trees, and with Ioo heaters to the acre, thermometers suspended from the branches of the trees show a rise of only $4^{\circ} \mathrm{F}$.

As to whether oil or other materials, such as coal, brush wood, etc., is best for making such fires, opinions seem to differ in America, ${ }^{2}$ and, of course, in this country oil is not likely to be used for such a purpose, at any rate, at present. Where coal is used, 50 to $60 \mathrm{lbs}$. are required for each fire which has to last for six hours, and about half a gallonj of oil is required to light it. The uneconomical nature of the process may be estimated by the fact that the heat from the burning of the oil used in lighting three fires, if it were fully utilised, would suffice to raise the temperature of a layer of air 20 feet deep over an acre of land by about $\mathrm{ro}^{\circ} \mathrm{F}$.

The larger the fire, the less will be the direct heating of the air at the level of the trees; one large fire in a plantation would result in the formation of a large volume of heated gases, which would rise vertically to a great height, and involve a large indraft of cold air at the ground level, probably doing more harm than good. For any direct heating of the air, the smaller the fires, the greater their efficiency. The ideal form of heating would consist of a large number of fires or flames, so small that the heated gases from them would not rise above the tops of the trees; they should be p'aced, not at the lower portions of the ground, but near the higher portions, where the cold air is being manufactured, and should be so arranged that this cold air, as it flows downwards, passes the heaters, and has its tem-

1 Church and Fergusson, loc. cit., p. I24.

2 See West and Edlefsen, loc. cit., p. I26, and O'Gara, loc. cit., p. I28; also Lewis and Browne, Oregon Expt. Station, Bulletin, IIO, I9I I, and Greene, Iowa State Coll., Bulletin, I29, I9r2. 
perature raised above the danger point, but not raised sufficiently to cause it to ascend to a high level.

The relative effect of one large source of heat and of numerous small sources in heating air at the lower levels, may be easily established by burning in a room the same amount of oil, in one case in one large lamp, in another in a number of small ones: the relative efficiency of the latter in warming the air throughout, instead of causing an accumulation of hot air at the ceiling, is very marked.

The practical application of such a principle appears to be possible. The burning of $6 \frac{1}{2}$ quarts of paraffin is capable of raising the temperature of a layer of air 20 feet in depth over an acre by $10^{\circ} \mathrm{F}$; ; and that amount of oil would be burnt in six hours in about 200 small lamps, each burning 6 c.c. of paraffin per hour.

There are, of course, many circumstances which render it impossible to calculate what the heating effect of such flames on the air would be in actual practice, and any calculations must simply be taken as indicating possible results. The initial cost of small tin lamps for such a purpose would not be large, but the use of them might involve more labour than would be practicable: a more feasible plan would be to have recourse to coal gas, distributed through small pipes pricked with holes at intervals. In some parts of the country electricity might be available for the purpose.

Investigations on the subject are being conducted at Woburn, by making a survey of the relative temperature conditions obtaining in different parts of the ground when radiation is active, after which it will be possible to ascertain how these conditions may be modified by various heating arrangements.

The temperature of the air may sometimes be raised by natural conditions, and the beneficial effect is then very apparent. It has been shown that in the vicinity of a river, there is a zone on either side of the water where damage from frost rarely occurs, the relatively warm water heating the air above the danger point; similarly, in the neighbourhood of the sea, trees hardly ever suffer from spring frosts. Artificial heating of the air by means of irrigation, when a natural source of comparatively warm water is available, has also been adopted in California for the protection of orange groves, and has been found much more effectual than smudge fires-all of which instances, it may be remarked, afford evidence that moisture in the air daes not always increase the damage done by frost (cf. p. I27). 


\section{Chapter XIII}

\section{THE FRUITING OF TREES IN CONSECUTIVE SEASONS (Report XV, I)}

PoInts of considerable interest, both scientific and practical, are raised by the question as to whether a tree which fruits exceptionally well as compared with its fellows in one season, will tend to fruit exceptionally well, or the reverse, in the following season. We know of no definite reason why the behaviour of a tree as regards fruiting should alternate in consecutive years, and no such behaviour has been observed in the case of animals. Its doing so would imply that fruiting is due to the gradual accumulation of some substance in the tree, which becomes exhausted whenever heavy bearing occurs, and that the stock of this substance does not become properly replenished till after another season has elapsed. This is quite possible, and seems to be in harmony with known cases where fruiting occurs only at intervals of several years; but that anything of the sort takes place with apples, or other ordinary fruit trees, has not yet been proved. Indeed such an alternation seems, from one point of view, to be actually opposed to the well-established fact that growth and fruiting are antagonistic to each other; for the exceptionally feeble growth which accompanies exceptionally heavy cropping, must tend, as all restriction of growth does, to the formation of an increased number of blossom-buds for the following season, and probably, therefore, to heavy cropping also; unless, of course, the cropping has been so heavy as to seriously impair the vigour of the tree, an excessive condition which need not be considered at present. We might, further, actually expect similar behaviour as regards fruiting in consecutive years, on the general ground that individual trees must differ from each other in fertility, as in every other respect. On the other hand, there is a strong, and, apparently, well-founded belief amongst horticulturists that a tendency to alternate fruiting, as it may conveniently be termed, does really exist, at any rate, in the case of certain kinds and varieties of fruits; so much so, that the recommendation is often made, to severely thin the fruit from a tree which is bearing 
heavily, with the object of destroying this tendency, and of obtaining moderate and more uniform bearing in future years.

One observation which lends some support to such a view is that the prevention of a young tree from bearing for a year or two after it is capable of doing so, results in its subsequently bearing very heavy crops. From some apple trees of a precocious variety which had been disblossomed for two years longer than their fellows, the crops obtained during the succeeding five years were, on the average, $3 \cdot 3$ times as heavy as those from their neighbours; after which time their superiority disappeared $(X V, 3)$. It may be argued, however, that the delaying of the first coming into bearing of a young tree is not altogether comparable with the restriction of the crop of a tree which is already in bearing.

The difficulties in obtaining exact measurements of the relative behaviour of any two or more trees in consecutive seasons are considerable. The weight of fruit or the number of fruits may be recorded, but, unless the trees are absolutely similar in size, disposition of branches, situation, etc., which is impossible, the superiority of the one over the other as regards inherent fruiting capabilities may be misleading. On the other hand, the trees under observation may be classified by inspection, grouping them according to the extent which they are loaded with fruit, independent of their size, and then comparing the classification in one year with that in the following year. This method avoids errors due to differences in the size of the trees, but it has the disadvantage of being based on the judgment of the observer, and not on actual weights. This latter method was adopted in the case of one series of observations on trees at Harpenden, and the former in the case of the other series on trees at Ridgmont.

Whichever method of observation was adopted, the results were treated as follows : two selected trees were numbered I or 2 , according to which of them bore the heavier crop in any particular season; then, comparing the results in two consecutive seasons, if the order of fruiting had been the same (consecutive fruiting), the difference between the numbers given to the trees would be 0 , if the order had been reversed (alternate fruiting) the difference would be I; whereas if neither consecutive nor alternate fruiting prevailed, and the results were dependent solely on chance or on external conditions, the differences would, on the average, be 0.5 . An average difference, for instance, of 0.75 would be halfway between $I$ and 0.5 , indicating that the results were dependent 
on the alternating tendency to the extent of 50 per cent., and on chance fruiting to the extent of 50 per cent.

All the trees compared together were of the same age, and had received exactly the same treatment since they had been planted; in some cases they were compared in couples, in other cases the groups compared together consisted of three or six trees; in which latter cases the actual differences in the " numbers" given to the trees would not be the same as where only two trees were compared. But the percentage tendencies towards the different forms of fruiting need alone be given here; these are entered in the following table, the first series applying to dwarf apples and a few pears of several different varieties at Harpenden, the others to dwarf apples at Ridgmont. The dates to which the observations apply are entered in the second column, and the number of instances on which the results depend, in the third column.

\begin{tabular}{|c|c|c|c|c|c|}
\hline & & & Fruit & ing indicate & \\
\hline $\begin{array}{l}\text { Varieties. } \\
\text { ๘. Several . }\end{array}$ & Dates. & Instances. & Consecutive. & Alternate. & Chance. \\
\hline 2. Bramley. & - I904-I9I3 & $\begin{array}{r}332 \\
1050\end{array}$ & 12 & $\begin{array}{r}44 \\
0\end{array}$ & $\begin{array}{l}50 \\
88\end{array}$ \\
\hline 3. Cox . & . I898-I909 & 840 & I 6 & $\mathrm{o}$ & 84 \\
\hline 4. Potts . & - I897-I904 & г 266 & 5 & o & $95^{\circ}$ \\
\hline 5. Stirling. & . $x 897-1913$ & 366 & o & 6 & 94 \\
\hline 6. I I 7 varieties & s $1906-1913$ & 1207 & I 5 & o & 85 \\
\hline
\end{tabular}

There can be no doubt but that the results at Harpenden are very different from those at Ridgmont, for, whereas the former indicate a strong tendency towards alternate fruiting, the latter, with one exception, indicate a tendency, though a feeble one, towards consecutive fruiting. The Harpenden results must, however, be discounted to a certain extent, for the number of instances available was smaller, and the period over which the observations extended was shorter, than in any of the other cases: also, there were some preliminary observations made on these same trees in $1894-7$, when the results were of an opposite character, there being then 20 instances supporting alternate cropping, and 30 supporting consecutive cropping. This may have been, however, due to the youth of the trees at the time, for with trees which have not yet come into proper bearing, precociousness, or the reverse, in certain individuals, would increase the number of trees behaving in the same way in consecutive seasons.

The difference between the Harpenden and Ridgmont results cannot, however, be explained away on any of the above grounds, and is, no doubt, real. There are probably tendencies both to 
alternate and consecutive cropping, and, whether the one or the other predominates, depends on the conditions of soil, climate, etc. There can be no doubt, however, that the main factor determining the fruiting of trees in consecutive years is neither of these tendencies, but chance, that is, external conditions: with the Ridgmont results, this is potent to the extent of about go per cent., and, even with the Harpenden results, it is the predominant factor. That it should be more potent at Ridgmont than at Harpenden is easily explained, for the former of these stations is much more subject to spring frosts than the latter, and it is to spring frosts that the failure of crops is generally attributable.

In the case of the plantation of II7 varieties of apples, there were eight trees of each variety, and these were divided into pairs, one pair on the paradise stock, which had been very lightly pruned since they were planted, and one pair on the same stock, which had been more severely pruned; there were also two pairs on the crab stock, which had been treated in like manner. An examination of the results indicates that the tendency towards consecutive bearing becomes more marked as the age of the trees increases: thus, dividing the results into two periods, I906-9 and I909-I3, it was found that the tendency in this direction, taking all the trees together, amounted to 8 per cent. for the first period, and 26 per cent. for the second, and, further, the differences were uniformly exhibited by each of the four classes of trees: this is what might be expected, for any habit exhibited by a plant or animal tends to become more established as its age increases. As to the influence of the stock: trees on the paradise stock showed uniformly a smaller tendency towards consecutive fruiting (II per cent.) than did those on the crab stock (30 per cent.); whilst as regards pruning, the results were equally uniform, the tendency towards consecutive fruiting being less marked with the more severely pruned trees (Io per cent.) than with those very lightly pruned ( 26 per cent.). Apparently, the more a tree is left to natural development, the more does its fruiting become conditioned by extraneous, circumstances.

In the case of observations on a plantation containing different varieties of trees, it is probable that the influence of chance on the bearing of the trees will be unduly exaggerated; for some of the instances which counterbalance each other will consist of cases where the consecutive and alternate fruiting is attributable to the inherent properties of the trees, and not merely to the effect of chance or extraneous circumstances. From the results of general, though, perhaps, not very exact, observations 
made by fruit growers, it appears fairly certain that some varieties of apples do exhibit a marked tendency towards alternate fruiting, and, doubtless, there are other varieties which exhibit an equally marked tendency towards consecutive fruiting, though such instances, naturally, do not attract special attention. It would be necessary, therefore, in a strict examination of this subject, to treat the results with each variety separately. This has been possible in the case of four sets only ( 2 to 5 in the above table), and, consequently, more weight must be attached to these than to the results from those of the mixed plantations, I and 6 .

The good and poor fruiting of a plantation as a whole in alternate seasons, must argue against any tendency in the individual trees towards alternate fruiting, for it shows that this alteration of bearing has been determined by some extraneous circumstance which has affected all the trees alike; whereas if there were any innate tendency towards alternation, it would not be exhibited by different individuals in the same year, and, consequently, in a plantation consisting of many individuals, even of the same variety, an average uniformity of production would result. But that there is a tendency towards alternate fruiting of a plantation as a whole, there can be very little doubt, at any rate in the case of most of the trees at Ridgmont: the results obtained there with Stirling Castle, Bramley and in the Variety plantation are set out on the page opposite, the numbers giving the relative magnitude of the crops, compared, in the case of Stirling Castle, with the crop in Igoo as Ioo, and, in the other cases, with that of IgII as IOo. ${ }^{1}$

A plus or minus sign has been placed after the values showing whether they are above or below the means of the preceding and succeeding seasons. The extent to which these signs alternate, though not without some irregularities, is very remarkable, and when the results are examined on more strictly mathematical lines, it is found that the correlation between the behaviour in alternate seasons is undoubted: further, it appears that there is an independent correlation, not merely between consecutive seasons, but between any one season and those preceding it in the third and fourth places: so that we must conclude that fruit trees have, so to speak, long memories, and that their behaviour in any particular season is conditional, not merely by immediately antecedent circumstances, but by their previous behaviour during at least the three foregoing seasons. To

1 These values differ in some details from those given in the Fifteenth Woburn Report, having been recalculated on a slightly different basis. 
establish this correlation the series with Stirling Castle was the only one which was sufficiently extensive: the records with Bramley, it is true, extend over as many years, but up to Igo4 the crops were insignificant, and had evidently been insufficient to bring about any alternation in behaviour. Judging by general appearances, the results with Bramley, and also with the variety plots, should, if they can be continued for a sufficient number of years more, lead to even more marked results than those with

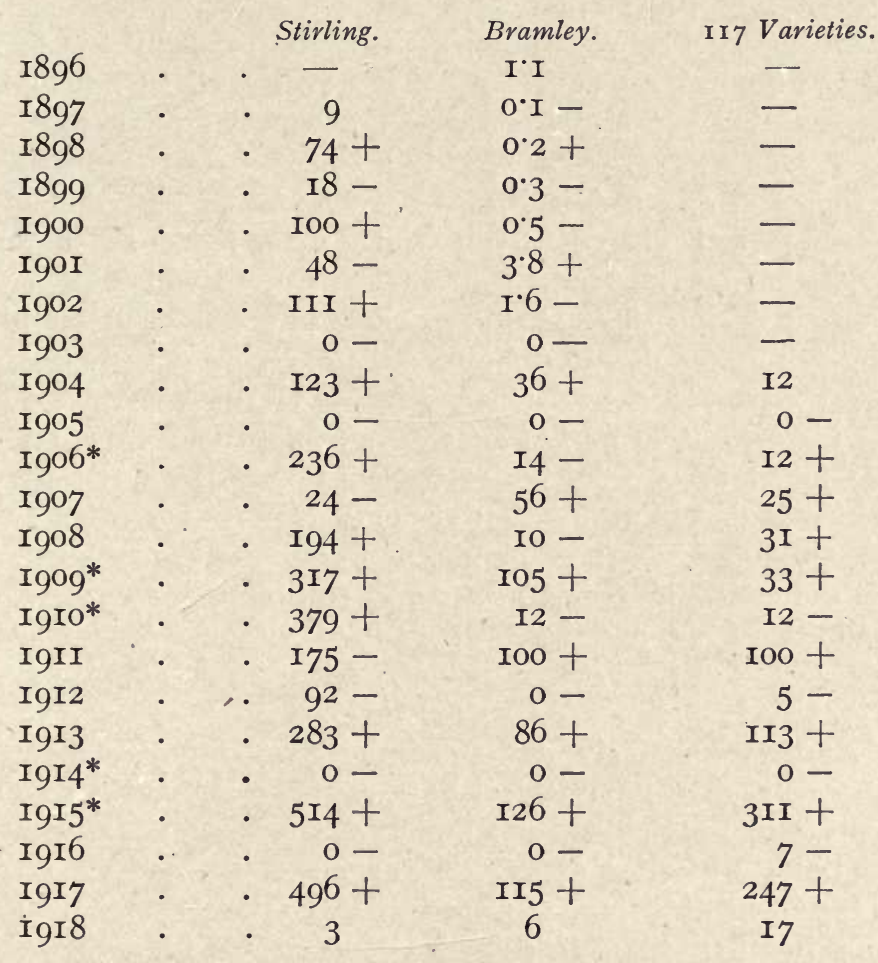

Stirling Castle have done, and they will, moreover, carry more weight with them, for they represent observations on a much larger number of trees.

The regular alternation of good and bad seasons becomes upset in the case of Stirling Castle during the period from Igog to I9II : such a break is, of course, inevitable, whenever exceptional climatic conditions occur sufficient to counterbalance the tendency to alternation which has been impressed on the trees. But it is probable that the irregularity in this case is really less than it appears to be, for the weight of the crops is not a complete 
measure of the drain caused on the trees by cropping; small, imperfectly developed fruits, though weighing less than fully developed ones, contain almost the same amount of food-material (see p. I06), and hence the number of fruits, as well as the weight of the crops should be taken into consideration. It has been found in this case that, when the number of fruits is examined, the alternation of + and - signs is complete throughout the whole series, with the sole exception of the occurrence of two consecutive - signs in IgII and IgI2.

One external condition which has been prominent in affecting the fruiting of trees at Ridgmont has been spring frost, and the first question which arises is whether there is any alternation in the incidence of frosts such as would account for the alternations in the good and bad fruiting seasons. An examination of the meteorological records from Igo6 to I9I5, failed to show any alternation of the kind, ${ }^{1}$ the five seasons in which such frost occurred during these years-marked by asterisks in the above list-exhibiting no alternation, and coinciding only in one case (I9I4) with a marked deficiency in the crops.

An examination of the general meteorological data has likewise failed to afford definite evidence that the alternation of fruiting is due to alternation of meteorological conditions. The data examined were: maximum and minimum air temperatures, earth radiation temperatures, earth temperatures, relative humidity of air, and rainfall; in each case the values for the four seasons of the year, as defined in Chapter XI (p. II7), as well as for two twelve-month periods, January to December, and May to April, respectively, were examined separately. The possibility of such meteorological data showing alternations in consecutive seasons should not be summarily dismissed, for, out of the thirty-six series of values, there are three which give an arrangement of + and - signs in which alternation is decidedly more frequent than it should be according to mathematical " expectation," whereas in the other thirty-three cases the values agree closely with this expectation: moreover, the three exceptions relate to connected phenomena, namely, the maximum and minimum air temperatures in winter, and the relative air-humidity, in winter also, the direction in which they all point being, that a cold, dry winter is favourable to a heavy crop in the following summer, a by no means improbable connection. Yet a stricter

1 These data had not been examined at a time when a paper dealing with the fruiting of trees was published in the Journal of Agricultural Science (VIII, I35), and the alternation in the fruiting was there attributed to alternations in the occurrence of spring frosts. 
examination of these results, whilst not disproving the existence of alternations, afforded no satisfactory evidence in its favour.

There can be but little question, however, but that the initial occurrence of a specially good or bad fruiting season must be the consequence of some meteorological condition, and that such conditions may also intensify the alternations of the fruiting, without there being any alternation in the meteorological conditions themselves: just as the swaying of the branches of a tree may be originated and intensified by wind, although there may be no regular alternations in the gusts of the wind. It would appear, however, so far as the investigation has been carried at present, that some such correlation does probably exist between the fruiting and certain of the meteorological factors, notably the mean maximum temperatures during the twelve months preceding the fruiting season.

Heavy cropping in one season must cause a drain on the resources of the tree adversely affecting its cropping in the succeeding season, and any external conditions which resulted in exceptionally heavy bearing one year (or the reverse) would initiate an alternation of good and bad fruiting seasons for the future, though the regular sequence of such seasons would be liable to be upset occasionally by exceptional external conditions, just as the records show that they have sometimes been upset. Moreover, though the majority of varieties would be affected in the same way by the external conditions, they would not necessarily all be so affected, so that some varieties might show heavy cropping in the seasons when the majority showed light cropping, and vice versa : the records prove that this, also, does occur.

It may appear at first sight that an alternation in good and bad fruiting seasons is inconsistent with the fact, previously established, that similar neighbouring trees show little or no tendency to alternate in their relative behaviour in consecutive seasons. There is, however, no real inconsistency here. The effect of meteorological conditions on the fruiting of a plantation may be very great indeed, ranging from the production of a crop which overloads the trees to breaking point, to the absence of any crop at all; and such differences would be ample to set up an alternation in future years; whereas in the case of two similar trees, growing side by side, and subject to the same conditions, the differences in their relative behaviour would, on the average, be very small, and quite insufficient to set up any appreciable alternation.

How far a thinning of the fruit in years of plenty may be 
expected to remedy alternations in the fruiting of trees, and to induce more regular cropping, was examined, by removing the blossoms or fruit from apple trees of four different varieties. In one case all the blossoms were removed, and in another they were all left; whilst in other cases the fruit was removed when it was of about half its full-grown diameter. The effect on the trees was measured by the growth which they made during the season. The results indicated that this effect was nil, unless the thinning was done on the blossoms.

\begin{tabular}{cccc} 
& \multicolumn{3}{c}{$\begin{array}{c}\text { Half- } \\
\text { grown }\end{array}$} \\
Relative Growth, I9I7 & $\begin{array}{l}\text { Blossoms. } \\
\text { removed. }\end{array}$ & Ionits \\
removed. & Fruits & left.
\end{tabular}

These results-which require further extension, rendered impossible in I9I 8 by the failure of the crop-are in harmony with the fact that the greatest drain on the tree occurs when the fruit is forming, not when it is developing (p. I06), but, of course, it bears only indirectly on the question of the effect of thinning in one season to increase the crop in the subsequent year, the probability being that if nothing but very early thinning is effective on the growth, nothing but such early thinning will be effective on the subsequent behaviour of the tree in other respects. 


\section{Chapter XIV}

\section{THE FLOWERING OF APPLE TREES \\ (Report XII, 35) ${ }^{1}$}

ONE of the plantations at the Woburn farm, which consisted, of apple trees of II7 different varieties, was utilised during the years I905 to I909, inclusive, for obtaining information on points connected with the order in which different 'varieties blossom. The trees were from eight to thirteen years old during the observations, and were all bush trees, four in each case being on the crab stock, and four on the paradise.

The date of blossoming was taken to be that on which any of the blossoms on the trees in question first became fully expanded. These dates for the earliest blossoming varieties were-

$$
\begin{aligned}
& \text { In I905, April } 29 \\
& \text { ", I906, " } 30 \\
& \text { " I907, „ } 27 \\
& \text { „, I908, May Io } \\
& \text {, I909, April } 28
\end{aligned}
$$

There was found to be so little difference between the dates of blossoming of the same variety on the crab and paradise stocks, that a separate analysis of the results in the two cases was superfluous : in 49 per cent. of the cases the difference was nil, whilst in 36 per cent. the paradise were the earlier, in the remaining I5 per cent., the crab. Where any difference existed, it was generally a matter of only one day, the maximum difference observed being four days.

In comparing the general results for different seasons, the starting point taken for each year was the earliest date of blossoming of any variety in that year : thus, if a certain variety was entered as blossoming on the tenth day, it meant that it blossomed nine days later than the variety which blossomed earliest in the same season.

1 Other observations on this subject have been collected by C. Hooper (Journ. Board of Agric., 1908, 678; 1910, 32; Journ. Roy. Hort. Soc., xxxvi, 559). 
The general results during the five years showed that the dates of blossoming bore no relation to the character of the fruit, i.e. whether the varieties were dessert or culinary; but that there was a distinct relationship between the date of blossoming and the date of ripening of the fruit-the earlier the ripening, the earlier the blossoming-though to this general rule there were many individual exceptions: for, as will be seen from the maxima and minima below, there is considerable overlapping in the dates of flowering of the different varieties.

\section{DATE OF BLOSSOMING}

\begin{tabular}{|c|c|c|c|c|c|}
\hline & & & \multirow{2}{*}{$\begin{array}{c}\text { Average. } \\
\text {. } \quad 6.8\end{array}$} & \multicolumn{2}{|c|}{ (Min. and Max.) } \\
\hline Early . & . & . & & $(2 \cdot I$ & II'2) \\
\hline Mid-Season & . & . & . $7 \cdot 7$ & $\left(4^{\circ} \mathrm{O}\right.$ & II 5) \\
\hline Late . & . & . & 94 & $\left(5^{\circ} \mathrm{O}\right.$ & $\left.I_{4} \cdot 6\right)$ \\
\hline Average & . & . & $8 \cdot 0$ & $(2 \cdot I$ & I $4 \cdot 6)$ \\
\hline
\end{tabular}

The earliness of flowering, however, can have no direct influence on the date of ripening of the fruit; between the dates of flowering of early and late varieties there is, on the average, a difference of only two or three days, and such a period would be a very insignificant fraction of the total period during which the fruit is developing. Early flowering and early ripening can only be correlated properties, and do not play the rôle of cause and effect.

On examining separately the results for different seasons, and setting out $\mathrm{B}$, the average difference in date of blossoming of the individual varieties as compared with the average date of blossoming of all the varieties in that same year; $\mathrm{C}$, the average

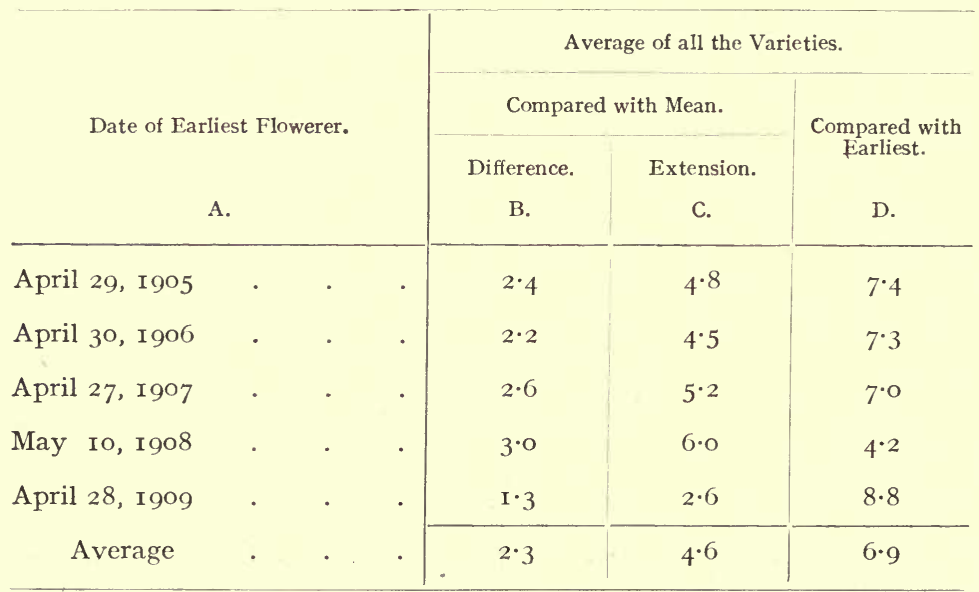




\section{THE FLOWERING OF APPLE TREES}

extent in days of the blossoming period, and $\mathrm{D}$, the average date to which the different varieties lagged behind the earliest blossomer, the results show considerable differences in different seasons, notably so in I908 and I909, and it was found impossible to connect these differences with any of the special meteorological conditions of the seasons in question, so that they must be ascribed to irregularities in the behaviour of the varieties themselves.

It is a question of practical importance, as well as of interest, how far the relative earliness or lateness of flowering of any particular variety is a constant quantity, and how far it varies according to the season. That some varieties are habitually early or late flowerers is accepted as a matter of general knowledge, but it has never yet been shown how far such properties may be relied upon as constant, or to what extent the bulk of varieties exhibit distinctive characteristics in this respect.

According to the analysis on p. I42, the Woburn records indicate a considerable amount of variation in the behaviour of different varieties in different years, and these records may be further examined from this point of view, for they supply, in the case of each variety, ten different pairs of years in which the relative dates of flowering can be compared. The following values were obtained for the average difference between the relative dates of flowering of individual varieties in any two years :-

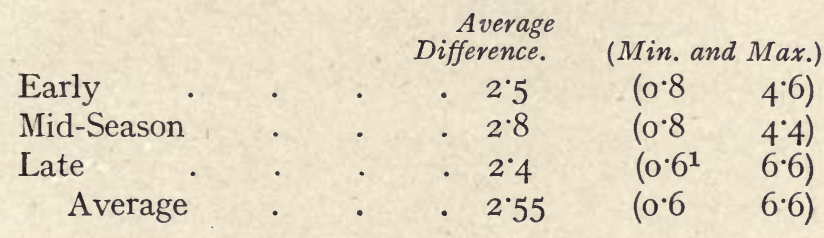

The values did not seem to be dependent at all on the class of apple examined, whether dessert or cooking, late or early, so that the average results need alone be considered, and these show that, if any variety flowers on a given relative date in one season, the probability is that it will flower within 2.55 days of that date (either earlier or later) in any other season : the difference, of course, may be much less, or much greater, the actual differences found with individuals in pairs of seasons ranging from o to 13 days, but rarely exceeding 8 or 9 days.

1 One variety in this case gave a difference of $o$, and another a difference of $0 \cdot 5$, but as only two seasons of flowering were available in those cases, they have been omitted. 
Such variation is considerable, and shows that it would be hopeless to attempt to arrange a number of varieties of apples in a series according to their order of flowering with any degree of precision. There is, undoubtedly, some tendency towards maintaining the same order of flowering in successive seasons; thus, the above values for the variation of the same varieties in different years are-

Average 2.55 days, Maximum I3 days,

and these may be compared with the variation of different varieties in the same year, which was found to be-

$$
\text { Average } 3 \cdot 3 \text { days, Maximum I7 days. }
$$

Both of the latter values are 30 per cent. greater than the former, so that we may say that, of the differences observed in the order of flowering of a collection of apples, ten-thirteenths are due to peculiarities in the season, and three-thirteenths to differences inherent in the varieties; or, that the season is three times more effective in determining the order of flowering than is any intrinsic peculiarity of the variety itself.

Besides the apples forming the subject matter of the above inquiry, records were taken of the flowering of 67 other varieties of apples from countries other than England.

In the case of the French apples, there was one variety (Grosse St. Clement) which blossomed very exceptionally late, and, if that be omitted, the averages for all the varieties of different nationalities come very close to each other, varying only from $9 \cdot 8$ to $10 \cdot 6$, thus affording no inclication that the country of origin has any effect on the date of blossoming. These values, however, are all appreciably higher than the average with the English apples, which was 8 . 


\section{Chapter XV}

\section{INSECTICIDES, FUNGICIDES, ETC.}

ANY detailed account of those investigations on the nature of certain insecticides and fungicides which have been undertaken at Woburn, would be somewhat out of place in the present work, and those who wish to inquire into the matter should refer to the original communications dealing with these subjects. The number of substances investigated, however, has not been large, and to supply a more general view of the subject, a quotation may be made, with the publishers' permission, from an article on plant-sprays, written by one of the present authors, for Sir E. Thorpe's Dictionary of Applied Chemistry.

\section{Plant-Sprays}

Spraying may be taken in a wide sense to embrace the application of solids, liquids or gases to plants, with the object of freeing them from insect or fungoid pests, or of cleansing them from dead bark, and such adventitious deposit or growth as interferes with the healthy functions of the plant.

\section{Solids}

Many liquid spray-fluids, or washes, contain solids in suspension, but it is only in a few cases that solids are used in the dry state; in such cases they are blown on to the plants by means of bellows, and the operation must be performed while the plants are wet with dew or mist, so that the solid may adhere to them.

Sulphur, in the form of flowers of sulphur, is applied extensively in this way to hops for destroying mildew and red spider, and in certain other cases it is applied mixed with lime. The nature of its action is at present obscure, but most probably depends on its being slightly volatile, for, when used in hot-houses, the most satisfactory results are obtained when it is painted on to the hot-water pipes, or otherwise heated. At the same time its effectiveness is increased by the presence of moisture, though it hardly seems possible that the traces of sulphuric acid formed under such conditions can account for its action. 
Hellebore, consisting of the root-stock and roots of Veratrum album (Linn.) and $V$. viride (Ait.), is effective in destroying caterpillars on gooseberries, etc. : it acts chiefly by poisoning their food, but is probably also injurious to them by contact with their bodies. As it is less poisonous than arsenical compounds, and loses its properties rapidly on exposure to air, it may be used with safety within a short time of the ripening of the fruit.

Pyrethrum, obtained from the ground heads and stems of Chrysanthemum (Pyrethrum) roseum (Web. et Mohr), and C. Marschallii (Aschers.), and C. (Pyrethrum) cinerariafolium ((Trav.) Bocc.), contains an oil which appears to act on insects only by contact. Besides being used in the dry form, it is used as a decoction, and also as a fumigant.

\section{Liquids}

A. Insecticides.-For a determination of the nature of the insecticide which is likely to be effective in any particular case, a knowledge of the life-history of the insect is necessary, to indicate at what period it is most vulnerable, and by what means it may best be combated. Insects which chew the leaves are best dealt with by poisoning their food, whilst others which pierce the leaves and bark, extracting the juices from below the surface, are best attacked by the application of some corrosive substance to their bodies (p. I4). The most effective procedure, where practicable, is to destroy the eggs of the insect : for this a corrosive substance is required, and such can only be applied to the plants while these are in the dormant condition. For facilitating insect eggs being reached by a fluid, as well as for reducing the number of crevices in which insects can deposit their eggs, the application of a detergent wash in the winter, to remove dead bark, moss, lichen, etc., from the trees, is an important adjunct to an insecticide (p. I4).

Many of the most popular insecticides and fungicides have come into use by accident, and, although practical experiments have introduced considerable improvements in them, much uncertainty still prevails as to the method of their action. It is remarkable that in very few cases has science provided satisfactory substitutes for these chance selections.

The chief classes of insecticides are (I) vegetable poisons consisting of alkaloids, (2) soft soap, with or without excess of alkali, (3) sulphur, and sulphides, (4) phenol, (5) paraffin oil, (6) arsenical compounds, (7) lime.

(I) Of the vegetable poisons, hellebore and pyrethrum have 
already been mentioned, and these may be sprayed on to the trees in the form of a 3 or 4 per cent. admixture with water or dilute paraffin oil emulsion (p. I52). If a decoction is used it should not be boiled.

Quassia with soft soap is much used for destroying aphis. The wash is made by boiling $\frac{1}{2}$ to 3 lbs. of chips of the wood with Io gallons of water, and adding $\frac{1}{2}$ to 3 lbs. of soft soap.

Nicotine appears to be by far the most effective of the vegetable insecticides. A decoction of "denatured" tobacco-which contains about 70 per cent. of tobacco mixed with sulphur, asafœetida and flour-may be used, but owing to the great variation in the nicotine-contents of tobacco, it is better to use nicotine itself. The results obtained at Woburn (pp. 223, 224) show that a solution of 0.075 per cent. is very effective for aphis, apple psylla, etc. : it is well to add to the solution 0.5 per cent. of soft soap.

It is noticeable that various alkaloids, such as aconite, hyoscyamine, nux vomica, etc., which are highly poisonous to vertebrate animals, have but little action on insects (p. 226).

(2) Soap is generally used in connection with other substances, as in the instances just mentioned, but it is also used effectively alone for killing certain aphides, such as those attacking roses. It is probable that its action in such cases is due to its clogging the breathing apparatus of the insect: its low surface tension also enables it to wet bodies more effectively than other sprayfluids, though, it may be remarked, a similar action in the case of saponin does not appear to increase the effectiveness of substances to which it is added (p. I95). Soap is also largely used as an agent for emulsifying paraffin oil. In connection with this, and especially if alkali is added as well, it is used for the destruction of insect eggs, although its chief function under such circumstances is that of a detergent (pp. 107, 202).

(3) Sulphur is generally used in the solid condition, as mentioned above, although it occasionally is made into a liquid wash with water and other substances. As an insecticide, and still more as a fungicide, the sulphides play an important part. The origin of their use seems to have been the application to trees of a liquid used as a sheep dip, and known as the lime-sulphur-salt wash (California wash) or the lime-sulphur-soda-salt wash (Oregon wash). There are many recipes for making these, the more usual being to boil together for 45 minutes 3 to $6 \mathrm{lbs}$. of quicklime with $3 \mathrm{lbs}$. of sulphur, $3 \mathrm{lbs}$. of salt, and a limited quantity of water, the resulting liquid being afterwards diluted to ten 
gallons. In the Oregon wash, about I lb. of caustic soda is added in addition to the above materials, and the heat generated on adding water to the mixture is sufficient to obviate the application of external heat. A wash of this strength can be used only on dormant trees, and is then more effective when applied hot; but at a lesser strength it is now being used on trees in leaf, chiefly as a fungicide. The wash always contains a considerable proportion of unaltered lime, the sulphur going into solution as calcium thiosulphate and pentasulphide. The latter undergoes rapid change, even in absence of air, the pentasulphide becoming converted into thiosulphate with the liberation of sulphur, and the thiosulphate into sulphite and more free sulphur: the sulphite ultimately oxidises to sulphate. Where caustic soda is used in its preparation, the sulphur reacts with it in preference to the lime. The method of operation of this wash is uncertain. It is used habitually in the Western States of America for combating San José scale, and according to certain experiments, none of the substances which it contains, when used separately, have any effect on the scale; according to other authorities, a mixture of potassium sulphide and lime is as effective as the wash. It appears that its action is in part mechanical, the sulphur deposited from it on to the trees glueing the scales to the bark, and preventing the egress of the young insects. What function the salt performs is obscure, and, according to some investigators, it may be omitted without detriment. Owing to the excess of lime present in it, and to the destructive action of sulphides on lichen, etc., the wash is a good detergent.

Lime and sulphur mixed with water without heating are sometimes used for aphis, mites and red spider, being preferable to sulphur by itself; such a mixture always contains some products of the interaction of the two substances. Calcium sulphide solution is also used for the same purpose, but potassium sulphide is preferable, as soft soap can be added to it without causing decomposition: 3 to Io ozs. in Io gallons are the proportions recommended. It can also be mixed with an emulsion of paraffin oil.

(4) Phenol, either dissolved by itself in water, or with the addition of soap or glycerol, has been tried as a general insecticide, without much success; but a solution of carbolic acid soap is very effective for certain aphides, as well as for mildews (e.g. of roses), and phenol figures as one of the ingredients of several proprietary insecticides which are now in use.

(5) Paraffin oil has been found to be a most valuable insecticide, 
and it has formed the subject of some considerable inquiry at Woburn, an account of which will be found below (p. I52).

(6) Arsenical compounds. - These supply some of the most powerful insecticides for leaf-eating insects. An aceto-arsenite of copper (Paris green), made by the action of arsenious oxide on verdigris, was one of the first of these substances to come into use, but it is liable to injure the foliage, the leaves becoming scorched, and often falling: this action is intensified if the Paris green contains excess of arsenious oxide, as it often does, and it is well to guard against this by the addition to it of an equal weight of lime. Calcium arsenite, made by boiling arsenious oxide with lime, is also used, although more frequently in the form of London purple, which is a waste product from dyeworks, containing 75 per cent. of the arsenite. The compound which has come most into favour of recent years, chiefly on account of its causing very little leaf-scorching, is lead arsenate, also called gypsine, from its being first used for the gipsy-moth caterpillar. The results of an inquiry into the nature and action of this compound will be found on pp. I69, 227.

(7) Lime has been used of late years together with salt, as an insecticide in special cases (apple psylla). The lime-salt wash most recently recommended is made by slaking $\mathrm{I}_{5}-20 \mathrm{lbs}$. of lime, adding $2-3 \mathrm{lbs}$. of salt, $\frac{1}{2}-\mathrm{I} \mathrm{lb}$. of water-glass, and making up to Io gallons. It is applied to the trees, as hot as possible, a few weeks before the buds open. The wash appears to act, partially by destroying the eggs, and partially by glueing them up and preventing the egress of the insects. What function the salt performs it is difficult to see. Strong brine will destroy insect eggs by depleting them of their liquid contents, but the salt is hardly present in this wash in sufficient proportion for such an action (p. 2Io). As a detergent for removing moss, lichen and dead bark from trees, which is a most important operation in ccmbating any insect attack, lime is inferior to a stronger alkali such as caustic soda. This is one of the subjects which has been examined at Woburn (p. I68).

B. Fungicides.-Sulphur, and the sulphides previously described, are important fungicides, the latter being of special use in the case of surface moulds or mildews. Phenol and the salts of iron appear to have but very feeble fungicidal properties, and mercuric chloride, although of great value in the laboratory, has not been successfully applied to plants. By far the most important fungicide appears at present to be copper, and it has been applied in a great variety of forms, but these all group 
themselves under the main headings of basic sulphates, and basic carbonates of copper. Both of these have been examined very fully at Woburn, and the results are given in the following pages (pp. I7I, I83).

\section{Gases}

Hydrocyanic acid is used in the fumigation of hot-houses for the destruction of plant lice, etc. ; it is also used in many countries for disinfecting imported nursery stock, and in California it is applied to peach trees in plantations for scale, each tree being covered with a tent during the operation. For each Ioo cubic feet of space, $\frac{1}{3}$ to $\frac{1}{4} \mathrm{oz}$. of "lump" potassium cyanide is generally used, and for each ounce of the cyanide, one liquid ounce of acid, previously diluted with 3 to 4 ounces of water (see p. 220).

Hydrocyanic acid is liable to cause some injury to young plants, and in fumigating these they should not be exposed to the direct stream of gas as it ascends from the generating vessel. Its action in destroying insect eggs is, according to the Woburn results, unsatisfactory, and in the case of green-houses it is often necessary to repeat the fumigation after a fortnight's interval, to destroy insects which have hatched out from the eggs (pp. 206, 2I9). For freeing nursery stock from woolly aphis, an advantageous substitute for fumigation is to immerse the trees bodily in water at $\operatorname{II} 5^{\circ} \mathrm{F}$. for Io minutes (p. 220).

Sulphur, as already mentioned, probably acts as an insecticide owing to its volatility, and it is often used for fumigating houses by heating it, taking care not to let it catch fire. Smouldering tobacco and pyrethrum are used in the same way. 


\section{Chapter XVI}

INSECTICIDES, FUNGICIDES, ETC. (continued)

\section{Paraffin ANi Paraffin Emulsions (Reports, VI, I6, I35, I96; VIII, I8; X, 7, I3)}

(I) Their nature, and their effect on trees.

Kerosene, or paraffin oil, was used for the treatment of trees almost as soon as it came into use for lighting purposes. The first definite recommendation for its application to plants seems to have been made in 1865 , the object being the destruction of scale on orange and other trees.

Under the name of paraffin, as commonly understood in this country, we may be dealing with a variety of mixtures of some 20 or more different chemical compounds, these mixtures differing from each other very widely as regards composition and essential properties. With the exception of certain oils obtained in Scotland and elsewhere by the distillation of shale - to be avoided by fruit growers, as containing sulphur and other compounds, which would probably be injurious to their trees-the paraffins on the market are natural products imported from America, Russia, Roumania, Borneo, etc., and consist chiefly of compounds of carbon and hydrogen belonging to one particular series of hydrocarbons, known scientifically as the paraffin series. The most volatile of them include benzine, naphtha and petrol, which contain little or no oil with a boiling point higher than about $150^{\circ} \mathrm{C}$.: the least volatile include such substances as vaseline, petroleum jelly, paraffin wax, and some lubricating oils: the intermediate class include the oils known as lighting oils, petroleums, kerosenes, solar distillates, etc.; these vary considerably in composition, from oils which distil entirely below $300^{\circ}$. C. to others of which only a fraction will distil below this temperature. Even if the fruit grower confines himself to the oils of this intermediate type, he may be using one which is so volatile that it does not remain on the trees long enough to do any good, or else one which contains so large a proportion of non-volatile constituents, that the result will be much the same as if he had 
smeared his trees with vaseline. Yet, this point appears never to have been considered in this country, and only to a limited extent elsewhere, chiefly in the direction of comparing the action of " crude oil" with that of " kerosene," which, in the absence of details as to the composition of the oils used, can afford but little guidance.

So far as undiluted paraffins are concerned, their use in this country has practically been abandoned. In applying them in a diluted form, the oil and the water were originally sprayed on to the trees simultaneously, through separate jets, and it was not till 1878 that emulsions of kerosene and soap were recommended to the public (by Cook, in America), although it is probable that the "mixtures" used by George Cruikshank, of Whitinsville, Mass., since 1870 , were in reality emulsions.

The part played by the soap in an emulsion had been assumed to be merely a physical one, and the proposal has recently been made to use flour, scorched flour, or lime, as a substitute for it. But the Woburn results show that the soap in the emulsion has an appreciable insecticidal action, and that the proportion of it used is by no means a matter of indifference.

The multiplicity of recipes recommended in this country for making emulsions, renders it evident that they have been formulated on little or no principle, and are not the outcome of actual investigation. A casual search in the literature of the subject brought to light 24 different recipes for emulsions, the strongest containing 80 times as much paraffin as the weakest, with the proportions of paraffin to soap showing a 200-fold variation. Of the 24 recipes, no less than I3 were issued by the same authority-the Board of Agricultureonly to be withdrawn within a year or two of their issue (VI, I9). It is, no doubt, necessary that emulsions of different strengths should be used for different purposes and under different conditions, but research has not been so complete yet as to show that every insect requires a special strength of emulsion, or that its requirements vary from year to year; and the only conclusion must be that such recommendations were based on the mere fancies of those advocating them, and not on the requirements of the case as determined by direct experiment.

Some attempt has been made at Woburn to remedy this state of confusion, by a careful examination of the action of various emulsions, as well as of undiluted paraffin and other substances, on the mussel scale, of which a more detailed account will be found in Chapter XX: at the present moment attention may 
be confined to the results so far as they bear on the question of the action of paraffin itself as an insecticide.

Undiluted paraffin is considered in this country, and very rightly so, to be too dangerous a substance to apply to fruit trees, even in the dormant season, and even the most carefully selected oil cannot be used, as a rule, on apple trees in leaf. As regards insecticidal value, measured by the destruction of the eggs of mussel scale, it was found that the more volatile oils-naphtha, petrol, as well as wood spirits and methylated spirits-were practically useless, and that for a petroleum oil to be effective, at least 40 per cent. of it must have a boiling point of over $250^{\circ} \mathrm{C}$. This condition is fulfilled by most of the oils used for lighting purposes, and to a more satisfactory extent by a heavier oil, known as solar distillate, which at the time of these experiments was much cheaper than the lighting oils ${ }^{1}$ (VI, 75).

The dependence of the results on the boiling point of the oil used is illustrated by the mortality caused in the eggs by using oils of different degrees of volatility : thus-

$\begin{array}{ccc}\text { Light Oils. } & \text { Medium Oils. } & \text { Heavier Oils. } \\ \text { Benzine, Petrol, etc. } & \begin{array}{c}\text { Ordinary } \\ \text { Lighting Oils. }\end{array} & \begin{array}{c}\text { Crude Petroleum, } \\ \text { Solar Distillate. }\end{array} \\ \text { - II } & 88 & 97\end{array}$

$\begin{array}{llll}\text { Mortality . } & \text {. II } & 88 & 97\end{array}$

Also by applying the different fractions of a particular oil obtained during the distillation of sample of it-

Fraction boiling at-

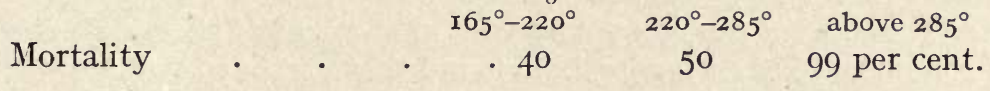

When this same oil was used in the diluted form of an emulsion, the results, were, naturally, less satisfactory, and showed no probability of becoming more so until the proportion of oil was raised to about 25 per cent.; thus with-

Emulsions with I per cent. Soap and

$\begin{array}{rrr}\text { I } & \text { per cent. of oil } \\ 2 & \text {, } & , \\ 4 & \text { " } & , \\ 6 & \text { " } & , \\ 8 & \text { " } & , " \\ \text { I0 } & \text { ", } \\ \text { I5 } & , "\end{array}$

Mortality.

o per cent.

$\begin{array}{cc}\text { o } & , \\ \text { o } & , \\ \text { I5 } & , \\ \text { I3 } & , \\ 40 & , \\ 43 & ,\end{array}$

1 Its initial boiling point was $240^{\circ} \mathrm{C}$., 94 per cent. of it boiling above $250^{\circ} \mathrm{C}$. 
However satisfactory undiluted paraffin might be as an insecticide, its action on the trees had to be considered. To examine this, a number of apple trees were painted with various oils on dates between March Io and April 3. In all cases much damage was done, extending from the destruction of the fruit buds to the injury of shoots; and the damage was on the whole greater, the less volatile the oil. With the lighter oils, though the fruit buds were injured, the wood of the tree and the growth buds did not seem to have been much affected, and, consequently, considerable growth followed the treatment, though it did not start till a late date. The weather conditions-cloudy or clear-at the time of applying the oil, did not have any appreciable effect on the results, as they are sometimes stated to have, the mortality of the fruit buds being 89 per cent. with cloudy weather, and $9 \mathrm{I}$ per cent. with clear weather; but warm, windy conditions following the application, reduced the damage by hastening the evaporation of the oil, and hence a later date for such treatment would generally be preferable to an earlier one. It was very noticeable that, for weeks after the application of the paraffin, the trees were continually wet, drops of water often hanging on the branches; evidently, when any moisture had been deposited on the tree, the paraffin left on the bark had spread over it, and prevented its evaporation. This condition of continual wetness would, no doubt, be sufficient in itself to account for much of the injury (VI, I35).

The effect of dipping young trees in oil was also examined, as a consequence of its having been found that undiluted paraffin was one of the most effective remedies for woolly aphis. Some stocks affected with this pest, had been worked, and were subsequently lifted, and dipped bodily into paraffin, being left in it for five minutes, and then exposed for another thirty minutes before being replanted. Where the oil used was the less volatile solar distillate, all the trees were killed; where it was lighting oil, two-thirds of the scions and 8 per cent. of the stocks were killed; but where petrol was used, the mortality of the scions was only Io per cent., and the surviving trees showed in the succeeding year a vigour of growth as good as that of the untreated trees. Such treatment proved to be quite fatal to the aphis (p. 220), and, therefore, taking care to use petrol, may be safely and effectively applied to nursery stock $(\mathrm{X}, 7)$.

In view of the disastrous effect of spraying fruit trees with paraffin oil, even when the trees are in the dormant condition, 
it appeared almost superfluous to examine the effect of such a spraying on them while still in leaf : yet observations were made on the subject, and proved to be of some interest. As in the previous case, the object was to ascertain whether under any circumstances such a treatment might be applied for the destruction of woolly aphis.

The oils were applied to the trees (apple trees) by means of a pneumatic sprayer giving a very fine mist. The general results were, that the heaviest and lightest oils used both did much damage, but that those of intermediate volatility - the lighting oilswere comparatively innocuous. With the heavier oils, such as solar distillate, the damage was not noticeable at first, and did not attain a maximum till five days later, when the leaves and some of the shoots were found to be killed, the other shoots being flabby, though these subsequently recovered, and gave rise to fresh leaves. With the lightest oils (petrol, etc.) the maximum damage - over 90 per cent. of the leaf surface being affected--was noticeable within a few hours of the spraying, and remained at this maximum for a month, after which the shoots recovered, and new growth started. It seemed probable that in this case much of the damage was attributable to the low temperature resulting from the evaporation of the volatile oil, for, with oils of intermediate volatility (lighting oils) no damage was visible till from five to ten days after the spraying, and the maximum-reached only after one to two months-did not entail injury to more than one-quarter or one-third of the whole leaf-surface $\left(X, I_{3}\right)$.

It is, therefore, quite possible to spray trees in leaf with a lighting oil without any serious consequences; but, at the same time, such treatment should be regarded in the light of an heroic remedy, which it would be well to apply only to trees which are of no great value.

One further point of interest was, that it is better to apply the oil undiluted than diluted in the form of a strong emulsion. To be effective in killing woolly aphis, the emulsion would have to contain 50 per cent. of oil, but such an emulsion was found to do more damage to the trees than undiluted paraffin. A similar conclusion was deduced from experiments on the black currant gall mite (p. 2I5). Doubtless the soap and water in the emulsion retarded the evaporation of the oil, so that it had a longer time during which to act on the foliage (VIII, I04).

In the treatment of nursery stock with paraffin, the injury was much more noticeable on the scions than on the stocks, indicating 
that the roots were comparatively little affected by the oil : and this conclusion was borne out by experiment on the application of paraffin to the soil in which trees were growing. A number of apples of seventeen years of age were selected, and the ground round them sprinkled with paraffin, either in January or in March, using solar distillate, a lighting oil or petrol in various cases. In every instance the presence of the paraffin in the soil was evident for several months afterwards, yet the trees did not appear to have suffered in any way, either in growth or cropping power $(\mathrm{X}, 22)$; indeed, in one case, where observations were extended to the second year after the application, the cropping appeared to have been increased by the treatment. Such a result is quite in accordance with what might be expected from the action of paraffin and other antiseptics in increasing the fertility of the soil (p. 249). In these experiments the amount of oil applied varied from one pint to two quarts per tree, and two quarts would be much more than would be likely to reach the ground when the tree was sprayed even with undiluted oil, so that no injury to the soil need be expected from such spraying, and still less, from spraying with a paraffin emulsion.

(2) The nature of emulsions (VI, I96; VIII, I8; App., p. xxi).

When paraffin oil is churned up with water, by means, for instance, of a garden syringe fitted with a rose jet, it is broken up into minute globules, which, however, almost at once recoalesce to form an unbroken layer of the oil. But if the water contains a little soap, the globules do not thus coalesce, and, as a result, the liquid remains milky in appearance. On leaving it at rest for some time, these globules rise to the top, just as cream rises from milk, leaving, eventually, the excess of soap solution as a more or less clear liquid at the bottom; rarely quite clear, however, for some of the oil globules are so small that they remain permanently suspended in the liquid. Those that rise to the surface are found to differ in size according to the nature of the oil used, and other circumstances, but are generally about $0.0075 \mathrm{~mm}$. in diameter, which is double the diameter of the globules in the cream from milk. A mass of globules, whatever their size may be, provided they are all of the same size, will occupy 74 per cent. of the volume of the cream formed, the remaining 26 per cent. representing the interstices between the globules, occupied by the liquid in which they are floating, and this is (approximately only, owing to the lack of uniformity in size) the composition of the cream which rises from an emulsion of 
paraffin in a soap solution. A concentration slightly less than this (say, 67 per cent.) is the best to aim at in making a stock emulsion, to be diluted with water when required for spraying. One volume of a I or 2 per cent. solution of soft soap should have two volumes of paraffin added to it in small quantities at a time, churning the mixture between each addition. It is preferable, but by no means essential, that the soap solution should be warm. Emulsification appears to occur suddenly, and its occurrence is recognisable by the increased difficulty in working the syringe. A stock emulsion of the above strength will require dilution with from to to 50 times its volume of water before use.

Even from a 74 per cent. emulsion, some watery liquid will generally separate after a time, for the globules constituting the cream are lighter than the water, and press upwards, becoming somewhat distorted from their spherical shape in order to pack closer together. Such closer packing may be carried much further by churning the cream with more paraffin; the cream becomes thicker on each addition, till it is almost șolid, like a blancmange, and eventually forms a translucent jelly with a bluish tinge. An emulsion of this sort containing as much as 99 per cent. of paraffin has been obtained. The particles of paraffin present in it can then no longer be spherical, but dodecahedra, closely fitting against each other, and separated only by the thinnest film of soap solution; under the microscope its structure is no longer visible. On exposing it to dry air, the film dries up, and the whole is transformed into a mass of liquid paraffin; whereas on exposing it to moist air, or on putting it into water, it becomes opaque, the particles of paraffin resuming their globular form.

The reason why a soap solution, and not water, will allow of paraffin becoming emulsified in it, had always been assumed to be that the soap alters what is known as the surface tension between the water and the oil; but the Woburn results showed that this explanation is insufficient, for scores of instances were found where emulsification occurred without any alteration in surface tension, and the results with soap-solution itself disprove such a theory, for the alteration in surface tension progresses regularly as the amount of soap is increased, whereas the power of emulsifying does not; it disappears entirely when the soap present exceeds a certain limit. Thus, to get an emulsion containing 75 per cent. of paraffin, the soap solution must not contain more than $\mathrm{r} \cdot 8$ per cent. of soap; to get one with 40 per cent. of paraffin, the limit of strength of the soap solution is 
25 per cent.; these limits, however, varying with the nature of the soap.

A more satisfactory explanation of emulsification was found in the view that it is due to the presence of minute, solid particles in the liquid, such particles being, according to well-known laws, attracted by the oil globules, and forming a coating or pellicle over them, thus preventing them from coming into contact with each other and coalescing-unless, however, the particles are wetted more easily by the oil than by the water, for in that case they will enter the globules instead of remaining on the surface of them : this is so with sulphur, purple of Cassius, etc., which, though very finely divided, will not emulsify paraffin. It was found that the mere addition of a very finely divided insoluble substance to water rendered the emulsification of paraffin possible, and amongst such substances the basic sulphates of copper, iron, and other metals were conspicuous. When any such emulsifier was deeply coloured, it was possible to see under the microscope the dark coating of particles enclosing the globules. Just as this coating prevents the globules from coming into contact with each other, so it prevents them from coming into contact with, and "wetting," the vessel containing them: it is one of the most certain tests that emulsification has occurred to find that, though containing so much oil, the liquid does not make the vessel oily, any more than milk does.

To render such an explanation acceptable, there must be solid particles present in a soap solution, since it produces emulsification; and such particles certainly are present, for soap in water always decomposes partially, becoming cloudy through the separation in minute particles of an "acid" soap. Such a separation, it may be mentioned, occurs less readily in strong solutions, and this explains why a soap solution, when above a certain strength, will not emulsify oil.

\section{(3) De-emulsification. Emulsions with solid emulsifiers.}

Anything which will destroy the coating of solid on the oil globules must result in de-emulsification; a trace of acid will do so in most cases, though not if the solid is insoluble in acid, as, for instance, where finely divided clay is the emulsifier. With a soap solution the solid present is not in a very stable condition, but is continually redissolving, and then separating again from the liquid, the result of which is that the globules occasionally find an opportunity of coalescing, and hence in time 
an emulsion made with soap generally becomes de-emulsified. De-emulsification, once it begins, progresses rapidly.

Spontaneous de-emulsification does not occur with solid emulsifiers, such as the basic sulphates, and emulsions made with them may be kept for years without any visible change. Another great advantage which they possess is that a caustic alkali may be added to them, so as to increase their detergent properties, without causing de-emulsification; with a soap emulsion the addition of caustic soda to soft (potash) soap converts this into the nearly insoluble, flocculent, soda soap, and destroys the emulsion; whilst the addition of the more expensive potash causes gelatinisation unless the emulsion is very dilute.

It was, indeed, an endeavour to obtain an alkaline emulsion which led to the discovery of the power of finely divided solids to act as emulsifiers. A mixture of lime with paraffin had been used in the United States, under the name of limoid, for spraying purposes; but an examination of such a mixture showed that it was not really a true emulsion; the globules of oil in it were comparatively large, and irregular in shape, appearing to be only entangled in the particles of lime: when water was added to it, some of the lime settled to the bottom, carrying with it a little of the oil, whilst the bulk of the oil rose to the surface, carrying with it some of the lime. Moreover, the mixture, unlike a true emulsion, made the containing vessel oily. Such mixtures have been termed quasi-emulsions, and many fine powders besides lime may be used to make them. The addition of caustic soda to a soap emulsion converts it into such a quasiemulsion, the texture of which varies considerably with the nature of the soap used. In all quasi-emulsions there are some particles present sufficiently small to act as true emulsifiers, hence every gradation is possible between a true and a quasiemulsion. It was found, in the case of the lime mixture, that the addition of some copper or iron sulphate resulted in the formation of a very different product, namely, a very perfect true emulsion, which does not render the vessel oily, and which is not separated at all into its components on the addition of water, but which rises or sinks as a whole, according to the proportions and densities of the substances forming it. It was the basic sulphates, formed by the action of the lime on the sulphates, which acted as emulsifiers of the paraffin. To obtain the most perfect emulsions, no excess of lime should be present; clear lime water should be added to the solutions of the sulphates, and on churning paraffin with the resulting 
mixture, perfect emulsification occurs at once. To such emulsions caustic soda may be added without causing decomposition, at any rate in the case of the emulsion with iron sulphate. With the copper sulphate emulsion, decomposition does occur, but only gradually, and only if the emulsion is concentrated: the cause of this decomposition has been ascertained, but it is not necessary to explain it here. In both cases it is preferable, if a strong stock emulsion is required (i.e. of about ten times the strength indicated below), not to add the caustic soda till the emulsion has been diluted preparatory to its being used, for, even in the case of the caustic iron emulsions, de-emulsification is liable to occur on shaking when the emulsions are very concentrated. Where a fungicidal effect is not required, iron instead of copper sulphate should be used, and in all cases a comparatively high boiling paraffin oil, such as solar distillate, is preferable to ordinary lighting oil.

For use in summer as a fungicide and insecticide, where no caustic action is required, the following recipe is given-

\begin{tabular}{|c|c|}
\hline Copper sulphate & \\
\hline Water . & \\
\hline Clear lime water & \\
\hline Paraffin . & • \\
\hline
\end{tabular}

The sulphate is dissolved in the water, and the solution added to the lime water, after which the paraffin is churned up with the mixture. The resulting emulsion will be of about the same density as water, and will, therefore, show very little tendency either to rise or to sink. This emulsion can be manufactured of ten times the strength indicated, and diluted with water when required.

For winter use, as a fungicide and detergent, the following are the proportions recommended-

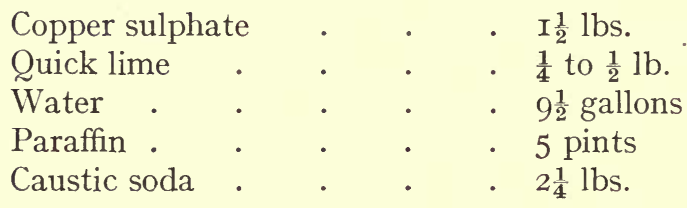

The emulsion is made as in the previous case (though the lime water need not be clear), the caustic soda being added just before use. 
When a fungicidal action is not required, the above recipe may be altered to-

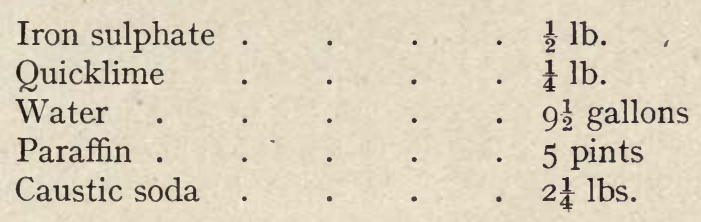

Both these emulsions may be made in a concentrated form (ten times the above strengths), requiring dilution and the addition of the caustic soda before use.

The iron in the iron emulsion, after it is sprayed on to the trees, oxidises, and becomes brown, but this does no harm whatever.

When speaking of a detergent action on fruit trees, it must be remembered that something different is meant from a detergent action on the human body, etc. In the former case, the cleansing refers to the removal of moss, lichen, dead bark, etc., and for this a caustic alkali is required; in the latter, it refers to the removal of grease and dirt, in doing which soap is most effective. The detergent action of soap is attributable to several causes, and one of those most recently brought to light ${ }^{1}$ is its power of actually dissolving and combining with oils; soft soap, when worked with paraffin, etc., will absorb as much as its own weight of the oil, and, when the resulting magma is left with water, part of the oil separates as an emulsion, but part (sometimes the whole of it) goes into actual solution. It is improbable that in the case of spray-fluids sufficient oil is dissolved to affect the action of the fluids, but the possibility that it may be so should be borne in mind when considering their effects.

In a patent insectide, known as paranaph, it is claimed that the addition of naphthalene to soap increases the power of the latter to take up paraffin, and that, on adding water, a very superior emulsion is obtained. It was found, however, that such statements were not supported by facts; that the greater part of the naphthalene-which dissolves to a certain extent in soft soap-separates out on dilution, and that its presence actually reduces the amount of paraffin remaining in solution.

(4) Nature of the action of paraffin.

How paraffin acts on the cells or tissues of vegetables or insects,

1 Pickering, Trans. Chem. Soc., I9I7, Vol. III, p. 86. 
is a matter of speculation at present. The paraffins as a class are remarkably sluggish in their chemical action, their name, indeed, implying this (parum, affinis); yet they are not so inert as is generally supposed. They are capable of acting, like other antiseptics, on the organic compounds in the soil, increasing the proportion of these which are soluble in water (p. 252 and IX, App. p xxvii), and, as stated above, it has been found that they combine with soaps, which are salts of various organic acids. It is probable that some combination of this sort occurs between the paraffin and the substances present in the cells, or in those constituting the walls of the cells, and that a reduction, or deoxidation, follows. The deoxidising action of paraffins is supported by the fact that ordinary paraffin oil will reduce the higher oxides of iron to the lower oxides. If an emulsion is made with paraffin by means of a basic sulphate of iron and excess of lime, this basic sulphate becomes partially oxidised by the air, and produces a higher oxide of iron, which is almost black; but on being left to stand for some time in a closed bottle, it loses its dark colour, owing to the paraffin gradually deoxidising it back to ferrous oxide.

Any action of this sort would be much facilitated by the ease with which paraffin wets substances, and penetrates vegetable matter (and presumably, therefore, animal matter), even when no actual wetting can be observed. Thus, it was found that when a thick-skinned Tasmanian pear was smeared with even the semi-solid paraffin known as vaseline, this, in a few weeks, penetrated the fruit sufficiently to give the whole of it, even to the core, a very strong oily flavour. The liquid paraffins acted more quickly, both on apples and pears, even after a temporary immersion, and they hastened the decomposition of the fruit as well. Thus, some observations were made by smearing fruits of Scarlet Nonpareil apple with various oils on December I4, and observing the intervals which elapsed before partial decomposition set in. This interval, in the case of the untreated apples was about three months, but under treatment with-

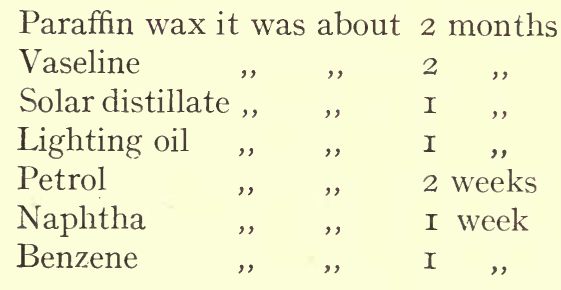


It would not, however, be safe to assume from these rtsulis that the decomposing action of the lighter oils is in itself greater than that of the heavier oils, for the effect produced must depend, not only on the intrinsic chemical activity of the substances, but on their powers of penetration, and on their volatility: the former would increase the effect, whilst the latter, by reducing the amount of oil remaining on the fruit, would diminish this effect.

The destructive action of paraffin oil cannot be attributed to the accidental presence in it of a certain amount of other oils (unsaturated hydrocarbons) not belonging to the paraffin series, for three different preparations of paraffins, carefully purified from such unsaturated compounds, were examined, and were found to have as great an action on foliage as the commercial oils. 


\section{Chapter XVII}

\section{INSECTICIDES, FUNGICIDES, ETC. (continued)}

\section{(I) Alkaline Washes (Report VI, II, 53, I43)}

To remove moss, lichen and dead bark from fruit trees, as well as to destroy the eggs and breeding places of certain insects, the stems of the trees are often painted with lime wash. It is better, however, to spray the wash on to the trees, so as to reach the branches as well as the stems, and for spraying purposes a solution of caustic soda is preferable to a lime wash. Either caustic soda alone, or caustic soda mixed with potash, is generally recommended for the purpose, at a maximum strength of 2 per cent., sometimes with the addition of 0.5 per cent. of soft soap or agricultural treacle.

The term soda is, unfortunately, applied both to caustic soda (sodium hydroxide or hydrate), and also to the much less caustic alkali, sodium carbonate. No confusion, however, appears to have been made on this account in the case of these washes, and the soda used is always the caustic soda. But it is otherwise in the case of the potash: a similar opportunity for confusion exists, and the confusion has constantly been made, so that it is sometimes impossible to ascertain whether caustic potash or the carbonate is signified. Caustic potash (potassium hydroxide or hydrate) corresponds, of course, with caustic soda: the carbonate is known under various names, such as pearlash, purified potash, potashes and crude potash. It appears to be the carbonate, and not the caustic potash, which was originally suggested for this wash, and which is still generally recommended. The reason of this, we surmise, can only be that at the time when this wash was introduced the price of caustic potash rendered its use prohibitive, for it is evident that effectiveness cannot be enhanced by using a mild alkali instead of a strong one, and if there were any special property of the carbonate rendering it more effective than the hydroxide, this would have been equally so as regards the sodium compound.

What the origin of using a mixture of soda and potash (in any 164 
form) was, is uncertain. It probably was the outcome of a belief that two things are always better than one, which doubtless may have met with apparent support in this case by some chance results obtained on certain occasions (pp. 200, 208), but it is evident, if merely from the proportions recommended, that the recommendation is without theoretical or practical basis; for, so far as alkalinity is concerned, one part of caustic potash is by no means equivalent to one part of caustic soda, and there is no reason why equal weights of them should be used : the proportions required for equivalence (making allowance for the fact that commercial potash contains only 87 per cent. of the alkali) being $I^{\circ} 6$ parts of the former to $I$ part of the latter. The relative quantities of these, and also of potassium carbonate, required to produce the same alkalinity, and the cost of them at pre-war prices, are as follows-

Caustic soda, I lb.

Caustic potash, I. $6 \mathrm{lb}$.

Carbonate of potash, $3 \cdot 8 \mathrm{lb}$.

- costs $4 d$.

, $\quad 2 \frac{3}{4} d$.

I5d.

The substitution, therefore, of the potassium compounds in any form for their equivalent of caustic soda is economically unsound.

It has been suggested that such a substitution has its advantage in that the potash which reaches the ground possesses a manurial value. If that were the reason for using it, it would be better to use nothing but potash, or better still to apply the potash to the soil in some cheaper form, and use the soda on the trees.

That there was no intrinsic difference in the action of caustic soda and caustic potash was established by examining the action of each of them on mussel scale (p. 20I). Taking the caustic alkali in equivalent proportions ( $\mathrm{I}$ of soda or $\mathrm{I} \cdot 6$ of potash) there were 35 cases for comparison: in I6 of these the action on the eggs was the same with either alkali, whilst in 9 it was in favour of soda, and in Io in favour of potash; or, omitting some uncertain results, out of $3 \mathrm{I}$ cases, 8 were in favour of soda, and 7 in favour of potash. Evidently a case of equality of effect.

In contrasting the effect of a mixture of the alkali with that of either soda or potash by itself, the alkalinity being the same, Io series of experiments were made : in 4 of these there was no difference between the results, in 5 cases the values were very slightly in favour of a mixture, whereas in the remaining case they were strongly in favour of a single alkali; evidently, again, a case of practical equality of action.

No experiments were made with potassium carbonate by itself, 
but only as a substitute for part of the caustic soda in the wash, and in every case where such a substitution was made there was a reduction in effectiveness. The proportions of carbonate used, however, were only half of those mentioned abovenamely, $I \cdot 9$, instead of 3.8 parts, for every I of soda ${ }^{1}$ - though they were double those usually recommended (VI, 53).

A comparison was also made between caustic soda and caustic potash as regards their efficiency in c'eansing trees from moss: in three cases soda was the more effective, and in three cases, potash; and there was no gain in using a mixture of the two, instead of one only; nor in substituting potassium carbonate for a part of the caustic soda (VI, I46).

Where an alkaline wash is sprayed on to trees there is a rapid disappearance of caustic alkali, this becomes converted by the carbonic acid in the air into carbonate, and then, partially, into the acid carbonate. But the wood of the tree plays a part in these actions. When a glass rod was taken, dipped into a 2 per cent. solution of caustic soda, and exposed to the air, it was found that, after 24 hours' exposure, all the caustic soda in the wash applied to it had been converted into normal carbonate, and about three-fifths of the latter had been converted a stage further into the acid carbonate. The amount of the two carbonates together corresponded very satisfactorily with the amount of caustic soda in the wash applied. In the case of fresh cut twigs, however, no trace either of caustic soda or of normal carbonate, was found after 24 hours' exposure, and the acid carbonate extracted during I6 hours' soaking in water corresponded to but three-quarters of the caustic soda in the wash applied, so that, evidently, some of this soda must have penetrated very deeply into the wood, or must have reacted with the substances present in it. On further soaking, more acid carbonate was extracted, till, after 4 days, the amount of it apparently corresponded to about 50 per cent. more than that in the wash applied, so that some of this acid carbonate extracted, or, rather, some other organic salt which behaves in a similar manner towards the tests used as does the acid carbonate, must have been derived from the juices of the twig.

A similar result was obtained when the caustic soda solution applied contained paraffin or soap.

If, instead of a fresh twig, one was taken which had become

1 It having been ascertained only more recently (Proc. Roy. Soc., A, 93, 548 ) that to produce the same alkalinity it was necessary to use an amount of carbonate containing double the proportion of alkali metal of that in the caustic alkali. 
thoroughly dried up, the carbonation of the alkali proceeded much more slowly. Thus, in such a case I3 per cent. of the soda in the wash applied was found to be still in the caustic form after 24 hours, whereas under like conditions with a fresh twig no trace of caustic alkali was found after I2 hours.

In practical spraying it is improbable that the meteorological conditions would ever be such as to approximate to the prolcinged soaking in water applied to these twigs, and the spraying would, doubtless, result in a certain amount of the soda applied being still retained in the wood of the tree; but absorption of it, and subsequent partial liberation on washing, explains one fact which was observed, namely, that a single spraying with the alkali, followed by a spraying with water only, yielded almost as good results as two sprayings with alkali (VI, Io6).

The insecticidal value of an alkaline wash was found to be very conspicuously increased by the presence of paraffin in it; and an account of the results with such a mixture will be found on p. 204. As regards detergent action, however, the addition of paraffin appears to produce little or no increase in effectiveness. The destruction of moss on trees when soda of various strengths was used, without and with the substances mentioned below, was (VI, I47)-

\begin{tabular}{cccccc} 
& \multicolumn{5}{c}{ Soda- } \\
Moss destroyed & 46 & 53 & 68 & 74 per cent.
\end{tabular}

Thus, the presence of soap, and to a lesser extent, that of treacle, increased the action of the alkali, but only a very small further increase was produced by the presence of paraffin in addition to that of the soap. It was also found that comparatively strong emulsions containing no soda, as well as undiluted paraffin itself, were without action on moss, unless the paraffin contained a considerable proportion of high-boiling oil; in other cases, even when the oils contained a moderate proportion of high-boiling constituents, the damage to the moss was only of a temporary character, the trees soon becoming as green as before.

The strength of the alkali which had to be applied to ensure the destruction of moss and lichen on trees was found to be about 2 per cent. of caustic soda, or its equivalent $(3 \cdot 2$ per cent.) of caustic potash (VI, I43, VIII, 56); in a few cases complete destruction was not affected with this strength, whereas in others 
a I per cent. solution was found to do so ; to allow a safe margin, the strength finally recommended was $2 \frac{1}{4}$ per cent.

The results with lime, when used as a milk containing Io per cent. of quick lime, did not compare well with those with the 2 per cent. soda solution, the destruction of moss amounting to only 50 per cent.; but the action of the lime was found to be enhanced, up to 90 or roo per cent., by the addition of solar distillate, the oil, no doubt, coating the particles of lime, thus preventing them from becoming rapidly carbonated, and so prolonging their caustic action on the trees. A ro per cent. solution of common salt or of calcium chloride was found to be quite ineffective in destroying moss.

Some examination was undertaken of the action of various substances in improving the adhesive powers of lime, and of preventing it from flaking off the trees after application. The directions in which success was sought were: (I) the addition of some soluble substance of a sticky or viscous nature, such as glue, size or treacle; (2) the addition of an oily substance, such as paraffin or rosin; (3) mixing the lime with a fibrous substance, such as wood pulp, which might possibly act in the same way as hair does in plaster; (4) adding something which would bring about a slow chemical action in the wash, resulting in the formation of an insoluble substance, which, being formed in situ, might act as a cementing agent between the rest of the solid and the trees; sulphur, sodium silicate, and the sulphates of iron and copper were tried; (5) the effect of the addition of common salt to the lime; this was examined, not because it was anticipated that any good results could follow from the presence of a soluble and chemically inert substance, but because such an addition had been persistently recommended.

In one series of experiments the various washes were applied to similar apple twigs, which were then left exposed in a vertical position for four weeks in July, during which time a considerable amount of rain fell. In another series, lead pencils were similarly treated, and exposed for two months dating from October I5. After exposure, the amount of solid left adhering to the twigs or pencils was determined by chemical analysis, as well as by estimation based on the appearance presented by them.

The strength of the wash used was in all cases I part of quick lime, slaked, and then mixed with 4 parts of water.

The general conclusions were, that none of the substances examined satisfactorily prevented the flaking off of the lime from the trees, but a considerable improvement in the adhesion of the 
lime was obtained by mixing it-after it was slaked and coldwith sulphur ( 5 per cent. of the total wash), or with solar distillate ( 6 to I 2 per cent.) : the addition of I per cent. of sodium silicate (soluble glass), whilst often quite inoperative, gave, on occasions, better results-than anything else which was tried. Glue or size, when not less than 3 per cent. was used, improved the adhesicn to a certain extent. Soap, treacle, the basic sulphates, and other substances examined, were all detrimental in their action.

Lime was found to adhere to the trees far better than whiting (calcium carbonate), although it is itself soon converted into the carbonate: an instance of how a substance formed in situ may behave differently from the same substance when applied after it has been already made (VII, 73).

\section{(2) Lead Arsenate (Reports, VI, I57; VIII, I6)}

Lead arsenate has proved itself an invaluable substitute for Paris green and other arsenical preparations as an insecticide for caterpillars, owing to no appreciable scorching action on the leaves following on its use. There are few preparations, however, as to which so much error and confusion has arisen in the recipes given for its manufacture, partly because the nature of the arsenate formed by different methods was not known, and partly because the reagents used were obtainable on the market in several different forms. These uncertainties were removed by a chemical investigation of the reactions concerned. The results, however, are not at the present day of so much importance to the fruit grower as they were at the time, since most growers are now able to obtain the arsenate in the form of a paste, instead of having to make it for themselves.

Lead arsenate is made by adding a solution of the acetate or nitrate to a solution of sodium arsenate. If the acetate is used, the arsenate formed is $\mathrm{Pb}_{3}\left(\mathrm{AsO}_{4}\right)_{2}$, and some acetic acid is produced at the same time: when the sodium arsenate taken is the "pure," "crystallised" or " hydrated" substance, the proportions required are $I \cdot 9$ parts of lead acetate to every I part of sodium arsenate: if the latter be in the form of the " dry," " anhydrous" or " crude" arsenate, then for every I part of it taken 3.5 parts of lead acetate are required. Such proportions ensure the presence of a slight excess of lead, which is advisable, as an excess of lead produces less scorching, than an excess of sodium arsenate (VI, I80). Owing to variations in the composition of chemicals concerned, it is preferable not to add the whole of the lead acetate at once to the arsenate, but to 
add in the first place only three-quarters of the amounts mentioned above, and then add more in small quantities at a time, only so long as such additions cause a further cloudiness.

When the nitrate of lead is used, instead of the acetate, a different lead arsenate is formed, namely, $\mathrm{Pb}_{2} \mathrm{H}_{2}\left(\mathrm{AsO}_{4}\right)_{2}$, though it is not very constant in composition. The proportions of the reagents required in that case are $I_{4}^{1}$ parts of the nitrate to every I part of crystallised sodium arsenate, or $2 \frac{1}{2}$ parts to every I part of the crude arsenate.

It was found that, contrary to statements made in various recipas, it was immaterial whether the sodium arsenate were added to the lead salt, or the lead salt to the arsenate, but that it was advisable that the arsenate solution should be as weak as possible, and, therefore, the lead solution (whether acetate or nitrate) as strong as possible; since the weaker the arsenate, the more finely divided was the precipitate of lead arsenate formed. The precipitate formed by using lead acetate is more finely divided than that obtained when lead nitrate is used.

The lead arsenates formed, whichever reagent is used, are appreciably soluble in water, but not sufficiently so to cause any recognisable scorching of the foliage of apple trees, and in this respect lead arsenate compares very favourably with Paris green, even when the latter is mixed with its own weight, or even double its weight, of lime (VI, I92); with still larger proportions of lime-ten times its weight was tried-the scorching action of Paris green was prevented.

Lead arsenate may, contrary to statements made on the subject, be mixed with Bordeaux mixture without decomposition, so as to obtain fungicidal as well as insecticidal effects; but it must not, of course, be mixed with potassium sulphide (VI, I84).

Calcium arsenate, which had been suggested as a cheap substitute for lead arsenate, was examined. It was found to have the same constitution as the lead arsenate obtained from lead acetate, but to be more soluble than it. This solubility, however, was reduced by adding excess of lime, a suitable spray-fluid being obtained by the addition of I part of lime, in the form of milk of lime, to every I part of crystallised sodium arsenate dissolved in 400-500 parts of water. Its insecticidal value was about equal to that of the lead arsenate (VIII, I7, 92). ${ }^{1}$

1 Such obervations as have been made with nicotine and other insecticides will receive sufficient notice under the headings of the insects for the destruction of which they have been applied (pp. 196-229). 


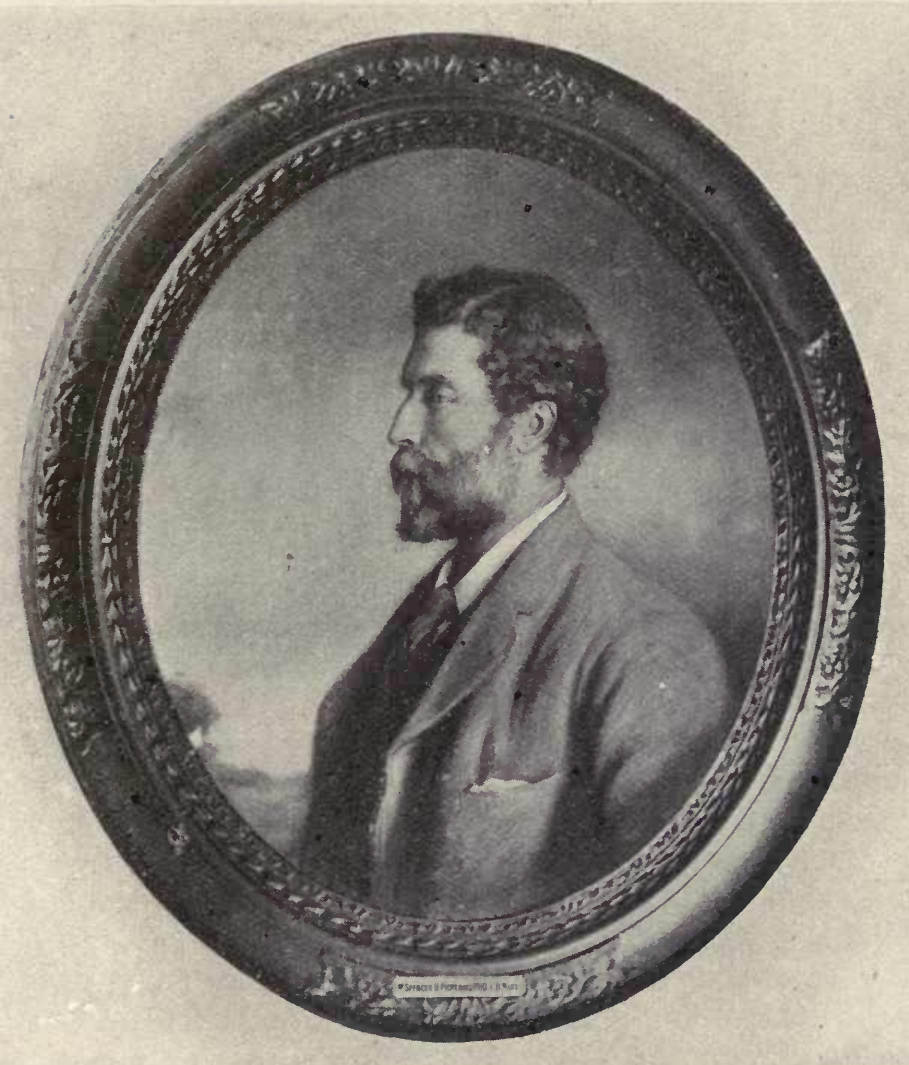

Yirs fruly Sfencer Délering. 


\section{Chapter XVIII}

\section{INSECTICIDES AND FUNGICIDES (continued)}

\section{Copper Fungicides (Reports, VIII, 5 ; XI, I; XIV, App.)}

OF the various compounds of copper used as fungicides, the chief ones are the basic sulphates and the basic carbonates. The former are the active substances in Bordeaux mixture, the latter in soda Bordeaux, more recently termed Burgundy mixture.

\section{(I) Bordeaux Mixture}

This has been in use since 1882 , the recognition of its value as a fungicide being due to accident. It had been the practice in the vineyards in the neighbourhood of Bordeaux to sprinkle those vines which were near a road with verdigris, in order to give them the appearance of having been poisoned, and so to prevent depredations. A mixture of lime and copper sulphate was soon substituted for the verdigris, being cheaper, and, when the downey mildew of America (Peronospora viticola) made its appearance in Europe, it was noticed (I882) that those vines which had received the copper dressing were those which kept their leaves longest, and were least affected by the disease.

The mixture in general use in this country is made by adding I. 6 parts by weight of quick lime, previously slaked and made into a milk, to $x \cdot 6$ parts of crystallised copper sulphate, dissolved in Ioo parts of water ( $16 \mathrm{lbs}$. to Ioo gallons). This is known in America as the "normal" or " $\mathrm{I} \cdot 6$ " mixture. Occasionally, stronger or weaker mixtures are used, and al:o the proportion of lime to sulphate is varied. For complete decomposition, the crystallised sulphate requires only one-fifth of its weight of pure lime, therefore the lime used in practice is always in considerable excess, even when a liberal allowance is made for impurities in it.

It is somewhat remarkable that, in spite of the large amount of work which had been done on Bordeaux spraying, both in France and America, no attempt had been made to obtain information on the point of most fundamental importance, 
namely, the compound present in it. This question was attacked at Woburn, ${ }^{1}$ and was found to be one of great complexity.

The addition of lime, preferably in the form of clear limewater, to a solution of copper sulphate, forms a series of different compounds (basic sulphates) according to the proportions taken. The simplified chemical formulæ of these, and the proportions of sulphate $\left(\mathrm{CuSO}_{4}, 5 \mathrm{H}_{2} \mathrm{O}\right)$ and lime required for their formation, are as follows-

\begin{tabular}{|c|c|c|c|c|}
\hline \multirow{2}{*}{\multicolumn{2}{|c|}{ A. $\mathrm{IoCuO}, 2 \cdot 5 \mathrm{SO}_{3}$ (or $4 \mathrm{CuO}, \mathrm{SO}_{3}$ ) }} & \multicolumn{3}{|c|}{ Proportions required. } \\
\hline & & . I & : & $0 \cdot 169$ \\
\hline B. $\mathrm{IOCuO}_{2} \mathrm{SO}_{3}$. & . $\quad$. & I & & 0.18 \\
\hline C. $\mathrm{IOCuO}, \mathrm{SO}_{3}$. & . & I & : & $0 \cdot 203$ \\
\hline D. $\mathrm{IoCuO}, \mathrm{SO}_{3}, 3 \mathrm{CaO}$ & . & I & : & $0 \cdot 270$ \\
\hline F. $10 \mathrm{CuO}, 30 \mathrm{CaO}$. & . & & : & 0.674 \\
\hline
\end{tabular}

The compound A is formed when the lime is just sufficient to precipitate the whole of the copper; $\mathrm{C}$ is the product when the proportion of lime is increased up to the point when any further addition would make the liquid alkaline, and $F$ is the product finally obtained with excess of lime. In ordinary Bordeaux mixture, the proportion of lime taken is greater than that required to form any of these compounds, but the whole of this lime will not dissolve in the water taken, and the greater part of it remains inoperative, so that it is mainly the compounds $\mathrm{C}$ and $\mathrm{D}$ which are formed, and these are only gradually, after several days, transformed into $\mathrm{F}$, as the excess of lime acts on them.

In instructions for making Bordeaux mixture, great stress is always laid on the necessity for insuring the complete precipitation of the copper : doubtless this is quite right, for carelessness in manufacture might result in there being enough copper left in solution to do serious damage to the trees: but the insistence on this point is probably responsible for a very general misconception on the elementary principle which must govern fungicidal action; for, such action, being fundamentally a chemical one, is subject to the laws of chemistry; and one of these laws is that, for any chemical reaction to be possible, one or more of the reagents must be in the liquid (or dissolved) condition. A reaction between an insoluble solid outside the cells of a fungus spore, with the contents of those cells while still enclosed within the cells, is a chemical impossibility. Either

1 Pickering, Trans. Chem. Soc., I9I 7, Vol. III, p. 86. 
the copper of the fungicide must be soluble, and penetrate into the cell, or the contents of the cell must come out, and attack the copper compound. Ex hypothesi, they can not do so when the spores are in the resting condition; and, as fungicidal action occurs even then, it is the copper which must be in the active, i.e. soluble, condition.

In the case of the first three compounds mentioned above, this condition does exist, for they are all appreciably soluble. The extent to which A dissolves in water is sufficient to allow of copper being recognised in the solution of it by the ordinary tests for that metal; with $\mathrm{B}$ and $\mathrm{C}$ the solubility is smaller, and the copper is recognisable only by special methods. One of these consists in placing a piece of bright iron (not steel) in the mixture, when a deposit of metallic copper will appear on the iron, and, in time, the whole of the copper will be removed from the mixture, iron taking its place, and changing it from blue to yellow. The rapidity with which this action occurs, in spite of the excessively minute proportions in which the basic sulphate dissolves (less than 0.00005 per cent. of metallic copper in the case of the compound C), may appear surprising, but is quite in accordance with the known laws of chemical action, for as soon as such copper as is in solution is removed by the iron, more dissolves to take its place, only to be removed in a similar manner, till all has been removed. In yo hours one three-inch iron nail, if the surface be kept bright, will remove the whole of the copper from 0.5 or 0.6 grams of the basic sulphate. The rapidity of such actions depends on the extent of surface exposed, and that exposed by the nail would be very small in comparison with that offered by a tree to the same amount of sulphate sprayed on to it, so that a fungicide of scarcely recognisable solubility may exercise a comparatively rapid fungicidal effect (XIV, App. 276).

Passing on to the compound $\mathrm{D}$, which is the main constituent of ordinary Bordeaux mixture, it is found to be quite insoluble; no action on iron takes place, and there should, therefore, be no chemical action on the fungus. But, in using it as a spray-fluid, it becomes exposed to the air, and it is found that when a stream of air, or, better still, a stream of carbonic acid, is passed through it, it, after a certain time, begins to act on iron, proving the presence of dissolved copper; this may be equally established by adding a drop of ferrocyanide of potassium, which now gives the characteristic red colour of copper ferrocyanide, which it did not do before the passage of the air. The change is easily explained, for as soon as the excess of lime present in the 
mixture, as well as that which forms part of the compound itself (represented by $3 \mathrm{CaO}$ in the formula $\mathrm{D}$ ), becomes converted into carbonate (chalk) the residue will consist of $\mathrm{IoCuO}, \mathrm{SO}_{3}$, which is sufficiently soluble to enter into chemical reaction. The carbonation of the lime necessary before any copper becomes soluble, explains a fact which had been fully established by previous observers, namely, that a considerable time elapses after spraying, before the fungicidal action of Bordeaux mixture begins to occur: thus, Millardet and Gayon ${ }^{\mathbf{1}}$ found that 18 days elapsed before Bordeaux mixture, which was being washed with water, yielded any copper in the drip-water. The delay in actual spraying is, however, probably considerably less than such a result (or the results obtained at Woburn, to be mentioned on p. IgI), would indicate; for, when the drops of Bordeaux mixture dry up on the leaves, some of the particles of basic sulphate become separated from those of the lime, and are decomposed by the carbonic acid, just as if no excess of lime were present: by substituting a piece of paper impregnated with potassium ferrocyanide, for a leaf, red spots make their appearance here and there, just before the mixture dries up. Thus there may be an almost immediate, though limited, fungicidal action, even with ordinary Bordeaux mixture.

Soluble copper being necessary for fungicidal action, it might appear at first sight that the ideal fungicide would be one in which the copper was all initially in the soluble form, for its action would be more prompt, and it would be a simple matter to determine the strength suitable for use in any case. But general experience has pronounced against such compounds, and it is easy to see that, if they were used, any rain or dew would readily wash them off, and necessitate further sprayings: added to which, they would not really afford a coating of uniform strength over the foliage, for when they dried up they would become concentrated into separate droplets of great strength, producing excessive action and scorching at a few points, and leaving the rest of the leaves unaffected. What must be aimed at, therefore, in a fungicide is to obtain a material which will yield a gradual supply of soluble copper, sufficient to kill the fungus, or to prevent its development, but insufficient (if possible) to injure the host plant.

Whichever of the basic sulphates of copper is used, this gradual supply of soluble copper is obtained, owing to their being themselves slightly soluble, or, in the case of $\mathrm{D}$, becoming so after

$$
{ }^{1} \text { Journ. d'Agric. prat., 1887, } 7 \text { or. }
$$


exposure to the air: but the air, or, rather, the carbonic acid in it, helps to liberate soluble copper from all these compounds, and not from D only, for it converts the basic sulphate into basic carbonate, the other product of the change being ordinary copper sulphate. The chemical equations representing such actions are-
A. IoCuO, $2 \cdot 5 \mathrm{SO}_{3}+3 \cdot 75 \mathrm{CO}_{2}=3 \cdot 75(\mathrm{CuO})_{2} \mathrm{CO}_{2}+2 \cdot 5 \mathrm{CuSO}_{4}$.
C. $\mathrm{IoCuO}, \mathrm{SO}_{3}+4 \cdot 5 \mathrm{CO}_{2}=4 \cdot 5(\mathrm{CuO})_{2} \mathrm{CO}_{2}+\mathrm{CuSO}_{4}$.

The proportion of copper sulphate thus liberated is different in the different cases: the above equations represent the same amount of copper as being present in the two compounds taken, namely, roCuO, but the sulphate obtained from $\mathrm{A}$ is $2 \frac{1}{2}$ times greater than that from $\mathrm{B}\left(2 \cdot 5 \mathrm{CuSO}_{4}\right.$, against $\left.\mathrm{CuSO}_{4}\right)$. It is evident, therefore, that the amount of copper contained in even very similar substances, is by no means necessarily a measure of their efficiency, and that growers who gauge the value of a copper fungicide simply by the percentage of copper in it, may be very much misled.

The copper liberated in the case of the compound $\mathrm{A}$ will be 25 per cent. of that contained in it; in the case of $\mathrm{C}$, only Io per cent.: with ordinary Bordeaux mixture, although it contains copper and sulphur in the same proportion as C (Io : I), the proportion of copper liberated will be still less, for it contains also excess of lime, and this will destroy some of the copper sulphate formed, re-making some of the compound $\mathrm{C}$, which, in its turn, will be decomposed, yielding, again, only ro per cent. of the copper in it. Direct experiment verified these conclusions : by the action of carbonic acid, 25 per cent. of the copper in A became soluble in about two hours, and ro per cent. of that in $\mathrm{C}$, when the main action was complete; whereas with ordinary Bordeaux mixture no soluble copper made its appearance till after several hours, and the amount eventually passing into solution was only 3 to I per cent. of the total present (XI, 3I). The results, however, are very much complicated by the presence of by-products - calcium sulphate and carbonate-and after the main action is complete, subsidiary actions occur, resulting, first in a gradual increase, and then a decrease in the soluble copper present (XI, 28, 62; XIV, App. 279; Proc. Roy. Soc., A. 94, 317); moreover, if air, instead of undiluted carbonic acid, is used, the actual amounts of copper liberated are much reduced, but the general results are sufficient to indicate that, judging by the amount of copper becoming soluble, the basic sulphate A should 
be about twelve times (or possibly eighteen times) more effective as a fungicide than ordinary Bordeaux mixture; or, that to get the same effect, it would be necessary to use only one-twelfth as much copper.

For making the individual basic sulphates it is necessary to use clear lime-water, so as to avoid excess of lime, and a fungicide prepared in this way had, in fact, been in use in parts of Italy for some time. It was found, however, that the basic sulphate A, which would be the most economical as regards the proportion of copper sulphate liberated by the action of air, was of too dense a nature to constitute a satisfactory spraying material, and that it was preferable to use the more highly basic compound, C, ( $\mathrm{roCuO}, \mathrm{SO}_{3}$ ), at some sacrifice in economy. The relative volumes occupied by the various compounds, after being allowed to settle for the same times, were found to be as follows-
A. $\mathrm{IOCuO}, 2 \cdot 5 \mathrm{SO}_{3} \quad$. $\quad$. $\quad . \quad 8$

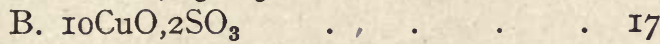
C. $\mathrm{IOCuO}, \mathrm{SO}_{3}$. . . . . 86
D. $\mathrm{IoCuO}, \mathrm{SO}_{3}, 3 \mathrm{CaO}$. $\quad$. $\quad$. 98
F. $\mathrm{IoCuO}, 30 \mathrm{CaO} \quad$. $\quad$. $\quad . \quad 5$

A mixture of the sulphates $B$ and $C$ has been put on the market under the name of Bordeaux paste or Bordorite. It consists of the precipitates obtained by the action of lime-water on copper sulphate, with the excess of water drained off, so as to leave the product in the form of a paste of convenient consistency, to which it is only necessary to add water to reproduce the original precipitates in the same condition as they were when first precipitated: ${ }^{1}$ such a spray-fluid also presents the advantage over ordinary Bordeaux mixture, of containing no gross particles of lime to clog and wear the nozzles of the spraying machine.

It must be borne in mind, however, that this paste is a substitute for ordinary Bordeaux mixture, and does not reproduce the ordinary mixture when diluted with water; it could not do so,

1 G. H. Pethybridge (Journ. of Irish Board of Agric., XV, 498) states that the paste is "colloidal " when first prepared, but changes from this condition after being kept for no very long period. But he is evidently under some misapprehension as to the meaning of the term colloidal, which cannot be applied to any of the basic sulphates, and some explanation is required as to the condition they are supposed to be in when they lose these " colloidal " properties. As a matter of fact, these precipitates remain quite unchanged in physical properties for an indefinite time, so long, of course, as they are not decomposed by chemical agency, or deprived of their combined water by drying or freezing (see p. 227). 
for it and the ordinary mixture consist of different substances. A misconception on this point, and on similar points as regards other spray-fluids, has led at various times to polemics as to the relativé merits of home-made, or freshly made, spray-fluids, and of preparations supplied by manufacturers. Such a controversy is only raised by those who are not sufficiently versed in chemistry to understand the nature of the substances under discussion. Some spray-fluids must be used at once after preparation, because they change their nature on being kept: ordinary Bordeaux and Burgundy mixtures are cases in point; others which do not change on being kept-such as the pure basic sulphates of copper-need not be used at once, and are certainly made much better by the manufacturer, who has special chemical knowledge, special appliances at his disposal, and extended experience, than by the fruit-grower, who has none of these advantages.

Determinations of the relative efficiency of Bordeaux paste and of ordinary Bordeaux mixture, showed that considerable variation in the ratio $12:$ I must be expected according to the circumstances of the case: on the one hand, experiments based on the scorching action on the foliage of fruit trees-which, as will be shown below, is a good index of fungicidal activityplaced the ratio higher, namely, at about 20 I (XI, I55); whereas experiments carried out during several seasons on potato disease, placed it considerably lower, namely, at about 5 to I $(X I V, 7)$. There can be no doubt but that the ratio must necessarily vary according to the nature of the disease to be dealt with, and of that of the host plant attacked, for the actual efficiency of a fungicide must depend, not only on the potency of its fungicidal properties, but on the extent to which it adheres to the plant to form a coating which will protect it from further fungus attacks. Where a rapid action is required, the pure basic sulphates would have the advantage; where a slower action is sufficient, or where the retention of a deposit on the leaves for some considerable time is necessary, the advantage would often lie with Bordeaux mixture, not because it is more adhesive than the paste, but because the actual amount of copper applied is generally greater when using the mixture than when using the paste. The nature of the climate and of the season would also affect the relative efficiency of these, or any materials; the one which formed the smaller deposit on the leaves being likely to suffer most by persistent rain.

In the advocacy of Burgundy mixture during the last two years, it has been repeatedly stated the Bordeaux paste is less 
adhesive than either Burgundy or Bordeaux mixtures. No evidence for such a statement appears to exist, and recent experiments ${ }^{1}$ indicate that precisely the opposite is the case. Plots of potatoes were sprayed at the same time with these three substances, and with each of them at three different strengths, the copper content ranging from the equivalent of $2 \mathrm{lbs}$. to $5 \frac{3}{4} \mathrm{oz}$. of the sulphate to Io gallons : the plots were sampled, by taking a leaf from each plant in them, cne week after the spraying, and again, three weeks later. The average relative amounts of copper found on the leaves were--

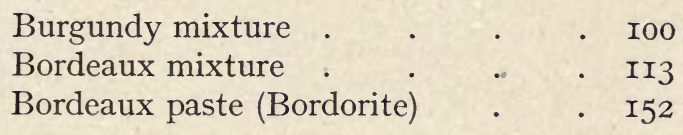

Thus, in every case the paste left a considerably larger deposit of copper than did Burgundy mixture, and in five cases out of the six, Bordeaux mixture was also superior in this respect to Burgundy mixture, but to a less marked extent than was the paste.

The ultimate form of the deposit on the leaves is in all cases copper carbonate: with Burgundy mixture, it is the carbonate itself which is applied; with Bordeaux mixture and paste the carbonate is formed in situ from the decomposition of the sulphate, and such a deposit thus formed, would, naturally, adhere better to the leaves than the ready-made carbonate in the Burgundy mixture: hence the results actually found. The reason why Bordeaux mixture appears to be less adhesive than the paste, is that it contains a large excess of lime (soon becoming converted into chalk), the particles of which are comparatively gross, and, are easily shaken from the leaves, carrying with them, of course, a certain amount of the copper.

Several points in connection with making ordinary Bordeaux mixture have been investigated at Woburn. The common source of failure in preparing a satisfactory mixture is, of course, not starting with fresh lime, or not slaking it properly before making it up into a milk with water; but this is merely a question of carelessness in following simple textbook instructions (XI, 50). As the lime used is five times that required for precipitating the copper, there should be little risk of any of the latter remaining in solution; but the mixture should always be tested; and the best way of doing so is by adding a drop of potassium ferrocyanide solution to some of the clear liquid obtained by

1 Gardener's Chroncile, Sept. 28, 1918. 
filtering the mixture, or by allowing it to settle. Testing it by inserting a knife-blade into it, and seeing if a deposit of copper forms on the steel, is apt to be very misleading, for it was found that steel would often remain quite bright for a long time, even in a ro per cent. solution of the sulphate. An iron wire nail is preferable to a piece of steel.

A more interesting point, however, was the change which Bordeaux mixture undergoes after it has been made. The proportion of lime to copper sulphate taken is more than sufficient to form the compound F (p. I77), and that is a very compact substance; but the lime which reacts with the sulphate in the first instance is limited to the amount which is actually dissolved in

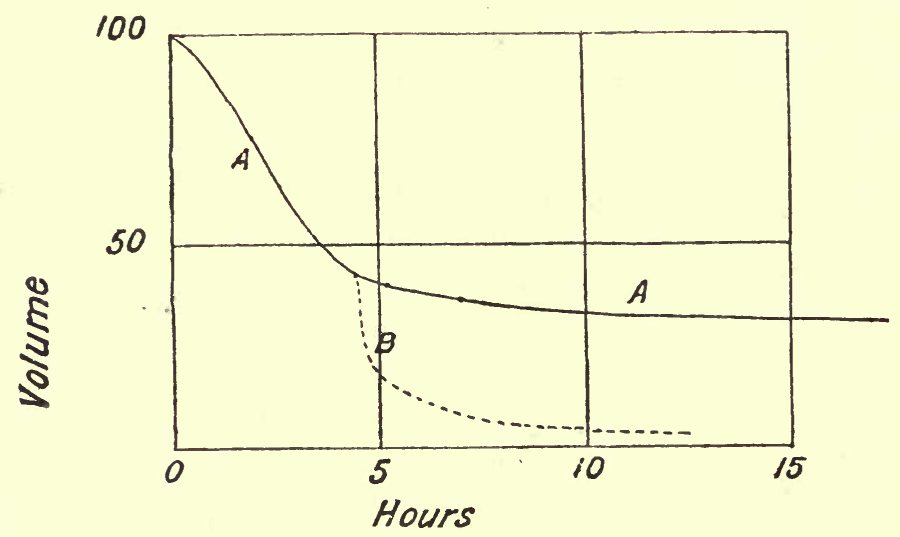

Fig. I8.-SETTLEMENT OF PRECIPITATES CONSISTING OF ORDINARY BORDEAUX MIXTURE $(A B)$ AND OF THE BASIC SULPHATE $\mathrm{IOCuO} \mathrm{SO}_{3}(A A)$.

the water; consequently, the first product is one of the less basic sulphates, for the formation of which the amount of lime in solution is sufficient, and these are bulky substances: but the lime, having thus been removed from the water, some of the excess present will dissolve in it, and this will react with the basic sulphate already formed to produce the more basic compound, which is much more compact. In other words, there will be a considerable shrinkage in the precipitate some little time after the reagents have been mixed. The line AA in Fig. I8 shows the volume occupied by $\mathrm{IoCuO}, \mathrm{SO}_{3}$ made by adding the requisite amount of lime-water to copper sulphate, whilst the line $\mathrm{AB}$ shows that of the precipitate obtained when the lime added is five times greater than that dissolved by the water, the 
proportions between lime and sulphate being those used for ordinary Bordeaux mixture. The contraction occurs after about four hours, but if the mixture is stirred, it occurs much sooner.

To obtain the most suitable liquid for spraying purposes, therefore, the mixture should be used immediately after its preparation, though as regards actual fungicidal properties, Bordeaux mixture shows no deterioration on being kept (XI, I38).

Considerable importance from the point of view of the bulkiness

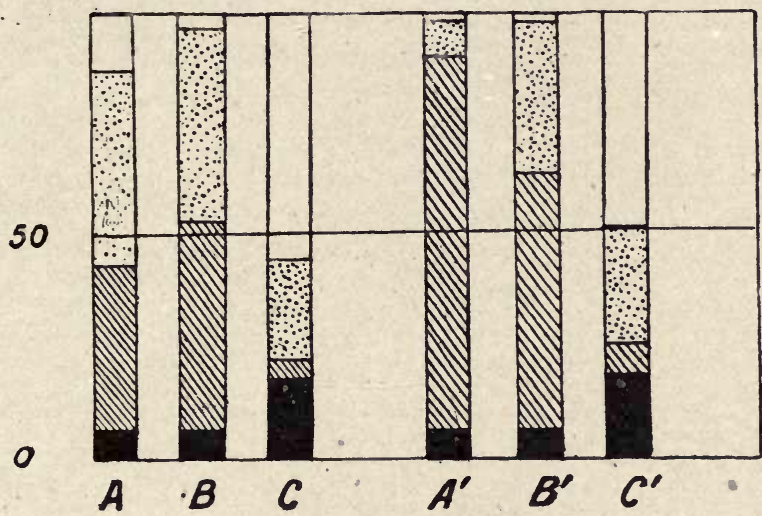

Lightest shading shows level after 30 minutes.

Intermediate " , " " 2 hours.

Darkest " " " ". ", I8 hours.

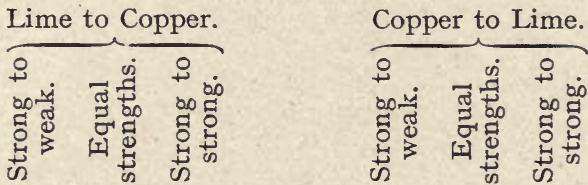

FIG. 19.-SETTLEMENT OF ORDINARY BORDEAUX MIXTURE PREPARED IN DIFFERENT WAYS.

of the precipitate attaches to the manner in which the lime and the sulphate are mixed. The results are illustrated in Fig. I9, and will sufficiently explain themselves, with the added statement that the strong and weak solutions contained, respectively, 8 and 92 per cent. of the total water used. The variations according to the conditions of mixing appear to be hopelessly erratic, but, nevertheless, every feature which they present can be satisfactorily explained $(\mathrm{XI}, 54)$; it is hardly necessary, however, to enter into that explanation here, and attention need only be drawn to the main result, namely, that when Bordeaux mixture is to be used within an hour or two of its being made (as always 
ought to be the case) the copper solution should be added to the lime-not the lime to the copper-and this copper solution should be as strong as possible, nearly the whole of the water being previously mixed with the lime.

The changes occurring in Bordeaux mixture are by no means complete within the I8 hours allowed in the experiments here illustrated, and eventually all the deposits, whatever the method of mixing may have been, become similar, and consist more or less entirely of the compound $\mathrm{F}$, ( $\mathrm{IoCuO}, 30 \mathrm{CaO}$ ), which is of a violet-blue colour, and is very dense. This compound is, apparently, a cuprite of calcium, the copper in it being in a different condition (electronegative) from that of the copper in ordinary copper salts, and it does not respond to the ordinary tests for that metal, just as is the case with iron present in ferrocyanides. One characteristic of copper in this condition, besides its peculiar colour, is that it combines with various organic substances. Amongst these may be mentioned dextrose and cellulose. In treacle, this compound dissolves completely, forming a violet-blue solution, and such a solution attacks and dissolves cellulose. Bordeaux mixture mixed with treacle has been used as a fungicide, and it is probable that the action of it on the fungus is different from that of ordinary copper salts, not being merely a case of poisoning by copper, but of the destruction of the cell walls of the fungus-which are composed of celluloseby the action of the cuprite. Indeed, it is probable that copper when in this form has no direct poisoning effect (see p. I94).

But Bordeaux mixture and treacle is not a satisfactory sprayHuid, as it decomposes spontaneously, forming cuprous oxide, and it is also decomposed by carbonic acid, with the result that an unknown, and often dangerous, amount of copper in the ordinary form is liberated; for alkalinity is one condition of the existence of copper in the form in which it is present in the cuprite, and carbonic acid destroys this alkalinity. The compound D, $\left(\mathrm{IoCuO}, \mathrm{SO}_{3}, 3 \mathrm{CaO}\right)$, is also alkaline, and shows properties akin to those of the compound $F$, for, though it does not dissolve in dextrose to any recognisable extent, it gradually decomposes it, forming cuprous oxide (XI, 44).

Various other alkaline solutions of copper, with ammonia as the solvent, have been used for spraying purposes (XI, I6), but none of them have proved satisfactory, and experiments at Woburn (XI, I9, I32) have shown that the presence of ammonia greatly increases the scorching effect on the leaves, without increasing the fungicidal action of the copper present. 
Sundry preparations of the basic sulphates of copper in the dried form are used as fungicides, being either mixed with water before use, or blown on to the plants as powders. Their action is substantially the same as that of the undried preparations, but, when mixed with water, they do not reproduce a suspension at all comparable with that obtained with a freshly prepared, undried precipitate, and all of them, it may be noted, contain a considerable amount of their copper in the soluble form to start with (XI, 8I).

Bordeaux mixture or any of the basic sulphates of copper may be mixed with Paris green, lead arsenate or nicotine, so as to give them insecticidal properties, and these additions do not interfere with the fungicidal value of the copper. The basic sulphates-Bordeaux paste-may also be emulsified with paraffin, as has been mentioned on p. I6o, with the same result. Ordinary Bordeaux mixture does not emulsify the oil satisfactorily, owing to the presence of the grosser particles of lime in it.

\section{(2) Burgundy Mixture, Soda Bordeaux (XI, 86, App.)}

Sulphate of copper, precipitated by carbonate of soda, and mixed with molasses, was used in France in r89o. More recently a similar mixture, but without the molasses, has been advocated as a substitute for ordinary Bordeaux mixture, and has received the above names. It has been used somewhat extensively, but without any very good results, in New Zealand, and, with better results, for potato-spraying, by the Board of Agriculture and Technical Instruction in Ireland. Following this lead, the Food Production Department of the Board of Agriculture and Fisheries in England has, since I9I6, advocated it for potato-spraying, to the exclusion of all other materials. The proportions of the ingredients recommended by them for making the mixture - I lb. of crystallised sulphate of copper to I.I5 lbs. of sodium carbonate ${ }^{1}$ in 5 gallons of water-are, however, based on the supposition that the carbonate of copper formed is a substance which every student of elementary chemistry knows to be incapable of existing, namely, $\mathrm{CuCO}_{3}$, and in ignorance of the

1 The proportion recommended by the Irish Board was rather higher, $\mathrm{I}: \mathrm{I} \cdot 25$, and the English Board adopted these proportion in a leaflet (F.P. I42/H) published in I9I8; at the same time they reduced the strength of the mixture recommended to $\mathrm{I} \mathrm{lb}$. of sulphate to ten gallons of water. As no reasons are given for these alterations, they cannot be regarded as final, and it has, therefore, not been considered necessary to alter the above text so as to harmonise with the recommendations of the moment. 
fact that an investigation of the subject carried out at the Woburn Farm showed that the carbonate formed consisted of $5 \mathrm{CuO}, 2 \mathrm{CO}_{2}$, the proportions in which the hydrated reagents react being I of copper sulphate to $\mathrm{I} \cdot 84$ of sodium carbonate, according to the following equation-

$$
\begin{aligned}
5 \mathrm{CuSO}_{4}+8 \mathrm{Na}_{2} \mathrm{CO}_{3}+ & 3 \mathrm{H}_{2} \mathrm{O}=5 \mathrm{CuO}, 2 \mathrm{CO}_{2}+6 \mathrm{NaHCO}_{3} \\
& +5 \mathrm{Na}_{2} \mathrm{SO}_{4} .
\end{aligned}
$$

Hence, the proportions of I : I.I5 give a deficit of soda, leaving some of the copper unprecipitated; but not so much as might be expected, for the bicarbonate of soda $\left(\mathrm{NaHCO}_{3}\right)$ formed, is itself capable of precipitating most of the copper left in solution, with the production of another basic carbonate of copper. The percentage of copper left in solution when the proportion of the reagents are varied are as follows, the values applying to a case where the copper sulphate taken amounted to $20 \mathrm{lbs}$. in IOO gallons-

Carbonate to
I of Sulphate
I. I·OO
2. I.I5
3. I.84
4. $2 \cdot 30$
5. $2 \cdot 80$

\section{Copper left dissolved.} -034 per cent. $\cdot 02 \mathrm{I}$ .003 $\cdot 008$ $\cdot 008$
Changes in

$$
\text { I3 days }
$$$$
3 \text {, }
$$$$
\text { IO , }
$$

33 ,

39 ,

Thus the copper left in solution when such wrong proportions, as in No. 2, are taken, is seven times greater than when the correct proportions are used (No. 3), and amounts to 4 per cent. of the total copper present. The damage to the plant, when such is caused by Burgundy mixture, ${ }^{1}$ appears, however, to be due, not to this comparatively large amount of dissolved copper, but to the by-products present-sodium bicarbonate and sodium sulphate-these two together amounting to 2 per cent. of the liquid. Experiments were made by immersing leaves for 24 hours in Burgundy mixture on the one hand, and, on the other, in solutions containing such by-products as would be present in this mixture; and, as will be seen, the scorching produced by both by-products together, measured by the percentage of the

1 This damage appears to have been very considerable in many cases in I9I 7, and is attributed in the leaflet referred to above to various " concomitant" circumstances. Concomitant circumstances, however, are always present, yet they do not appear to result in damage by spraying when it is Bordeaux mixture or paste which is used. 
total leaf surface affected, was practically the same as that caused by the Burgundy mixture (XI, I45)-

\begin{tabular}{ccccc} 
& Burgundy & \multicolumn{3}{c}{ By-products of Burgundy } \\
Mixture. & Sod. Sulph. & Mod.ture. & Sodicarb. & Both. \\
Scorching & 64 & 37 & 42 & 60
\end{tabular}

Other experiments supported the view that it was the byproducts which were mainly responsible for the damage, and previous work had shown that similar salts, such as sodium chloride, would in many cases produce serious scorching (VIII, I06). The effect, however, was subject to much greater variation when the material was sprayed on to the leaves, instead of the leaves being immersed in the solution, the explanation of this being very simple; for when a solution containing a highly soluble salt such as sodium sulphate is sprayed on to a plant, the drops, whatever the proportion of substance contained in them, will become concentrated to the maximum before they dry up, and intense, but local, action will result, very much modified, however, by the condition of the weather, the size of the drops, etc. One great advantage presented by Bordeaux mixture over Burgundy mixture is that the by-product in the former case-calcium sulphate-is very sparingly soluble, dissolving to the extent of only 0.25 per cent., and it exercises, therefore, no appreciable scorching action on foliage.

Like Bordeaux mixture, Burgundy mixture changes after a time, the copper carbonate present becoming converted into another carbonate, malachite, which forms as minute, spherical particles, settling very rapidly in the liquid, and rendering the mixture quite unsuitable for spraying purposes. The change, which generally occurs suddenly, does not take place for some days if the mixture is left at rest, the time elapsing under various conditions being recorded on p. I84; but when the mixture is agitated, it may take place within a few hours. The same change must always occur sooner or later to the deposit of material sprayed on to the leaves, and the solubility of malachite in water must give the measure of the strength of copper solution which after a time will be in contact with the leaf. This solubility is from 0.00008 per cent. of copper in pure water, to 0.006 per cent. in water saturated with carbonic acid. 


\title{
Chapter XIX
}

\section{INSECTICIDES AND FUNGICIDES (continued)}

\author{
The Fungicidal and Scorching Action of Copper \\ (Reports, XI, 93; XIV, App.)
}

AN excellent résumé of the work done prior to 1896 on the fungicidal action of copper will be found in Bulletin Io of the Bureau of Vegetable Pathology, U.S. Department of Agriculture, by W. T. Swingle; though it must be borne in mind that the chemical nature of Bordeaux mixture had not at that time been elucidated, and, consequently, the statements made respecting it are often wide of the mark and misleading. Six years later J. F. Clark (Botanical Gazette, 33, p. 26) published an important paper dealing with various fundamental aspects of fungicidal action. Unfortunately there are uncertainties attaching to his statements; owing to their not appearing always to tally with the figures which he quotes, and to the loose, and often unintelligible manner in which his ideas on chemical questions, and his names for chemical compounds, are expressed (XI, 93). In various series of experiments with 15 different fungi he determined the dose of copper which produced death after 24 hours' immersion, as well as that which produced the smallest recognisable effect on the fungus. Though the lethal strength varied from 0.005 to 0.00025 per cent. of copper - a twentyfold variation-in the májority of cases it approximated to 0.0015 per cent.; and this lethal dose was the same in whatever form the copper was supplied, namely, as sulphate, chloride, nitrate, acetate or formate. When the fungus was supplied with nourishment in the form of molasses, its resistant power was enormously increased, even up to eightyfold. It is probable, however, that this was not really a question of nourishment, but was due to the alteration in the viscosity of the solution, which would affect the rate at which the copper penetrated the cells, since a similar increase was obtained on the addition of such inert substances as the sulphates and chlorides of potassium or sodium, and any other explanation of the effect of these salts based on chemical grounds, such as was given by Clark, is certainly untenable. 
The efficiency of a fungicide in actually killing the fungus, or in preventing the germination of its spores, appears from Clark's work to be simply a question of the amount of soluble copper present; and in the case of every copper fungicide known there is, either initially, or after it has been subjected to the action of the air, sufficient soluble copper to kill the spores of most fungi. Even in the case of the carbonate, malachite, the solubility may exceed the average lethal strength of 0.0015 per cent. found by Clark (see p. I86); and, doubtless, the lethal dose would be reduced if the action were prolonged for more than the 24 hours which Clark allowed.

In view of the presence in, or liberation from, the fungicide of this soluble copper, it would appear unnecessary to resort to any theory attributing its presence to the action of the fungus itself. Yet the opinion that it is excretions from the fungus itself which renders the copper soluble has often been put forward, and has recently been pressed by Barker and Gimmingham. ${ }^{1}$ There are certainly no reasons for regarding excretions from an active fungus spore as being otherwise than probable, but fungicides act on spores when they are in the dormant condition, and can be excreting nothing; whilst it is highly improbable that they should ever start into activity, so as to produce excretions, in a liquid containing a lethal dose of copper, such as must, according to Clark's results, be nearly always present in the case of these fungicides.

The experiments at Woburn showed that there was no question as to acid excretions from fungi (XI, ro6), and that, even in cases

1 Journ. Agric. Science, III, 69; VI, 220. Their main argument is based on the fact that fungi are affected when in contact with the basic sulphate, but not affected when in the supernatant liquid from which the basic sulphate has been allowed to settle. This proves nothing. There is, of course, no such thing as actual contact in such a case: the fungus and the basic sulphate would always be separated by a film of liquid. On the one view, the basic sulphate gives off particles which pass through this film and act on the fungus; on the other, the fungus gives off particles, which travel to the basic sulphate, attack it, and then travel back to the fungus. Except for there being a single journey in the one case, and a double one in the other, the modus operandi is precisely the same, and the results can not be invoked to settle between the two views. The reason why the fungicidal action is inappreciable at some distance from the basic sulphate, is very simple: the passage of the particles of copper salt from the basic sulphate to the fungus must follow the laws of diffusion, and if when the two are in so-called contact the distance between them is, say, even as much as one-thousandth of an inch, their action on each other would be a million times greater in a given time than if they were an inch apart: if in the one case enough copper reached the fungus in one hour to affect it, it would take (in the absence of convection currents) I I I years for the same amount to reach it at the distance of one inch. No wonder that no fungicidal action was recognised by Barker and Gimmingham in the short duration of their experiments. 
where acids were present, such as in that of leaves of the nettle, no excretion of acid occurred unless the leaf was injured. But, besides acids, various organic substances are capable of dissolving copper carbonate, and decoctions made from the leaves of the apple, pear and damson were all found to do so to a notable extent. Leaves which had been injured in any way-those which had become scorched by atmospheric agency, or had been attacked by mildew-showed a like solvent action; ${ }^{1}$ but none whatever was shown by perfectly sound leaves. Leaves of the lime, horse-chestnut, etc., which naturally excrete liquids, were found to dissolve copper, even when uninjured.

Though mildewed apple twigs dissolved copper, the spores of the mildew, when separated from the twigs, were found to be quite incapable of doing so, and all the experiments which have been adduced in favour of the view that the copper is dissolved by excretions from the fungus really afford no evidence on the point, for precisely the same results may be obtained by substituting for the fungus, a piece of iron or some potassium ferrocyanide, neither of which give off solvent excretions, but which, however, show that dissolved copper is present (XI, III; XIV, App. 276). That fungicidal action may be exhibited by Bordeaux mixture while it is still alkaline is equally inconclusive, for the basic sulphates of copper will act on iron while the liquid is alkaline, so long as any of the compound $\mathrm{IoCuO}, \mathrm{SO}_{3}$ is present (XIV, App. 277; Chem. Soc. Trans. 98, I85I); added to which, lime itself possesses a certain fungicidal action (p. $194^{2}$ ).

The entry of copper into the leaf of a tree is easier of investigation than its entry into a fungus spore, and a considerable amount of literature exists on the subject, from the work of Millardet and Gayon in 1887 (loc. cit.) onwards. To the conclusions of these workers it was objected that their results were obtained by using copper solutions much stronger than those which would be present in any spraying material, but the results at Woburn (XI, II3) showed that absorption occurred, and occurred rapidly, even from the weakest solutions: sound apple leaves immersed in a solution containing $0.00 \mathrm{I}$ per cent. of copper, reduced the strength of the solution to 0.0007 per cent. in 24 hours, and to 0.0004 per cent. in three days. A highly suggestive observation was made in connection with this experiment, namely, that the entry of copper into the leaf was accompanied by the exodus of

1 Explaining the presence of dissolved copper in the drip-water from trees sprayed with Bordeaux mixture, noticed by Crandall (Bulletin I35, Illinois Agric. Exp. Station, 1810).

2 See also, Freeman, Journ. Agric. Science, III. 400. 
iron from it, the one metal probably displacing the other. How long the copper may remain in the leaf under ordinary conditions, and how far it may preserve the leaf from fungus attacks while there, requires further investigation. What is known at present is that the protective effect of spraying does not generally last for more than a few weeks, and that even this effect is not due solely to the absorption of copper by the leaf, but depends also on the deposit of fungicide left on the surface.

Clark's value for the smallest amount of copper which affected a fungus in those cases which he investigated was 0.00004 per cent. of the metal, and copper, even in some of its most insoluble compounds, will dissolve almost to this extent: ignited copper oxide in aërated water gave a solution containing 0.00003 per cent. of the metal (XI, IO9), and the action of the oxide in causing leaf-scorching was not only perceptible, but even energetic (XI, I50). The toxic effect of copper on plant-growth has been traced in water-culture experiments down to strengths of 0.00002 per cent., ${ }^{1}$ and even metallic copper itself is sufficiently attacked by water to prevent the development of plant roots in its vicinity: such roots will not grow through a sheet of clean copper gauze; but if the gauze be coated with a protective covering of paraffin wax, they will do so.

In view of these facts it is somewhat remarkable that no deleterious effect on the fertility of the soil has been noticed as resulting from spraying with copper. The application of only 6 or $7 \mathrm{oz}$. of copper sulphate to an acre would convert the water in the top 6 inches of soil into a solution containing copper sufficient to affect plant-growth, whilst the amount of copper applied may, in the case of Burgundy mixture (according to the recommendations for I9I7), amount to an quivalent of $25 \mathrm{lbs}$. of sulphate to the acre at each spraying. That even several such sprayings may not affect the fertility of the soil was shown at Woburn, where various plots of grass and of potatoes were sprayed in I9I7 with Burgundy mixture from one to seven times: in the following season the crop of grass from the sprayed plots, as compared with that from the unsprayed ones, showed an excess of 3 per cent., and a crop of onions, grown on the tilled portions of the plots, showed a deficit of $0^{\circ} 2$ per cent., such differences being quite insignificant. Yet the soil contained much copper : when sampled, fourteen months after the spraying, the top 6 inches were found to contain 0.0026 grams of metallic copper per kilogram of dried soil where there had been one

1 Brenchley, Annals of Botany, XXIV, 57I. 
spraying- 52 per cent. of the total copper which had been applied-and $0^{\circ} 005$ grams per kilo where there had been seven sprayings, this quantity representing I9 per cent. of the total applied in that case. But the copper was in a very insoluble form, no doubt in the form of carbonate, for both these samples on treatment with ordinary distilled water yielded a solution containing only I part in 2,000,000. This, indeed, is stronger than a solution which has been found to be appreciably injurious in water-cultures ( $\mathrm{I}$ in 5,000,000), but plants are, no doubt, much more sensitive to deleterious agents when they are growing under the abnormal conditions of water-culture, than when growing under natural conditions in the soil. At the same time, however, it must be remembered that soil-gases and soil-water may contain much carbon dioxide, and the presence of this would materially increase the amount of copper dissolved; hence, as a precaution, it is well to reduce the amount of copper applied in spraying as far as possible, and as far as is consistent with there being no reduction in the fungicidal effect.

\section{Copper Injury}

As has been pointed out, since a fungus and its host plant are both organisms built up of vegetable cells, it is impossible to kill the one without running the risk of injuring the other. The scorching of the leaves of the tree is generally a necessary accompaniment of fungicidal action. Much misunderstanding on this point exists in this country, growers imagining that scorching by fungicides is evidence that the spray-fluid has not been properly made.

A considerable amount of work has been done on Bordeaux injury, especially in America, and valuable information on the subject will be found in a Bulletin of 1907 by U. P. Hedrick. ${ }^{1}$ Besides references to previous work, this Bulletin contains the results of experiments made at the station in I906, and of reports received from 108 growers as regards their experiences in 1905 . On all essential points the experiments and the reports are in satisfactory agreement.

The nature of the injury inflicted by Bordeaux mixture consists in a destruction of the cells of the plant. In the case of the leaves, this causes brown patches to appear, similar to those produced by various diseases, and by frost; often the whole leaf turns yellow, and partial or entire defoliation may occur. In the case of the fruits, a similar spotting or russeting is produced,

1 No. 287 of the Geneva (New York) Station. 
and, in extreme cases, they may split, owing to the growing cells tearing themselves away from the dead ones. The spotting of the leaves is most conspicuous in parts situated under patches of the Bordeaux mixture, and seems to arise from the copper entering at the stomata, or at the base of the fine covering hairs; but the yellowing of the leaves may occur when no spotting is observed, and, in that case, the toxic substance has probably entered the leaf at the axil, where it is united to the branch. The yellowing would, on that view, depend on the strength of copper solution which happened to reach the axils, and, hence, on the weather conditions. This tallies with results obtained at Woburn : thus, in I908, a number of trees of Cox's Orange Pippin, sprayed with various copper fungicides, were so much affected that most of them become defoliated, whereas in the following season, the injury under similar treatment affected little more than I per cent. of the foliage (XI, roo).

The erratic character of Bordeaux injury is always noticeable, but it is certainly greater in damp, muggy weather, and as regards the fruit, it is more marked when this is young. According to Hedrick, the injury does not become apparent till about two weeks after the spraying, often not till after several months; but results obtained at Woburn (XI, II7) indicate a shorter interval as usually elapsing, namely, about $\mathrm{I}_{4}$ days in the case of ordinary Bordeaux mixture, and only $3 \frac{1}{2}$ days in cases where the spray-fluid contains nothing but soluble copper. It was also found that the effect occurred two or three times more rapidly in October than in August. This is not inconsistent with the effect being greater in spring than in summer, for both in spring and in autumn the leaves are in a susceptible condition, owing to extreme youth in the one case, and to extreme age in the other. Hedrick found no evidence that the lime in ordinary Bordeaux mixture produced any scorching effect, but evidence that it has such an effect has been afforded by the Woburn work (see p. I94), though the main injury done by the mixture is, undoubtedly, due to the copper.

The connection between fungicidal and scorching action is a very intimate one. In the investigations on scorching action at Woburn, two methods of procedure were adopted: in the one, leaves were immersed for (generally) 24 hours in the liquid, taken out, washed, and the percentage of leaf-surface affected estimated by an observer kept in ignorance of the treatment applied; this immersion method was applicable only in cases where the substance investigated was soluble: in the other, the 
leaves were dipped into the mixture to be examined, the superfluous liquid shaken off from them, and then left on glass plates, being kept moist by spraying with water once or twice a day.

The scorching action was found to be so dependent on the various conditions of the experiment, that determinations all made at the same time could alone be compared with each other. The action was also complicated by the occurrence of what may be termed natural scorching, due to the dying of the leaf, and the effect of this could not always be discriminated from the effect of the copper: it was insignificant in amount, however, when the treatment did not extend beyond 24 hours. It was found to be essential that all the leaves taken in any series should be of the same age, and, of course, all sound. Differences of 60 per cent. were found in the behaviour of similar leaves of different ages, the younger being the more susceptible in the case of pears, and the older in the case of apples; but this reversal with apples of what appears to be a general rule-the greater susceptibility of young leaves-was due to the fact that in this case the young leaves were more hairy than the old ones, and were, therefore, wetted less readily: rubbing the leaf, however lightly, increased the action by improving the contact with the liquid. Leaves taken in July were always found, unless they were leaves of a second growth, to be too much injured to yield concordant results; but one curious effect was noticed in their case, that the apparent scorching effect of weak copper solutions was less than that of water only. The explanation of this was, that the apparent effect is the combined result of copper injury and of the natural dying of the leaf; but this natural dying is not a simple chemical change; it is hastened by, and is, perhaps, entirely dependent on, the action of fungi, bacteria and other organisms; the copper would impede the action of these, and, hence, retard decay: in fact, copper is a preservative, as well as a destructive agent, and is made use of in the former capacity (though very improperly) for preserving vegetables.

Leaves of apples (two varieties), pears, damsons, privet and rose were examined by the immersion method in solutions of the sulphate, chloride and acetate of copper containing from 0.32 to 0.00016 per cent. of the metal. The three salts gave throughout closely similar values, the means of all the series being actually identical; so that, as regards scorching, the result is the same as that obtained by Clark in respect to fungicidal action, namely, that the effect is independent of the nature of the copper salt producing it. 
Moreover, the strengths of solutions effective in two cases are of the same order of magnitude, and must, in many cases, be identical. Thus, the scorching action, which in the strongest solutions amounted to about 90 per cent., did not entirely disappear with the weakest solutions, but at a certain strength became constant, the residual effect being evidently due to the natural dying of the leaf. On plotting out the results, it was possible to determine the point at which this constancy was reached, that is, the point at which the scorching action of the copper became nil; this varied, according to the nature of the leaf investigated-

from $\cdot 00016$ to $\cdot 0025$; mean, $\cdot 0007$ per cent. copper.

Clark's values for the smallest effective close (see p. I86), on different fungi varied-

from $\cdot 00004$ to $\cdot 00024$, mean, $\cdot 00017$ per cent. copper,

or, taking the mean of his values for the smallest effective dose and smallest lethal dose, the variation was-

from 00015 to $\cdot 0026$, mean, 0008 per cent. copper,

values practically identical with those for the scorching action.

Such close concordance is, of course, accidental, but its existence is sufficient to show how closely the scorching and fungicidal action hang together. This does not mean, however, that it is impossib'e to have fungicidal action without scorching, for both fungi and leaves vary so much in their sensitiveness - a variation of ten- to twentyfold - that a sensitive fungus on an insensitive leaf might well be affected or killed, without the leaf being perceptibly injured. Taking the particular fungi examined by Clark, and the particular leaves examined at Woburn, the minimum dose of copper which causes scorching would be four times as great as the minimum producing a fungicidal effect.

When the various series of results on scorching were examined by plotting them out in a certain way, it was found that they all lay on straight lines, the nature of the equation expressing these lines ${ }^{1}$ implying that a large increase in strength produces only

1 The effect is represented by the equation $\log \frac{p}{a} \times \frac{b}{2 \log .2}, p$ being the percentage of copper, and $a$ and $b$, constants which would vary with the particular leaves taken, the former being the percentage strength at which the action ceases, and the latter the rate of increase of the action with the strength. 
a small increase in effect. This explains why attempts to determine the most efficient strengths of copper fungicides so often lead to contradictory results; for a doubling of the strength produces such a small increase in action, that this may be entirely counterbalanced by chance differences in the conditions attending the spraying.

Experiments made by the dipping method gave results similar to those made by the immersion method, except that the values throughout were only about one quarter as large, a consequence, of course, of there being a smaller amount of substance available on the leaf; and in this case the progress of the scorching could be followed throughout nine days, and was found to proceed at a uniform rate of II to I4 per cent. per diem.

It was proved that lime in water exercised a decided scorching effect on leaves, and presimably, therefore, would act as a fungicide, so that part of the efficacy of ordinary Bordeaux mixture must be attributed to the excess of lime in it. Such an action was further manifested in the fact that when older leaves were taken, lime had, just as in the case of copper, a preservative, or anti-scorching, effect (XI, I5I). Water alone appeared to have a scorching effect in the case of older leaves, due, no doubt, to the moisture favouring the development of the destructive organisms present.

In one respect the scorching and fungicidal effect did not appear to go together: Clark found that the presence of neutral salts, such as potassium sulphate, increased the fungicidal action of copper (p. I86), whereas it was found at Woburn that scorching action was reduced by the presence of this salt. There is, however, no difficulty in reconciling these opposing results-provided the action of the salt be explained on physical grounds, instead of on the chemical grounds (quite unacceptable) suggested by Clark--for vegetable cells of a different character behave very differently as regards exosmosis, and such differences probably exist between those of leaves and those of fungus spores.

A considerable amount of work was done in an endeavour to determine the nature of the action of electronegative copper on the leaf, and presumably, therefore, on the fungus. As copper in this condition passes spontaneously, or by the action of the air, into the ordinary form, it would be impossible to recognise any difference in the action of the two forms, unless the electronegative copper was the more active; all the experiments showed that this was not the case. The probability, indeed, was that electronegative copper, as such, had no scorching or fungicidal 
action, and produced an effect only by becoming converted into electropositive copper (XI, I32).

The extent to which a fungicide is capable of wetting the leaf or the fungus, must be an important factor in determining its efficiency. Soap, as is well known, possesses great wetting powers, but it cannot be used with copper compounds, as it forms with them an insoluble copper soap. Saponin (or quillaia, which contains saponin) possesses still greater wetting powers, and so its effect on the scorching action of copper compounds on leaves was examined. Leaves dipped into a solution of saponin were found to retain two to four times as much liquid adhering to them as when they were dipped into water: possibly, however, this gives an exaggerated estimate of the wetting powers of saponin, for some of the liquid is spread over the leaf in the form of a film, stretching from point to point, without really wetting intermediate portions : a rose leaf wetted, apparently, by saponin, when put in a stream of water, comes out practically dry, showing that no actual wetting of the surface has taken place. The addition of saponin to copper sulphate was found to have no appreciable effect on the scorching action of the latter; the results of several series of experiments with different sorts of leaves showed an increase of only a few units per cent. (XI, I63). With the basic sulphates of copper, however, the presence of saponin did produce some increase in the action, though not uniformly so in every series; but this increase was probably not due to any increase in the wetting of the leaf, but to the fact that the saponin, when present in quantities exceeding a certain proportion, dissolves the basic sulphate entirely. Such a solution is, of course, open to all the objections applying to the use of a mere solution as a fungicide (p. I75), and thus the addition of saponin to copper fungicides cannot be recommended. It might, of course, be of value in the case of some insecticides. 


\section{Chapter XX}

\section{INSECTS}

\section{Mussel Scale (Reports, VI, 6; VIII, 33)}

THE common mussel scale (Lepidosaphes ulmi) is one of the best known coccid pests, attacking the pear, hawthorn and other plants, besides the apple. It owes its common name to the resemblance of the scale to a minute mussel shell, but another name is also given to it in America and Canada (and also by our Board of Agriculture), namely, that of the "Oyster-shell bark louse," although it bears no resemblance to an oyster-shell, and although, also, that name has already been applied appropriately to another scale-Aspidiotus ostreceformis - met with only under glass in this country. ${ }^{1}$

The mussel scale may be found thickly studded over the bark of apple trees (Fig. 20), especially on those parts of the tree where growth is not very active, as the trunk, main branches and fruit spurs. It may easily be removed with the finger nail, and, when examined under the microscope, will be seen to consist of a shell covering a large number - often 40 or $50-$ of white eggs (Fig. 2I). The insect itself is much smaller than the scale which it manufactures, and occupies only the apex of this latter; but, as it dies in September, nothing can be seen during the winter but the remains of its shrivelled body, and the eggs which it has laid. At the end of May or the beginning of June (or up to the end of June, according to Canadian authorities), the eggs hatch out, giving rise to active white larvæ; these soon fix themselves to the bark, from which they suck the sap, and begin covering themselves with scale. The male insect is winged, and is exceedingly rare; it forms a much smaller scale than the female insect.

These insects have enemies: ladybirds and their larvæ eat them, and the larvæ of a species of chalcidida (Aphelinus mytilaspidis) are often found in large numbers under the scales, feeding on the eggs. These, however, are much localised, and even

1 See Newstead, Journ. Roy. Hort. Soc., 1900, 236. 


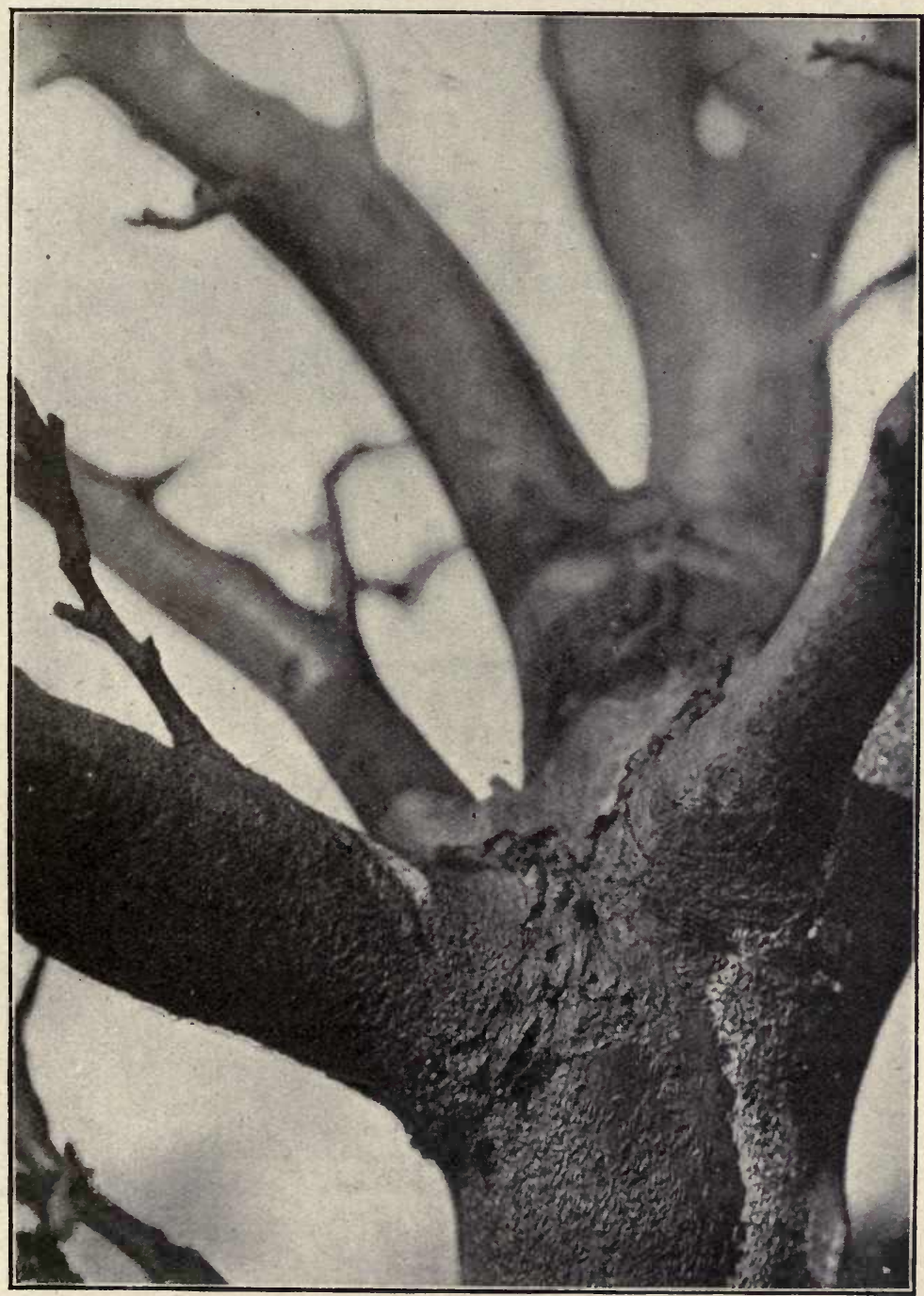

FIG. 20.-APPLE TREE INFESTED WITH MUSSEL SCALE. 
an abundance of their food supply does not appear to ensure their spread and multiplication. In I904-5, when the mussel scale was first investigated at Woburn, the chalcids were not very prevalent, but in I906-7 they were so numerous as to interfere materially with the experiments: on the average 50 per cent. of the scale eggs were destroyed by them, often every egg under a scale having been depleted of its contents, though many of the scales had escaped altogether. ${ }^{1}$ Generally a more important enemy of the scale is the tit, aided, perhaps, by some other birds, and branches will often be found to have been quite cleared of scale by them. Unfortunately the birds can reach only certain parts of the trees, so that their good offices can never be effectual in ridding these of scale.

From this brief account of the mussel scale it will be seen that any spray-fluid used between September and the end of May can do no good, unless it destroys the eggs, the insect itself being already dead; moreover the fluid, in order to reach the eggs, must soak in under the scale. Perhaps the chalcidide just mentioned are of more use indirectly than they are directly, for they bore a hole in the scale, and this facilitates the entry of any spray-fluid. A greater destruction of eggs by insecticides was found in the case of scales which had becn thus bored, than of those which were intact. Under normal conditions, and in the absence of spraying, less than 20 per cent. of the eggs hatch out.

It is evident that the time when the scale-insect is most vulnerable is in June, shortly after it has hatched, and, if it can be reached then, a mild insecticide, such as a weak paraffin emulsion, or even quassia and soap, might be sufficient; but it is hardly possible to effectually spray the branches and spurs when the trees are in leaf, and, moreover, the period in the summer when the scale is vulnerable is a limited and variable one, and the proper time for doing it might easily be missed by the grower. The inefficiency of summer spraying in the corresponding case of the San José scale has been recognised in America. ${ }^{2}$

Although it must be admitted that an insect which lives on the sap of the tree cannot be otherwise than injurious, it is questionable whether the damage generally done by scale may not have been exaggerated. In a plantation where scale exists, it

1 See also Canada Expt. Farms' Report, 1903, I 88.

2 The case of this very serious pest is not quite similar to that of the mussel scale, as the insect is generally viviparous. Much work has been done on it in Canada and the United States, a summary of which will be found in the Woburn Report, VI. p. I50. 


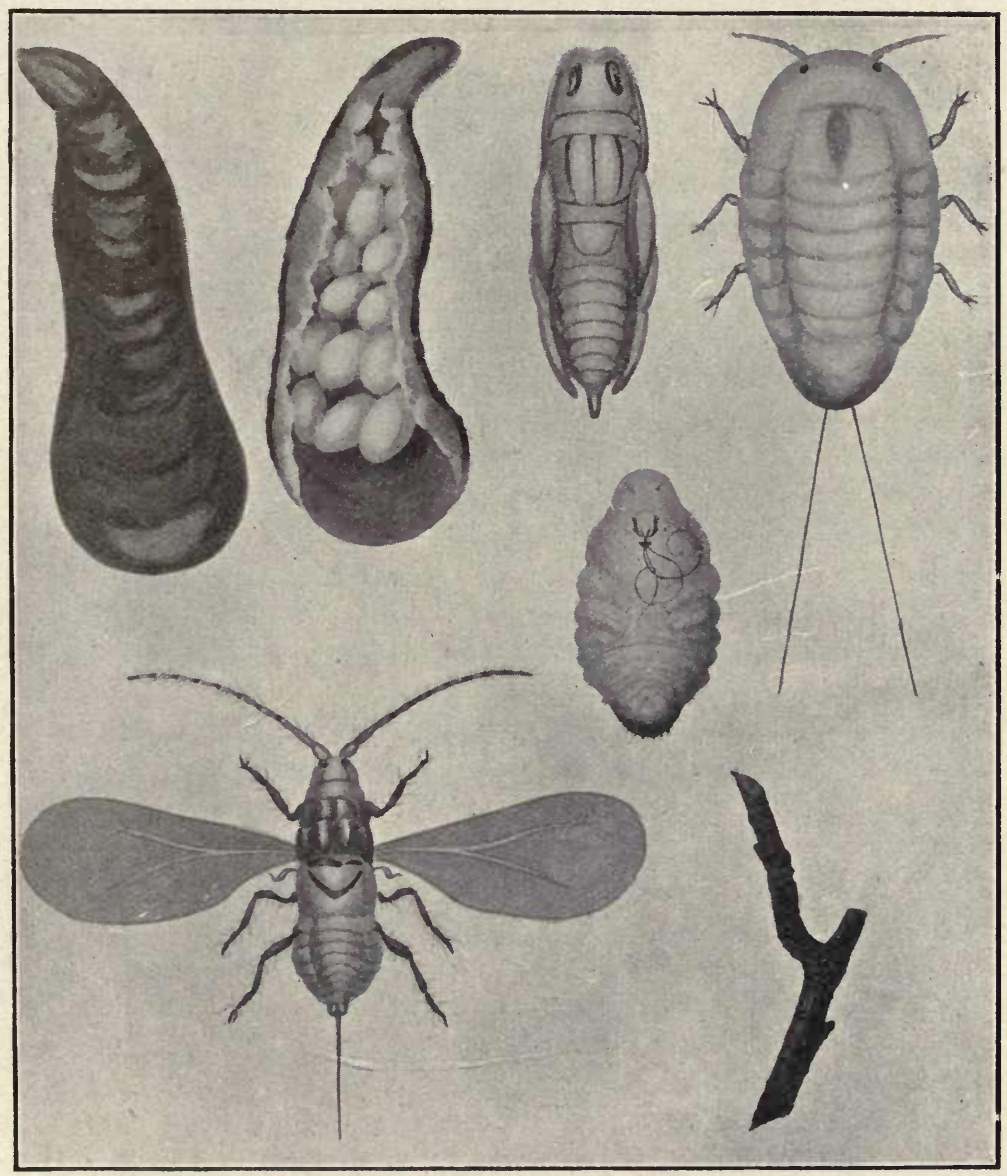

Scale with eggs. Length of scale, one-sixth of an inch. Female insect in different stages of development. Winged male insect.

FIG, 2I,-MUSSEL, SCALE (Lepidosaphes ulmi). 
is usually found that those trees which are attacked most freely, are the ones which are the most stunted; and it seems probable that in many cases the scale is the consequence, and not the cause, of this stunting. Thus, from a plantation where a certain amount of scale existed, some 200 trees were moved, at an age when removal checked their growth for several years: all the moved trees were found to become covered with scale to a very much greater extent than their former unmoved neighbours, and the only possible conclusion was that stunting was the cause. of this increase. Nor is it difficult to see the reason of this, for a tree which is in active growth must, even during the winter, experience such expansion and contraction of its bark as would loosen the attachment of the scales to it, and render the removal of these by heavy rain or other agents a simple matter. In the case of the drier bark of a stunted tree, the scales would remain unloosened. ${ }^{1}$ Nevertheless, when the scale has increased to such an extent as to cover the greater part of the bark, it cannot be doubted that the amount of injury done by it will be very serious, if not fatal.

It may be laid down as a general rule that the examination of the action of insecticides or fungicides should consist of two parts: laboratory experiments, in which the action on the insect or fungus to be destroyed is studied under the most exact conditions possible; and field experiments, in which the insecticide is applied to the trees in the plantation itself, under the variable conditions existing in practice. Laboratory experiments are necessary, not only as forming the groundwork for trials in the ficld, but they are essential in affording a check on the results of the latter; for field trials may often fail owing to a variety of accidental circumstances, generally dependent on the weather, and, in the absence of more precise evidence to the contrary, any failure of this sort may lead to very erroneous conclusions. The investigations at Woburn afford striking examples of cases where experiments, had they been confined to trees growing in the open, would have led to nothing lut conflicting and misleading results.

Laboratory experiments, however, should be rendered as nearly similar as possible in all essential features to field trials. In the case of those on mussel scale, they were made on the scales while these were still attached to infested branches which had been severed from the trees, and they were kept in the open

1 See Marlatt, Year Book of U.S. Dep. of Agric., I9oo, p. 248. 
air during treatment, though protected from the rain. One series of experiments was conducted in February and March I905. whilst eleven other series extended from November I905 to May I906.

The effect of the application was measured by examining at intervals under the microscope 20 to 80 scales from each branch, and ascertaining the percentage of eggs killed. The change in the appearance of the eggs when affected is not difficult to recognise: from being white and opaque, they become transparent, and, as the action proceeds, turn brown, and become shrivelled. So far as could be ascertained, the change showed the same characteristics in all cases where any action occurred. The effect of an insecticide on the eggs is easily distinguishable from that of the parasitic chalcid when it attacks them, for this insect confines its attention to one egg at a time, and sucks all the contents out of it, till nothing but the empty egg-sack is left.

The efficacy of an insecticide for scale must depend conjointly on its virulence in destroying the eggs, and on its power of getting at them, by soaking under the scales, for the substance of the scale itself is most resistent, not being destroyed by even a Io per cent. solution of caustic soda. Various experiments were made to ascertain whether, in consequence of the branches having been severed from the trees, any drying up of them occurred, sufficient to. affect either the adherence of the scales to the bark, or the vitality of the eggs: but the results were satisfactorily negative (VI, 34).

As a rule, though with sundry exceptions, the effect of the insecticide was complete within I4 to $2 I$ days. In the spraying of trees in the open the action might be more prolonged, owing tc it recrudescing after a fall of rain (see p. 209), but, as the application of the insecticide by means of a spraying machine would be less perfect than that by means of a paint-brush in the laboratory experiments, the sum total of the effect could not be assumed to be the greater with the growing trees.

In the first place, it was ascertained that the destructive action of caustic alkalis when these were used alone, and in solutions of moderate strength, was very small. Out of 37 cases where they were tried, at strengths ranging up to 2 per cent. of caustic soda or its equivalent of caustic potash, no mortality was observed, except in three instances, and then it amounted to only 2 per cent. Even with three or four dressings, and with the 
strongest solutions ( 2 per cent.), a mortality of only io per cent. was ever reached. As has been already mentioned (p. I65), a mixture of the two alkalis produced no better results than either of them separately. Subsequent experiments showed that an almost complete mortality of the eggs might be obtained by increasing the strength of the soda up to 2.5 to 3 per cent., but, unfortunately, such a strength cannot be used without risk of damage to the trees, and danger to the workmen (VI, 53; VIII, 4I).

Although the effect of the 2 per cent. alkalis on the eggs is so small, their inefficiency as insecticides is not so complete as might be inferred, for they appear to glue the scales on to the bark so effectually, that the egress of the insects after hatching is prevented (see p. 207). This glueing down of the scales is preceded by their being softened and loosened. A similar action in the case of lime-sulphur and res ir-soap washes has been noticed in America in reference to the San José scale. ${ }^{1}$

The next point examined was whether the destructive action of alkalis could be enhanced by the presence of small amounts of paraffin, soap or treacle. With treacle $(0.6$ per cent. of the liquid) no improvement was obtained: with soap (up to 0.6 per cent.), and with weak paraffin emulsions ( $1 \cdot 25$ per cent. of paraffin), there was some improvement, but the mortality did not exceed Io per cent., and, therefore, could not be regarded as satisfactory. The effect of using methylated spirits, both by itself, and as a substitute for the whole or part of the water in these alkaline solutions, was examined, with the result that it appeared to be nil, and, as regards the removal of moss from the branches (which is one of the desirable functions of any winter wash), the use of water as a solvent was preferable (VI, 73).

The addition of larger amounts of soap to the alkaline washes gave much more satisfactory results. These may be summed up as follows-

Soda 2 per cent,

\begin{tabular}{|c|c|c|c|}
\hline Soap, & \multicolumn{3}{|c|}{0.63 per cent } \\
\hline , , & I & , & , \\
\hline ,', & 2 & ,', & , \\
\hline ," & 3 & ", & , \\
\hline , & 4 & ', & \\
\hline, 5 & & ,, & \\
\hline
\end{tabular}

Mortality

caused.

II per cent.

28

49

85 ,", ,

$76, .$,

$70,, \quad$,

1 Lowe \& Parrott, Geneva, N.Y., Bull., 228. 
Thus, with anything above from 2 to 3 per cent. of soap the mortality is about 70 per cent., and, when an allowance is made for the probability that many of the apparently unaffected eggs have been too much injured to hatch out, the real effectiveness might be placed even as high as 90 per cent.

But the addition of so much soft soap to a solution of soda presents mechanical difficulties, for a curd of hard soap separates, occupying quite half of the liquid, and rendering its use as a spray-fluid impracticable. This difficulty might be obviated by keeping the mixture warm during use, or keeping the constituents separate till they reached the trees, by using two jets : but both these devices would complicate spraying operations considerably. The substitution of the more expensive caustic potash for caustic soda does not improve matters, for, though little actual separation of soap takes place in such a case, the mixture is too viscid for spraying purposes, and eventually gelatinises.

Observations made in connection with these soap-soda solutions suggested that the liquid filtered from the curd gave nearly as high an insecticidal value as the mixture itself. This filtered liquid would contain none of the soap, and only such constituents of the soap as were soluble, the chief of which would be glycerin. This, however, would be present in the liquid to the extent of only 0.12 per cent., at most. Some independent observations seemed to confirm the view that glycerin, even in such small quantities, considerably enhanced the action of the alkalis, but that no proportionate further enhancement occurred when the proportions were increased to $I$, and even Io per cent. The possibility of traces of certain substances modifying insecticidal action, though not, perhaps, fully established in this case, is certainly one which should be borne in mind (VI, 65; VIII, 43).

The results obtained with undiluted paraffin oils have alieady been referred to (p. I53), and they showed that, provided the oil contained a sufficient proportion of high-boiling paraffin, complete destruction of the eggs of the mussel scale could be effected. But the danger to the trees attending the use of such undiluted oils, puts them out of court, and their use in the diluted condition as an emulsion was not attended with success. Even when the emulsion contained as much as I5 per cent. of the oil, less than half the eggs were killed, and, judging by the results obtained in America with, San José scale, it would require the presence of 25 per cent. of oil to produce satisfactory results (VI, 83 ; VIII, 44). 


\begin{tabular}{|c|c|c|c|c|c|c|c|c|c|}
\hline & $\begin{array}{l}\text { Em } \\
\text { per }\end{array}$ & ent. & and & & & & \multicolumn{3}{|c|}{$\begin{array}{l}\text { Mortalitv } \\
\text { of eggs. }\end{array}$} \\
\hline I & per & en 1 & raffin & - & - & & $\mathrm{O}$ & per & cent. \\
\hline 2 & , & ," & ," & - & - & • & o & ," & ", \\
\hline 4 & ," & ; & ," & - & - & • & 0 & , , & , \\
\hline 6 & , & , & , & - & - & • & I5 & , , & ,' \\
\hline 8 & , , & , & , & - & - & & I3 & , & ," \\
\hline IO & ,' & ', & , & - & - & & 40 & , & , \\
\hline 15 & , & ,, & , & . & . & . & 43 & , , & , , \\
\hline
\end{tabular}

Following the indications already obtained in other cases, it was considered possible that, whilst a moderately strong emulsion, and also an alkaline solution, might both be ineffective separately, yet when acting together the results might be satisfactory. At that time the emulsifying powers of the basic sulphates of iron, etc., had not been ascertained, and the emulsions used were made with soap. The addition of alkali to these separated soda-soap, and the emulsion was converted into a quasi-emulsion (see p. I59), which could not be applied so satisfactorily as a true emulsion: yet in spite of the irregularities attributable to such a cause, the general results showed considerable uniformity. Thus-

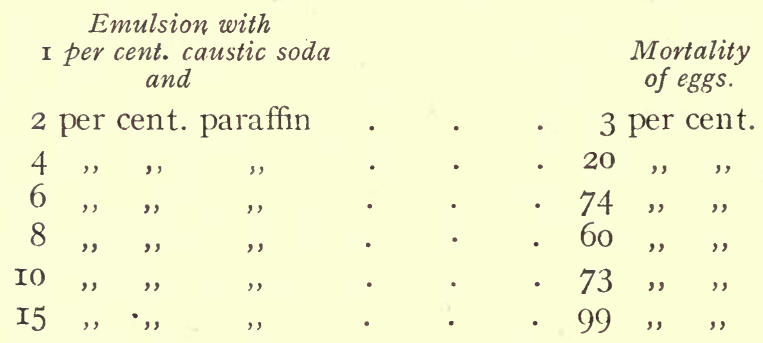

The 6 per cent. paraffin emulsion by itself, according to the results previously quoted, caused a mortality of only I $_{5}$ per cent., and the I per cent. solution of caustic soda by itself caused no mortality at all (p. 20I), but the two together caused a mortality of 74 per cent.; and this probably understates the true effect, for in I2 out of the I7 sets of observations on which this value depends, the mortality was complete, the mean value being pulled down by five cases where exceptionally low values were obtained, doubtless owing to the difficulty in applying a quasi-emulsion satisfactorily. The efficiency in all these cases was also under-estimated from the cause mentioned on p. 207.

Various subsidiary questions in connection with these caustic 
emulsions were examined, such as the character and proportion of the soap used, and the nature of the oil. Out of five brands of soap examined, four gave practically the same results, and the proportions used could be reduced without detriment from the I per cent. taken in the above series, to 0.3 per cent.; whilst any oil, so long as it was not more volatile than an ordinary lighting oil (used in the above series) gave equally good results, the heavier oils, however, producing such results more rapidly. A subsequent examination of the action of these caustic washes in removing moss from trees showed, however, that for that purpose the proportion of alkali must be increased up to 2 or $2 \frac{1}{4}$ per cent. of soda, and with such an increase, and the substitution of iron sulphate as an advantageous substitute for soap in emulsifying the oil, the winter wash for which the formula has been given on p. I60, has been advocated (VI, 87; VIII, 46).

This wash has been in use at Woburn for ten or twelve years, and both as regards mussel scale, as well as other pests, it seems to have been eminently successful. The mussel scale which was very prevalent throughout the ground, has practically disappeared; indeed, after its first application, the scale had been so effectually destroyed, that sufficient was not found for further experiments on the subject, and material had to be obtained elsewhere. For cleansing purposes it need be applied only once every three years.

Its effect is more satisfactory when the date of its applicatior is deferred as long as possible : one series of experiments (VI, I33), for instance, giving-

Applied.

Dec. I5.

Jan. 6-22

Feb. $18-25$
Mortality

of eggs.

30 per cent.

42 , ,

99 " ,

whilst in another series (VIII, 54) an application in December proved less satisfactory than applications on January $3 \mathrm{I}$ or March I5. No damage attending its use has been noticed, even when the spraying was deferred till the end of March, except in the case of some gooseberries, which were then in leaf, and no permanent injury was caused even to them. It has also been used without bad effect on peaches and nectarines, when the buds were almost bursting.

Various other substances were examined for destroying mussel scale, without any indications being obtained that they would 
be preferable to the caustic emulsion. Thus: a 2 per cent. solution of copper sulphate caused no appreciable mortality, even after repeated sprayings, and a I per cent. solution of sulphuric acid proved little better. Turpentine, though fairly effective, was much less so than paraffin. Lead arsenate and sodium arsenate had some slight effect on the eggs. A Io per cent. milk of lime effected no mortality on one application, though a second application resulted in 20 per cent. of the eggs being killed. No higher percentage than this was obtained with a lime-sulphur-salt wash, or a lime-sulphur-soda wash, whilt various solutions of sulphides gave still more unsatisfactory results (VI, 99).

A good deal of attention was devoted to the question whether lime could not be substituted for the caustic soda in the caustic emulsion, and, also, whether the efficacy of a lime-sulphur wash could not be satisfactorily enhanced by the addition of paraffin. Some enhancement, indeed, appeared possible; but as the manufacture of such a wash is much more complicated than that of a soda-paraffin wash, there did not appear to be any advantage in adopting it. The substitution of lime for all or part of the soda in the simpler caustic emulsion, resulted in a reduction of efficiency (VIII, 48).

A Io per cent. solution of brine or of calcium chloride was found to be fairly effective, killing 30 to 45 per cent. of the eggs (VIII, 53).

Fumigation with hydrocyanic acid was also tried, owing to its having been recommended by the Board of Agriculture for the destruction of mussel scale. It has been used in America for destroying San José scale on peach trees, the trees being covered by tents during the fumigation. Such a process is not likely to be adopted in this country at present : but fumigation might be applied to trees before planting, placing them in closed chambers. A process which is effectual with San José scale, might, however, be quite ineffectual with mussel scale, where the eggs, and not the live insects, have to be killed. To examine this, some pear trees affected by scale were covered over with felted boxes, and fumigated. ${ }^{1}$ The scales themselves seemed to have been shrivelled and rendered brittle by the process, but they regained their former condition before long, and the eggs were found to have been uninjured. Very considerable injury, however, was

1 Using the high proportion of $\frac{1}{2} \mathrm{oz}$. of sodium cyanide (equivalent to 2 oz. of potassium cyanide) to every roo cubic feet in one case, and double this dose in another. With potassium cyanide, $\mathbf{I} \cdot 3 \mathbf{o z}$. is equivalent to $\mathrm{I} \mathrm{oz}$. of sodium cyanide. 
done to the trees, and three out of four of them were killed (VI, 99).

In all these cases, the effect of the various treatments had been measured by the change in appearance of the eggs, and it was naturally advisable to check the conclusions obtained in that way, by some other method. With this object, branches of trees affected with scale were painted with different insecticides on March 8, and were severed from the trees on May 15 , three weeks before the hatching began, the number of scales on each branch being then counted. The branches were placed in covered glass jars, after the ends of them had been sealed with paraffin wax to prevent evaporation, and the insects as they hatched out, were counted every day, and removed: some branches which had had no dressings were treated in the same way for the sake of comparison. The hatching period extended from June 6 to 23 ; and the total number of eggs hatched in any one jar varied from over 3000 to nil. Naturally, the results were subject to many sources of uncertainty, but a comparison between them and those based on the examination of the eggs, led to interesting conclusions. In the case of treatment with hydrocyanic acid, both methods showed that the treatment was quite ineffective; in the case of treatment with five different paraffin oils, and with two strong soap-soda solutions, both methods led to the same estimate of the efficiency of the treatment, the mortality in those cases having amounted to $80-90$ per cent. : but with the simple emulsions the hatchings gave a much higher estimate of efficiency ( 77 per cent.) than the examination of the eggs had done (I8 per cent.), indicating that the paraffin had injured many of the eggs which had to all appearances been unaffected. A similar result was obtained with the emulsions containing caustic soda, the actual mortality being 94 per cent., against one of 60 per cent. as deduced from the examination of the eggs in these particular cases. Thus with all emulsions the method of examination first adopted had led to an under-estimation of effect.

That, however, was subsequently found not to be due so much to the eggs having been injured without showing any signs of that injury, but to the fact that these signs make their appearance slowly, and that the two or three weeks' interval all wed in I904-5 between the treatment and the final examination of the eggs, had not been sufficient to permit of the injury becoming fully developed (VIII, 46).

In the case of the simple solutions of caustic soda, or potash, 
there was a much greater discrepancy between the results of the examination of the eggs and the hatchings, for the former, in the instances selected, had indicated a mortality of only 5 per cent., whereas the hatchings showed a mortality of as much as 96 per cent. This high value, however, was in a sense fictitious, for on examining the contents of the scales, it was found that the eggs had not really been killed, but that the insects had hatched out, and had been unable to emerge from the scales, owing to these having become glued to the bark (see p. 202).

Though the ultimate effect of simple alkalis may thus be as good as that of alkaline emulsions, a preference should certainly be given to the latter, for it is evidently better to kill the eggs, than to trust to the glueing of the scales to the bark, as this may be much influenced by the weather conditions, the date of the spraying, and the condition of the wax forming the scales; for it was noticeable that in many cases the scales had not become glued down, and that then there was a free hatching of eggs (VI, II4). It seems probable that, where aqueous solutions of alkalis of not more than 2 per cent. strength are used, the alkali never penetrates at all to the eggs, and that the great enhancement of effect obtained by the addition of soap, paraffin, etc., to the alkali is due to their enabling the liquid to soak in between the scale and the bark, and thus reach the eggs. This also happens when the strength of the alkali is sufficient to destroy the substance of scale, as when $2 \cdot 5$ to 3 per cent. solutions are used.

In practical spraying the application of the wash is necessarily less perfect than when it is applied, as it was in these experiments, by means of a paint brush, and a 90 per cent. efficiency is the maximum which might be anticipated with the most effectual wash. If, as the Woburn results indicated, 20 per cent. of the eggs in the untreated scale hatch out, and the:e are on the average 40 eggs under each scale, a 90 per cent. efficiency would reduce the number of insects hatching to about one per scale, and, as there must be a considerable mortality amongst the insects after they are hatched, the pest would, at this rate, very soon become exterminated. This is in accordance with the practical results obtained at Woburn (see p. 205).

For a more rapid riddance of this pest, winter treatment of the trees may be supplemented with summer treatment, as is now generally recommended in the case of the San José scale: for this purpose a weak paraffin emulsion, such as that mentioned on p. I60, may be used, spraying it on to the trees, or 


\section{INSECTS}

preferably painting it on with a hard brush, when the insects are emerging from the scales (VI, I23).

The effect of rain after the application of an insecticide was examined by comparing the results obtained with two sets of branches infested with mussel scale, both of which had been painted with various insecticides, but in one case without, and in the other case with a wetting of water, this being applied by means of a scent sprayer, a few days later. The results showed that the wetting had no effect in all those cases where the wash was weak or ineffectual, and had left no appreciable amount of substance on the bark, whereas with stronger washes, which had already much damaged the eggs, that damage was materially increased by the subsequent wetting, the extra dose of insecticide thus reaching the eggs, though probably very small, being sufficient to kill many eggs which had already been injured by the original application. This was very noticeable in cases where the washes contained much soap or nonvolatile paraffins (VI, Io6). The manner in which rain, falling after the spraying, enhances the action of an alkali, has already been explained (p. I66).

These experiments on scale brought into prominence some of the conditions on which the successful action of insecticides depends : namely, a sufficient prolongation of the action, and the cumulation of independent actions which, by themselves, might each be inoperative. The effect of rain after spraying is, as just stated, due to insecticidal action being prolonged, and other instances leading to the same conclusion may be quoted: thus, three applications of the same weak insecticide caused far more than three times the mortality that one application did, and the effectiveness or non-effectiveness of various paraffins was, also, entirely a question of the duration of the action, as determined by the volatility of the particular paraffin (p. I53).

The cumulative effect of insecticides which, separately, have but little action, was demonstrated fully by the action of soapsoda solutions, and emulsion-soda washes, as compared with soap alone, soda alone, and emulsions alone. Even an emulsion-soda wash may be thoroughly effective when made with a paraffin which by itself is comparatively inoperative, though the emulsion contains only 6 per cent. of that paraffin, together with a percentage of soap and soda, neither of which alone are capable of occasioning an appreciable mortality.

These facts led to some questions of fundamental importance. Why, and how, do these insecticides destroy the eggs; what are 
the changes which they themselves undergo when they are sprayed on to trees?

As to the changes undergone by the insecticides, but little work has been done, except in the case of lime-sulphur washes in America, ${ }^{1}$ and in that of alkaline washes at Woburn (p. I66): as to the action of the insecticide on the eggs, there are three main possibilities.

Firstly, the action may be a mechanical one, the insecticide coating the eggs so as to deprive them of such access of air and moisture as may be necessary for their development. This is not a very acceptable explanation, as the eggs are in a dormant condition, and even the drying up of the infested twigs produces no visible effect on them. The glueing of the scales to the branches is another form of mechanical action which certainly is operative in one case.

Secondly, the action may be of a physical character, the watery contents of the egg-cells being drawn out by the insecticide, through plasmolytic action. The mussel scale eggs when immersed in brine, become shrivelled up and killed in this way. But most of the insecticides used are too weak to effect appreciable plasmolysis, and some of them, such as paraffin, would not produce plasmolysis at all.

Thirdly, the action may be purely chemical, the insecticide destroying the cell-walls, and gaining an entry into the cells. This is, perhaps, the best explanation, but one which is not free from difficulties. It harmonises with the alteration in colour observed in the eggs when they have been attacked (see p. 20I), and it is an action which substances such as the caustic alkalis, paraffin or sulphuric acid are capable of causing. On the other hand, it does not remove the difficulty of explaining why the action of caustic alkalis in aqueous solution is so feeble in comparison with their action when a certain amount of soap, or other substances, is present with them; nor does it explain altogether how the action becomes so much enhanced by subsequent wetting. It can only be suggested that moisture, being necessary for the chemical action, the presence of soap, glycerin, etc., helps to attract or retain this moisture, and so prolongs the action till the cells are effectively destroyed; whilst in the case of both those substances, as well as of paraffin, the penetrative power of the wash is enhanced by their presence (see p. 208).

1 Haywood, Journ. Amer. Chem. Soc., 27, 3, 224; Smith, Nere Jersey State Bull., I $78,8$. 
What the destructive action of paraffin on vegetable and animal cells consists of, we do not exactly know, but it is probably a reducing action, the paraffin abstracting oxygen from the substance in the cells (VI, I23; cf. p. I6I).

Evidently there is much still to be learnt as to the nature of insecticidal action. 


\section{ChAPTER XXI}

\section{INSECTS (continued)}

\section{Currant Gall Mite (Reports, II, 7; XIV, 69)}

THE Black Currant Gall Mite, or Big Bud (Eriophyes ribis, Nalepa), is an insect which is very prevalent, and one which constitutes a serious drawback to the cultivation of black currants in this country.

The mites enter the buds during the summer, and from that time onwards they rapidly increase, so that, by the commencement of winter, the interior of the buds are swarming with them. As many as 3000 have been counted in a moderate-sized bud. Before June many of the mites leave the old buds, and lay their eggs on the newly-formed shoots, between the leaf stalk and the young buds. Before the end of July some of them have entered the young buds, and by the end of September many of these latter show the undoubted signs of infestation, being rounded and much swollen (Fig. 22). The mite then remains in the bud, which continues to swell, and it survives the cold of winter, without any evil effect beyond a certain amount of sluggishness, which disappears as soon as the temperature rises. The buds which are infested, though they may expand, do not develop, and as the season progresses, they dry up and die. Whether the majority of the mites leave them before then, or not, is uncertain, but the dead buds always contain a mass of dead mites.

Where this insect originated is not known, but records of its existence in Scotland date back to I850. Any attack on it is beset with difficulties. Its minute size renders transportation by the action of the wind and other agencies a matter of great ease: its period of activity, while migrating from bud to bud, is a very extended one, and, apparently, covers nearly the whole time during which the bushes are in leaf; and while enclosed in the bud it is thoroughly protected from the action of most insecticides, the currant bud being especially compact and close-knitted in structure. 


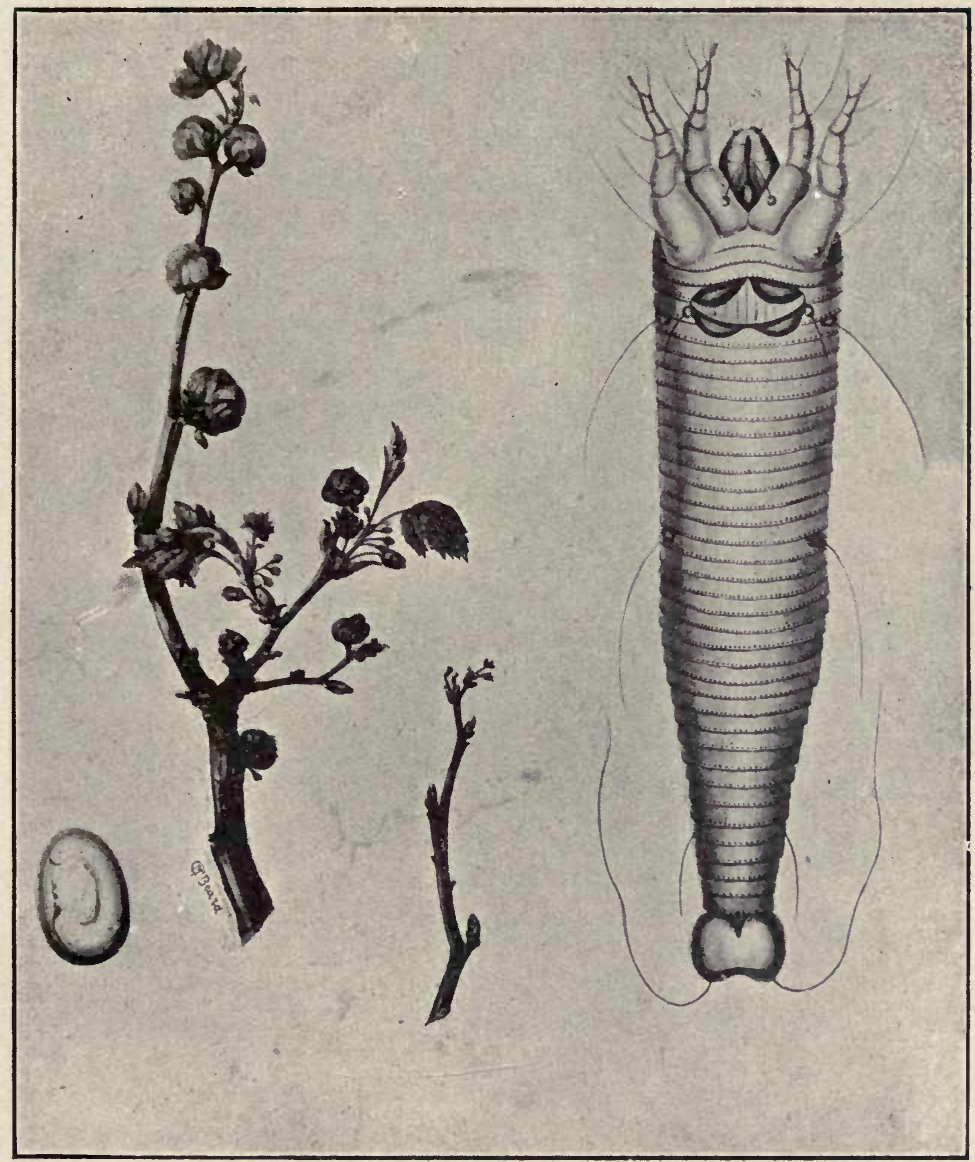

Branches of black currants showing rounded swollen buds infested by the mite, and smaller pointed buds not infested.

Length of insect, one-hundredth of an inch.

FIG. 22.-CURRANT GALL MITE -(Eriophyes ribis). 
The bushes which formed the subject of the experiments at Woburn (II, 7; XIV, 69) were, for the most part, planted in the autumn of I895, and formed an extensive, but not crowded plantation. The varieties composing it were Black Naples and Baldwin's Black. Though the ground had never been used for growing black currants before, signs of infection by the mite appeared in 1896 , and, in spite of continuous removal of the affected buds, the disease increased rapidly. Thus, in the case of five selected bushes, where the affected buds were counted and removed each year, the average number of them in three successive years were 933, I797 and 6875.

Experiments with various insecticides were carried out in I897 and I898, with the assistance of Mr. R. Newstead and Miss Ormerod. They consisted in either spraying or painting the bushes with, or lifting and dipping them into, various liquids, the sprayings being repeated once a month, but using the sprayfluids at a continually diminishing strength after the buds had expanded. Thus, with paraffin emulsion, various strengths up to Io per cent. were used on the bushes while dormant, and whatever the initial strength was, it was gradually reduced to I.25 per cent. before the end of the season. The buds were examined microscopically one week after each treatment from February 26 to September 22 . In the first series of experiments the substances used, and the maximum strength at which they were applied, were-

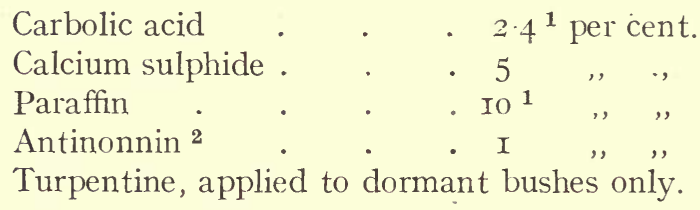

In the case of the bushes treated with turpentine, all the mites were found to have been killed, and in those treated with the strongest carbolic acid and antinonnin, half of them were killed. But such success was useless, for all three of these dressings had seriously injured the bushes, partially killing them, and entirely killing the buds, so that the mites may have been killed only as a consequence of having had their food supply cut off. A good deal of injury to the bushes was done by the

1 Carbolic acid, 2 per cent., and paraffin emulsion, 5 per cent., had been recommended by the Board of Agriculture for the destruction of the mite.

2 Sodium orthodinitrocresylate. 
calcium sulphide, and some little by the paraffin emulsion; but neither of these had affected the mites; and, even in cases where the bushes had been cut down before treatment, the new growth was found to be heavily infested.

In the following season further series of experiments were conducted, monthly applications of the following substances being made-

\author{
Methylated spirits, 50 per cent. \\ Naphtha. \\ Naphthalene in naphtha. \\ Formalin, 2, 0.5 and 0.1 per cent. \\ Paraffin. \\ Paraffin emulsions, 40 and 20 per cent.
}

but in no case was any effect on the mites observed. It was noticeable in these experiments that the undiluted paraffin did much less harm to the bushes than the strong emulsion, a fact which has been observed in other cases as well (p. I55).

That bushes which had been cut down before treatment should produce new growth infested by the mite, was strongly suggestive that the insect might harbour in the ground, or elsewhere than in the buds; but a careful examination of the stools, and of the earth in contact with them, failed to reveal any signs of it. A number of experiments were then made in which batches of bushes which had been cut down, and soaked for various lengths of time in a mixture of equal volumes of methylated spirits and water, were replanted, either in different situations in the farm, or in ground at Harpenden and St. Albans where no mite existed. In the latter case the bushes remained quite free from mite, whereas with those replanted in the farm, the new growth was slightly affected, and to an extent dependent on the proximity of already infested bushes. Thus it appears that the mite harbours nowhere but in the buds, and that its appearance in the new growth is due simply to re-infection. It was noticeable in these cases that an immersion in the diluted spirits, even for six hours, did not injure the bushes much, so long as they were left exposed sufficiently for all the alcohol to evaporate before they were replanted.

Cutting down the bushes in a plantation is, however, not sufficient to ensure the eradication of the disease, presumably because some buds may be overlooked or left on the ground, or possibly because some mites may exist even in dormant 
buds. The whole of the bushes at Woburn were cut down after these experiments had been concluded, but the new growth which came up was, apparently, as badly infested as the old: two years later they were again cut down, as well as all the red and white currants in the ground-for it has been proved that the mite may occasionally exist in the red currant; yet the fresh growth was still infested. Such cutting down, if performed every year for either two or three seasons, and accompanied by a careful removal of all buds found to be affected, has proved to be effective in some localities (e.g. Holmes Chappel), and has, in consequence, been recommended by the Board of Agriculture; but it has proved ineffective at Woburn. On two separate occasions, at an interval of many years apart, plantations were treated in this way, and under the direction of a manager who had applied the method successfully at Holmes Chappel; but in both cases, after some promise of success at first, the procedure had to be abandoned as a failure (XIV, 72).

Fumigation of the bushes by means of hydrocyanic acid was also examined, each bush being enclosed in a box covered with tarred felt, and the proportions of potassium cyanide used being I ounce to every I50 cubic feet of air space. The results were altogether unsatisfactory, as, also, were those of a similar treatment with a substance consisting of nicotine and camphor, known as "XL All." Subsequently to these trials, H. H. Cousins ${ }^{1}$ claimed to have obtained success in treating bundles of cuttings and young bushes with hydrocyanic acid; but experiments on the treatment of bushes in situ, though suggested, were not described. The treatment of cuttings or young bushes before plantation may be successful, but it is a question of but little importance, for cuttings should never be taken except from bushes which are quite clean: and, though fumigation may conceivably under favourable circumstances kill the mites, it is extremely improbable that it would kill their eggs, and these, according to Newstead, are present in the buds during every month of the year (II, 34). Fumigation of a small bush would be likely to yield very different results on different occasions, for the gas is soluble in water, and very different quantities of it would be absorbed by the soil according to the condition of wetness obtaining in it.

Further experiments were made at Woburn as to the possibility of killing the mite by dipping the bushes in hot water. Such treatment, like fumigation, could not be regarded as being

1 Journ. of S.E. Agric. Coll., Wye, 9. 67. 
of much practical importance, as it could only be applied to cuttings or very young bushes, which, as has just been remarked, should never require treatment : but there were points of interest attaching to it, independent of its practical application to black currants.

As a result of thirty experiments with immersions for different lengths of time at twelve different temperatures, the conditions which proved fatal to the mites were-

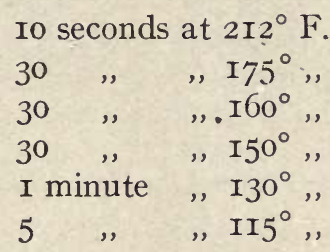

Subsequent experiments were made (XIV, 69) to ascertain whether such heating, as well as heating at still lower temperatures, had killed the eggs as well as the mites, and also, what the effect of the heating had been on the bushes themselves. Infested cuttings were used, with the big buds removed from them in some cases, and not removed in others ; after treatment, they were planted, and their condition noted eighteen months later, by recording the number of big buds then found on them. Thie results may be summarised as follows-

\begin{tabular}{|c|c|c|}
\hline Treatment. & $\begin{array}{l}\text { Big buds } \\
\text { developed. }\end{array}$ & $\begin{array}{l}\text { Mortality } \\
\text { per cent. } \\
\text { of cuttings. }\end{array}$ \\
\hline $5 \mathrm{~min}$. at $135^{\circ}$ & . - - & IOO \\
\hline $5^{-10}, \quad, \quad, 125^{\circ}$ & . $\quad 0.5^{1}$ & 95 \\
\hline $5^{-15},, \quad, I I 5^{\circ}$ & . 20 & 55 \\
\hline $10-20, ", 105^{\circ}$ & - 34 & 53 \\
\hline I5-30 " $" 95^{\circ}$ & - 30 & 44 \\
\hline
\end{tabular}

It is clear from these results that, though a temperature of II $5^{\circ}$ may have killed the mites, it had not killed the eggs, for the infection reappeared after the treatment, and even a temperature of $125^{\circ}$ did not seem to have killed them entirely, whilst such a temperature had proved almost completely fatal to the plants; even temperatures down to $95^{\circ}$ killed nearly half the plants. Immersion in hot water is, therefore, useless as a remedy.

1 Three big buds in six sets. 
One conclusion which was drawn from the observation at Woburn was that infestation by the mite is greater, the stronger and healthier the bushes are, this being probably due to such bushes affording more sustenance for the insect

Varieties of black currant certainly differ in the degree of suscep. tibility to an attack, Baldwin's Black being the most susceptible of the six varieties examined, and Old Black least so. But this difference is probably due, more to differences in vigour of growth, than to any intrinsic differences in susceptibility. 


\section{CHAPTER XXII}

\section{INSECTS (continued)}

\section{(I) Woolly ApHIS (Report X, 2)}

Woolly ApHIs or American Blight (Schizoneura lanigera) is unfortunately a well-known pest, the treatment of which is rendered difficult by the white, cottony threads, covering the body of the insect, which prevent it from becoming wetted by insecticides unless these are sprayed on to it with great force; and also by the fact that the adults, besides existing on the stems and branches of the trees, infest the roots, migrating spasmodically during the summer to the above-ground portions of the trees. In winter the insect exists as a purplish brown adult in the crevices of the bark or roots, or occasionally in the egg stage, which eggs, in the spring, give rise to larvæ, and these, when mature, form the mother queens, producing viviparously the woolly insect familiar in the summer.

No systematic investigation of the treatment of trees in the summer for this pest has been conducted at Woburn, though it was shown that undiluted paraffin oil might be used for the purpose, without any very serious damage to the trees, provided the oil was neither one of the lighter nor heavier oils (p. I54); more attention, however, was paid to the treatment of nursery stock, and such stock, especially when received from abroad, should always be treated for woolly aphis before being planted.

The treatment usually recommended is fumigation with hydrocyanic acid; but this was found to be very unsatisfactory: out of some thousands of trees which had been fumigated, 20 per cent. were found to be affected by the aphis in the following June and July, whilst another 43 per cent. became affected before the end of September. It was in accordance with the results obtained at Woburn with the black currant gall mite and the mussel scale (pp. 206, 2 I6) that such fumigation, though it might kill the insects, would not kill the eggs, and would, therefore, be at best but an imperfect remedy. Apparently, F. V. Theobald has on occasions obtained satisfactory results with hydrocyanic 
acid when applied in strong doses ${ }^{1}$ (namely, I oz. of sodium cyanide, or $\mathrm{I}^{\prime} 3 \mathrm{oz}$. of potassium cyanide, to every Ioo cubic feet of air space); but such results cannot always be counted upon, and the effect of the gas, which is soluble in water, would probably vary considerably with the degree of dryness of the trees at the time of fumigation.

Certainly the use of such a deadly poison is one which should be avoided, if possible, ${ }^{2}$ and the Woburn investigations showed that more satisfactory results could be obtained by dipping the trees in a low-boiling paraffin oil. The trees to which this treatment was applied were similar to those used in the fumigation trials, and consisted of paradise and crab stocks which had been worked in the previous season. The immersion lasted for 5 minutes, and the trees were allowed to drain for another 30 minutes before being planted : 40 trees were used in each set of tests. With a high-boiling oil, such as solar distillate, all the trees were killed, and with an ordinary lighting oil there was considerable mortality; but with petrol, the mortality was only Io per cent. when the scions were considered, and 5 per cent. when the roots were considered-values probably in excess of those which might usually be expected, as the trees were far from being in a robust condition-and the surviving trees remained quite free from aphis during the ensuing season, showing as much vigour of growth as others which had not been treated. Equally good results were obtained by dipping the trees into the alkaline winter wash containing 6 per cent. of solar distillate (p. I6I).

A form of treatment which proved preferable to any of those depending on the use of paraffin consisted in immersing the trees bodily in water at $\operatorname{II} 5^{\circ} \mathrm{F}$. for Io minutes; the mortality amongst them was only half of that observed in the case of those treated with paraffin, and was probably due entirely to their feeble condition, and not to the treatment itself; whilst the absence of aphis in the following season was complete, and the trees seemed otherwise to have actually been benefited by the treatment. In selecting the temperature and duration of the immer-

1 Report on Economic Zoology, 1908, 52.

2 A hitherto unnoticed source of danger was found in cases where the cyanide was wrapped up in paper, and lowered into the sulphuric acid from a distance by means of a string; for the acid sometimes acted on the paper, converting it into parchment paper, and preventing the access of it to the cyanide. An improved method of making the gas is to enclose the cyanide in small zinc boxes, which may be placed directly into the acid, giving the operator time to leave the house before the zinc is dissolved. 
sion, guidance had been obtained from previous work carried out on black currants in treating them for big bud (p. 2I7). Immersion for 5 minutes at $125^{\circ}$ or even $120^{\circ}$ was found to be less satisfactory so far as the subsequent behaviour of the trees was concerned, as the vigour of their growth was thereby considerably impaired; but a prolongation of the immersion to I5 minutes at $I I 5^{\circ}$, or to 20 minutes at $I I 0^{\circ}$, had no bad effect. It would appear that any deleterious effect on the trees by heating them, is simply a question of temperature, and that, provided the critical temperature is not exceeded, the duration of the heating is immaterial.

An attempt was made to apply the heating treatment to trees in situ, using a steam fire-engine for the purpose. The result was not successful; though the steam was at a pressure of $90 \mathrm{lbs}$. to the square inch, the temperature produced by it on the branches was not above $90^{\circ} \mathrm{F}$., and to obtain even that temperature on all the branches would have involved a very prolonged operation.

\section{(2) Apple Sucker (Reports, VIII, 58; X, 26)}

The Apple Sucker (Psylla mali) lays its eggs singly on the young shoots and spurs, chiefly around the leaf rings, amongst the fine hairs of the shoots, and in the axils of the buds. They hatch in April, and the insect then forces its way into the nearest blossom- or leaf-bud. The buds thus attacked, either do not expand, or, after expanding, wither, the leaves turning brown. The insect becomes fully matured and winged in May or June, and lays its eggs in September or October. Though there can be no doubt but that much damage is done to apples by psylla, there are grounds for questioning whether the insect is really responsible for all the mischief attributed to it. The pest was rife at Woburn in I908, and the blossoming twigs were swarming with the insects, yet it was difficult to find any trusses exhibiting the shrivelled appearance characteristic of psylla injury; moreover, many of the apple blossoms had been enclosed in bags for the purpose of certain cross-fertilisation experiments, and when these were eventually opened, abundance of psylla were found in them-20 to 30 in one bag-yet in every case the blossoms had set well.

The difficulty in treating trees for this insect lies in the position which it takes up on the trees, for any effectual spraying of the extremities of the branches is very difficult, and even if these are thoroughly wetted by the spray-fluid, this runs off immediately on to other parts of the tree; also, the date of hatching of the 
eggs, coinciding as it does with that of blossoming, presents difficulties in applying any remedy just at the time when the insect is most vulnerable.

In preliminary laboratory experiments it was found impossible to ascertain the damage done to the eggs by an insecticide, as the change in appearance of the eggs when injured, was much less marked than in the case of the mussel scale; consequently, the method of counting the hatchings after the twigs had been treated and placed in covered jars, was adopted. The fertilisation of the eggs appears to be very complete, for in the absence of treatment a 98 per cent. hatching was obtained. Treatment with the alkaline winter wash containing 6 per cent. of solar distillate, emulsified by means of copper sulphate (p. I6I), proved almost absolutely fatal ( 96 per cent. mortality), and the action of it appeared to depend chiefly, though not entirely, on the caustic soda contained in it, for a lime-sulphur-soda wash containing the same amount of solar distillate caused a mortality of only 39 per cent., which was not raised beyond 70 per cent. on increasing the proportion of paraffin to as much as I2 per cent. A mixed salt and caustic soda solution (Io and 2 per cent., respectively) produced a satisfactory mortality of 90 per cent., and salt alone gave one of 75 per cent.

Compared with these promising results, the treatment of trees in situ was disappointing, doubtless due to the difficulty, already mentioned, of applying the washes satisfactorily to the parts affected. None of the washes in question, after being applied on March I2 to 2I, caused any mortality of the eggs, except in the case of the lime-sulphur-soda wash with 6 per cent. of solar distillate added to it, and there a mortality of 20 per cent. was recorded.

Other experiments were conducted on the treatment of the trees with a wash containing 20 per cent. of whiting and 2 per cent. of salt, which had been recommended for the purpose. ${ }^{1}$ No good results followed the application of this, and the substitution of lime for whiting proved equally ineffective, at any rate when applied as early as February $26(\mathrm{X}, 27)$. What rôle the salt could play in such a wash is somewhat obscure, and further attempts at Woburn to establish any effect from salt, even at strengths of 5 and Io per cent., either alone or in conjunction with other insecticides, failed $(X, 26)$.

Treatment with lime-salt, it is stated, to be effective, should be made not earlier than two weeks before the buds burst, and in that

1 F. V. Theobald, S.E. Agric. Coll., Wye, 1907, 40. 
case it is in the nature of a spring, and not a winter treatment. Further experiments with lime washes under such conditions were not made, but other forms of spring treatment were examined, branches of trees being treated in situ on April 24, May 6 and May 20 - the trees were in full bloom on this last date-and the results observed, both on branches left on the trees, and on other branches which had been removed and kept in jars. The results were, that of the spray-fluids tried, a 2 per cent. decoction of tobacco proved the most effective, causing a mortality of nearly roo per cent. in the applications on the first two abovementioned dates: a I per cent. solution, with 0.33 per cent. of lead arsenate added to it, was considerably less effective, especially in the case of the twigs left on the trees, and the addition of I per cent. of solar distillate to this mixture, did not much improve its action (VIII, 58).

This is not the only case in which tobacco was found to be highly satisfactory as an insecticide; but, unfortunately, tobaccos vary enormously in the percentage of nicotine which they contain, and consequently in their effectiveness. The same applies to what is known as tobacco powder, which is in use for the treatment of hops, and which contains 68 per cent. of tobacco mixed with sulphur, asafœtida and sago flower (the powders used for fumigation and sheep dipping have an entirely different composition); it is preferable, therefore, to use a solution of nicotine of known strength, and such solutions are now prepared by dealers in insecticides.

In I908 further experiments were made at Woburn $(\mathrm{X}, 26)$ to determine the strength of nicotine solutions which should be used for psylla and other pests. The strengths examined varied from $0^{\circ}$ II 3 down to $0^{\circ} 038$ per cent., and three series were undertaken, the trees being sprayed, in one case on May 7 , before the blossom opened, in another on May I7, when the blossoms were just open, and in a third on May 26, when they had nearly fallen. The effect in the case of the latest spraying was not quite so good as that in the earlier ones, but all three series indicated that a mortality of from 90 to 99 per cent. would be obtained by using a solution of 0.075 per cent. strength. The addition of lead arsenate to the nicotine produced no enhancement of the effect; and treatment with I per cent. carbolic acid, with paraffin emulsion, or with salt solutions on May 7 were quite ineffective.

In the case of nicotine, it was found that moderate rain falling, even within a few hours of the application, did not reduce the 
effect, but only retarded it. Nicotine did no damage whatever to the trees, and, so far as could be ascertained, it had no effect on bees and other insects, for these continued their visits to the flowers immediately after the spraying, and no dead insects were found near the trees or in the adjoining hives.

\section{(3) ApHIs (Reports, VIII, 95; X, 42)}

Various series of experiments on treating apples and plums for aphis were carried out at Woburn, the trees being sprayed with paraffin emulsions, and also with tobacco decoctions of various strengths. Considerable variation was observed in the different series as to the efficiency of the emulsions : in one case a complete mortality was obtained with all emulsions containing more than 0.5 per cent. of paraffin, whereas in another series a I per cent. emulsion caused a mortality of only Io per cent; in a third series a $I^{\prime} 5$ per cent. emulsion gave entirely satisfactory results with the mealy plum aphis. The results with tobacco in that season were more uniform, and indicated a complete mortality as being effected by a solution containing about 075 per cent. of nicotine; and a weaker tobacco solution could be used, if supplemented by paraffin emulsion, but calcium arsenate produced no enhancement of the effect. Paris green caused a mortality ranging up to only 50 per cent.

In the following season nicotine solution was further examined as regards its effect on six different species of aphis-Aphis pomi, Chermes laricis, Beech aphis, Aphis pruni, Hyalopteris pruni, and Schizoneura lanigera. Five different strengths of nicotine were used in most cases, from 0.075 to $0^{\circ} 005$ per cent., and the sprayings were performed on various dates from July 2 to September I. One of the most conspicuous features of the results, was the great variation in the effect produced, just as in the case of the sprayings with emulsions in the preceding season; in some cases the whole of the aphides were killed, even by the weaker solutions, whereas at another time, and with the same aphides, even the strongest solutions had very little effect. Such variation is not surprising, for aphides pass through various stages of existence, when their susceptibility to poisons may be very different, and, moreover, the effect of the spraying must vary greatly with the extent to which the leaves have become curled and afford a protection to the insects from the sprayfluid. As an instance of the character of the results obtained, (which have not yet been published), those with the Aphis pomi 
may be quoted, the numbers entered giving the percentage mortality consequent on the spraying-

\begin{tabular}{|c|c|c|c|c|c|c|}
\hline & Nicotine & $\cdot 075$ & $\cdot 038$ & •OI9 & •oro & -005 per cent. \\
\hline & & & Morta & caus & & \\
\hline July 2 & . & IOO & IOO & IOO & IOO & - \\
\hline ," 23 & - & 30 & 5 & 90 & IO & - \\
\hline August 6 & $\cdot$ & IOO & 70 & 5 & $I$ & 0 \\
\hline September & C. I & 90 & 63 & 53 & 30 & 35 \\
\hline
\end{tabular}

The general results confirmed the previous conclusion, that the strength of solution most suitable for use was 0.075 per cent.; in some instances a weaker solution might be used, and in others a stronger solution would give better results; but the variations in the effect due to extraneous or unknown conditions were too great to render any deviation from $0^{\circ} 075$ per cent. advisable.

\section{(4) Caterpillars (Report X, 35)}

Series of laboratory experiments were conducted in I906 to ascertain the relative effect of various insecticides on caterpillars. Leaves were wetted with the insecticides in question, and enclosed in jars with a certain number of caterpillars, the mortality amongst these being observed after various intervals. The interval allowed had to be varied with the various kinds of caterpillars, owing to their different susceptibility to the insecticides, and to the different rapidity with which they were passing into the chrysalis form, after which passage, of course, observations were no longer possible. In most cases 30 to 40 insects were taken for each trial, being representatives of the winter moth, lackey moth, tent moth, common vapourer and Vanessa utica. These, naturally, varied much in their susceptibility to poisons, the winter moth caterpillar being the most susceptible, and the tent moth caterpillar the least so. An actual measure of susceptibility, however, could not be obtained, for the results depended, not only on the susceptibility of the insect, but also on the readiness with which it fed on the poisoned leaves.

Amongst the substances examined was methylated spirits, though this could hardly be used in practical spraying, even if it had less effect than it has on the leaves. When strong, or diluted with an equal volume of water, it was completely fatal to the caterpillars in nearly every case. All the other substances were examined at various strengths, and it was noticeable that an increase in strength had very little effect on the results. Details need not be given here, and the following values for 
the percentage mortality must be taken as merely comparable inter se under the particular conditions of the experiment.

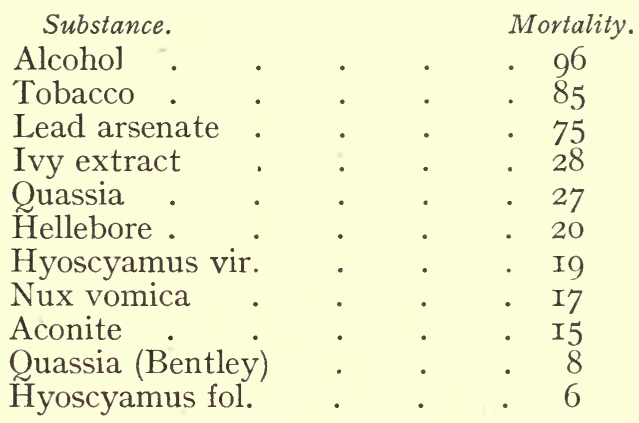

Thus, with the exception of alcohol, the only substances giving satisfactory results were tobacco and lead arsenate, and it is noticeable that the ineffective substances included many which act as virulent poisons towards animals. It must, of course, be remembered that the sensitiveness of a caterpillar to poisons must depend very much on the age of the insect, and in these experiments the caterpillars were in the adult stage.

In the following season a further examination was made of those substances in the above list which had proved most effective, and other experiments were added with pyrethrum, Paris green and paraffin emulsion (containing I per cent. of solar distillate). The general results indicated that an equal degree of effectiveness might be obtained with tobacco, Paris green, lead arsenate, pyrethrum or decoction of ivy leaves, provided the strengths were suitably adjusted; hellebore gave less satisfactory results. The paraffin emulsion caused a higher mortality than that obtained in any other case, but this result was looked upon with suspicion, as it was higher than that caused by the emulsion when used in conjunction with other insecticides: in eight cases various insecticides had been used alone, and with the emulsion added to them, and this addition had raised their efficiency from an average of 42 to 60 per cent., whereas with the emulsion alone an efficiency of 85 per cent. had been indicated.

To set this question at rest, a comparison was made in the following season between emulsions and lead arsenate, the experiments in this case being carried out under ordinary spraying conditions. About 300 dwarf apple trees of a large number of different varieties were divided into similar sections, 
one section being sprayed with arsenate $(0.4$ per cent. of the paste), and two others with emulsion (I per cent. of paraffin), made, in the one case, with copper sulphate, and in the other with iron sulphate. The difficulties in forming any trustworthy estimate of the results in such experiments is considerable: the method adopted was to examine each of the trees, and give it " marks" according to its freedom from caterpillar attack; this " marking" was done by an observer ignorant of the treatment applied to the trees; as a general result of two inspections at different times, a balance of $\mathrm{I} 2$ per cent. in favour of the arsenate was obtained. Where copper, instead of iron, had been used in making the emulsion, no advantage had accrued, nor was there any appreciable difference between the trees sprayed before or after the blossoms had opened.

As a general conclusion, therefore, lead arsenate would seem to be the most serviceable insecticide for dealing with caterpillars. Though tobacco, Paris green or pyrethrum might yield equally good, or even better results, there are objections to all three of them; tobacco is a very expensive remedy, and the results obtained with it in practical spraying for caterpillars have not borne out the anticipations based on laboratory experiments (see p. 226), Paris green is very poisonous and liable to cause serious scorching, and pyrethrum varies greatly in strength, and deteriorates on keeping.

Lead arsenate, however, has its drawbacks, for it also is poisonous, and should not be used on trees within five or six weeks of the fruit being gathered. This generally renders it impracticable for the treatment of gooseberries or currants for sawfly, and a similar objection applies to treatment with hellebore. In that case paraffin emulsion (made with iron or soap, and not with copper), is a valuable substitute for arsenate; indeed when the percentage of solar distillate in it is increased to $\mathrm{I}_{5} 5$ per cent.-as it was found possible to do without any risk of damage to the foliage-it proved to be even more efficacious, or, at any rate, more prompt in its action, than lead arsenate. An attack of gooseberry sawfly was thus dealt with, and on the second day after the spraying no live caterpillars could be found; whereas in the case of similar bushes treated with arsenate, there were still a few which had not succumbed. The leaves of the bushes sprayed with the iron emulsion were somewhat stained, but the fruit was unaffected, and exhibited no flavour of paraffin; some of it, indeed, was marketed within two or three days of the spraying $(X, 4 I)$. 
In all such work with insecticides, the need for caution in drawing any definite conclusions is continually being impressed on the worker; the relative superiority of two given insecticides may repeatedly be found to reverse itself in different seasons, according to the special conditions obtaining at the moment. Thus the superiority of arsenate over paraffin emulsion, indicated by the experiments on 300 apple trees quoted on p. 226, is not borne out by the results with the gooseberry sawfly, nor by other results obtained in 1908 with the caterpillar of the common vapourer moth and the small ermine moth $(\mathrm{X}, 35)$; whilst the effectiveness of nicotine as indicated by the laboratory experiments, was not borne out by field trials with it on the winter moth caterpillar, no mortality having been caused by solutions containing up to O.II per cent. of that substance $(X, 39)$. Similarly, though emulsions made with iron were as effective as those made with copper according to the experiments already quoted, the reverse was the case in some subsequent trials $(\mathrm{X}, 38)$, indicating that the copper may have to a certain extent a poisonous action on the insects.

The superiority of a paraffin emulsion to lead arsenate, in cases where such superiority was noticed, is, however, partially due to the fact that a stronger emulsion was used in the later than in the earlier experiments ( $I^{\circ} 5$ instead of $I$ per cent. of oil), and the superiority was noticeable both as regards the percentage of mortality ultimately caused, and the rapidity of the action (X, 38). The emulsion has proved eminently. satisfactory in dealing with the winter moth, but, unfortunately, it cannot be used when the blossoms are expanded, and, where psylla and winter moth have both to be dealt with, and where separate sprayings for each cannot be afforded, it would be best to defer the spraying till after the blossoms have fallen, and then to use an emulsion with 0.075 per cent. nicotine added to it. Nicotine and arsenate may be applied to trees in blossom without injuring them, but such a mixture would injure the bees visiting the flowers.

In combating caterpillar and other insect pests we can hardly overrate the truth of the saying that "Prevention is better than cure." The insects ought, if possible, not to be allowed to come into existence at all, for to kill them once they are swarming on the trees, and these trees are in leaf, is by no means a simple problem. The efficacy of winter washes in actually destroying the eggs of many caterpillars, etc., is very doubtful, but there is no question that winter washing is the most effective way of dealing with such pests, acting chiefly, in all probability, by 
cleansing the trees, and opening up or destroying the lurking places of the eggs or insects, which thus fall a prey to their enemies. The trees at Woburn were formerly infested every year to an exceptional extent by various caterpillars, but the virulence of these attacks have notably diminished during the last ten years, and, as summer spraying has not often been practised, this can only be attributed to the winter washing of the trees, the caustic emulsion (p. I6r) having been applied once in about every three years. The efficiency of such treatment was strikingly illustrated in I9I5: owing to a miscalculation, sufficient of the

- wash had not been obtained to spray the whole of the ground, and an acre of it had to remain untreated; in the following season the trees throughout the farm were remarkably free from caterpillar, except on this one acre, and there the caterpillar attack was severe. 


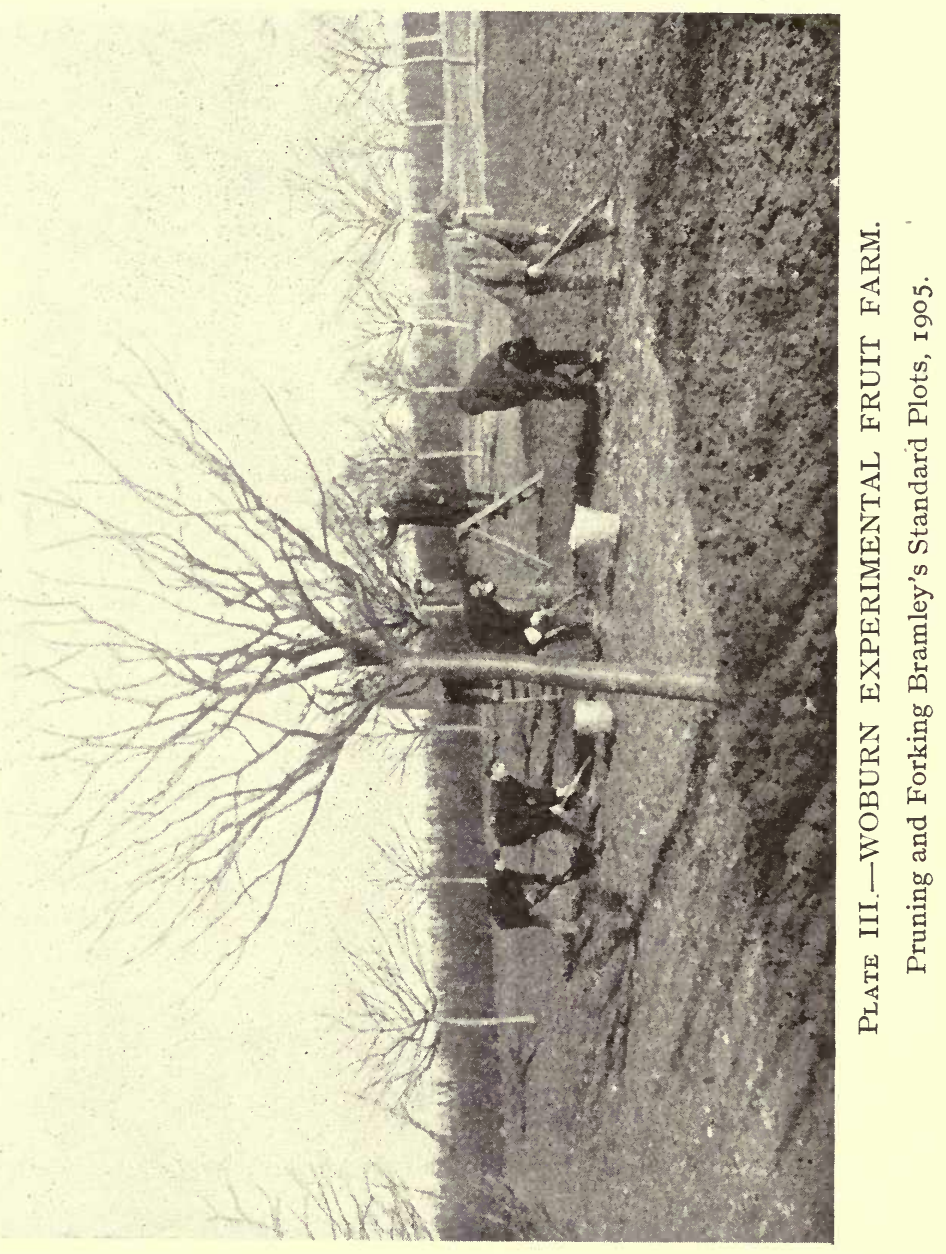




\section{CHAPTER XXIII}

\section{FUNGI}

\section{Silver-Leaf Disease (Reports, VI, 2 Io; XII, I)}

SILVER-LEAF, or silver blight (Stereum purpureum), is a disease which has long been known to fruit growers in this country: it manifests itself by the foliage of the affected trees becoming light and silvery in appearance; a tree thus attacked often dies, though death may not supervene till after several years, and, while suffering, it may still bear a certain amount of fruit, and may even show considerable vigour of growth. This silvering of the leaves was first connected with fungoid action by Professor Percival, ${ }^{1}$ who attributed it to the action of a fungus known as Stereum purpureum, which fructifies only on the dead wood of a tree killed by the attack. Apparently the mycelial threads of this fungus, which penetrate the cells of the living tree, and thus bring about its death, are very fine, and the difficulty experienced in discovering them, coupled with the fact that the fungus never fruits on the wood till after death, resulted in Professor Percival's conclusions being looked upon with some scepticism. Independently of his results, however, those obtained at Woburn would be quite sufficient to place the matter beyond doubt; for the inoculation of a tree with a piece of the fungus has nearly always been found to produce silver-leaf, whilst neighbouring trees which were not thus inoculated remained quite healthy. Further, trees which have died, partially or entirely, after an attack of silver-leaf, so often develop the stereum on the dead wood, that it is impossible to avoid connecting the one with the other, especially as no single instance is on record of the appearance of this fungus on a tree which has been known to have shown no signs of silvering whilst alive.

The fungus itself forms flat, roundish disks on the bark of the dead wood, often two inches or more in diameter, and generally shows a purple or pink colour, though sometimes it is nearly white (Fig. 23). For the purpose of inoculation, it is

1 Linn. Soc. Journ., "Botany," 35, 390, 1902. 
only necessary to insert a small portion of this fungus, rendered active by having been kept in a warm, moist atmosphere, in a cut made in the bark of the tree, and binding up the cut so as to prevent the fungus from being washed out.

The first sign of infection consists of a gradual appearance of silvering of the leaves, which, when the tree is in active growth, may occur in two or three weeks after the inoculation, whilst the whole tree may become seriously affected within four or five weeks. In many cases it is noticeable that the infection seems to spread from the point of inoculation: if one branch only has been inoculated, that branch is the first to suffer, and if one side of the stem has been inoculated, it is on that side that the silvering first appears.

The outward manifestation of disease is, no doubt, due to a poison formed during the growth of the fungal threads-probably this is so with all fungoid and bacterial diseases-for no evidence of the presence of the fungus itself, i.e. its mycelium, can be found in the leaves. The silvery appearance is but one of the manifestations of the disease, and seems to be due to the cells composing them having become partially disconnected, owing to changes brought about in the nutrition of the plant. There is no reason for supposing that a similar silvering might not be produced by other means, and there is some slight evidence that this is occasionally so, ${ }^{1}$ but no argument could be based on such a fact (if established) in support of the view that the disease known as silver-leaf disease is not of fungoid origin. The change noticed in the leaves is often accompanied, though not always, by a change in the wood, this becoming dark and discoloured, even to the centre of the branch, and the discoloration in partial attacks extends below the lowest point at which the leaves show silvering.

Silver-leaf disease is conspicuous in its attacks on plum trees and other stone fruits, but it appears capable of attacking almost any tree or shrub. It has been noticed on apples, pears, gooseberries, currants, laburnums, Portugal laurels, walnuts, birch, beech, horse chestnut, sycamore, spiræa, white dead nettle, etc. ${ }^{2}$

The spread of the disease amongst plum trees in this country became serious in about I904, due, probably, to the exceptionally wet character of the summer of I903. In New Zealand, where the disease has caused much damage, its attacks appear to have become acute in about Igoo. Whether in either of these

1 Brooks, Journ. Agric. Science, V, 293, 304.

2 Cf. Brooks, loc. cit., IV, I33; V, 288. 

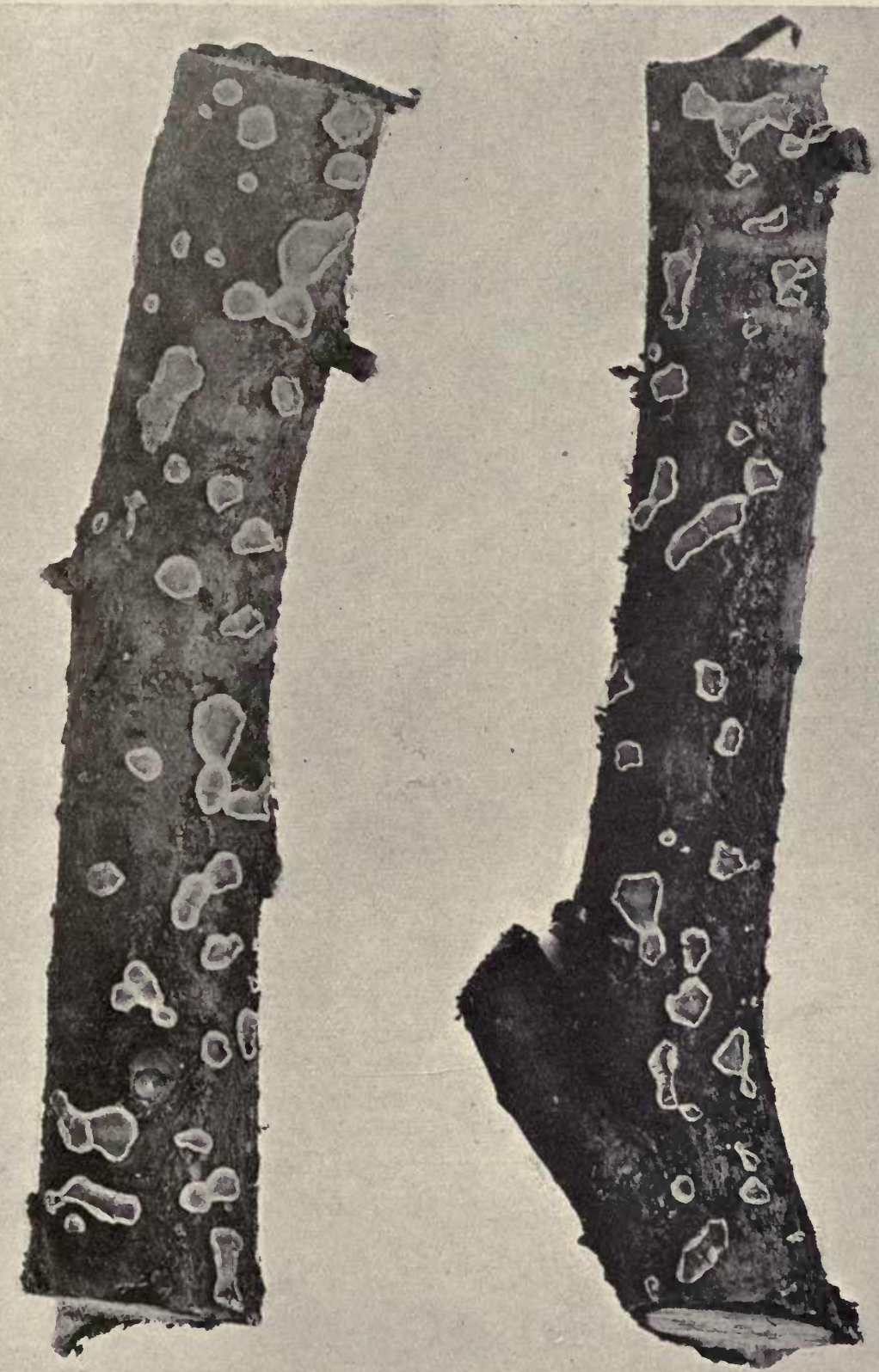

FIG. 23.-DEAD PLUM BRANCHES WITH "STEREUM PURPUREUM." 
countries the disease has shown signs of abating since the dates mentioned, cannot be stated with any confidence, but it is certainly still very rife in England.

At the time the Woburn experiments on the subject were started, the fungoid nature of the disease was not so freely accepted as it is at present, some authorities attributing it to overfeeding, ${ }^{1}$ and others to mechanical injury of the trees. Even where its fungoid nature was accepted, doubts existed as to whether infection occurred through the fungus spores entering by wounds in the branches, etc., or whether it occurred through the spread of the mycelium in the ground-a view advocated at first by Professor Percival.

To investigate the matter, a plantation of II 2 two-year-old bush plum trees was established in I906, the varieties planted being Monarch, Czar, Rivers' Early Prolific and Victoria.

Forty-eight of these trees were inoculated early in the year with stereum, and, of these, 39, or 8I per cent., showed silvering before the end of July, four of them having been killed outright by that time, and two others being half dead. This is a high percentage of infection, especially when it is remembered that the inoculation was not performed by a trained mycologist. On the other hand, not one of the 64 uninoculated trees showed any signs of silvering, nor have they, unless subsequently inoculated, become infected during the succeeding years. These results afforded ample proof that the disease was a consequence of inoculation with stereum purpureum. But beyond this, of the inoculated trees, I9 died during the first two years after planting, and all of these developed stereum on the dead wood, whilst none of the uninoculated trees died, or showed any signs of the fungus.

In different cases the inoculation was effected in the roots, branches or stems of the trees, and the results, measured either by the percentage of individuals which took the disease, or by the virulence of the attack in those trees which. were affected, showed that inoculation in the stem was the most fatal, but that as regards inoculation in the roots or branches, there was nothing to choose between the two.

\begin{tabular}{|c|c|c|c|c|c|}
\hline $\begin{array}{l}\text { Inoculated } \\
\text { in }\end{array}$ & & & & $\begin{array}{l}\text { Per cent. } \\
\text { trees affected. }\end{array}$ & $\begin{array}{l}\text { Relative } \\
\text { virulence } \\
\text { of attack. }\end{array}$ \\
\hline Stem . & & . & • & IOO & 86 \\
\hline Root . & • & - & & 56 & 58 \\
\hline Branches & . & . & . & $8 I$ & 40 \\
\hline
\end{tabular}

1 Massee, Journ. Hort. Soc., XXX, 36. 
The time of year at which the inoculation was performed appears to have had no influence on the results, provided, of course, that sufficient time had been allowed to elapse for the fungus to operate before observations were taken, Thus-

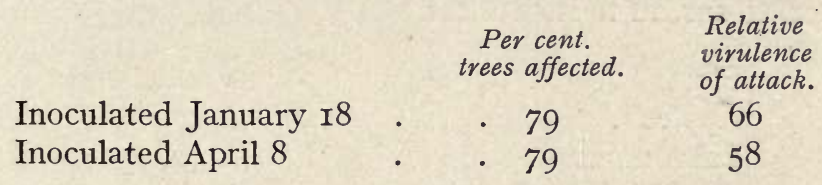

Whilst in another case, where trees were inoculated on July 4, I906, November I5, I906, and January I7, I907, the results by the end of 1907 were exactly the same in all three cases.

It is generally held that when once a tree is attacked by silverleaf it never recovers. There can be no doubt, however, that this opinion is erroneous. Observations made throughout three years on trees which had been inoculated, showed that the number of individuals manifesting the disease declined regularly, though the virulence of the attack in those which remained affected, increased; or in other words, where the disease had not been taken badly, the tree might recover, whilst in other cases the disease progressed gradually to a fatal conclusion. It was noticeable, however, that recovery occurred in several instances where the disease appeared to have been taken severely, and the whole tree had become silvered.

\begin{tabular}{|c|c|c|c|c|c|c|}
\hline & \multicolumn{3}{|c|}{$\begin{array}{l}\text { Per cent. trees } \\
\text { affected in }\end{array}$} & \multicolumn{3}{|c|}{$\begin{array}{c}\text { Relative virulence } \\
\text { of attack. }\end{array}$} \\
\hline & - I906 & 1907 & 1908 & 1906 & 1907 & 1908 \\
\hline & . $\quad 79$ & $\begin{array}{l}52 \\
69\end{array}$ & $\begin{array}{l}44 \\
67\end{array}$ & 68 & $\begin{array}{l}70 \\
63\end{array}$ & \\
\hline
\end{tabular}

In the case of trees other than plums, recovery has also been noticed, as well as apparent recovery, followed by a relapse, in subsequent seasons; often, too, the trees which had recovered from the outward signs of the disease, never recovered their vigour completely, but gradually languished and died. This, however, was not always the case. With Portugal laurels no cases of recovery, or partial recovery, were noticed, but the progress of the disease, if more certain, was slower in their case than in others: ten trees inoculated in January 1907 showed no signs of the disease that year, and only a 9 per cent. affection in 1908 ; this rose to 60 and 75 per cent. in the next two years, and finally all the trees died. None of these bushes developed stereum on the dead wood.

The degree of susceptibility of different kinds of trees to the 
disease is illustrated by the following values, though they do not in all cases give a true measure of susceptibility, for the observations were taken two years after the inoculation, and, in the case of the laurels, that had not allowed sufficient time for the fungus to spread to its utmost.

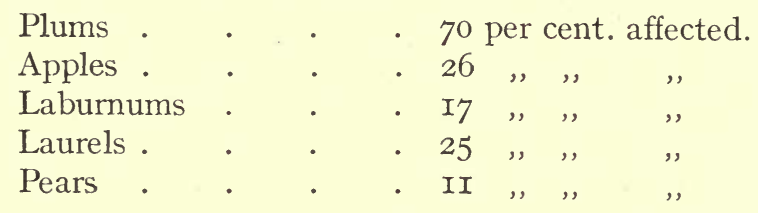

In these experiments stereum derived from the apple and laburnum, as well as that derived from the plum, was used, and it was found that the fungus caused infection in all these kinds of trees whatever its origin might have been; no definite evidence was obtained to show that the fungus was in any way modified by the nature of its host, or that it varied in potency according to the source from which it had been derived.

The susceptibility of different varieties of plum trees was investigated in the case of the four varieties, Monarch, Czar, Early Prolific and Victoria; but no difference in their behaviour was apparent: the percentages of trees, taking the varieties in the order mentioned, which took the disease after inoculation were-

$$
78,78,69 \text { and } 70 \text {; }
$$

and the severity of the attack was in the proportion of-

$$
36,57,70 \text { and } 63 \text {. }
$$

These results gave no support to the view, held by certain authorities, that soft-wooded varieties are the most susceptible; yet it is very probable that soft-wooded varieties, under the conditions existing in a plantation, suffer most, for they are more liable to mechanical injury, and hence present more frequently wounds through which the fungus spores may obtain an entry. Even the injury caused by aphis may be sufficient to afford a means of access for the spores: and this, also, is probably the origin of another opinion, which is sometimes expressed, that aphis causes silver-leaf.

It is probably due to the liability to mechanical injury which would follow on rampant growth produced by over-feeding, that such over-feeding has been assigned as a cause of silver-leaf; for vigorous growth in itself does not appear to favour the disease: in a separate series of experiments with the same four varieties 
of plums, it was found that it was the less robust individuals which took the disease more readily on inoculation, the percentage of trees becoming affected being-

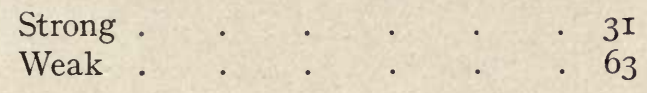

but the virulence of the attack in those which had become affected did not show such marked difference-

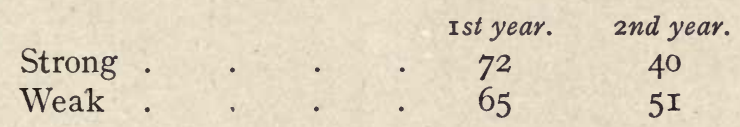

the values indicating that, though the stronger trees eventually suffered less than the weaker ones, the spread of the disease in them was more rapid at first, due no doubt to this spread being facilitated by the more ready flow of sap.

It was considered possible that a tree which had become infected, and had subsequently recovered, might prove to be immune from subsequent attack; but experiment negatived this possibility. Twenty-four trees which had recovered from an attack were reinoculated, and the results compared with those obtained on the inoculation of a similar number of trees which had never suffered from the disease; the difference in the behaviour of the two sets was quite inappreciable, amounting to only a few units per cent.

As to remedial measures, only one form of treatment has been suggested, and that consists in applying, either to the ground or in holes drilled into the stem, sulphate of iron. The former method of application has been adopted to a considerable extent in New Zealand, where as much as I2 $\mathrm{lb}$. of the sulphate is sometimes applied to the ground round one large tree. The reports as to the effect of such a dressing are not always favourable, and, where good results have followed, these unfortunately have to be discounted by the fact, now established, that trees may often recover of their own accord, independently of any dressing at all. The results at Woburn certainly do not favour the view that such a dressing has any effect on the disease. About 50 trees were examined in this way; in one series they had been inoculated before being planted, and the dressing applied consisted either of I $\mathrm{lb}$. or $\frac{1}{4} \mathrm{lb}$. of iron sulphate to the square yard. The means deduced from two years' observations showed 
only a slight difference between the various sets, and that was against the dressing-

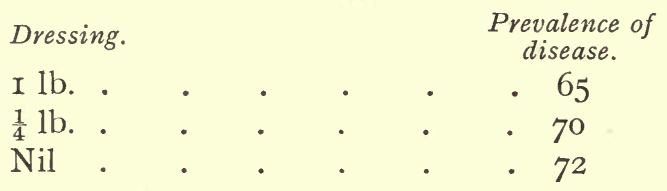

Similar results were also obtained in the case of trees which were not inoculated till after they had been planted-

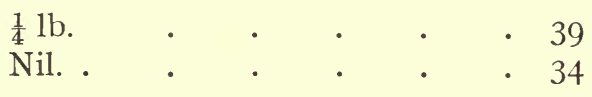

Subsequent experiments in which a daily dressing of $\frac{1}{4} \mathrm{oz}$. of sulphate per tree, together with liquid manure, was given, failed to bring about the recovery of any of the silvered trees on which it was tried.

In combating any disease, the method in which it spreads is the most important point to be determined. All these inoculation experiments with stereum prove conclusively that this disease is a wound disease, the fungus spores entering through some opening in the bark; but whether it could spread in any other way, had to be determined. To see if it could be carried from one tree to another in the absence of active fungus spores, and in the ordinary operations of pruning, two rows of plum trees were planted, with only two feet between the rows; one row was inoculated, the other was not. In pruning these, cuts were made alternately on the silver-leafed trees and on the sound ones, but in no single case did the latter become affected by the disease. Further evidence that the disease cannot be communicated in this way is afforded by the various plum hedges at Woburn, for, here and there in these, isolated cases of stereum have occurred; but the disease has not spread from the tree affected to the neighbouring ones, in spite of the hedges having been pruned from one end to the other, regardless of the presence of the diseased trees. Evidence accumulated from many growers was also emphatic in showing that the various diseased trees in a plantation, though often not far from each other, were generally not contiguous. Of course, if in pruning trees, the pruning instrument happens to collect actual fungus spores from any active stereum, inoculation of the next tree on which it is used would probably follow; and hence in pruning a plantation where stereum exists, it is well to sterilise the pruning tool by 
occasionally dipping it into a solution of carbolic acid, or some such disinfectant.

Inoculations were attempted with the pulp from silvered leaves, but in no case was the disease communicated in this way. It was also sought to ascertain whether the scion or bud from an infected tree could communicate the disease to a sound stock, but no evidence of this was obtained, for such scion or bud never effected a junction with the stock. In the same way it was found impossible to graft sound scions on to affected stocks.

Evidence that the disease was not communicated from tree to tree underground was obtained, as in the case previously mentioned, by growing a row of diseased trees two feet away from a row of sound ones, and aggravating matters by digging roughly between them, so as to injure the roots. But in no case did the sound trees develop the disease. The fact that plum trees may often be silvered in the leaves of the branches, without there being any signs of silvering in those on the suckers arising from the roots, is a further proof that the disease does not originate in the roots.

Evidence collected both in this country and abroad failed to connect silver-leaf with any special character or condition of the soil in which the trees are growing.

The general conclusion from the Woburn experiments was that silver-leaf is a disease which is communicated solely by the entrance of the fungus spores through a wound on the trees, and can be combated solely by reducing the chances of such an entry. To do this it is necessary, in the first place, to diminish the production of fungus spores; every tree which is badly attacked by the disease, and certainly every affected tree which contains any dead wood, should be rooted out, and promptly burnt. Inasmuch as recovery is possible, it may be advisable in some cases to leave a tree which has been attacked, to give it a chance of recovery, but that certainly should not be done if the attack is a severe one; and, where only one or two trees are affected, their immediate removal, whether they are badly attacked or not, would be by far the wisest course. Where removal is not carried out, the affected branches at least should be cut off, and cut off well below the point at which silvering has started.

In the second place, everything possible should be done to prevent wounds being left open in any plantation where silverleaf exists; any broken surfaces should be trimmed, and covered with a coating of tar, and the wounds caused in pruning should likewise be tarred. It is very noticeable that an attack of silver- 
leaf often follows the severe pruning of plum trees, when the wounds have not been treated in this way. It is to be feared, however, that no such precautions can ever be quite effectual in destroying weak spots where the fungus may enter; luckily, entry by the leaves appears not to be possible, otherwise, owing to damage by aphis, there would always be an open door for the fungus. The sterilisation of the pruning tools has already been mentioned as advisable. 


\section{Chapter XXIV}

\section{FUNGI (continued)}

\section{Potato Disease (Reports, I, I50; XIV, I)}

THE ordinary potato disease (Phytophthora infestans) has probably been the subject of more trials and of more pamphlets than any other disease. The importance of the potato crop, and the disastrous degree to which it may be affected by the disease, is, however, a sufficient explanation of this, as well as of the number of the remedies advocated.

All these remedies consist of copper in some form or another, and an impartial consideration of the mass of literature on the subject leads to a conclusion very much akin to that drawn in the case of insecticides for caterpillars, namely, that no one of them is superior to the others under all circumstances, but that sometimes the one, or sometimes the other, may prove the best. One of them may be the more suitable in a persistently wet climate, or in an exceptionally wet season, the other may be the best under drier conditions; one may present facilities in its preparation which others do not; one may necessitate the use of a larger amount of material than others in order to obtain the same results; or, again, one may entail the presence of byproducts which under certain circumstances may cause damage. But with a suitable adjustment of the amount of material used, or of the number of applications made, all these substances will yield equally satisfactory results under certain stated conditions.

It is much to be regretted, therefore,- that a recently formed Government Department - that of Food Production-should have embarked on such a vigorous campaign in which they are spending much public money in advocating one particular remedy to the exclusion of all others, and that, too, without having made any trials of the remedies in question, or without even having made themselves acquainted with the nature of or the proper way of making, either that which they advocate, or those which they decry (see p. I83). It is true that at the present time of writing (I9I8) the Department are having some belated trials made; but trials made with the object of justifying a course 
of action which has already been taken, instead of determining what that course shall be, must stand discredited, even before being made.

A blind advocacy of spraying is naturally accompanied by exaggerated pictures of the advantages to be gained by it, and exaggeration always ends in injuring the cause which it is supposed to aid. In an habitually wet climate, such as that of Ireland, where the potato disease is always more or less virulent, the average benefit resulting from spraying is, no doubt, considerable; but it is much less so in the drier climate of England, and, indeed, spraying here is not always attended with any benefit at all. It would be unsafe to draw general conclusions from results obtained in any one locality, but, though those obtained at Woburn must be open to the objection of localisation, they are, in other respects, more varied than is generally the case. They extend from I895 to I9I7, and, whilst many of the series apply to crops grown on the heavy soil of the farm, which is not favourable for potato growing, the more extensive series were made on the light sandy soil at the adjacent farm of the Royal Agricultural Society. The number of varieties examined in any one season ranged from fifteen downwards, and the number of sprayings applied to the various plots in each season were generally one, two and three in the different plots. The nature of the fungicide was also varied, being in most cases ordinary Bordeaux mixture, Bordeaux paste or one of the forms of Bordeaux mixture sold in the dry form, whilst in a few cases Burgundy mixture was used. The average percentage increase in the yield of sound tubers produced by spraying was as follows-

$\begin{array}{rrrrrr}\text { I89.5 } & \ldots & \text { I2 } & \text { I9I3 } & \ldots & -8 \\ \text { I896 } & \ldots & 3 & \text { I9I4 } & \ldots & 9 \\ \text { I9I0 } & \ldots & 29 & \text { I9I5 } & \ldots & 20 \\ \text { I9II } & \ldots & 3 & \text { I9I7 } & \ldots & -4 \\ \text { I9I2 } & \ldots & \text { I0 } & & & \text { Mean } 8.2\end{array}$

In I9I 2 one of the three series which were made yielded the high value of an increase of $5^{\circ}$ per cent., but, as there were exceptional conditions applying to that series, it is safer to omit it, and base the annual value on the other two series. The general mean, as will be seen, is an increase of a little over 8 per cent. in the crop, rising on occasions to nearly 30 , but, on the other hand, being often negligibly small, and sometimes even negative.

These values are sufficient to show the necessity for not drawing conclusions from the results of one year's trials only; 
and, just as the general effect of spraying may vary greatly from year to year, so also does the relative effect of different sprayfluids. Different varieties of potatoes, too, often show marked differences in their behaviour towards spraying in different seasons: thus, in 1896 , out of seven varieties used in some spraying experiments, the effect was considerable in the case of only two of them; but in the preceding season these sarre two varieties were amongst those which had been affected least by the spraying.

The effect of spraying may be measured in three ways: by the appearance of the haulms, by the percentage of diseased tubers in the total crop, or by the yield of sound tubers. The last of these is the only sound and practical basis of measurement. The appearance of the haulms is generally most misleading, both as to the amount of disease in the tubers, and as to the magnitude of crop of sound tubers. Thus, in I9I2 the following results were obtained-

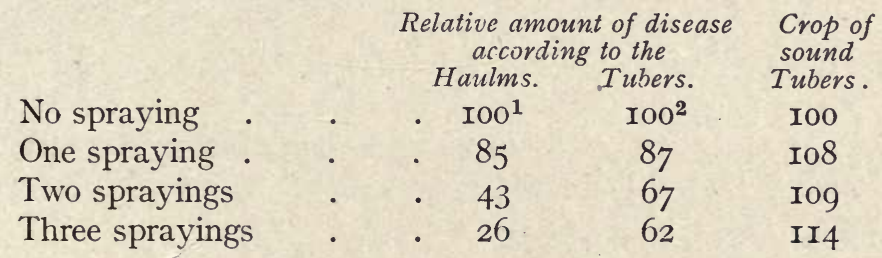

So that, whilst according to the haulms, three sprayings had reduced the amount of disease by three-quarters (74. per cent.), the actual reduction of the disease in the tubers had only been 38 per cent., and the increase in crop of sound tubers was as small as I4 per cent.

As a consequence of such results, the comparative effect of different fungicides must never be judged by the appearance of the haulms: thus, in I9I0, certain results with ordinary Bordeaux mixture and with Bordeaux paste gave-

\begin{tabular}{|c|c|c|c|}
\hline & \multicolumn{2}{|c|}{$\begin{array}{l}\text { Relative amount of } \\
\text { disease in the }\end{array}$} & $\begin{array}{l}\text { Crop of } \\
\text { sound }\end{array}$ \\
\hline praying & $\begin{array}{l}\text { Haulms. } \\
\text { IOO }^{3}\end{array}$ & $\begin{array}{c}\text { Tubers. } \\
\text { I00 }^{4}\end{array}$ & $\begin{array}{c}\text { Tubers. } \\
\text { I0o }\end{array}$ \\
\hline Mixture. & . 39 & 66 & I33 \\
\hline Paste . & 64 & 89 & I33 \\
\hline
\end{tabular}

so that, according to the haulms, the mixture had made a much

1 Eighty per cent. of the total leaf surface was diseased.

2 Fourteen per cent. of the total crop was diseased.

3 Ninety per cent. of the total leaf surface diseased.

4 Twenty-seven per cent. of the total crop diseased. 
greater reduction in the disease than had the paste, and, according to the tubers, a much smaller reduction, whereas as regards the total sound crop obtained (the only point of importance) they had both had exactly the same effect.

It is evident, therefore, that the bolstering up of special remedies by a display of illustrations of sprayed and unsprayed plots, should be unhesitatingly condemned, as being misleading: indeed, the appearance of the haulms is in any case, whether spraying has been adopted or not, no criterion of the total yield of tubers. It is well known that potatoes when grown in a virgin soil show a phenomenal development of haulm, whilst the crop of tubers is generally very small.

Much of the work on potato-spraying done at Woburn was directed to determine the proportion of Bordeaux paste which would generally be equivalent in its effect to ordinary Bordeaux mixture, and the results from that point of view have been stated on p. I78. Some results of more general interest, however, were obtained.

In the first place it was clear that spraying sometimes, but not always, caused an actual decrease in the crop of sound tubers obtained, especially in seasons where there was not much disease; a fact which has already been noted by other observers. Thus, in $\mathrm{I} 895$, there were 5 cases out of 25 where spraying had slightly reduced the crop, and in 1896,8 cases out of I4. In I9I3, when the total disease was as low as $0^{\circ}$ I2 per cent., spraying had a more marked effect on reducing the yield, there being a reduction of 5 per cent. when an average amount of fungicide was used, and a reduction of II per cent. when the amount of fungicide was increased threefold. In IgI8, in the case of some plots where there was no disease, and where Burgundy mixture and Bordeaux paste, each at three different strengths, had been used, the crops obtained were in the proportion of $\mathrm{gI}$, III and I27 where the strongest, medium and weakest sprayfluids had been used, respectively. On the other hand, however, there are exceptions found to such an action, for in IgII, where the amount of disease was very small, the effect of spraying, though somewhat insignificant, was in the direction of increasing the crop (by 3.5 per cent.).

Any deleterious effect of spraying, when such exists, is easily accounted for by the fact that copper is toxic towards all plant growth, and that it is only in cases where the harm done by it to the plant is more than counterbalanced by the good done in destroying the fungus, that the result will be beneficial. 
From every point of view it is probably better to use small doses, and repeat the sprayings, than to use a double or treble dose in one application. According to the principles governing fungicidal action established by the Woburn results (see p. I92), an increase in the dose beyond a certain point produces but a comparatively small increase in the effect, and that was borne out by the results on potato spraying itself, where the benefit from a single and double dose amounted to 14.5 and 15.5 per cent., respectively (XIV, I5). There is also a very strong reason for increasing the number of applications in the fact that the effect of a single spraying does not generally last for more than three or four weeks, and may have worn off before the disease makes its appearance.

Another set of experiments which afford interesting evidence on the subject of potato spraying were made in I9I2, when potatoes were grown in sixty plots which had been manured differently for the previous sixteen years": one half of each plot being sprayed; and the other half not. The ground was not specially prepared for the crop, and the yield was consequently a small one, but the effect of the spraying-probably as a result of the smallness of the crop-was very great. A summary of the results is shown in the following table.

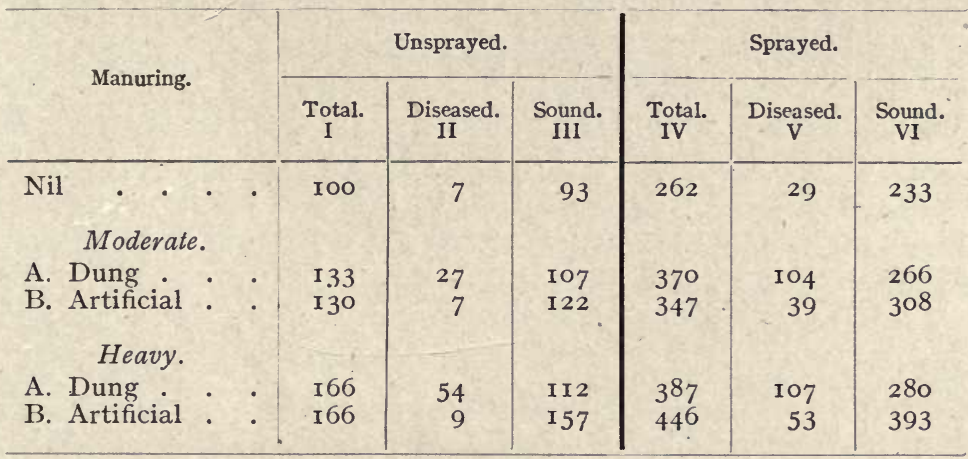

Taking the results in the unsprayed plots, it will be seen that manuring had, as might have been anticipated, a notable effect on the total yield (col. I), but that, contrary to what might have been expected, the effect was the same whether the manure was dung or artificials. On the other hand, dung and artificials had had a very different effect on the amount of disease present, for artificials had not increased the proportion of diseased tubers at all (col. II), whereas dung has increased it four- and eight-fold, 
according to the heaviness of the dressing; as a consequence, the yield of sound tubers (col. III) was less in the unsprayed plots dressed with dung than in those dressed with artificials, being, indeed, not much greater than in those with no dressings at all.

Passing on to the results in the sprayed sections, it will be seen that the spraying had in every case increased the weight of diseased tubers present (col. V, compared with II), though it had increased the total yield (col. IV, compared with I) still more, so that there was a large balance to the good of sound tubers as a result of the spraying (col. VI, compared with III). When the percentage, instead of the actual weight, of diseased tubers in the crops is examined, it is found that the increase had occurred only in cases where the proportion of disease was low; where it was high, as in the dunged plots, no increase had occurred.

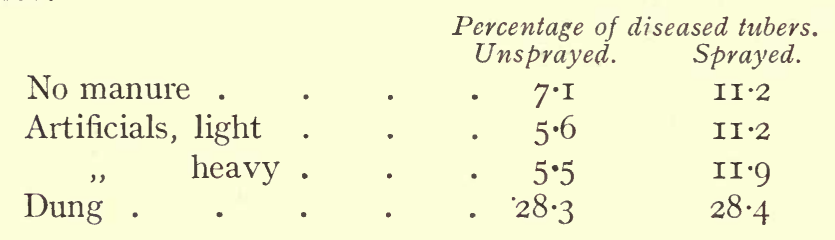

Just as the prejudicial effect of spraying, in increasing the proportion of disease, depends on this proportion being otherwise low, so the beneficial effect, in increasing the total yield of sound tubers, depends on the lowness of this yield. In this series the increase was phenomenally large-I5O per cent.-and the yield was phenomenally small-3 tons to the acre in the unsprayed plots;-whereas in two other series carried out in the same season elsewhere, and in which the yield was eleven tons to the acre, the effect of spraying was to produce an increase of only 9 and I9 per cent., respectively. An examination of the various results in other seasons $(\mathrm{XIV}, 27)$ helped to confirm this view : but no connection could be observed between the benefit produced and the amount of disease in the crop: taking the two instances out of eight series where the benefit was least, in one of them the percentage of disease was the lowest recorded, in the other, the highest.

From these facts, it would appear that the whole question of potato spraying should be considered from a wider point of view than that generally adopted. Spraying tends to kill, not only the fungus which causes the potato disease, but other fungi as well, and these other fungi are probably important 
factors in hastening the dying down of the haulms, and the ripening of the tubers. ${ }^{1}$

That spraying can destroy all the spores on the leaves, and render the plant quite free from disease, is amply disproved by all the results obtained; and, where disease is present, two effects are produced (apart from any possible toxic action of the copper on the potato plant itself alluded to on p. 244); on the one hand, the fungoid growth is partially destroyed, but on the other, the haulms are thereby rendered more vigorous and succulent, and they, consequently, present a readier passage for the mycelium from such fungus spores as have not been destroyed.

The percentage of diseased tubers can, therefore, be no measure of the general result of the spraying, it is only one of the results, and it may be that, as in the case just quoted, this percentage is actually increased, even doubled, by the spraying. In the same way, neither the increase in the total crop, nor even that in the sound portion of the crop, can be taken as a true measure of the results of the treatment, though the latter is, at any rate, a practical measure, for the yield of sound tubers is the only one which is of value to the grower.

That disease is encouraged by the vigour of the plant, and especially by the vigour and succulence of the haulm, may be inferred from the large increase of disease noticed when dung, instead of artificials, was used, although the total crop of tubers was the same in the two cases (p. 245); and in that case, as was seen, spraying produced no further increase in the vigour of the haulms, and, consequently, no increase in the percentage of tubers affected.

That the effect of spraying, or of any other treatment benefiting the plant generally, should be greater when the plants are in a bad condition than when they are flourishing, is what naturally would be expected, and hence the greater effect of spraying in increasing a poor than a heavy crop.

Two other points connected with potato disease were investigated at Woburn : the one was the steeping of the seed in copper sulphate solution of various strengths prior to its being sown. The results were not satisfactory. When soaked for io minutes in a I per cent. solution, there was no apparent benefit, the crop of 'sound tubers being practically the same as with unsteeped

1 Sprayed potatoes are generally about a fortnight later in ripening than unsprayed ones. This, indeed, is one of the disadvantages attributed to spraying, for the delay in ripening may not only cause inconvenience on the farm, but may result in a certain amount of "growing out" of the tubers. 
seed ( $98:$ I0o), and the proportion of diseased tubers being actually greater (II6: IOO). The proportion of diseased tubers was, however, diminished to 83 per cent. where stronger solutions were used ( 5 per cent. for 5 minutes, and Io per cent. for 2 minutes), but the crop was materially reduced, especially where a Io per cent. solution was used, the yield, then being only 62 per cent. of that in the plots with unsteeped seed. ${ }^{1}$ The other point was, the effect produced on the crop by cutting off the haulms as soon as the disease made its appearance, a practice which is often recommended. In two series where the haulms were cut off ten days after the disease appeared, the disease in the tubers was practically eliminated, being reduced to only 7 per cent. of that in the uncut sections; but the results were otherwise unsatisfactory, for the total crops were so reduced that the yield of sound tubers was 4 per cent. less than in the uncut sections, and there was a reduction of 8 per cent. in their average size. Similar results had previously been obtained by other observers. ${ }^{2}$

1 Similar results were obtained by Pethybridge, Journ. of Board of Agric. and Technology, Irelaind, $\mathrm{I} 3,450$.

2 Journ. R. Hort. Soc., 1847, 33; 1849, 65: 1850, 105; Trans. Highland and Agric. Soc., I845-7, 436; Vermont Agric. Expt. Station, I90I-2, 209. 


\section{Chapter XXV}

\section{HEATED AND TREATED SOILS \\ (Reports, IX, Appendix; XIII, Appendix)}

From a study of the changes produced in the nature and behaviour of soils when they are heated, or when they are treated with antiseptics, to the action of grass on fruit trees, would appear to be a far cry; yet these studies are but different chapters of the work on the effect of one crop on another, which figures so largely in the investigations at Woburn, and the one has a very intimate bearing on the other. Though the examination of such soils was not made till after the work on the effect of crops on each other had been in progress for several years, the results may be more conveniently described as a preliminary to the main work.

The researches of Russell and Hutchinson ${ }^{1}$ were the first to establish satisfactorily that, when soil is heated to a temperature of $80^{\circ}$ to $100^{\circ}$, though there is a considerable mortality amongst the bacteria present, there is a complete mortality of the protozoa which live upon the bacteria, and that, consequently, after such heating, the surviving bacteria multiply unchecked, and attain to a degree of activity much greater than they do in unheated soil. The beneficial effect of treatment with antiseptics is explained on similar lines. These facts must now be regarded as beyond dispute; but it is a question still how far they explain the increased growth of plants in heated or treated soils; it is certain that such heating and treating brings about changes other than bacterial ones, changes which are purely chemical in their nature, and which must effect the behaviour of the soil very materially.

Plants depend for their sustenance on the soluble matter in the soil, and, when this is heated, the amount of soluble matter in it is rapidly increased; when the temperature of heating, for

1 E. J. Russell and H. B. Hutchinson, Journ. Agric. Sci., 1909, III, III-I I 4 ; I 913 , V, I 52-22I. 
instance, is as high as $150^{\circ} \mathrm{C}$., the soluble inorganic matter is increased threefold, and the organic matter twelvefold, it being chiefly in the nitrogenous organic matter that the largest increase occurs. These values vary very greatly, as might be expected, with the nature of the soil, and the amount of water present in it during the heating; but, whilst the maximum effect is not produced till about $200^{\circ}$, it is still well in evidence when the temperature is as low as $60^{\circ}$, and, when the results are set out for a series of samples heated to different temperatures, as shown in Fig. 24, it is clear that, whatever changes the heating has produced, these are continuous down to a point below even $25^{\circ} \mathrm{C}$.; that is, they are continuous with changes occurring in soils which

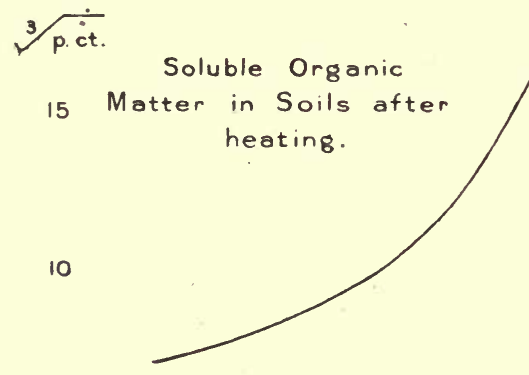

5

$50^{\circ} \quad 100^{\circ}$

$100^{\circ} \quad 150^{\circ}$

Temperature of Heating.

FIG. 24.-RELATION BETWEEN TEMPERATURE AND

ORGANIC MATTER.

have not been heated artificially above atmospheric temperatures (XIII, Appendix, p. 267).

When such heated soils are kept for any length of time, further changes of a somewhat complex nature occur in them, for, as might naturally be expected, there are many substances of different degrees of stability formed by the heating, and the relative proportions of these depend on the temperature reached; but the general results are clear, namely, that if air is excluded, or if the soils are kept dry, the heated soils undergo but little change, whereas, if there is free access of air and moisture, the proportion of soluble matter decreases gradually, the excess present in the heated soil becoming, after about Ioo days, reduced to half its original amount.

The behaviour of such soils towards plant life was first - examined by studying the germination of seeds in them, for this presented the twofold advantage of its being a method 
which could be applied before the heated soils had had time to alter their character to any appreciable extent, and also that the results of germination are not complicated by bacterial changes in the soil, germination being independent, as was proved, of the presence or absence of bacteria.

The results of this examination were to show that the substances rendered soluble in soils by heating, act as toxins towards germinating seeds, not only retarding their germination, but reducing the number of seeds which eventually germinate (IX, Appendix, p. ix), and that this action gradually disappears with the disappearance of the excess of soluble matter when the heated soils are kept for any length of time exposed

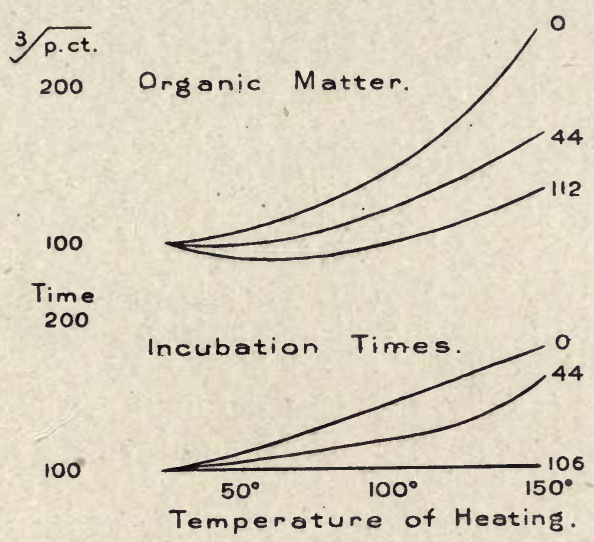

FIG. 25.-RELATION BETWEEN TEMPERATURE, ORGANIC MATTER AND INCUBATION.

to atmospheric influences. The drawings in Fig. 25 (XII, Appendix, pp. 27 I and ii) show the relative values obtained with heated soil, as compared with that obtained with unheated soil represented as Ioo; the curves in the upper portion refer to the soluble organic matter present 0,44 and II 2 days after the heating; whilst those in the lower portion refer to the incubation times of the seeds when they germinate in these same soils. The general connection between the two sets of phenomena is obvious, though the proportionality between them is not a direct proportion, since the upper figure represents the cube root of the percentages of soluble matter, whereas the lower figure represents the actual incubation periods; also it will be seen that, when the incubation times of seeds in heated soils become reduced nearly to their original value, as happens after I6o days, there still remains in the soil a considerable portion 
of the excess of organic matter rendered soluble by the heating. Twelve different soils were examined, and they all behaved in a similar manner on heating, though the amount of organic matter rendered soluble by the heating was not an invariable guide as to the extent to which germination was affected. Similarly, though germination generally occurred less readily in those unheated soils which contained a smaller amount of total soluble matter, this was not invariably the case, as would follow from the soluble matter differing in different cases. Whether any of the soluble constituents of soils is actually favourable to germination, or not, appeared doubtful; certainly, in general, they are the reverse, and germination was found, in such cases as were examined, to take place more readily in an inert medium (e.g. wet sand) than in earth; this affording further evidence that a substance having a toxic effect on germination is present in some soils even under ordinary conditions (see p. 250).

That bacterial conditions do not play any part in these results on the germination of seeds is evident from the results of the experiments themselves: thus, the bacterial changes consequent on heating soils result, after some lapse of time, in a large increase in the bacterial contents, provided the temperature to which the soil has been heated has reached $60^{\circ}$ to $\mathrm{roo}^{\circ}$; but it leads to an extinction of bacterial life if it has been as high as $125^{\circ}$. The germination values, on the other hand, show a continuously progressing effect from the lowest to the highest temperature of heating, $150^{\circ}$. Added to this, it was found that seeds will germinate in a sterile medium; that sterilised and unsterilised seeds germinate with equal readiness, and that sand, even when thoroughly inoculated with soil bacteria, behaves in the same way towards germination, whether it has, subsequently to the inoculation, been heated or not.

Against this view, however, it may be urged that the treatment of soil with antiseptics produces the same effect as that of heating it, and that with antiseptics, such as benzene, ether, chloroform, carbon disulphide, etc., there can be no chemical action on the substances in soil, and that their action must, therefore, be confined to the organisms in the soil. But this contention seems untenable; for the only way in which such substances can act on organisms, either as antiseptics or as anæsthetics, is by affecting the chemical processes on which life depends: this implies chemical activity. Moreover, these antiseptics undoubtedly act on organic substances in the absence of living organisms, and act on them very rapidly; this was 
shown by exposing sound apples to the vapour of various antiseptics under bell-jars at ordinary atmospheric temperatures: with chloroform, ether, or carbon disulphide the fruit was found to have become much discoloured after twenty-four hours, and after eleven days it was soft, brown and decomposed, nearly, or quite to the core. The action with ether was more energetic than with the other two substances; but petroleum ether had comparatively little effect. Instances have been found in which much simpler chemical changes than those occurring in vegetable matter can be effected by the antiseptics: ${ }^{1}$

To all appearance the effect of heat and antiseptics on soil is closely similar; the soluble matter is increased, the germination of seeds is adversely affected, and the growth of plants is favourably affected; and from all three of these phenomena a similar estimate of the relative magnitude of the effects is obtained, namely, that the treatment with antiseptics is equivalent to heating to about $70^{\circ} \mathrm{C}$. The increase in soluble matter might be accounted for by the removal of some coating of oily or resinous matter from the particles of soil, but this is rendered somewhat improbable by the fact that the treated soil when kept for some time, even in a fairly dry condition, reverts towards its original state, just as heated soil does. That the increase produced by the treatment is not due to altered bacterial activity consequent on the treatment, was shown by the fact that the increase was found to have occurred within one hour after the treatment, during which time no appreciable action from bacteria could have occurred. Eighteen hours later a very appreciable diminution in the soluble matter was observed.

-All. these facts render it clear that no true estimate can be obtained of the behaviour of freshly heated or freshly treated soils towards plant-growth by growing plants in them, for, long before these will have grown sufficiently for measurements to be made, the soils will have become materially altered. The results which are apparent are that growth is very largely increased - even up to 200 per cent.-with the temperature to which the soil has been heated, so long as this temperature does not exceed $80^{\circ}$ or $100^{\circ}$. Russell and Darbishire's results ${ }^{2}$ with a number of different plants may be quoted, and similar results with apple trees have been obtained at Woburn (IX, Appendix, p. ii); but none of these would disprove the presence of a toxic

1 S. Pickering, Chem. Soc. Trans., 109, 242: "Action of Heat and Antiseptics on soil," Journ. Agric. Soc., I908, III, I-2 I.

2 E. J. Russell, Journ. Agric. Sci., I905, I, 26I-79; E. J. Russell and F. V. Darbishire, Journ. Agric. Sci., 1907, II, 305-26. 
substance in the soil immediately after the heating, for such a toxin would have had ample time to become decomposed into food-material before growth was complete-indeed, it was suggestive that in the experiments with trees, those in the heated soils were much slower in coming into growth than their fellows in unheated soil. But, as the germination results taught, the proportion of toxic matter is rapidly increased by raising the temperature of the heating, and so by extending the observations to soils which had been heated to as high as $150^{\circ}$, sufficient toxic matter was formed to outlive the time required for the growth of the plants, and its effect on these then became evident.

Figs. 26 and 27 illustrate the results obtained in the case of some of the plants examined. The seeds were sown in the recently heated soils in April, the temperatures to which they had been heated being marked on the pots (the "unheated" soil is marked $30^{\circ}$, though, perhaps, $25^{\circ}$ would more nearly represent the maximum temperature to which it may have been exposed). In the case of the tobacco and tomatoes, photographs taken on two different dates are shown; on the first of these it is evident that the toxic effect in the case of the highly heated soils is still operative, the plants being very stunted, though the presence of an ample supply of nitrogenous food, even at that date, is evidenced by the size and appearance of the leaves. As time went on this toxic effect was reduced, and the ultimate growth of the plants, though still exhibiting some signs of stunting, is much in excess of the growth in the unheated soil, and in some cases in excess of that in soil heated to $100^{\circ}$. The average growth eventually obtained in the case of spinach, tobacco, and tomatoes, on the one hand, and of three different grasses, on the other, were-

$\begin{array}{ccc}\text { Soil heated to } & \text { Non-grasses. } & \text { Grasses. } \\ 30^{\circ} & \text { I00 } & \text { I00 } \\ 60^{\circ} & \mathrm{I} 93 & 243 \\ 80^{\circ} & 243 & 2 \mathrm{I} 5 \\ \mathrm{I00}^{\circ} & 248 & 329 \\ \mathrm{I}_{25^{\circ}} & 192 & 42 \mathrm{I}^{1} \\ \mathrm{I}_{50^{\circ}} & \mathrm{I} 20 & 37 \mathrm{I}^{\mathbf{1}}\end{array}$

With the grasses, as will be seen, the effect of the toxin had nearly entirely disappeared by the time growth was complete, and the increase in growth due to the heating was very great; this

1 If the roots are included the maximum occurs at $150^{\circ}$. 


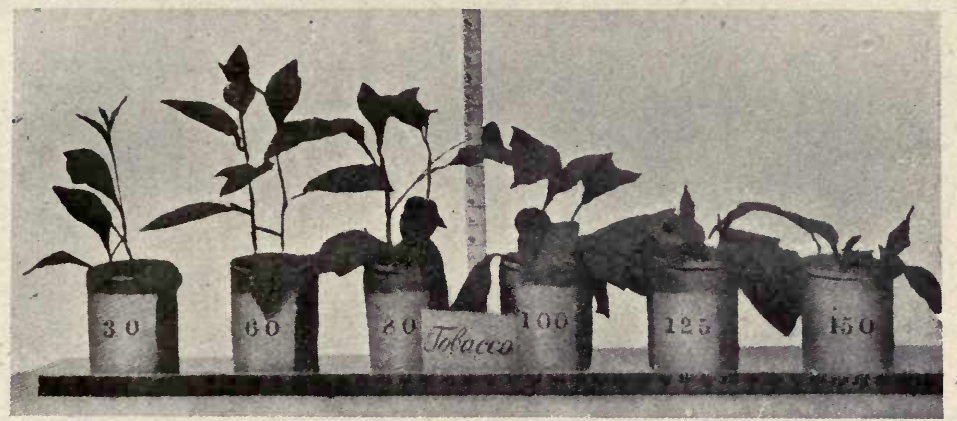

- Tobacco, July 28 .

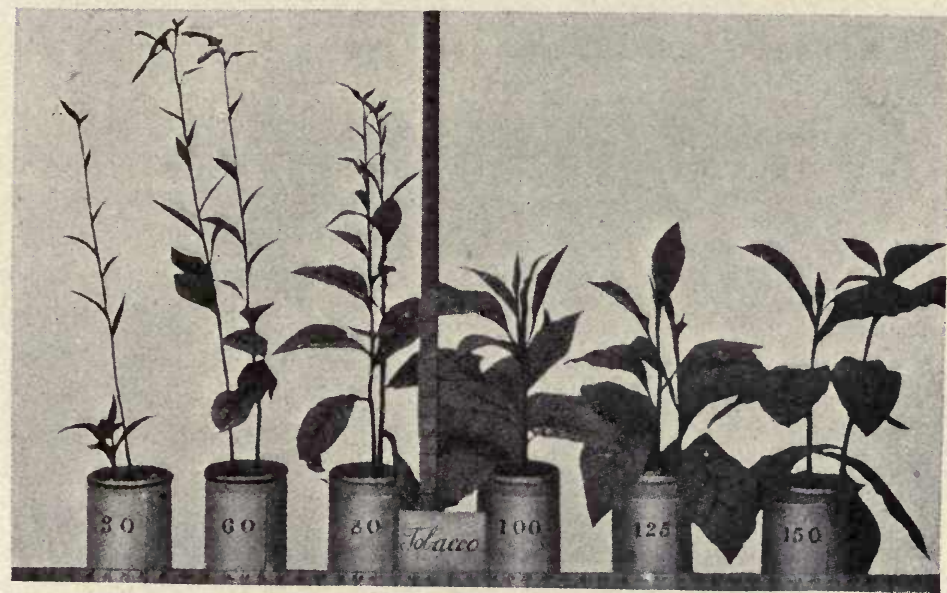

Tobacco, August 25.

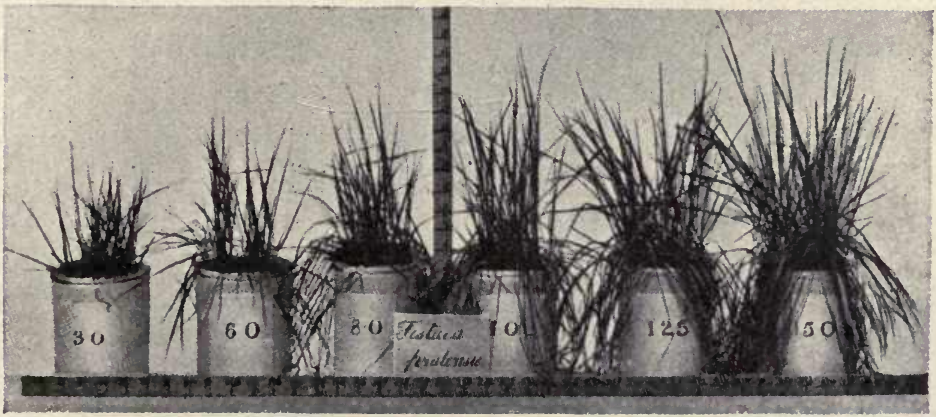

Festuca pratensis, July 28 .

FIG. 26,-PLANTS GROWN IN SOIL HEATED TO DIFFERENT TEMPERATURES. 


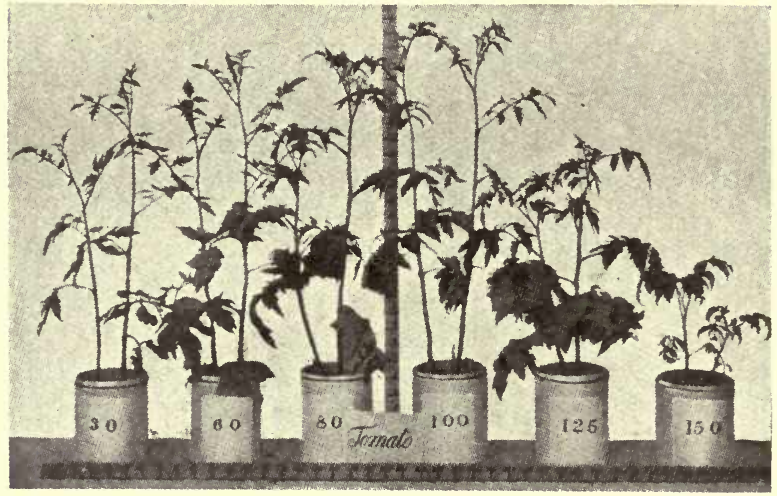

Tomato, July 28.

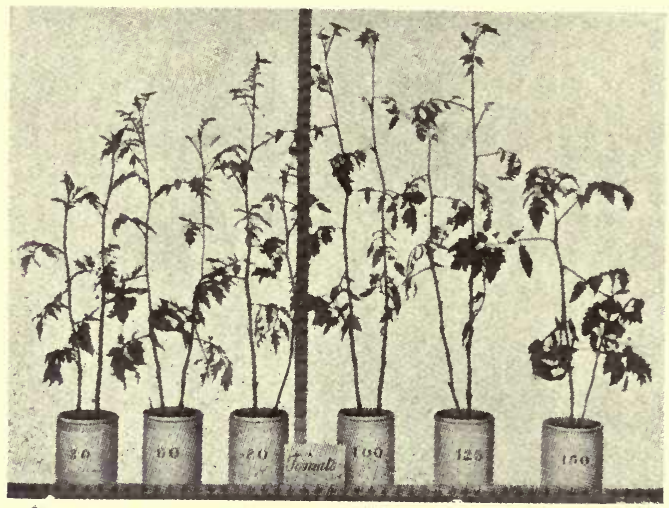

Tomato, August 25 .

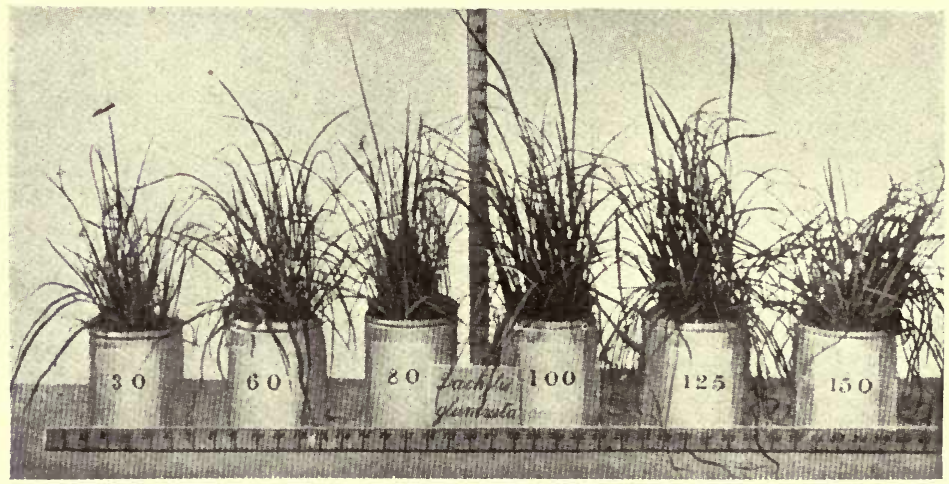

Dactylis glomerata, July 28 .

FIG. 27.-PLANTS GROWN IN SOIL HEATED TO DIFFERENT TEMPERATURES. 
increase, however, did not manifest itself till after the grasses had been growing for some time.

That the free access of air is necessary for the toxic substance in heated soils to become converted into plant-food, was established by a series of experiments in which young apple trees were grown in large bottles containing soil heated to different temperatures, the necks of the bottles being closed so as to admit of only a very limited supply of air, such as would pass through wide tubes packed with cotton wool. The growth measurements of the trees showed a fairly steady decrease according as the temperature of the heating had been higher.

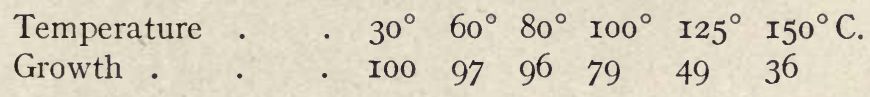

The original object of packing the air-tubes with cotton wool was to exclude bacteria; also, half of the trees were sterilised before planting; but no indications were obtained that the results were influenced by the degree of sterility of the conditions. At the same time other experiments showed that the changes occurring in heated soil on its exposure to air took place equally under septic and aseptic conditions, so that in the above experiments it is the limitation of the air supply, and not the exclusion of bacteria, which must explain the results obtained.

The evidence thus derived from a study of these heated and treated soils shows that the organic matter existing in soil decomposes very readily, forming, first, a substance which is toxic towards germination and plant-growth, and, ultimately, one which acts as a plant-food; also, that such changes must be occurring in soils which are not subjected to temperatures higher than those naturally occurring. That such changes, and analogous ones in the case of soils treated with antiseptics, are sufficient to explain all the phenomena observed, may be an open question; indeed, there can be little doubt but that bacterial changes co-operate in producing some of them, such as the increased growth in moderately heated soils: the rôle played by bacteria and protozoa in the soil has been placed beyond the region of uncertainty. But there is now no question of accepting one explanation to the exclusion of the other; the bacterial and chemical explanations are equally true, and the only point remaining to be settled is the relative importance of the two in determining the results. The evidence as it stands at present certainly seems to point to the chemical factor as being the more important of the two; the trophic protozoa are killed at 
a temperature of $57^{\circ}$, and the cysts at $70^{\circ}$, so that if their existence were the only, or the main consideration, soils heated to $70^{\circ}$ should prove more fertile than any others, and heating beyond that point should cause a reduction in fertility, till, with a temperature of $\mathrm{I} 25^{\circ}$, a minimum would be reached, all the bacteria having then been killed, and growth depending on chance re-

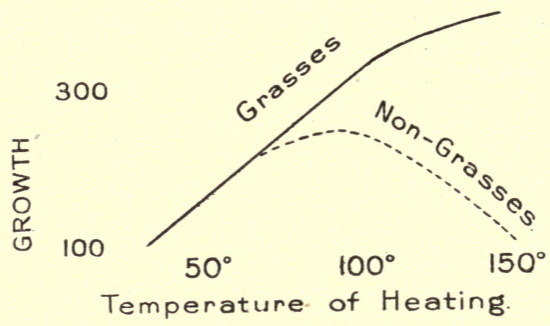

FIG. 28.-GROWTH OF PLANTS IN SOIL HEATED

TO DIFFERENT TEMPERATURES.

inoculation; but from the Woburn results, which are shown diagrammatically in Fig. 28, it appears that the maximum effect occurs in the case of non-grasses with soil heated to $100^{\circ}$, not to $70^{\circ}$, and in the case of grasses with soil heated to $125^{\circ}$ or $150^{\circ}$ (see p. 254), according as the roots are excluded or included.

Such a fact argues strongly in favour of chemical change being the principal factor in the case. ${ }^{1}$

1 Cf. "The Chemistry of Steam-heated Soil," U.S. Dept. of Agric. Bureau of Soils, Bull. 89, I91 2, by Schreiner and Lathrop. This paper also contains many references to earlier work. 


\section{ChAPTER XXVI}

\section{THE EFFECT OF GRASS ON TREES \\ (Reports, I, 97; II, I60; III, 3; V, 46; XIII, I; XIV, Appendix)}

THE story of the Woburn investigations on this subject is necessarily a long one, for the work started with the existence of the farm, and has been in progress ever since. The time which has been devoted to it, has, however, been justified by the results, for the question has developed into one of fundamental importance wherever crops of any sort are grown.

Roughly, the work may be divided into (I) the examination of the effect of grass on trees, which is but one particular instance of the general phenomenon; (2) the search for an explanation of this effect; (3) the extension of the observations to plants in general, and, finally, (4) the study of another particular instance - the effect of similar plants on each other when massed together.

Some of the plots of standard and bush apple trees planted in the farm in 1894-5 were grassed over in the following season, sowing seeds recommended as suitable for grassing orchards on heavy land. The results are sufficiently illustrated by photographs of some of these trees (Figs. 29 and 30) taken three years later; a quotation of the values obtained on measuring the vigour of the trees would hardly be more impressive. It need only be added that no form of ill-treatment examined at Woburn, except lifting the trees every year, caused a reduction of vigour comparable with that produced by grass. Bramley's Seedling, which is shown in the illustrations, is a very strong-growing variety; other varieties of a weaker habit-Cox's Orange Pippin, Lane's Prince Albert and Potts' Seedling-were examined in the same way, and gave even more striking results.

It was at first considered probable that such an effect was the result of grassing the trees before they had become well established in the ground, and that the results would be very different with trees which were in a state of vigorous growth. But the case proved to be otherwise: plots of Bramley, Cox and Potts', which had been growing in tilled ground for four years, were laid down to grass. The effect was remarkable; all growth was arrested, even in the first year of the grassing, and within five 


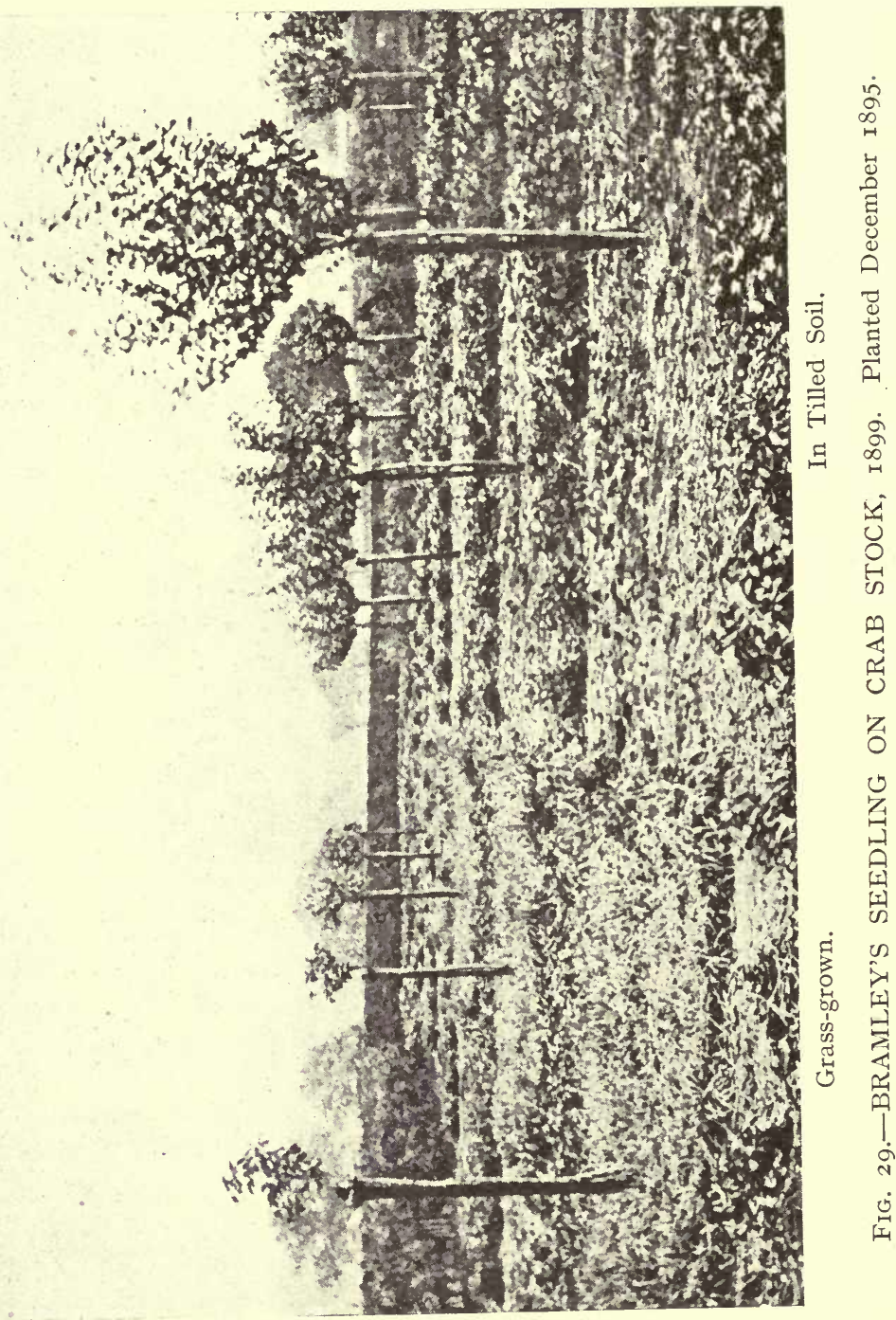




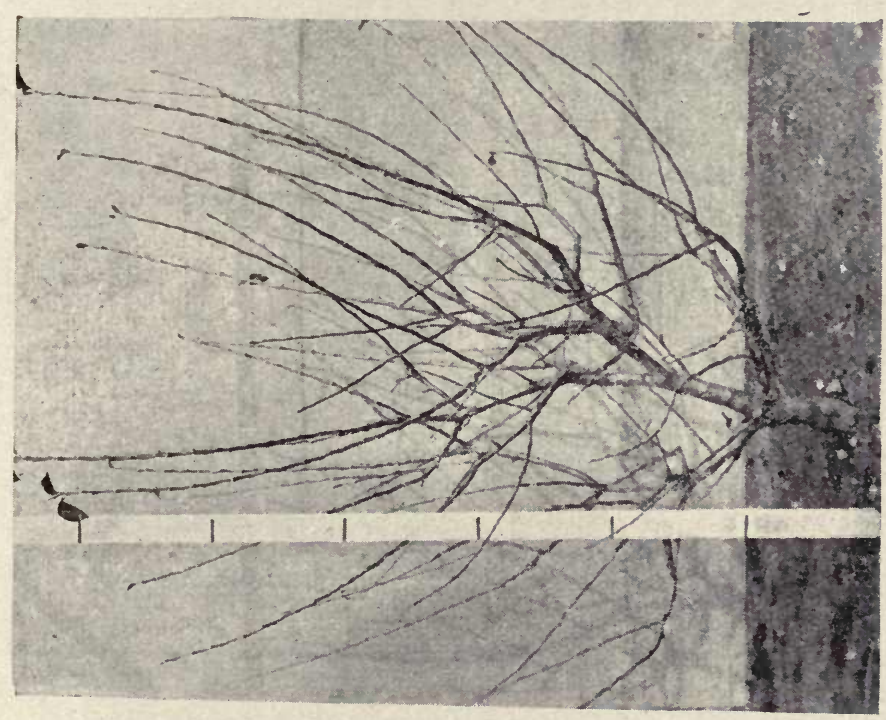

$\ddot{\circ}$

田

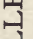

当

导是

㘝

됭

近

学 沓

ज苍

ती त

昶

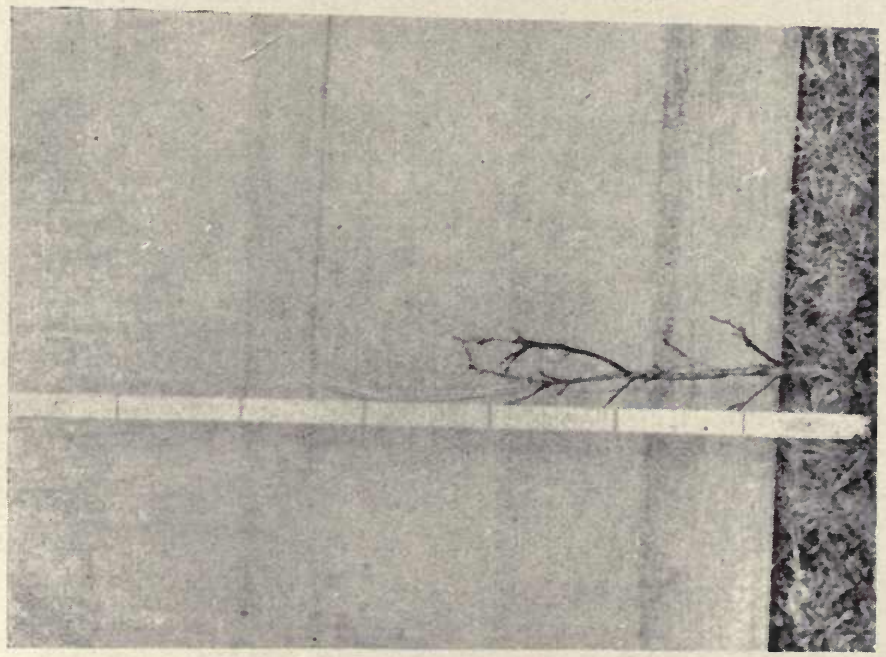

$A>$

学声

息

A 
years the majority of the trees of the weaker varieties were actually dead, as will be seen from Fig. 3I. Somewhat similar experiments were made at the same time on the Bramley's standard trees, by grassing them over, either entirely or partially, after they had been established in the ground for eight years, when similar results were obtained (III, I7) ; even a very partial grassing of the ground round the trees having a marked effect on them.

Again, in 1907, two mixed plantations planted in I894, consisting of standard and dwarf apples and pears, were each divided into two similar sections, as to which sections previous records showed that the various trees in the two were closely similar in vigour and bearing. One section in each plantation was then laid down to grass. In spite of the long time which the trees had had to become established, the grass still proved most deleterious: photographs taken three years later of two originally similar trees are reproduced in Fig. 32, and will serve to illustrate the average general effect. The intensity of this effect, however, varied greatly with the different varieties $;^{1}$ in some cases the grassed trees were killed, in others they suffered very little. The extent of the variation may be judged by the following summary of the relative values of the crops from them during the nine years following the grassing, the values for the trees in the ungrassed sections being represented by I0o. In one case, a pear, the effect had been beneficial.

Apples.

Pears.

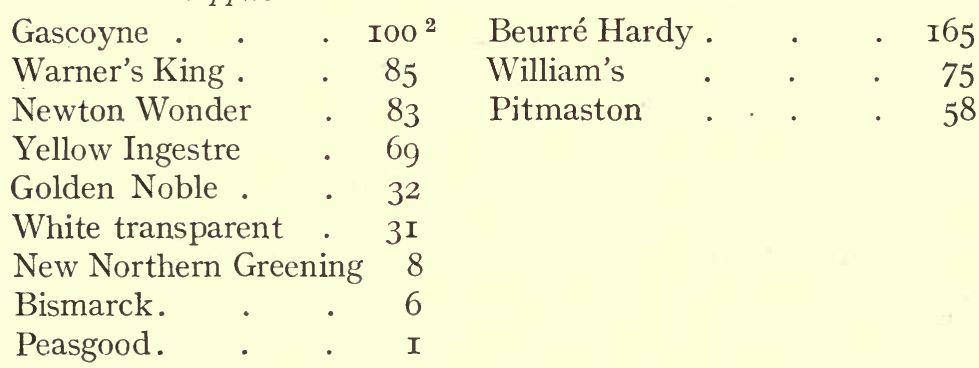

The leaf-weights, which were examined during the four years after the grassing, told a similar tale, those in the grassed section being, on the average, 25 per cent. less than those in the tilled sections.

1 But is attributable, from recent observations, more to the different drainage in the plots (p. 308).

2 Probably much too high owing to a very exceptional value in one season. 


\section{THE EFFECT OF GRASS ON TREES 263}

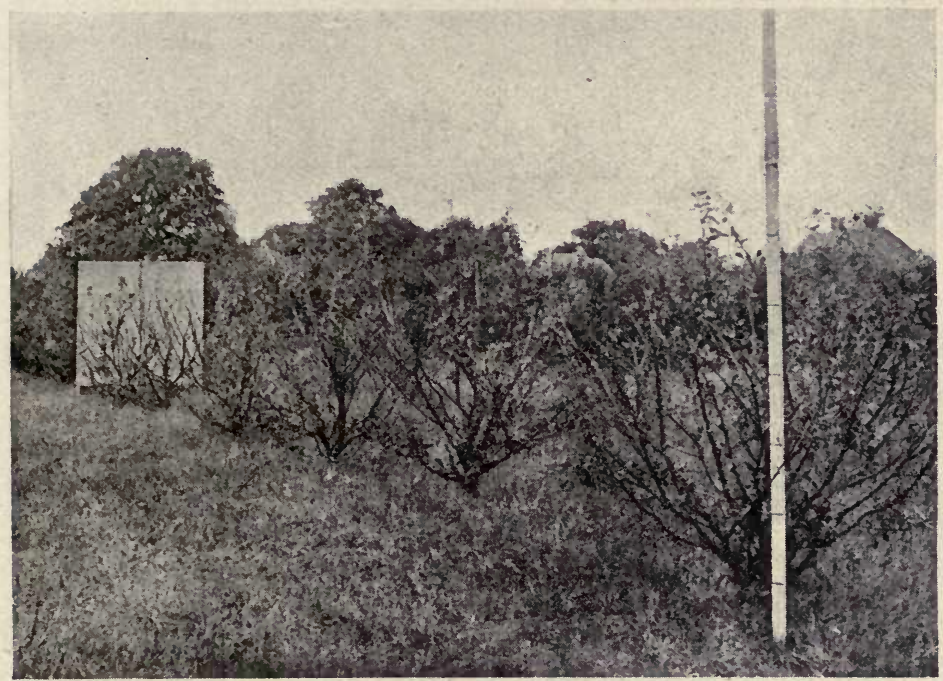

Trees grown for four years in Tilled Soil and then Grassed over.

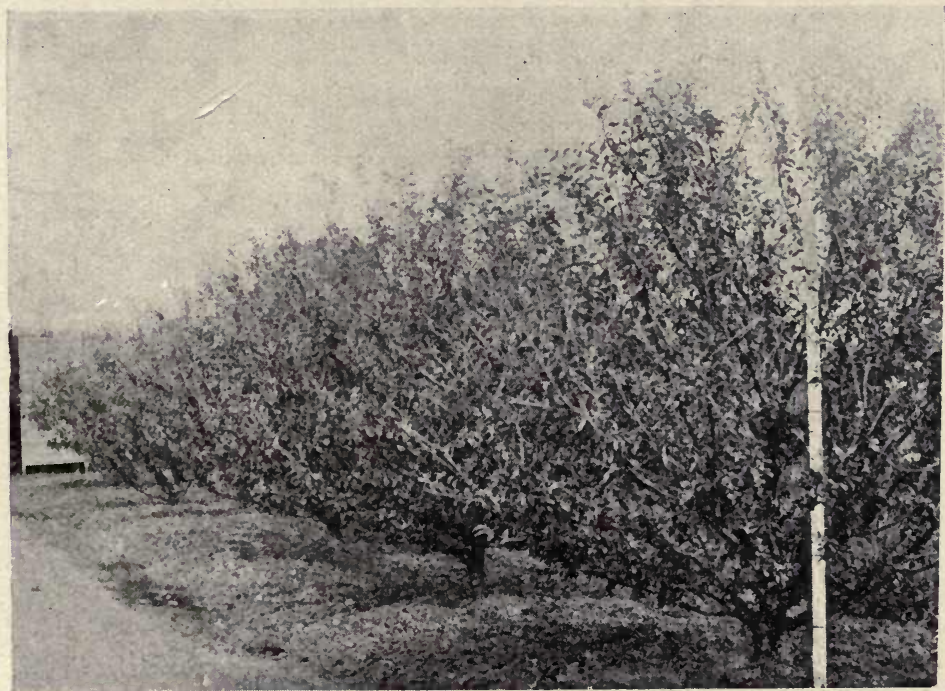

Trees grown continuously in Tilled Soil.

FIG. 3r.-COX'S ORANGE PIPPIN ON PARADISE STOCK, I905. Planted I 894-5. 


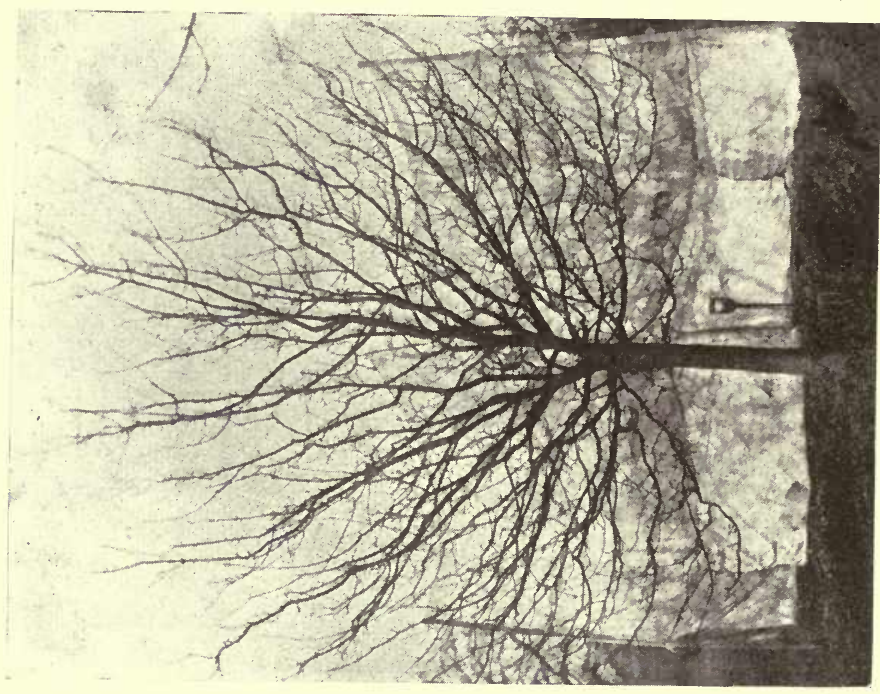

ن

回

II 至

ن. 四

$\Xi$ «U

우 되 थ

U

的

台宗

丘寈

$\exists$ 要

点空

红

万资

(I)

学学它

娄空

I.

Tी

记点

开

出皆

$13 \times 1$ J 12

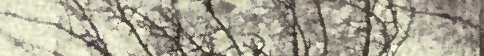

- $2+2,120$

on

되요

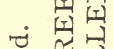

2)

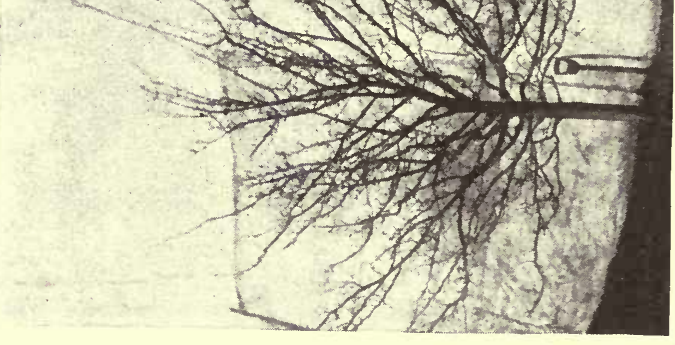

品旦

된

至

A 1

A o

$\int_{1}^{4}$

i 되

$\dot{0} m$

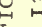


Finally, a plantation of standard Bramley's Seedling apples, which had been established for twenty-three years, and consisted of remarkably vigorous specimens of this variety, was selected, and half of it laid down to grass in I9I7. The grass did not come up well, and the hay from it amounted to only three-fifths of a ton to the acre, yet the effect of it on the trees was very apparent, even in that first year. In June the foliage of the grassed section exhibited the light unhealthy tint characteristic of trees suffering from grass, and in the autumn the leaves fell two weeks earlier than those from the trees in the tilled section, whilst the fruit crop was adversely affected to the extent of 5 per cent. In the following season the crop was affected to as much as 89 per cent., and, since the trees were then being evidently ruined by the grass, this latter was removed.

All these observations justify the conclusion that grass operates prejudicially on fruit trees whatever their age may be.

That the effect is not confined to apple trees, is shown by two of the three varieties of pear trees mentioned above having been materially affected, whilst several other experiments with pears, plums and cherries, grown both as dwarfs and standards (III, 36), show that the effect of grass on these is similar to its effect on apples. Figs. 33-35 illustrate some of the results obtained. An exact comparison between the magnitude of the grass-effect in the case of these different sorts of trees is hardly possible, but the results of six years' observation may be thus summarised-

\begin{tabular}{|c|c|c|c|}
\hline \multirow[b]{3}{*}{ Cherries. } & \multicolumn{3}{|c|}{$\begin{array}{c}\text { Values compared with ungrassed } \\
\text { trees }=\text { Ioo. }\end{array}$} \\
\hline & Leaf-size. & Prunings. & Crops. \\
\hline & . 88 & - 32 & 8 \\
\hline Pears : & 72 & $2 I$ & 0 \\
\hline Plums & 72 & 7 & $\mathrm{I} \cdot 5$ \\
\hline Apples . & 68 & - & $6^{\circ}$ \\
\hline
\end{tabular}

The cherries are probably less affected than the other kinds of trees examined, but these others show no very certain differences as to their susceptibility to grass. The results with apples, however, it should be mentioned, are not quite comparable with the others, as they apply to values obtained with trees in the ordinary soil of the farm, whereas the other trees mentioned were grown in a raised border with a double depth of soil; and this, no doubt (see p. 308), reduced the effect of grass on them.

Subsequent experiments with trees grown in pots indicated 

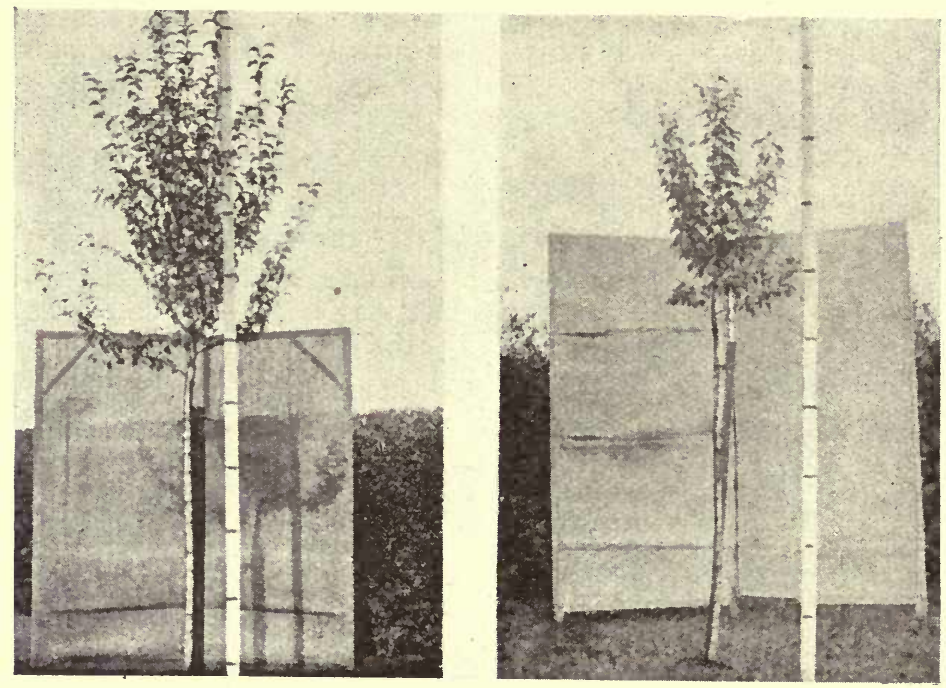

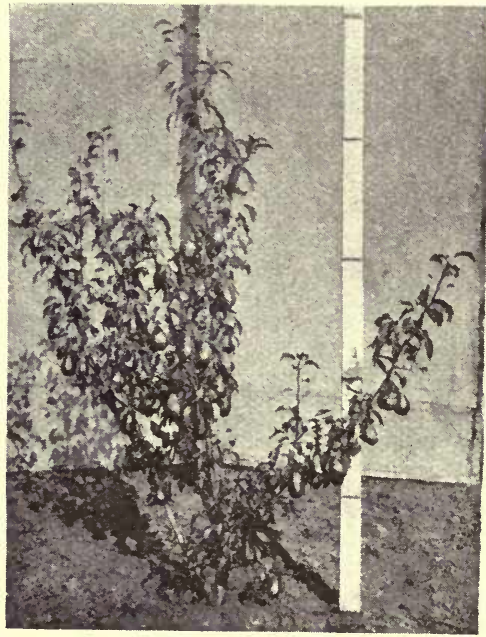

Tilled.

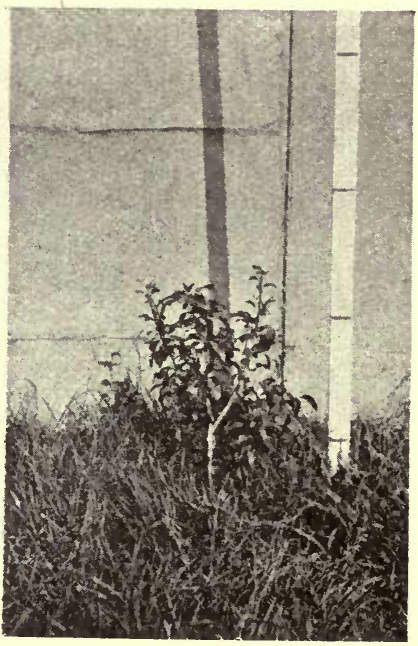

Grass-grown.

FIG. 33.-LOUISE BONNE OF JERSEY PEARS IN TILLED !ANI) GRASS-GROWN SOIL, I906. Planted January I903. 


\section{THE EFFECT OF GRASS ON TREES 267}

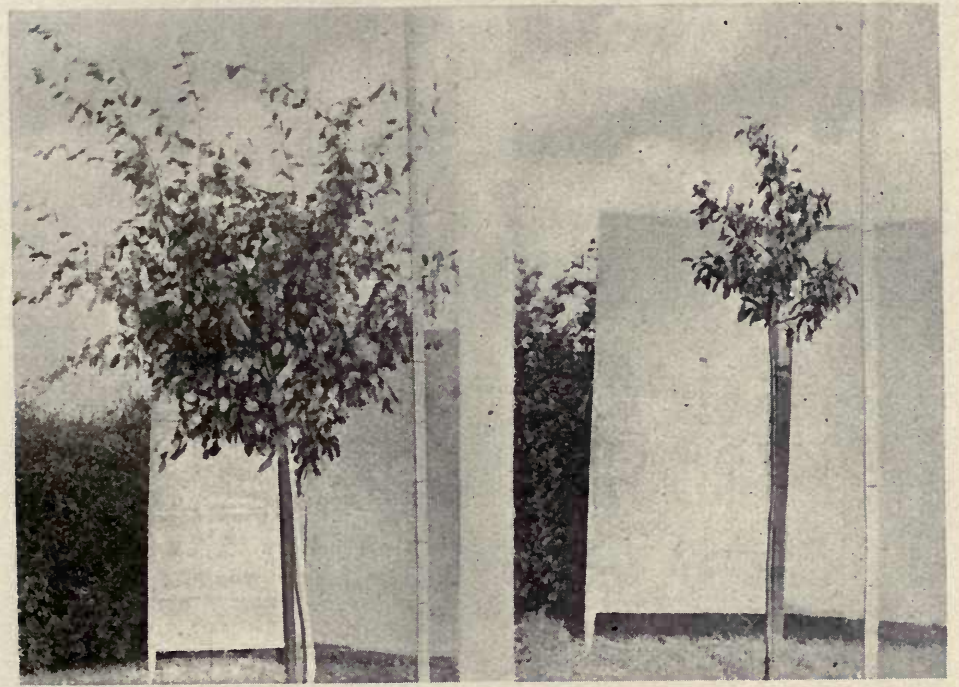

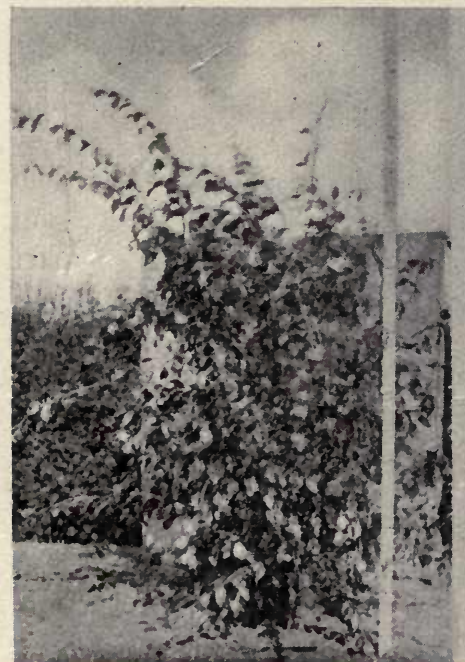

Tilled.

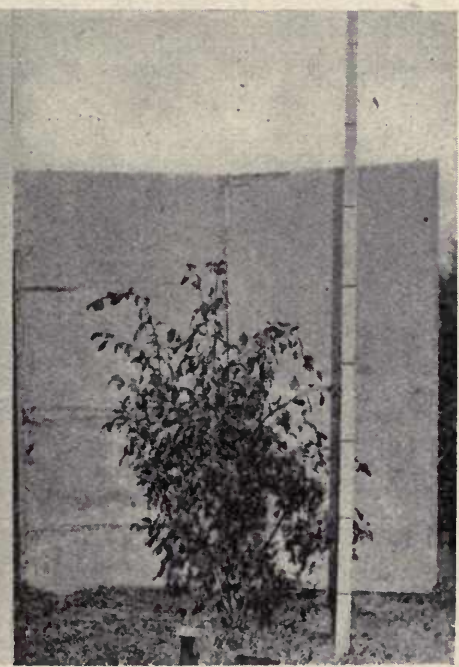

Grass-grown.

FIG. 34--VICTORIA PLUMS IN TILLED AND GRASS-GROWN SOIL, I906. Planted-January 1903. 
a difference in the susceptibility of apples and pears to grassin so far as the results with one variety of each could justify any conclusion - the apples suffering a reduction in vigour about twice as great as did the pears (XIII, 90), so that the evidence as to variation in the effect in the case of different kinds of fruit trees is somewhat uncertain.

Observations on the effect of grass on trees were extended to six varieties of forest trees grown, both at the Fruit Farm, and in the more congenial sandy soil at Millbrook (XIII, 40); the results of three years' observation, based on the length of new wood formed, gave-

Values compared with ungrassed trees $=$ Ioo. Length of new wood.

Ridgmont.

\begin{tabular}{|c|c|c|c|c|}
\hline Spruce . & . 65 & & & . $\quad 58$ \\
\hline Larch . & . 27 & 48 & . & 88 \\
\hline Scotch fi & . 52 & & . & 78 \\
\hline Beech . & . 53 & & . & 76 \\
\hline Oak & . 35 & 48 & . & . 47 \\
\hline Ash & . 55 & & . & 36 \\
\hline
\end{tabular}

The conifers at Millbrook were less affected than the other trees, and these, again, show considerably less effect than the fruit trees do, the weight of prunings in the latter case (p. 20) being the feature which has to be compared with the length of new wood measured in the case of the forest trees (III, 40). The comparatively small effect of grass on conifers in a sandy soil was further emphasised by clearing the grass away from part of an already established plantation of firs and larch; the effect of the clearance was beneficial, but only to the extent of 8 per cent. (XIII, 30). Subsequent results, however (p. 308), have indicated that the smallness of the effect of grass on conifers in this sandy soil, was due, more to the action of such soil in facilitating the removal of the toxic products of the grass, than to any want of susceptibility of the conifers to the toxin.

The next point examined was whether the action varied with the nature of the grass; and experiments on the subject were carried out on young apple trees grown in earthenware pots for three years. Sixteen different grasses, two mixtures of grasses, and two clovers were used. The general results indicated that the extent of the effect was not dependent on any factor other than the vigour of growth of the grass, the vigour of the tree being 


\section{THE EFFECT OF GRASS ON TREES 269}
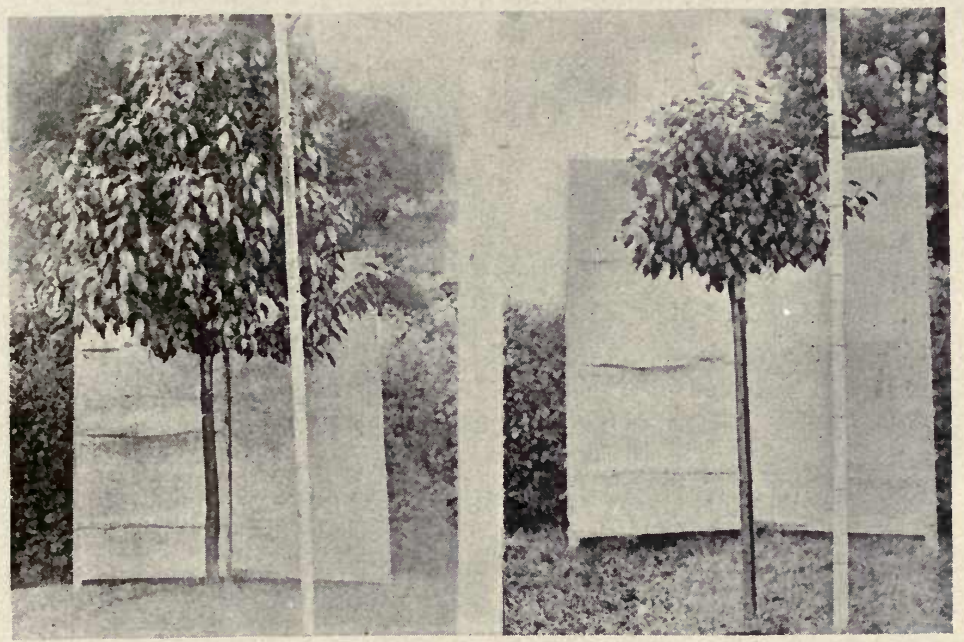

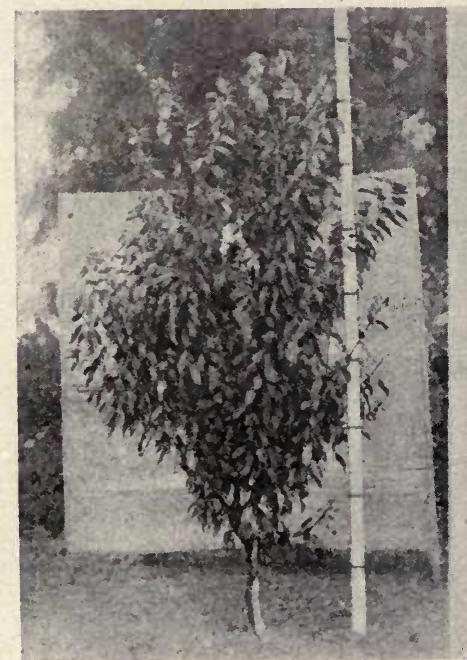

Tilled.

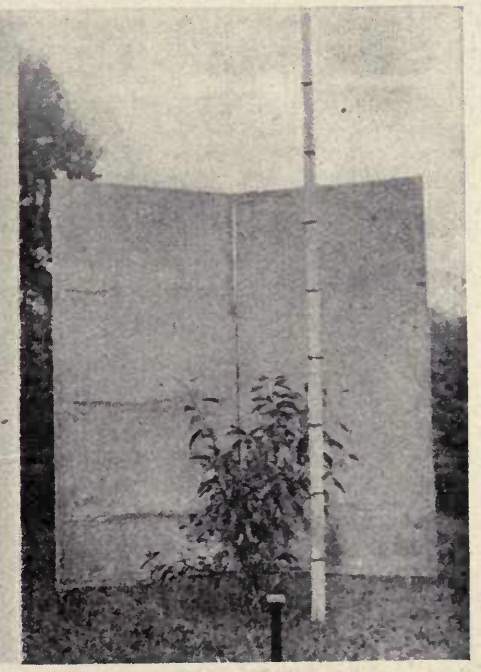

Grass-grown.

FIG. 35.-MAY DUKE CHERRIES IN TILLED AND GRASSGROWN SOIL, I906. Planted January I903. 
reduced by the grass from Ioo down to 43, I9 and I, respectively, according as the grass was shallow-rooting, intermediate or deeprooting. Clover exercised about the same effect as shallowrooting grasses, and the only peculiarity in its action consisted in its not affecting the colour of the leaves of the trees (XIII, 45).

Then came the question as to the influence of the nature of the soil on the action of grass. As a result of general observation it is fairly evident that the action varies very greatly in different localities, but whether that is due to differences in the nature of the soil, differences in the depth of soil, or to other differences, is not so clear. Many of the experiments on grassing trees were made at Harpenden, where the soil is considerably deeper than at Ridgmont, less retentive of water, and overlies a different geological formation. The results obtained there showed considerable divergence: in one case the planting of trees in old meadow pasture, with the turf replaced over the roots, resulted in the death of the trees (III, 20), and the grassingover of a section of a twelve-years-old orchard effected a reduction in vigour equal to that observed in a similar case at Ridgmont, the leaf-size being reduced in five years to 73 and 76 per cent. in the two cases (III, 20): but, on the other hand, in two other situations at Harpenden the gradual grassing over of established trees produced but little visible effect in one case, and none at all in the other, though actual measurements, and a comparison with check plantations in tilled ground, were not available (XIII, 24).

The Fruit and Cider Institute at Long Ashton is one of the few places where definite observations on the effect of grass on fruit trees have been made, and there can be no doubt but that the effect there is considerably less than it is at Ridgmont, as some of the results, quoted on p. 307, will show. The relative action of grass on trees in the Ridgmont and Long Ashton soils was, therefore, examined, under such conditions that all factors were eliminated except the nature of the soil itself, the experiments being conducted in pots; at the same time a light sandy soil from the Stackyard Field at the Royal Agricultural Society's farm was similarly examined, as well as pure sand with the requisite nutrients added to it. Instead of growing apple trees in the pots, tobacco plants were grown, with (or without) a surface crop of grass, the arrangement being one which will be described later on (p. 29I). The general results were 


\section{THE EFFECT OF GRASS ON TREES}

to show that the presence of this surface crop reduced the vigour of the tobacco plants from Ioo to

$$
\begin{aligned}
& 71 \text { in Ridgmont soil, } \\
& 52 \text { in Long Ashton soil, } \\
& 63 \text { in Stackyard soil, } \\
& 55 \text { in sand. }
\end{aligned}
$$

These values (XIV, Appendix, p. I4I) certainly show no reduction in the action of grass in the case of the Long Ashton soil as compared with the Ridgmont soil, nor even in the case of the sandy soil and of pure sand. Numerous other experiments were also made wherein the comparative effect of grass on fruit trees was determined when these were grown in the Ridgmont soil or in sand, and eleven such series gave $5 \mathrm{I}$ and 48 as averages of the vigour of the trees in the two cases-practically identical (XIII, I05). It may be concluded, therefore, that the action of grass is almost independent of the actual nature of the soil. But differences in the consolidation of a soil in situ, differences in the depth of soil available for growth, differences in drainage, and differences in the nature of the subsoil are not reproduced in pot experiments, and it is to these, therefore, that we must look for an explanation of the different effect of grass on trees in different localities (see p. 307).

The action of grass on trees is evident from an examination of any part of the tree; the weight of the crop is affected, so is the leaf-size, the total weight of foliage, the length and vigour of the new wood formed, the increase in weight of the stems, and the development of the roots. The roots of grass-grown trees have been repeatedly examined to see if any definite affection or modification in structure could be detected, but without success; the action of the grass appears merely to consist of a reduction in the number of new rootlets formed by the tree, and still more a reduction in the rate of development of these. Thus, in a number of cases, where both established and recently transplanted trees were examined, grass was found to have reduced the number of rootlets forming in the season from roo to $7 \mathrm{I}$ (a reduction of 29 per cent.), whilst the weight of them was reduced from Ioo to 36 ; so that these 7 I new rootlets had a comparative weight of only 36 , and their rate of development must have been reduced by nearly 50 per cent. (XIII, I6).

The effect on all the features of grass-grown trees which have so far been mentioned can be expressed numerically, but there 
are other effects for which no numerical expression can be found, and these are even more eloquent of the action to those who have the results continually before their eyes: they consist in the effect on the colouring matter in the trees. The pale, sickly green of the leaves of grass-affected trees in early summer is very noticeable, and is quite unlike the changes produced by drought, leaf-scorch, or other affections; whilst, in the autumn, the grass-effect is still more marked, the autumn tints coming on whilst trees in tilled ground are still quite green, and the fall of the leaf occurring two or three weeks before its usual time. The colouring matter of the bark is equally affected, the. stems and branches becoming light coloured and sickly in appearance, or œdematous, as it has been aptly described. The effect on the colour of the fruit is even greater: where the apple is inclined to be yellow, it becomes much lighter and waxy in appearance, but where it is naturally green, this gives place largely to red, producing a highly coloured fruit (II, I08; III, 48). This effect is well known, and it enhances the market value of fruit from grass-grown trees; but it would be advantageous to the grower only in the case where the action of the grass could be limited, so as not to materially reduce the total crop or the size of the fruits; a limitation which it would be difficult to fix at will.

A limited action of grass on fruit trees may result in advantage to the grower, not only as regards the colour of the fruit, but as to the total weight of the fruit borne, for the first effect of a reduction in the vigour of the tree is to make it bear heavily, and it is only when the reduction exceeds a certain value that the crops are adversely affected. ${ }^{1}$ For this reason it is necessary to be careful in interpreting results based on measurements of crops. The limited action of grass on apple trees is illustrated by some of the results at Woburn, where trees grown in tilled ground have grass either on one or on both sides of them, and at a distance of $5 \frac{1}{2}$ feet from their stems. Instead of the crops being reduced to almost nil, as was the case with the fully grassed trees, those with one grassed plot near them showed, during the first ten years, an excess of 98 per cent. over the crop from trees quite free from grass, and those with a grassed plot on either side, an excess of 138 per cent. (V, II8; XIII, I0). It was only four or five years after the planting that the effect of the grass near these plots became evident (III, 48), and it is very remarkable how small the proportion of the roots in the

1 In Wayne Co., New York, tilled orchards gave a crop 8o per cent. higher than those under grass.- Jour. Board of Agric., I905, XII. 557. 
grassed area need be for the trees to show such an effect, for, even after ten years, when the total weights of the trees were one to two hundredweights, the weight of roots within the grassed region was found to amount to only 0.9 to 2.4 ounces per tree.

Just as a small fraction of the roots of a tree being under grass may cause the appearance of the grass-effect, so the extension of a small fraction of them beyond the grassed area will, in the case of a tree which is under grass, result in some recovery of vigour (III, 9); and no recovery has yet been noticed with fruit trees other than that which might be explained in this way. Partial recovery, it is true, has been noticed with other plants suffering from the effect of a surface crop (p. 297), and no doubt may occur with trees, but it is less probable in such a case, for hard-wooded plants recover only with difficulty from any stunting effect in early life, and even the complete removal of the grass from above their roots, will often not restore them to their natural vigour.

To what distance it is necessary to remove the grass from a tree when planting it, so as to avoid the grass-effect, must depend on the size of the tree, as well as on many other circumstances; and no very definite pronouncement on the subject can be made. In one series of experiments at Ridgmont, the vigour of young apple trees, as measured by their leaf-size during four years, and their total weight when subsequently lifted, was

$$
58, .62,74,89 \text { and } 100 \text {, }
$$

when the grass was removed to distances of

$$
0,0.5, \quad I, 2 \text { and } 20 \text { feet }
$$

from the stems; showing the existence of some benefit by removing the grass even from the six inches of soil around the trees: whilst in another series at Harpenden, where the distances of the grass from the stems were

$$
0,2,4 \text { and } 6 \text { feet, }
$$

the increments in the weights of the trees after four years were found to be

$$
0,43, \quad 160 \text { and } 228 \text { per cent., }
$$

showing an increase in the benefit from the removal of the grass, certainly up to six feet, though, as there were no trees with the grass removed to more than a six feet distance, it was not possible to say whether the limit had even then been reached. 
The trees with the grass replaced right up to their stems were, in this case, all killed (XIII, I2).

Connected with the probable tendency towards recovery of trees from the grass-effect when circumstances are favourable, there is another factor in the case which is of considerable importance both from a practical and theoretical point of view, namely, that a great reduction in the deleterious effect occurs when grassing is effected gradually. Thus, a plot of dwarf Cox's Orange Pippins was laid down to grass immediately after the trees were planted, and, when they were lifted fifteen years later, their weight was found to be only 9 per cent. of that of similar trees grown in tilled soil; whilst in a neighbouring plot, which had. been allowed to become weed-grown from the first, and where the weeds had gradually been ousted by grasses, the trees weighed 30 per cent. of trees in tilled ground, or over three times as much as the trees which had been grassed at once (XIII, 25; see also III, 54). In another experiment wherein standard apple trees were used, the yearly growth, as compared with that of similar trees in tilled ground represented by Ioo, gave the values shown in the first line below for trees over which the turf had been replaced immediately after planting; whereas others, wherein the turf had been removed to a distance of three feet from the stems, and the cleared area had been allowed to grass itself over gradually, yielded the values set out in the second line. In the latter case no deleterious effect was observed in the first season, and, taking the average of the six succeeding seasons, the growth of these trees had been twice as great as that of those which had been grassed at once.

Mean.

$\begin{array}{lccccccc} & \text { I9Io. } & \text { I9II. } & \text { I9I2. } & \text { I9I3. } & \text { I9I4. } & \text { I9I 5. I9II-I 5. } \\ \text { Turf replaced } & 76 & 30 & 6 & 5 & \text { II } & 7 & \text { I2 } \\ \text { Grassed gradually } & \text { IOI } & 38 & \text { I2 } & \text { IO } & 33 & 28 & 24\end{array}$




\section{CHAPTER XXVII}

\section{POSSIBLE CAUSES OF、THE GRASS EFFECT (Reports, III, 2; XIII, I)}

In the preceding chapter an account has been given of the main features presented by the action of grass on trees; the present chapter contains a review of the search made at Woburn for an explanation of this action. The more obvious suggestions are, naturally, those based on an interference with the water- or food-supply required by the tree; but, before discussing these, it will be well to clear the ground by some account of the examination of other possible causes.

The aerration of the soil is no doubt different under grass from what it is in tilled ground, but this appears to have little or no value in determining the action of the grass. Trees planted in meadow land, with the soil round the roots aërated to different extents by making and keeping open holes in the ground, showed no differences corresponding with the extent of the aëration. Thus-

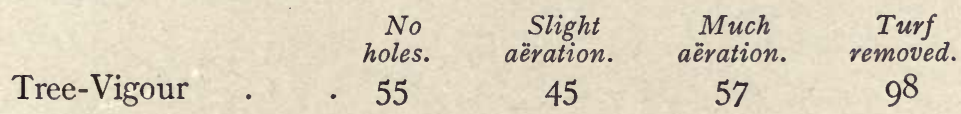

These experiments (III, 39) were made at Harpenden, whilst similar ones were conducted at Ridgmont, and with like results (III, 29). At this latter place there were also other experiments in which the air-supply was reduced below that which must obtain in grassed soil, by driving down into the ground round the trees, two feet from their stems, iron hoops, reaching to a depth of eighteen inches below the surface, and covering the earth within the hoops with a layer of two inches of cement, so that no air (or water) could reach the trees, except that which made its way through the stiff clay subsoil below them. Yet such drastic treatment failed to reproduce any of the evil effects of grass, and, indeed, until the soil within the drums became exhausted, these trees did even better than those in tilled ground, probably owing to the enclosed soil being less subjected to 
fluctuations of temperature and humidity than in other cases (III, 40).

Other experiments with trees grown in covered pots, with the air excluded as far as was possible, yielded equally negative results (III, 32).

Though some air is undoubtedly necessary for the welfare of plant-roots, and for the proper functioning of the soil, the minimum which is essential is probably very small, as is evidenced by the flourishing of trees in cities when their roots are nearly entirely covered by flagstones. An interesting instance in point is presented by some trees in the old burying-ground at St. Pancras, which in I900-I were covered up with a layer of rubble and slag thirteen feet in depth, long since thoroughly consolidated, leaving little more than the heads of the trees above ground. Yet these trees are in a fairly flourishing condition at the present day (Fig. 36).

Intimately connected with the question of aëration is that of the accumulation of carbon dioxide in the soil surrounding the tree-roots. This was examined in a series of determinations made between the end of May and the middle of October, I902, in which the air from a depth of six inches below the surface, and twelve inches distant from apple trees, was drawn, in one case where the ground was kept tilled, and in the other from ground which was grass-grown. On every occasion, with only one exception, it was found that there was less ${ }^{\mathbf{1}}$ carbon dioxide in the soil under the grass than in the tilled ground, the averages being

Grassed ground Tilled ground
I3. 8 vols. $\mathrm{CO}_{2}$ per $\mathrm{I0}, 000$ $2 \mathrm{I}^{\circ} 4$

though in both cases there was a much larger proportion of that gas than exists normally in air -3 to 4 volumes in 10,000. As might have been expected, the air immediately above the soilone inch above the surface-was found to contain an excess of carbon dioxide derived from the overladen air in the soil, the average values being 6.2 volumes for the air above the grassed ground, and $8 \cdot 0$ for that above the tilled ground.

1 Wollny (Forsch. Geb. Agrik.-Physik., 3, I) also found this to be so during the summer months, but not so in winter. The composition of soil-gases has been the subject of much investigation, the results of which, up to date, will be found summarised in a paper by Bizzell and Lyon (Journ. Amer. Soc. of Agronomy, I0, March, I918). The composition is evidently affected by numerous factors: the nature of the soil, and its bacterial contents; the nature of the crop; the temperature, humidity, and the time of year. 


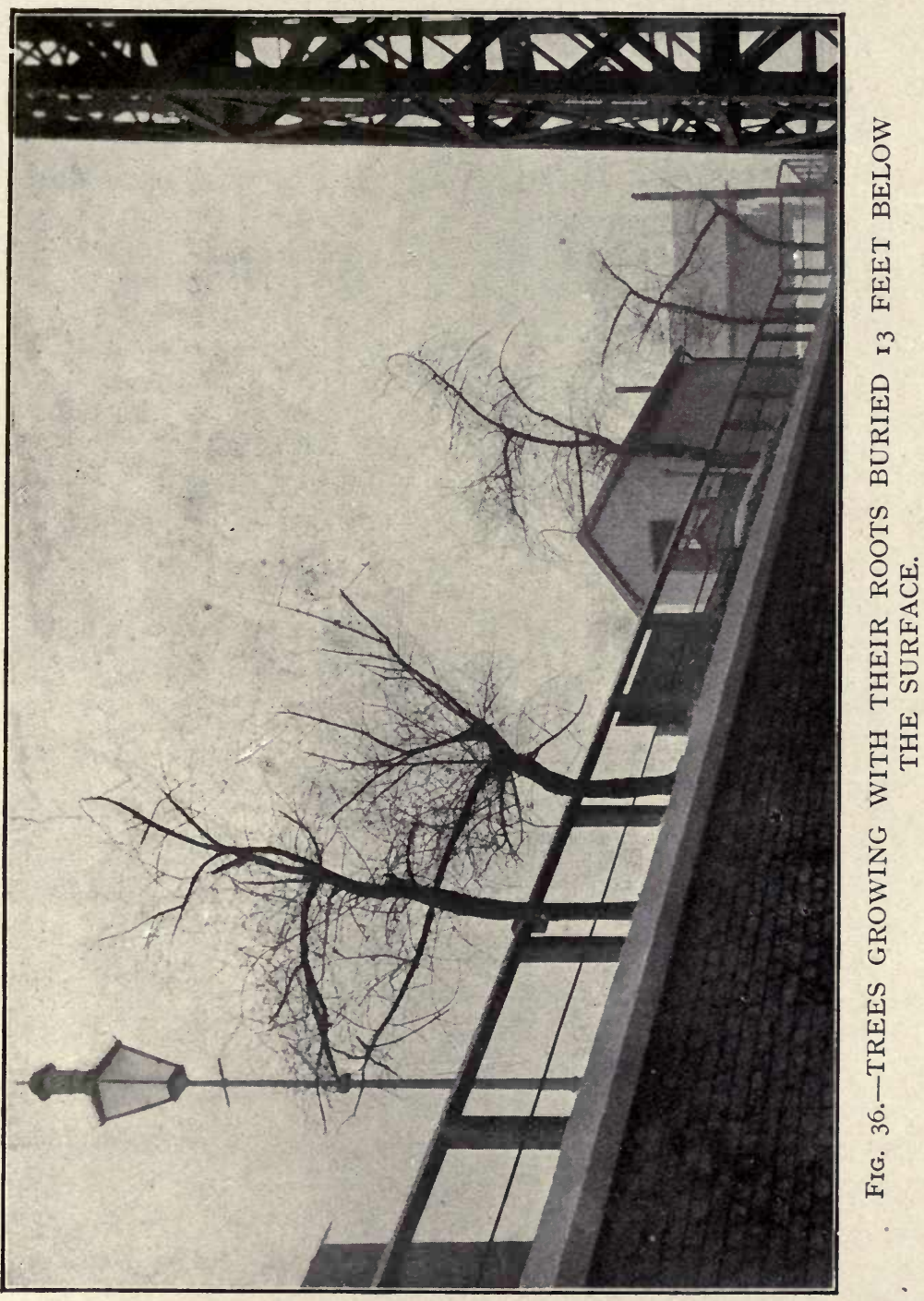


That the effect of grass on trees can in any way be attributable to there being less carbon dioxide in the soil than there is in ungrassed ground is, of course, highly improbable, and was definitely negatived by growing trees in soil wherein the proportion of that gas was artificially increased by directing a continuous stream of it in to the ground throughout every alternate week during the growing season, and finding that this had no stimulating effect on the trees. It was also found that in the case of the trees grown in the cemented enclosures, as described above, there was a much greater accumulation of carbon dioxide in the soil than in tilled ground- $-3 \mathrm{I}^{*} 3$ vols. compared with $2 \mathrm{I}^{*} 4$ vols.-without there being any corresponding increase in vigour of the trees, for the cement-covered trees were at that time considerably less vigorous than those in tilled soil (III, 42).

Differences in soil-temperature suggested another explanation of the effect of grass on trees. This was examined by determining the temperature of the soil six inches below the surface at several different stations in the farm where there were grassed and tilled plots adjoining each other. During the daytime the tilled ground was the hotter, and during the night it was the cooler. Under ordinary summer conditions the average excess of temperature in the tilled ground was $2^{\circ}$ to $3^{\circ} \mathrm{F}$. during the day, though on occasions it might rise to $\mathrm{Io}^{\circ}$, as, for instance, when the air was dry and the temperature was high; but as an average difference of $2^{\circ}$ or $3^{\circ}$ is less than differences occurring in consecutive summers, it is clear that they can afford no explanation of the grass-effect, for this is in evidence just as much in hot seasons as in cold ones (III, 45).

The bacterial conditions of grassed and tilled soil are, no doubt, very different, and still require much investigation. So far as experiments have gone at present, no connection can be observed between the mere number of bacteria in the soil and the behaviour of trees growing in it. Thus, trees were grown in earth, and also in sand, with and without a surface crop of grass, and the number of bacteria per gram determined. The results were-

In earth, no grass

In sand, no grass .

,, ,, grass
$2 \cdot 3$ millions

- $9^{\circ} 0 \quad$,

- $0.5 \quad$,

- 2.5 ,

so that, though in both media the presence of grass largely increases the number of bacteria, there are practically the same 
number in the earth without grass, where the trees are flourishing, as in the sand with grass, where the trees are suffering (XIII, I23).

Alkalinity may arise in soil through the growth of grass in it, for grass in growing decomposes some of the minerals present, absorbing the acid constituents of them more readily than the bases. The resulting alkalinity might conceivably be an explanation of the deleterious effect of grass on trees. To examine this, trees were grown for two years in pots of sand with the necessary nutrients added: in some cases the sand was made alkaline by the addition of sodium bicarbonate, whilst in others, either no alkali was added, or acid was supplied to them. In a further set of pots the trees were grown under a surface crop of grass. The mean vigour of the trees for the two years may be expressed thus:-

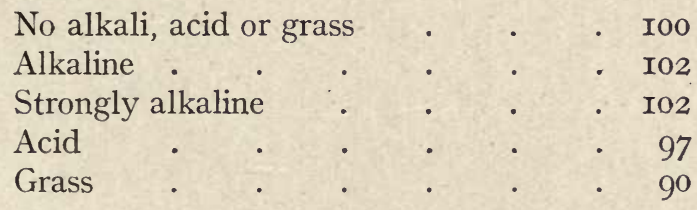

The action of the grass in these experiments was considerably less than that usually found, due to circumstances which need not be specified here, but it was, at any rate, appreciable, and was much greater in the second year (vigour of the trees, 68) than in the first; whereas no similar action resulted from making the sand either alkaline or acid, the differences of 2 or 3 per cent. being well within the limits of experimental error (XIII, 96).

The presence of alkali in soil might, however, have some action, whereas none might occur where the medium was sand. To examine this, a number of apple trees growing in the open were watered once a week during the summer throughout three years with various amounts of potassium carbonate solution, the quantity supplied, where the full dose was given, being equivalent to $8 \mathrm{IO}$ grams of potash $\left(\mathrm{K}_{2} \mathrm{O}\right)$ for twelve trees, representing 0.04 per cent. of the weight of soil in the upper nine inches. The mean results showed that such a dose was deleterious to the trees, as also was a half dose, though to a lesser extent, but that the harm done, even by the stronger doses of alkali, amounted to much less than that done by grass, where the trees, at the end of the three years, were actually moribund, showing during the third season a deficiency in growth of as 
much as 92 per cent. (XIII, 96). The average values for the three years were-

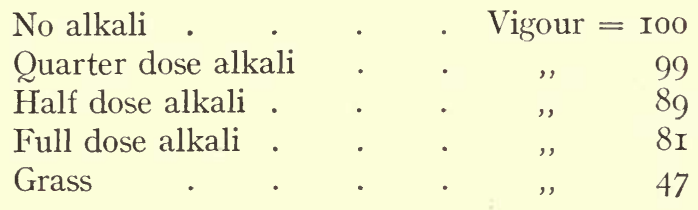

The physical condition of soil under grass and under tillage was then examined. Five pairs of stations: with tilled and grassed ground, immediately adjoining each other, were selected at Ridgmont, two similar pairs at Harpenden, and one pair at Millbrook ; these were sampled to three successive depths of six inches each, and the samples shaken with water. In one case the liquids were allowed thirty minutes for settlement, and then the supernatant liquid drawn off, which would contain in suspension the finest, and also the moderately fine matter; in another case the liquid was left for eighteen hours before being decanted, and this, of course, would contain only the finest particles. Taking the three depths of six inches together, there was practically no difference between the proportions of fine matter in the tilled and grassed soils: the averages, when thirty minutes were allowed for settlement, were $r \cdot 677$ and $I \cdot 662$ grams, respectively, per Ioo grams of soil taken, and when eighteen hours were allowed, the percentages were 0.332 and $0^{\circ} 3$ I 3 , respectively.

Nor did there appear to be any radical difference in the distribution of the fine particles throughout the eighteen inches. This may be best seen from the accompanying illustrations. In Fig. 37, $\mathrm{A}$, the line $\mathrm{T}$ represents the distribution of the fine particles in the tilled soil, and the line $G$ that in the grassed soil; they are almost identical, showing that, though the proportion of fine particles increases considerably as greater depths are reached, it does so at almost the same rate-at a very slightly diminishing rate in the case of the tilled soil, and at a practically constant rate in the case of the grassed soil. When the values for the finest particles are similarly set out (Fig. 37, B) the results bear a very different aspect, there being a great accumulation of these finest particles at about nine inches below the surface, but the accumulation is, again, practically the same for the tilled and grassed soils, the figures representing the results being almost coincident. Hence there are no differences in the distribution of soil particles such as could 
account for the different behaviour of trees in grassed and tilled ground (XIII, I06).

Depth.

o

$$
\text { A. Finer Porticles. }
$$

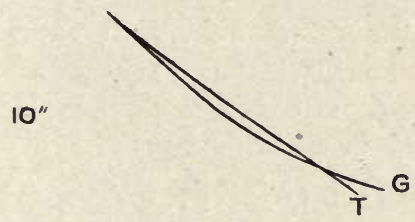

$20 "$ 80
B. Finest Particles,

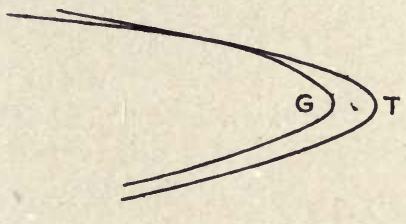

80

100

120

FIG. 37.-DISTRIBUTION OF FINE PARTICLES IN TILLED AND GRASSED SOIL.

The Water Supply.-It is to an interference in the supply of water to the trees that the deleterious effect of grass has generally been attributed: yet there are several general considerations which tell strongly against such an explanation, perhaps even more strongly than do the results of definite experiments on the subject. The symptoms of injury by grass are not those of injury by drought; there is no wilting of the leaves, as in the case of a sudden drought, nor do the leaves dry up and fall, as in the case of a gradual, prolonged drought: the grass-effect is evidenced by the light unhealthy colour of the leaves quite early in the season, while the ground is, generally, still moist, and while the vigorous growth of the' grass itself proves that the supply of water in the soil is abundant, for the grass would certainly feel the effect of drought before the more deeply rooted tree would: lastly, the grass-effect is manifest in a wet season just as clearly as it is in a dry one.

A closer examination of these arguments serves only to strengthen them. It is true that the growth of grass may result in the drying up of the soil below: this is especially the case in a light sandy soil, where the average annual evaporation from grassed land may be more than four times as great as that from tilled land, ${ }^{1}$ and tillage of the surface, independent of the absence of grass, reduces the evaporation ${ }^{2}$ but in

1 Lawes, Gilbert and Warington, Journ. Royal Agric. Soc., I881, p. 325 (see also I, p. 10o).

2 King, New York Experiment Station, Ann. Report, p. 180, and Winconsin, Ann. Report, 8, p. I05 (see also II, I75). 
heavier soils, such as those at Ridgmont or Harpenden, the difference caused by grass is much less, and may even be in the opposite direction; for, whilst the grass by its physiological action removes water from the soil, it affords a covering to this same soil, protecting it from the drying action of sun and wind.

The numerous series of experiments made at Woburn wherein plants have been grown in pots, with and without a surface crop, afford evidence as to the effect of this surface crop on the watercontent of the soil, for these pots were weighed at frequent intervals, thus supplying exact information as to the loss of water occurring. When the pots were under glass, the loss due to physical causes was, naturally, very small, and that due to the physiological action of the surface crop was the predominant factor; consequently, it was found that, during the summer months, 30 per cent. more water was lost from the pots where there was a surface crop than from those where there was none: but when the pots were in the open, exposed to the sun and wind, the reverse was often-not always - the case, and the evaporation from the pots with the surface crop might, during the season, be even less than half of that from those without a surface crop. Whether the difference was in the one direction or the other depended, as may readily be conceived, on the character of the seasons (XVII). ${ }^{1}$

An examination of the water-conditions in grassed and ungrassed ground at Harpenden was carried out in I905 to I907, so as to give a view of the conditions obtaining at different times of the year. Three depths of nine inches each were examined separately, but the results may be sufficiently illustrated by setting out those for the total depth of twenty-seven inches (Fig. 38): the horizontal line represents the watercontents of the tilled soil, and the curved line that of the grassed soil, showing that during the winter the latter contains the most water, to the extent of about I per cent., whereas during the summer it contains less water, the deficiency extending to about 5 per cent. The variations in the top spit were, naturally, greater and more irregular, the excess under grass in the winter reaching 3.4 per cent., and the deficit in the summer, 6.3 per cent. But the result of most importance was that this deficiency never reached the point at which it could possibly affect the trees growing under the grass-and there were trees growing in these very grass plots which were evidently suffering-

1 The seventeenth Report is still in the Press. 
for it has been shown ${ }^{1}$ that the optimum proportion of water in a soil, so far as the flourishing of plants is concerned, is from 40 to 50 per cent. of the maximum which that soil will hold: but the maximum water capacity of this soil was found to be 35 per cent., so that the optimum water-content would be from I4 to $I 7.5$ per cent.; yet, during the period of plant-growth (June and July) the water-contents of this grassed soil-taking even the top spit where there was the greatest lack of watervaried between $I 3.8$ and $I 7.7$ per cent., so that it was practically in the best condition as regards moisture for plant-growth; yet in spite of that, the grass effect was manifest (XIII, 54).

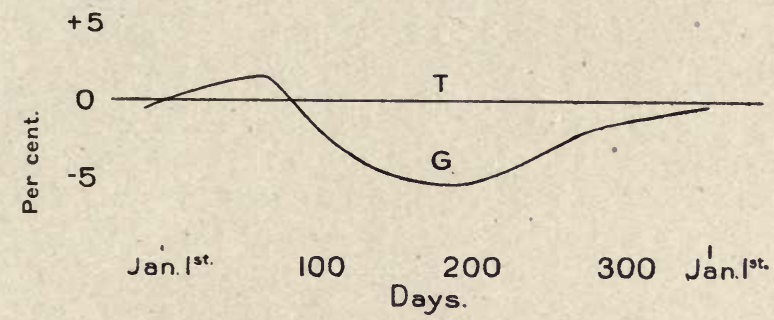

FIG. 38.-DIFFERENCE BETWEEN THE WATER OF TILLED (T) AND GRASSED (G) SOIL.

When a comparison is made between the grassed and tilled soil during the months of May, June and July it is found that, according to the results obtained at Harpenden, there is an average difference of 4 per cent. of water in favour of the tilled ground, and this would be equivalent to about 120 tons of water per acre in a layer of soil twenty-seven inches thick, a weight which corresponds to a rainfall of $I \cdot 2$ inch : if a difference such as that could account for the action of grass on trees, it is evident that a similar action, but one of much greater magnitude, should occur in a dry season; for the differences in rainfall in dry and wet seasons often extend to four or five inches of rain. As a matter of fact, no differences in the deleterious effect of grass on trees can be noticed in wet and dry years, and a comparison of the rainfalls in March to July for the years I896 to I908 with the behaviour of trees under grass, showed that the two years of heaviest rainfall (ten to twelve inches during these months) did not in any single case correspond with any exceptional vigour of the grass-grown trees, nor did the three driest years

1 Hellriegel, Beitrage zu den Naturwissenschaftlichen Grundlagen des Ackerbaues, Braunschweig, 1883 . 
(five to six inches of rain) coincide with any increase in the deleterious effect of the grass (XIII, 53).

However conclusive the water determinations in the Harpenden soil were against a deficiency of water being the explanation of the grass-effect, they were still more so in the case of the Ridgmont soil, for there it was found that the grassed soil was actually wetter than the tilled soil, at any rate as regards some of the chief plots where the action of grass had been studied. These were four in number, consisting of plots which had been under grass since I 895 or I899; each plot was a strip of ground 2 I3 feet long by II feet wide, and there was one tilled plot in the middle of the grassed plots, and others on either side of them. The plots were all sampled to a depth of nine inches, on three dates during August, I907, and on one in September, I9I0, when it was found that, on three out of four of these occasions, the grassed ground was the wetter of the two, the maximum difference being $2^{\circ} 5$ per cent. of water, with an average of $0^{*} 7$ per cent. for the four dates. Similar, though even larger $\left(2^{\circ} 9\right.$ per cent.) differences were found at two other stations in the farm, and, though such differences did not appear to hold good throughout the whole of the ground-for the ground varies considerably in different parts-their existence at the very stations where the effect of grass on trees is most noticeable, is conclusive against this effect being attributable to lack of moisture (XIII, 59).

Direct experiments on the effect of increasing the water-supply in the soil were carried out, giving trees under grass weekly allowances of water through pipes placed in the ground under their roots, the supply being adjusted so as to represent about one-and-a-half times the previous week's rainfall. The experiment was continued for eight years in one case, and for two years in another. In both cases (XIII, 63) the extra water had increased the vigour of the trees, but had failed to raise this vigour to that of trees grown in tilled ground without additional water; the results were-

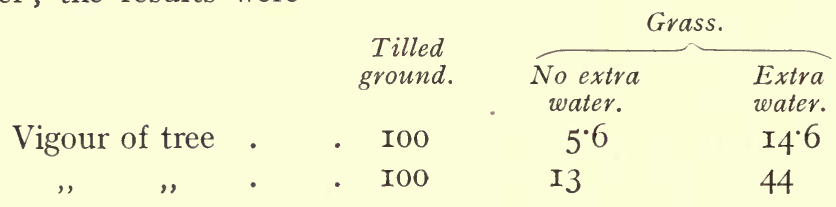

Field experiments such as these are not always satisfactory, owing to many complications which may arise when attempts are made to alter the conditions in the small patch of ground occupied by a tree, so as to make them different from those in 
the surrounding soil, and much more conclusive results were obtained by pot experiments. The value of pot experiments is so generally recognised that we rarely hear now the objection which used to be urged against them-that they do not reproduce the conditions prevailing in ordinary practice: it is true that they do not do so, but it is therein that their value lies; for by modifying these conditions, and eliminating the multitude of unknown factors which must attach to experiments in the field, pot experiments simplify matters so far, that the influence of one factor alone can be studied. The case of the water-contents of the soil is a very good instance in point, for, when dealing with trees grown in pots, it is easy to keep the soil in the same condition as regards moisture, whatever the other conditions may be, weighing the pots at frequent intervals, and adding such water as is necessary to supply any loss. In that way it was proved beyond question that the water-content of the soil had nothing to do with the action of grass on trees; for trees grown under these constant conditions, but with a surface crop of grass, showed, at the end of two years, a total growth amounting to only 24 per cent. of that shown by trees without grass (XIII, 67). Nor could it be urged, however improbable such a suggestion might be, that, though the water in the soil was the same in both cases, the grass absorbed the greater part of it to the detriment of the trees, for in some cases a layer of fine copper gauze was spread four inches below the surface, so that the grass roots could not penetrate down to the tree roots, and the water was supplied from the bottom of the pot, thus enabling the tree to get whatever it wanted before the water reached the grass : yet the results were exactly the same, the total growth after two years being only 24 per cent. of that of trees without grass.

The pots used in these experiments were of glazed earthenware, holding about one hundredweight of soil, and in some subsequent experiments a device was adopted whereby the separation of the grass-roots from the tree-roots was made more complete than by the mere interposition of the layer of gauze between them; for the grass was grown in a separate tray made of sheet iron, coated with paraffin wax, the tray being perforated at the bottom, with a sheet of copper gauze covering the perforations; the tray simply rested on the soil, and could be removed at any time (Fig. 39, A, p. 292). The water required was added to the tray, and soaked down through it to the tree below. In the check experiments, where no surface crop was present, the arrange- 
ments were precisely similar, but the trays contained earth only. Yet, with this complete separation of the grass from the tree, the effect on the latter was almost as great as in other cases. A summary of the results obtained in some twenty series of experiments gave the following values for the vigour of the trees under the different conditions of experimentation (XIII, 93, and XVII)-

\begin{tabular}{cccc} 
No grass. & \multicolumn{3}{c}{ Grass. } \\
\cline { 2 - 4 } Ioo & $\begin{array}{c}\text { No ganze } \\
\text { or trays. }\end{array}$ & $\begin{array}{c}\text { Gauze. } \\
\text { Trays and } \\
\text { gauze. }\end{array}$ \\
& 59 & $6 \mathrm{I}$ & 66
\end{tabular}

There is, it is true, a small progressive decrease in the effect of the grass, as the separation of it from the tree-roots becomes more complete; but this is so small that it is probably not due to the more perfect separation at all, for it is not greater than would be accounted for by the diminution of vigour of growth of the grass itself owing to the restriction of its root-development. Whether this is so or not, it is abundantly clear that the tree suffers owing to what passes down to it from the grass, and not from the grass abstracting from the soil about the tree-roots anything which those roots require.

Whatever the deleterious substance formed by the grass may be, it appears to be formed, and to act, equally under varying conditions. Many experiments were made in which the trees or the grass, or both of them, were grown in sand, instead of earth, or in sand with different admixtures of earth; but the results were substantially the same in all cases, though grass grown in sand appeared generally to be rather more deleterious than grass grown in earth, probably owing to the greater facility with which any deleterious substance formed in it would be washed down; but strict comparisons were difficult, because it is impossible always to get an equally good growth of grass in sand and in earth. Also it was found that but little difference was made whether the grass was grown continuously in the trays, or whether relays of trays with fresh grass seeds germinating in them were used (XIII, 94).

These pot experiments were generally allowed to run either for two or for three years; after three years the trees suffered from the limitation of earth space. In many cases the effect of the grass during the first season was but small, for the growth during this first season, before the tree has become well established, is largely dependent on the stock of material stored in the tree itself. To allow the grass to exert its full 
influence it was always raised in the trays two or three weeks before the tree started into activity, and not placed in the pot till it was in full growth.

The Food Supply.-The question of the food-supply is almost identical with that of the water-supply, though not quite so, for, though plants absorb their nourishment mainly by absorbing the soil-solution as a whole, they do exercise a certain amount of selective absorption, abstracting some of the constituents from the soil-solution, and leaving others. It was possible, therefore, that the grass might act on trees by depriving the trees of some substance necessary for their welfare. The experiments described above prove, however, that it is not what the grass abstracts from the soil, but what it adds to it, that does the damage. But before such proof had been obtained various investigations on the food-supply had been undertaken.

In all the field experiments there was, to start with, a strong probability against there being any interference with the foodsupply due to the grass, for the crop of grass was never removed from the ground, and such food-material as was contained in the crop actually growing at the time would represent the sum total of the impoverishment of the soil; but this impoverishment would be far less than that brought about by the growth and cropping of the trees themselves, and it has been found that such growth and cropping can be continued in the unmanured Ridgmont soil for twenty-two years without effecting any reduction in the vigour of the trees (p. 90).

Additional evidence was also supplied by an examination of trees in the numerous manurial experiments at the farm, for the manurial plots abutted on paths which had been grassed, and the action of this grass began to tell on the end trees of the plots after a time: but the particular trees affected bore no relation to the manurial treatment of the plots: the percentages of trees suffering were 33,56 and 40 in the case of plots receiving an excess of manure, a moderate dressing, and a deficiency, respectively (XIII, $7 \mathrm{I}$ ).

The supply of extra nourishment to trees under grass would appear to be equally ineffectual in counteracting the effect of the grass. Trees grown with a weekly dressing of manure water, conveyed to the roots below the grass in the manner described on p. 284 , produced the same effect as water containing no nutrient; and, though trees planted with a liberal supply of dung around their roots suffered from grass less than those without such a dressing, they still showed only half the vigour 
of those in tilled ground without the dung. The good done by the dung in this case was probably the result of the alteration in the physical surroundings of the roots, and not of the additional nutrient supplied, for experiments in pots under more stringent conditions showed that extra nourishment, even when supplied to the tree from below, did practically nothing to counteract the baleful effect of the grass, the relative vigour of the trees with and without such nourishment being 28 and 24 per cent., respectively, of that of trees with no grass and with no extra food. A determination of the total nitrogen contained in the leaves of these trees showed that, whilst the grass had reduced the nitrogen from Ioo to 44 , the extra nourishment had mitigated the action of the grass only so far as to diminish the reduction to 53 (XIII, 77).

Similarly, the feeding off of the grass by sheep or poultry was found to have no effect in diminishing the harm done by grass. The following values were obtained with standard apple trees planted in Igog-

\begin{tabular}{lrrrrr} 
& & \multicolumn{4}{c}{ Vigour of trees. } \\
No grass & & I910. & I91 1. & I912. & I913. \\
Grass &. & I00 & I00 & I00 & I00 \\
Grass fed off &. & 76 & 30 & 6 & 5 \\
&. & 69 & 30 & 9 & 28
\end{tabular}

During the first two seasons the feeding off was done by sheep, and during the next two by poultry, and the rise in values during the last season was evidently the result of much of the grass round the trees having become destroyed by the birds (XIV, 47).

So far from the action of grass on trees being explicable on the ground that it impoverishes the soil, it, as a matter of fact, actually enriches it. This has been fully established now for many years, ${ }^{1}$ and experiments at Woburn have demonstrated that soil in which grass has been growing for ten or twelve years is actually much more suited to the growth of trees than soil in its vicinity which has been kept tilled: the vigour of the trees grown in it when the turf was removed was more than double that of the trees in the tilled ground, whereas in this same rich soil, when the turf was replaced over the roots of the tree, the vigour of the latter was only half that of trees in the poorer ungrassed soil (XIII, 79). In other pot experiments, where the

1 Lawes, J. B., and Gilbert, H., "Determinations of Nitrogen in the Soil of some of the Experimental Fields at Rothamsted," Rothamsted Memoirs, V, (6). Also Am. Assn. for the Advan. of Sci., Montreal, I882; and Lyon and Bizzell, Cornell Univ. Agric. Expt. Station, Memoir, I. 


\section{POSSIBLE CAUSES OF THE GRASS EFFECT 289}

soil taken was the same in all cases, it was found that after the experiment was concluded, that left in the pots containing the trees with grass over them was actually richer in nitrogenous matter to the extent of about 40 per cent. than that in the pots without grass, though the trees were dying in the former case, and flourishing in the latter.

It is evident, therefore, that the action of grass on trees is not a question of lack of nourishment: there is ample nourishment there, but the trees are incapable of utilising it. This can be due only to some toxic influence interfering with the physiological action of the plant, and preventing it from utilising the food which is present. 


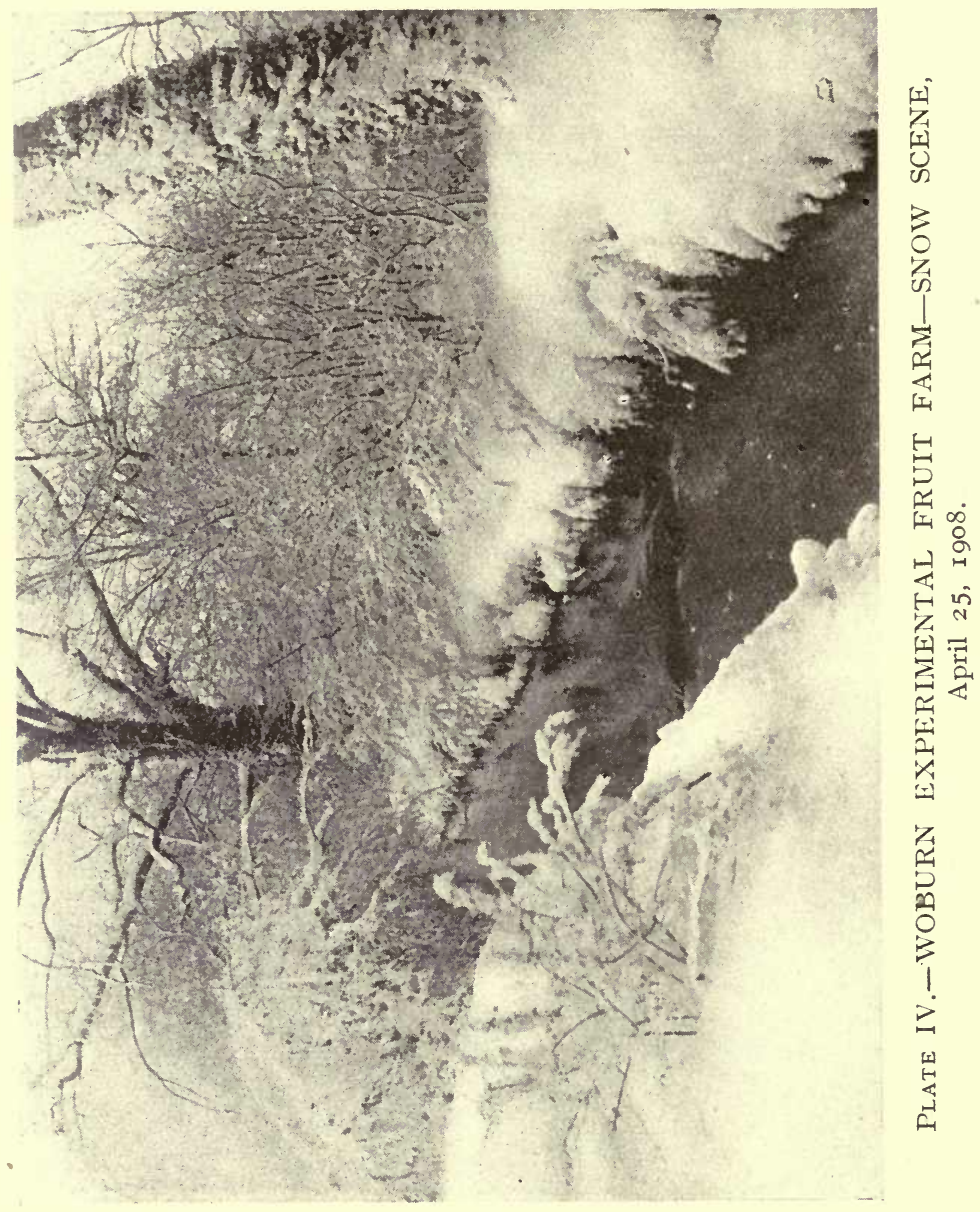




\section{Chapter XXVIII}

\section{THE TOXIC ACTION OF ONE CROP ON ANOTHER}

(Reports, XIV, 46 and Appendix; XVII ${ }^{1}$ )

IT has been seen how the results obtained at Woburn, first by the exclusion seriatim of other possible explanations, and then by the presentation of more positive evidence, led to the conclusion that the effect of grass on trees must be due to toxic action. Before, however, entering more fully into this question, it will be well to give some account of experiments which showed that the effect of grass on trees was but one special instance of the general effect of one crop on another.

The investigation of the growth of other plants under a surface crop was conducted chiefly by means of pot experiments, and some modification was necessary in the construction of the pots used for trees. They measured internally $I 7 \frac{1}{2}$ inches in diameter, and $\mathrm{I} 2$ inches in depth, and the tray, or collar, containing the surface crop was made of earthenware, instead of sheet iron: the central opening in it was $5 \frac{1}{2}$ inches in diameter, so as to leave sufficient space for the growth of the plants in the pots through it. Fig. 39, B, p. 292, will make the construction clear. The pots held about $70 \mathrm{lbs}$. of earth, and the trays $20 \mathrm{lbs}$. The plants were raised either from seeds, or by transplanting seedlings, and these were thinned out by removing the more weakly ones, till (generally) two or three plants only were left. The plants in the trays were raised a few weeks ahead of those in the pots, and suitable means were adopted for preventing them from overshadowing those in the pots. As in the experiments with trees, all the water supplied was added to the trays, and the perforations in these-those in the check experiments includedwere covered by a sheet of fine copper gauze.

In this way, and by other experiments in the field, it was found that the action of a surface crop is a general one : the plants which have so far been found to be susceptible to the

1 The majority of the results dealt with in this and the following chapter are described in the XVIIth Report, which at the present time of writing is still unpublished. 


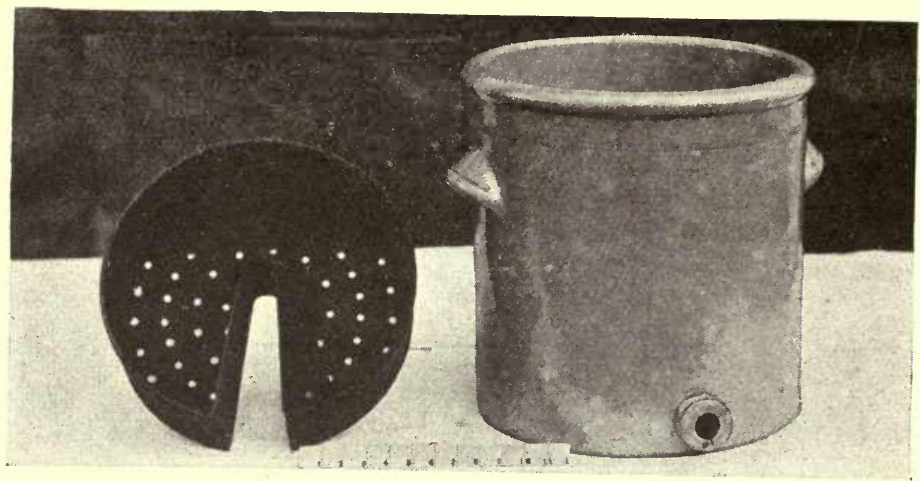

A.-Pot and Iron Tray.

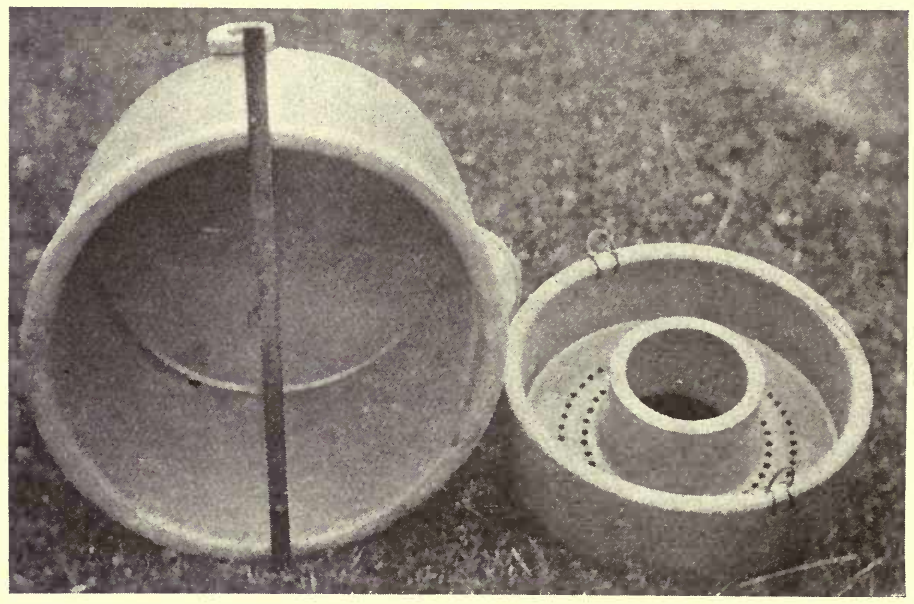

B.-Pot and Earthenware Tray.

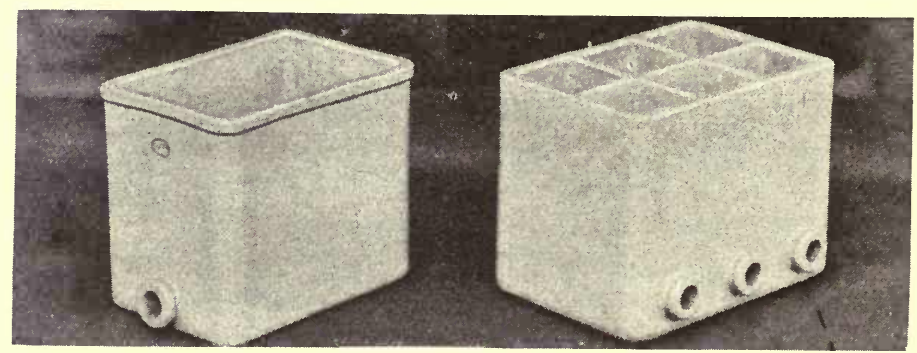

C.--Rectangular Divided and Undivided Pots.

FIG. 39.-POTS USED IN POT EXPERIMENTS. 
baleful influence of a surface crop were:-mustard, tobacco, tomatoes, barley, clover, two varieties of grasses, Brussels sprouts, pears, plums, cherries, many varieties of apples, beech, oak, ash, larch, spruce and firs; whilst those found capable of affecting other plants were:-mustard, tobacco, tomatoes, clover, apple trees, and sixteen varieties of grasses. In no case have negative results been obtained, either as to the susceptibility of a plant to the influence of surface growth, or to the deleterious effect of a plaint when grown as a surface crop. It would be premature, however, to conclude that no such exceptions exist, and, as will be seen more clearly from what follows, the existence of such exceptions, extending even to cases where the action of a surface crop may be beneficial, are quite conceivable.

Some illustrations of the results obtained are shown in Figs. 40 and $4 \mathrm{I}$, and they include one wherein the action has been very great, for the clover, grown there as a surface crop, has so stunted the tobacco in the pot, that the latter has not developed sufficiently to make its appearance above the rim of the latter.

Very great variations were observed as to the extent of the effect in different cases : taking cases where the same plant was grown in the pots, but different plants in the trays, the vigour of the former, as determined by the weight of the plants when dried after growth had finished, was found to have been reduced from roo to the following values-

\begin{tabular}{|c|c|c|c|}
\hline 9 series & $\begin{array}{l}\text { Plant in } \\
\text { the pots. } \\
\text { Mustard }\end{array}$ & $\begin{array}{l}\text { Plants in } \\
\text { the trays. } \\
\text { Various }\end{array}$ & $\begin{array}{l}\text { Relative vigour of } \\
\text { plant in the pots. } \\
\text { (I to } 77=\text { ) } 33\end{array}$ \\
\hline & Tobacco & 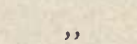 & ( 3 to $78=$ ) 47 \\
\hline 3 & Tomatoes & ," & $(33$ to $54=) 44$ \\
\hline
\end{tabular}

Equally great variations were observed when comparison was made of cases where the plant in the trays was the same, but those in the pots different, a result in accordance with the difference observed in the susceptibility of different plants to the toxin in heated soil (p. 254).

\begin{tabular}{|c|c|c|c|}
\hline & $\begin{array}{l}\text { Plants in } \\
\text { the pots. }\end{array}$ & $\begin{array}{l}\text { Plant in } \\
\text { the trays. }\end{array}$ & $\begin{array}{l}\text { Relative vigour of the } \\
\text { plants in the pots. }\end{array}$ \\
\hline Io series & Various & Grass & $(24$ to $85=) 53$ \\
\hline $6 \quad$, & 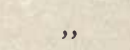 & Mustard & (I to $40=) 2 I$ \\
\hline , & , & Clover & $(3$ to $77=) 32$ \\
\hline
\end{tabular}

and, even in cases where there was no alteration in the nature 


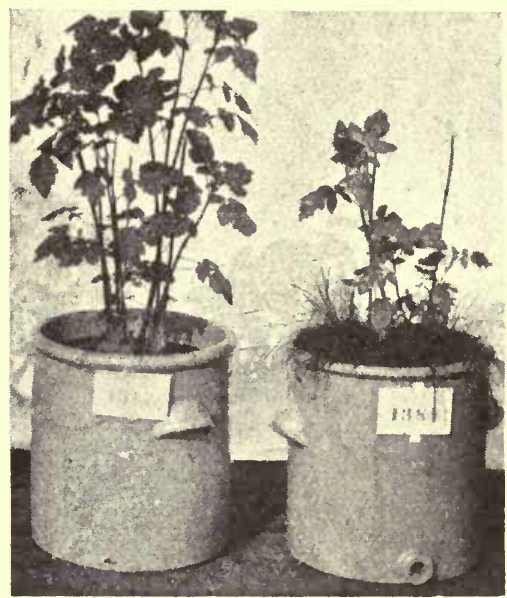

Mustard.

No Grass in Tray. Grass in Tray.

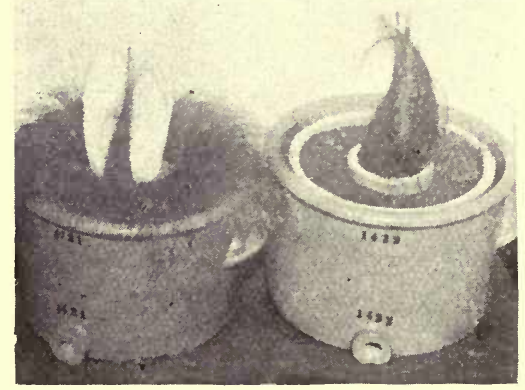

Festuca.

Festuca in Tray. No Festuca in Tray.

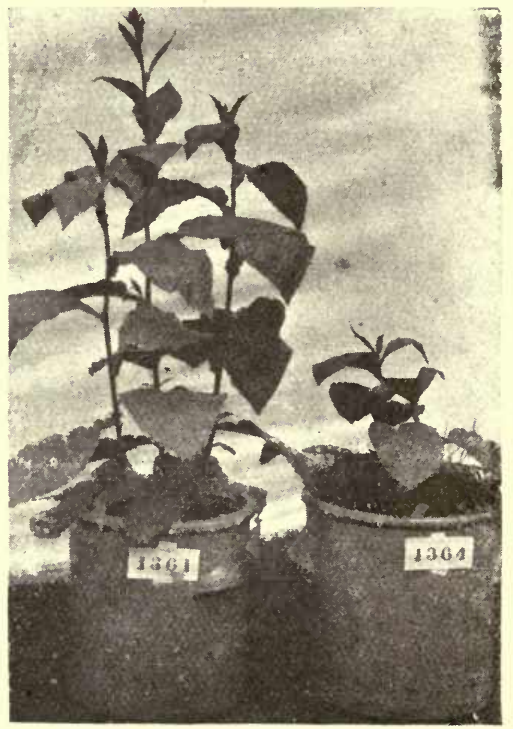

Tовассо.

No Grass in Tray. Grass in Tray.

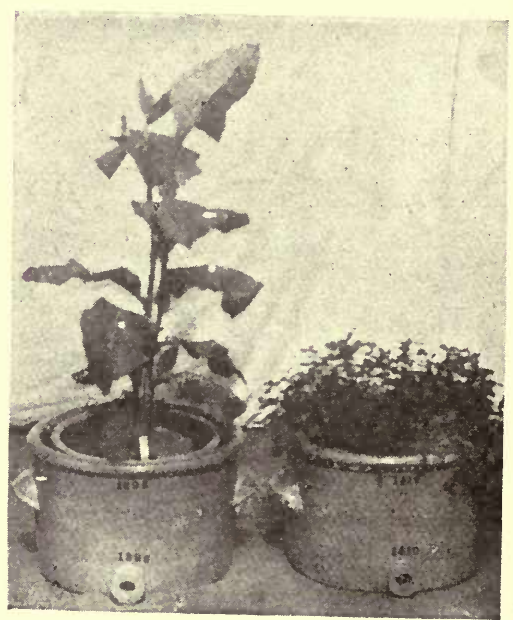

Tobacco.

No Clover in Tray. Clover in Tray.

FIg. 40.-PLANTS GROWN WITH AND WITHOUT A SURFACE CROP. 
TOXIC ACTION OF ONE CROP ON ANOTHER 295

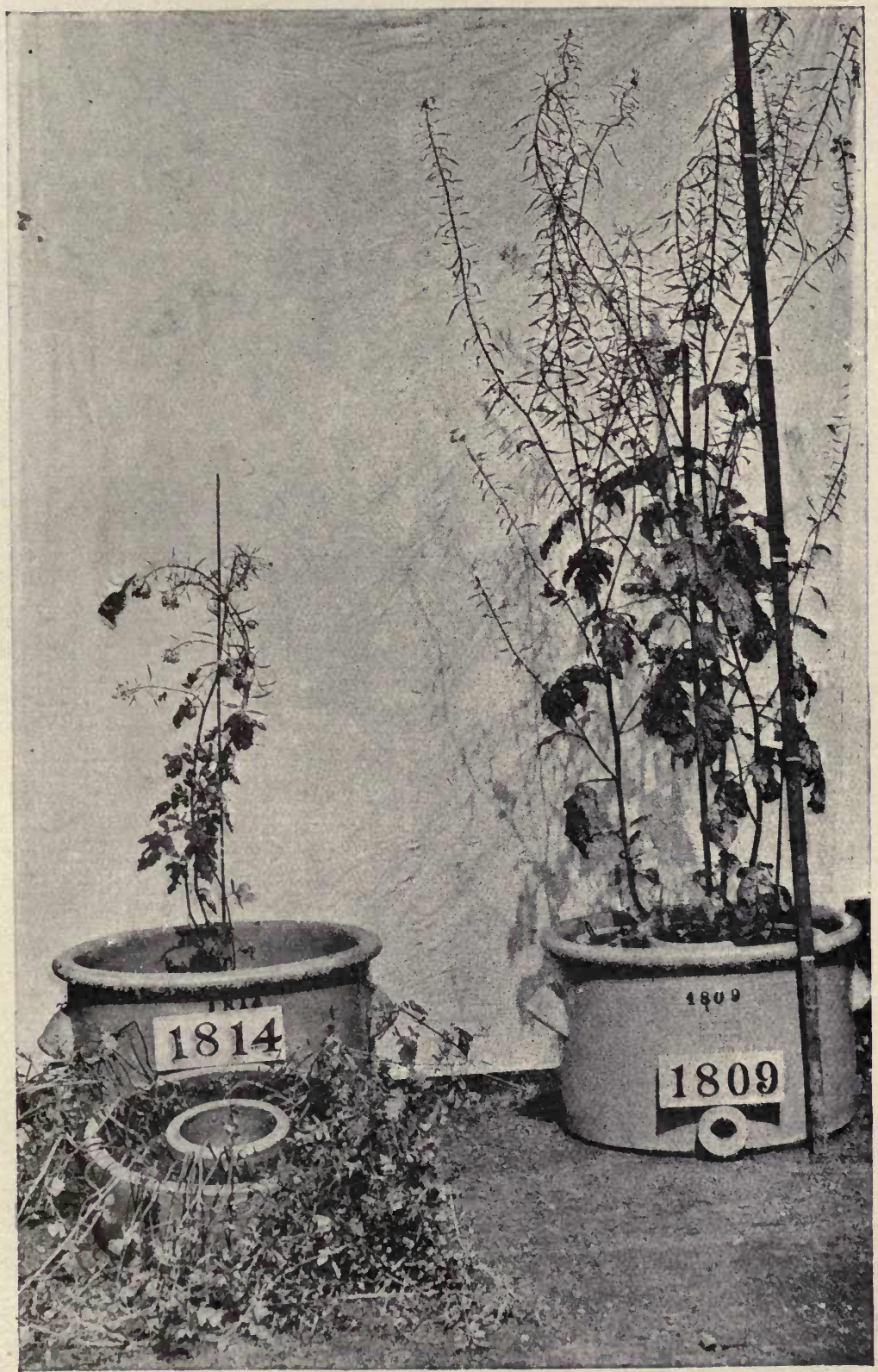

Mustard in Tray.

No Mustard in Tray.

FIG. 4I.-MUSTARD GROWN WITH AND WITHOUT MUSTARD IN THE TRAYS. 
of the plant either in the pots or the trays, similar variations were obtained in different seasons : thus-

\begin{tabular}{|c|c|c|c|}
\hline & $\begin{array}{l}\text { Plant in } \\
\text { the pots. }\end{array}$ & $\begin{array}{l}\text { Plant in } \\
\text { the trays. }\end{array}$ & $\begin{array}{l}\text { Relative vigour of th } \\
\text { plants in the pots. }\end{array}$ \\
\hline 6 series & Mustard & Mustard & $(\mathrm{I}$ to $40=) 2 \mathrm{I}$ \\
\hline & Tobacco & Grass & $(29$ to $78=) 60$ \\
\hline ," & Mustard & Grass & $(42$ to $54=) 48$ \\
\hline
\end{tabular}

To these, in order to make the list of experiments complete, may be added-

\begin{tabular}{cllc} 
& $\begin{array}{c}\text { Plant in } \\
\text { the pots. }\end{array}$ & \multicolumn{1}{c}{$\begin{array}{c}\text { Plant in } \\
\text { the trays. }\end{array}$} & $\begin{array}{c}\text { Relative vigour of the } \\
\text { plants in the pots. }\end{array}$ \\
I series & Barley & Grass & 85 \\
,, & Clover & Clover & I6 \\
," & Festuca prat. & Festuca prat. & 24 \\
," & Dactylis glom. & Dactylis glom. & $3 \mathrm{I}$ \\
," & Tobacco & Tobacco & 36 \\
," & Tomatoes & Tomatoes & 33
\end{tabular}

The variations in comparable series were sometimes traceable to exceptionally great or small vigour of the growth in the trays, but the more frequent cause was evidently due to variations in the rapidity of growth of the seedlings in the pots, as conditioned by atmospheric peculiarities; for, where growth was slow, as when the season was unsuitable, the plants in the pots were subjected, while they were still young and in a susceptible condition, to the baleful influence of the surface crop for an exceptionally long time, and the stunting was much greater than where growth had been rapid.

So far as any comparison can be made, the action of a surface crop on these soft-wooded plants is quite as great as that of grass on trees, probably greater; it reduces the vigour of the plant to an amount which may be roughly averaged at 40 per cent. of what its vigour is in the absence of a surface crop, whilst in the case of the action of grass on trees, the average reduction may be placed at about 50 per cent. after two or three years' growth. But the cases are very different, for with hard-wooded plants the effect is cumulative, owing to the action extending over successive seasons, and, as has been seen, this cumulation of effect may eventually result in the death of the tree. Certainly these results do not indicate that grass has any exceptionally baleful influence as compared with other crops, rather 
the reverse ; but for any strict comparison it would be necessary to have the same amount of surface growth in the various cases : this might, perhaps, be accomplished, but it would necessitate numerous series of experiments, which, with these heavy and bulky pots, would require many seasons for their completion.

For these same reasons conclusive evidence has not yet been obtained on another point of considerable importance, namely, whether a plant when grown as a surface crop will affect a plant of the same nature to a greater or lesser extent than it affects a plant of a different nature. That it does affect one of the same nature as itself, there can be no doubt, and the evidence as it stands indicates that it affects it even more than plants of a different nature. Thus-

Relative growth of a plant when acted on by other plants.

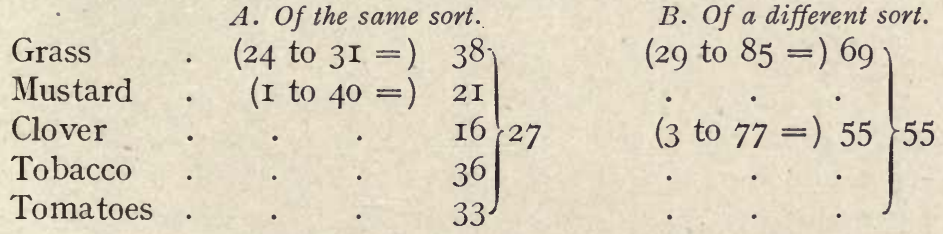

In these experiments it was often evident that the influence of the surface crop was effective, not only in reducing the total growth of the plant, but in delaying its development. This was not always the case, but when it did occur, it introduced some difficulty in making a comparison between the growth of the plants with and without the surface crop, for maturity was not reached at the same time. By leaving the plants with the surface crop longer to develop, greater errors, however, were introduced, for a considerable increase in weight occurs in a plant after it has apparently completed its functions and ripened its fruit. This led to an erroneous conclusion that plants under the influence of a surface crop would, before the end of the season, more than recover the ground lost, and would outstrip plants without any surface crop (XIV, Append. I47). Yet, some recovery undoubtedly takes place as time goes on, for when one set of plants-both with and without surface growth-is turned out and examined before growth is complete, whilst another set is left till growth is complete, the latter series will lead to a lower estimate of the effect of the surface crop than the former. Out of ten series of experiments of this sort (XVII), only one-and that possibly erroneous through accident-gave different results; 
, the mean values in the other nine series gave for relative vigour of the plants affected by the surface growth-

$22 \cdot 6$ when measured earlier.

$30 \cdot 7$ when measured later.

That the effect of the surface crop on the plant in the pot must be due to something which is washed down from the former on to the latter, is as evident as in the similar experiments with trees and grass (p. 285), but in this case a modification in the experiment was made which still further excluded the possibility of any other explanation. This modification consisted in growing a surface crop equally in two sets of pots, but, whereas in the one, leachings from the crop in the trays were allowed to soak through to the plant in the pots, in the other, this was prevented by blocking the holes in the trays. The effect on the plants in the pots in this latter case was found to be practically nil. The pots numbered I795 and 1794 in Fig. 42 illustrate the results with and without a surface crop when the holes in the trays were blocked, the average difference ketween the plants in those cases being II per cent.- a value less than the experimental error, which, as will be seen from the details entered kelow, is large, owing to difficulties arising in adjusting the water supplied to the plantwhereas when the trays were perforated, the surface crop reduced the growth of the plants in the pot by as much as 63 per cent.

Relative Weights of plants with and without a surface crop.

Trays not perforated.

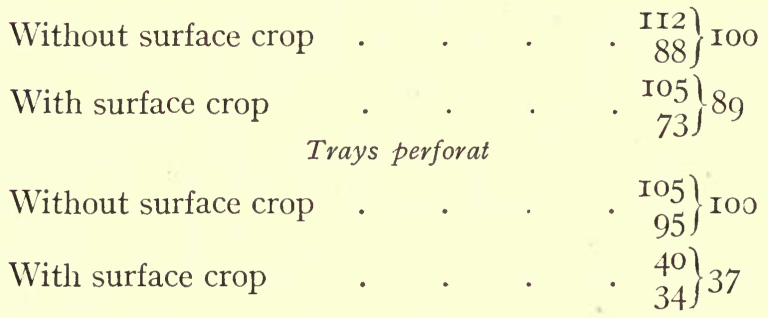

This experiment affords evidence on another point of great general importance. It may be seen from the figure that the crop of mustard in the unperforated tray (I795) is much lighter than that in the perforated one (I792), and this was so in every case, in spite of the utmost care being taken to foster its growth: the relative weights of the surface crops in the two classes of trays were as Ioo to 45 . The explanation of this is evident: 
TOXIC ACTION OF ONE CROP ON ANOTHER 299

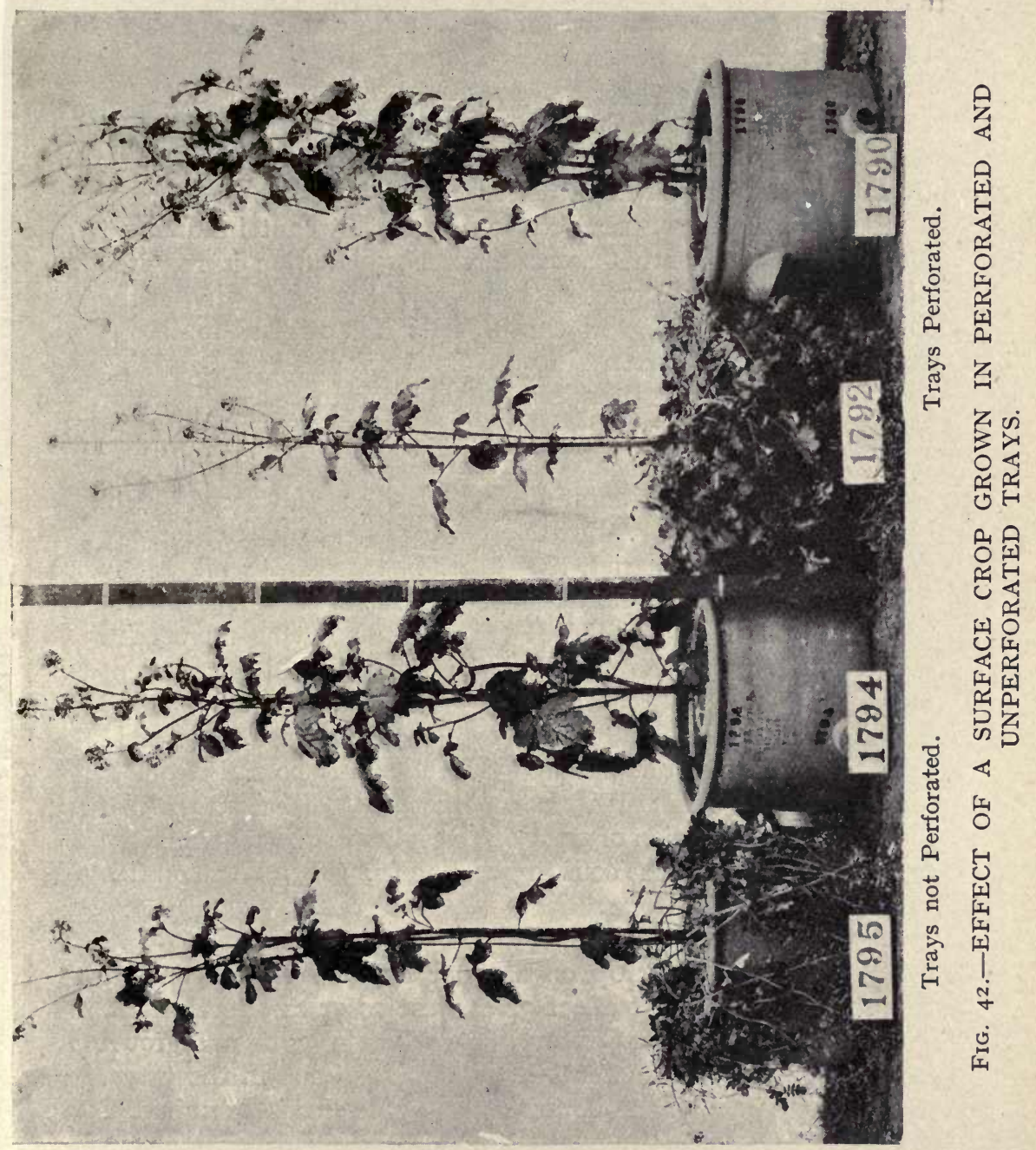


when the tray is perforated, the toxin formed by the plant in it is washed out, and affects the plant in the pot; when the tray is not perforated, the toxin is retained, and affects the plant in the tray itself. We have here a new light thrown on the reason why good drainage is so essential for the welfare of a plant, namely, to remove the toxin produced by its growth. Up to the present drainage has been regarded as essential owing to its facilitating the access of air to the roots : the roots themselves may want air, and certainly the soil does, but, as has been pointed out already (p. 276), the supply of air which is essential appears to be very small, and any water in the soil would probably contain sufficient for the purpose, so that some further explanation is required of the disastrous consequences following the water-logging of the soil. That it is afforded by the accumulation of plant-toxin was proved by growing mustard in a series of perforated trays, adding to each, at every watering, sufficient water to raise the water contents just short of the maximum which the soil would retain -as determined by independent trials - and then adding to some of the trays an additional three litres of water, which, of course, drained away. But though this leaching would remove much of the food-material, the plants in these trays did better to the extent of 30 per cent. than those which were not leached, the good done by the removal of the toxin having more than counterbalanced the harm done by the removal of nutrient matter.

This experiment opens up possibilities for increasing the yield in cases where repeated leaching of the soil is possible, and it further affords one explanation of the great differences which may occur in the action of grass on trees due to differences in the drainage capacity of the soils in question (p. 308). Work on this subject is still in progress.

The action of one crop on another being a general one, it follows that trees must affect grass, just as grass affects trees. This was realised in pot experiments wherein grass was grown in the pots, with apple seedlings as a surface crop in the trays. The action was small, because the apple seeds germinated very unsatisfactorily; nevertheless, all the experiments were concordant in showing that an effect did occur (XVII).

In practice it is difficult to estimate the effect of trees on the grass below them, because there are always other conditions to be taken into consideration, such as the shading effect, and the composite character of the grass, which latter results, when the 


\section{TOXIC ACTION OF ONE CROP ON ANOTHER 301}

grass becomes affected, in an alteration in its composition. In the case of fruit trees, the effect of shading is probably insignificant. It was noticed in one instance where Brussels sprouts had been grown in a mixed plantation, that, although the crops under the trees had been very much affected, there was no difference observable between the more shaded and less shaded positions. A definite experiment on the subject emphasised this point. A piece of ground occupied irregularly with fruit trees -mostly standard apples up to 23 years of age-was planted with sprouts : in the rest of the ground plots similar in size and number to the spaces occupied by the trees. were marked off, and shaded by canvas screens five feet above the ground, which certainly shaded the plants more than did the trees : at the same time, other plots were marked off where trees had been growing until the sprouts were planted, these trees having been cut down, without disturbing the subsoil, for the purpose of the experiment. The results obtained in two successive years gave the following values for the relative crops from the different plots-

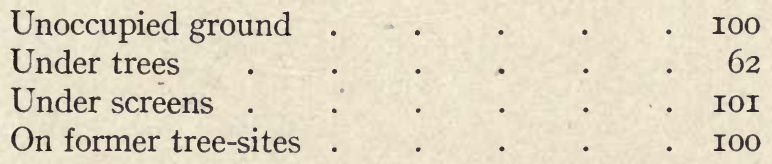

Thus, the effect of the trees was to reduce the vigour of the plants by 38 per cent., but this reduction could not be attributed to shading, for the still greater shading produced by the screens had caused no reduction at all; nor was it due to the ground having become exhausted by the trees, for no similar reduction had occurred where the sprouts occupied former tree-sites.

Practical ${ }^{1}$ men have long ago made up their minds that plants do have a very great effect on the soil in which they are growing. But the old idea, handed down from mediæval times, and taught in the best text-books of the eighteenth century, was that the soil was the source of life and food for the plant, and that the plant played simply a passive part, accepting whatever thè soil supplied to it. When, however, modern scientific investigation began, it was discovered that the plant was by no means a merely passive agent, but that it got much of its sustenance from the air, and that even such sustenance as it derived from the soil, was not really food in the proper sense of the word, but only the raw

1 The following seven paragraphs form an abridgment of an article on the subject written by E. J. Russell for the XIVth Woburn Report, p. 5I. 
material, which had to undergo an elaborate manufacturing process in the plant before it could be correctly described as food. The soil was regarded merely as the storehouse of this raw material, and the only recognised effect of the plant on the soil was an exhaustion of the material which it contained.

Running alongside of these ideas were others relating to the action of one plant on another. It has always been thought that certain plants had the remarkable power of injuring the crop that came after them. In the seventeenth century-the palmy days of the Traveller's Tale-Sir Hans Sloane gravely presented the learned world with an account of a vegetable called the Tartarian Lamb, which possessed something like four feet and a body covered with a kind of down, and was remarkable among plants in that it would suffer no vegetable to grow within a certain distance. A later traveller searched for it in I7I5, but failed to find it in his journey from St. Petersburg to Ispahan.

Traditions of very similar kind are still current, and it is maintained to this day by some who have been in the East that there are plants growing which have a decidedly harmful effect on vegetation. Most practical men will maintain that land which has grown the same crop for a number of years becomes "sick," and will not grow the same crop again, although it will grow a good many others. It wants, in fact, a change. Among many gardeners in this country it is not uncommon to speak of " onionsick land," while, on the Continent, "sugar-beet sick land" is recognised by the growers. When nurserymen in this country speak of " cucumber-sick soil " and " tomato-sick soil," in each case it is presumed that the crop has done something to injure the soil, although the injury is not necessarily felt by another and totally distinct crop (see p. 336).

These ideas appealed very much to the older botanists, and were expressed clearly by a famous physiologist, De Candolle, in a book published early last century, and which for many years played an important part in scientific work. De Candolle supposed that plants not only draw part of their food from the soil, but also excrete into it certain waste substances, just as an animal would, these excretions being harmful to other plants of the same kind, but not to plants of a different order.

Such an hypothesis readily explained why farmers prefer to grow their crops in rotation, instead of continuously, and why also certain crops, such as clover, will not grow year after year on the same land. When the hypothesis was considered, however, it was seen to be inconsistent with many obvious facts of nature : 
grass goes on growing in the fields for ever: primroses, foxgloves, wood anemones, and a host of other wild flowers, seed themselves and come up year after year in the same woods and dells. Braconnet was among the first to give voice to this feeling of dissatisfaction, but the careful experimental inquiry came in the 'thirties and early 'forties, when Daubeny, Sibthorpian Professor of Rural Economy at the University of Oxford, conducted a classical series of experiments in the Physic Garden to test the hypothesis.

A series of thirty-two plots was laid out: sixteen had certain different crops grown on them continuously, whilst on the other sixteen the same crops were grown, but in rotation, so that no plot bore the same crop twice. With two possible exceptions, no differences were apparent between the continuous and rotational cropping other than might be attributed to exhaustion of the soil. Thus no evidence in favour of the excretion postulated by De Candolle was obtained.

More definite evidence against such an hypothesis, however, was obtained by Lawes and Gilbert in later years. ${ }^{1}$ Five out of the six crops tested-barley, wheat, oats, swedes and mangold -grew well enough continuously, but clover failed after a very short period. This, however, did not prove either the exhaustion of the soil or the contamination by poisonous excretions, for on examination the dying plants were found to be infested by two pests, an eel worm and a fungus.

At a later date ${ }^{2}$ the subject was again taken up at Rothamsted, and in a series of pot experiments wherein any disturbing element introduced through the exhaustion of the soil was eliminated by adding whatever nutrient the previous crop had removed, it was proved that there no lasting toxic effect was produced on the soil by either rye, buckwheat or spinach, and that, if anything is excreted by the roots, the amount of it which accumulates during six years is insufficient to cause any appreciable depression in the next crop.

The Woburn experiments emphasise and extend this conclusion, for they show that such toxic matter as may be formed in the soil as a result of plant-growth has only a very temporary existence, and does not accumulate in the soil at all. It is only while the surface crop is actually growing that trees are

1 Gilbert, Results of Experiments at Rothamsted on the Growth of Leguminous Crops for many years in succession on the same land. I889. Rothamsted Mem., VI, 15, pp. I-6o.

2 Russell, Soil Conditions and Plant Growth, 1917: pp. 150-I 5I. 
affected by it, and, so long as the tree has not become hidebound and stunted beyond recall, it is only necessary to remove the surface growth in order to restore it to vigour. The effect of weeds as a surface crop is certainly less than that of grass, and Fig. 43, A and B, illustrate the effect which weeds have on a tree when they are allowed to occupy the ground for only one season after the planting. (In the particular instance shownthe only one now available - the effect of the weeds was increased by an absence of cutting back.) After the first season, the weeds were removed, and the photograph reproduced in Fig. 43, C, shows how complete the recovery was after two years; indeed, the recovery commenced immediately; in the season following the removal of the weeds, the deficit in vigour of the trees amounted to only Io per cent., whereas in the previous season, before the removal of the weeds, the deficiency had been 56 per cent. (I, I62; II, 90).

Another instance in point has been afforded by the increase in the vigour of trees when grown in soil from previously grassed, instead of from tilled, ground (p. 288), and in that case only two or three months had elapsed between the removal of the soil and the growth of the trees, so that the disappearance of the toxic property must have occurred in that interval. Similarly, when plants are grown in soil which has been moderately heated, although the amount of toxin present is probably much greater than that produced by merely growing plants in it, the presence of the toxin becomes unrecognisable after a few weeks (p. 250). But the destruction of the toxin, at any rate when in the dissolved condition, appears to be a matter of hours, rather than of weeks or months, for when, in the pot experiments, the leachings from the surface crop in the trays, instead of being allowed to run directly on to the plant growing beneath, are collected and not applied to it till some hours afterwards, they are found to have lost their toxic property, and, indeed, to have become slightly beneficial. In two series of experiments where the surface crop was grass, and the plants in the pots were apple trees, the average increase in vigour of the trees watered with aërated leachings was I 8 per cent., whereas there was a decrease in their vigour amounting to 40 per cent. when the leachings reached the trees without aëration (XIII, 86). In other experiments with grass as the surface crop and tobacco as the plant in the pots, the aërated leachings gave an increase of 7 per cent., against a decrease of 22 per cent. with the unaërated leachings. Even the interposition of a layer of two inches of 


\section{TOXIC ACTION OF ONE CROP ON ANOTHER 305}

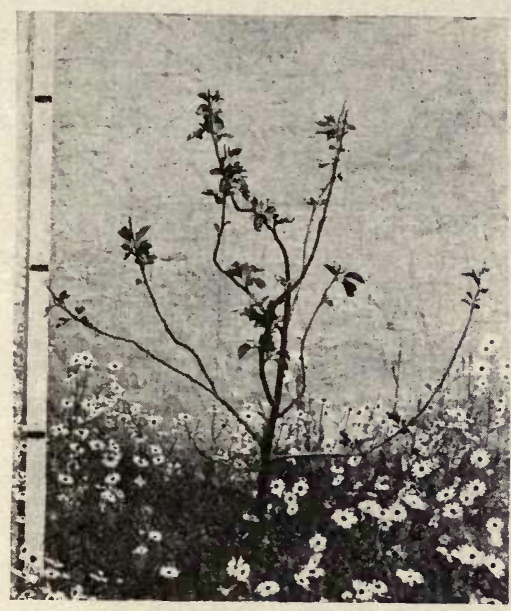

A.-Weed-grown.

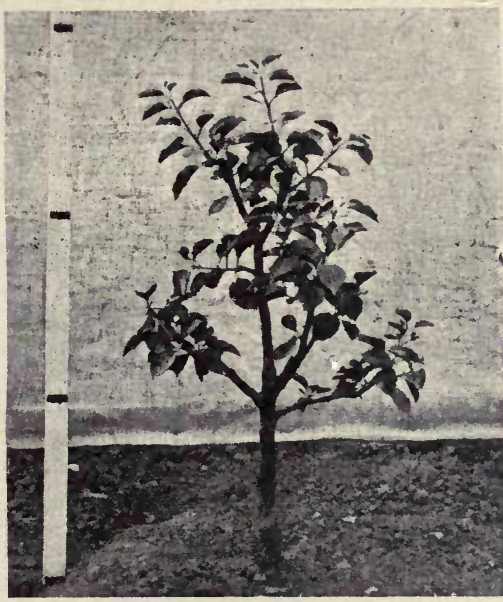

B.-Soil Tilled.

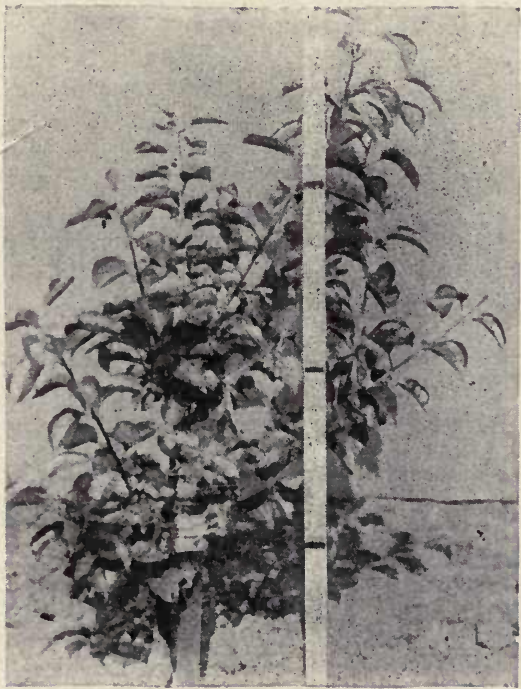

C.-After the Removal of the Weeds.

FIG. 43.-THE EFFECT OF WEEDS AND OF THEIR SUBSEQUENT REMOVAL. 
pumice stone between the trays and the earth beneath probably produces some reduction in the toxic effect (XVII).

These results are quite in accordance with those obtained in a chemical examination, now in progress, of the properties of the aqueous extracts from soils in which plants have been growing, for it has been found that such extracts become materially modified in the course of only a few hours.

The conversion of the product of plant-growth from a harmful to a beneficial substance may result in the proximity of grass to trees proving actually beneficial to the latter. Standard apples were planted in land which had been grassed some years previously, this grass being replaced over the tree-roots in the case of one plot, and either removed entirely, or replaced up to a certain distance from the stems, in others. The records of these trees during the succeeding years, as given by the annual growth measurements, are of considerable interest.

Relative growth during

I. Tilled ground
2. Grass up to stems
3. Grass to $\mathrm{I}_{2} \mathrm{ft}$. from
stems .

I9Iо. I9II. I9I2. I9I3. I9I4. I9I5. I9I6. I9I7.

4. Grass to $3 \mathrm{ft}$. from stems . • • . $\begin{array}{llllllll} & \text { I04 } & 94 & 82 & 6 \text { I } & 88 & 63 & \text { I03 }\end{array}$

5. Gradually grassed. IOI 38 I2 Io - - -

The effect of complete grassing is to reduce the vigour of the tree in three years to an average of ro per cent. of that of trees in tilled ground ( 2 compared with I), whilst in both cases where a space has been kept open round the trees ( 3 and 4 ) the reduction, after the first two years, has been only to about 80 per cent. : but during these first two years, whilst the trees in the larger open areas (4) were practically unaffected by the grass, those in the smaller areas (3) were actually benefited by it, to the extent of nearly 40 per cent. : the toxin formed by the grass had evidently had time to become changed into food-material before reaching the tree-roots, and it was only after these had extended so as to be actually within the grassed area that the effect of this toxin was felt.

Another set of trees in this series-the last of those entered above-affords information as to the comparative effect of grassing trees at once, and of allowing the grass to establish itself gradually: in the latter case there was no effect during the first season, and that produced in subsequent years resulted, 
up to the time when this experiment was discontinued, in the trees showing twice as much vigour as those which had been grassed from the first (XIV, 48). In another case where apple trees, which had been grassed over immediately after being planted, were lifted and weighed at the end of fifteen years, they were found to weigh only one-third as much as similar trees where the grassing had been allowed to occur gradually (XIII, 25).

These results enable us to deal with an objection which is always raised when the Woburn results on the grassing of trees come under discussion, namely, How can such results tally with the flourishing condition of fruit trees under grass in other parts of the country? The flourishing condition of such trees, however, may require some qualification: they may not be affected to the same extent as those in most of the Woburn experiments, but, in the almost invariable absence of definite measurements, and of the means of comparing them strictly with similar trees in tilled ground, it is impossible to state that they have not suffered at all from the grass. In every case where strict comparisons have been made, such an effect is noticeable, and may be of considerable magnitude, even where to all appearance the trees are flourishing satisfactorily. An instructive instance in point is afforded by the experiments at the National Fruit and Cider Institute, Long Ashton : ${ }^{1}$ eight varieties of standard apples were planted in grassed land, and in some cases the grass was allowed to re-establish itself round the stems, whereas in other cases, spaces measuring about nine feet in diameter were kept tilled. After three and five years the differences in girth of stems of the two sets of trees were only I7 and I3 per cent., and any one examining the grassed trees would have pronounced them as being in a flourishing condition. But differences in girth and in the weight of the trees would be in the proportion of a square to a cube, so that the deficiency in weight of the grassed trees would be 22 per cent., and, on the conservative assumption that the trees had not more than doubled their weight since being planted, this would mean that the increase in weight of the grassed trees had only been half that of the trees in the tilled ground. In another case where similar experiments were made in Gloucestershire under the auspices of the Fruit and Cider Institute, ${ }^{2}$ differences in girth

1 Nat. Fruit and Cider Inst. Rpts., 1908, I909, I9Ir. Also Jour. Bath and West Soc., Series V, I910-I I; VIII, I 40.

${ }^{2}$ Pamphlet of the Gloucestershire Education Committee, by G. H. Hollingworth, Oct. I9I3. 
measurement of 33 , instead of $I 5$, per cent. were obtained : ${ }^{1}$ and in all these cases, it may be remarked, the grass cannot have exerted its greatest possible effect, for the grassing of the trees was allowed to occur gradually: added to which, with the trees under tillage, the open spaces round them were not large enough to prevent some of the roots from penetrating into the grassed area before the expiry of the four years, so that they did not form an adequate standard with which the grassed trees could be compared.

In ordinary practice the grassing of trees is allowed to take place gradually, thus reducing the effect of the grass as indicated, but probably the most potent factors in rendering this effect less than at Ridgmont are generally the greater depth of soil available, and a more efficient drainage. The good soil at the Fruit Farm is not more than six or seven inches in depth, and kelow it there is a stiff clay subsoil into which roots will not readily penetrate, and which must retard the removal of toxic products : even in the case of stocks which are naturally deeprooting, the roots spread themselves out near the surface as if they were of a shallow-rooting habit: the illustrations in Fig. 44 will afford sufficient evidence of this. But, as has been seen from the experiments quoted on p. 306, the deleterious action of grass is not felt, and may even be changed into a beneficial action, when the tree-roots are separated (in an horizontal direction) by only a few inches of soil from the grass-roots, and in the case of a deep, fertile soil, where the tree-roots find no difficulty in penetrating downwards, they may well get away from the grass-roots sufficiently to materially reduce the deleterious effect of the latter on them. The soil at Long Ashton, is of exceptional depth and fertility.

The effect of good drainage is probably still more potent in reducing the toxic action of the grass: a striking illustration of this has been afforded (p. 298) by the growth of plants in trays under conditions where drainage occurred, and where it did not: a similar difference of effect would exist in the case of trees under the toxic action of grass. It is noticeable that the effect of grass on trees is often very small in light and well-drained soils, whilst at Ridgmont, where the effect is very great, the drainage of the soil is particularly bad. Even at Ridgmont itself there is a striking illustration of the importance of drainage, for there are in the farm two similar plantations

1 Similar experiments at the Harper-Adams College (Joint Report, I912) gave differences of 25 per cent. after one year, and 45 per cent. after 5 years. 


\section{TOXIC ACTION OF ONE CROP ON ANOTHER 309}

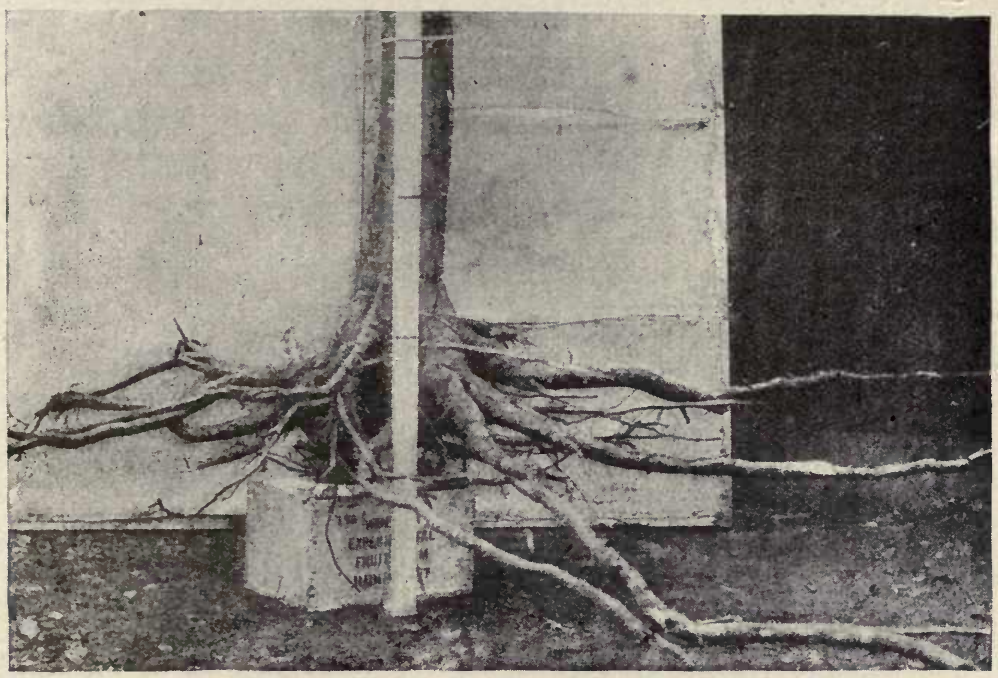

Roots of a Tree of Bramley's Seedling on Crab Stock. Fourteen years after planting.

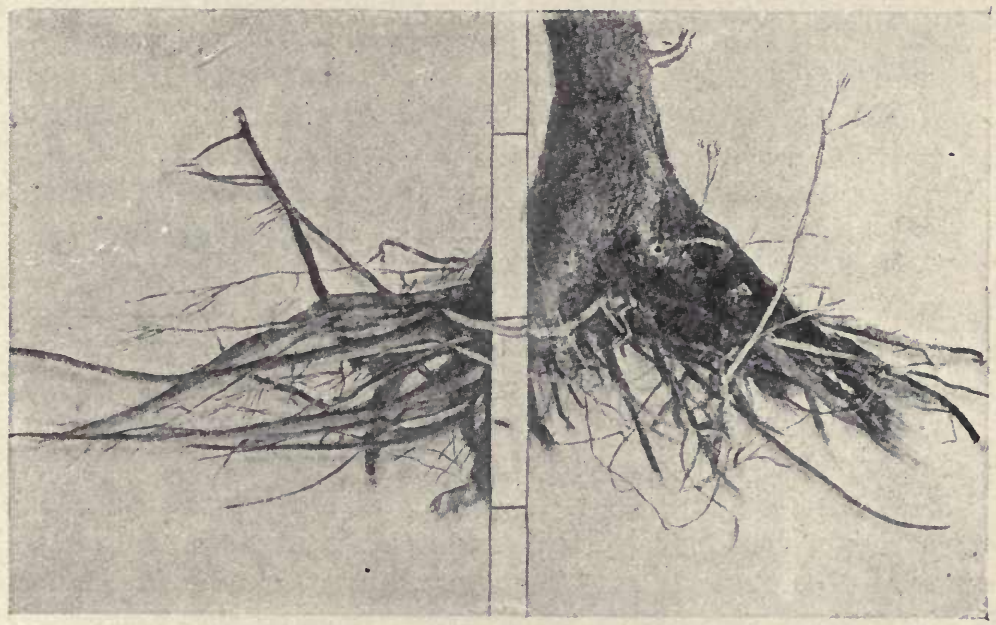

Roots of a Tree of Beurre Hardy on Pear Stocls. Eleven years after planting.

FIG. 44. 
side by side, half of each of which was grassed over some years ago; but whilst the grass has killed many of the trees in one of these, it has not very much affected those in the other. This latter plantation occupies one of the best-drained positions in the field, the former one of the worst-drained ones (p. 262).

Apart from these considerations there are others which may account for differences in the grass-effect in different localities: the nature of the toxin is not yet known, and still less do we know how far its formation and subsequent decomposition may be effected by the chemical and physical nature of the soil : it is possible, too, that trees may, in cases where they are not too much enfeebled at first by the action of the grass, be able to adapt themselves more or less to their altered environment by means other than that of extending their roots downwards. At present, however, this is all speculation, and the formation of a toxin which rapidly becomes converted into a food would appear to supply all the conditions necessary for explaining the existence of great differences in the final results in different localities.

The problem as to the nature of, and as to the method of formation and decomposition of this toxin is still to be solved. Much of the opposition to the idea of a toxin being formed during plant-growth is due to the fables connected with the subject (see p. 302), and to a misconception of what is necessarily implied by the formation of a toxin. It does not imply that the roots must excrete some substance which acts as a virulent poison to other plants : it is true that instances of excretions from flowers, leaves, stems and seeds of plants, either under normal or abnormal conditions, are known, and hence the possibility of there being excretions from the roots cannot be overlooked: but the view that such occurs in the present case is by no means necessary, for we have an ample explanation of the results in the fact that plants in growing leave much organic detritus in the soil (see p. 2), and that such organic matter in its decomposition under natural conditions forms, first a toxin, and then a plant-food. The importance of the experiments on the action of heated soils on plant-growth and on seed-germination (p. 249), as bearing on this point, cannot be overrated.

Whether the toxic substance is in a soluble condition to start with, or is rendered soluble only by subsequent chemical change or by bacterial agency, is not yet known, nor is it known how far its subsequent conversion into plant-food is due to spontaneous decomposition or to oxidation. It is probable, however, 
that bacterial assistance is not necessary for this change, for it has been found that considerable change occurs in soil solutions equally in the presence or absence of bacteria.

The great rapidity of the change in nature of the substances in soil when they have been extracted from it to form a soil solution, may not hold good while they are still present in the comparatively dry soil, for it has been found that they adhere to that soil with considerable tenacity, and cannot be washed from it in the same easy way in which neutral salts can. Nevertheless, the changes would appear to be fairly rapid even in dry soils : direct experiments, based on chemical reactions, have established this, and so has the examination of the effect on germinating seeds of soils from immediately adjoining plots of tilled and grassed land; for fourteen such pairs of soils when examined, both in July and October, within a day or two after the samples had been collected, showed that germination was more rapid (to the extent of 4 per cent.), and that the percentage of seeds germinating was greater (to the extent of $I^{\cdot} 5$ ) in the soil from the grass, than in that from the tilled land; so that any substance toxic towards germination which may have originally been present in the former, had become altered in its nature during the interval elapsing before the seeds could be germinated in it (XIII, I3I).

Much work has been done of recent years by the Bureau of Soils of the United States ${ }^{1}$ on the substances present in fertile and infertile soils, assuming, which does not always seem justifiable, that the substances extracted from soils with the aid of various chemical reagents are those which are actually present in the soils originally. Amongst the deleterious substances thus obtained, dihydroxystearic acid is prominent. But it is certain that this is not the substance which the Woburn experiments now in progress indicate as being the toxin produced by plantgrowth: for this toxin, or the substance to which it immediately gives rise, is a reducing substance, that is, it absorbs oxygen, and converts iodine into hydriodic acid, whereas dihydroxystearic acid does not do so. The Woburn results have shown that this reducing substance is present in all soils, and that the proportion of it is generally increased, often very

1 Schreiner and Reed, "Certain Organic Constituents of Soil in Relation to Soil Fertility," U. S. Dept. of Agric. Bur. of Soils, Bull., No. 47, I907.

Schreiner and Shorey, "Chemical Nature of Soil Organic Matter," ibid., Bull., No. 74 , I910.

Schreiner and Lathrop, "Dihydroxystearic Acid in Good and Poor Soils," Journ. Amer. Chem. Soc., I 91 I, xxxiii., I412-1 7. 


\section{2}

\section{SCIENCE AND FRUIT GROWING}

considerably, by the growth of plants. But the case is evidently one of great complexity, and both from this work, and from all the facts discussed above, it is abundantly clear that we are as yet only on the fringe of an explanation of the changes accompanying plant-growth, and that very much work remains to be done before a true insight can be obtained into the reciprocal effect of plant and soil on each other. 


\section{Chapter XXIX}

\section{THE BEHAVIOUR OF PLANTS IN MASSES (Report XVII)}

SiNcE the toxin resulting from the growth of a plant acts on other plants of the same nature, it must infallibly act also on the plant producing it, and it will be impossible to grow any plant, even by itself, without its being affected by toxin action. This must be so in the pot experiments described in the preceding chapters, even when the trays contain no surface crop, and the only reason why the plants suffer so much more when there is a surface crop in the trays, is that they then receive the toxin from this crop, as well as that produced by their own growth: on an average, the amount of toxin then affecting them will be increased two- or three-fold.

When a number of plants are grown side by side, some of the toxin produced by each will become diffused through the soil, and act on the neighbouring plants. When the space ketween the plants is considerable, a certain portion of this toxin will become oxidised before it reaches a neighbouring plant, and hence spacing will diminish the general effect: but no arguments as to the existence of toxic action can be based on such a result, for increased spacing will at the same time increase the nourishment of the plants, by allotting to each a larger bulk of soil from which to draw its supplies.

The toxic effect of one plant on another and on itself introduces many novel factors which must be taken into consideration when inquiring into the behaviour of massed plants; and, for investigations on the subject, pots were constructed so that a number of plants could be grown together, with and without root-interference. These were rectangular (Fig. 39, p. 292), and all contained the same bulk of soil-about I7 lbs.- -but in some cases they were divided into six separate compartments, measuring 3 by 3 inches, and in the others they were not so divided. 
In the first place it was necessary to ascertain whether the same number of plants when grown with and without rootinterference would behave in the same way. They should do so, for the total soil available for growth would be the same in both cases, and so would the total amount of toxin produced. The results bore out this conclusion: thus-

Relative weight of 6 plants grown in Divided Pots. Undivided Pots.

\begin{tabular}{|c|c|c|c|c|c|}
\hline Mustard & - & . & - & IOO & IOO \\
\hline Tomatoes & . & . & . & IOO & IO \\
\hline Barley . & . & . & - & IOO & \\
\hline Tobacco & . & . & . & IOO & II \\
\hline
\end{tabular}

The difference is inappreciable, except in the case of tobacco; and it is easily explained there by the spreading habit of the roots in that case, which would put the plants grown in the small compartments of the divided pots at a disadvantage.

Root-interference, therefore, does not affect the results. The next question was, does branch-interference affect them?-including in the term "branch" all the above-ground growth of the plants. To investigate this, three small plantations were built up by means of the divided pots, so that the average distances between the individual plants were 4 inches, 6 inches and 9 inches, respectively. The average weights of the plants in the three cases were found to be-

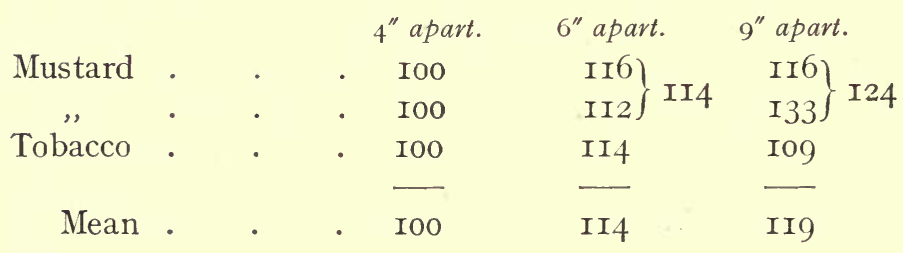

thus showing some advantage in separating the plants by more than 4 inches, but only a doubtful further advantage by increasing the distance between them to more than 6 inches. At the same time, a comparison of the outer rows with the inner ones in these (A, B in the table below) and in other similar plantations of mustard (C and D), gave further evidence as to the insignificance of the effect of branch-interference; for the comparison showed a smaller variation than what might reasonably be attributed to experimental error, and that variation was not uniformly in any given direction. 


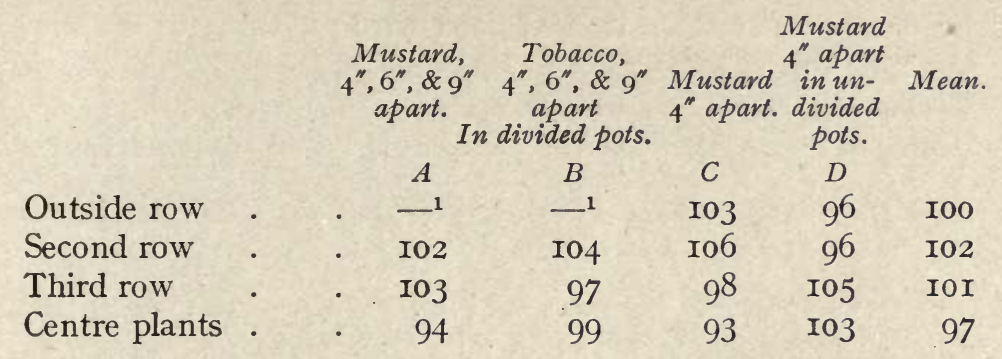

Though branch-interference has so small an effect on the total growth of the plant, it has a very great effect on the character of that growth: the mustard plants in the above experiments (p. 3I4) gave relative weights of-

$$
\text { IOO II4 and I24 }
$$

where the distances were 4,6 and 9 inches, respectively; yet the heights of the plants, as determined by measurements throughout their life, were in the reverse order-

I00 80 and 70 ,

indicating a considerable drawing up of the plant by crowding : but this drawing up was not accompanied by any appearance of weediness, as may be judged from Fig. 45, so that any one estimating the results by appearance only would not have hesitated in saying that the more crowded plants were the most flourishing - a good instance of the impossibility of estimating results by appearance: and such instances are continually occurring in the course of pot experiments.

Having proved that root-interference produces no effect when the same number of plants are grown in the same weight of soil, the next point to be examined was the question of rootcompetition when the weight of soil is the same, but the number of plants in it is altered. For this purpose the undivided pots were taken, and various numbers of tobacco plants up to I6, and of mustard plants up to 64 , were grown in different pots. The results showed that the total growth obtained in a limited and insufficient weight of soil was nearly independent of the number of plants: with tobacco constancy prevailed with from about 3 plants (nearly so from I plant) up to I6 plants

1 The outside rows in these series were grown in ordinary flower pots, and were not included in the experiment. 
per pot, with mustard it held good with anything over about I6 plants to the pot.

Tobacco.

Weight of plants

Mustard.

Weight of plants

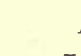

$I$

120

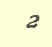

$\mathrm{I} 22$

4
4

I2I

16

89
I6 Plants per pot. I28 grams.

$6{ }_{4}$ Plants per pot. 9I grams.

These results may be expressed by the statement, that, in a limited amount of soil, the weight of a plant is proportional to the area occupied by it, or to the square of the distances of the plants from each other.

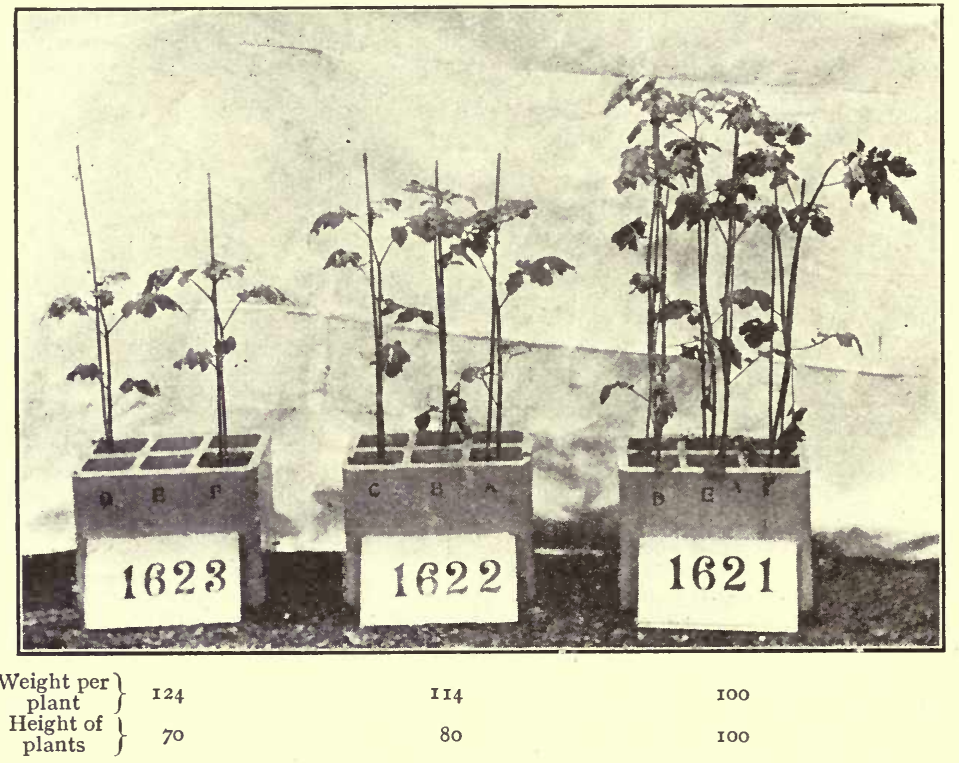

FIG. 45.-MUSTARD PLANTS EXHIBITING THE DIRAIVINGUP EFFECT OF CLOSE PLAN'TING.

Though root-interference does not affect the growth of a plant when all the plants are of the same age and vigour, it might do so if they differed in these respects. To examine this, three plants were sown, both in divided and undivided pots, on a given date, and another three were sown in each pot 20 days later: but the results were found to be not comparable; for the first sown plants in the undivided pots, owing to the larger amount of earth available, made much more growth than those in the divided pots. To correct this source of error, the interval of 20 days 
was reduced-by means of series of experiments wherein different intervals were allowed-so that the first sown plants in both sets of pots were of the same degree of vigour when the second sowings took place. The results of three series of experiments showed that the younger plants made only half the growth $(57,48$ and 52 per cent.) when subject to the interference of the roots of the older plants in the undivided pots, that they did when not subject to such interference in the divided pots. This might be explained, either by the older and stronger plants monopolising such nourishment as there was in the soil-an explanation which presents certain difficulties-or by the younger plants suffering from the toxin produced by the older plants, which, of course, they would not do when each plant was grown in a separate compartment. To settle between these alternatives, the experiment was modified : undivided pots were alone used, and the intervals between the sowings of the first three and second three plants was varied from 0 to 20 days, another set being added in which there were no second-sown plants at all. The mean results from two series of experiments with mustard, done in different seasons, were-

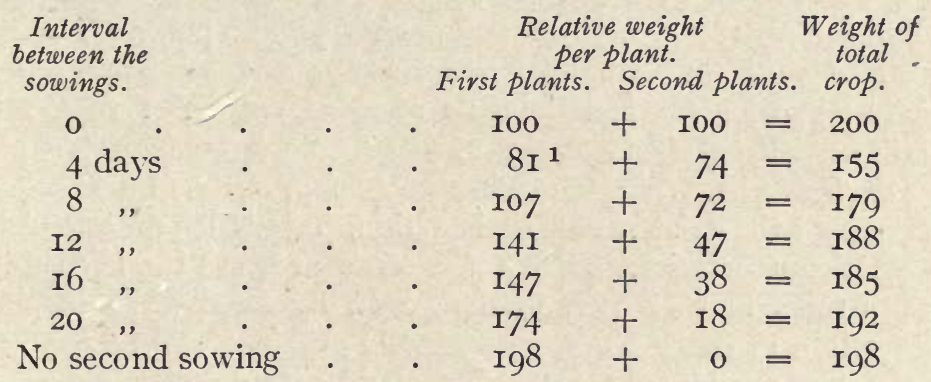

Now, it has been shown that when different numbers of plants of the same degree of vigour are grown in a limited and insufficient quantity of soil, the amount of growth obtained is the same whatever be the number of the plants; the soil is exhausted, and the nutrient in it is divided equally between the plants; if there are twice as many plants present in one case as in another, each plant will receive only half the supplies, and form half the growth, as in the other case (p. 3I5). This was evidently the condition obtaining in these experiments, for the first and last entries the total weight of growth

1 This low value is attributable to the results in one series only; the other series gave $9 \varsigma+64=162$. 
obtained was practically the same, whether there were six or only three plants in the pots. But in the intermediate cases, where the plants were of different degrees of vigour, some factor other than partition of the food-contents must have come into play; the whole of the food-supply was not exhausted, and less plant-growth was obtained than where either six or three plants of equal vigour were present: there must have been some factor preventing the plants from utilising the whole of the food-supplies available. Will the existence of a toxic action explain such a result?

It is an incontestable fact that every plant has some limit to its possible development; from which it follows that equal increments in either favourable or unfavourable conditionssuch as equal doses of manure or of toxin-will have less and less effect on the plant, the larger that plant is. ${ }^{1}$ Where two plants of different sizes are growing side by side, a certain proportion of the toxin formed by one will make its way to, and will act on, the other, and whatever extra dose the weaker plant thus obtains, the stronger will lose. But the deduction of a given dose from the stronger plant will have less effect in increasing its growth, than will the addition of a similar dose have in diminishing the growth of the weaker plant: hence the result will be that the combined growth of the two plants will be reduced owing to their being of unequal vigour. This exactly tallies with the facts observed.

Such results, whilst affording valuable additional evidence in favour of the existence of toxic action, have, also, an important bearing on practice. If half the seeds at a sowing lag behind the others in their germination, even by four days only, the reduction in the total crop eventually obtained will be as much as $22 \frac{1}{2}$ per cent. (I55, instead of 200) - at any rate in the case of mustard. The importance of uniform germination in the seed-bed is, therefore, great. Unfortunately, seeds are not at present tested according to this uniformity, and the farmer or gardener can do nothing to secure it, beyond seeing that the conditions in the seed-bed are as uniform as possible. It follows, also, from these results that to attempt to make up for deficient germination by a later sowing amongst the earlier plants, will only produce weaklings, and injure those plants which are

1 It is held that for every additional ton of dung supplied to a mangold field, an additional ton of produce will be obtained. If true at all, this can be only approximately true, and within very narrow limits : a mangold will not be infinitely small if grown without dung, nor infinitely large if grown on a dung heap. 
already growing. A glance at the numbers quoted above shows how great that injury may be, for even when the second-sown plants are only half the size of the first (third to fourth entries). they reduce the vigour of the first plants to 60 per cent. of what it would have been if they had been left to develop alone (from I98 to I24).

A familiar instance where the co-existence of plants of different degrees of vigour gives unsatisfactory results is where gaps in an established orchard are filled up by planting young trees: but in that case there may often be other causes-such as shading, etc.-which contribute to the unsatisfactoriness of the results; the exhaustion of the ground by the previous occupier cannot, however, be reckoned amongst these causes, as was shown by the Woburn results of growing crops on former treesites (p. 30I).

In the experiments last described, part of the reduction in weight of the second-sown plants must be attributed to the shorter time allowed to them for their growth; but reduction from this cause did not amount to much, as was proved by growing six plants in separate pots for the same lengths of time as in the experiment itself. The relative weights of the plants when the sowings were delayed by periods ranging up to 20 days are given in the first line below, whereas the weights of the second-sown plants in the experiments already quoted are those reproduced in the second line.

Crop obtained.

\begin{tabular}{|c|c|c|c|c|c|c|}
\hline No other plants present & $\begin{array}{c}0 \\
100\end{array}$ & $\begin{array}{c}4 \\
100\end{array}$ & $\begin{array}{l}8 \\
87\end{array}$ & $\begin{array}{l}12 \\
8 I\end{array}$ & $\begin{array}{l}16 \\
8 I\end{array}$ & $\begin{array}{c}20 \text { days. } \\
60\end{array}$ \\
\hline Other plants present & IOO & 78 & 75 & 45 & 40 & I9 \\
\hline
\end{tabular}

All these experiments were repeated with wheat. The difficulty of growing this crop in such small pots, and the fact that some of the plants became affected with smut, prevented the results from being sufficiently accurate for treatment in the way that the mustard results have been treated on p. 3I7; but it is clear from the following values that the general behaviour of the wheat was similar to that of the mustard, the inferiority of the second-sown plants (second line) being in no way explicable on the grounds of the mere delay in sowing (first line). It is clear, too, that both the effect of delay in sowing, and of the effect of one plant on another when these are of different ages, is considerably less in the case of wheat than in that of mustard, a 
conclusion which has already been rendered probable from the results obtained in experiments with barley (p. 296).

Crop obtained.

\begin{tabular}{|c|c|c|c|c|c|c|}
\hline$-5+2+2$ & & & 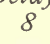 & 12 & 16 & 20 days. \\
\hline No other plants preser & 100 & $9^{8}$ & 90 & IOI & 93 & 94 \\
\hline Other plants present & IOO & 9I & 70 & $3 I$ & $5 \mathrm{I}$ & 37 \\
\hline
\end{tabular}

The toxic action of one plant on another must give rise to many interesting problems relating to plants when grown in masses. One of these is the behaviour of the outside rows as compared with that of the inner ones. As has been already seen, no appreciable difference exists when there is no root-interference (p. 3I5), but with plots in the field, where there is rootinterference, it generally appears that the outside rows contain the stronger plants. This is most noticeable in experimental plots, where care has been taken that the outer plants have not suffered accidental injury. Occasionally the outer plants appear to be the weaker ones, but this may be an instance where appearances are misleading, for in no case where measurements have been made, has this proved to be so, and the superiority observed was much greater than would have been anticipated. To investigate the subject, small plots of mustard were planted at Ridgmont with different distances allowed between the plants in different cases, and there were also similar plots of wheat; at the same time the examination was extended to wheat grown as a field crop on the light ground at Woburn, and to barley grown at Harpenden. Where a field crop was taken, the outside row had to be "made," by removing, early in the season, the rows which were really the outermost ones, owing to these having become damaged during cultivation.

\begin{tabular}{|c|c|c|c|c|c|c|c|}
\hline Row. & & $\begin{array}{l}\text { Musta } \\
\text { idgmo }\end{array}$ & & $\begin{array}{c}\text { Wheat } \\
\text { (Ridgmont). }\end{array}$ & $\begin{array}{r}W \\
(W o b\end{array}$ & $\begin{array}{l}\text { eat } \\
\text { urn). }\end{array}$ & $\begin{array}{c}\text { Barley } \\
\text { (Harpenden). }\end{array}$ \\
\hline Outside & 297 & $20 I$ & 200 & I3I & 204 & I6I & I26 \\
\hline Inner & . IOO & IOO & IOO & IOO & IOO & IOO & IOJ \\
\hline
\end{tabular}

The above values, which refer to the relative weights of the whole plants after drying, show that the excess in favour of the outside plants is always very considerable, and may amount to as much as 200 per cent.-in several cases it reached roo per cent. $^{1}$

1 Similar experiments have been made in India on cotton, sorghum, wheat and other crops. J. Fletcher: "Note on a Toxic Substance Excreted by the Roots of Plants."-Mem. Dept. of Agric. in India, I908, ii. 3, pp. I-I 7 . 
Observations in the case of plots of mustard led to the conclusion that, with that plant, the advantages of an external position do not extend much beyond six inches from the edge of the plot, the second rows generally showing a superiority over the average of the internal plants only when the distances between the rows were six inches or less, but none when they were nine inches. An alternation in the vigour of successive rows appeared possible, for the great vigour of the outer one would tend to reduce that of the second, and this relatively enfeebled growth of the second row would induce extra vigour in the third, and so on: but it was found that no such effect of any measurable magnitude existed, for out of nine series of experiments with mustard, alternation in the vigour of successive rows occurred only in two of them, and, even in those cases, did not extend beyond the fourth rows, being, therefore, probably accidental. 


\section{CHAPTER XXX}

\section{FLOCCULATION (Reports, XIV, 37; XVIJ)}

WHEN clay is puddled with water, and the turbid liquid is allowed to settle, the grosser particles fall to the bottom more or less rapidly, but the finer ones remain in suspension for a iong time, not settling for many days. If, however, a trace of any acid or salt be added to the liquid, the fine particles settle much more rapidly, and, when examined under the microscope, it is found that the acid or salt has caused them to collect together into groups, so as to form small flocs, and is, therefore, said to have caused the flocculation of the clay.

Another remarkable change accompanies flocculation. The minute particles while in suspension are seen under the microscope to be in a state of perpetual motion, moving suddenly and erratically, first in one direction and then in another, exhibiting what is known as the Brownian motion : but on the addition of the acid or salt, this motion at once ceases. Now, the Brownian motion is known to be merely a consequence of the smallness of the size of the particles, any substance, whatever its nature, exhibiting this motion if the size of the particles is below a certain limit; and the fact that the motion ceases on the addition of acid means, therefore, that the size of the particles must have been increased by the acid. But no such increase in the solid, visible particles can be noticed, so that the increase must have occurred by these visible particles having become united to something invisible, a composite particle, consisting of a solid nucleus surrounded by liquid, having been formed, these composite particles exceeding those limits of size for which Brownian motion is possible. The increase in the space occupied by the clay after flocculation was also established by measuring the volume occupied by it when it eventually subsided; and it was found that, as the proportion of acid or salt was increased, so did this volume increase, till, when flocculation became complete, as evidenced by the absence of any suspended matter in the liquid, the particles of clay occupied double or treble the space which they did before 
flocculation. The further addition of acid, etc., then produced no further increase in the volume, at any rate, till other changes supervened, into which it is not necessary to enter here.

Various theories had been put forward to explain flocculation, but none of them had satisfied all the facts of the case : ${ }^{\mathbf{1}}$ amongst. these the question of the combination of the acid, etc., with the clay had been considered, but had been dismissed, owing to the absence of evidence that any such combination did occur, or owing to the smallness of the proportion in which it must occur if there were any combination at all. But work done in connection with the Woburn Farm placed the occurrence of such combination beyond doubt; for, with acids, it was found that the clay actually removed nearly the whole of the acid from the liquid, carrying it down with it to the bottom, and, moreover, that the combination occurred in more or less definite proportions, for the clay would remove a certain quantity of acid, and that quantity only; if any excess were added beyond that limit, it remained unaffected in the liquid. The total proportion of acid thus combining was, however, small, only one-fiftieth to one twohundredth of the clay, and if it were simply a question of the acid itself combining with the clay, an addition such as that could not account for an increase of Ioo to 200 per cent. in the size of the particles. But the acid does not exist in the liquid as such, it is combined with a large proportion of water in the form of hydrates, which contain several hundred molecular proportions of water to each one of acid, and the union of these bulky hydrates with the clay particles would be quite sufficient to account for the composite particle being two or three times larger than the solid, uncombined clay particles.

In these composite particles we have, therefore, a solid nucleus enclosed in a liquid envelope of weak acid, the whole forming a sphere floating in the rest of the liquid, which consists of nearly pure water, and there must, therefore, be what is known as surface tension between the outside of this sphere and the water, just as there is in the case of the spheres of oil in an emulsion, or in that of the bubbles of air in a froth. When the surface tension is not great, the same thing will happen in all these cases; several of the spheres, or bubbles, will gradually coalesce, to form larger, irregular, masses, and if, as in the case of the clay, each of the spheres contains a solid nucleus, these solid particles will, when several spheres do coalesce, congregate towards the centre of the resulting mass of liquid, and give the impression of there having

1 Hall and Morison, Journ. Agric. Science, ii, p. 244. 
arisen an attraction between them: hence the aggregation of the particles into flocs after the addition of the acid, etc.

It was shown that with alkalis the results were substantially the same as with acids and salts, but that the combination of the clay with the alkali did not become complete till excess of alkali was present - a very frequent condition in chemical reactions - so that it required a much greater proportion of alkali than of acid to effect flocculation, with a further result, that where the proportion of alkali present was small, and insufficient to combine in any appreciable quantity with the clay, the latter, finding itself in a liquid for which it possessed a certain amount of attraction, subsided less quickly than it would in pure water, so that a small proportion of alkali produces the reverse of flocculation, though it is not deflocculation in the true sense, there being no actual diminution in the size of the particles themselves.

In practice, however, it should be remarked-when, for instance, a field is limed-the alkali may result in actual deflocculation, owing to its neutralising the acid in the soil, and forming insoluble and, therefore, inactive salts; and this result will follow, even if there is no acid present other than carbonic acid, for this latter is a flocculating agent, just as stronger acids are. The ease with which a clay soil may be worked is, as is well known, much affected by the nature of the dressings applied to it: the presence of alkali renders it sticky and unworkable, whereas a dressing of minerals improves the working of it.

Compounds such as those of clay with acids and salts play a very important rôle in the chemistry of the soil and of the plant, and their importance is every day becoming more fully recognised. They differ materially from ordinary, more stable, chemical compounds, and seem to occupy the border land between these and mere physical mixtures, being known as adsorption compounds. The stabler chemical compounds are formed by the intimate union of atoms or molecules, which become, as it were, fused together into a whole, so that the resulting compound possesses properties quite distinct from those of its components: in adsorption compounds, whole molecules, or masses of molecules, become joined together, the components simply adhering to each other, and each retaining for the most part its own distinctive properties. Such compounds may be very easily decomposed, even by physical means : thus, the acid united with clay may be gradually removed by continued washing with water, though not nearly so easily as could some inert substance, such as cane sugar, which had not combined in any way with the clay; the 
result of this is that the state of flocculation of a clay soil must vary with the amount of washing to which it has been subjected by the rain. Variation from this cause was found to be very considerable.

A small patch of ground was marked off at Ridgmont, and samples were drawn from it every month throughout I4 months, in order to determine the state of flocculation of the clay in it (XIV, 37). Three samples were taken on each occasion and mixed together, but those from the first, second and third depths of six inches each, were examined separately. Each sample was shaken up with ten times its weight of water for 24 hours, and, after allowing four hours for subsidence, the upper half of it was syphoned off, and the fine matter still suspended in it, determined. The percentage proportion which this fine matter bore to the weight of soil taken when the whole 18 inches depth of soil was considered, is depicted in the upper diagram in Fig. 46. The variation from month to month was considerable-from 0.2 to 0.5 per cent. - but did not show consistently any definite connection with the season of the year. If, however, the rainfall for the 20 days preceding the sampling be plotted out, as has been done in the middle diagram, a connection of a very intimate character between these two phenomena is observed: in every case, the higher the rainfall has been, the greater is the proportion of fine particles in the soil, the rain having deprived the clay particles of compounds united to them, and thereby caused their deflocculation. It was found, moreover, that the distribution of the fine particles throughout the I 8 inches of soil was altered in a similar manner, the relative proportion in the upper 6 inches being greater or less, according as the preceding rainfall had been greater or less: so that not only does the rainfall increase the total amount of fine particles present, but it affects in this respect the surface soil much more than the subsoil. The relative proportion of fine particles in the upper 6 inches as compared with that in the total 18 inches is shown in the lower diagram of the figure. The effect of rain in making a clay soil less workable is thus explained.

Of course if the rainfall during a much longer period were considered, no connection of the above description would be likely to be traceable, the effect of any given fall having become obliterated by subsequent meteorological conditions: similarly, if the period were too short, the changes wrought by the rain would not have had time to become complete. It was found that if periods of 30 days, on the one hand, or of Io days, on the other, were taken, the connection between rainfall and the condition of 
the soil was not nearly so evident as when the 20-day period was taken : but the time required for the rain to produce its full effect on the soil would necessarily vary considerably with different soils.

Fine particles, actual in 18.".

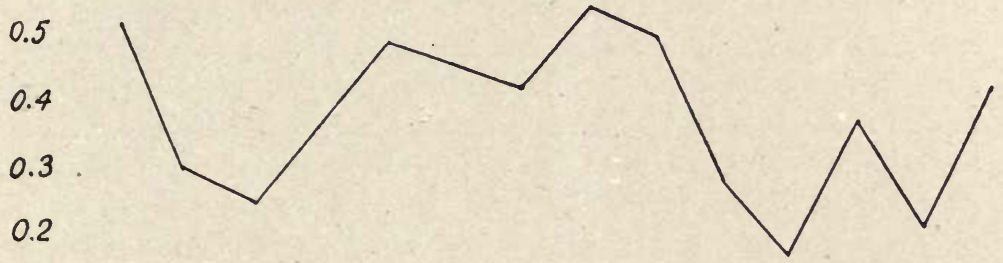

Rainfall, 20 days.

2.0

1.5

1.0

0.5

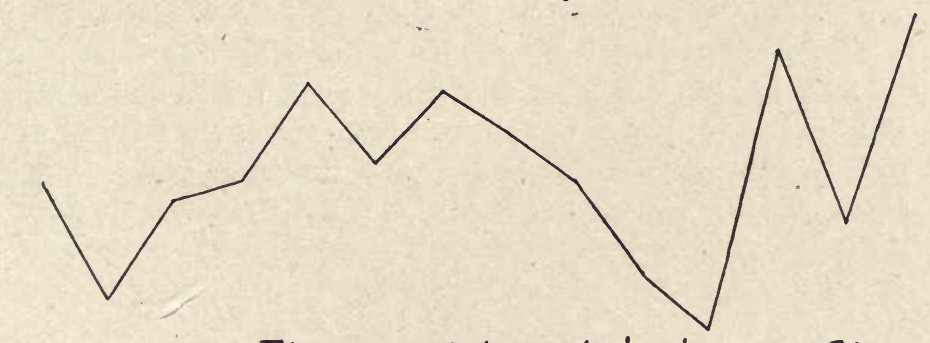

Fine particles, relative in upper 6."

20

10

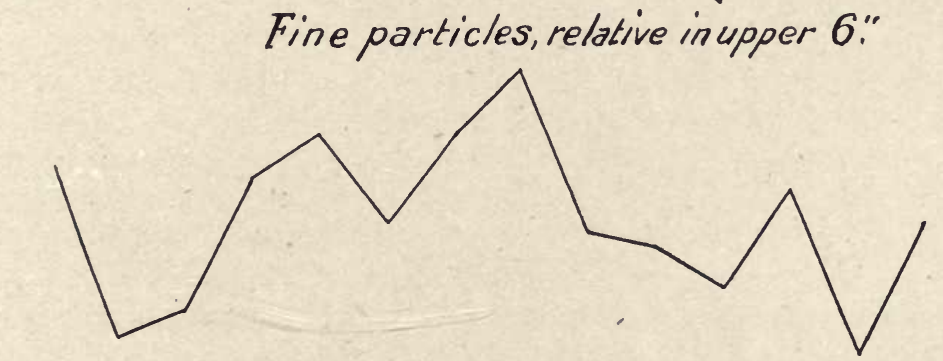

July. Aug. Sopt. Ocr. Nov. Dec. sarr. Fed Mor. Ap. May. June. July Aug. Fig. 46.-FLOCCULATION AND RAINFALL.

The action of frost on a clay soil improves its working capabilities, just as much as, and even more than, a favourable dressing does, and suggests, at first, that frost must cause flocculation. As a matter of fact, however, it was found that the action of frost was essentially of a diametrically opposite character to that of a flocculating agent, for it tended to reduce, instead of to increase, the size of the ultimate particles of the clay. Much 
of the beneficial action of frost consists in breaking down the large clods by mechanical disruption, due to expansion on the freezing of the water contained in them : but it also affects the ultimate particles themselves, and it was found that its action on them consisted in depriving them of the chemically combined water which they contained. The result of this is a shrinkage of the particles, which thereby become more dense, and at the same time agglomerate together, in consequence of which they subside more rapidly, forming a more compact sediment. This action was found to be common to all bulky substances containing a large amount of combined water, and the shrinkage observed in different cases varied between 40 and 90 per cent. With clay it amounted to 80 per cent., and was found to be the same as that occurring when the clay was deprived of its combined water by long exposure over sulphuric acid before being puddled with water.

Clay, and such substances, after they have been dehydrated by freezing, or other means, do not appear to be able to re-absorb the water which they have lost, even when they are left in contact with water for a long time; yet such re-absorption must. occur somehow under the conditions in the field. 


\section{Chapter XXXI \\ ODDS AND ENDS}

Comparative Bearing of Apples on the Crab and Paradise Stocks (Report XV, 74)

THE collection of II7 varieties of apples grown on the crab (or free) stock and on the paradise stock afforded data for a comparison of the relative bearing of trees on the two stocks. All the trees were of the same age, and had been grown as bush trees : each variety was represented by four individuals on each stock, and half of the trees had been subjected to a lighter form of pruning than the other half.

Representing the weights of fruit from the trees on the crab stock as Ioo in each season, the weights from those on the paradise stock were-

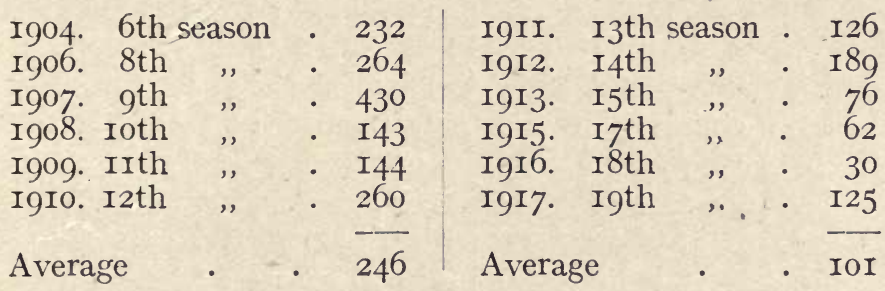

Taking the first six seasons to which these records apply, it appears that the yield from the trees on the paradise stock is about two-and-a-half times greater than from that of those on the crab stock, and a still greater superiority would have been shown if the records prior to the sixth season had been included, for this superiority gradually decreases as time goes on, though, naturally, with great seasonal irregularities: during the second six years over which the records extend, the average bearing on the two stocks is almost identical. Doubtless in future years - and, indeed, that is already so as regards three of the last four entries-the trees on the crab will be more profitable than those on the paradise.

An examination was also made of the relative size of the fruits 
from the trees on the two stocks, but no differences were observed, the records of the ninth to the fifteenth seasons, inclusive, showing less than I per cent. difference in the values.

Both the relative weights of the crops and the relative size of the fruits were examined separately in the case of the harder pruned and lighter pruned sections of the plantation; but it was found that the degree of pruning did not influence the comparative behaviour of the trees on the two stocks to any appreciable extent.

\section{Influence of the Stock on the Growth of Trees}

The thinning out of the above-mentioned plantation of the II7 varieties of apples afforded data for determining the relative growth of trees on the crab and paradise stocks, when grown in the same form-as bush trees-and under the same conditions. The trees had been budded or grafted in $1898-9$, and the thinning commenced in I906-7, so that the data apply to the early years of the life of the trees. On the average, those on the crab stock weighed 64 per cent. more than those on the paradise stock, and this relation appeared to be very little affected by the manner in which the trees had been pruned, the value in the case of the hard-pruned trees being 59 per cent., and that in the case of the light-pruned ones 69 per cent. Fig. 47 represents a typical instance of the difference in growth on the two stocks, and of the character of the roots themselves.

The relative growth of apples on those stocks appears to be very similar to that of pear trees on the quince and pear stocks : the thinning out of fifty trees from a plantation consisting of a large number of varieties of pears which were fifteen years old, showed that those on the pear stock weighed 77 per cent. more than those on the quince stock.

\section{Budding AND Grafting}

The relative merits of budding and grafting in the case of apples on the paradise stock was examined with several hundred stocks which had been planted in I909-Io. The growth measurements were taken in IgII and IgI2, and showed a balance of 22 and I7 per cent. in these two years, respectively, in favour of the budded stocks. This justifies the practice, which is very general in nurseries, of budding the stocks, and resorting to grafting only in those cases where the buds have not developed.

The effect of the scion on the nature of the tree must always 


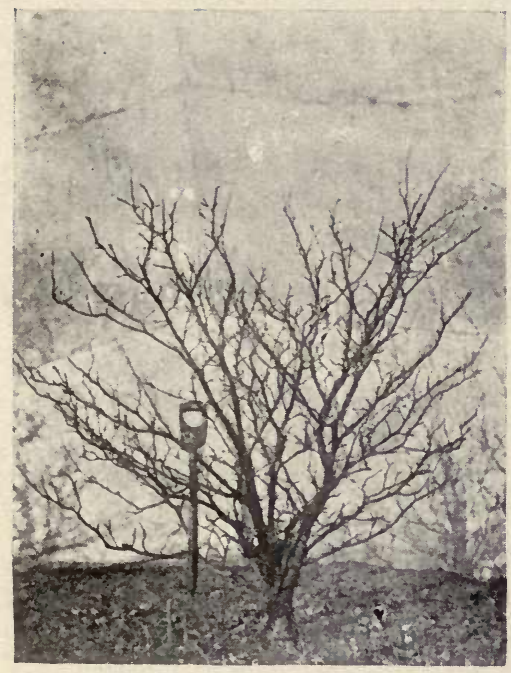

On Paradise.

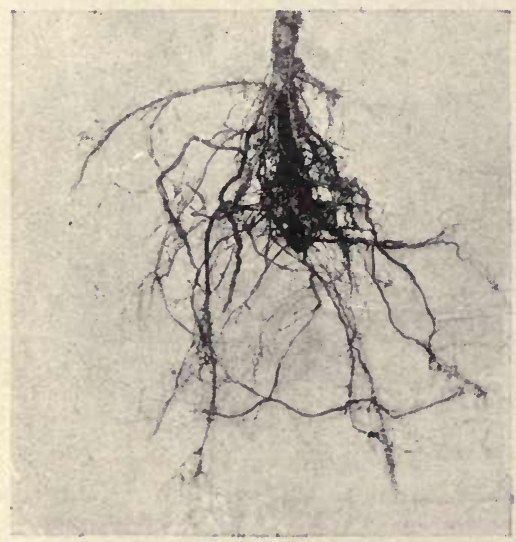

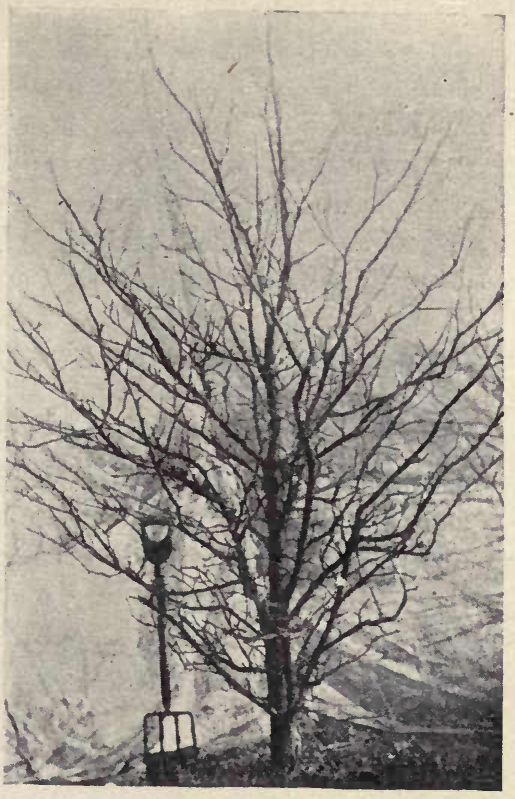

On Crab.

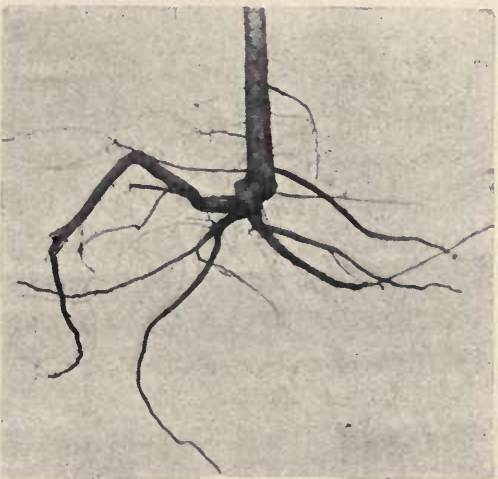

Paradise.

Crab.

FIG. 47.-APPLE TREES OF THE SAME AGE (FOURTEEN YEARS), AND VARIETY (GOSPATRIC), GROWN ON THE PARADISE AND CRAB STOCKS. 
be one of the standing marvels in horticulture. That this nature, so far as the character of the fruit and the leaves is concerned, should be entirely determined by the nature of the one bud from which it develops, independent of the character of the stock, which weighs many thousand times more than the bud in question, is, indeed, a subject of wonder. It is only in certain minor respects that the stock influences the growth of the scion: according to the nature of that stock, the tree exhibits more or less robust growth, and assumes a more or less erect habit, but such effects may be attributed simply to differences in the amount of water and food-material supplied by the roots, and the result does not amount to any alteration in the nature of the growth from the scion.

The nature of the scion, in the same way, appears to be generally without influence on the development of the stock, though there are some instances in which it affects this stock in much the same way as the stock affects the scion : one or two varieties of apples, e.g. Tyler's Kernel, when grown on the paradise stock alter the habits of the roots to such an extent that they assume the deep-rooting and straggling character of the crab stock.

The problems presented by the budding (or grafting) of a scion on to a stock are in many points akin to those presented by the raising of a plant from seed, except that there is here but one parent, and, therefore, no blending of diverse characteristics, the product being, not a new individual, but part of the same plant from which the bud was derived. The characteristics of the variety are thus reproduced much more closely than in the case of trees raised from seed. But are the characteristics of the individual tree reproduced, and, if so, are they reproduced even when they are merely acquired characteristics? Thus, if the bud is taken from an individual tree of exceptionally vigorous growth, or of exceptional powers of bearing, will these characters be reproduced in the tree developed from the bud? and will this still be so even if the vigour of growth or of bearing was not due to the individual nature of the tree, but to some treatment to which it had been subjected, such as liberal feeding, having had its growth checked, having been grown on different stocks, etc.? These are questions of great practical importance, as well as of scientific interest, for if such characteristics of the individual may thus be reproduced, it is clear that great care should be exercised in selecting special trees from which to take buds or scions; and, moreover, the door will be opened to means of gradually improving varieties of 
fruits, and eliminating their-defects, without recourse to the substitution of new varieties in their places.

This question has not yet been properly investigated at Woburn; all that has been done in the matter at present is to work a number of stocks with buds from trees which have had throughout many years a bad fruiting record, and from others which have had a good record. The worked stocks, during the three seasons after the budding, showed an average growth of 23 per cent. in the case of one variety, and 29 per cent. in that of another variety, in favour of the trees worked from the badfruiting individuals. Assuming that the bad fruiters were good growers - which was simply a probable assumption, as measurements of growth were not available-the evidence is in the direction of the characteristics of the individual tree being perpetuated through the buds.

Another question connected with the raising of trees by budding or grafting is being investigated at Woburn:- the life of any individual tree is limited : can it be prolonged indefinitely by budding or grafting a portion of it onto a fresh root-stock? or is such repeated rejuvenation of the individual accompanied by any modification or deterioration of its characteristics? does a variety wear out, just as a given tree wears out? These questions are being investigated by working root-stocks every year with certain varieties of apples and pears, using, in one case, scions derived from particular parent trees, and in the other, scions from those worked in the preceding season, so that at the end of, say, twenty years, there will be two collections of trees of corresponding ages, but in one case they will have been grafted up to twenty times more often than in the other case. These two sets of trees, and especially the character of the fruit from them, will then be compared. It is certainly in accordance with experience derived from the continuous growing of plants such as the potato, and also in accordance with our early recollections of the qualities of certain varieties of fruits, to believe that varieties do gradually deteriorate in the absence of any reproduction by raising from seed. 


\section{Behaviour of Different Varieties of Strawberries} (Reports, I, I2I; II, 35)

Experiments on the behaviour of different varieties of strawberries were carried out between I895 and I899. Eighty-six varieties were represented, thirteen plants of each having been planted every year, so that by I899 each variety was represented by plants of five different ages. As a standard of comparison, the crops of the two-year-old plants were taken as Ioo.

As regards the magnitude of the crops from plants of all ages, the results during the four chief years of bearing arranged themselves into two categories, the yields in 1896 and 1898 being double those of 1897 and I899, and an attempt was made to connect these differences with the meteorological conditions of the seasons in question, taking either the conditions prevailing during the five weeks preceding the period of gathering, or those existing during the time of gathering itself. The conditions examined were : average air temperature, maximum temperature as shown by a solar radiation thermometer, rainfall, humidity of the air, and minimum temperature four inches above the ground. In no single case was any connection traceable between these conditions and the cropping of the plants, for an arrangement of any of the data in question according to their order of magnitude did not coincide with the order of magnitude - or the reverse - of the crops. The cropping, therefore, must depend, either on minutiæ which are not brought to light by such average meteorological data, or on the meteorological conditions obtaining at some other periods of the year.

As to the variation of the crops with the age of the plants, the total yield from plants of different ages in any one particular season were found to be as follows:-

$\begin{array}{ccccc}\text { I year, } & 2 \text { year, } & 3 \text { year, } & 4 \text { year, } & 5 \text { year plants. } \\ 3 \mathrm{I} & \text { IOO } & \mathrm{I} 22 & \mathrm{I} 2 \mathrm{I} & \mathrm{I} 34\end{array}$

showing an increase up to the third year, but no diminution during the next two years. The size of the fruits, however, as shown by the average weight per berry, indicated a steady 
diminution throughout the five years, the relative values being $\begin{array}{lllll}\text { II5 } & \text { I00 } & 96 & 9 \text { I } & 82\end{array}$

In every case it was found that the cropping period of the older plants was longer than that of the younger plants, but that it did not begin so early, the ripening in the case of the older plants being on the average two and a half days later than in that of the one-year plants.

The different varieties were arranged in their order of merit as regards seven different desirable features - size of crop or of berries, uniformity, flavour, character, etc. - and it was found that there was no one variety which figured amongst the first twenty in all these lists; and, whichever property was considered, the first twenty in the list never contained more than three varieties which were first class as regards quality and character; this illustrating the practical impossibility of obtaining varieties which are satisfactory in all respects.

In addition to this collection of eighty-six varieties, there were five other somewhat less extensive collections of plants, grown within a short distance of the first collection - even adjoining them in places-but under slightly different conditions as to depth of soil, distances between the plants, shelter or manuring : a comparison of the behaviour of the same varieties in these different collections led to interesting results.

It is well known, of course, that a variety of any fruiting plant will often succeed in one place, while it fails in another at no great distance from the first; yet one of the stock experiments (so-called) in County Council gardens consists of an attempt to determine what varieties are suitable to the district, -by a few trials made in one small piece of ground. The futility of such trials may be best illustrated by results obtained with these collections of strawberries at Woburn. The crops from them were compared from the point of view of all the various features mentioned above, and in all cases similar results were obtained as to the, apparently, arbitrary variation of these properties under the slight differences of conditions obtaining. Thus, on arranging 64 varieties common to the two main series in their order as to magnitude of crops during the three seasons of full bearing, it was found that, of the 16 heaviest croppers in one series, only seven figured amongst the 16 heaviest croppers in the second series, whilst of the 16 worst croppers in the one, only Io figured amongst the 16 worst croppers in the other. In one or two instances a variety which appeared amongst the 
best 16 in one series, was amongst the worst 16 in another, whilst the average difference of position of the varieties in the two series was as much as twelve places.

With such differences in the comparative behaviour of different varieties in the same field, it is obviously impossible to determine their behaviour throughout an extensive district by a trial in one particular spot; the only way of gaining information on the subject is to make general observations throughout the whole district, and, even then, the conclusions, however carefully drawn, are likely to fail when applied to particular situations.

\section{Continuous Cropping with Strawberries}

The view that the continuous cropping of land with the same plant renders that land " sick," and unfit for the growth of that particular plant, though fertile for other plants, has already been alluded to (p. 302), and shown to be destitute of foundation. Amongst the plants which are supposed to render land "sick," the strawberry must be included, and the results at Woburn showed that in that case, also, such a view could not be maintained. A plot of ground had been used for growing strawberries continuously for fifteen years, but at each fresh planting the arrangement had been altered so that various parts of the ground had not carried any plants during five, and others not during ten years, out of the fifteen. On comparing the weight of the plants grown in these less-continuously cropped sections with those grown where the cropping had been continuous, a balance of 8 per cent. was found in their favour: but since of the five different varieties examined, two gave a balance in the opposite direction, and the probable error of the mean result was \pm 9 per cent., it was clear that this average difference of 8 par cent. had no significance, and afforded no evidence of the ground having become "strawberry-sick."

\section{Strawberry RunNers}

Another common tenet relating to strawberries would appear to lack foundation: this is, that the first runners thrown out are much stronger and more prolific than the later ones. This may be so to a certain extent as regards their cropping power during the first year after planting, for the first runners would be appreciably older than the later ones, and would form larger plants: but any advantage of this sort becomes inappreciable in subsequent years, and the later runners then show a con- 
siderable advantage over the earlier ones, at any rate as far as the third runners. The variety investigated was Profit, the number of runners used being 800 . The relative crops during five seasons were-

$$
\begin{array}{llllll}
\text { Crops per plant } & \text { Ist, } & 2 n d, & 3 r d, & 4 \text { th, } & 5 \text { th runners. } \\
\text { IoO } & 206 & 4 \mathrm{I} 8 & 355 & 49 \mathrm{I}
\end{array}
$$

Germination of Fruit Seeds (Reports, I, I6o; II, 2I0)

Some questions connected with the germination of seeds from different-sized fruits, and from cells containing different numbers of seeds, were examined in 1896 , '97 and ' 98 , crab apples, cultivated apples and pears being use? for the purpose. It was found that the size of the fruits from which the seeds were derived had no influence on the germinative capacity of these seeds; thus in I 898 the percentage germinations were-

$\begin{array}{ccc}\text { From Large, } & \text { Medium, } & \text { Small Fruits. } \\ 46 & 32 & 38 \text { per cent. }\end{array}$

showing no relationship between size and germination; and similar results were obtained in the other seasons.

In the same way it was found that the number of seeds per cell did not affect the germinative power of the seeds, the average percentage of germinations from the one-seed cells and two-seed cells being $2 \mathrm{I}$ and 23 , respectively.

\section{Potatoes (Reports, I, I50; II, 228)}

One or two points connected with potato-growing were investigated in some seasons at Woburn. In one instance the influence on the crop of the date of the sowing was examined; and in that case, the trials were made with seven different main-crop varieties 
and extended over three years, the dates of planting in the more important series being March 24, April 23 and May 26. The results may be summarised as follows-

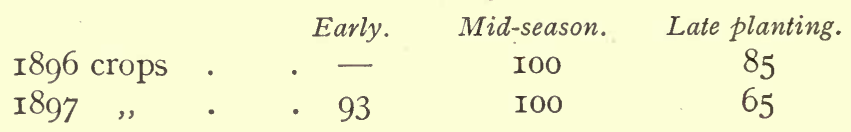

showing a more or less decided advantage in favour of midseason planting. The early sowing was attended with a further disadvantage than that indicated by the reduction of the total crop, inasmuch as the tubers exhibited a considerable amount of "growing out."

At the same time the effect of using sets of different sizes was examined, and considerable advantage was found to lie with the sets of medium size : thus-

$\begin{array}{cccc} & \text { Large. } & \text { Medium. } & \text { Small Sets. } \\ \text { Crops . } & 85 & \text { I24 } & \text { Ioo }\end{array}$

but the size of the sets was found to have no effect on the average size of the tubers in the crops.

The relative weights of the large and small sets used in these trials were as two to one.

The advantage of obtaining seed potatoes fresh from certain districts of Scotland is well known, but there is also a very prevalent belief that a mere change of seed from one locality to another is an advantage, though sometimes this opinion is qualified by stating that the desirable change is one from heavy soil to light soil.

In I899 potatoes-" The Bruce "-were grown in the heavy soil of the Fruit Farm, the seed having been obtained, in one case from a crop grown in light soil at Maulden, Bedfordshire, in another case trom the Oxford clay soil in the neighbourhood, and in a third and fourth case from crops grown at the Fruit Farm itself. The results showed no advantage whatever from a change of seed, whether from a light or a heavy soil, and the seed where there had been no change of soil at all, gave slightly the best results.

From Light soil. Heavy soil. The Fruit Farm.

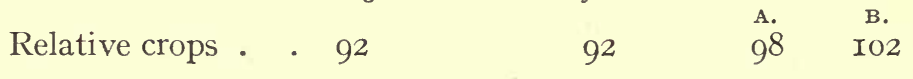

A similar trial was made in I9I7, but it was combined with the use of seed fresh from Scotland, and all the seed used was of 
the same variety - "Factor" - and had been obtained in the previous year from the same Scottish firm, having been grown in the meantime, (I) in light land on the Royal Agricultural Society's farm, (2) in heavier land in the neighbourhood, (3) in the heavy land at the Fruit Farm, actually in the same plots occupied by the trials in I9I7. The results were-

$\begin{array}{lcccc}\text { Fresh from } & \overbrace{\text { Sight }}^{\text {Scotland. }} & \begin{array}{c}\text { Heavier } \\ \text { soil. }\end{array} & \begin{array}{c}\text { At the } \\ \text { soil. }\end{array} & \text { Fruit Farm. } \\ \text { Total crop } & : \text { Ioo } & 43 & 58 & .65 \\ \text { Size of tubers } & \text {. Ioo } & 5 \mathrm{I} & 66 & 58\end{array}$

The superiority of the seed fresh from Scotland is thus very marked, the total yield from it, as well as the average size of the tubers, being about twice as great, as with the same Scotch seed after being grown one year elsewhere. There is a certain amount of evidence, also, in the case of this series, especially when the weight of the crop alone is considered, that it is better to take seed from a crop grown in heavy than in light soil : but there is nothing to show that a mere change of locality is in itself desirable, for, with the seed one year from Scotland, that grown at the Fruit Farm itself yielded actually better results than that grown elsewhere, just as was the case with the experiments in I899.

A Disease of Plum Trees (Reports, I, I64; II, 2I8)

A fungoid disease, which proved to be of a very fatal character, attacked a fruit garden at Harpenden, where there were I72 standard plum trees of different varieties. It was first noticed in I895, when two trees were found to have been killed by it. In the next year twelve more trees had died before the summer, and by the end of the following year the deaths amounted to sixty-seven. Three other trees, which were badly attacked, died in the following year (1898), so that the total deaths - amounted to seventy, or 4I per cent. of the whole plantation, whilst an equal number of trees were seriously attacked, and were only saved by severe surgical operations. 
The presence of the disease was first noticed by finding a large portion of cortex and cambium on the stems of some of the trees to be yellow and rotten. The periderm had not been affected, so that the only external sign of anything being wrong was the comparative flattening of the stem, owing to absence of growth in the parts attacked. The parts affected were moist, and possessed an unpleasant odour. The fungus had, also, in most cases, penetrated to a considerable distance into the wood, and could often be traced as having travelled along the wood or cortex from one seat of activity, and then to have broken out into a state of activity at some other point a considerable distance away. The principal seat of attack seemed to be about halfway up the stem, though in a few cases it extended nearly to the roots, and in others some of the main branches were affected. As a rule there appeared to have been no bark injury at the seat of the attack, but, no doubt, an injury, too minute to be visible, would be sufficient to allow of the entry of fungus-spores.

The spread of the fungus was evidently very rapid, the portions of the stem affected being often one to two feet in length, and trees which had failed to show any signs of disease when examined in the winter were found to be attacked to this extent before the following midsummer. As soon as the disease had spread right round the trunk, the supplies for the head of the tree were cut off, and the leaves turned pale and dropped off early; but up to this occurrence, the head of the tree continued to appear perfectly healthy, and to make vigorous growth. In the case of several trees where the disease had spread entirely round the stem, and even in that of some where a foot or more of the dead bark and cambium had been cut away right round the tree, the trees came into leaf and fruited, and the fruit, though poor, was saleable. These facts showed that, as a rule, both the roots and the heads of the diseased trees were perfectly healthy, the stems being the only parts affected.

The oldest of the trees were about nine years old in 1896 , and these suffered to the extent of 55 per cent., those of intermediate age suffered to the extent of $3 I$ per cent., and the youngest-about four years old-to only I2 per cent. As regards varieties, the Victoria, Diamond and Greengage were by far the heaviest sufferers.

Throughout the attack, the trees were treated surgically, by cutting away, where possible, such parts of them as were infested, and tarring the exposed wood. In most cases where the disease had not spread right round the trunk, the tree was saved, and 


\section{ODDS AND ENDS}

made vigorous growth to cover the wound. The rapid decline and practical disappearance of the disease cannot, however, be attributed entirely to these remedial measures, for it was not possible in any case to remove absolutely the whole of the tissues attacked, and several trees, which were too badly attacked to admit of treatment at all, were left standing in the orchard, and did not prove a source of infection to the remaining trees.

During these years a few trees at the Fruit Farm were attacked by, apparently, the same disease; but it did not spread there : other specimens of plums suffering in like manner were sent to the farm by various growers.

As to the nature of the disease, some doubts must exist, for the examination made by experts was not undertaken till after the stock of material sufficient to render such an examination satisfactory had become exhausted, and, moreover, the opinions expressed by different experts did not agree. One of these was that the disease was caused by the fungus Eutypella prunastri, Sacc., observed on cultivated plum trees in the Rhine Valley, and not uncommon on various rosaceous trees and shrubs, but not known to have caused an epidemic such as that which occurred at Harpenden.

Whatever the nature of the disease may have been, its fatal character and the rapidity with which it spread, must render it a thing to be dreaded by plum growers; but consolation must be derived from the fact that the rapidity with which it disappeared equalled that of its appearance, and the orchard where it caused such ravages up to 1898 has remained quite free from the disease ever since. 



\section{INDEX}

Absorption of heat, r26.

Acids, flocculation produced by, 323.

Adhesion of spray fluids, r 68 .

Adsorption compounds, 324

Agriculture, Board of, on emulsions, I 52.

$\longrightarrow,-$, on fumigation, 206.

$\longrightarrow,-$, on gall mite, 2 I 6. , Irish Board of, on potatospraying, 183.

Air, artificial heating of, r29.

, drainage, 127.

Alcohol, 2 I 5 .

Alkaline copper fungicides, 182 . washes, $x 64,167$.

for mussel scale, $20 r$. for psylla, 222 .

— method of action of, 210.

Alkalinity, effect of on plant growth, 279.

Alkalis, action of on mussel scale, 201 .

- flocculation produced by, 325 .

Alternation of good and bad fruiting years, 136 .

Antinonnin, 2I4.

Antiseptics, action of, 252.

$\longrightarrow,-$, on fruit, 162 .

- - , on soils, $249,253$.

Aphelinus mytilaspidis, 196.

Aphides, I3, I4, 224.

$\longrightarrow$, emulsions and nicotine used for, 224 .

Apple, flower and fruit of, 8.

- sucker, $22 \mathrm{r}$.

Apples, analyses of, ro 4 .

, bearing of, on different stocks, 329.

$\longrightarrow$, date of flowering of, $\mathrm{I}_{4} \mathrm{I}$.

- growth on different stocks, 33 .

__. manurial experiments on, 90. Arsenical compounds, 149.

Aspidiotus ostreceformis, I96.

Bacteria in soils after heating, 249. , in tilled and grassed soils, 278.
Barker, on fungicidal action, 187 .

Batchelor, on frosts, 127. , on pruning, 78 .

Big bud, 2 I2.

Bizzell, on soil gasses, 276 .

Black currants, behaviour of, in trenched ground, 28.

—, manurial experiments on, 97 . - varieties susceptible to mite, 218.

Blossoms, method of injury of, by frost, 128.

Bordeaux injury, 190.

- mixture, I7 $\mathrm{I}$.

$\longrightarrow$ - action of, I75, 186 .

—_, action of air on, $\mathrm{r} 75$.

- $\longrightarrow$, adhesiveness of, I 79 .

- change of, on keeping, $\mathrm{I} 78, \mathrm{r} 8 \mathrm{o}, \mathrm{I} 82$.

- delay in action of, 175 , I9I.

, dried forms of, $\mathrm{r} 82$.

- , efficiency of, 178,242 .

- - manufacture of, 179, r 8 I

- $\longrightarrow$ nature of, 173 .

- - on potatoes, 244 .

- , origin of, $x 72$.

—— testing of, 174 .

$\longrightarrow$, with insecticides, 183 .

- with treacle, 182 .

paste, I77.

—

- - adhesiveness of, I 79 .

- , efficiency of, 178,242 .

$\longrightarrow$, on potatoes, 244 .

$\overrightarrow{\text { Bordorite. }}$ Stability of, 177 .

Bracey, meteorological data, ir6.

Brenchley, toxic action of copper, r89.

Brooks, on silver leaf, $23 \mathrm{I}$.

Brownian motion, 323 .

Budding and grafting compared, 330.

Burgundy mixture, I79, 183 .

—_ adhesiveness of, 179 . by-products in, 185 .

- - change on keeping, 184 . , on potatoes, I 79, 242 . 
Burgundy mixture, scorching action of, 184 .

Burrill, on green manuring, I Io.

Calcium arsenate, I70.

chloride, I68, 206.

sulphide, 148 .

- on gall mite, 2I 4.

California wash, 147 .

Carbolic acid, I 48.

- - on gall mite, 2 I 4 .

Carbon dioxide, action of, on copper compounds, I 75 .

- - , in grassed soil, 276 .

Caterpillars, I 3, I4.

, insecticides used for, 225.

Chalcidida, on mussel scale, I96, 201.

Church, on frost prevention, I 24 , I 29, I3O.

Clark, on copper fungicides, I86.

Clay, action of frost on, 327 .

- , effect of rainfall on, 326 .

- , flocculation of, 323,326 .

Collier, analyses of fruit trees, IO4.

Colouring, effect of grass on, 272.

Copper, absorption of, by plant leaves, 188 .

- basic carbonates of, I83, I 85 . basic sulphates of, I 73, I 77 .

- - - action of air on, I 74 .

I 74 .

electronegative, action of, I 82, I 94 .

, fungicidal and scorching action of, $186,192$.

fungicides, I 72 .

—— ammoniacal, I 82 .

$\longrightarrow$ - dried, 182 .

-

, minimum fungicidal dose of, I 89.

-

- , retention of, by soil, I 89 .

- - scorching action of, I 90 .

tion of, 186 .

- toxic action of, 189 .

Cousins, on big bud, 2 I 6 .

Crops, measurement of value of, $x 9$.

Currant gall mite, 2 I 2.

- , cutting down bushes for, 2 I 5 .

—, fumigation for, 216 .

- - rate of increase of, 2 I $_{4}$.

- , treatment with hot water, 2 I 6.

Cutting back trees, 73 .

- , at different times, 75 .

Daubeny, on toxin formation, 303 .

De Candolle, on toxin formation, 303.
De-emulsification, $\mathbf{r}_{58}$.

Dew, formation of, I 26.

Dickens, on pruning, 78 .

Drainage and toxic action, 300 , 308. of air, I 27

Drinkard, on pruning, 78 .

Dyer and Shrivel, on manuring, 97.

Dyer, on the Rothamsted results, IO3.

Ebermayer, on forest tree requirements, I03.

Edlefsen, on frost fighting, 126,128 , I 30.

Emulsifiers, solid, I 58 .

Emulsions, action of, on mussel scale, 202.

, caustic, I60.

,-- , on mussel scale, 204.

, damage by, I55.

, introduction of, I 52.

- nature of, I 56 .

—-, on caterpillars, 226.

, recipes for, 152,160 .

Eriophyes ribis, 2 I2.

Eutypella prunastri, 34I.

Experimental plots, size of, 16, 17 .

Exposure before planting, 49.

Fibrous roots, removal of, on planting, 35 .

Fletcher, on plants in masses; 320 .

Flocculation, 323.

Flowering of apples, I4I.

Flowers of plants, 8 .

Food, available supply in soil, I03.

- Production Dep., on potatospraying, 24I.

supply, as influenced by grass, 287.

Forest trees, effect of grass on, 268.

- requirements of, 103 .

Formalin, for gall mite, 215.

Frosts, injury by, 125 .

- - prevention of, I 28 .

- , radiation, 124 .

- wind, 124.

Fruit, development of, 8 .

Fruiting, effect of pruning on, 64 .

- dependent on antecedent factors, I36.

- in consecutive seasons, 132 .

Fruits, affected by antiseptics, 162 .

Fumigation of plants, I5O, 220.

—, for gall mite, 216 .

_. , for mussel scale, 206.

—, for woolly aphis, 219.

Fungi, I, I2, 23 I.

-, excretions from, 187.

Fungicides, I45, 149 . 
Germination in heated soils, 250 .

-, importance of uniform, 318 .

- independent of bacteria, 25I. 252.

- of apple seeds, 337 .

Gilbert, on plant excretions, 303 .

Glycerin, on mussel scale, 203 .

Gooseberries, analysis of, $\mathrm{IO}_{4}$.

- effect of root-injury on, 35 .

- effect of trenching on, 28 .

-, manurial experiments on, 95 .

- peculiarities in behaviour of, 29, 35, 54, 107 .

Gooseberry sawfly, 228.

Grass, action of different kinds of, on trees, 268.

- effect of, on trees, 259.

- effect of, on trees, dependent on circumstances, 307.

_- effect of trees on, 300 .

- effect on physical condition of soil, 280 .

—_ feeding off of, round trees, 288.

- limited action of, on trees, 272.

- possible beneficial action of, 306.

- possible causes of the action of, 273.

- recovery from the effect of, 273.

Grassed soil, richness of, 304 .

Grasses, effect of different kinds of, 268.

Grassing trees gradually, 274, 306.

- partially, 273 .

Greene, orchard heating, I 30.

Growth, measurement of, 20.

Gypsine, I49.

Hall and Morison, on flocculation, 324.

Harper-Adams Coll., grass on trees, 308.

Haywood, lime-sulphur washes, 2 ro.

Heating soils, 249 .

Hedges, shelter, I 25.

Hedrick, on manuring, 92.

- on copper-injury, I9o.

Hellebore, I 46.

Holmes Chapel, big bud treated at, 216.

Hooper, C., on the flowering of apples, $\mathbf{I}_{4} \mathbf{r}$.

Hooper, F. G., on frost-injury, I27, 128.

Horticultural experiments, I6.

Hot water treatment for insects, 216.

Humidity records, 122.

Hydrocyanic acid, I50.
Injury by copper-spraying, I 86.

Insecticides, $145,146$.

- nature of action of, on eggs, 209.

- , systematic examination of, 200.

Insects, 13.

-, spraying for, 146 .

Ireland, potato-spraying in, 183

Iron salts, fungicidal action of, I49. sulphate, for silver leaf, 237. , in emulsions, $\mathbf{I} 6 \mathbf{r}$.

Irrigation, for frost-prevention, I3I.

Kerosene, I 5 I.

King, evaporation from soil, $28 \mathbf{r}$.

Koopman, on pruning, 67 .

Lawes and Gilbert, nitrogen in grassed soil, 288 .

Lawes, Gilbert and Warington, evaporation from soil, $28 \mathrm{I}$.

Lead arsenate, $\mathbf{1 4 9 ,} 169$.

- , on caterpillars, 227.

Leaf-size, measurement of, 20.

Leaves of plants, 6 .

Lepidosaphes ulmi, 196.

Lewis, on frost-fighting, 130.

Lichen, removal of, I64, I67.

Lime, I45, I 49, 206.

-, fungicidal action of, 194 .

Lime-salt wash, 222.

Lime-sulphur-soda wash, 147.

Lime-sulphur wash, I48, 206, 210.

Lime washes, 168.

Liming clay soils, 325 .

Limoid, I 59.

London purple, 149.

Long Ashton soil, trials with, 270.

Lopping trees, 70.

- at different times, 70 .

Lowe and Purratt, on San José scale, 202.

Lyon and Bizzell, nitrogen in grassed soil, 288 .

Manure, artificial, 86.

- loss in weight of, in transit, II2.

Manures, 87 .

- general results with, Ior.

-, on apples, 90.

$\longrightarrow,-$ in poor soil, 93.

, on currants and raspberries, 97.

- on farm crops, 92.

- on gooseberries, 95 .

-

$\longrightarrow$, on strawberries, 98.

Manuring, green, I09.

- practical conclusions on, I05.

Marlatt, on mussel scale, 200. 
Massee, on silver leaf, 234 .

Meteorological data, search for alternation in, 138 . records, II6.

Methylated spirits, treatment of caterpillars with, 226.

- - - gall mite with, 2 I 5 .

_- _ mussel scale with, 202.

$\longrightarrow$ plants with, 2 r 5 .

Mildew, spraying for, I 49 .

Mildews, 12, I3.

Millbrook, analysis of soil at, 83 .

- manurial experiments at, 93 .

Mist, formation of, 126.

trees, I26.

Mites, 13.

Moss and lichen, removal of, I64, I67.

Moulds, I2, I3.

Mussel scale, I 96.

- - experiments on, 200.

—. dates for winter treatment of, 205.

- hatching of eggs of, 207.

- - remedies tried for, 205.

208.

Mustard, difference of toxic action of, and wheat, 319 .

Naphtha, treatment of gall mite with, 2 I 5 .

Naphthalene, on gall mite, 2 I 5 .

$\longrightarrow$, solubility in soap, I6I.

National Fruit and Cider Institute, grass experiments at, 307 .

Newstead, on gall mite; 2 I 4 .

-, on mussel scale, I96.

Nicotine, I 5, I 47, 223.

Nursery stock, lifting of, 46 .

50.

—. , root-injury of, 45 .

-

$\longrightarrow$ worked above and below ground, $5 \mathrm{x}$.

O'Gara, on protection from frost, I 28,130 .

Oregon wash, 147.

Ormerod, on gall mite, $21_{4}$.

Paraffin oils, I48, I 5 I.

- - addition of, to alkaline washes, 167. action of, dependent on volatility, 153 .

, action on fruits, $\mathrm{x} 62$.

- damage by, r 54 .

-

-
Paraffin oils for woolly aphis, 220.

- nature of action of, 161 .

, on gall mite, 214 .

$\longrightarrow$, use of undiluted, I52, I53.

Paranaph, r6r.

Paris green, I 49, 170 .

Parkinson, on smudging, 128.

, on frost-injury, I 28.

Pears, growth of, on different stocks, 330.

Percival, on silver leaf, 231.

Pethybridge, on Bordeaux compounds, 177 .

Phenol, r48, r 49 .

Phytophora infestans, 24I.

Plant-growth in heated soil, 253.

Planting, 30.

- - arrangement of trees on, 54 .

- best age for, 47 .

- best time for, $4^{8}$.

_- deep, effect of, on stocks, 36 .

- deep, effect of, on trees, 36 , 49 .

- - high, 49 .

- in sand, 52 .

—., rough, 30 .

- , soil condition for, 42 .

Plants, action of one on another, 293.

, behaviour of inner and outer rows of, 3I5, 320 .

, branch interference of, 314 .

characteristics of, I .

, different numbers of, in same space, 3 r 5 .

, grown at different distances apart, 3I4.

, growth of, in limited soil, $3 \mathrm{r} 4$.

—, in masses, $33^{1} 3$.

of different ages growing together, 3 I 6 .

, physiological functions of, 10.

- root-interference of, 3 I 4.

Plant-sprays, gaseous, ${ }_{50}$.

$\longrightarrow$ - liquid, I46.

-, solid, I45.

Plum trees, a disease of, 339.

-, behaviour towards silver leaf, 234.

Pot experiments, 29I, 313.

Potash, I64.

P, removal of, from soil, Io3.

Potassium sulphide, $\mathrm{I}_{4} 8$.

Potato disease, 24r.

-haulms, appearance of, misleading, 243 .

——, cutting down, 248.

seed, steeping, 247.

spraying, effect of, on soil, 189 . 246. 
Potato spraying, general results of, 242.

-12 , measurement of results, 243. - results affected by manures, 246.

Potatoes, early and late planting of, 337.

- effect of change of seed, 338 .

- large and small sets, 338.

Pots used in experiments, 285 .

Propagation of varieties, 8.

Proportional percentages, 23.

Pruning, 57.

- at different times, 76 .

-, effect of, on growth, 59 .

$\longrightarrow$, effect of, on fruiting, 64 .

$\longrightarrow$, extremes in, 57.

- in experimental plots, 18 .

—, manner of, 78 .

—, necessity for, 67 .

- of old and ailing trees, 69.

$\longrightarrow$ root-, 79 .

, summer, 76 .

Psylla mali, 221.

Pyrethrum, I46, I50.

Quasi-emulsions, 159.

Quassia, I 47.

Radiation temperatures, I2I. of heat, 125 .

Rainfall, damage done by excessive, 123.

clay, 326.

$\longrightarrow$, records of, II9, I23.

Ramming, effect of, on soil, 42 . trees on planting, $31,33,40$.

Raspberries, manures on, 97 .

Reed, on frosts, 128.

Results, comparison of different, 2 I.

- expression of, 23.

- measurement of experimental, I6.

, taking means of, 24 .

Richter, on planting, 34 .

Root-formation after planting, 40.

Root-injury on planting, 33,35 .

to nursery stock, 45 .

Root-interference of plants, 314 .

Root-pruning, 34, 45.

Roots, distribution of new, 53 .

- effect of grass on, $27 \mathrm{I}$.

- function of, 2.

Russell and Darbishire, on heated soils, 253 .

Russell and Hutchinson, on heated soils, 249.

Russell, on plant-excretions,301,303.

Salt, I47, I48, I49, I68, I85, 206.
San José scale, 148, 198, 206.

Sand, planting in, 52 .

-, trees grown in, under grass, 286.

Saponin, action of, on copper fungicides, 195 . , wetting effect of, r95.

Schizoneura lanigera, 219.

Scion, perpetuation of characteristics of the, 330 .

Seeds, germination of, from different apples, 337 .

Shreiner and Lathrop, on heated soils, 258 .

- on organic constituents of soil, 3 Ir.

Silver leaf, $23 \mathbf{I}$.

- action of, on strong and weak trees, 236.

- inoculation with, at different times, 235.

$\longrightarrow,-$, in different parts, 234 .

- methods of combating, 238 .

- spores of different origin used, 236.

- , susceptibility of various kinds of trees to, 236 .

- treatment with iron sulphate, 237.

Smoke clouds, 128.

Smudges, 128.

Soap, emulsification by, 156 .

$\longrightarrow$ detergent action of, $\mathbf{I} 6 \mathbf{r}$.

$\longrightarrow$, in insecticides, 147 .

Soaps, for emulsions, 205.

Soda, 164 .

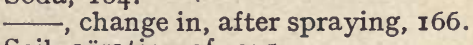

Soil, aëration of, 275 .

$\longrightarrow$, analyses of, 26, 8I.

_ effect of antiseptics on, 249.

$\longrightarrow$, effect of heating on, 249.

- effect of trenching on, 27. gases, 276.

, nature of, as influencing the effect of grass, 270.

$\longrightarrow$ temperature, 278 .

, weight of, 86

Solar distillate, I 53 .

Spider, red, 148.

Spraying, effect of rain after, 2 ro.

for fungi, 13 .

- for insects, 13.

Spring frosts, I 24

Stems of plants, 4.

Stereum purpureum, 231.

Stocks, effect of, on the growth of trees, 330.

- effect of, on the bearing of apples, 329.

Stopping of summer growth, 76 .

Strawberries, continuous cropping with, 336. 
Strawberries, relative behaviour of varieties of, 334 .

- , runners of different ages, 336 .

Stringfellow, method of planting, 34 .

Sulphides, I47, I $48, \mathrm{I}_{49}$.

Sulphur, $\mathrm{I}_{45}, \mathrm{I}_{49}, \mathrm{I}_{50}$.

Swingle, on copper fungicides, r 86 .

Temperature, earth, 122.

$\longrightarrow$ - records, II 7 .

Testing varieties, 336 .

Thawing after frost, I 28.

Theobald, on psylla, 222 .

-, on fumigation for woolly aphis, 2 I9.

Thinning fruits, $\mathrm{r}_{4} \mathrm{O}$.

Tobacco, $\mathrm{r}_{47}, \mathrm{I}_{50}$. mixture, 223

Toxic action, different in different cases, 293.

_- of plants on each other, 293.

_- of a plant on itself, 3 r 3 .

$\longrightarrow$, recovery from, 297.

Toxin, formed by growing plants, 30r.

, decomposition of, 3 ro.

Treacle, addition to Bordeaux mixture, $r 82$.

Tree-growth, as affected by trenching, 27.

Trees, arrangement of, in a plantation, 54 .

-

them, 300. , orientation of rows of, 56 .

Trenching, 25.

Trimming roots on planting, 33 .
Turpentine on gall mite, $2 r_{4}$.

U.S. Weather Bureau, on frostfighting, 128.

Van Slyke, analyses of fruits, I04.

Varieties, wearing out of, 323 .

Vigour of trees, measurement of, 20.

Washes, alkaline, I64, I67.

Water, action of towards heatradiation, 126,131 .

_- distribution of, between soil and sand, 53.

$28 \mathrm{r}$.

-, in soil, effect of surface crop on, 282 .

Weeds, effect of, compared with that of grass, 274, 304 .

Wells, on dew, I26, 129.

West, orchard heating, I 26, I 27 , I $28,130$.

Wheat, toxic action of, compared with that of mustard, 320 .

Winter washing, 14, 160, 205.

- , for caterpillars, 228 .

Woburn Experimental Fruit Farm, analysis of soil at, viii, $8 \mathrm{r}$.

- meteorological records at, i16.

-

$\longrightarrow$, origin of, $v$.

_-, scope of, viii.

$\longrightarrow$, situation of, vii.

Wollny, on soil-gases, 276 .

Woods, on manuring, 92.

Woolly aphis, 2r9.

, treatment of, with hot water, 220. 


\section{Publications of the \\ Woburn Experimental Fruit Farm}

REPORTS

First Report, 1897. Description of the Ground and Methods of Experimentation. Results with Strawberries and Potatoes, and on the Germination of Seeds. Price $5 / 4$, post free.

Summary only, price $6 \%$, post free.

Second Report, 1900. The Black Currant Mite. Results with Strawberries, Bush Fruits and Apples. Germination of Seeds; experiments with Potatoes; Meteorological results. Price $5 / 4$, post free.

Third Report, 1903. The effect of Grass on Trees. (Out of print.) Fourth Report, 1904. Manurial experiments with Strawberries, Bush Fruits, and Apples. (Out of print.)

Fifth Report, 1905. Cultural experiments on Apples, etc. Price $2 / 9$, post free.

Sixth Report, 1906. Mussel Scale and the Winter Washing of Fruit Trees. Investigations on Lead Arsenate, Paraffin Enulsion and other insecticides. Silver-leaf. Price $4 / 4$, post free.

Summary only, price $2 \frac{1}{2} d$., post free.

Seventh Report, 1907. Pruning. (Out of print.)

Eighth Report, 1908. Insecticides and Fungicides. Bordeaux Mixture, Paraffin Enulsion, etc. Mussel Scale, Psylla, Caterpillars, etc. Price $2 / 9$, post free.

Summary only, $3 d$. post free.

Ninth Report, 1908. Planting, etc. Price $2 / 9$, post free.

Tenth Report, 1909. Insecticides for Woolly Aphis, Psylla, Caterpillars, etc. Price $\mathrm{I} / \mathrm{I} \frac{1}{2}$, post free.

Eleventh Report, 1909. Copper Fungicides. Price $4 / 3$, post free.

Summary only, $6 \frac{1}{2} d$. post free.

Twelfth Report, 1910. Silver-Leaf Disease. Price $1 / 7 \frac{1}{2}$ post free.

Thirteenth Report, 1911. The effect of Grass on Trees. Price 4/9, post free.

Fourteenth Report,1914. Potato Spraying. Trenching. The Effect of one Crop upon another. Black Currant Mite. Loss of Weight of Manure in Transit. Price $2 / 9$ post free.

Fifteenth Report, 1916. Fruiting in consecutive Seasons. Injury to Roots on Planting. Cutting-back after Planting, etc. Price $2 / 3$ post free.

Sixteenth Report, 1917. Manurial experiments on Fruit Trees, Bushes, and other Crops. Price $2 / 9$ post free.

The Action of one Plant on another, etc.

(In the Press)

The above may be obtalned from any Bookseller, from

THE MANAGER, WOBURN FRUIT FARM, RIDGMONT, BEDS. or from the Publishers-

THE AMALGAMATED PRESS, LTD.,

The Fleetway House, Farringdon St., London, E.C. 


\section{COMMUNICATIONS TO SCIENTIFIC SOCIETIES AND JOURNALS.}

Note on the Arsenates of Lead and Calcium, Chem. Soc. Trans., I907, 307.

The Interaction of Metallic Sulphates and Alkalis, Chem. Soc. Trans. r907 r98I.

The Chemistry of Bordeaux Mixture, Chem. Soc. Trans., 1907, I988.

Emulsions, Chem. Soc. Trans., 1907, 2001.

Studies on Germination and Plant Growth, Journ. Agric. Science, II, 4 II.

The Action of Antiseptics on Soils, Journ. Agric. Science, III, 32.

The Hydration of Precipitates, Chem. Soc. Trans., I909, I23.

The Carbonates of Copper and the Cupricarbonates, Chem. Soc. Trans. r909, I409.

Bordeaux Spraying, Journ. Agric. Science, III, I7r.

Ueber Emulsionen, Zeit. f. Chemie v. Indust. d. Kolloide, VII, II.

Studies of Changes occurring in Heated Soils, Journ. Agric. Science, III, 258.

Plant Growth in Heated Soils, Journ. Agric. Science, III, 277.

The Constitution of Basic Salts, Chem. Soc. Trans., I9ro, I851.

Experimental Error in Horticultural Work, Journ. Bd. of Agric. Suppt. 7, I 9 I I, 38.

Copper Fungicides, Journ. Agric. Science, IV, 273.

Copper Salts and their Behaviour with Alkalis, Chem. Soc. Trans., I912, I74.

Organic Ferric Salts, Chem. Soc. Trans., I9I3, I358.

The Effect of Bastard Trenching on the Soil and on Plant Growth .

(with E. J. Russell), Journ. Agric. Science, V, 483.

The Effect of one Crop on another, Journ. Agric. Science, VI, I36.

The Fruiting of Trees in Consecutive Seasons, Journ. Agric. Science, VIII, I3I.

The detergent Action of Soap, Chem. Soc. Trans., I9I 7, 86.

Effect of one Plant on another, Annals of Botany, XXXI, I8I.

Flocculation, Proc. Roy. Soc., A. 94, 31 5.

The Action of one Crop on another, Journ. Hort. Soc., XLIII, 372. 


\section{EQUIVALENTS OF ENGLISH AND METRIC MEASURES.}

\section{Weight.}

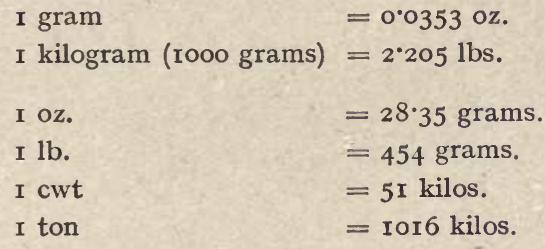

\section{Volume.}

I cubic centimetre (c.c.) $=0.0353 \mathrm{oz}$.
I litre (I00o c.c.)
$={ }^{*} \cdot 76$ pints $=0^{\circ} 0353 \mathrm{cub} . \mathrm{ft}$.
I oz.
$=28 \cdot 35$ c.c.
I quart
$=\mathbf{I} 136$ litres.
I bushel
$=36.35 \quad$ "
I cubic foot
$=28 \cdot 35 \quad$ "

\section{Length.}

$$
\begin{aligned}
& \text { I millimetre (mm.) }=0.04 \text { inches. } \\
& \text { I metre (m.) } \quad=39^{\circ} 37 \quad \text { " } \\
& \text { I kilometre (km.) } \quad=1094 \text { yards }=0.602 \text { mile. } \\
& \text { I inch } \quad=25^{\circ} 4 \mathrm{~mm} \text {. } \\
& \text { I foot }=0.305 \mathrm{~m} \text {. } \\
& \text { I yard } \quad=0.914 \mathrm{~m} \text {. } \\
& \text { I mile } \quad=I^{\circ} 609 \mathrm{~km} \text {. }
\end{aligned}
$$

\section{Area.}

I sq. metre $=I \cdot I 96 \mathrm{sq} \cdot \mathrm{yds} .=10^{\circ} 76 \mathrm{sq} . \mathrm{ft}$.

I hectare (Io,000 sq. m.) $=2{ }^{\circ} 471$ acres.

$$
\begin{array}{ll}
\text { I sq. yard } & =0.914 \text { sq. metre. } \\
\text { I acre } & =0.4047 \text { hectare. }
\end{array}
$$

grams per sq. metre $\times 0^{\circ} 03226=$ ounces per sq. yard. ounces per sq. yard $\times 3 \mathrm{I}^{\circ} 003=$ grams per sq. metre. kilos per hectare $\quad \times 0^{\circ} 000398=$ tons per acre. tons per acre $\quad \times \quad 2510=$ kilos per hectare. 
Printed in Great Britain by Richard Clay \& Sons, Limited, BRUNSWICK ST., STAMFORD ST., S.E. I, AND BUNGAY, SUFFOLK. 


U.C. BERKELEY LIBRARIES

c03364]243 
